Henning Bobzin

\title{
Von Bremen in die Anderswelt
}

\author{
Über Identität und Realität \\ in Prosahauptwerk, Poetik und Weblog \\ von Alban Nikolai Herbst
}

Dissertation zur Erlangung des philosophischen Doktorgrades an der Philosophischen Fakultät der Georg-August-Universität Göttingen 
Die vorliegende Arbeit ist die durchgesehene und lediglich leicht überarbeitete Fassung meiner Dissertation, die ich im Februar 2013 an der Philosophischen Fakultät der Georg-August-Universität Göttingen eingereicht und am 19. Juni 2013 verteidigt habe.

Veröffentlicht 2015 unter https://ediss.uni-goettingen.de.

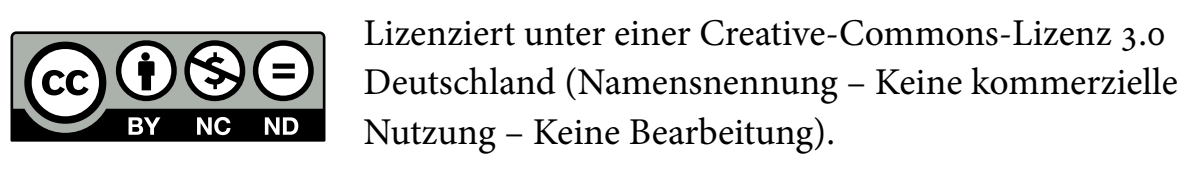

Gesetzt mit LuaLaTeX unter Verwendung von KOMA-Script, biblatex und biber. 


\section{Dank}

Bei Prof. Dr. Claudia Stockinger möchte ich mich für die Übernahme der Betreuung, für die Bestärkung in der Wahl meines Themas sowie für die konstante Unterstützung und Begleitung des Promotionsvorhabens bedanken.

Prof. Dr. Simone Winko möchte ich dafür danken, dass sie die Zweitbetreuung übernommen hat.

Beiden gilt zudem mein Dank für kritische und stets hilfreiche Rückmeldungen zu meinen Vorträgen im Doktorandenkolloquium sowie zu ersten Kapiteln der Arbeit.

Ich danke Prof. Dr. Irmela von der Lühe dafür, mir die Promotion nahegelegt zu haben.

Mein Dank gilt dem Evangelischen Studienwerk e. V. Villigst für die Gewährung eines Promotionsstipendiums, die Möglichkeit, mich im Studienwerk zu engagieren und für die Ausrichtung anregender Doktorandentreffen.

Der Graduiertenschule für Geisteswissenschaften Göttingen (GSGG) danke ich für ein Abschlussstipendium.

Ich danke Heinz Ludwig Arnold $(\dagger)$ und den weiteren Redaktionsmitgliedern des Kindlers Literatur Lexikons (v. a. Christiane Freudenstein-Arnold, Axel Ruckaberle und Ulrike-Christine Sander), mit denen ich während der Vorbereitungsphase der Promotion in meiner ersten beruflichen Station ein wunderbares Projekt verwirklichen durfte.

Herzlich danke ich meiner Familie, Arne Richter, Avishai Cohen, Stephanie Fischinger, Gerald Willms, Peter-Paul König, Hiemke Schmidt, Renaud García-Fons, Sergio René Araujo Enciso und - Veronika A. Andorfer. 



\title{
Inhaltsübersicht
}

\author{
Einleitung 13
}

Teil I Die Verwirrung des Gemüts 35

1 Von der »ungeformten« zur »ungesicherten« Identität 37

2 Die Realität als »Zwischenwelt« 95

Teil II Wolpertinger oder Das Blau 117

3 Heteronome Identitäten 119

4 Zwischen Mythos und Virtualität 187

\section{Teil III Die Anderswelt-Romane 229}

5 Identität zwischen Körperlosigkeit und Körperlichkeit 231

6 Multiplikation der Welten 281

Teil IV Die Poetik 315

7 Kybernetischer Realismus 317

Teil V Das Weblog 363

8 Das Weblog Die Dschungel. Anderswelt 365

Fazit und Ausblick 413

Literaturverzeichnis $\quad 423$ 



\title{
Inhaltsverzeichnis
}

\author{
Einleitung 13
}

Aufbau der Arbeit 16

Methodik 17

Begriffe 19

Forschungsüberblick und -kritik 29

\section{Teil I Die Verwirrung des Gemüts 35}

1 Von der »ungeformten" zur »ungesicherten « Identität 37

1.1 Einleitung 37

1.1.1 Handlungs- und Figureneinführung 37

1.1.2 Narratologische Analyse 38

1.2 Laupeyßers »Fluchten «: die Identitätskrise 47

1.2.1 "Kann ich mich noch entsetzen? « 48

1.2.2 Der Entschluss 49

1.2.3 "Der Abstieg des hoffnungsvollen Laupeyßer-Ulf " 51

1.3 »Was bin ich nur? Wer bin ich? - Die Suche nach Selbsterkenntnis 54

1.3.1 Der Versuch, sich selbst zu erkennen 54

1.3.2 Falbin: Der Kampf gegen Fremdbestimmtheit 64

1.4 Näherungen I: an sich und andere 72

1.4.1 Agnes und das Verständnis 74

1.4.2 Das »Prinzip Nadja«: B. und der >Autor<-Erzähler 77

1.4.3 Axel Schulze und die Aporie der Nähe 81

1.4.4 Kontakt aufnehmen 82

1.5 Der Versuch von Geschichtslosigkeit 84

1.5.1 Belastung durch deutsche Geschichte 85

1.5.2 Name und Pass als Identität 88

1.6 Zusammenführung 89

2 Die Realität als "Zwischenwelt" 95

2.1 Zu den Begriffen >Realität und >Wirklichkeit` 95

2.2 Das Begriffsfeld in Die Verwirrung des Gemüts 96

2.2.1 Realität und Wirklichkeit 96

2.2.2 Empirie 101

2.2.3 Wahrheit 102

2.3 Der Versuch, Wirklichkeit herzustellen 104

2.4 Näherungen II: an die Wirklichkeit 111 
Teil II Wolpertinger oder Das Blau 117

3 Heteronome Identitäten 119

3.1 Einleitung: »Es ist immer das gleiche« 119

3.2 Mythologische Identitäten 124

3.2.1 Dr. Elberich Lipom 125

3.2.2 Anna als Titania 129

3.2.3 Zusammenfassung 131

3.3 >Prinzipien in wechselnder Gestalt $\quad 132$

3.3.1 Mythos vs. Logos 134

3.3.2 Männlichkeit vs. Weiblichkeit: der >Geschlechterkampf $\quad 152$

3.4 Virtualität und `allegorische` Figurenidentität 163

3.5 Intertextuell geprägte Identitäten 166

3.5.1 Wielands Oberon und Huon de Bordeaux 166

3.5.2 Mephistopheles-Parallele 168

3.5.3 Shakespeares A Midsummer Night's Dream 169

3.6 Das Deters-Netzwerk 170

3.6.1 Hans Deters' Vorgeschichte - Bezüge auf Die Verwirrung des Gemüts 170

3.6.2 Die erste Ebene: Hans Deters 176

3.6.3 Die zweite Ebene: Deters II oder der >Autor 179

3.6.4 Die dritte Ebene: der >Dritte und Eckhard Cordes 180

3.6.5 Die Bedeutung des Figurengeflechts 183

4 Zwischen Mythos und Virtualität 187

4.1 Alles ist fiktiv: die Infragestellung der Wirklichkeit 187

4.1.1 Illusionsdurchbrechung und Kohärenzverweigerung 192

4.1.2 Formen von Realitäts- und Wirklichkeitsverständnis 199

4.2 Virtualität 207

4.2.1 Programmierung als Fiktion 208

4.2.2 Programmierung als Manipulation des Menschen 209

4.3 Alles ist konstruiert: Mythologie und Intertextualität 210

4.3.1 »Ist das eine Anspielung oder ein Kalauer? «: Die Referenzfrage 212

4.3.2 Leserwissen 221

4.3.3 Der Roman als Spiel 225

\section{Teil III Die Anderswelt-Romane 229}

\section{Identität zwischen Körperlosigkeit und Körperlichkeit 231}

5.1 Einleitung 231

5.2 Holomorfenidentität: Autonomie und Originalität 237

5.2.1 Die Identitätskrise des Herrn Drehmann 239

5.2.2 Ansichten der Rebellen und autonome Holomorfenkultur 241

5.2.3 Veränderungen an Herrn Drehmann nach dem Kontakt mit den

Rebellen 244 
5.2.4 Parallelen und Differenzen zur menschlichen Identität 246

5.3 Klonidentität: Individualität 250

5.4 Menschliche Identität in der Anderswelt 251

5.4.1 Gegenbewegung zum Autonomiestreben der Holomorfen 251

5.4.2 Ungefugger und der Weg zur Körperlosigkeit 254

5.4.3 Das >Wesenhafter des Körperlichen 260

\section{Multiplikation der Welten 281}

6.1 Anderswelt: Autonomisierung einer Fiktion 281

6.1.1 Verhältnis von Realwelt und Anderswelt 281

6.1.2 Aufbau der Welten 284

6.1.3 Scheinbare Autonomisierung der Anderswelt 285

6.1.4 Metaleptische Verbindungen von Welt und Anderswelt 288

6.1.5 Verschiedene Realitätssysteme 293

6.2 Virtuelle Realität: Alles ist simuliert 295

6.3 Multiplikation von Welten und Beobachtern 299

6.3.1 Weltenmultiplikation 299

6.3.2 Beobachterpositionen 303

6.3.3 Kybernetik im Roman 313

Teil IV Die Poetik 315

\section{Kybernetischer Realismus 317}

7.1 Einleitung 317

7.1.1 Kultursituation 319

7.1.2 Kunstanspruch 322

7.2 Grundlagen des Kybernetischen Realismus 325

7.2.1 Das Flirren und die Bedeutungshöfe 327

7.2.2 >Möglichkeitenpoetik

Dritten 328

7.2.3 Das Unbewusste in der literarischen Kommunikation 331

7.2.4 Perversionsbegriff 336

7.2.5 Pathos vs. Ironie 338

7.2.6 Mimesis und Technik 341

7.3 Der Kybernetikbegriff 345

7.3.1 Was ist Kybernetik? 349

7.3.2 Parellelen zwischen Kybernetik und Herbsts Romanen und Poetik 352

7.3.3 Worum es Herbst eigentlich geht: >Ökologie «, >Analogie 'Seeler 358 
Teil V Das Weblog 363

8 Das Weblog Die Dschungel. Anderswelt 365

8.1 Einleitung 365

8.1.1 Herbsts Internetpräsenz 365

8.1.2 Das Weblog 367

8.1.3 Aufbau des Weblogs 371

8.2 Literarizität und Kunstanspruch 375

8.2.1 Literarizität und Fiktionalität 377

8.2.2 >Institutionelle Zuschreibung von Literarizität 380

8.3 Das Fiktive im Realen: Arbeitsjournal und Autofiktion 382

8.3.1 Das Private im Weblog 382

8.3.2 Autofiktionales Schreiben im Weblog 387

8.3.3 Das Leben als Roman begreifen 391

8.3.4 Autobiographisches Schreiben im Weblog 394

8.3.5 Grenzen des Spiels zwischen Realität und Fiktion 395

8.4 Versteckte Identitäten: Anonymität und das Pseudonym 396

8.4.1 Anonymität 399

8.4.2 Pseudonym 400

8.5 Identitätskonstruktion und Inszenierung als Teil der eigenen Kunst 404

8.5.1 Status und Produktivität als Schriftsteller 406

8.5.2 Männlichkeit und Sexualität 410

Fazit und Ausblick 413

Literaturverzeichnis 423

Siglenverzeichnis 423

Quellenverzeichnis Alban Nikolai Herbst 423

Weitere Literatur 427

Verwendete URLs aus Herbsts Weblog 443 
Aus einer wirklichen Person, in die sie einigen Einblick zu haben glauben, machen sie zwei

Personen ihrer Geschichte, aus zwei ungeniert eine. Und darüber wird auch noch diskutiert! ${ }^{1}$

André Breton

Ist das eine Anspielung oder ein Kalauer? ${ }^{2}$

Alban Nikolai Herbst

$\mathrm{Da}$ ich selten eindeutig bin, macht den Leuten Probleme. ${ }^{3}$

Alban Nikolai Herbst

Von alledem, das begriff er, begriffe man nichts, und strengte sich einer noch so sehr an. ${ }^{4}$

Alban Nikolai Herbst

1 André Breton: Nadja [1928/1963], übers. von Bernd Schwibs, mit einem Nachw. von Karl Heinz Bohrer, Frankfurt am Main 2002, 15.

2 Alban Nikolai Herbst: Wolpertinger oder Das Blau [1993]. Roman, Taschenbuchausgabe, München 2000, 309.

3 Ulrich Faure: ») Jetzt hab ich Metall im Mund und kann um so kräftiger beißen««. Interview mit Alban Nikolai Herbst, in: Börsenblatt für den Deutschen Buchhandel 19 (7. März 1995), 12-15.

4 Alban Nikolai Herbst: Thetis. Anderswelt. Fantastischer Roman, Reinbek 1998, 295. 



\section{Einleitung}

Alban Nikolai Herbst, geb. 1955, ist ein umstrittener Autor. Auf der einen Seite finden sich nicht allzu viele Leser und Befürworter für seine schwer zugänglichen Romane, die in einigen Fällen über 1000 Seiten Umfang erreichen, und die ihnen zugrunde liegende Poetik. Aus diesem Grund wohl hat Herbst auch keinen festen Verlag; die bisherigen Bücher, obwohl u. a. in renommierten Verlagen wie Rowohlt, Berlin Verlag oder in Nachdrucken im Deutschen Taschenbuch Verlag erschienen, sind überwiegend vergriffen und werden zzt. nicht mehr aufgelegt. Abgesehen von einigen Preisen und Stipendien in der Vergangenheit, bleibt eine konstante finanzielle Förderung von Herbsts literarischer Arbeit weitgehend aus. Auch die tagesaktuelle Literaturkritik ist gespalten. ${ }^{1}$ Schließlich hat der Prozess um den 2003 erschienenen Roman Meere ihm neben einiger Aufmerksamkeit ein Buchverbot eingebracht. Generell ist Herbst auch ein streitbarer und provozierender Charakter. Neben »sexuell expliziter « Schreibweise beispielsweise in Meere oder auch provokanten Ideen wie der Versteigerung einer Romanfigur bei Ebay, ${ }^{2}$ ist Herbst dafür bekannt, seine Meinung gerade im und über den Literaturbetrieb offen darzulegen und auch aus seiner Sicht unsachliche Kritik mit persönlichen Angriffen zu vergelten. ${ }^{3}$

Auf der anderen Seite hat Alban Nikolai Herbst sich mit seinen über 20 Romanen, Novellen, Prosa- und Theaterstücken sowie Hörspielen zweifelsohne einen erheblichen Bekanntheitsgrad und Ruf als ernstzunehmender Autor erschrieben. Die wohl eindeutigste und prägnanteste Anerkennung, die Herbst selbst an prominentester

1 Vgl. für das Spektrum von positiv bis negativ beispielhaft: von Wilhelm Kühlmann: »Auf nach Hannoversch Münden«, in: Frankfurter Allgemeine Zeitung, 28. Mai 1994, und Martin R. Dean: »Warum die Kaffeemaschine wirklicher als die Krähe ist«, in: Basler Zeitung, 9. Mai 1997, über Dietmar Dath: »Flaschendrehen und andere Spiele«, in: Frankfurter Allgemeine Zeitung, 9. Okt. 2001, und Katharina Döbler: »Mitten hinein ins Wollknäuel«, in: Die Zeit, 3. Jan. 2002, bis zu Thomas Wörtche: »Pusteln und Pickel«, in: Freitag, 9. Okt. 1998, oder dem ersten, prägenden Verriss: Armin Ayren: »Die Verwirrung der Grammatik«, in: Frankfurter Allgemeine Zeitung, 5. Okt. 1983. Auf diesen ist noch zurückzukommen.

2 Dabei ist die Idee nicht neu: Laurence Sterne bietet beispielsweise in Tristram Shandy seinen Lesern an, eine Widmung zu kaufen, worauf Renate Giacomuzzi hinweist; vgl. Renate Giacomuzzi: »Die >Dschungel.Anderswelt $<$ und A. N. Herbsts >Poetologie des literarischen Bloggens « «, in: die horen 53/231 (2008): Panoramen der Anderswelt. Expeditionen ins Werk von Alban Nikolai Herbst, hg. v. Ralf Schnell, 137-150, hier: 148.

3 Vgl. beispielsweise URL-1, 29. März 2007. Die URLs aus Herbsts Weblog, die damit jeweils mit http://albannikolaiherbst.twoday.net beginnen, werden in den Fußnoten mit der nummerierten Sigle >URL und Datum angegeben. Die vollständigen Adressen sind im Literaturverzeichnis ab Seite $443 \mathrm{zu}$ finden. 
Stelle seiner Website ${ }^{4}$ zitiert, hat Wilhelm Kühlmann formuliert, einer der wenigen Herbst->Kenner< und -förderer:

[...] Herbst hat mittlerweile eine literarische Handschrift entwickelt, die ihn meines Erachtens zu einer der Führungsfiguren der ästhetischen Postmoderne werden läßt. ${ }^{5}$

Seit seinem zweiten Buch Die Verwirrung des Gemüts (1983) hat Herbst einen sehr individuellen Stil herausgebildet und setzt sich auf eigene, alle Bücher miteinander verbindende Weise mit Fragen der Identität und der Auffassung von Realität auseinander. Er ist ein Autor, der seinen Arbeitsprozess und seine Poetik in extremem Maß auch öffentlich reflektiert. Mehr als je zuvor ist dies durch das tägliche Arbeitsjournal in seinem »literarischen Weblog «Die Dschungel. Anderswelt ${ }^{6}$ gegeben. Seit 2003/2004 experimentiert er mit dieser neuen Gattung auf bisher im Literaturbetrieb einzigartige Weise. Doch auch zuvor hat er sich immer wieder in Vorträgen und Aufsätzen um die Erklärung und theoretische Fundierung einer eigenen Poetik bemüht. Dabei geht es ihm um die poetologische Bestimmung eines ıneuen` Realismus, den er mit dem Begriff »Kybernetischer Realismus« bezeichnet. Dieser ambitionierte Versuch einer Poetik soll nicht ausschließlich eine Autorpoetik bilden, sondern beansprucht - nicht normativ, doch zumindest in der Theorie - weiterreichende Gültigkeit.

Seit 2003 (mit Meere) führt Herbst zumindest teilweise auch wieder seinen Geburtsnamen Alexander von Ribbentrop parallel zu seinem Künstlernamen. Diesen hatte er 1981 angenommen, um Ausgrenzungen im Literaturbetrieb zu entgehen, die wegen seiner entfernten Verwandtschaft zu Joachim von Ribbentrop, dem deutschen Außenminister während der Zeit des Nationalsozialismus, entstanden seien. Auf die Gründe für den Namenswechsel und die zumindest teilweise Rückkehr zum Geburtsnamen gehe ich im Kapitel zum Weblog genauer ein.

Das Textkorpus meiner Untersuchungen bildet das Prosahauptwerk von Herbst. Dabei handelt es sich um folgende Romane:

- Die Verwirrung des Gemüts. Roman, München 1983 (im Folgenden zit. als VG)

- Wolpertinger oder Das Blau [1993]. Roman, Taschenbuchausgabe, München 2000 (im Folgenden zit. als WB)

- Thetis. Anderswelt. Fantastischer Roman, Reinbek 1998 (im Folgenden zit. als TA)

- Buenos Aires. Anderswelt. Kybernetischer Roman, Berlin 2001 (im Folgenden zit. als $B A$ )

Das Hauptwerk bilden sie zum einen durch die Größe der Einzelwerke, zum anderen vor allem dadurch, dass sie zusammen mit Argo. Anderswelt, dessen Veröffentlichung

4 http://www.albannikolaiherbst.de und http://www.die-dschungel.de. Siehe Abbildung 1 auf Seite 365 .

5 Wilhelm Kühlmann: »Postmoderne Phantasien. Zum mythologischen Schreiben im Prosawerk von Alban Nikolai Herbst (geb. 1955)«. Mit einem Werkverzeichnis, in: Euphorion 97 (2003), 499-516, hier: 499 .

6 Alban Nikolai Herbst / Alexander von Ribbentrop: »Die Dschungel. Anderswelt. Die Dschungelblätter«. Weblog, seit 2004, URL: http://albannikolaiherbst.twoday.net. 
nach Fertigstellung der vorliegenden Studie erfolgte, ${ }^{7}$ eine lose Pentalogie bilden, die fast die gesamte Schaffenszeit von Herbst seit Beginn seiner Publikationstätigkeit umspannt. Der Zusammenhang der Pentalogie ist nur ein loser, die Bücher werden bisher nicht explizit als eine solche angezeigt. Dies ist im Fall der drei Anderswelt ${ }^{8}$-Romane (Thetis, Buenos Aires und Argo) anders: im Klappentext des zweiten Romans (BA) wird auf den Zusammenhang der Bücher als Trilogie aufmerksam gemacht, im dritten (Argo) auf der Impressumsseite; zudem sind sie durch den gemeinsamen Untertitel miteinander verbunden. Bei diesen drei Romanen sind die inhaltlichen Anschlüsse enger als zu den zwei ersten ( $V G$ und $W B$ ). Kontinuität entsteht vor allem durch die Figur Hans Erich Deters, der allerdings in $V G$ noch nicht namentlich genannt wird, in $B A$ dann in den Hintergrund tritt. Eine genauere Darstellung der Zusammenhänge finden sich weiter unten in den Einleitungsabschnitten zum jeweiligen Buch.

Neben diesen Romanen hat Herbst noch etliche kleinere Romane, Erzählungen sowie in jüngerer Zeit auch Lyrikbände geschrieben, ${ }^{9}$ die aufgrund ihres Umfangs und Charakters eher als Nebenwerke anzusehen sind; es werden beispielsweise Motive aus den großen Romanen noch einmal aufgenommen und variiert. Die vorliegende Arbeit konzentriert sich auf den bis Anfang 2013 vorliegenden Teil der Pentalogie. Zusätzlich wird lediglich auf Meere im Zusammenhang mit dem Weblog genauer eingegangen.

Zur Darstellung seiner Poetik ziehe ich Herbsts poetologische Arbeiten heran. Wesentlicher Text ist diesbezüglich die Buchveröffentlichung der 2007 in Heidelberg gehaltenen Poetikvorlesungen. ${ }^{10}$ Daneben sind diverse Reden und Aufsätze in Literaturzeitschriften erschienen oder über Herbsts Website zugänglich.

Das Weblog Die Dschungel bildet neben den genannten Romanen und den poetologischen Texten einen weiteren wichtigen Teil meiner textlichen Arbeitsgrundlage. Dabei wird angenommen, dass es sich bei dem Weblog von Herbst um einen Teil seines Werkes handelt. Steffen Martus konstatierte bereits vor einiger Zeit in »einem Seitenblick auf Matthias Polityckis `Weiberroman` und die Computerphilologie«:

7 Argo erschien nach etlichen Verzögerungen im Herbst 2013: Argo. Anderswelt. Epischer Roman, Berlin 2013.

8 Im Folgenden als $A W$ abgekürzt.

9 Vgl. Marlboro. Prosastücke, Hannover 1981; Die blutige Trauer des Buchhalters Michael Dolfinger. Lamento/Roman, Göttingen 1986; Joachim Zilts Verirrungen, St. Gallen 1986; Die Orgelpfeifen von Flandern. Novelle, Frankfurt am Main 1993; Eine Sizilische Reise. Fantastischer Bericht [1995]. Roman, München 2002; Der Arndt-Komplex. Novellen, Reinbek 1997; In New York. Manhattan Roman, Frankfurt am Main 2000; Meere. Roman, hg. v. Denis Scheck, Hamburg 2003, verbotene Originalversion; Die Niedertracht der Musik. 13 Erzählungen, Köln 2005; Dem Nahsten Orient / Très Proche Orient. Liebesgedichte, übers. von Raymond Prunier, Frankfurt am Main 2007; Der Engel Ordnungen, Frankfurt am Main 2008; Azreds Buch. Geschichten und Fiktionen, Berlin 2010; Selzers Singen. Phantastische Geschichten und solche von fremder Moral, Berlin 2010; Das bleibende Thier. Bamberger Elegien, Berlin 2011; Die Fenster von Sainte Chapelle. Eine Reiseerzählung, Berlin 2011. Im August 2015 erscheint der Roman Traumschiff im mare-Verlag.

10 Alban Nikolai Herbst: Kybernetischer Realismus. Heidelberger Vorlesungen, Heidelberg 2008 (im Folgenden zit. als $K R$ ). 
Wichtig ist für die Philologie der Gegenwartsliteratur daran auf jeden Fall dies:

Die Homepage [...] gehört zum Gesamtwerk [...]. ${ }^{11}$

Auch wenn die Normativität dieser Feststellung für viele Autorenwebsites, die vielfach eher Werbemittel der Verlage darstellen, zu diskutieren wäre (bzw. wären die verschiedenen Formen von Autorenwebsites genauer zu untersuchen und die Aussage zu differenzieren), gilt dies sicherlich für Herbsts Weblog, wie später deutlich werden wird.

\section{Aufbau der Arbeit}

Das Ziel der vorliegenden Arbeit ist es, einen grundlegenden Beitrag zur Erforschung des herbstschen Werkes zu leisten. Die bisherige Sekundärliteratur besteht, wie gleich noch genauer dargestellt wird, vor allem aus älteren, eher kleinen Überblicksarbeiten, die wenig ins Detail gehen, sowie aus Aufsätzen und Buchkapiteln, die sich vor allem mit Teilaspekten oder Teilen des Werkes beschäftigen. Es stand daher eine ausführliche Darstellung und Einführung in die wichtigsten Werke von Herbst aus. Auf der einen Seite steht hier demnach die Notwendigkeit, die Grundstrukturen herauszuarbeiten, die Themen, Bezüge und Techniken zu benennen. Auf der anderen Seite setzt allein schon der Umfang des Euvres Grenzen und erfordert eine Konzentration auf die wichtigsten Themenfelder. In Darstellung und Interpretation wird daher auf Fragen der Identität und die Auseinandersetzung mit dem Verhältnis von Fiktion und Realität eingegangen. Weiter unten werden diese Themenkomplexe noch eingegrenzt und einige Begriffe erläutert, deren Verständnis in der Arbeit vorausgesetzt wird.

Jedem der oben genannten Bücher ist in chronologischer Reihenfolge ein Teil dieser Arbeit gewidmet, wobei die $A W$-Romane zusammen behandelt werden. In jedem Teil gibt es zwei Kapitel. Das erste beschäftigt sich mit Identitätsfragen und das zweite mit dem Themenkomplex Realität/Fiktion. Zu Beginn steht jeweils eine generelle Einführung mit einem schematischen und damit vereinfachenden Überblick über Handlung und Figuren, um ein besseres Verständnis der dann folgenden Ausführungen zu ermöglichen und um diese nicht durch Erläuterungen zu unterbrechen und dadurch zu verkomplizieren. Da die Einführung in die Zusammenhänge dennoch auch begleitend erfolgen muss, ist das `Identitätskapitel jeweils deutlich länger als das folgende >Realitätskapitel .

Aufgrund der Komplexität der Erzählsituation, der Leserführung und auch der Vielzahl an angedeuteten und verdeckten Anspielungen und Verweisen, die teils kryptisch oder gar hermetisch wirken, halte ich eine mikrophilologische Analyse bzw. ein close reading vieler Passagen für unabdingbar. Durch die Detailarbeit werden Motive herausgearbeitet, die für das Gesamtverständnis wichtig sind. Diese Detailarbeit geht teilweise über die Konzentration auf die untersuchten Begriffe hinaus. Das ist jedoch dem gleichzeitig fokussierten wie einführenden Charakter der Arbeit geschuldet. Es muss erst ein Grundverständnis der Gesamtzusammenhänge der kom-

11 Steffen Martus: » In der Hölle soll sie braten «. Zur Literatur der Literaturwissenschaft mit einem Seitenblick auf Matthias Polityckis `Weiberroman` und die Computerphilologie«, in: Zeitschrift für Germanistik 17/1 (2007), 8-27, hier: 21. 
plexen Erzähl- und Handlungsstruktur herausgearbeitet werden, um das Verständnis einzelner Themen zu ermöglichen.

\section{Methodik}

In dieser Arbeit versuche ich, ein Verständnis der Grundstrukturen und -motive in Herbsts Romanen herauszuarbeiten sowie seine Poetik sowohl anhand der impliziten Hinweise in den Texten als auch anhand der explizit ausgeführten Reflexionen in Aufsätzen und Reden, dem Weblog und den Poetikvorlesungen darzustellen. Durch die Wahl der wichtigsten Werke eines einzelnen Autors als Untersuchungsgegenstand, also einer werkmonographischen Arbeit, liegt eine autorzentrierte Perspektive nahe. Der Autor bzw. vor allem der Name Alban Nikolai Herbst fungiert dabei als eine Einheit stiftende Instanz für die Einheit des Werkes und für die Auswahl des der Arbeit zugrunde liegenden Textkorpus. Es wird davon ausgegangen, dass die Texte, die mit der Autorbezeichnung >Alban Nikolai Herbst $<$ über- oder unterschrieben sind, von diesem verfasst wurden und damit Relevanz für diese werkmonographische Arbeit haben.

Damit ist der Autor Herbst die Bezugsgröße für die Frage, was die Einheit des Werkes ausmacht, was die einzelwerkübergreifenden und verbindenden Themen sind. Es wird also gefragt, was die Ideen sind, die er in seinen »in bestimmter Form komponierten Texten zum Ausdruck [zu] bringen versuch $[\mathrm{t}] \ll^{12}$; dies bedeutet auch, nach den Intentionen des Autors zu fragen. Zur Herausarbeitung dieser Intentionen soll von einem `textorientierten Intentionalismus als »Interpretationsprogramm « ausgegangen werden, wie Tom Kindt es konzise zusammenfassend darlegt. ${ }^{13}$ Dabei wird davon ausgegangen, dass literarische Texte ebenso wie »Gesprächsbeiträge in pragmatischen Kommunikationssituationen ${ }^{14}{ }^{14}$ gedeutet werden sollten und die Annahme gelte, dass Autoren ihre Texte mit dem Ziel gestalten, verstanden zu werden. Textorientierung bedeutet dabei, dass von einem solchen gestalteten Text ausgegangen wird und das Ziel dabei ist, eine Textbedeutung herauszuarbeiten. Dafür wird als sinnvoll erachtet, auch textexterne Autoräußerungen einzubeziehen, die beispielsweise einem zeitgenössischem Leser nicht zur Verfügung standen. In dieser Hinsicht werden meist später oder gar posthum veröffentlichte Tagebücher oder Briefwechsel genannt. Auch veröffentlichte Selbstauskünfte oder poetologische Äußerungen werden hierunter gefasst.

Dementsprechend fungiert hier auch Herbst als `Auskunftgeber $\triangleleft$ d. h. es werden poetologische, werkgenetische und auch selbstinterpretierende Passagen aus Reden, Weblog und Poetiktexten hinzugezogen. Mit seinem Weblog liegt eine wohl bislang fast einzigartige Quelle vor, die sich im Gegensatz zur Untersuchung historischer Autoren und der posthumen Verwendung von Tagebüchern durch eine viel größere zeitliche Nähe auszeichnet. Solche textexternen Hinweise erhalten jedoch weniger Ge-

12 Tom Kindt: Unzuverlässiges Erzählen und literarische Moderne. Eine Untersuchung der Romane von Ernst Weiß, Tübingen 2008, 14.

13 Vgl. ebd., 14-25.

14 Ebd., 23. 
wicht gegenüber »textinterne[n] Evidenzen ${ }^{15}$. Die Interpretationskontexte können durch das Einbeziehen weiterer Quellen eingeschränkt werden. Hilfreich ist dies vor allem durch die Aufdeckung von Intertexten, die den Kontext für verwendete Begriffe einschränken. Dies ist wichtig für einen `theorielastigen`Autor wie Herbst, bei dem sich begriffstheoretische und philosophische Reflexionen in den Texten finden. Besonders deutlich wird die Vorgehensweise in der unten dargelegten Herausarbeitung des Wirklichkeitsbegriffs in Die Verwirrung des Gemüts, der für das Gesamtwerk prägend ist. Durch das Hinweisen auf wichtige Bezugstexte im Weblog ebenso wie in anderen Quellen wird es möglich, versteckte Hinweise im Text zu identifizieren und nutzbar zu machen.

Bei Herbst im Besonderen ist es durchaus auch nötig, auf autobiographische Elemente hinzuweisen. Dies dient allerdings weniger dazu, eine psychologistische Interpretation der Texte zu unternehmen, als Herbsts poetisches Programm aufzuzeigen, das die Verarbeitung eigener Erlebnisse im Rahmen der Autofiktionalisierung explizit einschließt. Herbst selbst hält die Trennung von Autorperson und Werk nicht für richtig, da er in seiner Poetik gerade die Ähnlichkeiten und die Herstellung von $\mathrm{Zu}$ sammenhängen betont, im Gegensatz zu binär-differenzierenden Unterscheidungen, wie im Laufe der Arbeit deutlich werden wird. In einem Weblogkommentar entgegnet er einem anderen Kommentator:

Daß Sie Person und Werk getrennt sehen möchten, halte ich [...] für einen methodischen Fehler. Überhaupt mißtraue ich Trennungen. ${ }^{16}$

Er geht gar so weit, in einer Reflexion über die eigene Psychoanalyse zu behaupten, »einige Grundfesten [s] einer heutigen Ästhetik« würden sich aus Kindheitserfahrungen ableiten lassen. Wichtig ist aber der Zusatz:

[...] die sich vom biografischen Anlaß, weil die Dichtung über die Jahre viel zu ausgearbeitet ist, längst abgelöst hat $\left[\ldots . .{ }^{17}\right.$

Dies bestätigt sich auch in der Betrachtung der Romane. Während bei bestimmten Aspekten in VG sich mithilfe von Anmerkungen im Weblog und inzwischen bekannten Informationen eine Erklärung mit Bezug auf die Biographie anbieten würde, da die Thematik noch näher an der Lebenswelt des Autors ausgerichtet ist, sind die fiktiven Welten der späteren Romane so weit von dieser entfernt, dass Bezüge nur noch abstrakt möglich sind. In allen Romanen sind autofiktionale Bezüge enthalten, spielen aber lediglich dahingehend eine Rolle, Herbsts Wirklichkeitsverständnis darzustellen. Wenn also seine Poetik herausgearbeitet werden soll, so ist es wichtig, seine außertextlichen Äußerungen einzubeziehen. Dass das Verständnis der Bücher ohne das Wissen um bestimmte Intertexte und Informationen erschwert ist, vermutet auch Herbst:

15 Kindt: Unzuverlässiges Erzählen und literarische Moderne, 24.

16 URL-2, 15. Juni 2005.

17 URL-3, 14. Juni 2005. 
Es bedeutet des weiteren [sic!], daß diese Bücher [die ihn geprägt haben] auch Schlüssel für meine Arbeiten sind; vieles, das manchen hermetisch vorkommen kann, löst sich über sie auf. ${ }^{18}$

Auf biographische Bezüge wird in den Interpretationen der einzelnen Bücher aber verzichtet. Erst im Kontext der Betrachtung des Autofiktionsbegriffs im Weblog-Kapitel wird darauf eingegangen.

\section{Begriffe}

Eine Fragestellung, die solch weite Begriffe wie $>$ Identität $<$ und $>$ Realität $<$ enthält, ist darauf angewiesen, den begrifflichen Kontext einzuschränken. Um überhaupt festzustellen, was diese Begriffe bedeuten und welche Fragen in Herbsts Werk damit verbunden sind, wurde eine noch recht allgemein gehaltene Vorstellung der Begriffe an die Texte herangetragen und mit Hinweisen aus diesen abgeglichen, wodurch der Bezugsrahmen eingeschränkt wurde. Wie eben dargestellt wurden zudem außertextliche Hinweise des Autors hinzugezogen, um relevante Intertexte auszumachen.

An dieser Stelle soll lediglich eine kurze Einführung in Begriffe gegeben werden, die in den Kapiteln der Untersuchung verwendet werden. Dabei liegt bezüglich des Identitätsbegriffs der Fokus auf sozialpsychologischen Fragestellungen, die vor allem in $V G$ eine Rolle spielen. In $W B$ wird von diesen eher abstrahiert, während sie in $T A$ wieder aufgegriffen werden. Weitere Aspekte von Identität wie die mythische Identität und Identitätsfragen in Anlehnung an Adorno werden im Laufe der Kapitel behandelt. Bezüglich des Realitätsbegriffs liegt der Fokus vor allem auf der Unterscheidung zwischen den Begriffen >Realität und >Wirklichkeit‘. Diese wird v. a. in direktem Bezug auf $V G$ herausgearbeitet, ist aber als allgemeine Grundlage im Denken von Herbst anzunehmen, wie immer wieder deutlich wird.

\section{Identität}

Der Begriff der `Identität` ist durch seinen vieldeutigen Gebrauch, der durch die Verwendung sowohl in einer Vielzahl unterschiedlicher Wissensgebiete als auch in der Alltagssprache bedingt ist, ein kontroverser Begriff. ${ }^{19}$ Ganz allgemein bezeichnet Identität (spätlateinisch ıidentitas : Wesenseinheit; von lateinisch sidem«: derselbe, dasselbe, der gleiche) die Übereinstimmung und völlige Gleichheit eines Subjekts oder Objekts mit dem, was es tatsächlich ist, also mit sich selbst. Dies wird in der Philosophie als numerische Identität bezeichnet und bedeutet eine zweistellige Relation, in der jede Entität ausschließlich mit sich selbst steht. ${ }^{20}$ Aus der Identität von A und B folgt nach dem Identitätsprinzip, »dass alle Eigenschaften von A zugleich auch Eigenschaften von B sind (und umgekehrt) « ${ }^{21}$. Die zweistellige Relation impliziert die

18 URL-4, 13. Jan. 2012.

19 Vgl. dazu Jürgen Straub: »Identität«, in: Friedrich Jaeger / Burkhard Liebsch (Hg.): Handbuch der Kulturwissenschaften. Grundlagen und Schlüsselbegriffe, Bd. 1, Stuttgart / Weimar 2004, 277-303, hier: 277 , dort auch diesbezüglich weiterführende Literaturangaben.

20 Vgl. Michael Quante (Hg.): Personale Identität, Paderborn u. a. 1999, 7.

21 Ebd. 
Unterscheidung von zwei miteinander zu vergleichenden Teilen, obwohl gerade von Übereinstimmung und Wesensgleichheit die Rede ist. ${ }^{22}$ >Identität steht also sowohl in Opposition als auch in Korrelation zum Begriff der `Differenz

In der Philosophie wird im Zusammenhang der Identitätsfrage bereits früh auf das Paradoxon vom Schiff des Theseus verwiesen. Überliefert ist es durch Plutarch:

Das Schiff, auf dem Theseus mit den jungen Menschen ausfuhr und glücklich heimkehrte, den Dreißigruderer, haben die Athener bis zu den Zeiten des Demetrios von Phaleron aufbewahrt, indem sie immer das alte Holz entfernten und neues, festes einzogen und einbauten, derart, daß das Schiff den Philosophen als Beispiel für das vielumstrittene Problem des Wachstums diente, indem die einen sagten, es bleibe dasselbe, die anderen das verneinten. ${ }^{23}$

So wird die Frage gestellt, was das Schiff eigentlich ausmacht (was im Zusammenhang mit der Substanzfrage steht). Durch Thomas Hobbes kommt ein weiterer Gedanke hinzu:

Denn wenn ein Schiff, beispielsweise das des Theseus (über dessen Verschiedenheit, wenn man die alten Planken nach und nach herausnähme und durch neue ersetzte, so daß es ständig wiederhergestellt würde, sich seinerzeit die athenischen Sophisten stritten), nach Austausch aller Planken numerisch dasselbe wäre wie zu Beginn, und jemand hätte die alten Planken, ganz wie sie herausgenommen wurden, aufbewahrt und, was er so aufbewahrt hatte, hernach in derselben Anordnung wieder zusammengefügt, also das Schiff neu aufgebaut, so unterliegt es keinem Zweifel, daß auch es numerisch dasselbe Schiff wäre wie zu Anfang, und wir hätten so zwei numerisch identische Schiffe, was völlig abwegig ist. ${ }^{24}$

Der paradoxale Charakter des Problems kommt im Grunde erst durch Hobbes' Erweiterung zustande. Die Frage lässt sich nun im Kontext neuerer medizinischer Entwicklungen und Vorstellung von zukünftigen Entwicklungen auch auf den Menschen übertragen. In den $A W$-Romanen wird diese Frage thematisiert und in den entsprechenden Kapiteln wird daher darauf verwiesen.

In den hier zunächst relevanten Gebieten handelt es sich bei dem Subjekt oder Objekt vornehmlich um eine (menschliche) Person. ${ }^{25}$ Eine Differenzierung verschiedener Formen von Identität lässt sich anschaulich über eine Zuordnung von Subjekt und

22 Daher erachtete David Hume die Vorstellung von Identität als einen »haltlosen Scheingedanken « (Dieter Henrich: »Identität‘. Begriffe, Probleme, Grenzen « [1979], in: Odo Marquard / Karlheinz Stierle (Hg.): Identität, 2., unveränd. Aufl., München 1996, 133-186, hier: 139). Etwas Einzelnem könne keine Identität, sondern lediglich Einheit zugesprochen werden, da Identität eine Beziehung von etwas zu etwas sei. Sie sei daher "eine Fiktion, welche die Kontinuität im Wechsel unserer Vorstellungen von Dingen zu einer Einheit von Dingen hypostasiert« (ebd.).

23 Plutarch: Theseus, in: Große Griechen und Römer, übers. von Konrat Ziegler, Bd. 1, Zürich 1954, 60.

24 Thomas Hobbes: Der Körper [De Corpore, 1655], in: Ders.: Elemente der Philosophie. Erste Abteilung, hrsg. und übers. von Karl Schuhmann, Hamburg 1997, Zweiter Teil, Kapitel XI, 141f.

25 Dies ist im Kontext dieser Arbeit durchaus von Bedeutung, da in TA (wenn nicht schon in WB) Identitätsfragen auch in Bezug auf nicht menschliche Wesen, die sogenannten Holomorfen, behandelt werden. Der Bezug wird allerdings gerade durch die Menschenähnlichkeit hergestellt. 
Objekt erreichen. Ist das Objekt der Identifizierung eine Person, das Subjekt aber andere Personen, so spricht man von sozialer Identität. Wenn das Objekt der Identifizierung Gruppen, Organisationen oder Kulturen sind, und das Subjekt eine Person, die das jeweilige System beschreibt und dadurch kenntlich macht, so handelt es sich um kulturelle oder kollektive Identität. Personale Identität, um die es im Folgenden vor allem gehen wird, wird schließlich als der Prozess gefasst, »in dem eine Person sich selbst identifiziert, indem also Subjekt und Objekt der Identifizierung in einer Person vereint sind ${ }^{26}$.

Die Unterscheidung zwischen Subjekt und Objekt kann begrifflich auch durch die Perspektive der Identifizierung bezeichnet werden. Für die soziale wie die kulturelle Identität gilt, dass sie aus der Außenperspektive definiert werden. Denn auch das Individuum, das als Mitglied eines sozialen Systems dieses definiert, ist nicht identisch mit ihm. Bei der personalen Identität handelt es sich dagegen um eine Identifizierung aus der Innenperspektive. Diese ist wiederum auch auf Signale aus der Außenperspektive angewiesen, sodass personale und soziale Identität nicht vollständig unabhängig voneinander sind.

Es gibt unterschiedlichste Möglichkeiten, sich selbst zu beschreiben und damit die eigene Identität zu definieren. Die wohl gängigste davon ist die Form der Aufzählung, die Eigenschaften, Fähigkeiten, Besitz, Erfahrungen oder auch Wünsche und Pläne nennen kann. Dabei haben sich bestimmte Definitionsmuster gesellschaftlich herausgebildet, die von größerer Relevanz sind als andere. In der Regel ist es jedoch mehr als ein Merkmal, das einen bestimmten Aspekt der Identität beschreibt, sodass es sinnvoll ist, von Definitionsräumen zu sprechen, also von einer »Merkmalmenge, die sich in einem multidimensionalen Raum eingeordnet vorstellen läßt ${ }^{27}$. Innerhalb der Definitionsräume der Identität können zwei weitere Räume unterschieden werden, der Begriffsraum und der Interaktionsraum. Der Begriffsraum umfasst die »strukturierte Menge an Designata ${ }^{28}$, die begrifflich gefassten Kriterien der Selbstbeschreibung; im Interaktionsraum werden diese Designata in gesellschaftlichen Beziehungen angewandt und ausgehandelt, wodurch ihnen erst ein Sinn gegeben wird, der sowohl subjektiv als auch in der Interaktion mit anderen gültig ist. Es gibt verschiedene, auch empirisch gestützte Versuche der Systematisierung, denen gemeinsam ist, dass sie sich auf die Stellung der Person in der Gesellschaft sowie auf ihre wichtigsten Bezugsfelder darin beziehen. ${ }^{29}$ Bei de Levita findet sich eine Aufzählung, die zum einen nicht zu differenziert und dennoch beispielhaft ist, zum anderen so allgemeingültig zu sein scheint, dass sie mit vielen Aspekten übereinstimmt, die sich auch aus den Texten von Herbst herauslesen lassen. $\mathrm{Zu}$ den von de Levita so benannten »Identitätsfaktoren « ${ }^{30}$ kann alles werden, was eine Person betrifft. Die Identitätsfaktoren können in zuge-

26 Hans-Peter Frey / Karl Haußer: »Entwicklungslinien sozialwissenschaftlicher Identitätsforschung «, in: dies. (Hg.): Identität. Entwicklungen psychologischer und soziologischer Forschung, Stuttgart 1987, 3-26, hier: 4 .

27 Ebd., 14.

28 Ebd., 15.

29 Siehe dazu ebd.

30 Vgl. David J. de Levita: Der Begriff der Identität [1965], 2. Aufl., Frankfurt am Main 1976, 210-226, 232-234. 
schriebene, erworbene und übernommene eingeteilt werden. Die zugeschriebenen sind nicht frei wählbar, zu ihnen zählen Alter, Geschlecht, Herkunft, Nationalität, soziale Schicht. Verallgemeinert bezeichnen sie die Zugehörigkeit zu einer Gruppe, die nicht selbst ausgesucht werden kann. Die erworbene Identität ist dagegen wählbar oder wird aufgrund von individuell erbrachter Leistung zuerkannt. Zu den zugehörigen Faktoren zählen beispielsweise Beruf, Amt oder Titel, aber auch eine Vereinsmitgliedschaft wäre hier einzuordnen. Die übernommene Identität ist eine Spezialform und beispielsweise in psychoanalytischen Therapien zu finden: jemand übernimmt die Rolle eines Helfers, der andere die desjenigen, dem geholfen wird. Wichtige Identitätsfaktoren, die besonders sind, weil sie keinen Rollen entsprechen, sind wiederum der Körper, der Name und die Lebensgeschichte. ${ }^{31}$ De Levita sieht den Körper als den wichtigsten Identitätsfaktor an, da er in den wesentlichen anderen enthalten ist. Die Bedeutung des Namens und der Namengebung begründet er vor allem durch die kulturgeschichtliche Konstanz, in der eine enge Beziehung zwischen Namen und Träger besteht. Gerade der Körper, seine Eigenschaften und das Verhältnis der Person zu diesem, spielt in verschiedenen Identitätstheorien eine wichtige Rolle, zum Teil in Abgrenzung oder Gegenüberstellung zum Bewusstsein (z. B. bei John Locke).

In der sozialwissenschaftlichen Identitätsforschung ist naheliegenderweise das Verhältnis von Individuum und Gesellschaft wichtig, nach der oben genannten Unterscheidung das Verhältnis zwischen Innen- und Außenperspektive. Es wird angenommen, dass sich die Identität von >Außen nach Innen` entwickelt, das Individuum in der Selbstreflexion die in der sozialen Interaktion angebotenen Merkmale mit der subjektiven Innenwelt in Einklang bringt. So sind die Definitionsräume einerseits als Sammlung der Identifizierungsmerkmale aus der Außenperspektive zu sehen, was durch den differenzierenden Begriff des Interaktionsraums betont wird und als soziale Identität bezeichnet wird, andererseits als übernommene und synthetisierte Merkmale in der Innensicht. Frey und Haußer betonen die Bedeutung der terminologischen Trennung »zwischen >öffentlicher oder >sozialer Identität im Sinne der Identifizierung einer Person durch andere (Außenperspektive) und Identität als SelbstErfahrung (Innenperspektive) « ${ }^{32}$, wobei letztere als persönliche Identität bezeichnet wird. Der Prozess der Herstellung und Darstellung der persönlichen Identität, von ihnen als Identitätsdynamik benannt, besteht nach ihrer Auffassung in der Herstellung von Relationen zwischen dem Außen und dem Innen, aber auch zwischen diesen

31 Vgl. Levita: Der Begriff der Identität, 215-225.

32 Frey/Haußer: »Entwicklungslinien«, 17. 
beiden in umgekehrter Richtung. Innerhalb der Identitätsdynamik unterscheiden sie zwischen vier wesentlichen Identitätsproblemen als »Fragestellungen

a) nach der Relation zwischen Außen- und Innenperspektive (Realitätsproblem),

b) nach der Relation zwischen verschiedenen Elementen innerhalb der Innenperspektive (Konsistenzproblem),

c) nach Stabilität und Wandel dieser Elemente (Kontinuitätsproblem) sowie

d) nach der Herstellung und Darstellung einer einmaligen, einzigartigen Identität (Individualitätsproblem).«33

Diese vier Fragestellungen werden unten in den Untersuchungen der Romane angewendet bzw. können als Probleme der Figuren identifiziert werden.

\section{Realität und Wirklichkeit}

Die Begriffe `Realität` und `Wirklichkeit` werden in Herbsts Texten im Gegensatz zu dem der `Identität $<$ explizit verwendet, weswegen sich ihre Bestimmung auch stärker am Text orientieren kann. Seit $V G$ verwendet Herbst einen Wirklichkeitsbegriff, der auf der Unterscheidung der Begriffe >Realität ‘ und >Wirklichkeit beruht. Diese leitet sich aus der Begriffsgeschichte her und ist durch Herbsts Lektüre verschiedener Philosophen und Psychologen grundiert. Die Begriffsgeschichte zieht sich durch die gesamte (westliche) Philosophiegeschichte. Es kann daher im Folgenden nicht um den Versuch einer umfassenden Rekonstruktion der Begrifflichkeit gehen.

Entgegen dem seit langem üblichen alltagssprachlichen Gebrauch der Begriffe $>$ Realität ` und >Wirklichkeit a als Synonyme, wird in VG zwischen diesen differenziert bzw. zumindest auf die Unterscheidungsmöglichkeit hingewiesen. An zwei kurz aufeinanderfolgenden Stellen wird auf die Unterscheidung von Realität und Wirklichkeit hingewiesen. In der ersten wird beschrieben, dass die Helligkeit, die in die Wohnung einer Figur dringt, ihn »davon abhielt, die Realität für Wirklichkeit zu halten« (VG, 137). Wenig später wird die Unterscheidung explizit thematisiert: »Was ist das: die Realität? Ist doch bezeichnend, daß das sehr viel treffendere Wort WirkLICHкEIT durch jenen Begriff geradezu unbemerkt ersetzt worden ist.« $(V G, 146)$ Da eine Definition der Begriffe nicht gegeben wird, bleibt dem Leser nur der Blick auf die Philosophie, in der die beiden Begriffe früher bereits unterschieden wurden.

Zunächst gibt es jedoch alltägliche Verwendungsweisen und ein entsprechendes (heutiges) Alltagsverständnis der Begriffe >Wirklichkeit $<$ bzw. $>$ Realität $`$ diesseits aller Theorien ${ }^{34}$, wie es Wolfgang Welsch in einem anschaulichen Überblick formuliert. Welsch konstatiert eine außerordentliche Vielfalt selbst in der unreflektierten alltäglichen Verwendung der Begriffe `wirklich` und `Wirklichkeit` und differenziert zwischen sieben Hauptbedeutungen (wobei auch er zunächst von der Synonymie von

33 Ebd.

34 Wolfgang Welsch: »Wirklich`. Bedeutungsvarianten - Modelle - Wirklichkeit und Virtualität«, in: Sybille Krämer (Hg.): Medien, Computer, Realität. Wirklichkeitsvorstellungen und Neue Medien, Frankfurt am Main 1998, 169-212, hier: 172. 
Wirklichkeit und Realität ausgeht, d. h. in seinen Überlegungen und Beispielen sind die Begriffe weitestgehend austauschbar) ${ }^{35}$ :

- die Wirklichkeit als das Insgesamt des Gegebenen (die Welt, wie sie ist),

- als das Tatsächliche bzw. Hart-Faktische,

- als das handgreiflich Geschehene (im Gegensatz zur Simulation),

- als die wahrhafte Verkörperung eines Wesens,

- als das Außerordentliche, das eine neue Wirklichkeitsreihe begründet,

- als das Wirksame und Intensive sowie

- die höhere Wirklichkeit als das Maß des scheinbar Wirklichen. ${ }^{36}$

Wenn es denn überhaupt eine klare Standardbedeutung geben sollte, so wäre es auch Welsch zufolge die der Tatsächlichkeit, des harten Faktenbestands, an dem sich verschleiernde Ausführungen im Diskurs messen lassen müssen; ${ }^{37}$ auch die scheinbar objektive Außenwelt der Dinge und Vorgaben, mit deren Unveränderlichkeit der Mensch konfrontiert ist.

Welsch fügt jedoch seiner Begriffsrekonstruktion die Überlegung an, auch im alltäglichen Sprachgebrauch könnten "professionelle Auffassungen der Wirklichkeit ihren Niederschlag gefunden haben «, sodass man es »oft mit historischen Sedimenten diverser metaphysischer Auffassungen $\aleph^{38}$ zu tun habe, um die es im Folgenden geht.

Auch wenn die Beschäftigung mit diesem Themenfeld wohl mit Beginn jeglicher philosophischer Reflexion einsetzt, ist Aristoteles noch in der Anfangszeit der Begriffsgeschichte zu verorten. ${ }^{39}$ Bei ihm geht es gleich sehr differenziert um die Unterscheidung zwischen dem Wahrnehmbaren, dem Denkbaren und dem Sein überhaupt, die von verschiedenen Begriffen bezeichnet werden. Während Platon das Wort $\pi \rho \alpha \dot{\gamma} \mu \alpha^{40}$

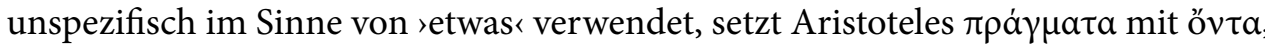
dem Seienden überhaupt gleich. Dadurch erhält es »eine ontologische Funktion als Oberbegriff des Wahrnehmbaren, der aỉ $\theta \eta \tau \tau \dot{\alpha}$, und des Wissbaren/Denkbaren, der voๆ $\dot{\alpha}^{\prime}{ }^{41}$. Für unseren Sachverhalt bedeutsam kommt durch das ebenfalls das Begriffsfeld prägende $\chi \rho \tilde{\eta} \mu \alpha$ - was schon bei Aristoteles die gegenüber der ursprünglichen

35 Welsch gibt dabei den interessanten Hinweis auf den Gebrauch des Wortes >Realitätsverlust $<$, was eigentlich durch das nicht gebräuchliche >Wirklichkeitsverlust ‘ bezeichnet werden müsste. Der Ausdruck >real wird also vorzugsweise dafür verwendet, »die Härte, Widerständigkeit und Unumgänglichkeit der Wirklichkeit zu bezeichnen « (Welsch: »Wirklich«, 175). Dies untermauert die Behauptung Wilhelm Weischedels, eine solche Unterscheidung ginge »nicht ohne begriffliche Willkür«, siehe Wilhelm Weischedel: »Die Frage nach der Wirklichkeit«, in: Wirklichkeit und Wirklichkeiten. Aufsätze und Vorträge, Berlin 1960, 118-141, hier: 119.

36 Vgl. Welsch: »Wirklich«, 175-184.

37 Dieser Gebrauch ist spätestens seit der zweiten Hälfte des 17. Jahrhunderts umgangssprachlich üblich, vgl. Tobias Trappe: »Wirklichkeit«, in: Joachim Ritter / Karlfried Gründer / Gottfried Gabriel (Hg.): Historisches Wörterbuch der Philosophie, Bd. 12, Basel 2004, 829-846, Sp. 829.

38 Welsch:»Wirklich«, 184.

39 Vgl. dazu insgesamt Hans Heinz Holz: »Realität«, in: Karlheinz Barck (Hg.): Ästhetische Grundbegriffe. Historisches Wörterbuch in sieben Bänden, Bd. 5, Stuttgart/ Weimar 2003, 197-227.

40 Zusammen mit dem lateinischen ^res` bestimmt dieses Wort das Begriffsfeld, das also, übertragen ins Deutsche, durch das >Ding` oder die `Sache` geprägt ist.

41 Holz: »Realität«, 202. 
Bedeutung `brauchbare Dinge` verallgemeinerte, nämlich `Geld(wert)<, erhält, die noch heute im Neugriechischen gültig ist - ein weiterer Aspekt, der unmittelbare Bezug zum Menschen hinzu: »Denn $\chi \rho \tilde{\eta} \mu \alpha$ ist immer die Sache, mit der die Menschen befaßt sind, gerade nicht die Sache an sich selbst (res ipsa). « ${ }^{42}$

Die eigentliche Wortgeschichte von $>$ Realität $\triangleleft$ beginnt jedoch im Lateinischen mit dem Wort >res‘. Dieses integriert dann auch den gerade eingeführten Aspekt und "meint sowohl die Sachen, um die sich die Menschen kümmern, Dingliches sowohl wie Beziehungen, als auch die Sachen selbst an sich, unabhängig vom Menschen «43. Durch die Antike und das Mittelalter hindurch gab es einige Bedeutungsverschiebungen bezüglich entgegengesetzter Begriffspaare, die durch Übertragung aus dem Griechischen ins Lateinische und später auch weiter ins Deutsche entstanden und teilweise geradezu eine Verkehrung ins Gegenteil bewirkt haben. Dies ist vermutlich als Grund anzunehmen, warum der Begriff >realitas` erst spät ins Deutsche übernommen wurde. Zudem war auch seit dem 13. Jahrhundert das Wort /Wirklichkeit gebräuchlich geworden, das von Meister Eckhart wiederum als Übersetzung des aristotelischen Begriffs $\dot{\varepsilon} \vee \varepsilon \dot{\varepsilon} \rho \gamma \varepsilon\llcorner a$ (bzw. des lateinischen `actus`) eingeführt worden war, und »die Tatsächlichkeit als ein Wirken bzw. als etwas im Wirken sich Herstellendes begreift«; damit hat es dem »statischen Terminus Realität lange im Weg gestanden « 44 . Ähnlich war vorher aber auch schon `res` mit `ens` (dem Seienden) gleichgesetzt worden, wodurch »die Beziehung auf den Menschen, auf seinen Willen und sein zusammentreibendes Denken in den Mittelpunkt ${ }^{45}$ gerückt wurde. Bis hierhin bleibt festzuhalten, dass sich verschiedene Begriffe teils ablösen, teils nebeneinander bestehen, dass zwei Aspekte aber immer wieder von Bedeutung sind; auf der einen Seite die unabhängig vom Menschen bestehenden Dinge, auf der anderen Seite der Bezug auf eine Aktivität vonseiten des Menschen.

Schopenhauer In genau diese Richtung zielt auch Schopenhauer, der in unserem Zusammenhang besonders wichtig ist, da sich Herbst in einem kleinen, aber ins spätere Zentrum seiner Poetik zielenden Hinweis auf diesen bezieht. In den Poetikvorlesungen versucht er, den titelgebenden Begriff »kybernetischer Realismus« in einem Satz zu charakterisieren:

Damit ist, grob umrissen, eine Auffassung gemeint, die sich von Schopenhauers auf Kant fußendem Satz herleitet, Wirklichkeit sei das, was wirke. ${ }^{46}$

Dabei scheint die gesamte »terminologische Verwirrung «47 bei Schopenhauer, die die Begriffe »Kausalität«, "Wirksamkeit» und auch »Materie« umfasst, gar nicht mitgedacht zu sein. Wenn man einmal von der Verbindung zum »kybernetischen

42 Ebd.

43 Ebd., 203.

44 Ebd., 206.

45 Ludwig Landgrebe: »Die Aporien des Dingbegriffs und die Fremdheit der Welt«, in: Actes du XIème Congrès International de Philosophie, Bd. 3, Brüssel 1953, 146f., zit. nach Holz: »Realität«, 204.

$46 K R, 21$.

47 Peter Welsen: Schopenhauers Theorie des Subjekts. Ihre transzendentalphilosophischen, anthropologischen und naturmetaphysischen Grundlagen, Würzburg 1995, 206. 
Realismus« an dieser Stelle absieht, die später besprochen wird, ${ }^{48}$ so bleibt eine scheinbar simple, fast schon tautologische Begriffserläuterung. Dennoch ist sie wichtig und durchaus ernst zu nehmen. Zum einen scheint sie in ihrer Schlichtheit nicht nur für den `späteren ২ Herbst zentral zu sein, wie das Zitat belegt; vielmehr zeigt schon ein Satz aus $V G-$

Ist doch bezeichnend, daß das sehr viel treffendere Wort WIRKLICHKEIT durch jenen Begriff [d. i. Realität] geradezu unbemerkt ersetzt worden ist. $(V G, 146)$

- deutliche Parallelen in Formulierung und Typographie zur vermutlich in der Vorlesung gemeinten Passage in Schopenhauers Die Welt als Wille und Vorstellung (1819/ 1859):

Ursach und Wirkung ist also das ganze Wesen der Materie: ihr Seyn ist ihr Wirken. [...] Höchst treffend ist daher im Deutschen der Inbegriff alles Materiellen WIRKLICHKEIT genannt, welches Wort viel bezeichnender ist, als Realität. ${ }^{49}$

Die schopenhauersche Auffassung des Begriffs scheint also schon in $V G$ zugrunde zu liegen. Zum anderen deutet auch die schlichte Begriffsfassung über sich hinaus. Umfasst Wirklichkeit alles, was wirkt, so ist sie umfassender als die durch ihre etymologische Herkunft auf die materielle Ding-Welt beschränkte Realität. Andererseits ist sie (zumindest mit dem Schopenhauer-Bezug) an das wahrnehmende Subjekt gebunden und auf dieses begrenzt. Für Schopenhauer ist die Wirklichkeit auf den Verstand (des Subjekts) begrenzt: »Umgekehrt ist alle Kausalität, also alle Materie, mithin die ganze Wirklichkeit, nur für den Verstand, durch den Verstand, im Verstande. ${ }^{50}$ Die Suche nach einer »wirkliche[n], d. i. wirkende[n] Welt« außerhalb der Welt als Vorstellung ist für ihn sinnlos, obgleich er bestreitet, dass es sich um »Lüge» oder »Schein « handelt. ${ }^{51}$ Holz fasst dennoch zusammen: "Wenn das Ding an sich uns unzugänglich bleibt, dann ist Wahrnehmen ein Für-wahr-halten, nicht ein Wahr-sein. Unsere `wirkliche` Welt ist eine Scheinwelt, die unser Wille, durch Bedürfnisse und Zwecke geleitet, uns vorstellt. " $^{52}$

Watzlawick Ein weiterer konkreter Bezugstext, der sich durch außertextliche Hinweise hinzuziehen lässt, ist das sehr bekannt gewordene Buch des Psychoanalytikers Paul Watzlawick Wie wirklich ist die Wirklichkeit? (1976). Über 20 Jahre nach der Niederschrift von $V G$ weist Herbst mehrfach im Weblog auf die Bedeutung dieses Buchs für ihn in dieser Zeit hin. Erst geschieht dies in einem Kommentar, in dem Herbst gleich auch das für ihn zentrale Thema benennt:

48 Vgl. Abschnitt 7.2.6 auf Seite 341.

49 Arthur Schopenhauer: »Die Welt als Wille und Vorstellung « [1819/1859], in: Ders.: Werke in fünf Bänden, Bd. 1, hg. v. Ludger Lütkehaus, Zürich 1988, 38 [d. i. \$ 4].

50 Ebd., 41 [d. i. $\$ 4]$.

51 Ebd., 45 [d.i. $\$ 5]$.

52 Holz: »Realität«, 217. 
Seit [...] DIE VERWIRRUNG DES GEMÜTS von 1983 habe ich, ausgehend von [...] Watzlawick, den geheimdienstlichen Begiff [sic!] der Desinformation immer wieder poetologisch in Bewegung zu setzen versucht $[\ldots] .53$

In ganz ähnlicher Formulierung, aber noch ausdrücklicher schreibt er zwei Jahre später in einem Theorie-Eintrag:

[...] Wie wirklich ist die Wirklichkeit? heißt ein Buch Paul Watzlawiks [sic!], das mich als jungen Mann ausgesprochen geprägt hat und am Anfang meiner Poetik der Desinformationen stand: [...] Die Verwirrung des Gemüts (1983).54

Ähnlich wie bei Schopenhauers Formulierung findet sich auch diesmal eine sehr knappe Übereinstimmung in VG. Genau dieser für Watzlawicks Buch zentrale Begriff der Desinformation wird gebraucht und fällt durch seine vor allem durch die Verwendung des bestimmten Artikels herausgehobene Stellung als ungewöhnlich auf:

Stets ist, was ich wahrnehme, so beschaffen, daß ich es durcheinanderbringen muß.

Die Desinformation ist kausal! Ist kausal, um Gottes willen! (VG, 221)

Selbst für einen mit Watzlawicks Terminologie bekannten Leser ist der Bezug nicht zwangsläufig herzustellen. Im Nachhinein ist der Bezug jedoch auffällig.

Die zugrunde liegende Auffassung von Wirklichkeit bei Watzlawick teilt sich in zwei »Begriffe von Wirklichkeit« auf, die im Grunde das pointiert noch einmal formulieren, was oben als Unterscheidung zwischen `Realität und `Wirklichkeit herausgearbeitet wurde.

Der erste [Begriff von Wirklichkeit] bezieht sich auf die rein physischen und daher weitgehend objektiv feststellbaren Eigenschaften von Dingen und damit entweder auf Fragen des sogenannten gesunden Menschenverstands oder des objektiven wissenschaftlichen Vorgehens. Der zweite beruht ausschließlich auf der Zuschreibung von Sinn und Wert an diese Dinge und daher auf Kommunikation. ${ }^{55}$

Die »Wirklichkeit erster Ordnung", wie sie bei Watzlawick auch bezeichnet wird, umfasst also die Wirklichkeitsaspekte, die sich auf den Konsensus der Wahrnehmung und vor allem auf experimentelle, wiederholbare und daher verifizierbare Nachweise beziehen; sie entspricht in der oben ausgeführten philosophiegeschichtlichen Herleitung dem Begriff $>$ Realität $\measuredangle$. Die »Wirklichkeit zweiter Ordnung « bezeichnet das, was die Tatsachen der Wirklichkeit erster Ordnung bedeuten oder welchen Wert (im weitesten Sinn des Wortes) sie haben (Beispiel Gold: Material und zugeschriebener Wert und daraus folgende Wirkungen). Sie kann auch als >Wirklichkeit in Gegenüberstellung von >Realität` bezeichnet werden.

Bei Wilhelm Weischedel findet sich - ohne Bezug auf bestimmte Quellen - eine prägnante Zusammenfassung, die das bisher herausgearbeitete noch einmal zuspitzt:

53 URL-5, 30. Jan. 2007.

54 URL-6, 8. Mai 2009.

55 Paul Watzlawick: Wie wirklich ist die Wirklichkeit? Wahn, Täuschung, Verstehen [How real is real?, 1976], München / Zürich 1998, $142 f$. 
Die >Realität $<$ eines Dinges wäre dann dessen faktisches Existieren, im Gegensatz dazu, daß es bloß erdichtet oder geträumt sein könnte. Die >Wirklichkeit `eines Dinges besagte demgegenüber, daß es in meiner Gegenwart steht, daß es für mich da ist, daß es zu meiner Welt gehört, genauer: daß es wirksam anwesend ist; eben dies Moment der Wirksamkeit steckt ja auch etymologisch im Wort >Wirklichkeit.$^{56}$

\section{Metafiktion und Metanarrativität}

Zwei weitere Begriffe, `Metafiktion` und `Metanarrativität $\iota$ sind in der Analyse von Herbsts Texten unumgänglich und werden daher im Folgenden vielfach verwendet. Da die Differenzierung zwischen den Begriffen zudem noch nicht durchgängig etabliert ist, soll eine kurze Erläuterung in diesem Fall bereits im Vorhinein erfolgen. Eine Unterscheidung muss im Anschluss vor allem an die Arbeiten von Ansgar Nünning und Monika Fludernik erfolgen, die sich um Differenzierung bemühen.

Unter Metafiktion sind »selbstreflexive Aussagen und Elemente einer Erzählung" zu verstehen, die dem »Rezipienten Textualität und `Fiktionalität $\iota$ - im Sinne von `Künstlichkeit`, `Gemachtheit` oder `Erfundenheit` - und damit zusammenhängende Phänomene zu Bewußtsein bringen ${ }^{57}$. Bei Metanarrativität wird der Akt oder Prozess des Erzählens im erzählerischen Diskurs thematisiert und nicht zwangsläufig auch dessen Fiktionalität. Die Unterscheidung wurde lange in der Narratologie ignoriert, zudem gibt es eine große terminologische Verwirrung zwischen den Sprachen Englisch, Deutsch und Französisch, die Nünning und Fludernik darzustellen und auszuräumen versuchen. Zwar gibt es Mischformen zwischen den beiden Begriffen, doch muss differenziert werden, da es sowohl metanarrative Kommentare gibt, die nicht metafiktional sind, als auch metafiktionale Elemente, die nicht metanarrativ sind.$^{58}$ Es wird nicht nur explizit wie implizit der fiktionale Status der Figuren deutlich gemacht und immer wieder daran erinnert - was die Metafiktion ausmacht -, sondern es ist auch der Status der Präsentation als eine erzählte durchgehend präsent. Außerdem werden auch poetische Überlegungen angestellt, poetische Verfahren reflektiert, die die Struktur des Buches selbst betreffen, und damit über eine Thematisierung der Fiktionalität hinausgehen. Wenn die Fiktionalität auch thematisiert wird, wie

56 Weischedel: »Die Frage nach der Wirklichkeit«, 119.

57 Werner Wolf: »Metafiktion«, in: Ansgar Nünning (Hg.): Metzler Lexikon Literatur- und Kulturtheorie. Ansätze - Personen - Grundbegriffe, 2., überarbeitete und erweiterte Auflage, Stuttgart 2001, 429-430, hier: 429 .

58 Vgl. für Beispiele und eine genauere Typologie Ansgar Nünning: »Mimesis des Erzählens. Prolegomena zu einer Wirkungsästhetik, Typologie und Funktionsgeschichte des Akts des Erzählens und der Metanarration«, in: Jörg Helbig (Hg.): Erzählen und Erzähltheorie im 2o. Jahrhundert, Heidelberg 2001, 13-47; Monika Fludernik: »Metanarrative and Metafictional Commentary. From Metadiscursivity to Metanarration and Metafiction«, in: Poetica 35 (2003), 1-39; Ansgar Nünning: »On Metanarrative. Towards a Definition, a Typology and an Outline of the Functions of Metanarrative Commentary«, in: John Pier (Hg.): The Dynamics of Narrative Form. Studies in Anglo-American Narratology, Berlin / New York 2004, 11-57; Birgit Neumann / Ansgar Nünning: »Metanarration and Metafiction «, in: Peter Hühn / Jan Christoph Meister / John Pier / Wolf Schmid (Hg.): The living handbook of narratology, Hamburg 24. Jan. 2014, URL: http://www.lhn. unihamburg.de/article/metanarration-and-metafiction. 
beispielsweise in den meisten expliziten Kommentaren in $W B$, handelt es sich um metafiktionale Metanarrativität.

\section{Forschungsüberblick und -kritik}

Die Sekundärliteratur zu Herbst ist bislang überschaubar. Auch wenn in den letzten Jahren die Beschäftigung von Literaturwissenschaftlern mit seinen Werken zugenommen hat, so gibt es bislang nur wenige größere Arbeiten und keine, die sich ausschließlich mit Herbst beschäftigt. Im Folgenden seien die wesentlichen Arbeiten - nach Autoren in chronologischer Reihenfolge aufgelistet - kurz vorgestellt.

Stefan Scherer Nach wie vor sind es Scherers Aufsätze, die Herbsts Poetik am umfassendsten darstellen. In »Die Metamorphosen des Wolpertingers" (1997), ${ }^{59}$ der ersten über den Umfang einer Rezension hinausgehenden Arbeit zu Herbst überhaupt, rekonstruiert Scherer vor allem anhand der 1985 bis 1989 von Herbst herausgegebenen (und größtenteils von ihm auch selbst geschriebenen) Literaturzeitschrift Dschungelblätter die Grundzüge von dessen Poetik: »Realität \& Simulation« sowie die »literarische Kritik des Identitätsprinzips«. Er deckt intertextuelle Bezüge vor allem zur Frühromantik auf und zeichnet die tatsächliche Präsentation dieser Poetik in den wesentlichen Texten von 1981 bis zu Eine sizilische Reise von 1995 in jeweils kurzen Abschnitten nach. Da es sich um einen Einführungs- bzw. Überblicksartikel handelt, muss eine starke Verkürzung zugestanden werden. Einige Fehler im Detail der Zusammenhangsbeschreibungen zeigen die Komplexität und Schwierigkeit der herbstschen Texte an.

Auf Grundlage dieses Artikels schrieb Scherer 1999 einen Beitrag zum KLG, der die Rekonstruktion der Poetik etwas kürzt, dafür aber genauer auf die einzelnen Texte eingeht und sehr knapp bis 1998 fortschreibt. Eine Aktualisierung des Artikels ist 2010 erschienen. ${ }^{60}$

Wilhelm Kühlmann Im Gegensatz zu Scherers Konzentration auf die wichtigsten Begriffe der Poetik, versucht Kühlmann im bereits erwähnten Aufsatz »Postmoderne Phantasien ${ }^{61}$ eine Einordnung des Werks in den größeren literaturhistorischen Zusammenhang. Dabei verwendet er vor allem den Terminus »Postmoderne«, dessen problematische Begrifflichkeit ihm bewusst ist und dessen Verwendung er im Sinne einer "Abkehr von einer moralisch oder politisch engagierten, einer neorealistischen oder per Programm sozialkritischen Literatur « ${ }^{62}$ definiert. Außerdem macht er auf die Bedeutung von Mythen und Mythologie in Herbsts Werk aufmerksam, die er

59 Stefan Scherer: »Die Metamorphosen des Wolpertingers. Zur Poetik und zum Werk vom [sic!] Alban Nikolai Herbst«, in: Juni 26 (1997), 167-190.

6o Stefan Scherer: »Alban Nikolai Herbst«, in: Hermann Korte (Hg.): Kritisches Lexikon zur deutschsprachigen Gegenwartsliteratur, begr. von Heinz Ludwig Arnold, 1. Jan. 2010, URL: http://www. nachschlage.NET/document/16000000226, Artikel erstmals 1999 erschienen.

61 Wilhelm Kühlmann: »Postmoderne Phantasien. Zum mythologischen Schreiben im Prosawerk von Alban Nikolai Herbst (geb. 1955)«. Mit einem Werkverzeichnis, in: Euphorion 97 (2003), 499-516.

62 Ebd., 499. 
gerade für ein zentrales Kennzeichen postmoderner Schreibweise erachtet, und weist sie in den einzelnen Büchern beispielhaft nach.

Kühlmann hat Herbst 2007 zur Poetikdozentur nach Heidelberg eingeladen, die in der Publikation der Vorlesungen als eigenes Büchlein gipfelte. Zudem hat sich Kühlmann mit Der Arndt-Komplex beschäftigt, ${ }^{63}$ und neben Rezensionen auch zwei Lexikonartikel zu Herbst verfasst. ${ }^{64}$

Ralf Schnell Schnell verwendet Herbst in seiner Literaturgeschichte der deutschsprachigen Gegenwartsliteratur im Gegensatz zu Kühlmann als ein Beispiel für das Schreiben in der Zeit "nach der Postmoderne ${ }^{65}$. Im Vergleich mit Christoph Ransmayr, Peter Handke und Elfriede Jelinek stehe Herbst v. a. mit seinen Anderswelt-Romanen für eine digitale Ästhetik, die durch hypertextuelle Strukturen in Romanform auf die medialen Umbrüche der Gegenwart reagiere. Schnell benutzt den in der Systemtheorie verwendeten Begriff der `Autopoiesis`, um Herbsts Ästhetik als Erzählsystem nach Verlust jeglicher poetologischer Instanz zu charakterisieren. Meine Kritik an dieser Begriffsverwendung findet sich unten in Abschnitt 6.3.2 ab Seite 311.

Schnell hat zudem 2008 in der Literaturzeitschrift die horen einen Band ausschließlich mit Beiträgen zu Herbst herausgegeben, ${ }^{66}$ der bislang die am breitesten gefächerte Einführung in das Werk von Herbst bietet. In diesem findet sich auch ein eigener Beitrag von ihm zu Meere. ${ }^{67}$

Thomas Malsch Gerade der »kybernetische« Roman Buenos Aires. Anderswelt hat das Interesse des Soziologen Thomas Malsch erregt, der erstmals eine nicht literaturwissenschaftliche Perspektive einbringt. Besonders aufschlussreich ist dabei der Vergleich von Herbsts Romanen ( $W B$ und die $A W$-Romane) mit neueren Erkenntnissen der Soziologie und speziell der Sozionik, einem neuen Forschungsfeld zwischen Soziologie und Informatik bzw. künstlicher Intelligenz. Auf diesen Aufsatz gehe ich im Kapitel zu den $A W$-Romanen ausführlich ein.

63 Wilhelm Kühlmann: „Störungen des `perfektionierten Geistes`. Anmerkungen zu Alban Nikolai Herbsts Der Arndt-Komplex«, in: die horen 53/231 (2008): Panoramen der Anderswelt. Expeditionen ins Werk von Alban Nikolai Herbst, 184-186.

64 Wilhelm Kühlmann: »Herbst, Alban Nicolai [sic!] «, in: Thomas Kraft (Hg.): Lexikon der deutschsprachigen Gegenwartsliteratur seit 1945, Bd. 1, München 2003, 525-527; Wilhelm Kühlmann: "Herbst, Alban Nikolai«, in: ders. (Hg.): Killy Literaturlexikon, 2., vollständig überarbeitete Auflage, Bd. 5, Berlin 2009, 292-294.

65 Ralf Schnell: »Prosa der Moderne - nach der Postmoderne. Ransmayr - Handke - Jelinek - Herbst «, in: Ders.: Geschichte der deutschsprachigen Literatur seit 1945, 2., überarbeitete und erweiterte Auflage, Stuttgart 2003, 602, 604.

66 Ralf Schnell (Hg.): Panoramen der Anderswelt. Expeditionen ins Werk von Alban Nikolai Herbst. die horen. 53/231 (2008).

67 Ralf Schnell: »Über die Wahrnehmung eines literarischen Kunstwerks. Rückblick auf einen verbotenen Roman: Meere von Alban Nikolai Herbst«, in: die horen 53/231 (2008): Panoramen der Anderswelt. Expeditionen ins Werk von Alban Nikolai Herbst, 195-204. 
Christoph Jürgensen In mehreren Aufsätzen hat sich Christoph Jürgensen über die Jahre mit Herbst auseinandergesetzt. Der erste Aufsatz »Ich sind auch andere « ${ }^{68}$ thematisierte vor allem Herbsts Frühwerk. Jürgensen untersuchte anhand von VG die Identitätsproblematik sowie die Zuordnung zur Postmoderne, ging insgesamt aber nicht wesentlich über Scherer hinaus.

Im horen-Band beschäftigte sich Jürgensen mit $B A$ im Kontext des Großstadtromans. ${ }^{69}$ In einem weiteren Aufsatz bietet er die erste ausführlichere Darstellung der Inszenierungspraktiken von Herbst im Weblog. ${ }^{70}$

Anton Moosbach/Gregor Patorski Einen Sonderfall bildet die Lizentiatsarbeit Das Ribbentrop-Rhizom von >Anton Moosbach $<.^{71}$ Der Verfasser passt sich in den HerbstKosmos insofern ein, als er den Namen einer Figur ${ }^{72}$ von Herbst als Pseudonym übernimmt. In Schweizer Bibliothekskatalogen wird diese Arbeit, die über Herbsts Website als PDF-Datei zur Verfügung steht, unter dem Namen Gregor Patorski geführt. Zudem ist ein späterer Beitrag im horen-Band unter beiden Namen erschienen. ${ }^{73}$

In beiden Arbeiten wird das Rhizom-Konzept, das Gilles Deleuze und Félix Guattari u. a. in ihrem gleichnamigen Buch von 1976 entwickelten, sowie weitere Konzepte der beiden auf Herbsts Werke angewendet. Da ich - wie oben dargestellt - die Interpretationskontexte in Bezug auf die Autorintention auswähle und mich bei der Hinzuziehung von Intertexten fast ausschließlich auf Texte beschränkt habe, die für Herbst nachweislich von Relevanz waren, habe ich diese Arbeiten konzeptuell nicht berücksichtigt; lediglich auf den Rhizom-Begriff gehe ich in Zusammenhang mit WB kurz ein. Meines Erachtens verschleiert die Anwendung der zusätzlich zu erläuternden Begriffe von Deleuze und Guattari die Interpretation mehr, als dass sie zu einer Klärung der komplexen und verwirrenden Zusammenhänge beispielsweise in WB beitragen.

68 Christoph Jürgensen: »Ich sind auch andere. Zur Pluralisierung des Selbst in der Erzählprosa von Alban Nikolai Herbst «, in: Ivar Sagmo (Hg.): Moderne, Postmoderne - und was noch? Akten der Tagung in Oslo, 25.-26.11.2004 (Osloer Beiträge zur Germanistik 39), Frankfurt am Main 2007, $145-157$.

69 Christoph Jürgensen: »Unwirkliche Städte, unwirkliches Ich. Zum Verhältnis von Stadt und Individuum in A. N. Herbsts Buenos Aires. Anderswelt«, in: die horen 53/231 (2008): Panoramen der Anderswelt. Expeditionen ins Werk von Alban Nikolai Herbst, 99-111.

70 Christoph Jürgensen: »Ins Netz gegangen. Inszenierungen von Autorschaft im Internet am Beispiel von Rainald Goetz und Alban Nikolai Herbst «, in: Christoph Jürgensen / Gerhard Kaiser (Hg.): Schriftstellerische Inszenierungspraktiken. Typologie und Geschichte, Heidelberg 2011, 405-422.

71 Anton Moosbach [d. i. Gregor Patorski]: Das Ribbentrop-Rhizom. Ein Experiment mit den Werken von Alban Nikolai Herbst und Gilles Deleuze/Félix Guattari, Lizentiatsarbeit, Zürich: Philosophische Fakultät der Universität Zürich, 2005, URL: http:// www. die - dschungel.de/ANH/txt/pdf/ ribbentrop_rhizom.pdf.

72 >Anton Moosbach` in Joachim Zilts Verirrungen.

73 Gregor Patorski / Anton Moosbach: "Die Anderswelt als Rhizom«, in: die horen 53/231 (2008): Panoramen der Anderswelt. Expeditionen ins Werk von Alban Nikolai Herbst, 11-21. 
Ursula Reber Die gleiche Kritik gilt auch für einige Abschnitte in Formenverschleifung $(2009)^{74}$ von Ursula Reber, in denen sie ebenfalls auf Deleuze und Guattari zurückgreift. Insgesamt ist dies jedoch die bislang wohl ausführlichste Arbeit zu Herbsts Romanen. In einer Fülle an Beobachtungen, Zitaten und Details untersucht sie vor allem WB, aber auch TA, in Bezug auf auf eine "Theorie der Metamorphose (weitere Untersuchungsgegenstände sind Ovids Metamorphosen sowie Texte der Romantik und der Jahrhundertwende um 1900). Ihre Ausführungen zu WB dienen oft auch als Kontrastierung oder Bestätigung zu meinen eigenen Beobachtungen. Flankiert wird diese Arbeit von zwei Aufsätzen, die sich mit den $A W$-Romanen befassen. ${ }^{75}$

Heinz-Peter Preußer Untersuchungsgegenstand von Heinz-Peter Preußers Studie Letzte Welten ist die Literatur »diesseits und jenseits der Apokalypse«, die er bei Herbst anhand von $T A$ in einem kurzen Abriss darstellt. ${ }^{76}$ Daran knüpft er in einem späteren Aufsatz an, wenn er vor allem an der Figur Achilles Borkenbrod aus TA und BA die Mythenverwendung darstellt. ${ }^{77}$

Judith Leiß Auch Judith Leiß beschäftigt sich mit $T A$ als einem unter mehreren Texten. In ihrer Studie Inszenierungen des Widerstreits versucht sie, den Begriff $>$ Heterotopie ‘ für ein »eigenständiges Subgenre der Utopie ${ }^{78}$ in einer postmodernen Spielart zu etablieren. Herbsts TA findet sich hier neben Peter Ackroyds The Plato Papers (1999), Herbert F. Frankes Sirius Transit (1979) und Murakami Harukis Hard-boiled Wonderland und das Ende der Welt (1985) und einigen >Grenzfällen als Beispieltext. Ihre klar strukturierte Analyse und Anwendung ihres vorher ausgeführten Analysemodells bringen einige hilfreiche Hinweise, allerdings wird auch die Interpretation auf diese Modellanwendung verkürzt. Zudem wird deutlich, dass $T A$ nur unzureichend ohne den Kontext der Vorgängerromane gelesen werden kann. Meine Einwände gegen ihre Interpretation von $T A$ als gesellschaftskritischen Text finden sich im $A W$-Kapitel.

74 Ursula Reber: Formenverschleifung. Zu einer Theorie der Metamorphose, München u.a. 2009.

75 Ursula Reber: »Ganz woanders zugleich. Simultaneitäten in Alban Nikolai Herbsts Cybercities«, in: Jahrbuch der ungarischen Germanistik 2003 (2004), 131-151; Ursula Reber: »Affektive Landschaften in Alban Nikolai Herbsts Anderswelt-Romanen«, in: die horen 53/231 (2008): Panoramen der Anderswelt. Expeditionen ins Werk von Alban Nikolai Herbst, 49-65.

76 Heinz-Peter Preußer: „Die Pluralität der Untergänge. Postmoderne bei Alban Nikolai Herbst und der Versuch einer Typologie: Enzensberger - Grass - Strauß«, in: Ders.: Letzte Welten. Deutschsprachige Gegenwartsliteratur diesseits und jenseits der Apokalypse, Heidelberg 2003, 9-32.

77 Heinz-Peter Preußer: »Achilles als Barde. Kybernetische Mythenkorrektur bei Alban Nikolai Herbst«, in: die horen 53/231 (2008): Panoramen der Anderswelt. Expeditionen ins Werk von Alban Nikolai Herbst, 73-89.

78 Judith Leiß: Inszenierungen des Widerstreits. Die Heterotopie als postmodernistisches Subgenre der Utopie, Bielefeld 2010, 16. 
Aus dem horen-Band sind schließlich noch drei weitere Aufsätze zu nennen, die sich mit Themen beschäftigen, die für diese Arbeit relevant sind.

Hans Richard Brittnacher schließt in seinem Aufsatz vor allem an Preußer an und untersucht ebenfalls die $A W$-Romane in Hinblick auf die Tradition der Apokalypse. ${ }^{79}$ Uwe Schütte wendet sich als erster der Poetik des `Kybernetischen Realismus` zu und beschäftigt sich vor allem mit den Heidelberger Poetikvorlesungen. ${ }^{80}$ Renate Giacomuzzi rundet schließlich die Vielfalt des Bandes ab, indem sie als erste eine Untersuchung des Weblogs vorlegt. ${ }^{81}$

Innokentij Kreknin Nach Fertigstellung der vorliegenden Arbeit ist die Studie Poetiken des Selbst von Kreknin erschienen. ${ }^{82}$ Kreknin versteht seine Arbeit als "poststrukturalistisch informierten [...] Beitrag zur Autofiktionsforschung und zur kulturwissenschaftlichen und kultursoziologischen Subjektforschung « ${ }^{83}$. Damit sind seine Untersuchungen auf das Thema Autofiktion ausgerichtet. Neben einer vor allem argumentatorisch vorbereitenden, an Christoph Jürgensen und Thomas Malsch anschließenden Beschäftigung mit $V G$ und $B A$ steht das Weblog im Mittelpunkt der Betrachtung. Dabei kommt er - unter ergänzender Einbeziehung einiger von Herbsts poetologischen Texten - zu der Einsicht, die Pluralisierung von Identitäten sei nicht nur bei Herbst literarischen Figuren von zentraler Bedeutung, sondern auch "fester Bestandteil der Selbstpoetik des Autors Herbst ${ }^{84}$. Zentrale These ist letztlich aber die Annahme einer »methodische[n] Aporie ${ }^{85}$ dergestalt, dass durch Herbst »in der Praxis eine Autor-Subjekt-Figur evoziert [werde], die keinen Zweifel an der

79 Hans Richard Brittnacher: "Der verspielte Untergang. Apokalypsen bei Alban Nikolai Herbst«, in: die horen 53/231 (2008): Panoramen der Anderswelt. Expeditionen ins Werk von Alban Nikolai Herbst, 29-42.

8o Uwe Schütte: »Erzählen für morgen. Zur poetologischen Genealogie des Kybernetischen Realismus bei Alban Nikolai Herbst«, in: die horen 53/231 (2008): Panoramen der Anderswelt. Expeditionen ins Werk von Alban Nikolai Herbst, 121-130.

81 Renate Giacomuzzi: „Die >Dschungel.Anderswelt $\triangleleft$ und A. N. Herbsts >Poetologie des literarischen Bloggens «, in: die horen 53/231 (2008): Panoramen der Anderswelt. Expeditionen ins Werk von Alban Nikolai Herbst, hg. v. Ralf Schnell, 137-150. Vorher - und nachher bis zum erwähnten Aufsatz von Jürgensen - gab es lediglich eher kurze Erwähnungen, vgl. Frank Fischer: »Der Autor als Medienjongleur. Die Inszenierung literarischer Modernität im Internet«, in: Christine Künzel / Jörg Schönert (Hg.): Autorinszenierungen. Autorschaft und literarisches Werk im Kontext der Medien, Würzburg 2007, 271-280; Florian Hartling: Der digitale Autor. Autorschaft im Zeitalter des Internets, Bielefeld 2009, 227-231; Thomas Ernst: »Weblogs. Ein globales Literaturformat «, in: Wilhelm Amann / Georg Mein / Rolf Parr (Hg.): Globalisierung und deutschsprachige Gegenwartsliteratur. Konstellationen, Konzepte, Perspektiven, Heidelberg 2010, 281-302.

82 Innokentij Kreknin: Poetiken des Selbst. Identität, Autorschaft und Autofiktion am Beispiel von Rainald Goetz, Joachim Lottmann und Alban Nikolai Herbst, Berlin u. a. 2014. Bereits vorab veröffentlichte Kreknin 2013 einen Beitrag in einem Sammelband, der inhaltlich weitestgehend identisch mit dem Abschnitt über Herbst aus der späteren Studie ist, vgl. Innokentij Kreknin: »Kybernetischer Realismus und Autofiktion. Ein Ordnungsversuch digitaler poetischer Phänomene am Beispiel von Alban Nikolai Herbst«, in: Martina Wagner-Egelhaaf (Hg.): Auto(r)fiktion. Literarische Verfahren der Selbstkonstruktion, Bielefeld 2013, 279-314.

83 Kreknin: Poetiken des Selbst, 6.

84 Ebd., 379.

85 Ebd., 417. 
Einheitlichkeit ihrer jeweiligen Ausprägung aufkommen ${ }^{86}$ lasse, die im Gegensatz $\mathrm{zu}$ seiner theoretischen Position stehe.

Trotz der wachsenden Menge an literaturwissenschaftlichen Arbeiten zu Herbsts Werken gilt nach wie vor die Einschätzung von Harro Segeberg, der 2005 vom »immer noch zu entdeckenden ehemaligen Wertpapier-Broker und Autor ${ }^{87}$ sprach.

Auch wenn das Weblog laut Herbst hohe Zugriffszahlen hat, bedeutet das nicht, dass auch die in Buchform veröffentlichten literarischen Werke gelesen werden. So sind viele der älteren Bücher nur noch antiquarisch zu erwerben und auch die neuen werden kaum in dem Maße verkauft, dass sie Herbst ein Auskommen sichern. ${ }^{88}$ Dafür, dass er nicht so viel gelesen wird, gibt es mehrere Gründe:

Der erste und einfachste ist die schwierige Zugänglichkeit der Texte. [...] Einzelausgaben scheitern [...] meist an den zweifelhaften ökonomischen Erfolgsaussichten bzw. dem mangelnden Kaufwillen des Publikums.

Der zweite Grund ist das sprachliche Niveau der Texte. [Die] Romane sind zu lang für eine immer kurzatmiger werdende Moderne, von seinen Sätzen ganz zu schweigen [...], die beim Lesen wie beim Mit-Denken eben einen langen Atem erfordern.

Der dritte Grund liegt in den behandelten Themen und Geschichten selbst. [...] Beinahe alle seine Romane [...] sind bis zum Bersten gefüllt mit mythologischem Personal, Phantasiefiguren aus Märchenwelten, $\mathrm{Zi}$ taten aus anderen Texten und Kontexten, Anspielungen auf alles nur Denk- und Wissbare. Diesem Bildungskosmos steht der heutige [...] Leser fremd gegenüber. [...]

Das leitet über zum vierten und vielleicht grundlegensten Verständnishindernis [der Werke], ihrer spezifischen [Art]. [Die] Texte rechnen mit einem mündigen, engagierten, aktiven Leser; für eine schnelle, leichte und oberflächliche Lektüre sind sie, trotz ihres Unterhaltungswertes, nicht zu haben.

Diese Passage fasst die Schwierigkeiten der meisten Leser mit Herbst recht gut zusammen - auch wenn sie nicht auf ihn gemünzt ist, sondern auf Christoph Martin Wieland. ${ }^{89}$ Mit dem Oberon hat dieser einen der wichtigsten Prätexte von Wolpertinger geschrieben. Als Hilfestellung für die Schwierigkeiten, die den dritten und vierten `Grund ‘ bilden, ist diese Arbeit gedacht.

86 Kreknin: Poetiken des Selbst, 400.

87 Harro Segeberg: »PParallelpoesien«. Buch- und/oder Netzliteratur? Einführung und Überblick«, in: Harro Segeberg / Simone Winko (Hg.): Digitalität und Literalität. Zur Zukunft der Literatur, 2005, 11-27, hier: 26 .

88 Herbst spricht im Weblog immer wieder offen über seine ökonomische Situation. Vgl. dazu auch Hartling: Der digitale Autor, 23 of.

89 Das Zitat stammt aus Jutta Heinz (Hg.): Wieland-Handbuch. Leben - Werk - Wirkung, Stuttgart / Weimar 2008, VIIf. 


\section{Teil I}

\section{Die Verwirrung des Gemüts}





\section{Von der »ungeformten « zur »ungesicherten« Identität}

\subsection{Einleitung}

Der Roman Die Verwirrung des Gemüts (1983) ${ }^{1}$ ist zwar nach Marlboro (1981) das zweite publizierte Buch von Herbst, dennoch kann es als die "Grundlegung von Herbsts Werk « ${ }^{2}$ gesehen werden. Erst in diesem - seinem ersten - Roman werden sowohl die Themen als auch die erzählerischen Strukturen eingeführt, die sein Hauptwerk ausmachen.

Als eine Einführung in den Roman wird eine narratologische Analyse dienen, die einen Eindruck vom Aufbau des Buchs im Allgemeinen sowie von der Erzählstruktur im Besonderen vermittelt. Die Erzählsituation ist dabei schon Ausdruck für thematische Aspekte, die dann im Folgenden inhaltlich im close reading anhand der verschiedenen miteinander verwobenen Motive dargestellt werden. Zunächst soll jedoch eine kurze Einführung in die Handlung und die Figuren das Verständnis erleichtern.

\subsubsection{Handlungs- und Figureneinführung}

Im Roman lassen sich drei Ebenen ausmachen, die zunächst hierarchisch angeordnet sind:

Auf der ersten Ebene will ein anonymer Ich-Erzähler, der aus noch zu erläuternden Gründen als >Autor`-Erzähler bezeichnet wird, aufgrund einer Identitätskrise aus seinem eigenen Leben fliehen. Er erfindet eine Figur, Ulf Laupeyßer, dem er diese Krise andichtet und die die Flucht stellvertretend für ihn unternehmen soll.

Auf dieser zweiten Ebene (im Folgenden der Anschaulichkeit halber LaupeyßerEbene genannt) wird die Entwicklung von Laupeyßer erzählt. Folgende Problemkomplexe sind bei ihm auszumachen: er leidet an der deutschen Geschichte im Nationalsozialismus, an der Schuld der Elterngeneration und deren unaufgearbeitetem Umgang damit; damit belastet ihn die Determiniertheit, die er durch seine Herkunft, seinen Namen und seine Sozialisation verspürt; kombiniert damit und durch einen Kinobesuch ausgelöst, geht es ihm um die Frage, ob er angesichts von Gewalt und Leiden das eigentlich zu erwartende Gefühl des Entsetzens überhaupt bzw. noch verspüren kann. Er möchte wie der >Autor`-Erzähler sein altes Leben und seine alte Identität hinter sich lassen und woanders unter neuem Namen ein neues Leben beginnen.

1 Alban Nikolai Herbst: Die Verwirrung des Gemüts. Roman, München 1983.

2 Jürgensen: »Ich sind auch andere«, 147. 
Mit seiner Figur verbunden sind eine (platonische) Freundin Agnes, der er von seinen Imaginationen berichtet, die auf der gleich zu beschreibenden dritten Ebene erzählt werden. Zudem lernt er einen Trinker Axel Schulze kennen, mit dem er philosophisch-reflektierte Gespräche führt.

Laupeyßer erfindet wiederum eine weitere Figur, Claus Falbin, womit die dritte Ebene (im Folgenden als Falbin-Ebene bezeichnet) etabliert wird. Dieser ist ein charakterlicher Gegenentwurf zu Laupeyßer. Er ist ein schüchterner, unsicherer Mensch, der sich zu Beginn der Imaginationen mehrfach ungewollt am Bahnhof wiederfindet, obwohl dieser gar nicht auf seinem eigentlich eingeschlagenen Weg liegt. Dieses »Irregehen « reißt ihn aus seinem bisherigen Leben und löst eine Gegenentwicklung zu Laupeyßer aus. Er entwickelt eine Einstellung der Härte und Stärke, die in brutalem Umgang mit Kollegen und auch Frauen gipfelt.

Laupeyßer erhält schließlich von Axel Schulze einen gefälschten Pass. In einer narrativen Metalepse verbinden sich die drei weitgehend getrennten Ebenen und lösen wie vorhergehende kleinere metaleptische Verbindungen die Hierarchie der Erzählebenen zumindest in Teilen auf. Am Bahnhof kommt es zu einem Treffen aller drei Figuren. Während Laupeyßer und Falbin auf der Bahnhofstoilette um den neuen Pass würfeln, werden sie vom `Autor`-Erzähler beobachtet. Er überrumpelt sie, gelangt an den Pass und verlässt schließlich an ihrer Stelle die Stadt, um eine neue Identität anzunehmen.

Das Treffen am Bahnhof ist jedoch lediglich von der Darstellung, dem >discours‘, her der Schluss; >chronologisch ‘ betrachtet, d. h. von der Handlung (der `histoire`) ist er nicht das Ende. Es wird vorweggenommen, dass die Flucht letztlich misslingt. Der >Autor -Erzähler ist zwar in Frankfurt angekommen und hat ein neues Leben begonnen, seine Probleme sind damit jedoch nicht gelöst. Er setzt große Erwartungen in seine Freundin B., die ihn aber verlässt, woraufhin er einen Selbstmordversuch unternimmt. Er findet schließlich zu einem neuen Konzept von Identität.

Wie in diesem Kapitel gezeigt wird, sind die drei Figuren in gewisser Weise als identisch anzusehen. Der Übersichtlichkeit halber und auch, da im überwiegenden Teil des Buches die Trennung der Erzählebenen eingehalten wird, werden im Folgenden die drei Figuren als verschiedene Figuren mit unterschiedlicher erzählerischer Funktionalität dargestellt. Erst im Abschnitt »Zusammenführung « wird das Verhältnis der drei genauer analysiert. Während den größten Teil des Buches die Erzählung von Laupeyßer bestimmt, die sich durch seine Imaginationen mit Falbin vermengt, nehmen im letzten Drittel des Buches die kursiv gesetzten Äußerungen des `Autor $<$-Erzählers einen immer größeren Platz ein.

\subsubsection{Narratologische Analyse}

Die Erzählsituation von $V G$ ist sehr komplex und umfasst auf den unterschiedlichen Erzählebenen zudem verschiedene Erzähler. Da sie durch eine verzögerte Informationsvergabe darauf angelegt ist, erst nach und nach vom Leser ${ }^{3}$ erschlossen und ver-

3 In der gesamten Arbeit wird das generische Maskulinum als geschlechtsübergreifende Bezeichnung für Leserinnen und Leser verwendet, falls nicht explizit anders vermerkt. 
standen zu werden, soll in diesem Abschnitt die narratologische Beschreibung nicht über eine `abgeschlossene` formalistisch-technische Zuordnung narratologischer Termini erfolgen. Vielmehr soll im Anschluss an Fotis Jannidis eine Beschreibung der Inferenzprozesse erfolgen, durch die der (Modell-)Leser sich den Text erschließt. ${ }^{4}$ Um die Beschreibung und die nötige Bezeichnung der Instanzen im ansprechendem $\mathrm{Maß}$ zu halten und für den Leser verständlich zu bleiben, kann nicht der vollständige Prozess dargestellt werden. So werden am Anfang also schon einige Eingaben gemacht, von denen erst im Nachhinein darzustellen versucht wird, wie und wann der Leser sie sich erschlossen hat.

Die drei Erzählebenen sind jeweils durch eine der drei Hauptfiguren gekennzeichnet: durch einen anonymen Ich-Erzähler, durch Ulf Laupeyßer und durch Claus Falbin. Während dies noch nicht bedeutet, dass damit auch ein Erzähler jeder Ebene zugeordnet werden kann, sind sie zunächst eindeutig dadurch voneinander geschieden, dass der anonyme Ich-Erzähler die Figur Laupeyßer erfindet und dieser dann wiederum die Figur Falbin. Für den Leser ist dies jedoch keineswegs von Beginn an klar, auch nicht wie viele Ebenen es gibt oder wer spricht.

Zunächst ist der Leser mit einem kursiven Absatz konfrontiert, der eher nebulös scheint. Nach einem für Herbst typischen rätselhaft-konstatierenden Eingangssatz (Im Bahnhof lebt die Stadt inwärts gekehrt: träumt sich fort.) $)^{5}$ wird fortgefahren:

Suche jemanden, also, dessen Geschichte, oder wie du's nennen willst, dort enden wird; eine überspannte Fantasie, nichts sonst zeichne ihn aus. Er soll es nicht mehr aushalten können. Darf nicht zu alt sein für meine Zwecke. Vielleicht fünfundzwanzig. - Weil: Man geht von dem aus, was man kennt. $(V G, 3)^{6}$

Bezeichnenderweise wird das Subjekt des Satzes, das »Ich «, weggelassen. Dadurch dass er das Vorbild für die erfundene Figur ist sowie durch die Leseranrede ist der Erzähler

4 Vgl. dazu als beispielhafte Analyse: Fotis Jannidis: „Wer sagt das? Erzählen mit Stimmenverlust«, in: Andreas Blödorn / Daniela Langer / Michael Scheffel (Hg.): Stimme(n) im Text. Narratologische Positionsbestimmungen (Narratologia 10), Berlin / New York 2006, 151-164, hier: 154-157. Jannidis geht von einem Modell narrativer Kommunikation aus, das auf Inferenz basiert. Unter Inferenz ist dabei jede Form der Schlussfolgerung zu verstehen, zu denen logische und auch probabilistische Schlüsse zählen. Er setzt dies von einem traditionellerweise angenommenen Code-Modell ab, das auf der Annahme beruht, sprachliche Konventionen würden ein Regelsystem vorgeben, nach dem der Autor eine Botschaft nach bestimmten Regeln codiert und der Leser diese Botschaft unter Berücksichtigung der Regeln eindeutig zurücküberträgt. Das Modell inferenzbasierter Kommunikation geht demgegenüber davon aus, dass die Bedeutung des Textes durch Inferenzen auf Grundlage des kulturellen Wissens, der sprachlichen Codes, der Regeln des Kommunikationssystems sowie weiterer Elemente erschlossen wird. Vgl. Fotis Jannidis: Figur und Person. Beitrag zu einer historischen Narratologie, Berlin / New York 2004, 15-83 (besonders 44-52), 237f., 254. Der Modell-Leser ist als vom Autor intendierter Leser zu verstehen, allerdings nicht als intendierter realer Leser, sondern als Versuch eines anthropomorphen Konstruktes, das aus dem Text rekonstruiert wird. Dieser Leser hat die nötigen Kompetenzen, »um die vom Text erforderten Operationen erfolgreich durchzuführen« (ebd., 254). Vgl. auch ebd., 28-33, 237.

5 Siehe VG, 7; vgl. die Anfänge von Wolpertinger und Thetis, die eine ähnliche Qualität haben. Dort handelt es sich quantitativ zwar sogar um drei Absätze resp. einen Absatz, doch erfolgt dann ebenfalls der Übergang zu Figureneinführung, Handlung, Erzählen etc.

6 Die Kursivierung im Original, die den `Autor`-Erzähler markiert, wurde beibehalten (auch im Folgenden). 
dennoch präsent. Das Weglassen des Subjekts deutet mündliche Rede an und ist zudem kennzeichnend für die Vagheit des Anfangs, die minimale Informationsvergabe an den Leser. Denn auch sonst sind die Angaben vage: weder werden die Umstände der `Suche` erläutert, noch die `Zwecke`. Lediglich kann darauf geschlossen werden, dass es sich bei dem Erzähler um eine Person handelt, die zudem etwa 25 Jahre alt ist. Weiterhin fällt die Leseransprache auf, die den gesamten Roman durchzieht, sowie die Vorläufigkeit der Formulierung, die den Eindruck einer gewissen Nachlässigkeit evoziert.

Kein Gerücht, nein, es gibt Menschen, die können sich tatsächlich noch entsetzen. Und nicht nur so getan als ob, nicht nur gestellt, während sie heimlich ihre Zungen rausstrecken, lüstern auf Neuigkeiten : - Hansen neulich : »Scheußlich, scheußlich «, sagte er beim Betrachten der auf Hochglanz farbig hingedruckten Verkehrstotenfotos, konnte sich nicht mehr lösen davon, tastete mit seinen unruhigen Blicken das Gerasterte nach unverletztem Brustfleisch ab. Und was vielen, im Kino hier, Anlaß zu Lachkrämpfen ist, stülpt nur wenigen noch Übelkeit über. [...] $(V G, 7)$

Dieser nächste Abschnitt, nicht kursiv und aus zwei Absätzen bestehend, wird ebenfalls von einem Ich-Erzähler geschildert und ist dadurch gekennzeichnet, nichts erklärend einzuführen. Thematisch scheint er medias in res einzusetzen, als ob in einem Gespräch auf einen Einwand reagiert würde (»Kein Gerücht, nein, [...]«). Der Name Hansen fällt ohne weitere Erläuterung, um wen es sich dabei handelt (eine Nebenfigur, die sehr viel später erst wieder auftaucht). Weder beschreibt der Erzähler sich selbst genauer noch die Gesprächspartnerin, der er anscheinend am Telefon von Hansen erzählt. Es folgt wieder ein kurzer kursiver Abschnitt und ein längerer nicht kursiver, der an den zweiten Abschnitt anzuschließen scheint (»nächstentags«).

Kann ich mich noch entsetzen? Als jemand existieren, den es nicht gab vorher, von keinem Leib ausgestoßen. Einfach Schluß machen mit der Empirie, zumindest so tun, es sich erfinden. Eine offensive Flucht: Angriff aus Unwägbarem.

Den Entschluß faßte ich nächstentags im Café, er überraschte mich: außerordentliche, geradezu dingliche Gegenwart. [...] $(V G, 8)$

Der Leser merkt also schnell, dass der Text in Abschnitte unterschiedlicher Länge, von wenigen Zeilen bis maximal mehreren Seiten reichend, eingeteilt ist. Aufgrund der besagten Vagheit kann ein Erzähler oder eine eindeutige Erzählperspektive noch nicht identifiziert werden. Im darauf folgenden Abschnitt gibt es einen weiteren Hinweis.

\footnotetext{
Ich ging ins Wohnzimmer, kramte die Unterlagen hervor, nahm die Cassetten, verstaute alles in dem Karton, den klebte ich am Boden und an den Seiten zu mit Tesaband, stellte das schwere, sich stumpf anfassende Ding auf den Tisch, wo es stehenblieb zweieinhalb Wochen unangerührt,

und Laupeyßer aus gepreßten Papieraugen unablässig belauerte : Der saß, war er nicht unterwegs, im Cocktailsessel und rauchte [...]. $(V G, 9)$
}

Zum ersten Mal wird ein Abschnitt nicht durch einen Punkt, sondern, mitten im Satz (obwohl so weit vollständig; es könnte also auch ein Punkt stehen), durch ein Komma `beendet‘. Im nächsten Absatz kann der Leser dann schnell erkennen, dass 
ein Sprecherwechsel erfolgt ist, nun kein Ich-Erzähler mehr spricht, sondern von außen auf eine Person geschaut wird, die als Laupeyßer bezeichnet wird. Durch diesen Wechsel innerhalb eines Satzes und den als ungebrochen erkennbaren thematischen Zusammenhang kann der Ich-Erzähler des vorhergehenden Abschnitts als diese Person Laupeyßer identifiziert werden.

Über die kursiven Abschnitte ist damit noch keine weitere Erkenntnis gewonnen. Gleich folgt wiederum der nächste von ihnen und verwirrt zunächst wieder mehr, als dass er aufklärte:

So etwa stellte ich mir vor, wozu mir in Wahrheit der Mut noch fehlte. Freilich hätte meine Behausung kahler nicht wirken können: Unterm Fensterbrett welke Blätter. Das mit dem achtundzwanzigsten Geburtstag allerdings stimmt. Selten war ich dermaßen berauscht. $(V G, 10)$

Der vorhergehende Abschnitt über Laupeyßer wird als eine Vorstellung dieses Erzähler-Ichs bezeichnet, als eine inauthentische Rede und damit als fiktional. ${ }^{7}$ Durch die Feststellung bezüglich des Geburstags, die sich auf eine entsprechende Schilderung im Abschnitt über Laupeyßer bezieht, wird eine vermeintliche Identität insinuiert, die sich erst später als (zumindest erzählerisch) nicht haltbar erweist. Zunächst ist jedoch die Annahme für den Leser möglich, dass es sich beim Ich-Erzähler der kursiven Passagen ebenfalls um Laupeyßer handelt, vielleicht zu einem anderen Zeitpunkt (d. h. als älterer Laupeyßer) oder in einer anderen (Erzähl-)Funktion (bspw. als metanarrativer Kommentator). Da die folgenden kursiven Abschnitte lediglich Kommentare zu den nicht kursiven Abschnitten enthalten, ergeben sich weitere Schlüsse diesbezüglich erst wesentlich später. Ein erster deutlicher Hinweis auf die Nicht-Identität des skursiven Ich-Erzählers und Laupeyßers findet sich im Satz »Kurz bevor Laupeyßer nach Frankfurt fährt.« $(V G, 32)$. An dieser Stelle wird Laupeyßer erstmals namentlich in einer kursiven Passage genannt, was eine externe Sicht auf diesen nahelegt. Wenig später findet sich dann erstmals das Erzähler-Ich und der Name Laupeyßer in einem Satz in einem kursiven Abschnitt: »Eine billige Reflexion, die ich vorhin angestell habe und von der Laupeyßer jetzt mit Agnes spricht.« $(V G, 37)$ Erst hier wird die Nicht-Identität der beiden eindeutig und außerdem auch ihr Verhältnis geklärt, was sich noch nebulös in den bereits zitierten ersten und dritten kursiven Abschnitten (VG, 7 und 10) angedeutet hatte: dass der anonyme Erzähler der Erfinder der Figur Laupeyßer ist. Um den durchgängig anonym bleibenden Ich-Erzähler der kursiven Abschnitte im Folgenden eindeutig bezeichnen zu können, greife ich auf eine sehr viel spätere Stelle zurück; dort bezeichnet er sich selbst en passant in einem metafiktionalen Kommentar als "erfundenen Autor des allen« $(V G, 308)$. Da die Erzählsituation, vor allem wenn man die bereits erwähnte, gleich näher zu erläuternde dritte Erzählebene hinzunimmt - eine Person erfindet einen Erzähler bzw. eine Figur (Laupeyßer), die wiederum eine Figur (Falbin) erfindet, die dann in einer Binnenerzählung agiert -, zudem die Situation eines realen Autors spiegelt, der einen Erzähler erfindet usw., scheint mir die Bezeichnung >Autor $<$-Erzähler passend zu sein. Die Komponente >Autor ist dabei zudem noch in einfache Anführungszeichen gesetzt, um sicherzugehen, dass keine

7 Für den Begriff der sinauthentischen« Rede vgl. Matias Martinez / Michael Scheffel: Einführung in die Erzähltheorie [1999], 2., durchgesehene Auflage, München 2000, 17 und 161f. 
Verbindung zum realen Autor (oder zum `impliziten Autor` oder ähnlichen Konstruktionen) gezogen wird, sondern nur der Erzähler der ersten Erzählebene gemeint ist, der die Funktion eines imaginären Autors in Bezug auf die anderen Erzählebenen hat. $^{8}$

Auf der Erzählebene ersten Grades ${ }^{9}$ fungiert der >Autor`-Erzähler als einziger Erzähler, der zudem am Geschehen selbst beteiligt ist; es handelt sich damit um einen autodiegetischen Erzähler. Dass diese Erzählebene eine eigene, mehr oder weniger 'vollständige‘ erzählte Welt bildet, mit Figuren und einer Handlung, wird anfangs nicht unmittelbar deutlich. Zwar gibt es die Hinweise darauf, dass es sich beim `Autor «-Erzähler um eine Person handelt, der einige wenige Eigenschaften zugeschrieben werden können, die über das Personalpronomen hinausgehen. Eine rudimentäre Handlung, weitergehend als Reflexionen zu den anderen Erzählebenen und zum Erzählen an sich, ergibt sich jedoch erst später, insbesondere nach Einführung der Figur B., der Freundin des >Autor«-Erzählers. Da sich die meisten Äußerungen auf die anderen Erzählebenen beziehen, handelt es sich um ein metafiktionales oder metanarratives Sprechen; die Fokalisierung ist dabei in gewissem Sinn auktorial, geht allerdings darüber hinaus, da er ja nicht nur in auktorialer Weise wahrnimmt, sondern auch schaffend oder zuschreibend agiert (vgl. z. B. »Denn Falbin soll wollen [...].«, 62); es könnte demnach

8 Wie hier dargelegt, habe ich die Bezeichnung aus dem Text abgeleitet und nicht nach der Verwendung des Begriffs bei Genette gebildet (vgl. Gérard Genette: Die Erzählung [1972/1983], München 1994, 164). Er verwendet den Begriff aber ähnlich, bezeichnet bspw. den Erzähler Robinson Crusoe als Autor-Erzähler, da dieser gleichzeitig der Erzähler und der imaginäre Autor des Romans Robinson Crusoe ist. Unterschiede können jedoch zum einen darin ausgemacht werden, dass der 'Autor`-Erzähler in $V G$ nicht der einzige Erzähler des gesamten Buchs, sondern lediglich auf seiner Erzählebene ist, zum anderen sehe ich ihn nicht auf einer extradiegetischen Ebene, ein Begriff, den ich - wie gleich erläutert - aber auch nicht benutzen werde.

9 Bezüglich der narratologischen Terminologie orientiere ich mich weitgehend an Genettes bzw. an der an ihm ausgerichteten, teils leicht modifizierten Systematik von Martinez und Scheffel (Martinez / Scheffel: Einführung in die Erzähltheorie). Die Bezeichnung der Erzählebenen (extra-, intra-, metadiegetisch) übernehme ich jedoch nicht, da mir die Begriffe insgesamt und vor allem für die Texte von Herbst irreführend erscheinen. Kritik vor allem am Begriff »metadiegetisch « findet sich schon bei Bal und Rimmon-Kenan, die diesem den Begriff »hypodiegetisch « entgegensetzen (vgl. Mieke Bal: "Notes on Narrative Embedding «, in: Poetics Today 2/2 (1981), 41-59, und Shlomith Rimmon-Kenan: Narrative Fiction. Contemporary Poetics, 2. Aufl., London / New York 2002, 93, 157). Da jedoch die ebenfalls nicht unproblematischen Bezeichnungen »extra-« und »intradiegetisch « übernommen werden und sich meines Wissens eine eindeutige Zuordnung noch nicht etablieren konnte, werde ich diese Begriffe nicht verwenden (siehe dazu die mir sehr einleuchtende Verwendung dieser Terminologie am komplexen Beispiel von Flann O’Briens At Swim-Two-Birds bei Malina, die meines Erachtens aber nicht ganz mit der intendierten Verwendungsweise bei Bal und Rimmon-Kenan übereinstimmt, vgl. Debra Malina: Breaking the Frame. Metalepsis and the Construction of the Subject, Columbus 2002, 12). Ich werde daher die, wie mir scheint, unmittelbar einleuchtende Bezeichnung als Erzählebenen ersten, zweiten usw. Grades verwenden. Gegen diese Begrifflichkeit (bzw. vor allem gegen das ähnliche `primäre, sekundäre etc. Ebene ) wurde schon von Genette eingewendet, dass hier eine wertende Hierarchisierung impliziert würde. Zum einen kann diese Problematik jedoch ggf. durch einen entgegenwirkenden Hinweis geklärt werden, zum anderen liegt gerade bei $V G$ durchaus eine Hierarchie vor, da die Erzähler ja erfunden werden und damit `abhängigく sind. Vgl. zu dieser Diskussion auch Manfred Jahn / Ansgar Nünning: »A Survey of Narratological Models«, in: Literatur in Wissenschaft und Unterricht 27 (1994), 283-303, hier $286 f$. 
als meta-auktorial bezeichnet werden. ${ }^{10}$ Bezogen auf die Schilderung der Handlung der eigenen Ebene, die dann in der Metalepse auch die Figuren Laupeyßer und Falbin umfasst, handelt es sich um aktoriales Erzählen, um eine interne Fokalisierung auf den Erzähler selbst (wobei die metafiktionalen Kommentare und Reflexionen keineswegs ausbleiben).

Die Erzählebene zweiten Grades wird zunächst etabliert durch den Ich-Erzähler Laupeyßer, also einen weiteren autodiegetischen Erzähler. Nach dem oben beschriebenen Wechsel wird ein weiterer Erzähler erkennbar; es handelt sich hier um einen nicht figürlichen, heterodiegetischen Erzähler mit interner Fokalisierung mit Laupeyßer als Perspektiventräger. Vermutlich handelt es sich dabei aber um eine lediglich dominant interne und damit um eine variable Fokalisierung. Denn auf dieser Ebene gibt es einen dritten Typus von Abschnitten, der einfach zu erkennen ist: die Gespräche Laupeyßers mit der Freundin Agnes, die durch Spiegelstriche abgesetzt sind und so den dramatischen Modus mit direkter und größtenteils sogar autonomer direkter Figurenrede markieren. Auch hier finden sich aber, abgesehen von den verba dicendi, zwischendurch, fast unbemerkt, Beschreibungen und Kommentare, die einen auktorialen heterodiegetischen Erzähler erkennbar werden lassen. So wenn Laupeyßer Agnes mit »einem leicht traurigen Ausdruck in den Augen « $(V G, 34)$ ansieht, diese "nachlässig" (ebd.) in ihrer Tasse rührt oder es ihr aber »in der Tat etwas zu viel wurde« $(V G, 45)$. Zudem gibt es auch Abschnitte, die weder Gedanken noch Gespräche oder Handlungen von Laupeyßer erzählen, aber durch figurale Verbindungen auf seiner Ebene angesiedelt sind, so z. B. die (auktoriale) Schilderung von Episoden aus dem Leben von Laupeyßers Großvater (vgl. VG, 35f.) oder wenige Abschnitte, die Handlungen von Axel Schulze schildern, der aus Abschnitten zusammen mit Laupeyßer bekannt ist (vgl. $V G, 152 \mathrm{f}$.). Ob es sich - da eigentlich unterschiedlichen Abschnitten zuzuordnen - um zwei verschiedene heterodiegetische Erzähler oder aber um eine variable Fokalisierung handelt, ist nicht eindeutig zu entscheiden. Da wiederum nichts eindeutig für eine Nicht-Identität und damit für eine weitere Vervielfältigung der Erzählinstanzen spricht, soll im Folgenden die Annahme einer variablen Fokalisierung gelten.

Laupeyßer erfindet nun die Figur Falbin, wodurch sich eine Erzählebene dritten Grades eröffnet. ${ }^{11}$ Hier spiegelt sich noch einmal die Konstruktion der zweiten Ebene. Wie Laupeyßer agiert auch Falbin als autodiegetischer Erzähler (auch wenn er recht spät in Erscheinung tritt, siehe $V G, 57$ ), wobei diese Abschnitte andeutungsweise als Tagebucheinträge bezeichnet werden (siehe $V G, 36$ und 149), was jedoch nicht bei jedem Abschnitt nachvollzogen werden kann. Ebenso wie auf der zweiten Ebene

10 Genette stellt eine ähnliche Überlegung an angesichts des traditionell gebrauchten Ausdrucks der Allwissenheit. Dieser sei, »wörtlich genommen, im Bereich der Fiktion absurd [...] (der Autor braucht nichts zu ‘wissen`, da er alles erfindet) und den man besser ersetzen sollte durch vollständige Information " (Genette: Die Erzählung, 242, Hervorhebung im Original). Was bei Genette durch die fehlende Unterscheidung zwischen Autor und Erzähler seine argumentative Stringenz verliert, wird beim >Autor`-Erzähler stimmig, da er durch seine metanarrativen Kommentare den Vorgang des Erzählens abbildet.

11 Damit zeigt sich wieder die Schwierigkeit, dem Erkenntnisprozess des Lesers auf übersichtliche Weise zu folgen; die oben beschriebene Identifizierung des >Autor-Erzählers erfolgt eigentlich nach der Erfindung von Falbin. 
wechseln sich die autodiegetisch erzählten Passagen ab mit solchen mit einem heterodiegetischen Erzähler mit dominant interner Fokalisierung, wobei diesmal Falbin Perspektiventräger ist. Und auch hier gibt es wieder die variable Fokalisierung, sodass sich auch in Abschnitten, die thematisch mit Falbin verbunden sind, auktoriale Kommentare finden (vgl. z. B. die Perspektive der Kollegen, $V G$, 54). Im Folgenden wird der Anschaulichkeit halber die Ebene zweiten Grades auch als Laupeyßer-Ebene und die Ebene dritten Grades als Falbin-Ebene bezeichnet. Diese umfassen aber nicht nur die von diesen selbst erzählten Abschnitte, sondern alle Abschnitte, die thematisch mit ihnen verbunden sind oder in denen sie sogar Perspektiventräger sind.

Es gibt viele Verbindungen zwischen den einzelnen Erzählern (und auch der verschiedenen Ebenen), die sich dadurch auftun, dass sie über die Abschnittsgrenzen hinaus aufeinander Bezug nehmen. Während die eingeschobenen Kommentare des >Autor<-Erzählers noch nachzuvollziehen sind, da er sich als »Autor des allen« zu erkennen gegeben hat, wird der Leser durch andere Bezugnahmen vor größere Schwierigkeiten gestellt. So endet der erwähnte Abschnitt über Laupeyßers Großvater mit einem Hinweis des (nicht figürlichen) Erzählers auf Falbin, der im folgenden, wieder nur durch ein Komma (und Leerzeile) separierten Abschnitt im Fokus steht (siehe VG, 36f.). Warum weiß also der Erzähler der zweiten Ebene etwas von Falbin, der auf der dritten Ebene angesiedelt ist? Zu Anfang ist es wohl so, dass Laupeyßer die Falbin-Passagen (zu diesem Zeitpunkt noch ausschließlich mit heterodiegetischem Erzähler) Agnes mündlich wörtlich genauso wie niedergeschrieben erzählt. Dies wird nicht nur durch Einwände von Agnes insinuiert, die durch Spiegelstriche und eigene Absätze markiert sind, sondern ganz explizit deutlich durch Laupeyßers Anrede an sie innerhalb der Falbin-Abschnitte und sogar ihre unfreiwillige >Integration ` in die Erzählung (vgl. die Passage VG, 20-24). Später ist in diesen Passagen der Erzähler ausschließlich ein nicht figürlicher, was inhaltlich damit korrespondiert, dass Laupeyßer seine Besuche (und Erzählungen) bei Agnes aufgibt. Es gibt daher keine Begründung dafür, weiterhin eine Übereinstimmung von Laupeyßer mit dem Erzähler anzunehmen (wobei er dennoch der >Autor der dritten Ebene bleibt bzw. ist).

Besonders augenfällig ist die Verbindung zwischen den Erzählern und Ebenen, wenn Falbin als Ich-Erzähler auf den ironischen Kommentar des `Autor`-Erzählers reagiert:

Seit zwei/drei Tagen war Falbin dazu übergegangen, irgendwelche Leute von der Straße aufzulesen [...].

Also Falbin nun als Florence Nightingale?

Ach was, darum ging es mir nun wirklich nicht, sondern : [...]. (VG, 251)

Im ersten Satz handelt es sich um den nicht figürlichen, heterodiegetischen Erzähler der dritten Ebene, dann folgt der Kommentar des >Autor<-Erzählers, dann übernimmt im nächsten Abschnitt Falbin selbst als Ich-Erzähler. Durch die Ironie des eingeschobenen Kommentars insinuiert der >Autor -Erzähler, der vorhergehende Erzähler sei autonom (eine Autonomie, die er nicht hat, da er von den übergeordneten Erzählinstanzen abhängig ist). Und Falbin wiederum reagiert auf einen Kommentar, von dem er aufgrund der ontologischen Trennung durch die Erzählebenen gar nichts wissen 
kann. Diese Stelle ist ein deutliches Beispiel dafür, dass die anfangs vom Leser mühsam rekonstruierte und in einen kohärenten Zusammenhang gebrachte Erzählkonstruktion als Ganzes ständig konterkariert wird. Denn bevor es zur stotalen`Metalepse kommt, also dem Zusammentreffen von >Autor-Erzähler, Laupeyßer und Falbin am Bahnhof, das die Verbindung aller drei Erzählebenen und damit den Zusammenbruch der Erzählkonstruktion zur Folge hat, gibt es schon etliche solcher kleineren metaleptischen Übertritte. Immer wenn ein Erzähler mehr weiß, als er eigentlich wissen dürfte, dieser "Informationsüberschuß $«^{12}$ aber nicht nur auf einen temporären, erzähllogisch eigentlich nicht erlaubten Wechsel in der Fokalisierung zurückzuführen ist (von Genette als >Paralepse ‘ bezeichnet), sondern sich auf eine andere Erzählebene bezieht, dann liegt schon eine Metalepse vor, auch wenn sie, weil sie en passant geschieht, kaum auffällt bzw. keine größeren erzählerischen Auswirkungen hat.

Im Allgemeinen geht ein Leser (nach Martinez und Scheffel) vom Wahrheitsanspruch des Erzählers in der erzählten Welt und von deren Konsistenz aus. ${ }^{13}$ Zwar weiß er von vornherein um den imaginär-inauthentischen Status ${ }^{14}$ der zweiten und dritten Erzählebene, doch wird ein Wahrheitsanspruch dem >Autor`-Erzähler und auch den Erzählern der Laupeyßer-Ebene zunächst zugeschrieben, da der Leser sich auch bei Laupeyßer prototypischem handlungsorientierten Erzählen gegenübersieht. Bei Falbin fehlt dagegen der Wahrheitsanspruch (im Sinne des >so hat es sich zugetragen $`$ ) von vornherein, da das Erzählen ständig von metanarrativen Kommentaren begleitet wird. Doch auch hier gibt es längere Abschnitte, die durch ihre Beschreibungsdichte und Handlungsorientiertheit das Bild einer weitgehend autonomen Welt etablieren. Durch die vielen `kleinen` Übergriffe, vielmehr jedoch durch einen größeren, wie den eben am Falbin-Beispiel geschilderten - wenn eine Figur selbst ihre diegetischen Grenzen überschreitet -wird die am `normalen` Lesen geschulte Erwartung der Autonomie der Figuren konterkariert. Alle Erzähler bzw. Stimmen erweisen sich als abhängig von der ihnen jeweils übergeordneten Erzählinstanz, sie sind nicht autonom, sondern simuliert. Das Kennzeichnende dieser ebenso metanarrativen wie metafiktionalen Erzählkonstruktion besteht jedoch darin, dass beides >stimmt ‘, die auf Kohärenz ausgelegte Analyse der Erzählsituation ebenso wie das Bewusstsein von der Fiktionalität und Inauthentizität der Erzählebenen.

Zusätzlich zu den bislang beschriebenen und ‘klassifizierten` erzählenden Abschnitten gibt es noch drei Abschnittarten, die etwas aus dem Rahmen fallen. Dies sind montiertes Material (Zeitungsausschnitte, Annoncen etc.), literarische Zitate sowie die Sentenzen für den >Pappkarton<. Während die montierten Schnipsel, die entweder aus tatsächlich eingefügten Bildern oder aber aus zitierten Sätzen bspw. aus der Werbung bestehen, in erzählende Abschnitte eingefügt sind, stehen die beiden anderen Arten als eigenständige Absätze gesondert von oder zwischen den anderen Abschnitten. Dabei ist mangels direkter Bezüge in den umgebenden Abschnitten der einzige Hinweis auf die Zugehörigkeit zu einer der Erzählebenen die typographische

12 Genette: Die Erzählung, 140.

13 Vgl. Martinez / Scheffel: Einführung in die Erzähltheorie, 95 und 103.

14 Vgl. noch einmal ebd., 17 und $161 f$. 
Gestaltung: alle literarischen Zitate, die als eigener Absatz gesetzt und mit einer ungefähren Quellenangabe (Autor und Werk) versehen sind, sind auch kursiv gesetzt und damit der Ebene ersten Grades, also dem `Autor«-Erzähler zugeordnet. Dieser Umstand fügt sich in die eben beschriebene Lesart einer metanarrativen Spiegelung des eigentlich (im Wortsinne) extradiegetischen Erzählvorgangs auf der ersten (diegetischen) Ebene: der >Autor`-Erzähler stellt unkommentiert seine Lektürefundstücke, seien sie `Quellen`oder Inspirationen, dem Leser zur Verfügung. Die Zuordnung des Pappkartons ist schon deutlich schwieriger. Dabei handelt es sich tatsächlich einfach um einen von Laupeyßer eingerichteten Pappkarton, in dem er alle möglichen Dinge sammelt, ${ }^{15}$ unter anderem auch aphorismenhafte Aussprüche, die dann mit der nachgestellten Bezeichnung »Pappkarton« versehen sind. So spricht in der Folge nichts dagegen, davon auszugehen, dass auch diese zitierten Sentenzen von Laupeyßer stammen. Schließlich spricht jedoch der >Autor<-Erzähler davon, »das Prinzip Laupeyßer in einen Pappkarton zu packen« $(V G, 213)$. Gleich auf der nächsten Seite findet sich dann am Ende eines kursivierten Abschnitts das Wort »Pappkarton«, wobei dies nicht eindeutig als Bezeichnung zu sehen ist, da es ebenfalls kursiv ist. Ab hier häufen sich jedoch die Pappkarton-Sentenzen in umgekehrter Markierung: der Absatz ist kursiv und die Bezeichnung »Pappkarton « am Ende recte gesetzt; bald kommen keine mehr vor, die nach diesem Schema Laupeyßer zuzuordnen wären. Schließlich erwähnt auch noch Falbin in einem sseiner Abschnitte, er habe »diesen Zettel in den Pappkarton gesteckt « $(V G, 290)$, wodurch auch er noch mit dem Pappkarton in Verbindung gebracht wird. ${ }^{16}$ Auch in diesem Randmotiv wird also, ganz unscheinbar, eine Verbindung zwischen den Ebenen hergestellt. Hierbei muss es sich nicht um eine Metalepse handeln, das Motiv Pappkarton kann auch auf allen Ebenen platziert sein, doch wird im Detail deutlich, dass eine eindeutige Zuordnung erschwert wird, sich ein Motiv von einer Ebene zur anderen verschieben kann und insgesamt bewusst im Dunkeln gelassen wird, wohin das Motiv/der Gegenstand nun gehört.

Zusammenfassung In der Annahme, dass es sinnvoll ist, so wenige Erzählinstanzen wie möglich anzunehmen, solange es keine Hinweise auf etwas anderes gibt, können wir die Erzählsituation also folgendermaßen zusammenfassen: es gibt eine Erzählebene ersten Grades mit dem `Autor<-Erzähler als einzigem, autodiegetischen Erzähler. Auf der Ebene zweiten Grades finden wir Laupeyßer als dominanten Perspektiventräger mit zwei Erzählern, ihm selbst als autodiegetischem Erzähler sowie einem nicht figürlichen heterodiegetischen Erzähler. Die dritte Ebene ähnelt der zweiten, diesmal mit Falbin als dominantem Perspektiventräger und autodiegetischem Erzähler sowie einem weiteren nicht figürlichen heterodiegetischen Erzähler. Es gibt also eine Vielfalt verschiedener Stimmen, die teilweise eindeutig, teilweise nicht eindeutig oder zumindest nicht sofort zuzuordnen sind. Das häufige Fehlen eindeutiger Hinweise zur Zuordnung sowie die metaleptischen Überschreitungen der Ebenen durch

15 Vgl. dazu später Abschnitt 1.6 auf Seite 90.

16 An anderer Stelle wird jedoch Falbin als der charakterisiert, "den der Pappkarton nicht drückte» $(V G, 322)$, was einerseits bedeuten könnte, dass er mit dem Pappkarton doch nichts zu tun hat, oder aber, dass er nur nicht unter dieser Belastung leide. Dass es sich um Einzelstellen handelt, spricht für eine nur unwesentliche Verbindung des Motivs mit Falbin. 
hetero- wie autodiegetische Erzähler etablieren ein Erzählverfahren, das systematisch Eindeutigkeit sabotiert und `normale < Lesererwartungen düpiert. Auch wenn nicht jeder Satz oder Abschnitt eindeutig einer Stimme oder einem Erzähler zugeordnet werden kann, so sind doch die Erzähler als solche voneinander zu unterscheiden. Das wiederum heißt nicht, dass sie eine feste, autonome Figurenidentität hätten; eine solche wird durch die Metalepsen und die fiktional-ontologischen Abhängigkeiten untergraben. Der im folgenden beschriebenen Bedeutung des Titels (Die Verwirrung des Gemüts) als Bezeichnung der Identitätskrise der Protagonisten wird damit eine weitere gegeben, die sich auf die Verwirrung des Lesergemüts bezieht.

\subsection{Laupeyßers »Fluchten«: die Identitätskrise}

Auch wenn der >Autor «-Erzähler im ersten Absatz des Buches das erste Mal auftaucht und damit auch die erste Erzählebene konstituiert, so ist doch Laupeyßer derjenige Erzähler bzw. vor allem Perspektiventräger, der nicht nur die Anfangsabschnitte, sondern weite Teile des Buches dominiert. Die Sozialisierung und Vorgeschichte Laupeyßers wird durch wenige, aber präzise Eckdaten skizziert, die eine Anlehnung an reale Ereignisse und Milieus andeuten. ${ }^{17}$ Dies erfolgt in einem kurzen Abschnitt mit heterodiegetischem Erzähler sowie durch einen weiteren in Laupeyßers eigener Schilderung.

Ulf Laupeyßer wird 1953 geboren und wächst in Bremen, erst unbestimmt als "Stadt im Norden der Bundesrepublik« ( $V G, 14)$, dann beiläufig mit Namen genannt, als Sohn eines Apothekers auf. Er studiert in Bonn Pharmazie, bricht das Studium jedoch ab, und kehrt nach Bremen zurück. Dort zieht er in ein Einzimmerappartement und der Vater beschafft ihm eine Stelle in einem Speditionsunternehmen. Der Abbruch des Studiums wird zeitlich zwei Jahre vor den im Roman geschilderten Ereignissen angesiedelt, muss sich also, da letztere im August 1982 datiert sind, 1980 zugetragen haben. Er ist ein grundlegender Einschnitt in Laupeyßers Leben und wird als »erste Flucht« $(V G, 14)$ den kommenden Ereignissen als zweiter Flucht entgegengestellt. Ursache der ersten Flucht ist ein Gefühl, das sich durch die Begegnung und Auseinandersetzung mit der (deutschen) Geschichte herstellt. Poetisch-enigmatisch wird diese Verbindung zuerst vom >Autor`-Erzähler hergestellt. Die personifizierte Geschichte tritt zu Laupeyßer ${ }^{18}$ und scheint ihn zu beschuldigen.

Reißt du sie auf, begegnet Geschichte leibhaftig: stand mir ins Zimmer, kroch in meine Kleider, unters Hemd, begrüßte mich gehässig beim Aufwachen. »Du bist ein Deutscher", sagte sie und lachte bös. $(V G, 14)$

>Aufgerissen ` wird nicht die Geschichte, sondern die unmittelbar vorher erwähnte »Larmoyanz«, die das Grauen verhüllen soll. Für Laupeyßer führt also die direkte Konfrontation mit der Geschichte zur Konfrontation mit der Tatsache, ein Deutscher in der Nachfolge der Ereignisse der nationalsozialistischen Herrschaft zu sein und den

17 Im Übrigen ähneln sie den bekannten Grunddaten des realen Autors Alban Nikolai Herbst, vgl. dazu im Abschnitt 2.4 auf Seite 113.

18 Oder aber zum >Autor $<$-Erzähler, das wird hier nicht deutlich, ist aber durch die imaginäre Natur Laupeyßers vermutlich gleichwertig. 
damit zusammenhängenden Schuldgefühlen. Wodurch diese Konfrontation erfolgt, wird nicht mitgeteilt, lediglich wird deutlich, dass eine nähere Auseinandersetzung mir ihr unterbleibt. Deutlich wird dies durch die Vagheit der Beschreibung als »Gefühl, das einsetzte im Gefolge von achtundzwanzig Jahren « $(V G, 13)$ und die mehrfach eingestandenen Formulierungsschwierigkeiten: »man kann es so nennen« $(V G, 14)$, "was ich eigentlich wünschte, doch nicht formulieren konnte" $(V G, 15)$ und besonders deutlich »Aber alles, was ich dir sage, trifft, was ich sagen will, nur ungenügend, Agnes.« (ebd.). Seine Situation zu diesem Zeitpunkt schildert er selbst dahingehend, dass er sich durch das Studium vor einer solchen Auseinandersetzung "verstecken « (ebd.) wollte. Zwar konnte er »wenigstens mit einigen Leuten noch Bekanntschaften innerer Art pflegen « $(V G, 16)$, doch fühlt er sich den »Aufsteiger $[n]$ « $(V G, 15)$ des Studiums, die nach Art des Vaters nach Familie, Wohlstand und Kindern, nach gesicherter Zukunft streben, fremd, empfindet diese als »das überall Gleiche« (ebd.). Er fühlt jedoch den Zwang (»es gälte«), »von etwas zu sprechen, das für die Ohren der meisten ungehörig war" (ebd.). Diesen Zwang unterdrückt er, er versucht ihn "mit gewöhnlicher Arbeit « (ebd.) zu betäuben, doch »Angst «, »Unlust«, »Lethargie« (ebd.) und »Überdruß« $(V G, 14)$ sind die Folge. Laupeyßer ergreift die Flucht. Zwar geht er zurück in den »Umkreis elterlichen Lebens«, doch »fort aus dem Dunst ihrer Gedanken « (ebd.). Dies erfolgt durch die berufliche Neuorientierung, die sich dem Verfolgen einer in den Spuren des Vaters verlaufenden Karriere widersetzt. Doch ist es lediglich eine Flucht und so ist der scheinbare Neuanfang durch eine Wiederholung desselben Verhaltens gekennzeichnet. Er versenkt sich in die "schnell eingefahrene Arbeit « $(V G, 15)$, versucht, zur Ruhe zu finden, verfolgt ein »leises [S]ichbescheiden « $(V G, 16)$. Auch hier gelingt ihm dies nicht. Seine Umgebung, vor allem seine Eltern, reagieren durch Unverständnis, eine Mitteilung seiner »Vermissungsgefühle« (ebd.) ist ihm gänzlich unmöglich geworden. Mit den Eltern kommt es zum Konflikt, zu Dingen entwickelt er Distanz ebenso wie zu Menschen seiner Umgebung, indem er diese zu hinterfragen beginnt und nicht damit zurechtkommt, dass "alledie schier zufrieden taten und so, als habe es deutsche Geschichte und diesen klebrigen Boden niemals gegeben, als lebten sie ohne das « (ebd.).

Seine Identitätskrise zeigt sich maßgeblich in der Frage »Kann ich mich noch entsetzen? « und dem noch näher zu erläuternden `Entschluss`. Sie umfasst dabei vor allem Aspekte der diachronen Betrachtung von Identität, des Harmonisierens verschiedener Elemente der Innenperspektive und der Herstellung einer individuellen Identität.

\subsection{1 "Kann ich mich noch entsetzen?»}

Nach dieser im Rückblick aufgezeigten Entwicklung ist ein Kinobesuch das Ereignis, das Laupeyßers Leben eine entscheidende Wendung gibt und die Handlung von VG in Gang setzt. Bei dem gezeigten Film handelt es sich um Pier Paolo Pasolinis Die 120 Tage von Sodom (1975), einer Adaptierung des gleichnamigen Buches des Marquis de Sade von 1785 (erstmals veröffentlicht 1904). Pasolini verlegte die Handlung des Buches, das von sadomasochistischen Sexualpraktiken erzählt, in den historischen 
faschistischen Marionettenstaat Salò, der auch im Originaltitel erscheint. ${ }^{19}$ Durch die extrem offene Zurschaustellung von Gewalt im Allgemeinen, Vergewaltigung, Missbrauch, Folter und Mord im Speziellen, wurde der Film zu einem Skandalfilm, der in Deutschland eine Kontroverse auslöste. Zuerst wurden Aufführungen in vielen Städten verboten, erst 1978 wurde die Freigabe durch die Freiwillige Selbstkontrolle der Filmwirtschaft (FSK) gerichtlich erlaubt. ${ }^{20}$ Überraschenderweise wird in VG die Verbindung des Films zur von 1943 bis 1945 unter Mussolini existierenden faschistischen »Italienischen Sozialrepublik« (mit der Hauptstadt Salò, deshalb auch unter dem Namen >Republik von Salò < bekannt) und damit zu faschistischen Praktiken nicht hergestellt. Der Film ist vor allem durch Wirkung auf Laupeyßer bzw. den >Autor-Erzähler sowie durch die Reaktion des Publikums Auslöser der Reflexionen. Das »Gemetzel« $(V G, 8)$ bzw. »Kinogemetzel « $(V G, 106)$ löst bei den anwesenden jugendlichen Kinobesuchern Lachen aus, Laupeyßer selbst »verwirrt und erregt « (ebd.) es, eine wörtliche Bezugnahme auf den Buchtitel, die ebenso wie die Platzierung des Kinoereignisses am Anfang von $V G$ auf die zentrale Stellung dieser Fragen hinweisen.

Bereits im ersten Satz seines ersten Abschnitts weist Laupeyßer auf die Thematik des "Entsetzens« hin. Seine Behauptung, dass es Menschen gebe, die sich noch entsetzen könnten und nicht nur so täten als ob, verfolgt er jedoch nicht weiter. Vielmehr führt er Beispiele für das Gegenteil an: die erst viel später wieder erwähnte Nebenfigur Hansen, die fasziniert von Verkehrstotenfotos ist, und eben die Jugendlichen im Kino. An diesen den Film thematisierenden Stellen mischt sich der >Autor`-Erzähler immer kommentierend ein. Anfangs fasst er die Thematik prägnanter als Laupeyßer in die Ausgangsfrage des Buches zusammen: »Kann ich mich noch entsetzen?«(VG, 8) Trotz der (durch Laupeyßers ontologischen Status als Erfindung des `Autor -Erzählers naheliegenden) Ähnlichkeit ihrer Reflexionen differieren ihr Umgang mit den Reaktionen und ihre daraus ableitbaren Gefühle. Der `Autor`-Erzähler verbindet die Frage gleich mit seinem späteren »Versuch von Geschichtslosigkeit« $(V G, 151)$ und trifft nicht nur die Feststellung, dass er sich nicht mehr entsetzen könne, sondern gesteht sogar seine Faszination ein. Er reagiert also emotional relativ nüchtern, stellt seine weitergehenden Überlegungen an. Laupeyßer dagegen geht es zunächst weniger um seine eigene Reaktion, als um die der anderen. Er ist immer wieder mit der Erinnerung an das Lachen der Jugendlichen konfrontiert, die ihn derart belastet, dass er das Gefühl empfindet zu ersticken. Explizit äußert er das Verlangen, das Lachen loswerden zu müssen (vgl. $V G, 106)$.

\subsubsection{Der Entschluss}

Durch die Erfahrung des Films ist Laupeyßer vollends in eine Identitätskrise gestürzt, die als zweite Flucht bezeichnet wird (vgl. VG, 14). Er fasst am Tag nach dem Kinobesuch einen »Entschluß« $(V G, 8)$, der im Kontext der Erwähnung nicht erläutert wird und daher einer eindeutigen Definition oder Zuordnung entbehrt. Durch verschiedene auf den Entschluss deutende Formulierungen kann er jedoch eingegrenzt werden.

19 Salò o le 120 giornate di Sodoma; auch in VG wird bei der einzigen Nennung des Titels der italienische Kurztitel verwendet, siehe $V G, 124$.

20 Vgl. Dietrich Kuhlbrodt: "Große Schnitte, kleine Schnitte«, in: die tageszeitung, 7. Mai 2003. 
Zum einen liegt der Entschluss wohl darin, »den Fragen « (ebd.) nicht mehr länger auszuweichen, die sich wie oben bereits erwähnt auf die deutsche Vergangenheit beziehen. Zum anderen, und darin ist deutlicher der Entschluss zu erkennen, nimmt er sich vor:

Nimmer nämlich $[\ldots]$ werde ich ausführen wollen weiterhin, was genannt wird GUT von mir fremden, entäußerlichten Instanzen, deren Durchsichtigkeit gelitten hat am Milchglas ihrer halbverborgenen Absicht; die sich aufgeteilt haben dann die Welt in große Begriffe von Freiheit und Sozialismus. Nein. (VG, 10f. $)^{21}$

Eingebettet ist dieser Entschluss in Andeutungen politischer Positionen und Zitate. Laupeyßer setzt sich von der marxistischen Ausrichtung der >Neuen Linken $`$ der 1968er ebenso wie der der DDR und UdSSR ab. Angedeutet wird die Unterstützung des chilenischen Diktators Pinochet nach dem Putsch von 1973 durch deutsche Politiker und nur noch wörtlich aufgeführt und damit in den Zusammenhang eingereiht der Korea- und der Vietnamkrieg. Laupeyßer fühlt sich also weder bei der Neuen Linken aufgehoben, kann auch nicht mit dem DDR-Sozialismus sympathisieren, noch fühlt er sich wohl in der Bundesrepublik, die Diktatoren und die USA in aus seiner Sicht unrechtmäßigen Kriegen unterstützt, ${ }^{22}$ und wo `nach Auschwitz ‘ wieder Judenwitze auftauchen. Er sieht sich folglich als (politisch) Heimatloser und sucht nach einem »Ausweg aus Familie/Arbeit/Vaterland « $(V G, 11)$. Der im Zitat formulierte Entschluss bedeutet zunächst also die Abkehr von snormaler`Arbeit, gesehen als Produktion für Andere. Tatsächlich geht Laupeyßer auch nur noch unregelmäßig und später gar nicht mehr ins Büro, bis ihm in der Folge auch gekündigt wird.

Laupeyßer beginnt damit, seine Verwandten und Freunde zu befragen, vor allem die Generation der Großeltern, die »aktiv dabeigewesen « $(V G, 8)$ waren, die die Generation der >Täter war. Er legt pedantisch genaue Aufzeichnungen an, macht Notizen, nimmt Gespräche heimlich mit Kassettenrekorder oder Diktiergerät auf, hört diese ab, aber verarbeitet sie nicht weiter. Er interessiert sich vor allem für die Details. Doch bald nimmt er davon Abstand, aus »Kraftmangel« und da die Fragen ihm »versieg[en] « $(V G, 9)$. Weder die Fragen noch die Antworten werden jedoch aufgeführt. Er hat nicht das Gefühl, durch die möglichen Antworten etwas klären zu können, vielmehr sieht er in den Fragen schon die Antworten, dass es also nicht um die Erfahrungen und Meinungen der Befragten geht, sondern um ihn als Fragenden selbst. Später gesteht Laupeyßer auch ein, dass es sich bei dem »eigentlichen Thema« $(V G, 8)$, das anfangs die Auseinandersetzung mit der Nazi-Vergangenheit bedeutete, um die Auseinandersetzung mit sich selbst handelt:

Hatte ich nämlich durch Tonbandaufzeichnungen und Notizen vorgeblich über andere etwas herausfinden wollen, so wollte ich in Wahrheit doch mich haben. Alles andere interessierte gar nicht.« $(V G, 101)$

21 Beide Formulierungen enthalten den Aspekt des Auflehnens gegen etwas, der auch mehrfach noch betont wird: »Auf keinen Fall mehr klein begeben zu wollen." $(V G, 56)$ sowie ex negativo erschlossen: »Ich fand mich immer noch ab, arrangierte mich.» $(V G, 107)$

22 Vgl. auch die späteren, mehrfachen Hinweise auf das Massaker von My Lai (1968), dazu mehr in Abschnitt 1.3.1 auf Seite 61. 
Die Befragungen lösen in ihm Reaktionen aus, die eine mentale und auch körperliche Veränderung in Gang setzen. Es baut sich durch die Befragungen die Empfindung von »Entfernung « $(V G, 8)$ auf, als körperliche Reaktion stellt sich erst einmal ein Grippegefühl ein. Die mentale Reaktion ist noch drastischer. Es schwindet schließlich das natürliche Bewusstsein seiner selbst als Einheit, oder, in seiner Formulierung, es wird das »mir« $(V G, 17) \mathrm{ihm}$ fraglich. Das bedeutet die Infragestellung seiner Identität, die Erschütterung seines Selbst in seinen Grundfesten.

\subsection{3 "Der Abstieg des hoffnungsvollen Laupeyßer-Ulf «"33}

Laupeyßers Entschluss beinhaltet oder geht zumindest einher mit einem planvollen "Abstieg" $(V G, 17)$. Die Tonbandaufnahmen und eigene Notizen häuft er nur noch an, er verarbeitet sie nicht mehr, wirft alles in den bereits erwähnten Pappkarton. ${ }^{24}$ Die Kollegen bemerken ein Gefühl von Hass, das ihn umgibt, doch Laupeyßer zieht sich absichtlich zurück, schränkt seinen Kontakt auf wenige Treffen mit früheren Klassenkameraden ein. Zwar sucht er noch täglich das bereits bekannte Café auf, doch ist sein Zustand einer der bewussten Isolation. Auf verschiedene Weisen durchbricht er diese anfangs noch. Er besucht regelmäßig Agnes, um ihr seine Imaginationen um Falbin zu erzählen und führt lange Gespräche mit ihr, er verbringt ein Wochenende unter nicht ganz geklärten Umständen in Frankfurt und besucht zwei Mal Freunde im Emsland und in Hamburg. Auch verbringt er einen unbeschwerten Tag mit Freunden an einem Badesee, wo er einmal nicht an seine neue Situation denkt. Durch diese lediglich am Rande erwähnten Episoden wird deutlich, dass Laupeyßer auch `normale soziale Kontakte zu haben und kein sozial gestörter pathologischer Fall zu sein scheint. Diese Deutung wäre naheliegend durch die Kennzeichen seiner sonstigen Entwicklung, die extrem ist. Gut eine Woche nach dem Kinobesuch, am 13.8., ${ }^{25}$ gibt er eine Annonce für den Verkauf seiner Wohnungseinrichtung auf, der am nächsten Tag erfolgt. Bis auf den Fernseher, einen Tisch, den Kühlschrank und ein wenig Besteck verkauft er alles, reißt dann auch das Telefonkabel aus der Wand und stellt die Türklingel ab.

Gleichzeitig wird die fundamentale Identitätskrise durch verschiedene Erfahrungen deutlich, die Laupeyßers tiefe Verunsicherung zeigen. Er stellt die Autonomie seiner Entscheidungen und seines Willens infrage, schließlich sogar die Wahrnehmung der Wirklichkeit; nichts scheint ihm mehr sicher zu sein. Dies drückt sich weniger durch theoretische Reflexionen aus, als durch von unscheinbaren Beobachtungen hervorgerufene emotionale Erlebnisse. So sinnt er beispielsweise lange dem Wort "Löffel« $(V G, 70)$ nach und stellt fest, dass er mit dem Wort an sich nichts mehr anzufangen weiß. Die Begriffe werden ihm fremd. ${ }^{26}$ In der Folge geht ihm der Bezug zum Gegenstand, zu den mit Begriffen bezeichneten Dingen, dem Signifikat, verloren. Er befreit sich also von der Außenperspektive und geht bis auf die Ebene der (gesell-

$23 V G, 107$, vgl. auch 14.

24 Vgl. dazu unten Abschnitt 1.6 auf Seite 9o.

25 Zur Funktion dieser genauen Datumsangaben vgl. Abschnitt 2.4 auf Seite 114.

26 Vgl. auch schon vorher direkt nach seiner Rückkehr nach Bremen die sich entwickelnde »Distanz zu beliebigen Dingen«, die »nur Schatten in meinem Kopf warfen« $(V G, 15)$, sowie später auch die »Dinge in ihrer falben Begrifflichkeit«, die »ungreifbar« werden $(V G, 76)$. 
schaftlich) vorgegebenen Begriffe auf Distanz. Daraus entsteht die Sehnsucht und der Versuch, »Wirklichkeit herzustellen « $(V G, 17$, auf den später zurückzukommen ist), um dadurch Sicherheit oder Absicherung zu erreichen.

Es setzt auch eine körperliche Veränderung ein. ${ }^{27}$ Ein unangenehmer Geruch geht von ihm aus, der auch durch sorgfältige Körperpflege nicht beseitigt werden kann, allerdings auch nur von ihm wahrgenommen zu werden scheint. ${ }^{28}$ Es beginnen sich im Gesicht Pickel zu bilden, die vorher ausschließlich ein Charakteristikum in der Beschreibung von Falbin gewesen waren. Laupeyßer bemerkt auch eine Verfeinerung des Nervensystems und damit einhergehend die Ausbildung verschiedener körperlicher Merkmale, die die Verwandlung in einen Vampir andeuten. ${ }^{29}$ Nachdem er nicht mehr ins Büro gegangen war, erfolgt die Kündigung, woraufhin er seine Aktivitäten größtenteils in die Nacht verlegt. Er beginnt, exzessiv seine Zimmerpflanzen zu pflegen, jeden Tag einzeln die Blätter zu reinigen und mit ihnen zu `kommunizieren • Ansonsten läuft der Fernseher, wobei er bei Nachrichtensendungen den Ton abdreht, wie er auch keine Zeitung mehr liest und also keinerlei Informationen der Außenwelt zu sich dringen lässt.

Das Bedürfnis nach Isolation, nach fast völliger Abgeschiedenheit von der Außenwelt, steigert sich schließlich sogar zu einer »Manie« $(V G, 162)$, zu einem Verfolgungswahn, der sich in der Befürchtung ausdrückt, dass jederzeit jemand an seine Wohnungstür klopfen könnte. Grund für diese Befürchtung ist die Angst, gewaltsam verschleppt zu werden. Diese gipfelt in mehreren (Wahn-)Phantasien, in denen Laupeyßer entweder aus seiner Wohnung oder aber aus Falbins Büro abgeholt und von einer Frau verhört wird, die eine Mischung verschiedener Frauenfiguren des Buches ist, aber vor allem als Agnes auftritt. Die Phantasie wird zunehmend brutal und rekurriert durch Anspielungen aufs Lachen der Jugendlichen im Kino auch auf die Thematik des Entsetzens und auf Pasolinis Film; sie gipfelt schließlich in der brutalen Tötung Laupeyßers.

Durch die Schilderung der Wahnvorstellungen ist ein objektives Geschehen nicht mehr wirklich festzumachen. Vornehmlich durch verschiedene Versionen eines ähnlichen Vorgangs oder durch offene Widersprüche werden Geschehnisse als Imaginationen kenntlich gemacht. Andere dagegen werden zumindest als real präsentiert. Demnach verbringt Laupeyßer immer mehr Zeit in seiner Wohnung, geht schließlich nicht mehr ins Café, hält sich dort aber in der Vorstellung auf. Dies geht soweit, dass er sich die Bedienung, mit der er oft im Café gesprochen hat, als wiederum auch in der Wohnung anwesend vorstellt, sie bedient ihn auch dort, bringt ihm seinen üblichen Kakao. Laupeyßer verlässt seine Wohnung nur noch durch das Fenster, da er Angst vor

27 Bereits im Motto des Buches, das aus Walter Benjamins Ursprung des deutschen Trauerspiels entnommen ist, wird diese Entwicklung vorweggenommen und kann sogar mit der Entsetzensthematik verbunden werden: »Die Ertötung der Affekte, mit der die Lebenswellen verebben, aus denen sie sich im Leibe erheben, vermag die Distanz von der Umwelt bis zur Entfremdung vom eigenen Körper zu führen. Indem man dies Symptom der Depersonalisation als schweren Grund des Traurigseins erfaßte, [etc.] « Vgl. VG, 5, sowie Walter Benjamin: Ursprung des deutschen Trauerspiels [1925], in: Ders.: Gesammelte Schriften, Bd. 1/1, hg. v. Rolf Tiedemann / Hermann Schweppenhäuser, Frankfurt am Main 1974, 203-430, hier: 319 und 322.

28 Weitere Darlegungen zum Geruch finden sich unten, vgl. Abschnitt 1.3.1 auf Seite 57.

29 Dazu vgl. unten Abschnitt 1.3.1 auf Seite 58. 
dem Treppenhaus hat. Er isst kaum noch und wenn dann nur noch nachts, außerdem reagiert sein Körper auf Essen hypersensibel. Die Pickel breiten sich nicht nur über das Gesicht, sondern über den gesamten Körper aus. Durch die `Kommunikation` mit den Pflanzen verfällt er auf die Vermutung, der Geruch, der eigentlich von ihm ausgeht, setze sich in den Tapeten fest, woraufhin er diese herunterreißt. Dies bringt keine Linderung, der Geruch verfliegt erst, als durch beständiges Lüften ein Wind einsetzt, der wohl aber auch eingebildet ist, da er mit Schließen der Fenster nicht aufhört. Das Abklingen des Geruchs bedeutet wieder eine Veränderung, bei der allerdings nicht klar ist, ob es sich tatsächlich um einen Prozess des »Freiwerdens « $(V G, 275)$ handelt. Vielmehr folgt der Hinweis auf den Gebrauch von Psychopharmaka, die Laupeyßer von seinem Vater, der Apotheker ist, geklaut hat, und zu denen er allabendlich greift, wenn das sich einstellende Gefühl der Erträglichkeit sich wieder verflüchtigt hat.

Der Hinweis auf die Psychopharmaka stellt auch die Verbindung zu mehreren rrealistischen $\triangleleft$ d. h. real möglichen Versionen des Geschehens her, die dem Leser angeboten werden. Das Klopfen an die Tür, das Laupeyßer in seinem Verfolgungswahn so sehr fürchtet, stellt sich tatsächlich ein, als sein Vater an die Tür klopft, nachdem er den Medikamentendiebstahl entdeckt hat. Doch kommt es zu keinem Kontakt und daher auch zu keiner Aufklärung. Schließlich werden im Stil von Zeitungsberichten zwei Varianten einer Entdeckung der Wohnung geschildert, die durch den kursiven (und damit dem >Autor<-Erzähler zugeschriebenen) Kommentar »Denkbar wäre aber auch:« $(V G, 244)$ verbunden sind. In der einen Variante brechen Beamte aufgrund einer Beschwerde wegen Geruchsbelästigung die Wohnung auf, entdecken eine »Fixerhöhle« mit Spritzen und Resten von Morphium sowie mit den Merkmalen, die auch in den Imaginationen Laupeyßers beschrieben wurden (fast leere Wohnung, zerfetzte Tapeten, wuchernde Pflanzen, implodierter Fernseher). In der anderen wird ein 28-Jähriger beim Versuch festgenommen, unter Drogen die Außenwand seines Hauses hinunterzuklettern. Er wird in psychiatrische Verwahrung genommen, gibt an, sich vom Blut junger Frauen zu ernähren, die er auch ermordet habe, und äußert die Vermutung, ein Sohn Eichmanns zu sein. Die Wohnung riecht nach verwesendem Fleisch und an der Wand steht in großen Buchstaben: "ICH BIN FASCHIST.« (VG, 245).

Neben diesen beiden Varianten, die außerhalb der Imaginationen Laupeyßers gestellt werden, und mögliche Außensichten repräsentieren, wird auch aus seiner Sicht berichtet. In paralleler Handlungsführung zu den Geschehnissen um Falbin kommt es zu einer Begegnung mit der Bedienung des Cafés, die sich trotz seines angeblich entsetzlichen Aussehens auf ein Treffen und eine Nacht in einem Hotel mit ihm einlässt. 


\section{3 »Was bin ich nur? Wer bin ich? « ${ }^{30}$ - Die Suche nach Selbsterkenntnis}

So wie die Erzählform des Buches komplex ist, gilt dies auch für die Verknüpfung der Themen und Motive. Diese werden meist nur in Andeutungen eingeführt, Erläuterungen und weitere Ausführungen werden nach und nach hinzugefügt. Dem Leser erschließen sich so erst im Laufe der Erzählung die Bedeutung und Zusammenhänge der Motive. Es stellt sich heraus, dass diese größtenteils miteinander verbunden sind und erst in der Zusammenschau Möglichkeiten ihrer Interpretation aufzeigen. Das sukzessive Preisgeben der Informationen in der Erzählung und die komplexe Bezugnahme der Motive untereinander erschweren jedoch auch ihre Darstellung. Vier `Versuche können ausgemacht werden - wie angedeutet werden sie nicht kategorisierend benannt, sondern beiläufig und verstreut -, die Laupeyßer unternimmt, um mit der Identitätskrise, seinem Leben und der Wirklichkeit zurechtzukommen:

- der Versuch, sich selbst kennenzulernen bzw. zu erkennen

- der Versuch, Nähe zu anderen herzustellen, die sogenannten »Näherungen« $(V G, 97)$

- der »Versuch von Geschichtslosigkeit« $(V G, 151)$ sowie

- die eben erwähnten »Versuche, Wirklichkeit herzustellen« $(V G, 17)$.

Dabei ist zu beachten, dass die >Versuche« nicht nur Laupeyßer zuzuordnen sind, sondern auch dem >Autor «-Erzähler und teils auch Falbin, was bei der Annahme einer gewissen Form von Identität jedoch nicht erstaunlich ist. Der zuletzt genannte Versuch wird im nächsten Kapitel behandelt (vgl. Abschnitt 2.3 auf Seite 104).

\subsubsection{Der Versuch, sich selbst zu erkennen}

Die mehrfach gestellte Frage nach dem eigenen Ich bringt die Frage nach der eigenen Identität auf den Punkt, wenn sie auch so allgemein formuliert ist wie in der Form »Wer bin ich?«. Wie im oben bereits erwähnten Zitat aufgezeigt - [...] so wollte ich in Wahrheit doch mich haben. Alles andere interessierte gar nicht." $(V G, 101)$ - ist die Identitätsfrage eine zentrale, wenn nicht die zentrale Frage von $V G{ }^{31}$

Das grundlegende Anliegen dieser Selbstreflexion ist zweifach. Zum einen geht es darum herauszufinden, ob Selbsterkenntnis überhaupt möglich ist. Diese stellt er sich als eine möglichst objektive und umfassende Bestimmung von Identität vor. Dabei beschränkt sich Laupeyßer fast ausschließlich auf die Innenperspektive (Reaktionen von außen, die die Außenperspektive darstellen, werden erst im Komplex der `Näherungen bedeutsam). Zum anderen ist es der damit verquickte Versuch, sich durch Selbstreflexion aus seiner Identitätskrise zu befreien und zu einem stabilen Zustand zu gelangen.

$30 V G, 225$

31 Anzumerken ist, dass André Bretons Nadja (1928/63) mit dieser Frage in genau dieser Formulierung beginnt. Diese Erzählung ist ein wichtiger Prätext von $V G$ und wird darin mehrfach explizit genannt, vgl. unten Abschnitt 1.4.2 auf Seite 77. 
Zudem geht es um das Konsistenzproblem. Im Folgenden werden Laupeyßers "Versuch, sich selbst zu erkennen « vor allem Motive zugeordnet, die dem Konflikt zwischen Bewusstem und Unbewussten entspringen, demnach widersprechenden Elementen der Innenperspektive. In der Figur Falbin wird an diese Motive angeschlossen und der Konflikt in anderer Weise noch einmal durchgespielt. In den Motiven wird gezeigt, wie verschiedene Facetten der Konstruktion und Auflösung von Identität über das Körperliche und körperliche Veränderungen bearbeitet werden. Körper und Geschlecht werden so als Definitionsräume von Identität etabliert.

Bei der Einführung des Motivs spielen Spiegel in mehreren Konstellationen eine wichtige Rolle. Durch die Betrachtung der eigenen Person im Spiegel möchte Laupeyßer Vertrautheit mit sich selbst und dadurch Selbstbestätigung erhalten. Es wird ihm zur Sucht, sich im Spiegel zu betrachten, jedoch nicht, wie er betont, aus »Narzißmus«, sondern aus Unsicherheit. Das Ergebnis ist jedoch gerade gegenteilig: »Ich war erstaunt über meinen Anblick, der sich nicht verbinden ließ mit mir.« $(V G, 18)$ Die Bemühungen führen also zu einer vollständigen Verunsicherung und deuten schon die Perspektive einer gespaltenen Persönlichkeitsauffassung an. Bereits in der Pubertät hatte die genaue Betrachtung im Spiegel zu Verunsicherung geführt, damals jedoch durch einen besonders ungewöhnlichen Anschauungswinkel. Mit etwa fünfzehn Jahren hatte Laupeyßer die Behauptung von ihn hänselnden Mitschülern, er habe einen »Entenarsch« $(V G, 27)$, mit Hilfe zweier Spiegel überprüft. Da er im Zuge dieser `Untersuchung ‘ auch seine Genitalien und seinen After erstmals genauer betrachtet, muss er erst lernen, den Anblick seines Körpers zu akzeptieren. ${ }^{32}$ Was hier auf recht ungewöhnliche, aber dennoch nicht unerwartete Weise geschildert wird, ${ }^{33}$ kann jedoch als Beschreibung der natürlichen Entwicklung eines Jugendlichen gesehen werden, der sich durch die Erkundung seines Körpers nicht nur körperlich kennen- und akzeptieren lernt. Diese natürliche Entwicklung wird durch die Krise jedoch gestört.

\section{Das Hinterkopf-Motiv}

Die Betrachtung des eigenen Körpers aus einem ungewöhnlichen Winkel und die daraus resultierende Verunsicherung spielt auch in einer Szene im Café, das zu LaupeyBers bevorzugtem Aufenthaltsort wird, eine Rolle, in der das Motiv des Hinterkopfs eingeführt wird. Die Wände des Cafés sind an den Längsseiten mit Spiegeln versehen, die den Raum weiter erscheinen lassen und durch die Platzierung einander gegenüber eine unendliche Vervielfachung der dazwischen sitzenden Gäste und Gegenstände erzeugt. Ein weiterer Effekt ist, dass Laupeyßer sich von hinten anschauen kann und, nachdem er sich überhaupt einmal erkannt hat, lange seinen Hinterkopf betrachtet. Durch den ungewohnten Blickwinkel kommt er sich fremd vor; die lange Betrachtung

32 Später wird das »Spiegelexperiment« auch Falbin `angedichtet`. Auch in dem Zusammenhang wird wieder die Formulierung gebraucht, dass er Tage brauchte, »um sich so zu akzeptieren« $(V G, 161)$.

33 Der offene sprachliche Umgang mit sexuellen Szenen, Fäkalsprache oder betont ekligen Schilderungen ist kennzeichnend für das Buch und changiert zwischen provokantem Tabubruch und dem versuchten Anschein von natürlichem und lockerem Umgang mit diesen Themen. 
erzeugt wie auch beim Gesicht keine Vertrautheit, sondern eine weitere Entfremdung, er kommt sich wie » $[\mathrm{e}]$ in anderer $(V G, 28)^{34}$ vor. Laupeyßer überlegt dennoch, ob die Betrachtung im Spiegel eine Möglichkeit ist, sich kennenzulernen. Dadurch wird das Motiv des Kennenlernens, der `Näherung` an sich und andere eingeführt, das später noch eine zentrale Rolle spielt. Doch kommt er hier lediglich zu der Erkenntnis: »Man paßt nicht zusammen, Hinterkopf und Gesicht sind nicht stimmig. Ich bin nicht stimmig. Daran könnte es liegen, daß ich so ganz und gar nicht stimmig bin." $(V G, 29)$ Erst noch ganz allgemein formuliert in dem Versuch, nicht mit einer individuellen, sondern einer allgemein gültigen Beobachtung konfrontiert zu sein, ist er jedoch gezwungen, die Aussage sofort auf sich selbst zu reduzieren. Diese Überlegung wird zwar auch erst wieder zurückgenommen oder eingeschränkt (»Lachhaft!«), doch wird der Gedanke an den Hinterkopf zur Manie. Nicht nur wird der Hinterkopf im Spiegel noch mehrfach beiläufig erwähnt ( $V G, 45,136,191)$, Laupeyßer möchte ihn am liebsten zeichnen oder fotografieren, um ihn jederzeit betrachten zu können ( $V G$, 82), wiederum in der vergeblichen Hoffnung auf Absicherung der eigenen Identität durch Vertrautheit.

Durch die Bezeichnung als »Ort der Hintergedanken« $(V G, 29)$ wird der Hinterkopf als Sphäre des Unbekannten, Unbewussten und auch Dunklen des Menschen, seiner vielleicht unterdrückten Kehrseite charakterisiert. Dem eigenen Hinterkopf, der aus der Distanz der Spiegel gleichsam als jemand anderer gesehen wird, traut Laupeyßer mehr zu als sich selbst. Dabei handelt es sich um zentrale Eigenschaften, die er an sich vermisst: zum einen die Entschiedenheit des Willens im Allgemeinen $(V G, 28)$, d. h. sich des eigenen Lebenssinns bewusst zu sein oder zumindest einen eigenen Lebensweg sicher zu verfolgen; zum anderen die Fähigkeit, der ihn irritierenden, im Kino erfahrenen Lust an Gewalt zu widerstehen $(V G, 124)$. Indirekt wird auch die Verbindung zur Phantasie bzw. zur "Herstellung von Wirklichkeit« gezogen, als dem Hinterkopf bescheinigt wird, im Gegensatz zu Falbin den Absprung zu schaffen, wegzufahren und eine neue Identität auch entgegen den Hürden der Bürokratie anzunehmen. Dies wäre jedoch nur möglich, so wird konstatiert, »sofern es einem gelungen wäre, [den Hinterkopf] vorzustülpen« $(V G, 112)$. Der Wunsch, dies zu tun und damit die verborgenen Gedanken und Charaktereigenschaften hervorzuholen und an die Stelle des »vorherige[n] Gesicht $[\mathrm{es}]$ « $(V G, 235)$ zu setzen, wie eine andere Persönlichkeit, die schon in ihm angelegt ist, hervorzukehren oder anzunehmen, wurde auch schon vorher ausgedrückt (vgl. VG, 29). Der Hinterkopf wird damit zu einem Motiv, das im Verbund mit einigen anderen die Entwicklung Laupeyßers begleitet und symbolisiert. Diese Entwicklung geht nämlich auch damit einher, dass sich der Hinterkopf tatsächlich allmählich vorstülpt und zum zweiten Gesicht wird (Vgl. VG, 124, 164, 166, 171, 235). Deutlich wird die Charakterisierung des Hinterkopfs als Ort des Unbewussten auch, als der Prozess des >Vorstülpens bereits fortgeschritten ist. Denn der Schilderung, dass sich der Hinterkopf über das Gesicht »wölbt«, wird entgegengesetzt: »Stets aber noch die Momente, da Laupeyßer zu völligem Bewußtsein kam [...].« (VG, 164) Nur angedeutet, aber dennoch deutlich wird das Fehlen von Bewusstsein im Zustand des `vorgestülpten` Hinterkopfs.

34 Vgl. später Falbins ihn erleichterndes Gefühl, jemand anderes zu sein, und Laupeyßers >Reaktion darauf: »Auch ich bin jemand anderes [...]. Aber wer, um Herrgotts willen, bin ich?!« $(V G, 101)$ 
Verbunden werden die Sehnsucht nach einem festen Willen, der Entschiedenheit und alltägliche Sicherheit im Leben bedeutet, und die Frage der Bewusstheit respektive Bewusstlosigkeit in einem Gespräch mit Agnes, ohne direkt auf das Motiv des Hinterkopfs Bezug zu nehmen. Durch die Hinweise aufs Bewusstsein wird jedoch indirekt die Verbindung zum Hinterkopf-Motiv hergestellt. Laupeyßer spricht gegenüber Agnes von dem Zerfall seines Ichs:

[D]enn nicht darum geht es mir, mich bewußtlos zu haben, Agnes. Ich will mich völlig, nicht nur in ungefragtem Handeln und in instinkthaften Reaktionen. Ich will, was mich treibt, annehmen können. $(V G, 135)$

Zum zweiten Mal wird damit die Formulierung des `sich wollens ' gebraucht, ${ }^{35}$ eine recht unpräzise Formulierung, die kennzeichnend für die Vagheit der Identitätssuche und die Vielfältigkeit der 'Suchrichtungen « und damit der Lösungsversuche ist. Eindeutig verweist sie jedoch auf die Ganzheit des Ichs. Diese Implikation wird in der Formulierung »Ich will mich völlig « noch betont durch den Aspekt der Totalität. Sie steht also der Auffassung von einem fehlenden oder fragmentierten Ich entgegen, zeigt jedoch nur die Sehnsucht danach und keinen Zustand an.

\section{Der Geruch}

Eng verbunden mit dem Motiv des Hinterkopfs als Versuch, sich selbst zu erkennen, ist das des Geruchs, der plötzlich von Laupeyßer ausgeht, jedoch nur von ihm wahrgenommen wird. Die Verbindung drückt sich nicht nur darin aus, dass beide mehrfach in einem Zusammenhang erwähnt werden, sondern auch dadurch, dass sie beide als symbolische >Begleiterscheinungen` der Entwicklung Laupeyßers fungieren. Eingebettet ist das Motiv in das größere Feld der Hygiene, das sowohl für Laupeyßer als auch für Falbin relevant ist.

Der Geruch geht von Laupeyßer aus, der jedoch nicht weiß, wie dies zu erklären ist. Zudem erinnert er sich auch nicht eindeutig, wann er den Geruch erstmals bemerkt hat. Entweder setzt er bereits am 13.8. in Kunzes Kneipe in Gegenwart von Axel Schulze ein (vgl. $V G, 145)$ oder aber erst am 16.8. morgens im Café, wo Laupeyßer allein ist ( $V G, 118 \mathrm{ff}$.). Anfangs argwöhnt Laupeyßer die Ursache des Geruchs in seiner Umgebung und verdächtigt andere Personen. Vor allem Axel Schulze gibt auch neben seiner vermutlichen Anwesenheit beim ersten Auftreten des Geruchs allen Anlass für diesen Verdacht: Seit »anderthalb Jahren« $(V G, 145)$ hat er sich nicht mehr gewaschen, wie er Laupeyßer `freimütig` erzählt. Doch dann stellt dieser fest, dass es sich nicht um den, wie nicht weiter verwunderlich ist, tatsächlich vorhandenen »André-Schulze-Geruch» $(V G, 145,152,211)$ handelt, sondern dass der Geruch von Laupeyßer selbst ausgeht.

Der zunächst nicht näher charakterisierte, lediglich als »unausstehlich « $(V G, 121)$ und »bestialisch $(V G, 170)$ bezeichnete Geruch stellt sich als von anderen nicht wahrnehmbar heraus. Da Laupeyßer sich (im Gegensatz zu Axel Schulze) regelmäßig wäscht, kann es sich nicht um rreale`Körperausdünstungen handeln. Er erklärt sich deshalb den Geruch vorerst damit, dass dieser von »inneren Insekten« ausgehe, »die er 
erfunden hatte« $(V G, 126)$, die von seiner `Erfindung« Falbin auf ihn übergesprungen seien. Diese `Erklärung « zeugt mehr von einer Vermischung der Wahrnehmung von Fiktion und Realität als dass sie einen realen Bezug hätte, was auch für die zweite Erklärung gilt. Denn gleich im Anschluss sieht er es als die sinnlich-körperliche Äußerung seines geplanten, imaginierten Abstiegs an, als eine »Häutung « $(V G, 126)$, eine Auflösung seiner selbst, die sich auch im oben genannten Vorstülpen des Hinterkopfs ausdrückt $(V G, 235)$. Anfangs beschließt er mangels Gegenmittel - denn auch extreme Reinlichkeit nützt ihm nichts - sich einfach an den Geruch zu gewöhnen. Doch später wird ihm dieser unerträglich. Positiv betrachtet erinnert ihn der Geruch an (seine) Vergangenheit, die er "als Gestank« $(V G, 236)$ zurücklassen kann, der durch Anzünden der Wohnung vernichtet werden müsste. Davon lässt er jedoch ab, im Gegensatz zum Abreißen der Tapeten, die er der Ausdünstung verdächtigt, das aber ebensowenig wie extremes Lüften der Wohnung etwas hilft (VG, 252, 256). Zusätzlich zu seinen penibelst gepflegten Zimmerpflanzen kauft Laupeyßer sich noch stark riechende Schnittblumen, die den Geruch nach »Abdeckerei« und »Fischmehlfabrik « ( $V G, 162 f$.) allerdings auch nicht überdecken können. Er schwindet erst durch einen inneren »Prozeß des Freiwerdens« (VG, 275).

Der ausströmende Geruch korrespondiert mit der mehrjährigen Weigerung Axel Schulzes, sich zu waschen. Dieser begründet es damit, dass er "an Substanz« verliere, wenn er sich wasche. Der `Autor-Erzähler bemerkt dazu: »Und hat daher dem körperlichen Hiersein wenigstens noch vertraut. (VG, 336f.) In Anlehnung an diese Formulierungen kann das Motiv als dafür stehend gesehen werden, dass Laupeyßers Identität in der Krise `an Substanz verliert. Gleichzeitig ist es die Zeit, in der er versucht, sein altes Leben mit allem für ihn Negativen hinter sich zu lassen. Ebenso wie Schulze wieder beginnen kann, sich zu waschen, als er anfängt, seine Lebenssituation anzunehmen, hört bei Laupeyßer der Geruch auf, als er einen gewissen Ausweg aus der Krise sieht.

Den oben geschilderten alles in allem nicht überzeugenden, da phantastischen $>$ Erklärungen`setzt Laupeyßer noch eine auf den ersten Blick realistischere entgegen. Er mutmaßt, dass der Geruch nicht neu aufgetreten sei, sondern schon immer vorhanden gewesen wäre, eigentlich sein `normaler Geruch sei. Der Grund für das Bemerken sei eine »allmähliche Verfeinerung des Nervensystems« (VG, 141). Doch damit bleibt auch hier eine realistische Erklärung aus, da ein rationaler Grund für die Verfeinerung nicht angegeben wird. Ganz im Gegenteil, diese steht in Verbindung mit dem am wenigsten rational zu erklärendem Phänomen in der Entwicklung Laupeyßers.

\section{Das Vampir-Motiv}

Die lediglich angedeutete Verwandlung Laupeyßers in einen Vampir ist wohl das einzige Motiv des Romans, das direkt an das Übersinnliche angrenzt. Darum stellt sich auch hier die Frage, ob es nicht als Imagination und damit bildlich zu interpretieren ist. An keiner Stelle wird das Wort Vampir erwähnt, die direkteste Anspielung ist der Verweis auf Klaus Kinskis Darstellung des Grafen Dracula in Werner Herzogs Film Nosferatu - Phantom der Nacht von 1979 (vgl. VG, 170). Die Hinweise sind verstreut und relativ subtil; sie lassen nur in der Kombination den Schluss auf die 
Verwandlung in einen Vampir zu. Anfangs beziehen sie sich auf eine merkwürdige Sensibilisierung seiner Sinne und Veränderungen des Körpers. Seine Zähne werden spitzer $(V G, 136)$, seine Nägel länger $(V G, 249$ und 170), er kann deutlicher hören $(V G, 141,162)$ und auch die Empfindsamkeit des Geruchssinns ist erhöht $(V G, 124)$. Zusammengenommen handelt es sich dabei um die eben erwähnte »Verfeinerung des Nervensystems « $(V G, 141,142)$. Seine Phantasien und Wahrnehmungen entwickeln sich in eine ähnliche Richtung, so stellt er sich vor, in Agnes' Fuß zu beißen ( VG, $158)$, ihm fällt ihre pochende Halsschlagader auf $(V G, 166)$. Direktere Andeutungen sind der Hinweis auf die Verlagerung seiner Aktivität in die Nacht sowie auf einen Umhang $(V G, 157)$, der in das mittlerweile stark durch Verfilmungen geprägte Bild eines Vampirs passt, und auf seinen Namen Laupeyßer, der etymologisch auf das Wort >Beißer $<$ verweisen soll. ${ }^{36}$

In weiteren Phantasien imaginiert Laupeyßer die Auflösung seiner Leiche durch Sonnenlicht (vgl. $V G, 198$ ) oder sein `Geständnis«, sich vom »Blut junger Frauen« $(V G, 244)$ zu ernähren; auch erfolgt in einer solchen Phantasie der genannte Verweis auf Nosferatu. Später berichtet er vom Verlust des Empfindens von Mitleid, der einhergeht mit einem sich nachts einstellendem »existentielle[n], boshafte[n] Hunger", der ihn »mordlustig« $(V G, 281)$ macht. Neben diesen Merkmalen findet sich hier recht unscheinbar der Bezug zum Vampirmotiv durch den zweiten expliziten Hinweis auf die literarische bzw. filmische Vorlage, indem Laupeyßer sich mit Rendfield, dem geistesgestörten Zoophagen aus Nosferatu vergleicht. ${ }^{37}$ Schließlich ist davon die Rede, Laupeyßer befinde sich "noch längst nicht in jenem Stadium, da es notwendig würde, sich vorm Tageslicht zu verkriechen« $(V G, 205)$.

Das Vampir-Motiv erscheint unerwartet, es wirkt merkwürdig unstimmig und nebensächlich und lässt durch die Spärlichkeit der Andeutungen einige Fragen offen. Aus mehreren Gründen sticht es aus dem Motivgefüge von VG heraus. Vornehmlich wohl dadurch, dass es sich um ein sehr bekanntes, aus der Literatur- bzw. Filmgeschichte übernommenes und damit relativ starres Motiv handelt. Während die anderen Motive des Buches weitgehend original sind und damit einen offenen, lediglich durch die Vorgaben und Erklärungen des Textes bestimmten Charakter haben, verbinden sich mit der Figur des Vampirs feste Vorstellungen und Erwartungen, die nicht zu erfüllen Fragen aufwirft. Angesichts der Bekanntheit des Motivs und des markanten Charakters einer 'tatsächlich angenommenen Verwandlung (wenn auch in einer fiktiven Welt) ist auffällig, dass es nur nebensächlich, durch beiläufige Erwähnungen eingebracht wird. Außerdem führt seine Entwicklung ins Nichts, bleibt folgenlos und wird im Grunde ‘fallengelassen`; beim Schluss des Buches spielt sie keine Rolle. Die Ausführung bleibt auch hinter den Erwartungen zurück, so erschöpft sich die angebliche Blutlust Laupeyßers lediglich in seinen recht milden Phantasien.

Einzig durch ein weiteres Merkmal der Entwicklung Laupeyßers, die sich auch wieder in Spiegelung bei Falbin findet, lässt sich eine Verbindung des Vampir-Motivs zu

36 » Witziger Name. Der auf Laues beißt. Ist gar nichts anzufangen mit. Der Peyßer, der Peißer, der Beißer«, VG, 164.

37 Vgl. VG, 281. Dass dieser nicht Renfield geschrieben wird wie in Bram Stokers Dracula (1897), der literarischen Vorlage des Films, deutet auf den Bezug zum Film hin. 
den anderen herstellen. Dies ist die Entwicklung eines »Animalismus«, der auch das Themenfeld der Sexualität und Männlichkeit bestimmt. Die Passage mit dem Hinweis auf Nosferatu ist in dieser Hinsicht ambivalent. Die Polizisten in der Imagination haben »ein sexualbesessenes Vieh mit abnorm spitzen Zähnen« $(V G, 170)$ erwartet, stoßen jedoch lediglich auf den wehrlosen Laupeyßer, der nur lange Fingernägel hat, die an die von Kinski in seiner Vampirrolle erinnern. Einerseits steht Laupeyßer also gerade im Kontrast zum »sexualbesessenen Vieh « und wird mit Kinskis Nosferatu in Verbindung gebracht, in dessen Darstellung die sexuelle Komponente des Genres nicht zum Tragen kommt. Andererseits wird aber gerade auf diese verwiesen, indem die Besessenheit von Sexualität mit spitzen Zähnen und damit mit dem Vampir verbunden wird. Zusammen mit den bereits erwähnten Hinweisen in Zusammenhang sowohl mit Agnes als auch der Ernährung vom »Blut junger Frauen« wird deutlich, dass motivisch an die starke sexuelle Komponente in der Gattung Vampirroman (und -verfilmung) angeschlossen wird.

Der Vampirmythos hat im Laufe der Jahrhunderte ein Konglomerat typischer Merkmale ausgebildet, die mal mehr mal weniger Eingang in die konkrete mediale Ausformung finden. Er kann »für vieles Sinnbild sein: für Macht, Ausbeutung, Sucht, Krankheit, Verbrechen, Atavismus und für Sex « ${ }^{38}$. In Bezug auf die sexuelle Symbolik steht der Vampir in einer Tradition, die von mittelalterlichen Vorstellungen von Incubi und Succubi über vor allem bildliche Darstellungen des Todes als Liebhaber in Skelettform bis zum irdischen dämonischen Liebhaber á la Don Juan reichen. Dabei steht der Vampir für die animalische Seite der menschlichen Sexualität, für die Verführung gegen eigenen Willen und gegen gesellschaftliche Normen, was vor allem im von Prüderie und Doppelmoral geprägten Viktorianismus, während dessen Stokers Dracula entstand, von Bedeutung war. Weiterhin bezeichnend für ihn ist der Sadomasochismus, wobei der Vampir die Rolle des Sadisten einnimmt. Das Opfer erlebt jedoch gerade durch die körperliche Eroberung, die bis zur Zerstörung führt, sexuelle Erfüllung der eigenen Wünsche. Der Vampir spielt dabei - symbolisch gesehen, da es eigentlich mit dem Tod des Opfers endet - die Rolle eines "Entwicklungshelfer[s] bei der Offenlegung der eigenen Geschlechtlichkeit « ${ }^{39}$, was sowohl für die weibliche wie die männliche gilt.

An diese Verbindung von Sexualität mit Macht und Sadismus finden sich Anschlussmöglichkeiten bei anderen Handlungssträngen und Motiven in $V G$, ebenso wie Ausbeutung, Sucht, Krankheit und Verbrechen eine wichtige Rolle spielen, was die eben zitierte Auflistung, obwohl aus einem anderen Zusammenhang, als ungewöhnlich passend erscheinen lässt. Damit erweist sich das Vampirmotiv als zumindest inhaltlich stimmig im Erzählgefüge des Textes und für die Bearbeitung der Identitätsfragen.

38 Norbert Borrmann: Vampirismus oder die Sehnsucht nach Unsterblichkeit, Kreuzlingen / München 1999, 224.

39 Ebd., 231. 


\section{Sexualität: Animalismus und Männlichkeit}

Sexualität spielt für Laupeyßer eine bedeutende Rolle im Umgang mit der eigenen Identität. Zwar ist dieses Thema nicht von Anfang an direkt präsent, aber zunehmend tritt sie in den Vordergrund und wird von ihm als Mittel eingesetzt, seinen Unsicherheiten zu begegnen.

Zur Darstellung der Thematik ist es nötig, erst einmal die in diesem Zusammenhang extremste Ausformung von Sexualität, die Vergewaltigung, in den Vordergrund zu stellen, die ein eigenes Motivfeld in VG bildet. Ausgangspunkt ist wieder die bereits genannte Frage nach dem `Sich Entsetzen Können`. Angesichts des Pasolini-Films und der Frage "Kann ich mich noch entsetzen? « stellen sich ihm zwei weitere Fragen, die an die für Laupeyßer immer präsente Verbindung dieses Komplexes mit den nationalsozialistischen/>deutschen « Verbrechen anknüpft: was die reinfachen Deutschen in Reaktion auf die Verbrechen empfunden haben und ob er bzw. seine Zeitgenossen inklusive der Leser (»wir«) zu solchen Taten fähig wären. Von diesen Fragen ausgehend, ergibt sich eine Verweiskette, die sich aus verstreuten Passagen ergibt. Beide Fragen werden gleich bei ihrem Aufkommen in den Kontext der Vergewaltigung gestellt (»Waren unsere Großväter erregt, als wir 1939 in Polen die ersten Mädchen zwangsgrätschen ließen? [...] Und wären wir wieder erregt, auf die eine oder andere Weise?«, VG, 124). Als Laupeyßer später die Frage nach der eigenen Reaktion eindeutig beantwortet, nämlich in dem Sinn, dass er zu solchen Taten fähig wäre, werden weitere Verbindungen gezogen. Durch die erstmalige Verbindung von My Lai und Auschwitz durch gemeinsame Nennung (vgl. VG, 214) wird die immer wieder thematisierte `natürliche` Grausamkeit des Menschen den Deutschen nicht abgesprochen, sondern den Amerikanern, die als sonst positiv gesehen geschildert werden, ebenfalls zugesprochen und damit universalisiert. Das Massaker My Lai, das US-amerikanische Soldaten 1968 während des Vietnamkriegs an vietnamesischen Zivilisten verübt haben, wird dabei als Metonymie für die amerikanischen Kriegsverbrechen in Vietnam verwendet in Analogie zu Auschwitz, das sich als Metonymie für die nationalsozialistischen Verbrechen im allgemeinen Sprachgebrauch eingebürgert hat..$^{40}$ An späterer Stelle wird diese Verbindung noch erweitert und auch in diesem Kontext der verlogene Umgang der Deutschen mit der Geschichte, gegen den Laupeyßer sich auflehnt, vorgeführt. Der Satz »Was meinst, wo wir jetz' wärn ohne die Amerikaner...? « $(V G, 302)$ leitet die Schilderung von Vergewaltigungen durch russische Soldaten am Ende des Zweiten Weltkriegs ein. Dieser wird der Hinweis auf Vergewaltigungen durch »unsere Großväter« $(V G, 303)$ entgegengehalten. Dem hinzugesetzten ironischen Kommentar "Jeder amerikanische Soldat verkörpert ein Stückchen Freiheit der westlichen Welt« folgt wiederum eine detaillierte, wenn auch fragmentarische Beschreibung eines Massakers im Dschungel, was sich durch diesen Hinweis eindeutig auf Vietnam beziehen lässt. ${ }^{41}$ Zum einen wird hier neben

40 Vgl. auch schon $V G$, 212, später dann 301.

41 Eingebettet ist diese Passage in einen längeren Abschnitt, der durch ein Themenmosaik mit Sprüngen nach fast jedem Satz zeitgenössische politische Ereignisse (d.h. ab 1968) mit historischen (Deutsche Geschichte) verbindet und intertextuelle bzw. -mediale Anspielungen (Celans »Todesfuge« und der Film Nuit et Brouillard, an dem Celan beteiligt war) mit den Figuren von VG verflicht. 
der Erfahrung des Pasolini-Films die menschliche Grausamkeit historisch konkretisiert und damit real veranschaulicht, zum anderen wird sie globalisiert und damit universalisiert.

Der Erkenntnis der Universalität zum Trotz sieht sich Laupeyßer mit der Notwendigkeit konfrontiert, sich individuell mit diesen Fragen auseinandersetzen zu müssen. Laupeyßer selbst ist allerdings kein >Vergewaltiger , diese Rolle wird Falbin in den Handlungsimaginationen als Stellvertreter übertragen, ${ }^{42}$ dessen Funktion als erfundene Figur ist, >anstatt< Laupeyßer bestimmte Entwicklungen zu durchleben. Gerade bei dieser gewaltsamen Thematik erinnert die Aufspaltung an das prototypische Vorbild Strange Case of Dr Jekyll and Mr Hyde (1886) von Robert Louis Stevenson. Bei Laupeyßer und Falbin ist das Verhältnis jedoch nicht von einem ähnlich hohem Kontrast wie bei Jekyll und Hyde, und liegt damit nicht in der Gegenüberstellung von 'gut ‘ und >böse`. In der Vergewaltigungsthematik gehen die theoretischen Überlegungen von Laupeyßer aus. Über die weitere Entwicklung des `Schwächlings` Falbin nachsinnend, greift er mehrfach das zugehörige Thema auf: die Bedeutung von Gewalt in der zwischengeschlechtlichen Sexualität. In einer ersten Passage ist Falbins Frauenbild der Auslöser für die Reflexionen. Falbin hätte ein idealisiertes, aus Romanen genährtes Frauenbild von einer "Zärtlichkeits- und Engelsfrau, der niemals [...], wenn auch noch so sublim, gewalttätig begegnet werden« $(V G, 114)$ dürfe. Hier wird durch Laupeyßer wieder eine zur Zeit der Entstehung von $V G$ aktuelle Debatte aufgegriffen. Er unterstellt der Frauenbewegung der 1970er Jahre, durch den "pauschale[n] Affront [...] gegen die Vergewaltigung « den Mann als Weichling geschaffen zu haben. Nur "Peggy Parnaß« (eigentlich Parnass geschrieben; deutsch-schwedische Schauspielerin, Journalistin und Autorin) habe ein »ehrliches Wort « gesprochen, indem sie sich zu Gewalt in der Sexualität bekannte. Die Debatte entzündete sich 1980 an dem kanadischen Film Mourir à tue-tête (1979, dt. Der Schrei aus der Stille) der Feministin Anne Claire Poirier, der Vergewaltigung thematisierte. Peggy Parnass wurde nach ihren Äußerungen stark angefeindet. ${ }^{43}$

Agnes steht in dieser Hinsicht für die hier angenommene Position der Frauenbewegung, auch wenn ihr eine Distanz zu dieser bescheinigt wird (vgl. VG, 42). Als Laupeyßer sie direkt nach dem Kinobesuch anruft, entgegnet sie »säuselnd « auf seine Erzählung: "’... körperliche Liebe ist doch sowas Schönes!«« (VG, 7). Schon hier von Laupeyßer als naiv und unreif charakterisiert, bezeichnet er die Aussage später gänzlich als »Unsinn « $(V G, 56) .{ }^{44}$ An dieser Stelle fällt jedoch auf, dass im direkten Anschluss auf den »Entschluss« rekurriert wird: »Er wußte nur eines: Auf keinen Fall mehr klein beigeben zu wollen.« (ebd.) Diese Kontextualisierung deutet darauf hin, dass die, nach seiner Ansicht, Romantisierung und Verkitschung von (körperlicher) Liebe für ihn Teil des falschen Lebens, der Heuchelei und Unehrlichkeit sind, gegen die er sich aufzulehnen versucht. An anderer Stelle wird dies noch deutlicher, nämlich

Etwas später folgt auch noch der Hinweis auf Algerien als dunklem Punkt in der Geschichte der Franzosen und der Hinweis, eigentlich - entgegen der Versuchung - nicht »aufrechnen« zu wollen, vgl. $V G, 304 \mathrm{f}$.

42 Siehe konkret dazu Abschnitt 1.3.2 auf Seite 70.

43 Vgl. dazu [Anonym]: »Penis im Hirn«, in: Der Spiegel, 28. Apr. 1980, 256-257.

44 Noch später wird dieser Satz in einer Pappkarton-Sentenz als »Legende« $(V G, 159)$ abgetan. 
als er sich angesichts der Waden der Bedienung sexueller Phantasien hingibt: "Sie sich selbst vom Gesicht zerren, die verlogene Sanftheit, das Gewebe der Domestizierung." $(V G, 106)$ Gleich darauf überlegt er, dass mit ihr (der Bedienung) nur ein »eingeschränkter Animalismus« denkbar wäre. Doch trotz der Einschränkung wird, wie schon einmal, ${ }^{45}$ die Bedienung nicht nur Objekt erotischer Gedanken, sondern Projektionsfläche seiner animalischeren Vorstellungen.

Entdeckt Laupeyßer eine »dem Instinkt verbundene Spannung $(V G, 42)$ auch in der (platonischen) Beziehung zu Agnes, so ist es eine keine weitere Rolle spielende Elke, mit der er, so angedeutet, sadomasochistische Sexualität entdeckt hat. Diese wird hier als erfolgreiches Mittel gegen das idealisierte Frauenbild der Frauengruppen und seine damit zusammenhängenden »Potenzprobleme« $(V G, 114)$ etabliert. Außerdem findet sich auch in Andeutung die mögliche Verbindung zum oben behandelten Vampir-Motiv: es ist der »Bißtrieb«, dem er zum ersten Mal nachgab. Damit werden die späteren Vampir-Verweise im Vorhinein sexuell konnotiert, der Vampir als Wesen animalischer Instinkte betont. Zusammengefasst wird dies in einer der bereits erwähnten Phantasien, in der die angedeuteten Erwartungen den Polizisten, die die Wohnung aufbrechen, zugeschrieben werden und die ein "sexualbesessenes Vieh" $(V G, 170)$ erwarten.

Auch Frauen wird der Reiz von Qual und Gewalt zugesprochen (vgl. VG, 85, 214), doch wird dies wenig thematisiert und ist vor allem durch Anspielungen auf Laupeyßers Beziehungen (die bereits genannte Elke sowie die wichtigere B.) zu erschließen. Ausführlichere Beschreibungen von sexueller Dominanz oder Gewalt durch Frauen, der sogenannten »Leopardenfrau « sowie von Agnes als folternder Kommissarin, sind dagegen von Anfang als Imaginationen Laupeyßers bzw. Falbins und damit als männliche Phantasien gekennzeichnet. Die »Leopardenfrau« wird erstmals vermutlich von Falbin auf dem Bahnhof gesehen und als vornehme Frau in einem Leopardenmantel beschrieben, die von einem anscheinend abhängigen, gedemütigten Mann begleitet wird. Später trifft Laupeyßer sie im Zug nach Frankfurt wieder, wo sie (in mehreren Imaginationen Falbins) als erotisch aufreizende und freizügige Verführerin dargestellt wird (vgl. VG, 58f., 6off., 63f., 67f.). Eindeutig wird ihr sanrüchiges` sexuelles Verhalten durch einen Warner charakterisiert, der sie Laupeyßer gegenüber als "Spinnin" bezeichnet: »Sie frißt Männer. Und mit Vorliebe solche jungen Herrn wie Sie. Sie verdirbt sie für das Leben, für die Arbeit.« $(V G, 83)$ Später verweist sie in Zusammenhang mit der lediglich erwähnten, aber nicht näher eingeordneten Figur Anna, die ihre Tochter sein soll, auf den Folgeroman Wolpertinger. In den Szenen mit Agnes als Kommissarin geht es dagegen nicht um sexuelle Dominanz oder Gewalt, sondern um schlichte Brutalität, wodurch Agnes in einer Weise imaginiert wird, die extrem vom ihr sonst zugeschriebenen Charakter divergiert.

Trotz dieser weiblichen Gewaltepisoden, die aber weitestgehend männliche Phantasien sind, wird in seinen Überlegungen zu Falbin - dem »Halbmannstum« und »kastratisches Wesen « zugeschrieben werden - deutlich, dass die sexuelle Gewalt für Laupeyßer für Männlichkeit steht und diese konstituiert. Zwar gibt ihm dies

45 Vgl. VG, 56: „Nein, nein, die Bedienung muß anders sein: gerissen nämlich, untreu, lüstern. Dann könnte ich sie lieben. "Obwohl es sich hier um eine Aussage des >Autor-Erzählers handelt, wird diese durch den Kontext in einer Vermengung der Ebenen auch als Laupeyßers insinuiert. 
auch Sicherheit, ein Mechanismus, der vor allem an Falbin durchgespielt wird, doch ist auch diese Zuordnung ambivalent. So schreibt er den Männern "permanentes Vergewaltigen« zu, was er "Das Pfeileabschießen aufs Ich» $(V G, 214)$ nennt. Auch stellt er sich hier selbstironisch als »Chauvi« dar und gibt zu bzw. konstatiert für sich selbst die wieder durch den Hinweis auf Auschwitz und My Lai eindeutig negativ bestimmte Veranlagung zu Gewalt und Vergewaltigung. Schließlich sinniert er über die Definition von Vergewaltigung nach, die er, in an die Konsequenz der Bergpredigt gemahnender Weise, weit ausdehnt. »[S]trenggenommen « sei es Vergewaltigung, »zu küssen, wo der Kopf abgewandt wird «. Da dieses aber auch strategisches "Lockspiel « sein könne, bleibt die Frage: »Aber wo sind die Grenzen?« $(V G, 199)$ Diese Frage markiert die unsichere Position Laupeyßers auf der Suche nach Absicherung und Identität. Sexualität als Definitionsraum von Identität gibt ihm nur unvollständig Halt. Gibt die dominante Männlichkeit ihm einerseits das Gefühl von Ehrlichkeit und Echtheit und zumindest den Anschein und damit das Gefühl von Sicherheit, so merkt er andererseits den schmalen Grat, auf dem er wandelt und auch, dass daneben auch noch Gegensätzliches in ihm liegt. Ausdruck findet dieses in dem immer wieder eingestreuten, teils nur unvollständig ausgeschriebenen Satz »Wo Männer Zärtlichkeiten am meisten lieben «. Von Laupeyßer erstmals als Schlagzeile in der Zeitung entdeckt, die das empirische Vorbild für Falbin liest, wird er ihm zu einer ihn konstant begleitenden Überlegung. Zwar beschäftigen sich diese Überlegungen meist eher mit dem "wo", das heißt mit ungewöhnlichen Orten oder auch Körperregionen, die ihm einfallen; auffällig ist allerdings erst einmal die für Laupeyßers sonstige Vorstellungen ungewöhnliche Kombination von Männern und Zärtlichkeit. Dies ist denn auch ein Gefühl, das ihn immer wieder überrascht, sich mit dem »eigentümliche[n] Animalismus« $(V G, 112)$ ablöst, nämlich ein »inniges Zärtlichkeitsbedürfnis« $(V G, 111)$. Selbst Falbin gegenüber überkommt ihn dieses Gefühl, das Bedürfnis, diesen einmal streichelnd anzufassen, »daß endlich jemand zärtlich wäre zu ihm« $(V G, 126)$.

\subsubsection{Falbin: Der Kampf gegen Fremdbestimmtheit}

Claus Falbin ist eine von Laupeyßer erfundene Figur. Ebenso wie der >Autor - Erzähler sich Laupeyßer als Stellvertreterfigur erschafft, erschafft sich Laupeyßer Falbin. Unter anderen Voraussetzungen wird eine weitere Möglichkeit durchgespielt, mit bestimmten Aspekten der Identitätskrise umzugehen. Falbin ist - wie gleich deutlich wird auf größtmögliche Unsicherheit und Fremdbestimmtheit angelegt. Seine Entwicklung zeigt den Versuch, sich aus dieser Situation zu befreien und größere Autonomie zu erlangen und deutet damit auf eine Bearbeitung der Identitätskrise über die Stärkung der Innenperspektive hin. Dies korrespondiert mit Laupeyßers später beschriebenem ,Versuch von Geschichtslosigkeit $\longleftarrow$. Falbin macht damit vergleichbare Entwicklungen wie Laupeyßer durch, allerdings stehen diese im komplizierten Geflecht der Motive teils auch in gegensätzlicher Ausrichtung.

Vorbild ist ein junger Mann, den Laupeyßer am Nebentisch im Café bemerkt. Seine Beschreibung ist kurz: »ein junger, sehr pickliger Mensch mit angeknabberten Fingerseiten« $(V G, 12)$. Er trägt einen Shetland-Pullover und liest Zeitung. Da dieser junge 
Mann nach etwa einer halben Stunde aufbricht und Laupeyßer ihn nicht wiedersieht, ist alles andere erfunden (auf Laupeyßers Erzählebene). Laupeyßer will in seinem Experiment von der »empirischen Person« ausgehen, die neben ihm gesessen hat, und »sie formen, indem ich ihr Qualitäten zusprach, die ihr nicht zukamen « (VG, 18). Er benennt die Figur mit dem Namen Falbin und erschafft ihn dadurch. ${ }^{46}$ Dem Namen schreibt er als etymologischen Ursprung sowohl »falb« als auch "fahl«(VG, 18) zu. Dementsprechend legt Laupeyßer den Charakter der Figur Falbin fest. Er erzählt Agnes von seiner Figurenerfindung und entwirft in Gesprächen mit ihr in groben Zügen Milieu und Charakterzüge. Die Herkunft Falbins sieht er als kleinbürgerlich beschränkt, charakterlich legt er ihn als nüchternen Menschen mit spärlichen Sozialkontakten fest, der sich in verschrobener, fast manischer Weise durch strukturierte Tagesabläufe und übertriebene Ordentlichkeit im Leben eingerichtet hat. Er ist schüchtern, von Bekannten wird er als »kriecherisch» $(V G, 30)$ charakterisiert; so verbringt er seine freie Zeit vor allem allein vor dem Fernseher, bloß sonntags sucht er regelmäßig eine Kneipe auf, um bis auf wenige Kontakte allein ein Bier zu trinken.

Er ist damit als Gegenbild zu Laupeyßer charakterisiert, der sich mit Eingefahrenem und Gewöhnung nie hat anfreunden können (vgl. $V G$, 21). Wie oben bereits geschildert, ist es gerade die »Unerträglichkeit [des] Alltag[s] « $(V G, 37)$, die ein Grund für seine Identitätskrise ist. Eben dies ist der Unterschied, dass Falbin sich mit der Begrenztheit des Alltags abgefunden hat, einen »Mangel« $(V G, 33)$ angesichts von Sinnlosigkeit und Beschränktheit nicht bemerkt bzw. nicht thematisiert. Doch ebenso wie der `Autor «-Erzähler gleich eingangs Laupeyßer `nach seinem Ebenbild` erschafft, ersinnt auch dieser Falbin nicht nur als eigenes Gegenbild, sondern auch in Anlehnung an sich selbst. Falbin ist nur drei Jahre jünger als Laupeyßer ${ }^{47}$ hat einen ähnlich unbestimmten Bürojob und stammt nach seinen eigenen wenigen Angaben ebenfalls aus dem Kleinbürgertum. Den spärlichen Eindruck, den Laupeyßer vom jungen Mann am Nebentisch bekommen hat, nutzt er, um aus einzelnen Kennzeichen größere Charakterzüge zu entwerfen. Das auf Unsicherheit deutende Nägelknabbern gibt Anlass zur Erfindung der Sicherheit spendenden Ordnungsmanie; die Pickel werden übertrieben zu einer körperlichen Hässlichkeit, die eine dem Ordnungswahn eher widersprechende Nachlässigkeit in der körperlichen Hygiene anzeigt, wobei diese gleich ein fehlendes Verhältnis zum Körper und mangelnde Eitelkeit offenbaren soll. Laupeyßer legt jedoch Falbins Charakter in solcher Weise an, dass er nicht ausschließlich eindimensional »realitätsbezogen« und ohne die Fähigkeit zu »Fantasiegebilden« (VG,

46 Das Namengeben wird später als eine »Gewohnheit« Laupeyßers bezeichnet, »ihm interessant erscheinenden Menschen nach assoziativem Gutdünken Namen zu geben « $(V G, 209)$. Beim mysteriösen Ausflug in ein Frankfurter Bordell will er dann auch nicht den Namen der Prostituierten wissen, vielmehr ১benennt er sie: »Sag ihn nicht, ich will dich Anna nennen.» $(V G, 209)$ So erschafft er auch hier eine Figur (die in Wolpertinger eine der Hauptfiguren wird) durch die Namengebung. Diese Anklänge an biblische Schöpfung finden sich auch in der Ähnlichkeit der drei Protagonisten, die sich gegenseitig >nach ihrem Ebenbild « erschaffen (was sich später darin zeigt, dass sie verwechselt werden). Gleichzeitig deutet dies auch die poetische Schöpferrolle des Autors an, der seine Figuren durch Benennen erschafft; vgl. dazu das Kapitel »Das Benennen der Figur « in Jannidis: Figur und Person, 109-149, besonders 129. Auch bei Falbin findet sich gleiches Verhalten, vgl. VG, 64.

47 Geboren am 11.7.1956, siehe $V G, 113$. 
20) dargestellt wird, sondern dass das Bewusstsein für den genannten »Mangel« nur soweit verdeckt ist, dass ihn unvorhergesehene Dinge, wie der ihm unverständliche Drang zum Bahnhof zu gehen, aus der Bahn werfen.

\section{Der Bahnhof und das »Irregehen«}

Die stereotype Anlage als unsicherer Charakter dient Laupeyßer dazu, größtmögliche Unsicherheit in seiner erfundenen Figur durch ein ungewöhnliches Ereignis zu erzeugen. Dies besteht darin, dass er Falbin eines Abends versehentlich zum Bahnhof gehen lässt. Falbin schlägt wie »in Trance« $(V G, 19)$ einen falschen Heimweg ein und kommt erst vor dem Bahnhofsportal wieder zu sich. Das "Irregehen « $(V G, 21)$ steht in starkem Kontrast zu Falbins normalem Verhalten und wirkt daher sehr verstörend auf ihn, zumal es sich wiederholt, er keine Erklärung findet und es sich von da an zu einem inneren, aber dennoch als fremd wahrgenommenen Drang entwickelt. Der Gang zum Bahnhof stellt für Falbin einen prägnanten »Einschnitt« $(V G, 31)$ dar, der eine Veränderung in ihm auslöst. Er sieht das seltsame Fehlgehen als eine Herausforderung an und beginnt, sich länger am Bahnhof aufzuhalten, ohne genau zu wissen, was er dort tun soll oder warum ihm das passiert. Anfangs sieht er das Bahnhofsgebäude als den Ursprung des Drangs an, als Gebäude, das durch Belebung Macht gewinnt. Er >unterwirft s sich dieser unbestimmten Macht und sieht sich erfasst vom »Mythos, der die Dinge belebt « $(V G, 33)$. Zu dieser Zeit ist diese Erfahrung und der Bahnhof selbst jedoch beängstigend für ihn, er fühlt sich vom Bahnhof angestarrt wie einen "persönlichen Feind «(VG, 26).

Dieser Eindruck ändert sich mit der Zeit ins genaue Gegenteil. Der Bahnhof wird für Falbin nicht nur ein Rückzugsort, an dem er sich täglich aufhält, sondern ein positiv belegter Ort, der ihm gegen die Angst hilft und Sicherheit gibt, sogar wenn er nicht dort ist. Immer wenn er sich im Büro eingeschüchtert oder verloren fühlt, »holt« er den »Bahnhofsgedanken heraus, der alles relativierte» $(V G, 130)$. Auch als er am Bahnhof selbst einmal in eine peinliche Situation gerät, gibt er trotzdem nicht auf und wiederholt sich seine selbstgewählte Devise, dass er sich »überhaupt nicht mehr verunsichern lassen [wolle], und vor allem nicht am Bahnhof $(V G, 149)$. Der Bahnhof wird für Falbin der einzige Ort, wo keine Angst ist, da ihr ganz einfach »die Nahrung" fehlt, die ihr vom »Niemandsland abgesogen « $(V G, 264)$ wird.

Das »Niemandsland «, auch als das »falbinsche Niemandsland « $(V G, 340)$ bezeichnet, ist Teil der Vorstellung, die den Bahnhof für Falbin zu einer Verheißung macht. Von Laupeyßer als "miese Metapher oder aber »keine Metapher (»Er steht für nichts.", VG, 133) bezeichnet, ist er vielmehr ein komplexes Symbol. Das beeindruckende Gebäude selbst mit seiner »Aura « $(V G, 133)$, dem erregten Treiben der Reisenden und den dazugehörigen, Falbin abstoßenden »Pennern« $(V G, 25,95,251)$ hat schon eine Wirkung, die ihn durch den Kontrast zu seinem bisherigen Leben verstört und anzieht. Es ist jedoch die Eigenschaft als »Tor», die die größte Strahlkraft hervorruft und eine Verbindung zu mehreren Themen schafft, die eigentlich Laupeyßer zugeordnet sind.

Dadurch, dass das Tor jedoch ein "verschlossenes Tor» $(V G, 95)$ ist, wird die Symbolhaftigkeit betont. Es reicht also nicht aus, wie die geschäftigen Reisenden einfach 
wegzufahren. Das Tor öffnet sich nicht jedem, nicht jeder erkennt die »Torhaftigkeit«; die »Penner « ahnen sie und versammeln sich daher an diesem Ort. Die Exklusivität betont zwei Bezüge. Zum einen wird durch die Bezeichnung als »Tor aus dem Einerlei« eine Verbindung geschaffen zum laupeyßerschen Konflikt mit dem Alltag und seiner versuchten Flucht daraus. Der Gang durch das Tor, die Abreise vom Bahnhof ohne Wiederkehr verspricht die Möglichkeit, aus dem Einerlei des Alltags auszubrechen und zu etwas Besonderem zu kommen. Wie bei Laupeyßer und seinem »Versuch von Geschichtslosigkeit« entsteht in Falbin der Drang fortzugehen und sein altes Leben und seine alte Identität hinter sich zu lassen. »Das Leben« fängt für ihn hinter dem Tor an, »[w]ährend man fährt«. Dieser Zusatz ist gleichzeitig der Schlüssel für die Wahrnehmung der »Torhaftigkeit« des Bahnhofs. Die Befreiung durch das Fortkommen erfolgt allein durch die Erkenntnis, dass es nicht um das Ankommen gehe, sondern um die Fahrt selbst. Damit ist jedoch wiederum nicht die spezifische Fahrt, der spezielle Zug, die Landschaft, durch die gefahren wird, oder die Fahrtrichtung gemeint. Gemeint ist der Akt der Fahrt, des Aufbruchs. Im Gegensatz zu Laupeyßers >Fluchten ist dieser Aufbruch positiv besetzt. Wieder wird versucht, dies anschaulich zu machen, durch das Bild des Niemandslandes.

Das Niemandsland bezeichnet weniger die räumliche, als die zeitliche Spanne, die durch die Fahrt zwischen zwei Bahnhöfen zugebracht wird. Daher ist sie unabhängig von äußerlichen, räumlichen Besonderheiten und Belangen. Es hat aber spezielle Eigenschaften: »Wenn man es durchfährt, wird das Vergangene und Kommende verschluckt. Man ist allein in sich selbst und gerade darum verbunden und angenommen.« $(V G, 116)$ Der eigentlich destruktive Charakter wird als tröstlich wahrgenommen und das erlebte Gefühl in fast religiös-mystischer Sprache beschrieben. So gewinnt das Bild vom Niemandsland schon durch die sprachliche Darstellung eine hervorgehobene, tröstliche Bedeutung. Doch wie jede Zugfahrt zu Ende geht, ist auch das beschriebene Gefühl begrenzt. Nicht nur wird es durch das Ankommen beendet. Durch die Rückfahrt, »nach Hause«, wird auch das auf der Hinfahrt Verlorene wiederaufgesammelt. Die einzige Möglichkeit dieser Wiedervereinnahmung durch die Vergangenheit ist es, so lange fortzubleiben, bis man die verlorenen Dinge nicht mehr wiedererkennt, bis die Heimat fremd geworden ist. Falbin empfindet diese ewige Flucht als einzige Möglichkeit des Sieges: »Nur dann hat man gewonnen.» Was räumliche Heimatlosigkeit und die Flucht vor einer neuen Identität bedeutet, erträumt er sich als Heimat: »Flugs verschwände ich im Niemandsland. Denn dem gehöre ich an." Doch gerade daran, ins Niemandsland zu verschwinden, fühlt er sich gehindert.

\section{Stärke, Männlichkeit und Animalismus}

Die durch das »Irregehen" ausgelöste Veränderung Falbins zeigt sich erst einmal durch scheinbar einmalige Ereignisse, die untypisch für sein Verhalten sind. Zusammengenommen verdeutlichen sie eine bestimmte Richtung, in die sich sein Charakter entwickelt. So wird er einmal betrunken randalierend auf der Straße von der Polizei aufgesammelt, wobei er sich vehement gegen die Festnahme wehrt. Als sich seine Mutter ein anderes Mal besorgt um sein Befinden erkundigt, reagiert er ungehalten, 
wird laut, in harmlosem Umfang zwar, doch ist dies ein für ihn untypisches Verhalten. Außerdem wagt er es, sich fälschlicherweise im Büro krank zu melden und stattdessen zum Bahnhof zu gehen. Laupeyßer selbst spricht Agnes gegenüber von der Notwendigkeit, Falbin das "Hartwerden lernen « zu lassen, "wenn wir ihn befreien wollen " $(V G, 115)$. Diese Zielsetzung verfolgt Falbin daraufhin in allen Aktivitäten. Zuerst von Laupeyßer bewusst als schüchterner `Schwächling«, als »kastratisches Wesen « von »Halbmannstum « $(V G, 214)$ angelegt, entwickelt sich Falbin Schritt für Schritt in Richtung animalistischer Männlichkeit. Er beginnt, ein selbstbewusstes Auftreten erst einmal einzuüben. Er fängt an zu rauchen und steckt sich die erste Zigarette »im Vollbewußtsein von Mannhaftigkeit« $(V G, 45)$ an. Er legt sich einen Revolver $\mathrm{zu}$, der zwar nur eine Spielzeugpistole ist, ihm aber das Gefühl von Sicherheit gibt. Mit diesem übt er die richtige Haltung vor dem Spiegel ein, in dem er sich bei jedem Vorübergehen überprüft und die beabsichtigte Wirkung trainiert. ${ }^{48}$

Die Entwicklung geht einher mit einem Wandel an Aufmerksamkeit, den Falbin sich selbst entgegenbringt. Er beginnt, sich zu beobachten, die Wirkung zu begutachten, die er auf andere erzielt. Das impliziert auch einen Wandel in der Behandlung seines Äußeren: er pflegt sich besser, entwickelt sogar eine »Waschlust $(V G, 130)$, die letztendlich wohl auch ein Zurückgehen der Pickel mit sich bringt, außerdem achtet er mehr auf seine Erscheinung bezüglich der Kleidung. Er legt sich ein »Papageienjackett« $(V G, 129) \mathrm{zu}$, das provokant sein neues Selbstbewusstsein zur Schau stellt. Konsequenterweise hat Falbin es nicht mehr nötig, sich durch strikte Ordnung Sicherheit zu geben. Dies resultiert jedoch darin, dass er diese irgendwann völlig aufgibt und seine Wohnung verkommen lässt. Die Aufmerksamkeit ist von der Umgebung vollständig auf ihn selbst übergegangen.

Die innere Entwicklung folgt der äußeren. So wie Falbin sein äußeres Auftreten trainiert, übt er systematisch eine innere Härte ein. Die Distanz, die er zu seinen Kollegen aufbauen will, erreicht er durch »bewußtes und gewolltes Verletzen« $(V G, 160)$. So weist er das Entgegenkommen der Kollegen, nach dem er sich vorher gesehnt hatte, bewusst schroff zurück. Auch beginnt er selbst, Schwächere lächerlich zu machen, so wie ihm dies vorher ergangen war. Er hat eine »Machtstellung « $(V G, 206)$ erreicht, die er ausnutzt, um sich zu rächen - dies jedoch weniger konkret an Einzelpersonen als allgemein an den Mitmenschen. Dieses Verhalten folgt einer Vorstellung von Stärke, die in einer Pappkarton-Sentenz vermutlich von Laupeyßer zusammengefasst wird:

Eine starke Persönlichkeit ist oder hat jemand, der anderen Leiden zufügt, ohne dafür bestraft werden zu können. Eine starke Persönlichkeit ist oder hat jemand, der anderen keine Leiden zufügt, dafür aber bestraft wird von ihnen.

Pappkarton. $(V G, 74)$

48 Zwei Bezüge werden dabei evoziert: zum einen zeigt sich hier bereits die Gegenbewegung zu Laupeyßer, dessen Betrachten im Spiegel ihm Sicherheit geben soll, aber gerade das Gegenteil bewirkt, vgl. oben Abschnitt 1.3.1 auf Seite 55; zum anderen ist angesichts der hohen Anzahl intertextueller bzw. intermedialer Anspielungen auch der Verweis auf den Film Taxi Driver (1976) von Martin Scorsese anzunehmen. In diesem Film steigert sich der New Yorker Taxifahrer Travis Bickle in den Wahn, die Stadt von allem >Abschaum $<$ befreien zu müssen. Er beschafft sich Waffen und tötet in einem Amoklauf mehrere Menschen aus dem Rotlichtmilieu. In einer berühmt gewordenen Szene trainiert er mit seinem Revolver vor dem Spiegel und simuliert/imaginiert eine Duellsituation. 
Es ist anzunehmen, dass im zweiten Satz eigentlich die "schwache Persönlichkeit « gemeint ist, dass es sich also um einen Tipp- oder Satzfehler handelt. Zum einen wäre die Wiederholung des ersten Satzteils von der Struktur her sehr ungewöhnlich und forderte eine hier aber nicht ersichtliche Begründung, zum anderen besteht ein direkter Widerspruch zwischen den beiden Sätzen; schließlich erscheint die vorhandene Version auch inhaltlich nicht sinnvoll, im Gegensatz zu einer möglichen korrigierten Version. Für die einzig verbleibende Möglichkeit eines Paradoxons lassen sich meines Erachtens jedoch keine Hinweise finden. Vielmehr wäre die korrigierte Version die knappe Beschreibung der zwei Pole, zwischen denen Falbin in seiner Entwicklung steht. Als schwache Persönlichkeit, gar als `Schwächling〈, als der er anfangs charakterisiert ist, wird er durch Anfeindungen und Hänseleien der Kollegen für keinerlei Handlungen oder Vergehen auf seiner Seite `bestraft‘; als er aber stark wird im Sinne dieser Definition, dreht er den Verhaltensmechanismus um: nun fügt er ohne Grund Verletzungen zu, kann dafür aber durch sein starkes Auftreten nicht >bestraft ‘ werden. Neben dem Verhalten den Kollegen gegenüber wird dieses Muster noch durch eine Szene auf dem Bahnhof illustriert. Im Toilettenraum nähert sich ein Homosexueller Falbin, der jedoch nicht, wie er selbst erwartet, beschämt auf den Annäherungsversuch reagiert, sondern diesen arrogant abweist. Einerseits vom Erzähler als »Entschiedenheit, Rückgrat« interpretiert, genießt Falbin andererseits vor allem das Gefühl, »unangreifbar zu sein« und, eben nach der genannten Stärkevorstellung, »[v]erletzen zu können, unbeschädigt verletzen zu können« $(V G, 131)$.

Im weiteren Verlauf ergibt sich ein Zusammenspiel von äußerlichen Verhaltensänderungen, die als >Training zu verstehen sind, und inneren Veränderungen, die sowohl Folge als auch Anlass des Verhaltens sind. Nach dem erst als Einzelfall angesehenen Vorfall mit der Polizei, wird es ihm zur Gewohnheit, jeweils nach dem Bahnhofsbesuch durch Kneipen und Diskos zu ziehen und sich zu betrinken. Auch sucht er einmal ein Bordell auf, was jedoch aufgrund seines Betrunkenseins in einer »elementaren Katastrophe« $(V G, 220)$ endet. Die Disko- und Kneipenbesuche unternimmt er jedoch nicht wirklich aus Vergnügen, er fühlt sich auch weiterhin fremd dort; vielmehr sind sie Teil seiner Strategie, indem er das Gefühl von Verlorenheit, das er empfindet, dadurch loswerden will, dass er sich ihm aussetzt. Ebenso beginnt Falbin, >Penner vom Bahnhof mit zu sich nach Hause zu nehmen. Was als Akt von Nächstenliebe verstanden werden könnte, ist bei ihm wieder nur dafür gedacht, Angstgefühle auszutreiben, die Angst, diese könnten während der Nacht die Wohnung ausräumen oder ihn angreifen. Er benutzt sie, sieht sie als »Instrumente «, um sich »selbst zu spüren « $(V G, 252)$, indem er sich von ihnen abgrenzt.

Zwar wird Falbin auf diese Art `härter`, selbstbewusster und gegenüber schwächenden Emotionen abgehärtet, doch geht mit der Härte auch die Entwicklung von nicht kontrollierten Aggressionen einher. Er zertrümmert seine Wohnungseinrichtung und tritt brutal auf André Schulze ein, der ihn für Laupeyßer hält und zu `belästigen scheint. Die Aggression wird dadurch ausgelöst, dass sich Schulze gegenüber bei Falbin das Gefühl einstellt, diesen zu kennen und von ihm am Leben gehindert zu werden, was eine Verbindung seiner Gefühle mit denen von Laupeyßer andeutet. Auch im Büro wird diese Veränderung manifest. Anfangs scheinen die Kollegen beeindruckt von Falbins neuem Selbstbewusstsein, laden ihn zu gemeinsamen Aktivitäten ein, was 
sie vorher nie gemacht hätten. Von ihm in seinem Bemühen um Härte und Distanz abgewiesen, kommt es schließlich zum Eklat, als sie wieder anfangen, sich über ihn lustig zu machen und damit seine Veränderung nicht anerkennen. Falbin ist durch die Ereignisse des vorigen Abends (als er Schulze verprügelt und seine Wohnungseinrichtung zerschlagen hat) aufgewühlt und fühlt sich geschwächt, sodass er seine Haltung nicht bewahren kann. Seinen einzigen Ausweg sieht er darin, dass er einen Kollegen mit dem Revolver bedroht, woraufhin alle entsetzt innehalten. Falbin löst die Spannung, indem er preisgibt, dass es sich um Spielzeug handelt, und zu lachen beginnt, worein die anderen einstimmen. Schnell wird jedoch klar, dass sein Verhalten nicht toleriert werden kann und er nicht mehr in der Firma geduldet wird, sodass schließlich die Kündigung erfolgt (ohne jedoch auf diesen Vorfall einzugehen). ${ }^{49}$

Auch in sexueller Hinsicht wandelt Falbin sich vollständig. War er anfangs schüchtern und verschämt und hatte keinerlei Verhältnis zu seinem Körper, so entdeckt er diesen im Laufe seiner Wandlung. Durch seine Waschlust erkundet er nach und nach seine körperliche Seite, empfindet Lust und Begehren, beginnt zu onanieren und lernt, seinen Körper zu akzeptieren. Doch auch in dieser Hinsicht schießt Falbin gewissermaßen über das Ziel hinaus. Er befreit sich nicht nur aus seiner verklemmten Haltung, sondern wandelt sich extrem. Angefangen mit ausführlichen erotischen Träumen und Phantasien, geht dies über in eine Parallelführung der Handlung mit Laupeyßer, der eine Nacht mit der Bedienung des Cafés im Hotel verbringt. Falbin geht am gleichen Abend mit einer jungen Frau, Marianne Liwald, die er am Bahnhof kennengelernt hat, ebenfalls ins Hotel. In dieser Szene sind seine neue dominante Art und auch ein neuer Sprachgebrauch mit sexuell explizitem, vulgärem Vokabular auffällig, der sogar vom Erzähler hervorgehoben wird (vgl. VG, 294).

Die extreme Entwicklung gipfelt schließlich in der Vergewaltigung von Agnes, die sich in einer Version Jahre nach den geschilderten Ereignissen abspielt. `Geplant wird diese schon ziemlich früh von Laupeyßer, dem die Idee im Gespräch mit Agnes einfällt, die natürlicherweise abgestoßen reagiert. In Bezug auf Falbin wird die Vergewaltigung als "Endpunkt «, »dissonante $[\mathrm{r}]$ Lustakkord « $(V G, 230)$ und »Abrundung seiner Existenz« $(V G, 231)$ bezeichnet. In Übereinstimmung mit Laupeyßers oben beschriebenen chauvinistischen Vorstellungen kann die Vergewaltigung tatsächlich als konsequenter Endpunkt der Entwicklung Falbins gesehen werden, der wieder in mehreren >Möglichkeiten ` präsentiert wird und auch die Anknüpfung an die Entsetzensthematik herstellt. In einer anderen Version vergewaltigt Falbin Agnes bereits zwei Jahre nach seinem Verschwinden. Sie hält ihn für Laupeyßer und nimmt ihn später vor Gericht sogar in Schutz, was in Verbindung mit der Verständnisthematik zwischen Agnes und Laupeyßer gebracht wird. ${ }^{50}$ Davor soll sich eine weitere Verge-

49 Seltsamerweise hat Falbin sich jedoch schon vor dem einschneidenden Ereignis des »Irregehens" auf seiner Arbeitsstelle - er verwaltet in einem Autohaus die Kasse - merkwürdig, d. h. seiner Charakteranlage widersprechend, verhalten. Regelmäßig hat er Geld unterschlagen, was anfangs nicht auffällt, doch entdeckt wird, nachdem seine »Bahnhofsexkursionen « $(V G, 33)$ begonnen haben. In dieser Zeit wird auch im Büro bemerkt, dass Falbin sich verändert, unzuverlässig und unkonzentriert wirkt, sodass eine Krise vermutet wird.

50 Vgl. Abschnitt 1.4.1 auf Seite 74. 
waltigung ereignet haben, im Gegensatz zur anderen als »Wirklichkeit« $(V G, 231)$ klassifiziert; dabei handelt es sich um die absurde Konstruktion einer bezahlten Vergewaltigung durch Streicheln - »Alle zwei Tage für eine halbe Stunde» $(V G, 231)$ über zwei Jahre hinweg - der Figur Anna, einer Prostituierten, die auf den Folgeroman Wolpertinger vorausweist und eigentlich eher diesem angehört.

\section{»Laupeyßer-Falbin«}

Das Verhältnis zwischen Laupeyßer und Falbin besteht nicht nur aus dem einseitigen Dominanzverhältnis zwischen Autor/Erfinder und seiner Figur. Durch das Prinzip der narrativen Metalepse ist es möglich, dass die Figur Falbin frühzeitig Einfluss auf ihren Erfinder Laupeyßer gewinnt. Dieser besteht nicht nur darin, dass Laupeyßer sich in seine Phantasien hineinsteigert und sie für »wirklicher « $(V G, 70)$ als seine eigenen »Lebensumstände« ansieht. In dieser Hinsicht erfüllt Falbin für ihn die Funktion "fort [zu]räumen«, »was da herumsteht « (ebd.), durch das fiktive Durchleben seine eigenen Probleme durchzuspielen. Darüber hinausgehend beginnt Falbin in einer Vermischung der Ebenen, die Handlungen Laupeyßers durch seine Wünsche zu beeinflussen. Der >Autor`-Erzähler lässt auf diese Weise Laupeyßer als Stellvertreter für Falbin fungieren, wie dieser eigentlich stellvertretend für Laupeyßer handelt. ${ }^{51}$ Diesem ist die Vermischung der Ebenen wiederum bewusst, wie er Agnes gegenüber mitteilt: »Ich erlebe seine Wünsche. Wir schweißen uns aneinander.« $(V G, 63)$ Im Gegensatz dazu steht Falbin, der zwar Laupeyßer etwas erleben lässt, bei dem jedoch nichts auf ein Wissen davon hindeutet, dass er eine Figur von diesem ist. Bei einer zufälligen Begegnung auf dem Bahnhof erkennt Falbin Laupeyßer nicht einmal, ist vielmehr verwundert, dass dieser ihn anschaut, als würde er ihn kennen (vgl. $V G$, $57 \mathrm{ff}.)^{52}$

Dieses >Aneinanderschweißen geht soweit, dass in mehreren Handlungssträngen irgendwann nicht mehr klar ist, wer von beiden eigentlich der Akteur ist. Vor allem gilt dies für den mysteriösen Ausflug nach Frankfurt am Main. Ist anfangs zwar nicht klar, ob die Fahrt überhaupt unternommen wird, so wird doch Laupeyßer eindeutig als Protagonist des Ereignisses oder der Imagination genannt. ${ }^{53}$ Später ist dann auf einmal, d.h. ohne weitere Erläuterung oder Kommentierung, Falbin derjenige, der die Fahrt unternimmt bzw. vor allem derjenige, der auf die Prostituierte Anna in Frankfurt trifft. ${ }^{54}$ Auch die Gespräche mit Axel Schulze sind zuletzt nicht mehr eindeutig Laupeyßer zuzuordnen. Erschwert wird die Zuordnung durch die Tatsache, dass Laupeyßer sich Schulze gegenüber als Falbin ausgibt. In diesen Passagen

51 Vgl. VG, 62f., wo dies erstmals auftritt, anscheinend wie eine plötzliche Idee: »Oder doch. // Denn Falbin soll wollen, daß Laupeyßer die Frau trifft. [...] Deshalb läßt er Laupeyßer die Frau finden. Stellvertretend."

52 Dabei ist wieder unklar, wer hier wen treffen >lässt`, da Laupeyßer selbst erstaunt ist, Falbin zu treffen; es bieten sich aber verschiedene Möglichkeiten an: Laupeyßer kann das >reale Vorbild Falbins gesehen haben und sich die Falbin-Passage imaginieren oder es bleibt der >Autor`-Erzähler bzw. der von ihm eingesetzte heterodiegetische Erzähler der Laupeyßer-Ebene der Urheber. Dies ist wohl nicht eindeutig zu klären.

53 Falbin trifft Laupeyßer ja, als dieser in den Zug nach Frankfurt steigt, siehe VG, 59.

54 Vgl. VG, 224 und $297 f$. 
wird mehrfach »Laupeyßer-Falbin« als Doppelname verwendet (vgl. VG, 140 und 200). Da der Eigenname eigentlich zur eindeutigen Identifizierung einer Figur dient, handelt es sich hier um die systematische Störung der Identifizierung. ${ }^{55}$ Zwar kann die Figur mit großer Wahrscheinlichkeit als Laupeyßer erfasst werden, da sie im gleichen Abschnitt meist als Laupeyßer bezeichnet wird; die Verwendung des Doppelnamens sorgt jedoch für Irritation. Sie betont die Verbindung der beiden und insinuiert zudem die Möglichkeit einer Identität. Diese Konstruktion kommt jedoch in der Tat nur in den Abschnitten vor, in denen Laupeyßer mit Schulze redet und von diesem für (eine Person namens) Falbin gehalten wird. Tatsächlich nehmen die Ähnlichkeiten zwischen beiden, Laupeyßer und Falbin, zu. Der heterodiegetische Erzähler eines Falbin-Abschnitts konstatiert dies auch nebenbei: »Die Ähnlichkeiten nehmen zu, ich weiß. Es läßt sich nicht ändern." $(V G, 293)$ Doch auch durch andere Figuren wird dies bestätigt. So trifft Schulze Falbin auf der Bahnhofstoilette und hält ihn fälschlicherweise für Laupeyßer (den er aber Falbin nennt, weil Laupeyßer sich so vorgestellt hatte, vgl. $V G, 257$ f.) und Agnes verwechselt Falbin ebenfalls, als dieser, wie bereits erwähnt, später nach Bremen zurückkommt und sie vergewaltigt (vgl. VG, 232). Beide Vorfälle implizieren eine optische Verwechselbarkeit, die bei Erfindung von Falbin, als Laupeyßer den jungen Mann im Café betrachtet, keineswegs angedeutet wird.

Die Bezeichnung mit dem Doppelnamen Laupeyßer-Falbin kann also als das zugespitzte Symbol für das Verhältnis der beiden gesehen werden, das von der relativen Ähnlichkeit der äußeren Lebensumstände und ihrer charakterlichen Verschiedenheit über eine Gegenentwicklung in der symbolischen Geruchs- und der animalistischen Verhaltensentwicklung zu einer Angleichung der Ziele (das Fortgehen) und des Aussehens reicht. Neben der absichtlichen Störung der Identifizierung geht damit gleichzeitig eine Form von Identifizierung einher, da die Möglichkeit einer Identität nahegelegt wird, deren genaue Ausformung jedoch im Ungewissen bleibt.

\subsection{Näherungen I: an sich und andere}

Das Prinzip der Näherung wird zuerst von Laupeyßer thematisiert, findet sich aber ebenso auf der Falbin-Ebene und in den Reflexionen des >Autor`-Erzählers. Eingeführt wird es zunächst gar nicht als Zielsetzung, Handlungsweise oder Prinzip, sondern lediglich als Ausdruck für Laupeyßers Unsicherheit. Er bemerkt Agnes gegenüber, nicht zu wissen, was er suche, einfach unruhig zu sein.

Manchmal denke ich, [...] daß ich mich irgend etwas annähere. Ich umkreise sozusagen ein Ziel, von dem ich nichts weiß. Eine Spiralbahn. Vielleicht gibt es das Ziel gar nicht, vielleicht kommt es einzig auf das Kreisen an, auf das ständige Kreisen. (VG, 32)

Was hier als einfaches Bild und Versuch gekennzeichnet ist, ein Gefühl in Worte $\mathrm{zu}$ fassen, bildet das poetische Verhaltensprinzip der Hauptfiguren und damit die Poetologie des Romans. Die Näherung bestimmt ihren Umgang mit den als zentral 
markierten Themen: den Umgang mit der Bildung der Fiktionen, der Herausbildung eines Verhältnisses zur Geschichte und zur Wirklichkeit sowie das Verhalten sich selbst und anderen Menschen gegenüber und damit die Konstruktion einer stabilen Identität. Zuerst einmal erinnert es an die simple Weisheit »Der Weg ist das Ziel«, doch ist dem darüber hinaus noch die Annäherung, die Spiralform beigefügt. Es geht also nicht darum, einen (möglicherweise geradlinigen) Weg zurückzulegen, der sich als eine persönliche Entwicklung wichtiger als das Ziel herausstellt, sondern sich etwas anzunähern, von dem nicht bekannt ist, ob es existiert. Die Annäherung und überhaupt die Bewegung ist hier nicht nur das Entscheidende, sondern das einzig Vorhandene. Dadurch, dass die Näherungen auf diesen unscharf gefassten Anfang zurückgehen, ist es vielleicht auch möglich und nötig, es von komplexer poetischer Aufgeladenheit als mysteriöses Prinzip, das von dieser Stelle an ohne weitere Erklärung als »Näherungen« oder »diese Näherungsschnipsel« fungiert, zurückzuführen auf einfache Grundlagen.

Bei den Näherungen müssen prinzipiell zwei Sphären unterschieden werden. Einmal handelt es sich um die Annäherung an Personen, an Andere. Dann gibt es noch die Näherungen an die Wirklichkeit, die weiter unten genauer behandelt werden (vgl. Abschnitt 2.4 auf Seite 111). Als Näherung an eine Person wird zum einen der Versuch bezeichnet, jemand anderen kennenzulernen und zu verstehen, Nähe zu ihm herzustellen. Zum anderen gibt es auch die Näherung an sich selbst, die mit dem oben beschriebenen Versuch, sich selbst zu erkennen kongruiert. In beiden Fällen spielt Verständnis eine wichtige Rolle und dies in doppeltem Sinn, nämlich jemanden $\mathrm{zu}$ verstehen, aber auch von jemand anderem verstanden zu werden. Jemanden zu verstehen bezieht sich vor allem auf das Selbst-Verständnis und wird auch darauf bezogen, dass Laupeyßer Falbin zu verstehen versucht. Im Sinne der Identitätsthematik geht es damit auch um den Aspekt der Innen- und Außenperspektive, die zur Konstruktion von Identität wichtig sind.

Die Näherungen an andere haben zunächst eine Dimension an sich, die wenig zu tun hat mit der regulären zwischenmenschlichen Erfahrung von Nähe oder Kontaktaufnahme. Ihnen ist ein Anspruch von Totalität eigen, der zum Scheitern verurteilt ist, weswegen ihnen ein irrealer und teils auch destruktiver Zug anhaftet. So schildert der `Autor-Erzähler unter Berufung auf Grimmelshausen die kurze Geschichte eines Landsknechts, der einen Gefangenen zu Tode quält und dies damit begründet, dass er habe wissen wollen, was das in ihm sei, die Seele. ${ }^{56}$ Der schlagwortartige Kommentar des >Autor -Erzählers am Ende des Abschnitts lautet: »Jemandem nahe kommen. Gesichter sammeln." $(V G, 103)$ Die Verbindung von Quälerei und (menschlicher) Nähe ist im oben beschriebenen Kontext der Frage nach der Verbindung von Menschlichkeit und Gewalt zu sehen, die sich in der Frage zuspitzt `kann ich mich noch entsetzen?«. Sie offenbart seine Irritation, wie mit diesen Zusammenhängen umzugehen sei, bezeichnet die menschliche Eigenheit, dass die Gewalt gegenüber anderen Menschen nicht weit von zwischenmenschlicher Nähe entfernt ist. Der Versuch, jemanden zu erkennen, ihm wie der Landsknecht auf den Grund zu gehen, findet

56 Die Wichtigkeit dieser Episode für Herbst zeigt sich auch darin, dass er sie immer wieder anführt: vgl. beispielsweise Alban Nikolai Herbst: "Grimmelshausen-Preisrede zum 15. November 1995", 1995, URL: http://www.die-dschungel.de/ANH/txt/pdf/grimmelshausen_rede.pdf, 5. 
sich im Ansatz, jedoch in harmloser Form auch in der Überlegung, was dazu nötig sei. Wieder stellt der >Autor<-Erzähler diese an. Er konstatiert: »Denn die Personen wechseln stets, und schon die völlige Annäherung an eine Person übersteigt die Möglichkeiten. [...] - Wievielen Menschen, zum Beispiel, habe Falbin sich angenähert? $(V G, 122)$ Es folgt eine lange Liste von Namen, über offensichtliche Verwandte, vermutlich Freunde, Bekannte, Lehrer bis zu aus der aktualen Welt ${ }^{57}$ bekannten Namen, Schriftstellern und Prominenten. Es wird also die Vorstellung demonstriert, um einen Menschen zu verstehen, müsse man alles kennen oder erleben, was dieser erlebt habe. »Denn es geht um jede Augenfalte, die Falbin gesehen hat in seinem Leben, um jeden Tonfall, den er hörte, jeden Handschlag, den er gespürt hat.« Bei einem solchen totalen Anspruch kann nur die Schlussfolgerung bleiben: »Es muß die Hoffnung aufgegeben werden darum, jemanden zu verstehen. Ich bekomme ja nicht einmal meine eigenen Begegnungen zusammen." $(V G, 123)$ Dieser offensichtlich unmögliche und daher absurde Anspruch impliziert ex negativo die Unmöglichkeit, einer anderen Person gegenüber in der Beurteilung oder Einschätzung gerecht zu sein und stellt damit die Möglichkeit einer Außenperspektive infrage.

Im Folgenden werden die Wege genauer betrachtet, auf denen versucht wird, dennoch Nähe und Näherungen zu erreichen. Die Erfüllung des Bedürfnisses, von anderen verstanden zu werden, wird von Laupeyßer und dem >Autor-Erzähler in geradezu >klassischer Weise von Frauen erwartet und wird im Folgenden wie im Buch am Verhältnis von Laupeyßer und Agnes geschildert. Wie in diesem Fall scheitert die Verständigung auch im Verhältnis des >Autor«-Erzählers zu B., wo es aber vor allem um die Herstellung von Nähe durch körperliche Nähe geht. Das Suchen von Nähe zu Fremden wird durch das wiederkehrende Motiv der Kontaktaufnahme beschrieben. Axel Schulze steht für die Resignation gegenüber dem Versuch, Nähe herzustellen, und die Einsicht in die Unmöglichkeit von Kommunikation und auch für die Schlussfolgerung, dass nur die Fiktion nah sei.

\subsubsection{Agnes und das Verständnis}

Agnes ist eine Freundin von Laupeyßer, alleinerziehende Mutter eines kleinen Sohnes. Ihr Verhältnis zu Laupeyßer ist prinzipiell erst einmal nicht von sexueller Anziehung geprägt, sondern manifestiert sich in regelmäßigen Besuchen Laupeyßers bei ihr mit langen Gesprächen. Zumindest während des Zeitraums der geschilderten Handlung stellt Agnes die wichtigste Gesprächspartnerin Laupeyßers und sogar seinen zentralen sozialen Kontakt dar. Er sucht sie alle ein bis zwei Tage auf und erzählt ihr seine Imaginationen um Falbin. Durch die Regelmäßigkeit, die nachfragende, aber ansonsten passive Rolle von Agnes, die nur durch die Achtsamkeit gegenüber ihrem kleinen Sohn gestörte Aufmerksamkeit des Zuhörens erhalten die »Agnes-Gespräche» $(V G, 118)$ den Charakter von Therapiegesprächen. Untermauert wird dieser Eindruck durch ihre einleitenden Nachfragen: »Du willst über Falbin sprechen ?« (VG, 118,

57 Ich übernehme diesen Begriff von Jannidis: »Gegenüber dem Begriff `Realität $`$ hat `aktuale Welt $`$ den Vorteil, durch die erkenntnistheoretischen Krisen und den linguistic turn hindurch gegangen zu sein, ohne die doch wesentliche Unterscheidung [zwischen Realität und Fiktion] zu verabschieden.» (Jannidis: Figur und Person, 66 FN 117) 
vgl. auch $V G, 145)$. Eine helfende Funktion ist wohl zumindest das, was Laupeyßer insgeheim erwartet, da er beispielsweise nach dem einschneidenden Erlebnis des Films sofort Agnes anruft, wobei die erwartete Hilfe weniger in Ratschlägen als im Zuhören liegt. Die erleichternde Funktion des Erzählens zeigt sich auch ex negativo, denn als Laupeyßer seine Besuche bei Agnes abbricht, stellt er fest, dass »er so gern gesprochen hätte«, verstärkt sogar noch in der Formulierung »Es trieb ihn, zu beichten." $(V G, 166)$ Die unausgesprochenen Erwartungen gehen aber noch weiter, als die passive Rolle eines Gegenübers zum Beichten zu erfüllen, da Laupeyßer vor allem das fehlende Verständnis seitens Agnes nicht nur bedauert, sondern unter diesem leidet.

Wie mehrfach angedeutet und auch schon in der Bezeichnung Näherung erkennbar, fällt es Laupeyßer nicht leicht, seine Gefühle und Überlegungen in präzise Worte zu fassen. Auch seine Erzählungen um Falbin sind recht exzentrisch für freundschaftliche Kaffee-Gespräche und strapazieren zeitweise durch das Ausreizen geschmacklicher Extreme das Interesse eines Zuhörers. Dennoch erhofft sich Laupeyßer immer wieder das Verständnis von Agnes bzw. sogar eine vollständige Verständigung mit ihr. Seine Versuche, dies mitzuteilen, sind im Grunde zu vernachlässigen, wobei sie auch nur mit einem Schulterzucken darauf eingeht (vgl. $V G, 18)$. Einmal teilt er ihr fast schon im Streit seinen Ärger über ihr Unverständnis mit (»Herrgott, du verstehst einfach nichts !«, 72), ansonsten stellt er die Vergeblichkeit dieser Hoffnung immer wieder für sich selbst fest (siehe $V G, 42,69,102,149,232,235$ ). Einerseits verlangt er viel von ihr, im Grunde, dass sie >zwischen den Zeilen` seinen Hilferuf hört, ${ }^{58}$ andererseits ist ihm bewusst, dass sie ihn aus "Selbstschutz« $(V G, 235)$ nicht habe verstehen können, dass sie ihn aus diesem Grund wohl sogar immer abgelehnt habe. Er gesteht ihr in dieser Hinsicht zu, auch wenn dies die Distanz erhöht, an die »hautnahe Realität« $(V G, 11)$, d. h. die Versorgung des Kindes, gebunden zu sein und daher keinen Sinn für seine extremen Gedankenexperimente zu haben, auch wenn diese für ihn existenziellen Charakter haben.

Doch scheinen hinter seinen Erzählungen und auch hinter seiner Sehnsucht nach Verständnis - darin allerdings schon enthalten - der simple Wunsch nach Nähe und zärtlicher Annahme zu sein, der auch sonst verschiedentlich angedeutet wird. Nach seiner eingangs zitierten Beschreibung der Näherungen folgt der Kommentar: »In Wahrheit wollte ich ihr sagen, sie sollte mich endlich einmal berühren." $(V G, 32)$ Doch wie bereits erwähnt steht der sexuelle Aspekt der Nähe nicht im Vordergrund, wie dies im Verhältnis von >Autor<-Erzähler und B. der Fall ist. Zwar ist von einer gewissen »dem Instinkt verbundene[n] Spannung « $(V G, 42)$ die Rede und es kommt zu mehreren mehr oder weniger erotischen Begegnungen (vgl. VG, 118 und 165f.); Agnes werden jedoch Gedanken imaginativ zugeschrieben (von Laupeyßer?), die jegliches erotisches Gefallen an ihm von sich weisen (vgl. VG, 159f.), und Laupeyßers Träume von ihr werden durch Zärtlichkeit und Nähe charakterisiert (vgl. VG, 158 und 165). Bezeichnend ist jedoch, dass ihre Beziehung abbricht, als es zum einen zu einer zärtlich-erotischen Begegnung kommt, diese sich zum anderen aber auch gerade dann ergibt, als Agnes »jetzt sich bemühte um ihn, dabei vielleicht zum ersten Mal wirklich etwas begriff« $(V G, 165)$. Durch ihre Mutterrolle vorsichtig und abgelenkt,

58 Vgl. VG, 149: »Schweig und hilf mir. // Was sie nicht hörte. Sie hörte einfach nie richtig zu, man muß ihr immer alles sagen. Immer muß man den Leuten alles sagen.« 
>zerbricht< etwas zwischen ihnen durch dieses Nahekommen, das sie beide auf Distanz gehen lässt.

Die Bedeutung von Agnes zeigt sich in mehrfacher Hinsicht. So ist sie die präsenteste Frauenfigur des Buches, die schließlich auch die verschiedenen Erzählebenen verbindet. Eigentlich eine Freundin von Laupeyßer, ruft sie später nach der Flucht nach Frankfurt den >Autor<-Erzähler an, der auch ihre Bedeutung für ihn erklärt: "Und es ist mir, Agnes, durchaus ernst mit dieser Frage, genauso ernst wie Tatsache ist, daß alle diese Näherungen anfingen erst, als ich mein stummes Zwiegespräch begann mit dir.« $(V G, 326)$ Auffällig ist, dass erstmals eine Verbindung zwischen ihr und dem >Autor`-Erzähler hergestellt wird, der sonst vornehmlich mit B. verbunden zu sein schien. Dann wird sie, ganz beiläufig, an den Anfang auch seiner Ausführungen gestellt. Schließlich fällt die paradoxe Formulierung des >stummen Zwiegespräch auf. Anzunehmen wäre eine ähnliche Konstellation zwischen ihnen wie zwischen Laupeyßer und ihr, was jedoch durch die Charakterisierung als stumm ausgeschlossen wird. Möglich wäre die Existenz einer Agnes in der Realität des >Autor`-Erzählers, der er über die Fiktion Laupeyßers die imaginären Zwiegespräche zuschreibt. Warum aber diese Agnes am Anfang der Näherungen steht, wird nicht weiter ausgeführt.

Für Laupeyßer verkörpert Agnes die zentrale Frauenrolle. Wie sich im Laufe der Darstellung mindestens Falbin und Laupeyßer, wenn nicht auch der >Autor/-Erzähler, aneinander annähern, so findet zumindest in den direkt als solche ausgewiesenen, in die >Haupthandlung « eingeflochtenen Imaginationen auch eine Amalgamierung der Frauenfiguren statt. Zu Beginn der paranoiden Verhörphantasien Laupeyßers wird das Erscheinen der zentralen Frauenfigur wie folgt beschrieben: »Eine Frau folgt: Die Kommissarin. Die Spinnin. Laupeyßer erkennt sie sofort wieder. Die Bedienung. Agnes.« $(V G, 169)$ Fast alle Frauen, mit denen Laupeyßer in Kontakt gekommen ist, werden hier vermengt zu einer Frauenfigur, die im Folgenden dann als Agnes benannt wird, eine Agnes jedoch, die sich völlig anders verhält als Laupeyßers Gesprächspartnerin. Bislang wurde sie vornehmlich in ihrer Mutterrolle beschrieben und in ihrer sexuellen Haltung von Laupeyßer als naiv charakterisiert. ${ }^{59}$ In der Verhörphantasie wird sie komplett anders dargestellt: sie gibt sich selbst nicht als Agnes aus, ist dadurch distanziert zu Laupeyßer und geht mit extremer Brutalität gegen ihn vor, die schließlich in seiner Tötung gipfelt. Bereits bei ihrem Eintritt erschrickt Laupeyßer: »Ach Agnes, nicht auch das noch. Bitte nicht. Nicht auch du.« $(V G, 169)$ Laupeyßer geht durch diese Imagination der Frage nach, die er auch an sich selbst gerichtet hatte: »Würde vielleicht auch sie mit ebensolcher Selbstverständlichkeit morden oder morden lassen? « $(V G, 102)$ Dadurch, dass auch Agnes in die Entsetzensund Schuldthematik >integriert ist, wird klargestellt, dass für Laupeyßer alle betroffen sind, selbst die als eindeutig positiv gesehenen Personen. Auch diese unterliegen für ihn den gleichen Prinzipien, was das ersehnte Erreichen von Nähe nicht leichter macht.

Durch Laupeyßers Hoffnung auf Nähe, auf Rettung durch Agnes, fungiert sie als die Erzählebenen überbrückende Vorgängerin von B. Dies wird noch deutlicher an einer

59 Siehe oben Abschnitt 1.3.1 auf Seite 62. 
einzelnen Stelle, in der Agnes mit dem im nächsten Abschnitt erläuterten »Prinzip Nadja« verbunden wird. Dieses hätte »sich schon in Agnes verkörpert[], als sie mir noch hätte helfen können, ganz zu Anfang also dieser Näherungskurve, [...].«(VG, 247)

\subsubsection{Das »Prinzip Nadja«: B. und der `Autor «-Erzähler}

So wie Agnes für Laupeyßer die wichtigste Frau ist, ist es B. für den >Autor`-Erzähler. Auch weitere Übereinstimmungen finden sich, werden jedoch eine `Stufe höher gehoben, was sich in der oberen Stellung in der Hierarchie der Erzählebenen sowohl wiederfindet als auch durch sie erklärt. Auch sie steht für mehrere Frauen, jedoch ist Agnes nun auch >integriert», sie ist "gleichzeitig Agnes, Leopardenfrau, Anna« (VG, 212). Damit verkörpert sie mehrere Prinzipien: mit Agnes das der wohlwollenden Naivität und Begrenztheit, mit der Leopardenfrau das der sexuellen Enthemmtheit und mit Anna das der Verständigung und der Suche nach Ausbruchsmöglichkeit. Im Gegensatz zu den anderen scheint sie eine (auf der als >real angenommenen Ebene des >Autor<-Erzählers) >reale` Person zu sein. Zwar wird konstatiert, »auch sie [sei] eine Erfindung, sicher« $(V G, 212)$, doch wird diese Aussage einschränkend erläutert:

Wenn sie merkt, wie sehr ich mir sie erfinde, versteckt sie ihre Augen mißtrauisch hinter den Pupillen. Sie merkt, daß meine Erfindung recht behalten wird. Sie hat Angst, sich zu verwandeln. Aber, wohlgemerkt, meine Erfindung von ihr ist keine Projektion. $(V G, 212)$

Sie ist also zum einen soweit Erfindung wie dies jede Person ist, die literarisch zur Figur wird, ${ }^{60}$ und zum anderen wie es der >Autor<-Erzähler bewusst durch prinzipielle Stilisierung und Überhöhung betreibt. Doch dahinter lässt er einen Freiraum für die auf seiner Ebene reale Person, die misstrauisch gegenüber seiner Fiktionalisierung ist und sich gegen diese wehrt, die ihn schließlich in für ihn schmerzlicher Weise verlässt. Zunächst ist sie aber die Frau, mit der er in Frankfurt nach seiner $>$ Flucht zusammen ist und von der er seine `Rettung` erhofft.

Retten soll sie ihn vor der angeblichen Unmöglichkeit der Herstellung von Nähe. Dem Leitsatz, nur die Fiktion sei nah, setzt der >Autor«-Erzähler das »Prinzip Nadja» (VG, 247) entgegen. Dieses bezieht sich auf André Bretons Erzählung Nadja (1928/63), was spätestens durch die explizite Nennung Bretons deutlich wird (vgl. VG, 230). In dieser Erzählung, einem der klassischen Texte des Surrealismus, begegnet der Ich-Erzähler Breton zufällig auf einem seiner Spaziergänge einer jungen Frau, die sich selbst Nadja genannt hat (dieser Name ist der Anfang des russischen Wortes für Hoffnung), und ihn sofort fasziniert. Ihre Fähigkeit, Dinge zu sehen und zu erahnen, die den Verstandesmenschen verschlossen bleiben, Visionen zu erleben und ihren Intuitionen zu folgen, lässt sie zur prototypischen surrealistischen Muse werden, sie

60 Thomas Pavel nennt saus der Realität übernommene Objekte - das können Orte oder historische Persönlichkeiten wie z. B. Napoleon sein - denn auch ıimmigrant objects`, was eine Bewegung oder Wandlung impliziert. Werden sie >signifikant abgewandelt $\iota$, heißen sie >surrogate objects Siehe Frank Zipfel: Fiktion, Fiktivität, Fiktionalität. Analysen zur Fiktion in der Literatur und zum Fiktionsbegriff in der Literaturwissenschaft, Berlin 2001, 97-102, vgl. auch Jannidis: Figur und Person, 67. 
ist eine Frau, die »den Surrealismus lebt ohne Netz ${ }^{61}$. Schließlich wird sie aufgrund von »einigen überspannten Auftritten « jedoch als »wahnsinnig « ${ }^{62}$ klassifiziert und in eine psychiatrische Anstalt gebracht. Ob sie `tatsächlich « wahnsinnig ist oder wie ihre Art, mit der Wirklichkeit umzugehen, anders zu interpretieren ist, wird von Breton nicht explizit ausgeführt, sondern in gegen die Psychiatrie gewandten Ausführungen als irrelevant verworfen.

Doch was bedeutet nun das "Prinzip Nadja«? Wie bei allen benannten Begriffen, Entschlüssen und `Prinzipien in $V G$ wird auch dieses `Prinzip $`$ nicht genau definiert. Eingeführt wird `Nadja als Benennung von B., womit der >Autor`-Erzähler sie zwar nicht anredet, aber die er in seinen Reflexionen und Aufzeichnungen verwendet. Mit der Benennung versucht er, dem Diktum "Nur die Fiktion ist nah « etwas entgegenzuhalten. Das Entgegenhalten impliziert die Möglichkeit, Nähe doch auch in der Realität (im Gegensatz zur Fiktion) erreichen zu können. Besieht man sich daraufhin die Nadja Bretons, so ist es die Faszination, die sie auf den Erzähler Breton ausübt, und vor allem die durch ihren Sinn für das Wunderbare veränderte Weltwahrnehmung, die sie in ihm bewirkt, die eine Übertragung auf die Hoffnungen des >Autor-Erzählers ermöglicht. Auch B. soll ihm eine Nadja sein, wie (der Erzähler) Breton sie getroffen hat.

Nun ist B. jedoch denkbar ungeeignet, das »Prinzip Nadja « zu erfüllen. Sie ist eher ängstlich, »traut der Möglichkeit eines Ausbruchs nicht « $(V G, 212)$. Auch bei ihr (wie bei Laupeyßers Agnes) findet sich das Verständnis nicht. Verdeutlicht wird das an ihren eigenen Versuchen, der sogenannten »Empirie« zu entfliehen, d. h. den Zwängen, der Wirklichkeit zu entkommen. Bei ihr äußert sich dies im Hören von vom >Autor -Erzähler so genannter »Kitschmusik« und dem Beharren darauf, »Traum müsse Traum und Wirklichkeit Wirklichkeit bleiben«, was die Träume seiner Meinung nach zum »Bonbon « und "purer Kompensation « $(V G, 320)$ erniedrigt und seinem Versuch, die Wirklichkeit durch Fiktion zu verändern, entgegensteht.

Vielleicht werden im »Prinzip Nadja« aber auch verschiedene Aspekte vermengt, die in Bretons Nadja eine Rolle spielen. Geradezu ein Vorbild für die in B. gesetzten Erwartungen findet sich in der Begegnung Bretons mit einer nicht namentlich bezeichneten Frau nach der Einweisung Nadjas und sogar nach dem eigentlich geplanten Abschluss der Aufzeichnungen. Peter Bürger hat dies prägnant beschrieben:

Die Begegnung mit X, die im Text durch ein blanc markiert ist, bricht in das Leben des Autor-Erzählers ein, verwandelt dieses und beschert dem Buch einen auch für den Schreibenden unvorhergesehenen Schluß. Das Rätsel des Selbst, das das Ich umtrieb, bedarf jetzt keiner Lösung mehr, denn die Liebe ist die Lösung. ${ }^{63}$

Was Breton (der Erzähler) bei Nadja nicht gefunden hat, nämlich »die rätselhafte, die unwahrscheinliche, die einzigartige, die verschmelzende und unzweifelhafte Lie-

61 Peter Bürger: Das Verschwinden des Subjekts. Eine Geschichte der Subjektivität von Montaigne bis Barthes, Frankfurt am Main 1998, 246; vgl. auch VG, 160-165.

62 Breton: Nadja, 116.

63 Bürger: Das Verschwinden des Subjekts, 165. 
be -, eine kurzum, die jeder Prüfung standhält» ${ }^{64}$, findet er bei `X`. Eine ebensolche >unwahrscheinliche< Liebe sucht der >Autor $<$-Erzähler bei B.

Im Gegensatz zu den Ausführungen Bretons ist die Beziehung zu B. deutlich sexuell bestimmt. An der Stelle, an der in Bezug auf Agnes zwar, aber auch das einzige Mal wirklich die Formulierung vom »Prinzip Nadja« verwendet wird, werden gleich mehrere Sachen in einen gemeinsamen Konnex gestellt, denn assoziativ wird fortgefahren: "Damals also schon: das Prinzip eines bißchen cremiger Feuchtigkeit. Das Prinzip Beinkissen. Das Prinzip Freiheit, das stets ein fiktives war und aus solcher Fiktion seine Kraft erst gewann.« $(V G, 247)$ Das hier genannte »Prinzip Beinkissen «, sei es identisch mit dem »Prinzip Nadja« oder bloß in enger Verbindung mit diesem stehend, wird immer wieder angeführt. Erstmals genannt wird es als Bild dessen, was für den >Autor<-Erzähler Heimat bedeute: »ich wiese auf B.'s Foto und sagte in beruhigter Furcht: Das ist mir nur das Kissen zwischen ihren Beinen.« $(V G, 207)$ Er beeilt sich hinzuzufügen, dass diese Aussage »nichts `Chauvinistisches « an sich habe, da er mehr ihr Objekt sei, als sie das seine. Eindeutig ist aber der sexuelle Bezug, doch nicht nur der, sondern auch der zu den "Liebesdingen « $(V G, 208)$, womit sowohl die körperliche wie die emotionale Liebe gemeint sein kann. Der `Autor`-Erzähler verortet sich, fühlt sich aufgehoben und wohl in der (sexuellen) Nähe zu B. Mehrfach wird die sexuelle, körperliche Rolle, die B. für ihn und seine Bemühungen um Nähe darstellt, betont. Die »Bemühungen, vermittelt durch Tasten und Wärme Nähe herzustellen« werden als »Umweg über die Haut « $(V G, 121)$ bezeichnet, das eigentliche Ziel ist immer eine nicht näher definierte, aber über das Körperliche hinausgehende Form von Nähe. Doch sieht er als den einzigen Weg zu dieser Nähe den über das Körperliche. Dieser Weg bedeutet für ihn zuerst einmal die »völlige Annahme des anderen Körpers« (VG, 296). Dies stellt die ins extreme gesteigerte Annäherung an eine Person dar, »die man lieben, streicheln, essen und pinkeln sehen will, vor der nichts, aber auch gar nichts mehr fremd ist « $(V G, 255)$. Auch hier findet sich eine Parallele in Nadja, wo die Liebe zu 'X « als gelungene Annäherung gesehen werden kann: »Du bist kein Rätsel für mich. / Ich sage, daß du mich für immer vom Rätsel abbringst. « ${ }^{65}$ Während hier poetisiert wird, ist die Körperlichkeit der Anknüpfungspunkt des `Autor`-Erzählers. Zugespitzt ist es dann der Beischlaf, in den die maximale Annäherung projiziert wird. Sexualität wird konzeptuell erhöht zum Prinzip der Nähe.

Dass die Nähe durch Sexualität »das einzige, was sich der überall vorherrschenden Fremdheit entgegensetzen läßt « $(V G, 295)$, sein soll, klingt jedoch eher wie unreife Ausflüchte eines Alleingelassenen bzw. eines Sich-allein-Fühlenden. Tatsächlich wird dieser Aspekt denn stellvertretend (für den >Autor«-Erzähler) auch von Axel Schulze und Laupeyßer diskutiert, der die gleichen Ansichten geäußert zu haben scheint, da die beiden sich im auf den >Autor-Erzähler-Abschnitt folgendem Gespräch auf sie beziehen. Axel Schulze wirft Laupeyßer vor, »die alte romantische Liebe geradezu aufs Kosmische auszuweiten, indem Sie fordern, noch die Exkremente des anderen seien zu lieben« $(V G, 296)$. Schulze sieht diese »Liebe« als Träumerei und Projektion

64 Breton: Nadja, 116.

65 Ebd., 136. 
par excellence. Eine Möglichkeit zur Nähe verneint er, im Gegenteil, er meint, man sollte »die Liebe aufgeben [...], wenn man die Befreiung will« $(V G, 297)$.

Für den >Autor`-Erzähler und im Gespräch mit Axel Schulze auch für Laupeyßer als sein `Sprachrohr ist diese Liebe der einzig ersichtliche Ausweg. Hier deutet sich auch an, dass der (unten näher betrachtete) Versuch, Wirklichkeit durch Fiktion herzustellen, nicht das Ziel des >Autor<-Erzählers ist. Vielmehr beklagt er bei der Trennung von B., gerade sie sei »endlich nicht mehr Fiktion« $(V G, 308)$ gewesen, werde es nun aber wieder und auch mit seinen Fiktionen werde es weitergehen, die Gestalten würden wiederkommen (vgl. VG, 337 ${ }^{66}$. Er begrüßt dies nun also gar nicht, das »endlich « zeugt eindeutig von seiner Sehnsucht, von der Fiktion loszukommen und eine Verbindung zur aktualen Welt herzustellen, oder in seiner Terminologie: Empirie und Fiktion zu verbinden. Diese Formulierung zumindest als Verbindung der beiden Begriffe wird zweimal verwendet: Mit B. wollte er sein fiktives Ich [...] gewissermaßen empirisch festigen « $(V G, 308)$ und auch die "Macht des Beischlafs [liege] eben darin, entschieden jenen Punkt zu markieren, an welchem Empirie und Fiktion zusammenfallen " $\left(V G, 295 \mathrm{f}\right.$.). ${ }^{67}$ In B. setzt er also nicht nur große, sondern alle Erwartungen, mit ihr will er seine »Vorstellung von der Nähe, auf welche alles hinauslief, die mir als einzige Möglichkeit noch von Befreiung erschien « $(V G, 308)$ verwirklichen. Über den Beischlaf soll damit die Herstellung und Fixierung einer individuellen Identität erreicht werden.

Wie B., die wie oben erwähnt mehrere Frauenfiguren integriert, tritt auch die Geliebte $>\mathrm{X}$ ` aus Bretons Nadja an die Stelle von anderen, u. a. von Nadja selbst. Doch wird sie zum Endpunkt einer Entwicklung stilisiert, so »daß diese Ersetzung von Personen mit dir aufhört, weil nichts dich ersetzen kann und für mich von aller Ewigkeit her diese Abfolge von Rätseln bei dir ein Ende finden mußte ${ }^{68}$. B. dagegen erfüllt diese enormen Erwartungen nicht und verlässt den >Autor<-Erzähler, der diesen Erwartungen entsprechend verzweifelt reagiert, »wieder einmal zusammen [bricht] « (VG, 285) und einen Selbstmordversuch unternimmt. Die Reflexionen danach bringen ihn zu einer möglichen Einsicht bezüglich der Ersetzung, ja Amalgamierung von Frauenfiguren: »Weil nämlich, was B. wirklich ist - Leopardenfrau, Anna, Agnes, Nadja -, doch mir nachhängen wird in einer jeden ıneuen Frau ?« (VG, 321) Er erkennt die Liebe zu B. als die Liebe zu einem Abstraktum, zu einer unterbewusst konstruierten Wunschvorstellung, was die tatsächlichen Vorgänge des Verlassens und des Selbstmordversuchs "fiktiv« (ebd.) erscheinen lässt, als im Prinzip ewig sich Wiederholendes sind sie vergeblich bzw. ohne grundsätzliche Wirkung und erscheinen daher >unwirklich ‘. Auch in der Wendung, B. habe seine »Nähe-Fiktion nicht real werden

66 Hier ist sogar vom »Ausbruch« die Rede, der sich auf die Verfolgung durch »die Gestalten« bezieht: »Und ich wußte, es werde weitergehen mit meinen Fiktionen, mögen sie mich eines Tages auch zur Abschreckung neben eine Straßenlaterne hängen, für jene, die immer noch nicht die Aussichtslosigkeit des Ausbruchs begriffen haben sollten.« $(V G, 337)$

67 Vgl. auch: »Der Orgasmus gar bedeutet ein kurzfristiges Zusammenbrechen derjenigen Grenzen, die es einem ansonsten erlauben, seine Miete zu zahlen und definierten Tätigkeiten nachzugehen." (Alban Nikolai Herbst: »Schöne Literatur muß grausam sein! Antimilitaristische Spekulationen zum Thema Krieg \& Katharsis«. Rede vor der Deutschen Literaturkonferenz am 23. März 2002 in Leipzig, in: Neue Deutsche Literatur 50/4 (2002), 176-187, hier: 178.)

68 Breton: Nadja, 136. 
lassen« (VG, 320) wollen, drückt sich die Vergeblichkeit seiner Nähe-Vorstellung aus, denn diese hätte gerade keine Fiktion sein sollen.

\subsubsection{Axel Schulze und die Aporie der Nähe}

Laupeyßer lernt Axel Schulze in der Eckkneipe kennen, die er häufig aufsucht. Dieser sitzt allein an der Theke und ist durch seine Physiognomie eindeutig als Trinker erkennbar. Beim zweiten Treffen erzählt Schulze Laupeyßer kurz, dass er den Krieg im KZ verbracht habe (siehe $V G, 119$ ), später zeigt er ihm auch die Nummerntätowierung am linken Unterarm, die ihn als Auschwitz-Häftling kennzeichnet (siehe VG, 168, vgl. auch 123). Er teilt mit, dass er, als Homosexueller auch nach dem Krieg ausgegrenzt, sich dann durch Prostitution am Bahnhof seinen Lebensunterhalt verdient hätte (vgl. $V G, 119)$. So wird er als ewig Ausgegrenzter klassifiziert, als jemand der im Gegensatz zu Laupeyßer tatsächlich unter der deutschen Geschichte zu leiden hat; nicht als Täter, was Laupeyßer sich vorzustellen versucht, sondern als Opfer. Er hält seine Erinnerungen nicht aus und flüchtet sich daher in den Alkohol.

Als entsprechendes Bild für die unerträgliche Verfolgung durch seine Erinnerungen steht sein $>$ Beruf $\iota$ Gesichter zu $>$ sammeln $\prec$. Das bedeutet, dass er Leute anschaut und sich die Gesichter einprägt. Später dann »reproduzier[t er sie] in Gedanken « $(V G, 91)$ und nagelt die imaginären Gesichter an die Wand seiner Wohnung. Indem er diese »[v]erdinglichte[n] Imaginationen ${ }^{69}$ als Bilder behandelt, versucht er sie loszuwerden. Dieser vergebliche Versuch, mit seinen Ängsten umzugehen, ergibt eine Asozialität, das Unvermögen, mit anderen zu kommunizieren, das in seiner Verwahrlosung und dem mehrfach erwähnten »André-Schulze-Geruch» $(V G, 145,152)$ seinen Ausdruck findet. Das Unvermögen ist ihm auch bewusst, denn er reflektiert über die Unmöglichkeit von Kommunikation, Nähe und Begreifen. Kommunikation mit anderen, der Versuch, mit anderen Kontakt oder Nähe herzustellen, sieht er als nicht möglich an. Die Isolation hat bereits in dem Versuch gegipfelt, die Sprache ganz aufzugeben, einen »Verlust«, den er direkt auf seine KZ-Erfahrung zurückführt (vgl. $V G, 119)$. Mit Anspielung auf Wittgensteins Diktum des Schweigens erzählt er, er habe aufgehört zu sprechen, doch resümiert er die Erfahrung damit, dass dies auch nichts geholfen habe (vgl. $V G, 92)$. Nähe ist für ihn ebenso eine »Projektion« ( $V G$, 89) wie Kommunikation »in Wirklichkeit Selbstgespräch« $(V G, 93)$ ist.

Damit ist er das theoretische Sprachrohr für die konstruktivistischen Ansichten, die den Reflexionen des Buches zugrunde liegen. Keine andere Figur stellt solche deutlichen Behauptungen auf. Dafür sprechen auch mehrfache Anspielungen auf bekannte Namen der Philosophie und Literatur, ${ }^{70}$ die sonst nicht in Gesprächen eingebracht werden und damit rein äußerlich einen höheren theoretischen Anspruch erheben.

Um trotz der konstatierten Unmöglichkeit von Kommunikation nicht gänzlich die Verbindung oder den Kontakt zu verlieren, verfällt Schulze auf »das einzige, was man haben kann, [den] Vorschein der anderen, niemals diese selbst« $(V G, 89)$.

69 Alban Nikolai Herbst: »Größenfantasien (Tel Aviv)«, 2002, URL: http://www.die-dschungel.de/ ANH/txt/pdf/groessenfantasien.pdf.

70 Wittgenstein, Adorno, Dostojewski, vgl. VG, 92, 284f., 311. 
Dieser »Vorschein « eines Menschen ist für ihn das Gesicht, das er in der absurden Tätigkeit des Gesichtersammelns zu fassen meint. Die Möglichkeit, Nähe zu erzeugen, sieht er nur durch die paradoxe Wendung gegeben, dass sie durch Ferne, also durch Gleichgültigkeit entsteht. Erst wenn der andere einem gleichgültig sei, projiziere man nicht das Eigene in ihn hinein, was als Nähe nicht auszuhalten sei. Seine Einstellung dieser Thematik gegenüber ist durch zwei Emotionen geprägt. Zum einen bringt das Gesichtersammeln weder Befriedigung noch Erlösung, da er immer wieder wie ein Mantra den Satz "Es ist schrecklich. « wiederholt. Zum anderen vertritt er, wie Laupeyßer ihm vorwirft, eine »Ideologie der Stärke« $(V G, 167)$. Diese drückt sich in seinen Entgegenhaltungen in zwei Gesprächen mit Laupeyßer aus. Im ersten geht es um Laupeyßers Bitte um einen falschen Pass. Mit Hilfe eines neues Passes will er ja seine alte Identität ablegen und in ein neues Leben aufbrechen. Schulze sieht darin keinen Sinn und vertritt die Ansicht, sich jeglichen Widerständen aussetzen zu müssen (vgl. VG, 166f.). Die gleichen Ansichten finden sich auch im zweiten Gespräch, in dem es um die Flucht durch Freitod geht. Auch hier sieht er die Flucht als die einfachere, aber sinnlose Möglichkeit an, der er das >Widerstehen` entgegenhält (VG, 199ff.).

Das Gefangensein in Aporien - weder sprechen/kommunizieren noch schweigen bringe etwas, Nähe sei durch Freundschaft und Kommunikation nicht möglich - wird durchbrochen, gerade durch diese Etablierung einer distanzierten Freundschaft zu Laupeyßer, die auch durch die Freundschaft von Falbin zu einer Spiegelfigur, Schulze 2 (vgl. $V G, 270)$, bestätigt wird. Es beginnt ein »Gesundungsprozeß« $(V G, 254)$, der zur Wiederaufnahme seiner Hygiene führt - ohne dass er die Gesichtermanie aufgibt. Schulze fungiert damit neben Agnes als zweiter Gesprächspartner für Laupeyßer mit dem er eher diskutiert als mit Agnes, der er vor allem seine Fiktionen erzählt; die beiden sind damit im Grunde die einzigen, von denen er positiv-kritische Einwände aus der Außenperspektive akzeptiert. Im Zuge der Entwicklung ändert Schulze auch seine Meinung bezüglich des Passes und der Flucht und besorgt (»spendiert«, VG, 218) Laupeyßer den ersehnten Pass.

\subsubsection{Kontakt aufnehmen}

Alle drei Hauptfiguren haben Probleme mit Nähe. Die `Näherungen an sich selbst bereiten Schwierigkeiten, andere, vor allem Frauen, sverstehen sie nicht in dem Maß wie erwartet oder ersehnt. Obwohl von Laupeyßer im Gegensatz zu Falbin bekannt ist, dass er einige Freunde und Bekanntschaften hat, findet sich bei ihm wie auch bei Falbin gelegentlich der Drang, fremde Menschen anzusprechen, als ob sie das dringende Bedürfnis hätten, wenigstens auf irgendeine Weise Kontakt oder Nähe zu anderen herzustellen.

Bei Laupeyßer ist dies jedoch weniger ein verzweifeltes als ein enthusiastisches Bedürfnis nach Mitteilung. So will er einer »junge[n] Person« etwas »einfach so« mitteilen: "Steh auf, nimm sie am Arm, erzähl ihr von dem Gefühl, das einsetzte im Gefolge von achtundzwanzig Jahren. [-] >Entschuldigen Sie ... -: Kennen Sie dieses ... dieses ...? - Unsinn!« $(V G, 13)$ Sofort wird diese Vorstellung von Kontaktaufnahme durch das »Unsinn« abgetan. Später spielt er auch einmal die Möglichkeit gedanklich 
durch, eine Frau, die er beobachtet, einfach mit den Worten anzusprechen: »Entschuldigen Sie bitte, ich würd' Sie gern mal berühren ...« $(V G, 85)$ Auch hier verwirft er diese Möglichkeit gleich wieder, verliert sich vielmehr in Reflexionen über die quälende `Spinnenhaftigkeit`der Frauen. So unterschiedlich diese beiden Beispiele sein mögen, zeigen sie doch beide den Wunsch, aus den eingefahrenen Verhaltensnormen auszubrechen und die Distanz zu fremden Menschen zu überbrücken. $\mathrm{Zu}$ diesem Zeitpunkt ist Laupeyßer jedoch noch in einem Stadium seiner Entwicklung, wo er dieses Bedürfnis sogleich unterdrückt. Später, wenn ihm das Aufgeben zivilisatorischer Selbstkontrolle eher zuzutrauen ist, zieht er sich aber von den Menschen zurück.

Bei Falbin zeigt das Bedürfnis, fremde Menschen >einfach so anzusprechen, eher seine soziale Unbeholfenheit, aber auch den Drang, daraus auszubrechen. Hier sind die Versuche jedoch zum Scheitern verurteilt. Einmal ist explizit vom »Bedürfnis, ihn anzusprechen « $(V G, 64)$ die Rede, das sich auf einen jungen Mann im Café bezieht. Falbin würde sich gerne mit ihm unterhalten, traut sich aber nicht, da er nicht weiß worüber. Später begegnet er auf der Straße dem ihm unbekannten Axel Schulze, der unter Stimmungsschwankungen leidet. Wieder wird er »ergriffen von dem Verlangen, den Unbekannten anzusprechen [...] - dermaßen also, daß er unfähig ist, es zu tun« $(V G, 119)$. Als er sich schließlich traut, einem solchen Bedürfnis nachzugeben, endet die Erfahrung durch seine Unbeholfenheit eigentlich mit dem schlimmsten erdenklichen Ergebnis. Da er sich zunehmend auf dem Bahnhof sicher und wohl fühlt, möchte er "wirklich mehr Kontakt zu den Reisenden haben. Einfach mal jemanden ansprechen. Warum denn nicht? « $(V G, 147)$ Er sucht sich einen älteren Herren aus und versucht, ihm beim Koffertragen zu helfen. Da dieser das Hilfsangebot jedoch im Lärm nicht hört, denkt der Mann, Falbin wolle seinen Koffer stehlen, woraufhin dieser in Panik davonläuft. Laupeyßer, der die Episode Agnes erzählt, fügt jedoch gleich hinzu, dass sie vor der oben dargestellten Entwicklung Falbins stattfindet. Dies legt nahe, dass die Annahme des Drangs zur Kontaktaufnahme und der Versuch ihrer Umsetzung gerade Teil der Entwicklung ist. Wie oben bereits beschrieben, nimmt Falbin später >Penner`vom Bahnhof mit zu sich nach Hause, um seine Angstgefühle auszutreiben. Dies kann als eine Travestierung der Sehnsucht nach Nähe und Kontakt gesehen werden, die ihm ursprünglich einmal eigen war, nach seiner Entwicklung dann jedoch unterdrückt wird.

An zwei Stellen wird das `Kontakt haben in abstrakter Form thematisiert. Einmal findet sich dies in einer der Imaginationen mit Agnes als Kommissarin (bzw. ist diesmal in wild durcheinander gehender Assoziation Mario Adorf der Kommissar). Im Verhör wird Laupeyßer gefragt: ")Geben Sie zu: Sie haben Kontakt!< [...] >Sie haben also noch Kontakt?! [ ...] >Es wird weniger«, sagt Laupeyßer entschuldigend. >Nicht mal Agnes mehr besuche ich. Ist alles stumm, äußerlich.« $(V G, 187)$ Auch wenn es sich hier um eine der expliziten Folterphantasien handelt, so ist dies doch bezeichnend für Laupeyßers Entwicklung. Er zieht sich immer mehr zurück, gibt jeglichen >Kontakt` und Anknüpfungspunkte für Nähe auf. Das wird auch in der zweiten Stelle direkt von Axel Schulze angesprochen, der Laupeyßer entgegenhält: ")Ich habe Kontaktı, sagte Schulze. >Im Gegensatz zu Ihnen habe ich noch Kontakt. Es ist schrecklich, ja, aber ehrlich.« $(V G, 200)$ Der Widerspruch, dass Laupeyßer zumindest zu Schulze ja noch Kontakt hat, wird dabei nicht aufgelöst. Sowohl bei 
Falbin als auch bei Laupeyßer bestand also vor ihrer Veränderung der Wunsch nach Reaktionen von außen, später ziehen sie sich auf die Innenperspektive zurück.

\subsection{Der Versuch von Geschichtslosigkeit}

Der vom `Autor-Erzähler` so genannte » Versuch von Geschichtslosigkeit « $(V G, 151)$ ist mit allen drei Protagonisten verbunden und versammelt verschiedene, miteinander zusammenhängende Themen unter einem Begriff. Dieser bezeichnet die Befreiung von vermeintlich vererbter Schuld der Elterngeneration, von Deutschsein und mit beidem verbunden sogar von der eigenen Sozialisation, und damit den Versuch, autonom von einer vorgegebenen und vorgeformten Identität zu werden.

Erstmals findet sich eins dieser Themen bei Falbin, der die Sehnsucht nach dem Weggehen beschreibt. Wie oben bereits dargestellt, bildet sich durch Laupeyßers Bestimmung in Falbin eine positive Einstellung zum Bahnhof, sodass er nach anfänglichem Fehlgehen sich dort gezielt aufhält. Schließlich stellt er bei Überlegungen, einen längeren Urlaub zu machen, fest, dass er eigentlich nicht wiederkommen will: "Denn das Problem ist: wirklich wegzukommen. Man müßte das Wegfahren zum Beruf machen. Nirgendwo länger als ein oder zwei Tage bleiben." $(V G, 57)$ Später verdichtet sich dann diese spontane Überlegung zum Bild des Niemandslandes, das die Erfahrung von vergangenheitsloser Unbeschwertheit während des Zugfahrens bezeichnet. Auch bei Laupeyßer bildet sich im Zuge seines Entschlusses das Bedürfnis aus wegzugehen. Bei ihm kommt hinzu, dass es sich um eine scheinbare Auflösung handeln solle, also niemand etwas wissen dürfe vom Weggang: »Keiner sollte etwas bemerken. Keine Spur hinterlassen. Verschwinden. Sich auflösen im Nichts. Meine Wahl war vollzogen.« $(V G, 109)$

Der Wunsch wegzugehen entwickelt sich im Folgenden parallel bei Falbin und Laupeyßer und wird von beiden zunehmend konkreter gefasst. Beim Versuch, offiziell eine Namensänderung zu beantragen (und damit eine weiterreichende Identitätsänderung anzustoßen), gesteht Falbin dem Beamten: »Ich will wegziehen und mich dabei hierlassen. Was ich war, was ich wurde, warum ich es wurde, wer ich bin ... noch bin ... Das, das soll weg! « $(V G, 113)$ Es geht also mithin nicht um einen bloßen Ortswechsel, sondern um das Abstoßen der eigenen Vergangenheit und des eigenen Werdegangs, der gesamten alten Identität, die zur Belastung geworden zu sein scheint. Bei Laupeyßer korrespondiert dies mit dem wiederkehrenden Motiv der Suche nach dem, >was bleibt . Im Zuge seines geplanten "Abstiegs « verkauft er in diesem Sinne fast seine gesamte Wohnungseinrichtung, doch läuft es letztendlich auch bei ihm auf einen radikalen Ortswechsel hinaus: »Umziehen, ohne etwas mitzunehmen. Daß man sich selbst mitschleppen muß, reicht ja wirklich schon aus. Was ich habe, habe ich bei mir. [...] Aber vorher diese Leere auskosten und erleben, was bleibt, wenn nichts mehr da ist." $(V G, 144)$ 


\subsubsection{Belastung durch deutsche Geschichte}

Die Begründung für den Fluchtgedanken liegt jedoch nicht in der Betrachtung des eigenen Selbst, sondern in der Belastung durch die deutsche Geschichte. Diese findet sich nun wiederum nicht bei Falbin, sondern ist mit Laupeyßer und dem >Autor`-Erzähler verbunden. Letzterer schreibt in Frankfurt und damit nach der zumindest äußerlich erfolgreichen Flucht, er könne sich nicht bei Agnes melden und so Kontakt zu seiner Vergangenheit aufnehmen, vielmehr müsse er beharren auf seinem "Versuch von Geschichtslosigkeit « $(V G, 151)$, dessen Verbindung mit Flucht und Aufgabe der Vergangenheit durch diese Kontextualisierung eindeutig gemacht wird. Die Begründung für den »Versuch « folgt im direkten Anschluss: „Die Betroffenen nämlich können nicht trauern, jede Erleichterung dahin ist ihnen versagt. Alle Ganglien voll haben sie zu tun, ihre Betroffenheit wegzuschaffen. Damit Platz für den Atem bleibt.« (VG, 151) Doch wirkt dies als »Begründung « unzureichend, wenn nicht gar deplatziert. Wenn es um Geschichtslosigkeit geht, um das Abstreifen der Vergangenheit, wie die anderen Textstellen nahelegen, was hat der Sprecher dann mit den Betroffenen zu tun? Eine Parallelstelle dazu ist bei Laupeyßer zu finden. Im Kontext eines Gespräches mit Axel Schulze, in dem dieser von seinem Aufenthalt im KZ erzählt, wird Laupeyßers innerer Entschluss dargelegt: »Was er zu akzeptieren auf sich nahm : betrauern die Geschichte, die er nicht begangen hatte. Sie betrauern als Betroffener, weil er nicht betroffen war.« $(V G, 120)$

In beiden Formulierungen ist vom Trauern die Rede. Auch wenn sich weder im Text noch in weiteren Äußerungen von Herbst ein direkter Hinweis finden lässt, so liegt hier nahe, an die sehr bekannt gewordene Studie Die Unfähigkeit zu trauern der Psychoanalytiker Alexander und Margarete Mitscherlich von 1967 zu denken. Kurz vor bzw. gerade zu Beginn der Studentenunruhen erschienen, die einen Umschwung im Umgang mit der Nazivergangenheit brachten, stellten die Mitscherlichs anhand von Fallbeispielen aus ihrer psychoanalytischen Praxis das Fehlen einer Aufarbeitung der eigenen Schuld in der Bundesrepublik fest. Ihre These war dabei, »die Bundesrepublik [sei] nicht in Melancholie verfallen, [...] [indem sie] alle affektiven Brücken zur unmittelbar hinter ihnen liegenden Vergangenheit abbrach ${ }^{71}$. Im Anschluss an Sigmund Freuds Aufsatz »Trauer und Melancholie« (1917) führen sie die Unterscheidung zwischen diesen beiden Begriffen genauer aus. Zur Trauer seien die Deutschen nach ihrer Ansicht gar nicht fähig gewesen, da es sich beim verlorenen (zu betrauernden) Objekt um die >Führer--Figur Hitler gehandelt habe, die aber nicht um ihrer selbst, sondern aus narzisstischen Gründen als `Liebesobjekt ‘ gewählt worden sei. Der >Führer` wäre dabei als Ich-Ideal in das eigene Selbst aufgenommen worden. Zunächst fällt in Bezug auf den Diskurs in VG auf, dass es nicht um die Trauer um die Opfer, sondern um die Trauer um den Verlust des >Führers` geht. Die damit einhergehende massive Selbstentwertung, auf die psychologisch reagiert werden musste, habe eine den anderen Nationen mögliche Trauer um die Opfer unmöglich gemacht. Doch ist es genau diese fehlende Aufarbeitung und ein Schuldeingeständnis sowie, wie in den eben zitierten Passagen deutlich wird, auch die fehlende Trauer, die Laupeyßer und

71 Alexander Mitscherlich / Margarete Mitscherlich: Die Unfähigkeit zu trauern. Grundlagen kollektiven Verhaltens, München 1967, $37 \mathrm{f}$. 
der >Autor`-Erzähler beklagen. Die von den Mitscherlichs wieder im Anschluss an Freud beschriebene, bei den Deutschen vor allem der älteren, >schuldigen $<$ Generation ausgebliebene >Trauerarbeit ` ist es, die Laupeyßer auf sich nehmen will (vgl. dazu genauer unten Abschnitt 2.3 auf Seite 109).

Auch die Betroffenheit der jüngeren Generation wird in Die Unfähigkeit zu trauern angesprochen. Durch die Erziehung und die damit einhergehende Identifikation mit Älteren sei es »illusionär, anzunehmen, eine junge Generation könne leicht das Joch der Vergangenheit [...] abwerfen " $^{72}$. In $V G$ ist diese Thema der Diskussionen des >Autor<-Erzählers mit Iris, seiner zwar häufig genannten, aber nicht näher charakterisierten Gesprächspartnerin. Diese Diskussionen stellen auch die Zitate zum Trauerdiskurs in einen größeren Zusammenhang und bestätigen ihre Verbindung über die Übereinstimmungen in der Wortwahl hinaus. Iris vertritt darin den gängigen Standpunkt, als `Nachgeborener k könne man sich nicht in die vergangenen Taten und Leiden hineinversetzen, man sei gewissermaßen unschuldig. Der >Autor-Erzähler gibt ihr zwar teils recht, doch sieht er in ihrer Position die Schuld der Elterngeneration fortbestehen. Durch ihre Argumentation, die wie eine Entschuldigung klinge, das Vorschützen von Nicht-Wissen, wie es schon die Zeitgenossen betrieben hätten, gebe sie »ihre Teilhabe zu, gestand sie den Sieg der Nazis ein" (VG, 120). Dem setzt er sein "fiktives Trauma" $(V G, 285)$ Auschwitz entgegen, seine manische Beschäftigung mit der Thematik. Er sieht es als gegeben an, dass die »Enkel« in der Verantwortung stehen (vgl. VG, 82 und 263). Obwohl er weiß, dass eine »Solidarität im Leiden« $(V G, 199)$ niemandem, keinem Opfer konkret etwas nützen würde, hat er eine positive Utopie, die zumindest das Gedenken verwirklicht:

\footnotetext{
Einem solchen Haus gegenüber [dem Bahnhof], dachte Laupeyßer, wäre tatsächlich Selbstaufgabe gefordert und ein exzentrisches Aufgehen. Dann erst befreiten sich aus den Nischen und eingekerbten Zeichen die gezwungenen und freiwilligen Reisenden und all die Züge, die nach Buchenwald gefahren waren und Theresienstadt, Majdanak oder Esterwegen, ins Moor. Dann stünden sie alle wieder dort, die zusammengetriebenen Menschenmassen, ängstlich, zusammengepfercht, gestoßen, resigniert, im Fahl der Augen ihrer ledernen Wächter. $(V G, 134)$
}

Dafür fungiert Laupeyßer als fiktiver Stellvertreter; dieser solle »anrennen dagegen, er soll gegens Nicht-sich-Hineinversetzen-Können einen Sturmlauf entfesseln, einen Ausfall reiten durchs Gebiet der mangelnden Verständigung «(VG, 120). Oder anders formuliert: "Daher Laupeyßers Ausbruchsversuch: Sich ganz bewußt fremde Schuhe anziehen und so tun, als hätte man sie noch gefertigt. Das ist die einzige Form von Widerstand, die uns bleibt.« $(V G, 285)$ Dieser Widerstand richtet sich gegen die beispielhaft vorgebrachte, Schuld nivellierende Position von Iris.

Dennoch wird ein Widerspruch nicht aufgelöst: Möchte (oder soll) Laupeyßer sich stellvertretend Schuld aufladen und stellvertretend Geschichte betrauern, so lässt er sich gerade auf Geschichte ein; dem steht der »Versuch von Geschichtslosigkeit « entgegen, wo er der Geschichte zu entfliehen versucht. Doch scheint es in diesem um die persönliche Geschichte zu gehen (obwohl das "nämlich « $[V G, 151]$ 
im oben genannten Zitat eine andere Verbindung zu etablieren versucht). Die eigene Vergangenheit, das was bei Falbin das "was ich war [...], was ich bin« ausmacht, soll abgestreift werden, was eine Flucht bedeutet aus Verantwortung, auch wenn sie vielleicht nur eingebildet ist.

Zur persönlichen Geschichte gehört auch die Schuld der Eltern bzw. der Elterngeneration. Die Schuld betrifft für Laupeyßer nicht nur die aktive Beteiligung an den nationalsozialistischen Verbrechen. Auch das Wegschauen, das Leugnen jeglichen Wissens um diese Taten sieht er als Schuld an (vgl. VG, 82, $101 \mathrm{ff}$., 263). Diese generelle Schuld der Elterngeneration, die er als eine Kollektivschuld sieht und deren Auswirkungen er, wie das Beispiel Iris zeigt, sogar als eine Art Erbsünde ${ }^{73}$ darstellt, untermauern den Wunsch, seine Vergangenheit abstreifen zu können:

Man müßte, dachte er, die Spuren seiner Eltern unkenntlich machen können :

Erst dadurch garantierte sich Geschichtslosigkeit und also ein autonomes Ich.

Aber das ging nicht. Oder doch? $(V G, 87)$

Ist dies noch die Reaktion auf den Brief des Vaters, der mit völligem Unverständnis und Vorwürfen auf Laupeyßers Lebenspläne antwortet, so bleibt die Idee haften und löst sich von den individuellen Eltern:

Ein völliges Verschwinden, dachte er, ließe erst sich vollziehen im Abstreifen seiner bisherigen Identität, einer solchen nämlich, die sich noch nie besessen hatte. Eltern müßte man annehmen, die man nicht kannte, mehr noch : die erfunden waren. Papierahnen. Eine Sozialisation vorweisen, die es nicht gegeben hatte. $(V G, 112)$

In einer weiteren Stelle wird dies sogar indirekt als das »Laupeyßer-, das Falbingefühl « $(V G, 337)$ bezeichnet, das jedoch am verschwinden sei. Da er, der >Autor<-Erzähler, jedoch immer noch das Gefühl habe, "von einer bestimmten Person geboren worden zu sein«, müsse er sich seine Eltern erfinden.

Fraglich ist, warum gerade Laupeyßer mit dem »fiktive[n] Trauma« zu kämpfen hat. Wie Falbins ist auch sein Name "mit keiner moralisch oder ästhetisch üblen Assoziation belastet « $(V G, 112)$; seine Eltern waren während der Nazizeit jung (seine Mutter noch ein Kind) und normale Mitläufer des Systems, »ich-los« $(V G, 105)$ in der Masse; sein Großvater war zwar »SS-Standartenführer« $(V G, 35)$ und hegte auch nach dem Krieg noch Sympathien mit rechtsradikalen und rechtskonservativen Kreisen, doch wird kein genauer Grund dafür ersichtlich, dass gerade Laupeyßer an der deutschen Schuld in solchem Maße leidet. Über die Identität des `Autor-Erzählers wird nichts weiter ausgesagt und auch weitere Hinweise bleiben aus, die diese Frage in Bezug auf ihn erklären würden. ${ }^{74}$

73 Die durch die sich selbst entlastende Argumentationsstruktur und das damit verbundene Denken tradiert wird. Laupeyßer empört sich aber auch darüber, dass die Schuld durch die Generation der >Betroffenen nicht eingestanden wird und rassistische und verharmlosende Bemerkungen und damit eben solches Denken weiterhin zu finden sind; vgl. VG, 11 und 78.

74 Dass Herbsts eigener Familienname von Ribbentrop mit einer "üblen Assoziation belastet « war, konnte ein Leser zur Zeit des Erscheinens von VG nicht wissen. Herbst hat seine Auseinandersetzungen mit diesem Namen später in Meere (2003) deutlich verarbeitet, als der Name bereits der Öffentlichkeit bekannt war, und geht auch im Weblog des Öfteren darauf ein. Vgl. dazu später Abschnitt 8.4.2 auf Seite 400. 
Doch auch der >Autor/-Erzähler hat die gleiche Sehnsucht wie Laupeyßer und Falbin, die zunehmend drängender wird: »Nur abfahren, abfahren, ihn verlassen, diesen Ort der abgeschnittenen Seelen, das Kinodunkel, die Masturbationsmaschinen " $(V G, 322)$. Wie für Laupeyßer ist es also die Erfahrung des Films und die damit verbundenen Überlegungen, die ihn in die Flucht treiben. Erst in einem späteren Telefonat mit Agnes (lange nach den geschilderten Ereignissen) bezeichnet er das Fortgehen in gelassener Weise als »alte[n] Traum von der Freiheit« $(V G, 333)$, wodurch die Verbindung zu Fluchtgedanken zumindest gemildert wird.

\subsubsection{Name und Pass als Identität}

Als konkretes Symbol für die gesamte Identität einer Person in dem Sinne, dass sie zurückgelassen werden soll, wird wiederholt der Pass verwendet. Zusammenhängend damit spielt auch der Name sowie die Namensgebung und -änderung eine wichtige Rolle. Den Überlegungen Laupeyßers zu Falbins Fluchtgedanken setzt Agnes die Idee bzw. Frage entgegen, warum er nicht einen anderen Namen annehme. Dem hält Laupeyßer in unerwarteter Rücksichtnahme auf Beschränkungen der empirischen Welt mögliche Schwierigkeiten mit der Bürokratie entgegen. Doch lässt er Falbin diese Möglichkeiten `durchspielen`, was zwar wie erwartet erfolglos ist, am Unverständnis des Beamten scheitert. So wird die Möglichkeit einer Namensänderung, die sich im Pass niederschlägt, eingeführt. Noch ist Laupeyßer aber davon überzeugt, dass Identitätsänderung in solcher Weise nichts bringen würde: »Nur eine Benennung änderte sich, als handelte es sich um eine Zahl. Aber das Symbol bliebe wirkungslos." (VG, 113) Erst später erkennt er die Bedeutung eines neuen Namens und eines neuen, falschen Passes, die etwas über den bloßen Namenswechsel Hinausgehendes zu schaffen vermögen. ${ }^{75}$ In Kombination, aber auch in wechselseitigem Bedingen mit einem Ortswechsel, der räumlichen Flucht, sollen sie ein `wirkliches Wegkommen` ermöglichen. Laupeyßer wendet sich an Axel Schulze, der ihm auch tatsächlich einen falschen Pass besorgt. Fortan ist für alle drei Protagonisten der (falsche) Pass äquivalent zu einer neuen Identität, was sich in wiederholter Kontextualisierung und sprachlicher Gleichsetzung ausdrückt (vgl. VG, 218, 322 und 333). Dieser Sprachgebrauch ist bekannt durch die Verwendung im Kriminalroman oder Thriller ( $>$ sich eine neue Identität verschaffen`), doch unterscheidet sie sich hiervon durch den fehlenden äußeren Zwang; vielmehr handelt es sich um eine symbolische Aufladung des imaginierten Dokuments. Der Wunsch, es zu besitzen, gipfelt schließlich im Kampf um den Pass auf der Bahnhofstoilette, der den `Showdown « des Buches bildet. Auch in der Frage der Identität der drei Protagonisten (im Sinne, eine Person zu sein) und ihrer Realität bzw. Erfindung spielt der Pass in einer paradoxen Argumentation eine Rolle. Im Zuge seiner paranoiden Anfälle versichert sich Laupeyßer seiner Identität durch den Pass: "Sie können mir ja gar nicht beweisen, daß ich in Wirklichkeit Falbin bin. Hihi. Und haha. In meinem Ausweis steht dick und vernehmlich der Name Laupeyßer. Steht einfach so drin. Weiß auch nicht. Ulkig." $(V G, 164)$ Später will er sich gerade das Gegenteil beweisen:»Wer will im übrigen behaupten, Laupeyßer habe jemals existiert? Er hat nie existiert, ich versichere Sie, ich, bitte, wollen Sie meinen Ausweis sehen?» 
(VG, 257) In beiden Fällen soll der Name im Pass die Versicherung des tatsächlichen, nicht eingebildeten oder imaginierten Namen bzw. entsprechender Identität sein. Gleicher Logik folgt auch das Streben nach dem neuen Pass und neuem Namen, die erst einmal dem Träger und weniger anderen Leuten oder der `Öffentlichkeit entgegen besserem Wissen die neue Identität beweisen soll.

\subsection{Zusammenführung: Von der »ungeformten« zur »ungesicherten" Identität}

Die Suche eines jungen Mannes nach seinem Platz im Leben, seinem Umgang mit sich selbst, Anderen und seinen genetischen und generischen Anlagen, mit seiner Vergangenheit und der seiner Eltern(generation), kurz: die Suche nach seiner eigenen Identität, ist das grundlegende Thema in Die Verwirrung des Gemüts. Die zentrale Frage danach wird immer wieder pointiert gestellt, auch wenn ihr Auftauchen zwischen den fragmentierten Erzählabschnitten geradezu beiläufig wirkt: »Aber wer, um Herrgotts willen, bin ich?!« (VG, 101, vgl. auch 225). In direkter Verbindung dazu steht die Frage, wie sich Identität überhaupt konstituiert, was das »Ich « ausmacht. Auf welche Weise die Suche nach der eigenen Identität das verbindende Thema aller drei Protagonisten ist, sei dabei noch einmal kurze Zeit zurückgestellt; es sei nur angemerkt, dass sich Hinweise auf die Frage über alle Ebenen hinweg finden.

Grundlegend ist die innere Verunsicherung, die bei allen drei Protagonisten zu finden ist. Auslöser für die Reflexion über die Verunsicherung sind bei Laupeyßer und dem >Autor -Erzähler der Pasolini-Film und die Frage nach dem Entsetzen, bei Falbin ist es das durch den `Erfinder L Laupeyßer hervorgerufene "Irregehen " zum Bahnhof. Beide sind externe Auslöser, die durch eine starke Verunsicherung die Aufmerksamkeit auf die sowieso schon vorhandene innere Unsicherheit richten. Verschiedene Schlüsselwörter und mehrfach aufgegriffene Formulierungen drücken diese sprachlich aus und markieren die zugrunde liegende Vorstellung von Identität und Ich: das »mir wurde mir fraglich « $(V G, 17)$, das Gefühl, »jemand völlig anderes zu sein« $(V G, 101)$, der Wunsch, sich haben oder sogar sich völlig haben zu wollen (vgl. VG, 101 und 135), die Rede von Auflösung und Zerfall des Ichs (bzw. bildlicher Stellvertreter, vgl. $V G, 135$ und beispielhaft auch 225 und 235) und das immer wieder beschworene Ideal der Autonomie bzw. des autonomen Ichs (vgl. VG, 69 und 87).

So zeigt sich eine ambivalente Vorstellung von Identität. Einerseits besteht die Vorstellung einer im (jedoch gerade nicht erreichten) Idealfall stabilen, festen Identität, die - wäre sie einmal erreicht bzw. hätte sich einmal gefestigt - sich nicht mehr verändern würde und auch durch externe Einflüsse nicht erschüttert, also verunsichert werden könnte. Diese Vorstellung zeigt sich ex negativo auch in den Fluchtgedanken der Protagonisten und dem Versuch von Geschichtslosigkeit. Exemplifiziert an Laupeyßer wird das Gefühl beschrieben, durch die historische Schuld der Eltern (und der gesamten Nation) eine vorgeformte, feste Identität mit sich zu tragen, die einen erdrückt. Zwar ist eine feste Identität im positiven Sinn (also Sicherheit gebend) nicht erreicht, doch geht die Vorstellung dahin, durch einen neuen Pass und das Fortgehen in eine andere Stadt, also durch eine Neubezeichnung und einen Neuanfang ließe 
sich eine erdrückende `ererbte oder zugeschriebene Identität ablegen und eine neue einheitliche und positive, da erworbene, eigene Identität ausbilden.

Andererseits besteht durch Zweifel und Unsicherheit die Konfrontation mit einer gerade unfertigen, nicht gefestigten Identität, mit völliger Unsicherheit demgegenüber, wie sich das eigene Selbst zusammenfügt. Für diesen Aspekt findet sich als Symbol ein Pappkarton, ein ganz normaler Verpackungskarton von Speiseöl, den Laupeyßer zuerst dafür verwendet, alle seine Tonbänder und Aufzeichnungen zu verstauen und später gezielt Aphorismen und Erzählschnipsel sowie `Belege`seiner Bekanntschaften und Imaginationen darin und dafür zu sammeln. Der Pappkarton nimmt alles auf, wird durch die Sammlung aller nur erdenklichen Dokumente und Gegenstände nach dem Prinzip der Näherungen eine Näherung an das, was Laupeyßer ausmacht. So wird er auch zur Belastung, die bildlich verdeutlicht wird:

Worum es wirklich geht allerdings, das ist, das Prinzip Laupeyßer in einen Pappkarton zu packen,

den er selbst einschlagen wird in braunsteifes Paketpapier. [...] Und ermessen Sie Ihr Erstaunen, wenn es klingelt bei Ihnen und 2 - in Worten: zwei - Briefträger erscheinen, weil einer allein es nicht tragen könnte, das riesige Dings, die ungeformte Wundertüte der Identität, die Sie irritiert öffnen jetzt und mit Vorfreude. (VG, 213)

Auffällig ist die explizite Gleichsetzung des Pappkartons mit Identität, wodurch die Belastung der alten Identität anschaulich gemacht wird. Dadurch, dass das Bild wörtlich genommen und fortgeführt wird, indem der Pappkarton einfach mit der Post verschickt wird, wird mit der Frage nach dem Ablegen einer Identität gespielt. Wird einerseits nahegelegt, dass solches nicht möglich ist, da es natürlich nicht einfach so 'per Post ‘ geht, wird andererseits insinuiert, dass es vielleicht doch eine Möglichkeit gibt, die dann auch durch das Wegfahren und Namenändern verfolgt wird. Die metaphorische Umschreibung als "ungeformte Wundertüte« betont offensichtlich die Kennzeichen von Durcheinander und überraschendem Inhalt; in der Übertragung auf die Identität weist dies auf die Vorstellung vom Ich als »Konstruktion einander schlicht widersprechender Präformationen « $(V G, 289)$ hin. Auffällig ist allerdings die Charakterisierung durch das Adjektiv »ungeformt«, das die Identitätsvorstellung recht treffend bezeichnet. Zwar fühlt sich der Protagonist (Laupeyßer und der >Autor-Erzähler werden hier einmal zusammengefasst) durch die ererbte Last deutscher Schuld mit einer vorgeformten und damit starren Identität konfrontiert; doch bemerkt er, dass dies nur ein Aspekt ist, dass seine eigene Identität aus der Innenperspektive heraus gesehen weder von ihm gestaltet noch von ihm erkannt ist, dass sie eben $»$ ungeformt « ist. Von ihm kann sie nur in Fragmenten oder, wie mehrfach formuliert wird, in »Schnipseln « beschrieben und damit erkannt bzw. erkennbar gemacht werden.

Die Implikationen der eben unterschlagenen Anrede an den Leser werden später noch einmal aufgenommen, indem der Pappkarton mit einem (jeden) Buch verglichen wird (vgl. VG, 278f.). Auf diesen zweiten Wert, den das Symbol Pappkarton neben der Gleichsetzung mit der alten Identität erhält, soll später noch genauer eingegangen werden (siehe unten, Abschnitt 2.4 auf Seite 115). 
Die ambivalente Vorstellung von Identität, die sich in der Belastung durch eine vorgeformte und in der Konfrontation mit der ungeformten eigenen Identität zeigt, ist der Ausgangspunkt für einen Erkenntnisprozess. Dabei wird die Frage virulent, wer diesen Prozess durchläuft, ob dieser Laupeyßer, Falbin oder den >Autor`-Erzähler betrifft. Es stellt sich also die Frage nach Identität oder Autonomie der einzelnen Protagonisten. Bisher waren der Übersichtlichkeit halber und auch aufgrund der den überwiegenden Teil des Buches eingehaltenen Trennung der Erzählebenen die drei Protagonisten als drei verschiedene Personen bzw. Figuren dargestellt worden. Von vornherein ist eine große Übereinstimmung zwischen den Figuren jedoch klar. Begründet ist diese darin, dass Falbin von Laupeyßer und dieser wiederum vom >Autor-Erzähler erfunden wird. Beide Schöpfer schaffen sich ihre Figur `nach ihrem Ebenbild «, da sie von dem ausgehen, was sie kennen, wie gleich im ersten Absatz festgestellt wird. Später wird durch den >Autor`-Erzähler mehrfach eine Form von Identität zwischen den drei Protagonisten angedeutet und thematisiert; außerdem finden sich etliche versteckte bzw. implizite Hinweise auf eine solche.

Es kann also davon ausgegangen werden, dass Falbin und Laupeyßer Teilaspekte des >Autor<-Erzählers darstellen und dadurch zwar nicht mit ihm identisch (im Sinne von austauschbar oder synonym) sind, aber ihm angehören und Teile seiner Persönlichkeit bilden. Dies ist nur sehr begrenzt als Teilpersönlichkeiten im Sinne des bereits genannten Beispiels Dr Jekyll und Mr Hyde bei Robert Louis Stevenson vorzustellen. Sind dort Jekyll und Hyde die Personifikation der guten und der bösen Seite einer Person, so handelt es sich hier um imaginierte Figuren, die anstatt eines anderen auf dessen Geheiß bestimmte Ereignisse durchleben und dabei in einem sehr weiten Sinn ein Prinzip veranschaulichen. Dies wird sehr deutlich im obigen Pappkarton-Zitat angesprochen, wo davon die Rede ist, das »Prinzip Laupeyßer in einen Pappkarton zu packen« (VG, 213).

In Zusammenfassung der Ausführungen der vorangegangenen Kapitel und ihrer Reduzierung bzw. Zuspitzung auf eine Art von abstraktem Prinzip lassen sich die Entwicklungen der einzelnen Protagonisten wie folgt beschreiben: Laupeyßer macht eine Entwicklung durch, die, ausgehend von der Frage, welches Maß an Gewaltbereitschaft und Sadismus auch in ihm steckt, ihn immer weiter auf einen animalischen und instinkthaften Kern seiner Identität reduzieren. Falbin wird durch Einwirkung von außen (durch den Willen seines `Schöpfers $`$ ) mit der Fremdbestimmtheit von Identität konfrontiert, die auch sein bisheriges Leben prägt, das von Unsicherheit und Abwehrmechanismen bestimmt ist. Durch eine bewusste Entwicklung zu innerer Härte und zu von klassischen Geschlechterstereotypen geprägter `Männlichkeit` versucht er, Autonomie zu erreichen. Bezüglich des oben genannten Erkenntnisprozesses bedeutet die Annahme dieser bestimmten Form von Zusammengehörigkeit oder Identität, dass sich ein solcher durch das Durchspielen von Möglichkeiten über die Erzählebenen hinweg vollzieht. Auch Falbin und Laupeyßer tragen zu diesem bei bzw. sind ein Teil von ihm. Die Erkenntnis akkumuliert sich dann aber im `Autor<-Erzähler und wird von ihm in Ansätzen formuliert. Durch die Abfahrt an ihrer Stelle wird er als derjenige präsentiert, der die Erkenntnis verwirklicht und umsetzt, zu der sie zu Teilen gekommen sind. 
Auf den Punkt gebracht führt der Erkenntnisprozess zu einem Aufgeben der Vorstellung einer festen, einheitlichen Identität, die zumindest implizit am Anfang der Überlegungen stand. ${ }^{76}$ Ausgelöst wird dies durch die Erkenntnis der zeitlichen Dimension von Identität und der durch die Frage »Was bleibt? « angestoßenen Aufgabe der Vorstellung von Autonomie.

Die Erkenntnis der zeitlichen Dimension von Identität wird bei Laupeyßer wieder durch die Schuldthematik angestoßen. Es stellt sich ihm die Frage, ob ein Achtzigjähriger für »die Geschichte gewordenen Morde bestraft« werden könne: »Habe denn er sie begangen, sei das heutige Ich nicht längst vom damaligen Er abgenabelt?« ( $V G$, 136) Dies wird jedoch nicht als konkrete juristische Fragestellung behandelt, vielmehr ist es in ironisch-zynisch formulierte allgemeine Überlegungen zum gesellschaftlichen Umgang mit der deutschen Geschichte eingebettet. Auch die eigene Erfahrung, sich selbst von vor zwei Jahren nicht mehr »vergegenwärtigen« zu können, spielt hier eine Rolle. Die Erfahrung, die er hier mit seinem Ich macht, entspricht dem Kontinuitätsproblem sozialwissenschaftlicher Identitätstheorie: der Betrachtung der eigenen Identität in diachroner Perspektive und der Frage nach der Stabilität der eigenen Identitätselemente. Verglichen wird sie mit der Erkenntnis der eigentlich nicht vorhandenen Gegenwart. So wie die Gegenwart nur aus einem Moment besteht, der sich sofort in Vergangenheit wandelt, so kann er auch zum Ich nur einen Moment lang einen Bezug herstellen, danach wandelt es sich in »ein Stückchen geschichtlichen Ers«. Dadurch bleibt dann »kein Ich» $(V G, 136)$ mehr übrig. Diese Überlegung ist der Auslöser, die Vorstellung von einem einheitlichen festen Ich und einer durchgängigen Identität zu verabschieden. Später wird sie noch einmal aufgegriffen und explizit erweitert auf die gesamte Lebensspanne: »Weil Identität nicht nahtlos sich weiterzieht, nicht einmal innerhalb eines Lebens, und weil sie, wo sie's doch tut, ungreifbar ist." $(V G, 275)$ Die Vorstellung, nicht mit einer früheren Form seiner selbst übereinzustimmen und die darin enthaltene Distanzierung finden sich auch später, als der >Autor`-Erzähler bereits in Frankfurt ist. Zweimal geht es um die Kontaktaufnahme zwischen ihm und Agnes. Beim ersten Mal überlegt er, sie anzurufen, doch verwirft er es wieder, da er so tun müsste, als wäre er "jemand ganz anderes, jemand, von dem [er] kein Bewußtsein mehr habe " $(V G, 151)$. Auch hier geht es wieder um die fehlende Übereinstimmung mit einem früheren Selbst; diesmal ist es Laupeyßer, der als eine frühere Gestalt des >Autor<-Erzählers das »Stückchen geschichtlichen Ers« darstellt. Als ihn dann Agnes tatsächlich auch unter dem neuen Namen aufspürt und anruft, bemerkt er, dass auch sie reine Andere geworden ist, nicht mehr die, die er kannte. Gleichzeitig spricht sie ihn mit dem alten Namen an, tut mithin so, als wäre er noch der alte und geht ganz alltagspraktisch von einer beständigen Identität aus. Sie geht seinen Weg, die theoretische Überlegung in der Praxis zu leben, nicht mit.

Die Frage »Was bleibt? « ist eigentlicher Zielpunkt des laupeyßerschen Entschlusses zum von ihm so genannten »Abstieg «, die die Suche nach sich selbst bezeichnet. Bei ihm ganz wörtlich genommen durch das Abstoßen fast allen Besitzes und die weitgehende Aufgabe sozialen Kontaktes ist es die Frage nach der Herstellung einer individuellen Identität (und damit dem Individualitätsproblem zuzuordnen). Vom 
>Autor<-Erzähler wird die Frage konkreter definiert als das was bleibt, wenn »Glauben, Moral, Illusionen und Erinnerungen « (VG, 264) >ausgeschaltet` wären. Im Grunde verbirgt sich also hinter dieser Frage die nach der Autonomie; was bleiben würde, wären die von außen kommenden Einflüsse nicht vorhanden. Wenig später wird diese Frage damit beantwortet, dass »das Gewimmer « $(V G, 270)$ bliebe. Dieses ist an anderer Stelle mit der Reduzierung des Menschen auf Angst und tierische Rudimente verknüpft (vgl. $V G, 44)$. Nimmt man diese Andeutungen nun zusammen, ergibt sich ein Bild vom Menschen, das wenig durch sich selbst bestimmt ist. Durch Erziehung und Sozialisation sowie durch sozialen Kontakt wird er bestimmt. Wenn dieses fortgenommen wird, bleiben Leere und Angst.

Daran schließt sich die Aufgabe der Vorstellung eines autonomen Ichs an. Während Laupeyßer anfangs noch auf der Suche nach einem autonomen Ich im Sinne einer Loslösung von ererbten Präformationen ist und Falbin nichts stärker anstrebt als soziale Autonomie, ändert sich dies beim >Autor «-Erzähler. Auch er beschreibt sich als nach Einheit strebend, zu der ihm die Geliebte B. verhelfen soll. ${ }^{77}$ Doch ist es gerade die Beziehung zu B. bzw. das Ideal- oder Wunschbild, das er von dieser Beziehung hat, das ihn seinen Wunsch nach Autonomie aufgeben lässt. Dieser fällt zusammen mit der Sehnsucht nach Verständigung und Verständnis, nach Annäherung und Überbrückung der Fremdheit und Laupeyßers `Lösung` durch Herstellung von Nähe durch Körperlichkeit und Beischlaf. Erst durch die völlige Annahme des Anderen in der Beziehung könne wirkliche Nähe erreicht werden. Daraus sieht er dann etwas Neues entstehen:

Erst dann höbe sich die permanente Abgrenzung gegen den anderen auf, den ich vielmehr unter Aufgabe der je Illusion gewesenen Autonomie mit mir verwachsen lassen will und woraus ein Drittes entstünde, das weder ich ist noch der andere, sondern etwas qualitativ Neues, ein unwägbares und erfülltes Geschöpf. (VG, 295f.)

Erstaunlicherweise soll das Neue an dieser Stelle tatsächlich durch ein >Verwachsen mit der (auf seiner Erzählebene) realen Person B. entstehen und nicht mit einer seiner imaginierten Figuren. Durch den Zusatz, dass dies aber nur »augenblicksweise" $\mathrm{zu}$ erreichen sein werde, wird die Bildhaftigkeit der Formulierung betont. Seltsam darin ist allerdings die Bezeichnung als "Geschöpf «, was eine Personalität impliziert, deren Sinn nicht recht klar wird, zumal eine solche Formulierung auch nicht wieder aufgenommen wird. An anderen Stellen, wo die Formulierung eines »Dritten« wieder zu finden ist, wird eher ein Zustand impliziert als etwas Personales, außerdem ist niemand anderes (wie hier B.) involviert (vgl. $V G, 289$ ). So ist es wohl als poetisierendes Bild für die Liebe zu nehmen, so wie es Laupeyßer auch von Axel Schulze vorgeworfen wird, der darin den $»$ Versuch [sieht], die alte romantische Liebe geradezu aufs Kosmische auszuweiten « $(V G, 296)$. Laupeyßer erhofft sich durch die Liebe Erlösung von der Auflösung seines Selbsts und dessen (Wieder-)Zusammenfügen. Doch scheitert dies an der Empirie, so seine Terminologie, daran, dass die reale B.

77 Vgl. VG, 227: »Und doch sollte gerade sie [B.] mir das Ende der Auflösung ermöglichen, mich wieder zusammenfügen.« 
nicht `versteht`, seine Vorstellungen nicht mitumsetzen will und kann. Sie verlässt ihn und überlässt ihn damit seinen Fiktionen.

Da dies das Scheitern seines Ausbruchsversuchs bedeutet, reagiert der `Autor<-Erzähler mit einem Selbstmordversuch, indem er mit einem Auto mehrfach gegen eine Wand fährt. Er überlebt jedoch und wird in eine psychiatrische Klinik zur Begutachtung eingeliefert. Wieder allein und damit auf sich zurückgeworfen, entwickelt er die Vorstellung einer neuen Umgangsweise mit Identität:

Und ich schreibe das heute, gerade heute, im Verlust und mal wieder allein, gescheitert, voll falschen Benehmens, voller Ansprüche, takt- und taktiklos, schreibe: Gerade darum gilt es, den Versuch zu wagen einer Identität, die zutiefst ungesichert ist, für welche es keinen Beleg gibt; eine solche steht mir im Kopf, die sich noch und gerade in ihrer Auflösung findet und der die Flüchtigkeit zum Konstituens wird von Kontinuität. $(V G, 325)$

Damit hat er sich vollständig von der Vorstellung verabschiedet, dass es eine beständige Identität gibt. Womit er bislang immer schon konfrontiert, was er jedoch nicht zu akzeptieren bereit war, ergreift er nun gerade als Chance. Die Ungesichertheit und Flüchtigkeit von Identität sieht er als ihr Merkmal an, das auf paradoxe Weise eine Kontinuität schafft. Seine Aufgabe ist es, sie »eigenständig auszufüllen[] (VG, 322). Wie dies jedoch konkret auszusehen hat, wird wiederum nicht ausgeführt. Es handelt sich aber um eine Wiederaufnahme der Fiktionen, die diesmal eindeutig auf die schriftstellerische Tätigkeit verweisen, folgt doch im Anschluss direkt eine Einladung an den Leser:

Also lade ich Sie ein - ausgehend von meiner ungesicherten, flüchtigen Position-, lade ich Sie zu einer Reise ein, die nie begann und von welcher unsicher ist, ob sie je und wer sie dann beginnen wird. Laupeyßer? Falbin? Nein, schlagen Sie sich das aus dem Kopf, die können gar nicht mehr abfahren. Es wird ein anderer sein, ein ganz anderer, der die Nacht verbringen wird mit Anna im Hotel, (VG, 325)

Diese Reise findet sich dann im Folgeroman Wolpertinger beschrieben, auf dessen Figuren und Schauplätze in Die Verwirrung des Gemüts mehrfach hingewiesen wird. 


\section{Die Realität als »Zwischenwelt«}

\section{1 »Was ist das: die Realität? « ${ }^{1}$ : Zu den Begriffen $>$ Realität‘ und `Wirklichkeits}

Gerade wenn von Literatur die Rede ist, die unter Schlagworten wie Metafiktion, Postmoderne oder magischer Realismus subsumiert wird, um nur einige der in den 1980er Jahren sich in Hochkonjunktur befindlichen zu nennen, wird oft die Formulierung vom »Spiel mit Realität und Fiktion« gebraucht, vom »Verschwimmen« oder gar der »Auflösung « der Grenzen zwischen Realität und Fiktion. Auch in Bezug auf Alban Nikolai Herbst ist dies öfter der Fall. Es stellt sich jedoch die Frage, ob die Auflösung der Grenze zwischen Realität und Fiktion nicht allzu vorschnell proklamiert wird, ob in diesen Formulierungen nicht nur eine Unschärfe in der Begrifflichkeit bzw. eine Vermengung der Fiktionsebenen vorliegt. Dahinter verbirgt sich die weitreichende ontologische Frage, ob eine Auflösung dieser Grenze überhaupt möglich ist oder aber, ob es sich immer um ein metaphorisches Sprechen handelt.

An dieser Stelle geht es jedoch nicht um die sekundäre Zuschreibung einer solchen Auflösung, sondern um ihre Behauptung im Text. Wenn Laupeyßer in $V G$ von seinen Versuchen spricht, »Wirklichkeit herzustellen « (VG 17), oder eine »Synthese gewissermaßen aus Fiktion und Empirie $(V G, 289)$ erreicht werden soll, wird deutlich, dass eine eindeutige Grenze zwischen Realität und Fiktion zumindest infrage gestellt wird. Dabei ist die erzählte Welt nicht offensichtlich >übernatürlich`, insofern womöglich die physikalischen Gesetze der uns bekannten Welt außer Kraft gesetzt wären oder in der es normal wäre, dass ausgedachte Figuren sich gleich in der Realität wiederfänden. Die Hauptfiguren der drei Erzählebenen, der >Autor`-Erzähler, Laupeyßer und Falbin bewegen sich zumindest bis zur narrativen Metalepse in Welten, die unserer Alltagswirklichkeit ähneln. Wenn also Laupeyßer mit Agnes redet, so ist er zunächst als ein junger Mann Anfang der 1980er Jahre in der alten BRD zu sehen, also auch mit den politischen und mentalen Implikationen dieser Zeit, der einer Freundin davon erzählt, was er sich für Geschichten ausdenkt und vorstellt. Für ihn und vor allem für seine Überlegungen, die ihn selbst und nicht seine Fiktionen mit Falbin betreffen, gelten also zunächst die Gesetze der uns bekannten Alltagswirklichkeit. Gleiches gilt erst einmal für Falbin. In der modernen Fiktionstheorie wird dies als "principle of minimal departure « (oder >Realitätsprinzip «) bezeichnet, das besagt, dass »eine fiktive Welt so nah wie möglich an der realen Welt zu konstruieren ist $\aleph^{2}$ und dass deren Gesetze

$1 V G, 146$

2 Zipfel: Fiktion, Fiktivität, Fiktionalität, 85; vgl. dazu erstmals Marie-Laure Ryan: »Fiction, NonFactuals, and the Principle of Minimal Departure«, in: Poetics 9 (1980), 403-422, besonders 406f., sowie Jannidis: Figur und Person, 70, und Remigius Bunia: Faltungen. Fiktion, Erzählen, Medien, Berlin 2007, 88-93. 
gelten, solange nichts Gegenteiliges aus dem Text ersichtlich ist. Obwohl wir als Leser also wissen, dass Laupeyßer eine erfundene Figur ist, können wir annehmen, dass für ihn in seiner Welt (auf seiner Erzählebene also) die gleichen Vorstellungen von Realität und Fiktion gelten wie in der unsrigen. Meines Erachtens ist daher davon auszugehen, dass die Infragestellung der Unterscheidung zwischen Realität und Fiktion nur über einen speziellen Realitätsbegriff und damit das Zugrundelegen einer nicht mit dem Alltagsverständnis übereinstimmenden Auffassung von Realität möglich ist. Um zu verstehen, was das bedeutet, und sich damit den eben aufgeworfenen Fragen zu nähern, ist eine genauere Untersuchung der verwendeten Begriffe vonnöten. Die diesbezüglich zentralen Begriffe in $V G$, die nebeneinander verwendet werden und somit voneinander abzugrenzen sind, sind $>$ Realität $\iota$, Wirklichkeit $\iota$ und $>$ Empirie Außerdem ist auch der Begriff der `Wahrheit` von Bedeutung, auch wenn er nicht gleichermaßen im Vordergrund steht.

\section{2 »tatsächlich und wirklich $\aleph^{3}$ : Das Begriffsfeld in VG}

In der Einleitung wurde das Begriffsfeld `Realität` und `Wirklichkeit $<$ bereits mit Bezug auf $V G$ allgemein eingeführt. Dort wurde bereits klar, dass die Begriffe in $V G$ nicht klar definiert, auf wenige Stellen beschränkt und deshalb undifferenziert ist. Daher soll nun vor dem Hintergrund der Begriffsklärung ein genauerer Blick auf

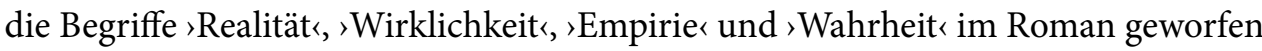
werden.

\subsubsection{Realität und Wirklichkeit}

Bei der Einführung der Unterscheidung zwischen $>$ Realität $\triangleleft$ und $>$ Wirklichkeit $`$ in der Einleitung - kurz gefasst: $>$ Realität $<$ in der Bedeutung der unabhängig vom Menschen bestehenden Dingwelt, ,Wirklichkeit ‘ als das auf das menschliche Bewusstsein bezogene >Wirkende - wurde bereits auf zwei Zitate hingewiesen, in denen auch in VG die Unterscheidung deutlich wird:

Ist doch bezeichnend, daß das sehr viel treffendere Wort WIRKLICHKEIT durch jenen Begriff [d. i. Realität] geradezu unbemerkt ersetzt worden ist. (VG, 146)

Dabei wird zwar wenig darüber ausgesagt, auf welche Weise eine Unterscheidung vorgenommen werden kann, jedoch erweist sich die oben herausgearbeitete Begriffsdifferenzierung als passend bzw. anwendbar. Wenn Laupeyßer in seiner leergeräumten Wohnung `haust‘, seine Aktivitäten in die Nacht verlagert, aber nicht zur Ruhe kommt, dann ist ihm - so das zweite Zitat -

»[h]öchstens tagsüber [...] der Schlaf möglich, wenn die Helligkeit, die in diesen gleichsam Rohbau fiel, Laupeyßer davon abhielt, die Realität für Wirklichkeit zu halten« $(V G, 137)$.

Umformuliert besagt dies, dass Laupeyßer nur schlafen kann, wenn er die Realität nicht für (seine) Wirklichkeit hält, wenn die Realität als unabhängig von ihm und

$3 V G, 70$ 
unveränderbar bestehend keine direkte Bedeutung und Wirkung für ihn zu haben scheint. Ansonsten hält er es auch nicht in seiner Wohnung aus und geht nachts zum Bahnhof, der für ihn zu diesem Zeitpunkt bereits die eigentlich für Falbin bestehende beruhigende Wirkung hat. Warum jedoch gerade die Helligkeit eine solche gedankliche Verbindung verhindert, wird in dieser kryptisch-verkürzten Passage nicht klar. In der kurz darauf folgenden zuerst zitierten Stelle wird direkt auf die alltagssprachlich gebräuchliche Synonymität der Begriffe hingewiesen bzw. auf die Ersetzung des Wortes `Wirklichkeit $\triangleleft$ durch $>$ Realität $`$ Implizit bedeutet dies, dass eine Unterscheidung besteht und dass Laupeyßer den Begriff > Wirklichkeit ‘ bevorzugen würde. Dass es >treffender` wäre, ist einer der wenigen Hinweise auf den etymologischen Bezug des Wortes auf Wirkung, auf die oben genannte Definition von `Wirklichkeit $>$ als das, was wirkt.

Dass dem Erzähler die Möglichkeit einer Unterscheidung bewusst ist, bedeutet nicht, dass sie auch konsequent thematisiert oder praktiziert wird. Die Realität scheint zumindest für Laupeyßer etwas zu sein, was als nicht veränderbare Ding-Welt aufzufassen ist. Als solche könnte sie auch Sicherheit geben, als unveränderliches Bollwerk in seiner verunsicherten Welt. Nachdem er das Studium abgebrochen und den Job im Büro angenommen hat, sich in einer Selbstfindungsphase sieht, sehnt er sich gerade nach solcher Art von Sicherheit:

[...] aber gerade, wonach ihm am meisten verlangte : die Realität, - gerade die gab es hier nicht.

Realität: zupackend, so etwa hatte er gedacht. Irrte sich. Sie wäre klotzig, dachte er, stünde einfach da, nicht wegzudisputieren. $(V G, 194)$

Auch dass er fragt, ob das Weinen der Opfer die Realität sei (vgl. VG, 147), geht in die gleiche Richtung. Natürlich sehnt er sich in diesem Fall nicht danach, aber auch das Leid der Opfer (es ist davon auszugehen, dass Holocaust-Opfer gemeint sind) gehört der >nicht wegzudisputierenden « Realität an, der »hautnahe[n] Realität « (VG, 11), die für Agnes beispielsweise darin besteht, dass ihr kleiner Sohn schreit und ihre Hilfe benötigt. Diese Beispiele, so heterogen sie zu sein scheinen, sind Ereignisse oder Lebensumstände, mit denen das Individuum konfrontiert ist, die zu Handlung zwingen und reine Reflexion nicht zulassen. Von einer solchen Art von Realität verspricht sich Laupeyßer Sicherheit, er sucht sie in der ihm ansonsten banal scheinenden Bürotätigkeit, jedoch findet er sie auch dort nicht. Beziehungsweise wirkt sie nicht, wie der `Autor`-Erzähler »ohne jeden Zynismus« kommentiert. Den »Hungernden der Dritten Welt« gebe die Arbeit, welche sie auch sei, Brot (d. h. ernähre sie), wie in plakativen Worten beschrieben wird, und mache damit die Realität erträglich; ihm selbst, dem Satten, »verlottert die Realität « jedoch am Arbeitsplatz, er ist nicht mit der Ding-Realität konfrontiert, die körperliches Leid erzeugt und Handlungen erzwingt, sondern ist auf Sinnsuche in seiner eigenen Wirklichkeit. Für den >Autor`-Erzähler wird die Realität daher erst »habhaft« $(V G, 195)$, als er sie von sich weist und das heißt für ihn, sie mit Fiktionen füllt.

Handke und der Elfenturm In ein poetisches Bild gefasst wird dies durch den knappen Bezug auf Peter Handkes Aufsatz »Ich bin ein Bewohner des Elfenbeinturms» 
(1967), der ohne weitere Verbindung oder expliziten Kommentar auf den Satz folgt, dass er die Realität von sich weise.

So wurde Realität mir habhaft erst da, wo ich sie scheinbar von mir wies, mit weit ausgestreckten Armen und die Finger im Zeichen gegen den Bösen Blick, den sie hat. Die Wirklichkeit des Elfenbeinturms. Ein Handke-Titel. Ich machte draus: Die Wirklichkeit des Elfenturms. (VG, 195)

Die»Wirklichkeit des Elfenbeinturms« kommt als Begriff in Handkes Aufsatz so nicht vor. Zwar geht es um Wirklichkeiten, um die Beziehung von Literatur zur Wirklichkeit und er bezeichnet sich, wie schon im Titel deutlich platziert, als "Bewohner des Elfenbeinturms«, d. h. »als `Formalisten «, als > Ästheten« «, der nach neuen Formen der Darstellung sucht und die alten, überkommenen ablehnt. ${ }^{4}$ Die Kürze der Anspielung in $V G$ ist jedoch wieder einmal nicht eindeutig und lässt daher vielfältige Auslegungen zu. Handke geht es als Autor (nicht als Leser, und als Autor ist er der Elfenbeinturmbewohner) nicht um die "wirkliche Wirklichkeit « ${ }^{5}$, sondern darum, "meine Wirklichkeit zu zeigen ${ }^{6}$. Die individuelle Sicht auf die Realität, als eigene Wirklichkeit bezeichnet, könnte damit am ehesten als die Wirklichkeit des Elfenbeinturms bestimmt werden. Handke geht es aber vornehmlich um zwei Punkte: zum einen ist sein Ziel (sowohl beim Lesen als auch beim Schreiben), sich über sich selbst klarer und allgemein aufmerksam zu werden, zum anderen hält er dafür die Fiktion, das Erzählen einer erfundenen Geschichte für unnötig, für eine überkommene, nicht mehr verwendbare Methode.

Jede Geschichte lenkt mich von meiner wirklichen Geschichte ab, sie läßt mich durch die Fiktion mich selber vergessen, sie läßt mich meine Situation vergessen, sie macht mich weltvergessen.?

Der erste Punkt ist auch zentrales Thema in VG (durch den Versuch, sich selbst zu erkennen), im zweiten stimmen Laupeyßer bzw. der >Autor`-Erzähler zunächst mit Handke nicht überein. Sie wollen die Fiktion gerade als Mittel einsetzen, um sich und der Geschichte (im Sinne der historischen Geschichte, nicht der `story`) nahe zu kommen, sich selbst zu verstehen. Doch sonderlich weit voneinander entfernt sind die Positionen nicht. Zwar lehnt Handke die Fiktion als »Mittel der Wirklichkeitsdarstellung « ${ }^{8}$ ab bzw. hält sie für >unnötigく, doch passen seine Zielsetzungen, »die Mitteilung von Erfahrungen, sprachlichen und nicht sprachlichen « ${ }^{9}$ und die Suche nach Selbsterkenntnis auch zum >Autor-Erzähler; lediglich die Wahl des Mittels bzw. der $>$ Methode $\triangleleft$ scheint eine andere. Und so bleibt offen, ob der `Elfenturm $\triangleleft$, den der >Autor`-Erzähler in $V G$ aus Handkes Elfenbeinturm macht, diesem entgegengesetzt ist

4 Siehe Peter Handke: »Ich bin ein Bewohner des Elfenbeinturms « [1967], in: Ders.: Ich bin ein Bewohner des Elfenbeinturms, Frankfurt am Main 1972, 19-28, hier: 26; diesen neuen Formen ist »die Fiktion als Mittel der Wirklichkeitsdarstellung« (ebd.) entgegengesetzt.

5 Ebd., 19.

6 Ebd., 25.

7 Ebd., 23.

8 Ebd., 26.

9 Ebd., 24. 
oder als Fortsetzung oder gar Steigerung zu sehen ist; die Formulierung "Ich machte draus: « ist nicht wertend. Festzuhalten ist, dass das Wort `Elfenturm ‘ - und sei es möglicherweise neben einem ungenauem Bezug auf Handke nur ein fast schon kalauerndes Spiel mit Worten - auf die Bedeutung von Phantasie, Phantastik und Fiktion hindeutet und nicht zuletzt eine weitere Vorausdeutung auf Wolpertinger ist, wo die Elfen eine wichtige Rolle spielen. Die zweite Erwähnung vom »Turm der Elfen« (VG, 255) enthält dann auch keinen direkten Hinweis auf Handke mehr, stellt aber eine direkte Verbindung zur immer nur erwähnten Figur Anna aus Wolpertinger her.

Durch das Handke-Zitat werden die Begriffe >Realität und >Wirklichkeit in Bezug auf diesen Umstand unkommentiert nebeneinander verwendet. Die Passage kann so verstanden werden, dass die Realität erst `habhaft ` wird, wenn sie zur Wirklichkeit, genauer noch zur »Wirklichkeit des Elfenturms« wird, also durch Fiktion verändert, zu seiner (Laupeyßers oder des `Autor`-Erzählers) Wirklichkeit wird. Ob tatsächlich die Realität (und eben nicht die Wirklichkeit) habhaft wird, ist fraglich, denn, wie der >Autor`-Erzähler an anderer Stelle zugibt: »Natürlich bleibt wahr, daß man von gedachtem Brot nicht satt wird. $(V G, 314)$ Doch scheint es ihm eben nicht um die Realität zu gehen.

Auch der Begriff > Wirklichkeit ` wird an einigen Stellen implizit genauer charakterisiert. Gegenüber Schulze stellt Laupeyßer fest: »Wirklichkeit, das ist doch subjektiv, rein subjektiv." $(V G, 167)$ Auch wenn er die Vehemenz dieser Feststellung durch seine nachgesetzte Frage »Meinen Sie nicht?» wieder etwas relativiert, so ist doch seine Überlegung deutlich; die Wirklichkeit wird zu sseiner 'Wirklichkeit, zur subjektiven, individuellen, charakterisiert durch die mitgedachte Verbindung mit dem Possessivpronomen..$^{10}$ In eine ähnliche Richtung geht die Auffassung von Wirklichkeit, wenn diese als »eine Collage von Pflanzen, Kalk und Larmoyanz« $(V G, 257)$ beschrieben wird. Die Aufzählung bezieht sich dabei auf das, was in der Wohnung Laupeyßers übrig geblieben ist und damit seine Wirklichkeit darstellt. Der Zusatz »Nichtsdestotrotz hatte sie Auswirkungen «, der sich auf das dann folgende Zusammentreffen von Laupeyßer und Falbin (und dann auch des `Autor«-Erzählers) bezieht, ist der deutlichste Hinweis im Text auf die oben genannte, außertextlich gestützte Definition von Wirklichkeit als das, was wirkt. An dieser Stelle zeigt sich auch wieder die Schwierigkeit, die Begriffe klar zu unterscheiden. Im vorhergehenden Satz -

Ulf Laupeyßer ist ebenso ungreifbar wie die Realität, von der nicht gesagt werden kann, Falbin umgriffe auch nur eines ihrer Teilchen.

- findet sich das Wort `Realität`, während dann >Wirklichkeit`>definiert` wird, als wäre es eine Erklärung für den gerade genutzten Begriff `Realität ‘. Der Kontext dieser Passage thematisiert wieder einmal auf metafiktionale Weise explizit die Existenz bzw. Fiktionalität von Laupeyßer und - im gerade zitierten Satz - damit auch die von Falbin. Während erst Laupeyßer als autodiegetischer Erzähler spricht, wechselt die

10 Hans Blumenberg weist darauf hin, dass die »Verbindung des Possessivpronomens mit dem Ausdruck Wirklichkeit [...] für diesen Begriff charakteristisch« ist, siehe Hans Blumenberg: »Wirklichkeitsbegriff und Möglichkeit des Romans« [1963/1969], in: Hans Robert Jauß (Hg.): Nachahmung und Illusion, München 1969, 9-27, hier: 13. 
Stimme zuerst in ein nicht eindeutig bestimmbares Durcheinander, dann zum heterodiegetischen Erzähler. Angesichts anderer Ungenauigkeiten in der Unterscheidung von Realität und Wirklichkeit ist jedoch auch hier mangels genauerer Ausführungen oder auch nur Andeutungen nicht von einer intentionalen Differenzierung auszugehen, vielmehr ist die Passage als Überleitung zur 'großen`Metalepse zu sehen, die am Ende des Abschnitts als Klimax präsentiert wird.

An dieser Stelle sind noch zwei weitere Passagen zu benennen, die zusätzliche Aspekte der Vorstellung von Wirklichkeit hervorbringen.

Die geschickteste Art, jemanden zu lehren, ist, ihn zu täuschen, indem man mit offenen Karten spielt (Pappkarton), und das Metaphysische aller Kunst, die unmittelbare Wirklichkeit in die wirklichere, nämlich die mittelbare zu transponieren, um in dieser die Strukturen jener in deutliche Kristalle zu frieren. Der Platoniker nennt letztere Idee. Ich ziehe Fiktion vor, weil diese nie sist, nur swird،. (VG, 283)

Zum einen ist hier die Rede von verschiedenen `Graden` von Wirklichkeit. Benannt sind diese als die »unmittelbare Wirklichkeit « und »die wirklichere, nämlich die mittelbare«. Kombiniert damit wird ein Bezug auf Platons Ideenlehre, die die zwei Wirklichkeitsebenen nahelegt. Die »unmittelbare Wirklichkeit« korrespondiert hier wieder mit der eigentlichen $>$ Realität $\triangleleft$ Interessant ist, dass hier in Übereinstimmung mit Platon bzw. dem späteren Platonismus, der die Welt der Ideen als die wahre Welt ansieht, die "Entwirklichung der hiesigen Wirklichkeit ${ }^{11}$ konstatiert wird und der Welt der Ideen bzw., in der Terminologie des >Autor -Erzählers, der Fiktion die eigentliche Wirklichkeit und Wirksamkeit zugeschrieben wird.

Zum anderen gibt es noch eine explizit so benannte »Definition « von `Realität $\triangleleft$, die weit von einer wissenschaftlichen Definition entfernt ist und wieder ein poetisches Bild darstellt, das verschiedene Bezüge aufmacht:

\section{Da muß sich einer also so erfinden, daß er schließlich empirisch als das Erfundene in Erscheinung tritt, bzw. tritt ein Drittes auf, die Synthese gewissermaßen aus Fiktion und Empirie. Womit denn meine Definition von Realität erreicht wäre. (VG, 289)}

An dieser Stelle sei lediglich darauf hingewiesen, dass wie im vorigen Zitat auch hier die Fiktion aufgewertet wird. Zu einem einfachen Verständnis trägt nicht gerade bei, dass die Unterscheidung zwischen Realität und Wirklichkeit wieder nicht eingehalten zu sein scheint. Da ein »Wandel im Sein der Dinge selber ${ }^{12}$ nicht möglich ist, kann eigentlich nur die Wirklichkeit gemeint sein, die so allerdings als konstruiert und damit veränderbar gekennzeichnet wird. Die Implikationen der Bezeichnung der Realität als "Zwischenwelt, die jenseits des Bahnhofs beginnt « (VG, 290) werden unten beschrieben. ${ }^{13}$

11 Weischedel: »Die Frage nach der Wirklichkeit«, 123.

12 Ebd., 119.

13 Siehe Abschnitt 2.3 auf Seite 107. 


\subsubsection{Empirie}

Beim Begriff $`$ Empirie scheint es fast noch schwieriger als bei den Begriffen $>$ Realität $<$ und >Wirklichkeit , die genaue Verwendung in $V G$ zu erfassen. Im Text wird diese Vagheit durch Axel Schulzes ironische Bemerkung angedeutet, als er Laupeyßer gegenüber von dem spricht, »was Sie immer so hübsch als Empirie bezeichnet haben bislang « $(V G, 312)$. Die Bevorzugung des Fremdworts, das wieder aus dem Altgriechischen stammt und damit potenziell auf die Begriffsgeschichte seit Platon verweist, anstatt der deutschen Entsprechung `Erfahrung ` (oder `Erfahrungswissen $`$ ) suggeriert eigentlich die Präzision einer zugrunde liegenden Definition oder Einheitlich- bzw. Eindeutigkeit der Verwendungsweise. Im heutigen Sprachgebrauch liegt wohl am ehesten der Bezug auf die wissenschaftliche Methodik nahe, Erkenntnisse durch systematische Beobachtung zu gewinnen - die Erfahrung im Gegensatz zum logischen Deduzieren. Während jedoch in einem solchen Kontext die attributive Stellung des Adjektivs empirisch beispielsweise in den Kombinationen rempirische Wissenschaft oder >empirische Sozialforschung` vorherrscht, wird in VG vornehmlich das Substantiv in einer Weise verwendet, die eine eigenständige Entität, wie sie beispielsweise die Realität im oben erläuterten Sinn als Ding-Welt darstellt, insinuiert oder eine ebenso eigenständige Handlungsweise. Gleich im zweiten Einschub des >Autor«-Erzählers wird der Konflikt mit der Empirie zusammen mit den oben behandelten Fragen des Sich-entsetzen-Könnens und des Abstreifens der alten Identität als eines der zentralen Themen eingeführt:

Kann ich mich noch entsetzen? Als jemand existieren, den es nicht gab vorher, von keinem Leib ausgestoßen. Einfach Schluß machen mit der Empirie, zumindest so tun, es sich erfinden. Eine offensive Flucht: Angriff aus Unwägbarem. (VG, 8)

Der Begriff sticht hier durch seine mit dem Kontext kontrastierende Sprachebene, der Nicht-Alltäglichkeit, heraus und darüber hinaus durch den Gebrauch des Substantivs und die damit einhergehende isolierte Stellung. Diese Verwendung ohne weitere Erläuterung erschwert das Verständnis dessen, was hier angedeutet wird (wie durch seine Komprimiertheit allerdings auch der Rest der Passage). Auffallend ist, dass der Begriff erst sehr viel später (im letzten Drittel des Buches) wieder verwendet wird, sodass die Passage einen Prologcharakter erhält, die wesentlichen Themen kurz angedeutet werden, während ihre Erläuterung oder Ausführung erst später erfolgt.

Der substantivische Gebrauch erinnert stark an Adornos Verwendungsweise dieses Begriffs. In Adornos Spätwerk Ästhetische Theorie ist `Empirie< ein häufig vorkommender Begriff. Zumeist wird er hier ebenso herausgehoben wie bei Herbst gebraucht: unerläutert als Substantiv mit bestimmtem Artikel. Interessanterweise wird als ein Merkmal von Kunst gleich eingangs $»$ ihre Differenz von der bloßen Empirie ${ }^{14}$ aufgeführt. Zudem wird ihr die »Absage an die Empirie « ${ }^{15}$ zugeschrieben. Diese Phrase korrespondiert direkt mit dem eben zitierten Passus aus VG und deutet zusammen mit der eher ungewöhnlichen sprachlichen Verwendungsweise auf den Einfluss durch

14 Theodor W. Adorno: Ästhetische Theorie [1970], hg. v. Gretel Adorno / Rolf Tiedemann, Frankfurt am Main 1990, 12.

15 Ebd., 10. 
Herbsts Adorno-Lektüre. Doch ergibt auch dieser Hinweis keine klare Begriffsbestimmung. Das in $V G$ zugrunde liegende Begriffsverständnis wird in Kontrastierung zu anderen Begriffen verdeutlicht. So wird die Empirie der Fiktion, der Abstraktion und der Weltflucht (vgl. VG, 308, 321 und 323) entgegengesetzt, sie steht also für etwas Festes, Dingliches, Unumgängliches. Außerdem sagt der besondere Sprachgebrauch in der Setzung des Begriffs als Substantiv in den späteren Passagen einiges aus. Während Laupeyßer den Konflikt mit der Empirie gegenüber Axel Schulze noch einmal, jedoch auf verstärkt aggressive Weise, thematisiert - »Zerschlagen wir doch einfach diese blöde Empirie!« $(V G, 266)$-, wird sie in Erzählabschnitten des >Autor`-Erzählers weiter zu einer eigenen Entität stilisiert und sogar geradezu personifiziert: erst »verteidigt[] « B. »die Empirie« $(V G, 320)$, dann »zwingt einen die Empirie [vielleicht] ja geradezu [...] nichtempirisch zu lieben « $(V G, 321)$, schließlich wird das »Primat [] der Empirie« (VG, 323) konstatiert. In all diesen Zitaten wird der Konflikt mit der Empirie deutlich, die Ablehnung der Determination durch die äußeren Umstände, die objektive Realität. Der negative Gebrauch wird auch in den attributiven Fällen deutlich. Dort sind es die »Unabdingbarkeit empirischer Bestimmungen « $(V G, 286)$ oder die »empirischen Fesseln « (VG, 320), von denen sich der >Autor«-Erzähler eingegrenzt sieht. Mehr noch als die Realität oder die Wirklichkeit wird die Empirie als Gegner und Gegenspieler, geradezu als Feindbild stilisiert.

Diese zentrale Stellung zeigt sich auch darin, dass noch vor jedem Bezug auf diese anderen beiden zentralen Begriffe die Empirie genannt wird. Zudem wird der Begriff fast ausschließlich durch den >Autor «-Erzähler verwendet, das Thema also auf der höchsten Ebene der Erzählhierarchie angesiedelt (bis auf die genannten zwei Ausnahmen, Gespräche Laupeyßers mit Axel Schulze, die Themen des `Autor`-Erzählers teils wörtlich wie eine Gesprächsfortsetzung wieder aufnehmen). Aufgrund der Belege ist anzunehmen, dass die Empirie in einer etwas eigenen Auffassung als sinnlich erfahrbare Welt im Sinne einer objektiven Realität als Ding-Welt verstanden wird. Theoretisch ist sie damit als Synonym zur Realität in der Weise anzusehen, die eine Unterscheidung zwischen Realität und Wirklichkeit vornimmt. Da in $V G$ jedoch diese Unterscheidung zwar thematisiert, aber nicht eindeutig vorgenommen und durchgehalten wird, also eher Realität und Wirklichkeit zumindest in der Verwendung als Synonyme zu sehen sind, wird der sich abhebende Begriff $`$ Empirie als deutliche Abgrenzung genutzt.

\subsubsection{Wahrheit}

Eine ähnliche Funktion wie dem Begriff `Empirie s scheint der `Wahrheit` zuzukommen. Die Verwendung dieses Begriffs ist wieder vornehmlich dem diffusen Gebrauch der Begriffe >Realität` und >Wirklichkeit ‘ geschuldet. >Wahrheit bezeichnet in VG einen Aspekt der Welt, der wirklicher oder eigentlicher als die Wirklichkeit oder gar die Realität ist. Ist dieser Aspekt im alltagssprachlichen Gebrauch des Wortes >Wirklichkeit enthalten, wie Welsch dargelegt hat, ${ }^{16}$ so kann er nicht funktionieren, wenn die Wirklichkeit an vielen anderen Stellen als subjektiv, konstruiert und veränderlich dargestellt wird. Während die Realität die dem Subjekt nicht direkt zu- 
gängliche Ding-Welt und die Empirie selbige in der negativ gesehenen Beschränkung des Menschen bezeichnet, stellt die Wahrheit in der vorliegenden Verwendungsweise einen unbestimmten und nicht zu verortenden >Weltzustand ‘ dar, der neutral bis positiv konnotiert ist. Diese Bedeutung ist vornehmlich ex negativo zu erschließen. So gibt der >Autor<-Erzähler zu, er

"glaube ja noch immer, Laupeyßer zu sein, oder habe das Gefühl, als Falbin ins Büro zu gehen. An beidem ist etwas Richtiges, aber es ist nicht wahr« (VG, 286).

Es wird also sogar noch ein Gegensatz aufgemacht zwischen Richtigkeit, die etwas Zutreffendes in Bezug auf bestimmte Aspekte bezeichnet und einer tieferliegenden Wahrheit. Auch spricht der >Autor $<$-Erzähler in einer metanarrativen, aphorismusartigen Passage davon, dass durch ein bestimmtes poetisches Verfahren

»Wahrheiten entspringen, an die man nicht dachte vorher und die [...] neue Wirklichkeiten formen bzw. bislang verdeckte Wirklichkeiten« $(V G, 283)$.

Die Wahrheit bzw. Wahrheiten werden hier direkt der Wirklichkeit gegenübergestellt, die durch die Verwendung des Plurals als nicht eindeutig und noch einmal in ihrem konstruierten, für das Subjekt wirksamen Charakter gekennzeichnet wird. Demgegenüber »entspringen « Wahrheiten, bestehen außerhalb des Bewusstseins und der Intentionen des Autors und werden dadurch als autonome Sphäre dargestellt. In die gleiche Richtung deutet ein weiterer Gegensatz, der aufgezeigt wird, wenn Laupeyßer eine zeitliche Einordnung als »chronologisch, also empirisch gesehen, nicht wahrhaftig « $(V G, 309)$ charakterisiert. Hier wird die Wahrheit also auch noch von der eigentlich auch autonomen, zwar nicht zugänglichen, aber unumstößlichen Empirie abgesetzt, die durch die Formulierung ein weiteres Mal abgewertet wird.

Neben der Charakterisierung von >Wahrheit $<$ durch Kontrastierung mit anderen Begriffen ist ein weiterer Aspekt die Thematisierung der Verwandtschaft mit dem Begriff >Wahrnehmung` und gleichzeitig dessen Hinterfragung. Dem >Autor`-Erzähler fällt dieser Zusammenhang scheinbar durch Zufall und Assoziation auf, als ihm bewusst wird, dass er beim Anblick von Elstern sofort an Diebe denkt, was er aufgrund seiner Überlegungen zum Autonomiediskurs sofort mit diesem in Verbindung bringt. Weiter führt er dann die »Stimmung [an], die sich mitteilt über solcherart Wahrnehmung. Wahr-nehmen. Etwas für wahr nehmen. Solcherart Falschnehmung. " $(V G, 154) \mathrm{Er}$ stellt also die etymologische Verbindung zwischen der Wahrnehmung und dem Fürwahr-nehmen her und konstatiert wortspielerisch das inzwischen Zweifelhafte einer solchen Verbindung. Und dennoch muss er eingestehen, dass er auf die Wahrnehmung angewiesen ist:

[...] und weil es zudem der Verläßlichkeit des Augenscheins bedürfte. Was aber ist unverläßlicher als dieser?

Und alles, was ich somit je als so oder so angesehen hatte, mochte in Wahrheit anders sein. Im Grunde ließe nie sich etwas sagen darüber, sofern ich nicht doch dem vertraute, was behauptet wird über Wahrnehmungsweisen und -inhalte. (VG, 255)

Die Wahrnehmung erkennt er als das Einzige, was zugänglich ist. Die Wahrheit ist dagegen eine autonome Sphäre, die nicht unmittelbar erkannt werden kann. 
Die Position des >Autor<-Erzählers wird im Wesentlichen durch Laupeyßer übernommen und im Gespräch mit Axel Schulze thematisiert. Laupeyßer konzentriert sich auf seine Vorstellung, die subjektive Wirklichkeit verändern zu können, und gibt der Wahrheit dabei einen geringeren Stellenwert, da er sie für nicht erreichbar, damit für abgekoppelt und für ihn nicht relevant hält. »Was schert mich die Wahrheit, wenn sie mir nicht hilft? « $(V G, 167)$, hält er Schulze entgegen. Dessen Einwand, dass sie auf ihn einwirke und man sich ihn nicht entziehen könne, widerspricht er: »Das stimmt nicht [...]. Sondern ich kann mich dem Falschen nicht entziehen. Könnte ich mich der Wahrheit nicht entziehen, wäre es vermutlich besser.« $(V G, 168)$ Schulze nimmt dazu eine Gegenposition ein. Er vertritt einen direkten Zusammenhang zwischen Wahrheit und Wirklichkeit (»Wenn keine Wirklichkeit, dann keine Wahrheit ...«,VG, 167), der sich auch im Einwand zeigt, dass die Wahrheit auf einen einwirke, was, wie oben dargelegt, das wesentliche Merkmal der Wirklichkeit ist. Damit einhergehend vertritt er auch die Auffassung, man merke, was die Wahrheit sei. Dies wird jedoch nicht mehr wie bisher argumentativ vertreten, sondern schließlich mit dem demonstrativen Hinweis auf seine Nummerntätowierung, d. h. auf seine KZ-Erfahrungen, > untermauert . Eine auch nur annähernd kohärente theoretische Position wird hier also nicht aufgebaut.

\subsection{Der Versuch, Wirklichkeit herzustellen}

Der >Versuch, Wirklichkeit herzustellen` ist zunächst mit Laupeyßer verbunden, der anfangs auch die dominierende Hauptfigur des Textes ist. Dieser Terminus wird jedoch als nicht erfolgreich eingeführt, es ist die Rede von der "Hoffnungslosigkeit meiner Versuche, Wirklichkeit herzustellen« $(V G, 17)$. Die Hoffnungslosigkeit wird nicht begründet, sondern ist vielmehr die Beschreibung seines momentanen Gefühlszustands, eines "periodischen Zustand[s] von Entfernung «. Ist es hier also noch eher das Misslingen, das ex negativo das Vorhandensein der Versuche aufzeigt, ohne sie näher zu beschreiben oder zu definieren, nimmt Laupeyßer diese später dann geradezu wörtlich.

Diese Konzeption, ohne sie noch einmal formell als einen »Versuch« zu beschreiben, entwirft Laupeyßer in einem der Gespräche mit Agnes: „Warum nicht das, was man fabuliert, in die Wirklichkeit übersetzen? Die Fiktionen, wie eine verspätete Genehmigung, der Realität überführen?« $(V G, 34)$ Die Fiktionen, die in den Gesprächen seine Geschichten von Falbin meinen, versteht er dabei jedoch allgemeiner, nicht >nur als fiktionale literarische Geschichten, sondern als alles Fiktionale, was alltäglich beispielsweise als Tagträume erdacht wird. Allen als Möglichkeiten ersonnenen Handlungen unterstellt er, sie entbänden davon, »es zu vollziehen. Denn jeder Traum als Traum verhindert seine Realisierung, weil er Befreiung oder Lust als bereits Erfahrenes vorgaukelt.« Bezogen auf seine Geschichten wäre danach Falbin lediglich eine "Ausrede« für ihn. »Ich hänge ihm ein Geschick an, das mich von meinem eigenen wegbringt. Er handelt an meiner Statt.« Die Konsequenz, die Laupeyßer aus diesen Überlegungen ziehen will, ist, tatsächlich das in die Tat umzusetzen, was er »ihm andichte 
Was schon durch die Offenheit des Fiktionsbegriffs über eine ausschließlich metanarrative Überlegung hinausgeht, wird in einer vorhergehenden Charakterisierung Falbins noch stärker an Aspekte alltäglichen Handelns angebunden. Falbin wird, wie oben bereits dargestellt, ein bestimmter Charakter verliehen, um ihn einer irritierenden Situation auszusetzen. Er wird also als ein Mensch 'geschaffen`, der sich mit dem Leben in einer solchen Weise arrangiert hat, dass er diese Lebensweise erträgt, indem er sie ausblendet (wodurch die Irritation durch das »Irregehen « zum Bahnhof umso stärker ist). Beschrieben wird dies dadurch, dass

»ihm jene Art von Fantasie ausgetrieben worden [sei], die es den meisten ermöglicht, mit sich selbst das in uneingestandenem Widerspruch auszuhalten, was nicht auszuhalten ist, und noch sich einzubilden, man sei glücklich dabei.« $(V G, 33)$

Bezogen auf die Wirklichkeitsthematik bedeutet dies, dass für die >meisten $`$ Menschen ganz normal ist, sich eine eigene Wirklichkeit zu >erfantasieren` oder, neutraler ausgedrückt, zu konstruieren. Der Erzähler unterstellt den Menschen also die gleiche, allerdings unbewusste Erfahrung eines Mangels, die Laupeyßer und Falbin erleben, nur dass sie eben durch eine bestimmte Art von Phantasie einen Umgang damit gefunden haben. Der spöttische Tonfall spricht allerdings dafür, dass dieser Umgang als falsch angesehen wird.

Bei mehreren Figuren wird Fiktion in unterschiedlichen Formen für den Umgang mit den Widersprüchen oder der Banalität des Alltagsgeschehens herangezogen. Der >Autor`-Erzähler verwendet zwar keinen dieser Begriffe, spricht aber vom »stilisieren«:

Das Elend ist wirklich: Es spielen die Erlebnisse sich nicht ab. Jedenfalls nie in der Gegenwart, allenfalls im Rückschauen. Doch kann man einen jeden Zahnarztbesuch zum Abenteuer stilisieren. Damit läßt es sich wehren, einigermaßen. (VG, 69)

Was er hier thematisiert, ist der Mangel an Erleben im Alltag. Erst im Nachhinein, durch eine narrative Stilisierung, und sei sie eine Erzählung für sich selbst, damit durch das Wort Abenteuer angedeutet - auch eine Erhöhung, wird das Leben erträglich. Diese Passagen sind wieder elliptisch gestaltet, beispielsweise wird nicht genannt, wessen es sich wehren lässt. Erst durch die Ähnlichkeit mehrerer Stellen, die durchaus unterschiedlichen Hauptfiguren zugeordnet sind, ergibt sich ein Zusammenspiel. Ist in der eben zitierten Passage bezüglich Falbin von der Form des Lebens die Rede, die »am schmerzlosesten ertragen werden konnte« $(V G, 33)$, und darauf vom von Falbin nicht thematisierten »Mangel«, so kann dies von der Thematik miteinander in Verbindung gebracht werden. Wird hier der Zahnarztbesuch mit dem Abenteuer kontrastiert, so wird das Gewöhnliche, ja Banale des Alltags herausgestellt. Aufgenommen wird diese Konnotation wieder im Zusammenhang mit dem falbinschen Niemandsland. Wie bereits oben zitiert kennzeichnet dieses das Verschlucken vom Vergangenen und Kommenden. "Die Erinnerung an das Gewöhnliche wird zu Schemen, mit denen ist es, als lese man ein Märchen oder einen Abenteuerroman.« (VG, 116) Dies bezeichnet den gleichen Mechanismus, den der `Autor`-Erzähler gegenüber 
dem Zahnarztbesuch anwendet. Im Nachhinein wird das Gewöhnliche zum Abenteuerlichen. Diesen poetischen Aspekt, das Erlebte in einer erzählerischen Struktur $\mathrm{zu}$ sehen, betont auch Laupeyßer, als er bemerkt, dass niemand von seiner eigenen Anwesenheit beim Bahnhof weiß:

Und weil keiner davon weiß, ist es nötig, sich jemanden zu erfinden, der es weiß. Sonst merkte niemand die Veränderung und erst recht nicht ihren Grund. Es sollen aber welche es merken. $(V G, 237)$

Hier geht es jedoch über die bloße Änderung der Sichtweise auf die Erinnerung und der inneren Einstellung hinaus, da er in einer Metalepse dies in die >Wirklichkeit umsetzt:

Also muß einer berichten davon; der nämlich, von dem ich mir erfunden habe, er finde meine Tagebücher und berichte davon in Form meinetwegen eines Romans. (ebd.)

Zum einen wird an diesen Stellen deutlich, dass die Figuren das Erzählerische auch im Alltäglichen anzuwenden versuchen, zum anderen wird der Verweis auf die Tätigkeit des Schriftstellers verstärkt herausgestellt.

Wie konkret diese Verbindung von Fiktion und Wirklichkeit bzw. Realität vorzustellen ist - abgesehen von der metafiktionalen Spielart -, ist auch den Figuren nicht klar. Dies zeigt sich in einigen Fragen, die unbeantwortet bleiben: der >Autor-Erzähler fragt sich, »Aber: Wie verwebe ich mich selbst der Realität? « $(V G, 143)$, während Laupeyßer Axel Schulze gegenüber die rhetorische Frage aufwirft: Vielleicht gelingt es, den Traum in Wirklichkeit zu bilden? $(V G, 167)$ Sich selbst ertappt er dabei, seine erfundene Figur Falbin auf der Straße wiederzuerkennen. Einerseits könnte dies damit zusammenhängen, dass er seine Figur nach einer realen Person im Café gestaltet hat, die ihm daher auch tatsächlich begegnen könnte, andererseits ist er so mit dem Erfinden der Falbin-Geschichte beschäftigt, dass er diesen aufgrund seiner Präokkupation schon überall zu sehen glaubt. Dabei benutzt er die wieder poetisierende Formulierung, ob »man sich die Realität erfantasierte, sie durch Erfindungen formte? $(V G, 69)$ Einerseits wird also wieder der Konstruktionscharakter der Wirklichkeit (die hier >eigentlich ' gemeint ist) klar, andererseits zeigen sich die Figuren auf der Suche danach, wie sie diese bewusst beeinflussen können.

Diese Beeinflussung der Wirklichkeit hat dabei unterschiedliche Qualitäten. Am Deutlichsten scheint die Umsetzung Falbin zugeschrieben zu werden. Als es zu einer parallel verlaufenden Liebesnacht bei Laupeyßer (mit der Bedienung des Cafés, in dem er immer sitzt) und Falbin (mit einer Marianne Liewald) kommt, fängt dieser an, seine sexuellen Träume in die Tat umzusetzen. Formuliert wird dies jedoch so, »daß nun auch er begann, Fiktionen in die Wirklichkeit zu gießen« $(V G, 323)$. Auffällig ist dabei, dass der zwar nirgends definierte oder beschränkte Begriff `Fiktion hier wieder sehr offen gefasst wird, indem er äquivalent mit (sexuellen) Träumen, Vorstellungen und Wünschen verwendet wird. Dies spricht den real auflösbaren, realistischen Aspekt des »Versuchs, Wirklichkeit herzustellen« an. Allerdings wird dieser auch wieder hinterfragt oder relativiert durch den etwas absurd scheinenden, ins Lächerliche ziehenden Zusatz »Nur daß freilich die Zimmereinrichtung nicht 
stimmte«, sowie durch die Bemerkung, es gebe nicht den geringsten Beweis für die gemeinsam verbrachte Nacht. Beim >Autor-Erzähler wird diese ambivalente Qualität noch deutlicher. Auf der einen Seite formuliert er den »Versuch" so deutlich und programmatisch wie keine andere Figur.

Habe aber jetzt mehr denn je die Absicht, die Distanz aufzuheben und die Träume real werden zu lassen. "Jeder Gedanke, der nicht Tat wird, ist Mord an der Seele", heißt es bei Heiner Müller. (VG, 321)

Hier ist sogar explizit von Träumen die Rede, doch inhaltlich entspricht es dem Fiktionendiskurs. Diese programmatische Formulierung seines Vorhabens findet sich nach der Trennung von B. und dem folgenden Selbstmordversuch. Wie oben beschrieben, war B. für den >Autor<-Erzähler die sehnsüchtig Erwartete, die »endlich nicht mehr Fiktion war « $(V G, 308)$. Mit ihr wollte er aber auf der anderen Seite wiederum auch der »Empirie« entfliehen, was wohl als ein gemeinsames Träumen und Phantasieren vorgestellt werden kann und was sie unter sich als »Fliegen « bezeichneten; B. sollte ja seine »Nadja« sein. Schon hier zeigt sich der Gegensatz und das Schwanken zwischen dem realistischen Verständnis des Umgangs mit Fiktionen (mit Träumen, Imaginationen) und dem poetisierten, nicht gänzlich ins Rationale auflösbaren. B. bestand auf der Vorstellung, »Traum müsse Traum und Wirklichkeit Wirklichkeit bleiben«, wohingegen er es »ernster und realer « $(V G, 320)$ nahm. Nach der Trennung bricht dann auch der Traum von der Verwirklichung seiner Vorstellungen mit B. zusammen, er fällt in eine Depression und weiß,

»es werde weitergehen mit meinen Fiktionen, mögen sie mich eines Tages auch zur Abschreckung neben eine Straßenlaterne hängen, für jene, die immer noch nicht die Aussichtslosigkeit des Ausbruchs begriffen haben sollten « (VG, 337).

Aus diesen verschiedenen Ausführungen des >Autor<-Erzählers lässt sich eine feine Unterscheidung herauslesen, die auf der Platzierung von Fiktionen auf unterschiedlichen Fiktionsebenen beruht. Die Versuche, seine Identitätsprobleme durch seine fiktionalen Stellvertreterfiguren in den Griff zu bekommen, sieht er als vergeblich an. Diese sind die Fiktionen und reinen Träume. Hingegen von der >realen B Beziehung mit B. hat er eine Lösung dieser Probleme erwartet. Verwirrend ist die Rede von der Verbindung von Fiktion und Realität oder Empirie, die er in der Beziehung verwirklichen will, da sie die Rede von den Fiktionen wieder aufnimmt. Es ist jedoch gerade das reale Ausleben, das Verwirklichen seiner Träume, das er ersehnt, wohingegen der eigentliche, nämlich Laupeyßers »Versuch, Wirklichkeit herzustellen« nur das fiktionale Durchspielen einer Möglichkeit, das imaginierende Durchdenken einer Idee ist.

Gerade die fiktionalen Möglichkeiten stellt der >Autor<-Erzähler in den Mittelpunkt seiner Realitäts- bzw. Wirklichkeitsdefinition. Im bereits erwähnten Zitat von der Realität als Zwischenwelt führt er mehrere zentrale Themenstränge noch einmal zusammen. Die Erinnerung an den (dann Laupeyßer untergeschobenen) Kinobesuch und die Entrüstung über seine eigene "Lachlust « führt zur Auflösung seines eigenen, ihm fremdkonstruiert scheinenden Ichs. Für diese Aufgabe, als eine Art »Konkursverwalter « $(V G, 289)$, hat er Laupeyßer und Falbin eingesetzt. Nun konstatiert er (nun etwas vollständiger zitiert): 
Übrig blieb dann die Fiktion, so daß etwas noch gar nicht Existierendes die eigenen Möglichkeiten bestimmte. Da muß sich einer also so erfinden, daß er schließlich empirisch als das Erfundene in Erscheinung tritt, bzw. tritt ein Drittes auf, die Synthese gewissermaßen aus Fiktion und Empirie. Womit denn meine Definition von Realität erreicht wäre. Der Rest ist pure Exposition. Denn die Realität ist eine Zwischenwelt, die jenseits des Bahnhofs beginnt. (VG, 289f.)

Der fremdbestimmten Identität setzt er zunächst die Fiktion, also seine Geschichten und Imaginationen, entgegen, mit der es ihm möglich ist, auf fiktionale Weise neue Möglichkeiten auszuloten. Auf wohl nicht vollständig rational auflösbare Art will er diese Möglichkeiten in die Tat, d. h. die Realität umsetzen, sie mit der Empirie, wie wir oben gesehen haben, also der gegebenen Welt vermengen. Verwirrenderweise nennt er dies nun wieder seine Definition von Realität. Wie bereits oben gesagt, ist damit nach seiner eigenen Unterscheidung die Wirklichkeit gemeint, als dasjenige, das wirkt. Durch den im letzten Drittel des Buchs komisch wirkenden Zusatz, der Rest sei pure Exposition, ${ }^{17}$ wird jedoch die Bedeutung dieser Passage hervorgehoben. Der letzte Satz ist für sich allein genommen sehr kryptisch, doch ist er als ein Verweis auf das falbinsche Niemandsland zu sehen. Der Bahnhof an sich ist schon klar mit Falbin verbunden. Die Welt jenseits des Bahnhofs, die auch noch `zwischen $<$ etwas, ganz simpel gesehen zwischen den Städten, liegt, hat im Text nur die Entsprechung des Niemandslandes. Wie oben bereits dargelegt, ist dieses ein tröstliches Bild der Konzentration auf die Gegenwart, des Ausschaltens heteronomer Bestimmungen. Der flüchtige Charakter dieser utopischen Vorstellung wird in die >Definition von Realität $<$ jedoch nicht aufgenommen.

Oben ist bereits der »Versuch von Geschichtslosigkeit« beschrieben worden, der die Konstruktion einer neuen eigenen Identität und das Erfinden einer neuen eigenen Vergangenheit und beispielsweise Eltern beinhaltet und damit im Grunde zum Versuch, Wirklichkeit herzustellen, gehört. Ein Teil davon sind damit die »Bemühungen um die Vergangenheit « $(V G, 42)$, die vor allem Laupeyßer unternimmt. Immer wieder nimmt er »die Opfer « - und damit sind bei ihm die Opfer der deutschen Nationalsozialisten gemeint - als Kontrast zu seinen Wirklichkeitsüberlegungen. Seine >Leiden an der Realität als vermeintliche Mystifikation werden dann relativiert durch die Leiden der Opfer: »Wobei wichtig bleibt, jederzeit: Die abgeschlagenen Hände sind keineswegs Mystifikation, jedenfalls nicht den Opfern.« $(V G, 177)$ Er bemerkt aber auch gleichzeitig, dass sie ihm dennoch als eine solche erscheinen. Es gibt für ihn also immer die Unterscheidung zwischen der handfesten, meist brutalen oder fordernden (im Falle von Agnes und ihren Pflichten als Mutter) Realität und der ihm nicht fassbaren, geschweige denn verständlichen Wirklichkeit, die ihm keine Sicherheit gibt. Die »Bemühungen" stellen seinen Versuch dar, eine Verbindung zwischen diesen Sphären herzustellen. Eine Pappkarton-Sequenz macht das deutlich:

Das Weinen der Opfer, ist das die Realität? Und wie bringe ich sie, wäre sie es, mit mir in Verbindung? (VG, 146f.)

17 Dieser wurde dann auch von der Literaturkritik gegen Herbst verwendet, vgl. Ayren: »Die Verwirrung der Grammatik«. 
Diese Verbindung hat mit der Schuldfrage zu tun, dass er sich stellvertretend für die Elterngeneration schuldig fühlt, obwohl er als lange nach dem Zweiten Weltkrieg und der Herrschaft der Nationalsozialisten Geborener nicht direkt mit den damals begangenen Verbrechen etwas zu tun hat. Anhand mehrerer Situationen schildert er seinen Ärger und die Verzweiflung darüber, dass er selbst zu seiner Zeit noch, d. h. Anfang der 1980er Jahre, sowohl mit der Leugnung eigener Schuld der früheren Generation als auch mit weiterhin vorhandenen antisemitischen Äußerungen konfrontiert ist. Margarete Mitscherlich hat sich 1983, also im Publikationsjahr von $V G$, in einem Aufsatz mit diesem Thema im Konnex von Literatur beschäftigt - mit Bezug auf ihre zusammen mit ihrem Mann verfasste, oben erwähnte Studie Die Unfähigkeit zu trauern. An dieser Stelle ist vor allem ihre Schilderung der Situation Anfang der 1980er Jahre interessant, die die Diskussionen im Anschluss an die Ausstrahlung der USamerikanischen Fernsehserie Holocaust (1979) sowie in verschiedenen Druckmedien geführte Auseinandersetzungen nachzeichnet. Mitscherlich stellt - wie eben auch Laupeyßer - zu dieser Zeit zwar das erste Mal eine Identifizierung mit den Opfern fest, aber beschreibt auch gleich darauffolgende Forderungen nach einer Abkehr von der Vergangenheit sowie Versuche von Schuldaufrechnungen. Sie konstatiert:

Ohne Übertreibung kann man sagen, daß neuerdings von Deutschen für Deutsche eine Unfähigkeit zu trauern geradezu gefordert wird. ${ }^{18}$

Eine solche Gegenwartsdiagnose verbindet sich bei Laupeyßer mit seiner Auseinandersetzung mit den eigenen sadistischen Gefühlen und mit seinen Überlegungen zur Fiktionsthematik. Er hat das Gefühl, dass oft eigentlich etwas anderes passieren müsste; so erwartet er nach der schockierenden Erzählung von Axel Schulzes Lebensgeschichte eine physische Reaktion, beispielsweise durch eine Explosion der Fenster. Doch niemals geschehe das, was eigentlich passieren müsste. Es erfolge kein Aufstand oder Aufschrei der Natur, die Menschen verhielten sich nicht so, wie dies eigentlich richtig wäre (vgl. VG, 274). Laupeyßer versucht diesem Mangel mit seinen Fiktionsüberlegungen zu begegnen. Seine Schlussfolgerung ist also, dass die ausbleibende adäquate Reaktion erfunden werden müsste. Dabei ist anzumerken, dass diese Überlegungen wieder einmal mit Laupeyßer ebenso wie mit dem >Autor/-Erzähler verbunden sind und sich ähnliche und sich ergänzende Überlegungen über beide Ebenen verteilen. Laupeyßer wird es zugeschrieben, er wolle »die Geschichte [betrauern], die er nicht begangen hatte. Sie betrauern als Betroffener, weil er nicht betroffen war« $(V G, 120)$. Auffällig ist die Gleichsetzung von Geschichte mit Verbrechen, die eigentlich `begangen` werden könnten, was hier die einschränkende Bedeutung von Geschichte auf eine Zeitperiode bezeichnet. Der Betroffenendiskurs erklärt sich durch eine spätere, in der Wortwahl sehr ähnliche Anmerkung des >Autor`-Erzählers, die Betroffenen könnten nicht trauern, da sie damit beschäftigt wären, die Betroffenheit zu verdrängen, um überhaupt atmen zu können (vgl. VG, 151). Wie oben in Abschnitt 1.5.1 auf Seite 86 bereits angesprochen, will Laupeyßer die >Trauerarbeit` auf sich nehmen, die nach der Studie der Mitscherlichs bei den Deutschen unterblie-

18 Margarete Mitscherlich: »Wie haben sich deutsche Schriftsteller gegen die Unfähigkeit zu trauern gewehrt? Dargestellt an Wolfgang Koeppens `Der Tod in Rom«", in: Neue Rundschau 94/3 (1983), 137-156, hier: 151. 
ben ist. Ob es sich bei den Betroffenen jedoch um die Opfer, die er sonst immer so bezeichnet, oder aber auch um die Betroffenen weil Schuldigen handelt, wird nicht recht deutlich. Auffällig sind jedoch die Ähnlichkeiten in den Formulierungen mit der Beschreibung von Trauerarbeit bei den Mitscherlichs:

Vielmehr müßten wir die Einfühlung in uns selbst erweitern, so daß wir uns in jenen Szenen wiedererkennen wie der des deutschen Offiziers im dänischen Café und in den entsetzlichen, in denen 100, 500 oder 1000 Leichen vor uns lagen - Leichen von uns Getöteter. Das würde eine einfühlende, nachfühlende Anerkennung der Opfer lange nach den Schreckenszeiten bedeuten. ${ }^{19}$

Auch hier ist also von »Einfühlung« die Rede, von »Wiederkennen« in Schilderungen, die man nicht selbst erlebt hat, die jedoch Beispiele für die kollektive Schuld sind. Auch später ist noch einmal explizit vom »einfühlende[n] Denken ${ }^{20}{ }^{20}$ die Rede, das nötig sei. Psychologisch wird das Erkennen der Schuld durch Einfühlung dabei nicht als Unmöglichkeit gesehen, was die Vorhaltung der bereits erwähnten Iris gegenüber dem `Autor`-Erzähler ist. Laupeyßer möchte ja im Grunde stellvertretend die Trauer übernehmen und dies durch ein fiktionales Hineinversetzen erreichen. Außer dann zufällig mit Axel Schulze hat er jedoch mit `Opfern` gar nichts zu tun, die Ideen entstehen in Gesprächen mit den ebenfalls >nicht betroffenen` Freundinnen Agnes und Iris. Es kann also gar nicht um die Erleichterung irgendwelcher Opfer oder um empathische Solidaritätsbekundungen gehen, auch weil sich die Frage stellen würde, ob es `den $<$ Opfern oder selbst einem ihm persönlich bekannten Individuum etwas nützen würde. Es geht vielmehr um Laupeyßer (und auch den `Autor<-Erzähler) selbst, um seinen Umgang mit der nationalen Vergangenheit und um den Umgang mit dem Gefühl persönlicher Schuld. Ihm ist selbst klar, dass sich nichts wiedergutmachen lässt, dass keine Gerechtigkeit hergestellt werden kann. Doch ist es ein Weg für ihn, vor allem mit der mangelnden Teilnahme seiner Mitmenschen klarzukommen. Er möchte, so ist es beim >Autor`-Erzähler ausgedrückt, durch seine Fiktionen fähig werden, "so etwas wie Verantwortung tragen« $(V G, 228)$ zu können. Auch wenn es eine virtuelle ist, scheint sie ihm selbst eine gewisse Art von Erleichterung zu schaffen.

Der Versuch, Wirklichkeit herzustellen, bedeutet demnach, Fiktionen in Form von (Tag-)Träumen, Vorstellungen und Phantasien in die Wirklichkeit, das alltägliche Leben einzubringen. Dies bietet die Möglichkeit, mit narrativen (literaturähnlichen) Mitteln das Erleben des Lebens zu formen und mit Problemen umzugehen. Der Versuch enthält aber auch den Aspekt, dass der >Autor`-Erzähler nicht den `Hilfsmittel-Charakter des Versuchs sieht, sondern sich nach direkter Erfüllung sehnt. Diese ist ihm aber verwehrt, ihm bleibt die narrative Konstruktion von Identität und die bewusste Formung der Wirklichkeitswahrnehmung.

19 Mitscherlich / Mitscherlich: Die Unfähigkeit zu trauern, 83.

20 Ebd., 223. 


\subsection{Näherungen II: an die Wirklichkeit}

Die Näherungen an die Wirklichkeit bzw. wie es genauer heißt, »an die Wirklichkeiten« $(V G, 203)$, sind ein weiterer Aspekt des oben bereits erläuterten Konzepts der Näherungen. Ging es dort um die Näherung an sich und andere, das Erreichen von Nähe und Verständnis, teils in der (auf die jeweilige Erzähl- und damit Fiktionsebene bezogen) realen Welt, teils in den fiktionalen Geschichten, tritt hier der metanarrative Charakter in den Vordergrund. Statt einer inhaltlichen Kategorie wird die der Darstellung thematisiert. Die Übereinstimmung in der Begrifflichkeit ist dabei nicht zufällig. Wie auch bei der Vorstellung, jemanden anderes völlig begreifen zu wollen, findet sich auch hier die Einsicht in die Unmöglichkeit einer vollständigen Annäherung, ist die vergebliche Natur des Bemühens bereits im Begriff enthalten. Eine genaue Charakterisierung dessen, was ich unter diesem nur nebenbei erwähnten Schlagwort als Konzept zu bündeln versuche, ist wie bei allen Modellen, Prinzipien und Begriffen in $V G$ nur schwer zu bewerkstelligen. Es umfasst ein disparates Konglomerat von Anspielungen, Begriffen und Konzepten, das poetologische Überlegungen verschiedener Figuren und letztlich die Poetik des Buches passend bezeichnet.

$V G$ ist ein durchgängig in hohem Maße metafiktionaler wie metanarrativer Roman. Große Teile des Textes, vor allem der Falbin-Geschichte, werden explizit als (mündliche) Erzählungen Laupeyßers gegenüber Agnes dargestellt. Die ständigen Unterbrechungen des Textes durch den >Autor`-Erzähler sind anfangs vor allem Kommentierungen zum Geschehen und auch zum Erzählvorgang selbst und damit auf einer Meta-Ebene angesiedelt. Während Laupeyßer, wie oben beschrieben, die Näherungen eher als Ziel seiner Ausführungen darstellt, finden sich beim >Autor-Erzähler die zugehörigen Begriffe als Bezeichnungen der Erzählweise. Dem Aufbau des Textes in (mehr oder weniger) kleinen Abschnitten entsprechend, wird vor allem der Begriff >Näherungsschnipsel verwendet. So ist einer dreizeiligen Charakterisierung Falbins, die unentscheidbar von Laupeyßer oder vom heterodiegetischen Erzähler der dritten Erzählebene stammt, die kursive Anmerkung vorgesetzt: "Noch ein Näherungsschnipsel « $(V G, 84)$ Dabei ist die Zuordnung zur Art der Näherung mehrdeutig. Es könnte zum Versuch der Annäherung an die Person Falbin gehören, aber auch den Versuch bezeichnen, die Figur Falbin dem Leser (oder vielleicht zuerst auch der Zuhörerin Agnes) durch die genaue Beschreibung eines Details anschaulich darzustellen. Diese Lesart wird in einer längeren Passage des >Autor`-Erzählers unterstützt. Gleich zu Anfang werden hier Geschichten und Näherungen parallel gesetzt, sodass die dann folgende Bemerkung »auch so ein Schnipsel « $(V G, 97)$ als verkürzte Form des Näherungsschnipsels zugeordnet werden kann. Genauer formuliert er dann die von ihm unterstellten Erwartungen des Lesers:

Offenbar wünschen Sie sich, von mir etwas als glaubhaft dargestellt zu bekommen. Ich muß mich dabei an Ihre Spielregeln halten, weil ja Sie letztendlich entscheiden, was glaubhaft ist für Sie und was nicht. Insoweit hänge ich tatsächlich schon von Ihnen ab. (ebd.)

Im Folgenden formuliert er das Programm einer realistischen Schreibweise. Der Leser, so fingiert er natürlich nur, erwarte, sich in glaubhaft dargestellte Figuren und Situationen hineinversetzen zu können. Die mimetische Abbildung soll Grundlage 
des Dargestellten sein, Ziel ist das Durchleben von Erfahrungen anderer Menschen, wenn diese spannend sind also von Abenteuern, ohne die Konsequenzen im realen Leben tragen zu müssen. Der >Autor<-Erzähler macht allerdings schon deutlich, wie im obigen Zitat zu sehen, dass er keineswegs mit diesem erzählerischen Programm übereinstimmt, setzt ihm jedoch auch nichts anderes entgegen. Er scheint sich zunächst den Regeln der Mimesis unterwerfen zu wollen. Dieses Realismus-Programm zieht sich durch den gesamten Roman, wird jedoch auch immer wieder konterkariert.

Im Zusammenhang des Namengebens und des Schaffens einer Figur ist bereits darauf hingewiesen worden, dass die Figuren sich `nach ihrem Ebenbild ‘ erschaffen. Dies wird zwar nicht mit der biblischen Formulierung bezeichnet, aber ergibt sich durch einige Bemerkungen und Detailangaben. Der >Autor-Erzähler charakterisiert seine sich erst später als dieser erschließende Erfindung Laupeyßer gleich im ersten Absatz: "Darf nicht zu alt sein für meine Zwecke. Vielleicht fünfundzwanzig. - Weil: Man geht von dem aus, was man kennt. « $(V G, 7)$ Wenig später erwähnt er dann seinen eigenen 28. Geburtstag, was das ungefähr übereinstimmende Alter bestätigt. Sehr viele Details der Lebensumstände erfährt der Leser vom `Autor`-Erzähler nicht, die Ähnlichkeiten lassen sich lediglich durch diese programmatische Bemerkung sowie durch seine späteren Kommentare über die Funktion der erfundenen Figuren sowie über die sich ergebenden Verwechslungen ableiten. Die bisherige Lebensgeschichte von Laupeyßer wird dagegen detailliert geschildert und mit deutlichen Referenzen auf die reale Geographie und Geschichte mit der aktualen Welt verbunden. So wird er in Bremen geboren, das auch als Handlungsort des Romans kenntlich wird, studiert in Bonn und geht später nach Frankfurt am Main. Das Geburtsdatum 1953 wird gleich zeitgeschichtlich eingeordnet als »drei Jahre also vorm Aufbau der Bundeswehr ( $V G$, 14), was inhaltlich den späteren Konflikt Laupeyßers mit der sich wieder ’normalisierenden` Bundesrepublik vorwegnimmt, aber ihn zunächst vor allem deutlich in der historischen Bundesrepublik verortet. Über das Geburtsdatum wird auch die Ähnlichkeit der äußeren Umstände zu Falbin hergestellt, der drei Jahre später, 1956, geboren wird. Charakterlich sind Laupeyßer und Falbin konzeptmäßig unterschiedlich angelegt, doch auch bei ihnen zeigen die späteren Verwechslungen, dass sie sich zumindest sehr ähnlich sehen, da sie - wie oben erörtert - auf eine bestimmte Art identisch sind. Ausgangspunkt vor den weiteren Entwicklungen der Figuren sind jedoch die Beschreibungen ihrer Lebenssituationen, die gänzlich durchschnittlich sind. Laupeyßer hat sein Pharmaziestudium abgebrochen, ist in einem nicht näher bezeichneten Büro untergekommen und Falbin arbeitet in einem Autohaus. Auch die Freizeitaktivitäten werden geschildert und fallen nicht aus dem Rahmen der abgesteckten Situation. Vor allem Laupeyßers Treffen mit Agnes erschließen sich, da er ihr ja die Falbin-Geschichte erzählt, seine Aufenthalte in Cafés und Kneipen werden geschildert. Zwei Besuche bei Freunden führen ihn kurz hintereinander ins Emsland und nach Hamburg.

In metanarrativen Kommentaren und im Vergleich der Schilderungen der Figuren zeigt sich also das Konzept, die fiktionalen Geschichten aus dem und nahe dem Umfeld des jeweiligen Autors bzw. Figurenerfinders zu bilden. Dies zeigt sich auch in der Fiktionalisierung von Freunden und Bekannten. Laupeyßer versucht mehrfach in den Gesprächen mit Agnes, sie in seine Fiktionen einzubeziehen. Dabei weist er 
darauf hin, dass niemand zufällig in der Geschichte auftauchen würde und vor allem, dass jede Figur »ihren Bezug zur Realität hat « $(V G, 68)$. Worin genau die einzelnen Bezüge bestehen sollen, wird nicht aufgedeckt und kann auch nicht erschlossen werden, da nicht genügend Informationen über das Umfeld Laupeyßers gegeben werden. Doch reagiert Agnes beispielsweise skeptisch bis ablehnend, wenn Laupeyßer sie in die Geschichte integrieren will. Er macht dies denn auch erst, als der Kontakt zwischen ihnen abbricht. Als er überlegt, sie habe ihn eigentlich immer abgelehnt, kommentiert der >Autor<-Erzähler, der, wie oben dargelegt, auch eine Verbindung zu Agnes hat: »Also wird nun sie zu meiner Figur, worin eine hübsche Rache liegt.«(VG, 235) Zunächst kann er die Fiktionsebenen noch auseinanderhalten, da er jedoch alle seine Erlebnisse fiktionalisiert, kommt er irgendwann durcheinander. So sind Agnes und Iris nicht erfunden, doch »haben [sie] sich ja längst dem Fiktiven integrieren lassen " $(V G, 151)$. Bei Schulze und Falbin kommt er angesichts dessen ins Schwanken und stellt infrage, wer nun erfunden sei. Bereits im Zusammenhang mit der Beschreibung der Beziehung zu B. zitiert, bemerkt der `Autor`-Erzähler, auch diese sei erfunden. An dieser Stelle spielt wieder die Doppeldeutigkeit eine Rolle, Erfindung könnte auch die Konstruktion eines Bildes von ihr sein, das seinen Umgang mit ihr bestimmt. Im aktuellen Zusammenhang ist jedoch wichtig, dass auch die eigentlich auf der Ebene des >Autor -Erzählers als real vermittelte Beziehung zu B. von diesem zumindest nach Ende der Beziehung in seine Fiktionen integriert wird.

Ein besonderer Fall ist der eigentlich in der Handlung keine Rolle spielende und nur gelegentlich erwähnte Freund Andreas Werda(n). Mit vollem Namen - diesmal Andreas Werda - wird er nur in einer Aufzählung mit Agnes als einer der »wirklich existierenden Freunde $(V G, 117)$ erwähnt. Später wird ein Andreas genannt, der einen Kommentar zu dem bisher Geschriebenen abgibt (siehe VG, 256). Das Besondere an ihm ist jedoch, dass er Teil der bis auf die Leseransprache einzigen Metalepse ist, die über den eigentlichen Text hinaus- und in den Paratext hineinreicht. Im Impressum ist nämlich »Andreas Werdan, Bremen« als für das Umschlagmotiv verantwortlich ausgegeben, das eine inszenierte Fotografie mit einigen zum Roman gehörigen Utensilien zeigt, u. a. einem Zettel mit dem Namen Agnes und einer Telefonnummer. Im Zusammenhang mit Fotografie ist der Name Andreas dann noch einmal im Text in einer assoziativen Aufzählung erwähnt, wobei die Fotografie dabei einen Handschuh abbildet, der einige Male auch im Text auftaucht. Natürlich ist dies ein kleines, leicht zu übersehendes Detail, doch stellt es einen möglichen Verweis auf die Welt des realen Autors dar. ${ }^{21}$ Dies kann den Blick dann auf die biographischen Angaben zum Autor im Klappentext (auf dem Schutzumschlag) lenken. Diese weisen ihn als einen zur Zeit der Niederschrift 26- bis 28-Jährigen aus, der in Frankfurt am Main lebt. Dass Herbst vorher in Bremen gelebt hat, ist in dieser kurzen Angabe allerdings nicht zu finden. Schließlich ist auf der letzten Seite des Textes noch die Angabe »Juli 1981 - Februar 1983 « $(V G, 342)$ zu finden, die, wie in allen späteren Büchern von Herbst, den Entstehungszeitraum angibt. Dieser überschneidet sich, wie gleich noch näher auszuführen ist, mit dem Handlungszeitraum des Romans. Ohne an dieser Stelle auf eine biographische Deutung hinauszuwollen, legen diese Hinweise

21 Im Nachhinein wird dies auch bestätigt, vgl. URL-7, 24. Jan. 2012. Der Name taucht zudem auch wieder in Buenos Aires auf (auch in Zusammenhang mit Agnes), vgl. BA, 76-81 und passim. 
doch den Blick auf den realen Autor nahe. Sie verweisen auf die Möglichkeit, diesen als weitere, dann extradiegetische Ebene der ineinandergeschachtelten Erzählsituation zu sehen. Ebenso wie Laupeyßer dem >Autor<-Erzähler in ein paar äußerlichen Angaben ähnelt und von diesem entworfen wird, gibt es Übereinstimmungen zwischen >Autor<-Erzähler und dem realen Autor. Die Konstruktion wird ein weiteres Mal gespiegelt, wobei konstatiert werden muss, dass sie immer noch lediglich recht abstrakt ist, da diese formalen Details nichts über die inhaltlichen Zusammenhänge aussagen. Ebenso wie der >Autor--Erzähler und Laupeyßer schreibt der reale Autor jedoch eine Geschichte auf, die ausgeht von dem, »was man kennt «. Hierbei handelt es sich um eine zumindest für den zeitgenössischen Leser kaum erkennbare Form der Autofiktion. In den folgenden Romanen wird Herbst das autofiktionale Schreiben wesentlich expliziter einbringen und schließlich im Weblog zu einem grundlegenden Thema machen (vgl. dazu Abschnitt 8.3.2 auf Seite 387).

Wie eben bereits angedeutet, geben auch die Zeitangaben den Eindruck, einen Bezug zur realen Welt herzustellen. Angesichts des fragmentarischen Aufbaus, des anfangs chaotisch wirkenden Durcheinanders der Erzählstränge, fehlender Überleitungen und der Schilderung von explizit als bloß imaginierten Möglichkeiten ausgewiesenen Ereignissen ist die Anzahl präziser Daten erstaunlich. Danach kann das Geschehen recht genau und fast widerspruchsfrei rekonstruiert werden. Die wesentlichen Ereignisse um die Entwicklungen von Laupeyßer und Falbin bis zum metaleptischen Treffen am Bahnhof sind in einem Zeitraum von zweieinhalb Wochen im August 1981 platziert. Dabei stimmen sogar die angegebenen Wochentage mit denen des Jahres 1981 überein. Macht ein Leser sich jedoch tatsächlich die Mühe, diese verstreuten, teils nur indirekt zu erschließenden Angaben zusammenzusuchen, wird schnell ein anderer Widerspruch deutlich. Zwar sind die Angaben präzise und ob sich ein oder zweimal eine Angabe widerspricht, die Rückkehr von einem Besuch an einer Stelle auf einen anderen Tag als an einer anderen datiert wird, hat keine Konsequenzen. Was nicht zu dieser genauen Datierung passt, sind die Entwicklungen, die mit den Hauptfiguren passieren. Dem auf knapp drei Wochen eingegrenzten Handlungszeitraum widerspricht nicht nur der mehrfach erzeugte Eindruck einer viel längeren Entwicklung, die möglicherweise impliziert, dass sie schon vor dem Kinobesuch eingesetzt hat; andernfalls wäre die Formulierung bezüglich Laupeyßers Treffen mit Freunden, die "von Zeit zu Zeit« $(V G, 17)$ stattfinden, unpassend. ${ }^{22}$ Durch die genaue Auflistung der Datumsangaben ergibt sich vielmehr, dass es für Laupeyßer kaum möglich gewesen ist, seine später geschilderte Entwicklung zumeist in seiner Wohnung verbracht zu haben, da er zu dieser Zeit oft gar nicht in der Stadt ist. Diese subtile Konterkarierung einer vermeintlich realistischen Chronologie könnte ein weiterer Hinweis darauf sein, dass es sich bei der Entwicklung um Imagination handelt.

Eine weitere `Inkorrektheit $\triangleleft$ datiert einen Prozess, der Falbin von Laupeyßer später angedichtet wird, auf "Ende 1983" (VG, 238). Diese Angabe sprengt jedoch nicht nur die textliche Chronologie. VG erschien bereits im Laufe des Jahres 1983 und auch

22 Vgl. auch ähnliche Formulierungen bei Laupeyßer - »für mehr als eine Woche saß er jeden Nachmittag am angestammten Platz « $(V G, 74)$ - und bei Falbin - »jetzt [...], drei Wochen, nachdem er erstmals irregegangen war, die er zugebracht hatte allabendlich auf den Bahnsteigen« $(V G, 131)$. 
die eben bereits genannte Angabe des Entstehungszeitraums am Ende des Buches (»Juli 1981 - Februar 1983«) zeigt, dass dieses beschriebene Ereignis in der damaligen >realen Zukunft lag. Sollte sie nicht nur ein Fehler sein, so stellt sie dennoch lediglich die Fiktionalität aus, sagt jedoch nichts über das tatsächliche Geschehen in der fiktionalen Welt.

Eine kleine Bemerkung in einem Laupeyßer-Abschnitt - die sich auf den Freitodversuch bezieht, der mit dem `Autor--Erzähler verbunden ist; obwohl nicht kursiv gesetzt, scheinen sich hier die Erzähler und Ebenen zu vermengen - greift die oben beschriebene Gegenüberstellung von Empirie und Wahrheit in diesem Zusammenhang wieder auf: »Und dies alles lange vor meinem eigenen Freitodversuch, chronologisch, also empirisch gesehen, nicht wahrhaftig." $(V G, 309)$ Dies kennzeichnet den Umgang der Erzähler mit der Chronologie der Darstellung. Auf den ersten Blick wird versucht, eine solche einzuhalten und deutlich zu machen. Sie scheitern jedoch daran, da das Wirkliche, was sie darzustellen versuchen, nicht mit der Empirie, also der Realität übereinstimmt und damit auch eine realistische, chronologisch genaue Darstellung der Ereignisse nicht möglich ist. Damit ist nur eine Annäherung an diese möglich. Wie schon bei den Näherungen an sich selbst und an andere ist auch hier wieder der Pappkarton das Bild dafür. Auch im Zusammenhang mit diesem ist von den "Schnitzeln seiner Näherungen " $(V G, 87)$ die Rede. Am deutlichsten wird es in der Gleichsetzung des Pappkartons mit dem Buch an sich. Der >Autor«-Erzähler bringt das in einem seiner Zwischenkommentare auf den Punkt.

Jedes Buch ist gewissermaßen ein Pappkarton. Ich könnte Ihnen also auch den vorliegenden Text zuschicken, anstatt das schwere Dings dort auf dem Wohnzimmertisch zur Post zu bringen. Beziehungsweise haben Sie den Text ja längst gekauft, einen tausendmal vervielfachten Pappkarton sozusagen, Lieferung frei Buchhandlung. Da spare ich die Portokosten.

Der Pappkarton ist an dieser Stelle also das Bild für das Buch als Kunstwerk und damit wird auch die mit ihm verbundene Sammlung von Schnipseln, Sentenzen und Fragmenten mit einem Konzept poetischer Schreibweise gleichgesetzt. Diese zeigt sich im fragmentarischen Aufbau von VG wiederum als die Poetik des Buches selbst. Diese vom >Autor`-Erzähler auch als »Aufzeichnungen und hybride[] Skizzen« (151) bezeichnete Form entwerfen fiktionale Welten, die parallel zueinander als mögliche Welten bestehen. Die Beschreibungen versuchen als "Näherungszeilen« $(V G, 214)$, sich so nahe wie möglich der realen Welt anzunähern, sind damit Näherungen an die Wirklichkeit. 

Teil II

Wolpertinger oder Das Blau 



\section{Heteronome Identitäten}

\subsection{Einleitung: »Es ist immer das gleiche ${ }^{1}$}

Wolpertinger oder Das Blau (1993) ist ein hochkomplexes und vielschichtiges Buch. Allein der Umfang von 1009 Seiten (in der Taschenbuchausgabe) ${ }^{2}$ macht es für den Leser schwierig, den Überblick zu behalten und die unterschiedlichen Handlungsstränge zu verfolgen. Verschiedene Zeit- und Handlungsebenen, eine Vielzahl an kleinen Motiven, intertextuellen Verweisen und mythologischen Anspielungen bestimmen die Struktur. Mehr noch als die Länge des Textes sind es der komplexe Aufbau, die beabsichtigt verwirrende Schreibweise und die, wie sich zeigen wird, nicht zu entwirrende Konstruktion, die das Verständnis erschweren. Durch eine leichte, eine oberflächliche Lektüre ist dieses nicht zu erlangen, die intensive Mitarbeit des Lesers ist dazu erforderlich. Im Folgenden soll der Roman anhand der bereits eingeführten Kategorien Identität und Realität analysiert und gleichzeitig ein Überblick über zentrale Motive und Themen geschaffen werden.

Bereits in $V G$ wurde die Identitätsthematik explizit aufgebracht. In $W B$ ist dies noch verstärkt der Fall. Durch zahlreiche Diskussionen ist der Roman sehr theoriehaltig. Zwar rücken nun andere Aspekte von Identität in den Vordergrund, doch ist die Identität wieder ein zentrales Thema, wenn nicht das wichtigste des Buches. Eingeführt wird sie gleich mit dem ersten Absatz des Hauptteils:

- Mein guter Freund, sagte ich - so gewiß ich ich bin und Sie Sie sind - Und wer sind Sie?, fragte er. — Bringen Sie mich nicht durcheinander, sagte ich. $(W B, 37)$

Zunächst wirkt die Passage durch ihre Kontextlosigkeit eher irritierend, was allerdings auch beabsichtigt zu sein scheint, da gleich durch den Ich-Erzähler angemerkt wird, dass er durcheinander gerät. Die Kontextlosigkeit ist jedoch nur scheinbar, denn es handelt sich um ein Zitat, worauf Renate Giacomuzzi hinweist. ${ }^{3}$ Es stammt wörtlich aus Laurence Sternes Tristram Shandy $y^{4}$ und ist damit erst einmal gar kein Gedanke von Deters, dem Protagonisten der Handlungsebene, sondern eine Passage, die er

1 Wolpertinger, 909.

2 Alban Nikolai Herbst: Wolpertinger oder Das Blau [1993]. Roman, Taschenbuchausgabe, München 2000. Im Folgenden wird aus dieser zitiert; bis auf einige Ausnahmen im Umbruch ist sie fast seitenidentisch mit der Originalausgabe und unterscheidet sich meines Wissens nur in einer Fußnote, auf die unten in Bezug auf Thetis kurz eingegangen wird. Die Erstausgabe erschien 1993 im Axel Dielmann-Verlag: Alban Nikolai Herbst: Wolpertinger oder Das Blau. Roman, Originalausgabe, Frankfurt am Main 1993.

3 Vgl. Giacomuzzi: »Die `Dschungel.Anderswelt $\triangleleft$ und A. N. Herbsts >Poetologie des literarischen Bloggens«", $139 f$.

4 Vgl. Laurence Sterne: The Life and Opinions of Tristram Shandy, Gentleman [1759-1767], hg.v. Melvyn New / Joan New, London [u.a.] 1997, Buch VII, Kap. XXXIII, 434. 
gerade liest. Angedeutet ist dies schon durch den Gedankenstrich am Anfang, der im Original die wörtliche Rede bezeichnet, und dadurch, dass Deters das Buch schließt, das aber dann nicht weiter erwähnt wird. Andererseits offenbart sich das Zitat dann doch wieder als ein Teil der literarischen Imaginationen von Deters, da es sich auch um einen Vorgriff auf eine spätere Stelle handelt. Auch dort (siehe $W B, 116)$ bleibt sie weitgehend zusammenhanglos, was auf ihre Funktion als Einstimmung in Thematik und kryptische Schreibweise hindeutet. Sowohl der Aspekt der Identität mit sich selbst als auch die Umkehrung der klassischen Identitätsfrage ( $>$ Wer bin ich? $`$ ) als Bezug auf ein Gegenüber verweisen auf eine Auseinandersetzung mit Fragen der Identität. Die Umkehrung erfolgt auch in der späteren Stelle, nicht der Protagonist wird gefragt, sondern er fragt das Gegenüber, wie in Tristram Shandy ein Commissarius.

Wie im Folgenden genauer nachgewiesen, wird direkt an die Behandlung des Themas in VG angeschlossen. Verschiedene Motive dieses Zusammenhangs werden übernommen. Wieder steht der (neue) Pass für die gesamte Identität, Deters wechselt seine, indem er sich einen neuen Pass beschafft, in eine andere Stadt aufbricht und beginnt, sich eine neue Vergangenheit auszudenken. Die Belastung der späteren Generationen durch die Nazivergangenheit der nahen Verwandtschaft taucht bei der Nebenfigur Klaus von Hüon wieder auf, dessen Vater als Arzt in die medizinischen Experimente in nationalsozialistischen Konzentrationslagern verstrickt ist. Der Aspekt der psycho-sozialen Entwicklung einer eigenen Identität und ihrer poetischen Darstellung, der in $V G$ im Mittelpunkt stand, spielt in $W B$ kaum noch eine Rolle. In den Vordergrund tritt die zunächst auf die Ebene der Darstellung bezogene Frage, wer eigentlich wer (oder was) ist, also die Identifizierung der Figuren. Dies ist dadurch begründet, dass die Figuren selbst mit diesen Fragen beschäftigt sind und eine Figurenentwicklung angesichts der intertextuellen Determination sowie der Fokussierung auf theoretische Reflexionen kaum vorhanden ist. Am deutlichsten drückt sich dies in der wieder auf ein Gegenüber bezogenen Identitätsfrage aus: Deters fragt mehrfach andere Figuren, wer sie eigentlich seien (vgl. $W B, 463,645$ f.). Da es verschiedene Ebenen und mehrere darauf angesiedelte Parallelfiguren gibt, also Figuren, die sich stark ähneln und zwischen denen es eine Verbindung zu geben scheint, wird zudem die Frage zentral, ob es sich hier tatsächlich um Identität handelt, ob die Figuren dieselben sind oder aber ob ein anderer Zusammenhang besteht. Dabei geht es also um die Frage der numerischen Identität. Prägnanten Ausdruck findet dieses in einer Formulierung, die sich auf Figuren verschiedener Ebenen bezieht: »Das ist identisch [...] - Prinzipien in wechselnder Gestalt.« $(W B, 659)$ Die Formulierung hat demnach auch dem Abschnitt dieser Arbeit die Überschrift gegeben, der diese Prinzipienhaftigkeit untersucht. Ein Großteil der folgenden Analysen geht dann auch diesen Fragen nach und versucht, durch genaue Textarbeit die Zusammenhänge zwischen den Figuren sowie die Identität der wichtigsten Figuren zu erfassen.

Die zentrale Beobachtung, die sich in Bezug auf die Identität der Gestalten ergeben hat, ist ihre Heteronomie. Sie sind in keiner Hinsicht autonom oder gar ein rautonomes Subjekt $`$, ein Begriff, der auch mehrfach genannt wird. Vielmehr kann nachgewiesen werden, dass sie immer von jemandem oder etwas abhängig sind, von jemandem fremdbestimmt und durch vorhandene Muster determiniert. Im Anschluss an VG ist der Bezug auf die genetische und soziale Prägung durch die Familie zu nennen. An 
erster Stelle steht in WB jedoch die Abhängigkeit vom Autor. Gemeint ist zunächst gar nicht der reale Autor Herbst, sondern die textinternen fiktiven Autoren. Die Ebenen sind in ein komplexes Netz literarischer Autorschaften verflochten, eine Ebene wird von einer Figur der anderen Ebene erdacht, die wiederum von jemandem anderen erdacht ist. Somit sind die Figuren von den Vorgaben ihrer Autoren determiniert; ein Umstand, der für jede literarische Welt gilt, hier jedoch von besonderer Bedeutung ist, da er thematisiert wird und sich die Figuren teils ihrer Abhängigkeit bewusst sind.

Das Zitat, das im Titel dieses Abschnitts enthalten ist, stammt aus einem der vielen metanarrativen Gespräche, das im Kontext kaum weniger verwirrend ist, als es so alleinstehend schon zu sein scheint.

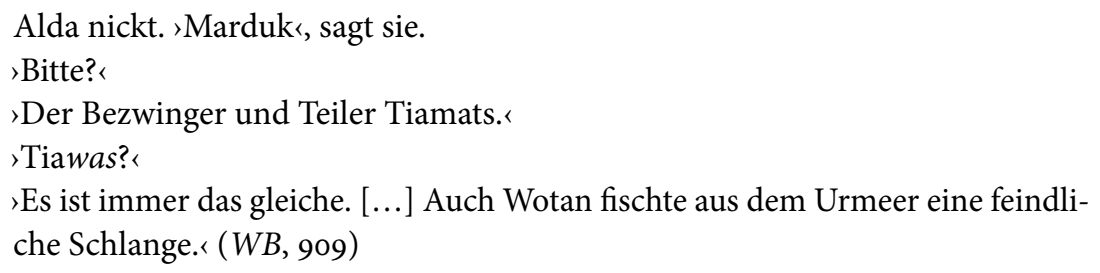

Die Rede ist eigentlich von der Nebenfigur Baumwolle und die hier genannte Alda interpretiert Deters' Erzählung in einer Weise, die ihm nicht bewusst ist, die er noch nicht einmal versteht, wie durch seine verwirrten Nachfragen deutlich wird. Wesentlich ist ihr Erkennen von Zusammenhängen, Ähnlichkeiten und Strukturen in der Erzählung. Sie zieht die Verbindung von der scheinbar autonom erfundenen Figur Baumwolle zur mythischen Gestalt Marduk (aus der babylonischen Mythologie, dazu später mehr), und von dieser wiederum zu Wotan aus der germanischen Mythologie. Die Handlungen der mythischen Gestalten und damit auch diese selbst sieht sie als »immer das gleiche« an und bringt damit eine zentrale Prämisse für die Figurengestaltung und die Erzählkonstruktion von WB auf den Punkt, die sich in diesem Zitat zwar nur auf die Mythologie bezieht, jedoch auch auf andere Bereiche ausgedehnt werden kann: keine Figur ist autonom und steht ausschließlich für sich als individuell ausgestalteter Charakter. Sie sind durch mehrfach kodierte mythologische Bezüge in ihrer Figurenindividualität eingegrenzt, stehen für Prinzipien und allegorische Muster, oder sind durch Intertexte vorgeprägt. Andererseits sind mindestens die Hauptfiguren originell gestaltete Charaktere, die sich wiederum von ihren Vorbildern abheben und damit doch eine individuelle Identität ausbilden. Die Ambivalenz zwischen Vorprägung und Originalität soll in den folgenden vier Abschnitten genauer nachzeichnet und über verschiedene Bereiche hinweg beschrieben werden.

Um jedoch zumindest in Grundzügen erst einmal zu klären, wer wer ist, wo er oder sie hingehört und mit wem er oder sie in Verbindung steht, soll ein kurzer Exkurs einen Überblick über die verschiedenen Ebenen und die wichtigsten Figuren verschaffen und damit das Verständnis für die dann folgenden Ausführungen erleichtern.

\section{Handlungs- und Figureneinführung}

Wie schon in $V G$ erschließt sich der Aufbau von $W B$ erst nach und nach durch Hinweise und metanarrative Erläuterungen. Schließlich können drei Ebenen identifiziert wer- 
den, die sich vor allem durch Zeitangaben sowie durch weitgehend unterschiedliche Figuren unterscheiden lassen. Dabei ist jedoch anzumerken, dass diese Einordnung nicht vollständig durchzuhalten ist. Vor allem gegen Schluss kommt es zu verschiedenen Überschneidungen zwischen den Ebenen. Wie später genauer ausgeführt wird, ist auch nicht eindeutig zu `klären`, welche Handlungsebene von wem erzählt wird; zudem sind selbst die Handlungsebenen eigentlich schon vervielfältigt, da nicht klar ist, was tatsächlich passiert und was imaginiert ist. Dennoch hilft eine provisorische Einteilung als heuristisches Mittel zur Orientierung des Lesers und ermöglicht eine einfachere Verständigung.

Die erste Erzählebene ist im Jahr 1981 angesiedelt. Die Figur Hans Deters wird als Protagonist einer heterodiegetischen-Erzählung eingeführt, wobei schnell deutlich wird, dass die Zugfahrt, die er unternimmt, an das Ende von $V G$ anschließt (dazu später mehr). Deters hat vor, von Bremen nach Frankfurt am Main zu fahren; ihm fällt bereits am Bremer Bahnhof eine Frau auf, die er während der Zugfahrt beobachtet und deretwegen er in Göttingen umsteigt und ihr in den Zug nach Hannoversch Münden folgt. Im Zug lernt er Dr. Elberich Lipom kennen, der ebenfalls in Münden aussteigt, wo Deters dann in Kontakt mit der Frau kommt. Nachdem er sie bereits in Gedanken Anna genannt hat, stellt sie sich als Anna Häusler vor. Sie wird begleitet von dem Schriftsteller Axel Bertrecht. Lipom, Anna und Bertrecht sowie ein kleines >Männchen` namens Professor Murnau erweisen sich als Mitglieder der ATG, der Akademischen Tischgesellschaft, die sich wie jedes Jahr im Hotel Wolpertinger ${ }^{5}$ in Münden zu einem mehrtägigen Treffen zusammenfinden. Erst später wird klar, dass es sich bei Lipom, Murnau und Anna um Geisterwesen oder Elben handelt, also um Gestalten verschiedener keltischer und nordischer Mythologien. Mit vielen weiteren Geistern halten sie ein Thing ab, eine Gerichtsversammlung. Auf dieser Ebene angesiedelt sind noch die Psychologin Dr. Weigan, die ebenfalls an dem Treffen teilnimmt, später stoßen hinzu Freiherr Klaus von Hüon und der frühreife Junge Ortnit, Lipoms Sohn. Schließlich gibt es Hotelpersonal, eine Gruppe von Lehrern, die sich im Wolpertinger trifft, später dann eine Gruppe von Verkäufern, die zu einer Schulung zusammengekommen ist, eine Gruppe von Terroristen, die sich als Bekannte von Bertrecht herausstellen, sowie einige andere Personen des Städtchens. Aus dem Figurenensemble der Zugfahrt ist vor allem der Agent Jeremias Baumwolle zu nennen, der Deters anspricht, ihm eine Art Spionageauftrag erteilt und später noch eine Rolle spielt.

Zwei Wendungen gibt es schon auf dieser Ebene selbst, die solcherart dargestellte Realitäten infrage stellen. In einer schon in sich mehrdeutigen Lesart denkt sich Deters die Ereignisse selbst aus und formt sie als literarischen Text oder aber halluziniert sie. In einer anderen Möglichkeit spielt eine weitere Figur eine Rolle, der Börsenbroker Dietrich Daniello. Er ist zwar der Besitzer des Wolpertinger und finanziert die Treffen der ATG, hält sich bei diesen aber am Rande. Es stellt sich schließlich heraus, dass er im Keller des Hotels einen Biocomputer betreibt, der sowohl die Geister als auch die Ereignisse elektronisch generiert und zudem Auswirkungen auf die anwesenden

5 Ist im Folgenden das Hotel gemeint, wird das Wort /Wolpertinger ist das Buch gemeint, wird es kursiviert oder als $W B$ abgekürzt. 
Menschen (u. a. Deters, Weigan und Bertrecht) hat. Doch sei angemerkt, dass auch diese Lesart nicht als absolut zu sehen ist und wiederum selbst infrage gestellt wird.

Die zweite Erzählebene spielt 1985 und ist zunächst sehr schwer von der ersten zu unterscheiden. Der Protagonist und Ich-Erzähler kann zunächst für identisch mit dem Deters der ersten Erzählebene gehalten werden, da er sich ebenfalls auf einer Zugfahrt von Bremen nach Frankfurt befindet. Später wird jedoch deutlich, dass es sich um eine Zugfahrt handelt, die vier Jahre später stattfindet. Der Protagonist trifft im Zug eine Frau, die er nach einer gemeinsamen spielerischen Übereinkunft ebenfalls Anna nennt, die sich aber später als Aldona bzw. Alda von Hüon herausstellt. Er kommt mit ihr ins Gespräch, sie verbringen eine Nacht weitgehend erzählend in Göttingen und fahren am nächsten Tag weiter nach Münden, wo sie sich im Hotel Andree's Berg einquartieren, das sich am selben Ort wie das Wolpertinger auf der ersten Ebene befindet, wodurch eine räumliche Identität nahegelegt wird. Dort treffen sie auf den Börsenbroker Otto Mallebron, ein Kunde von Alda, der den Erzählungen oft zuhört. Später kommen hinzu Alfred Rascher, ein Neonazi, sowie der Junge Ramon-Roger, eine Ortnit-Parallele. Außerdem ist eine Schauspielertruppe im Hotel einquartiert, die eine Vorführung eines Theaterstücks Die Winde vorbereitet. Da sich herausstellt, dass der Protagonist sich die erste Erzählebene zunächst ausdenkt, sie dann Alda erzählt und sie schließlich mit dieser gemeinsam weiterentwickelt, wird er größtenteils >der Autor ' genannt. Er nennt sich jedoch auch, in Anlehnung an die erste Ebene, Hans Deters, was, gemeinsam mit der anfänglichen Benennung von Alda als Anna ein Auseinanderhalten der beiden Ebenen behindert. Generell wird dieser Protagonist im Folgenden als Deters II bezeichnet. ${ }^{6}$

Die dritte Erzählebene ist wiederum vier Jahr später, also 1989, angesiedelt. Sie wird erst sehr spät in einem längeren metanarrativen Kommentar in dem Kapitel »Eine Dritte Ankunft, nämlich die Mitte« $(W B, 560)$ explizit eingeführt, wobei es sich sowohl in Bezug auf die Seitenzahl als auch auf die Kapitelaufteilung tatsächlich in etwa um die Mitte des Buches handelt. Der Erzähler führt sich als »Ich, der ich weder Deters noch eigentlich sein Autor bin" $(W B, 560)$ ein und die dritte Ankunft besteht darin, dass auch er nach Hannoversch Münden fährt und sich dort in das Jagdhaus Heede einquartiert. Dieses ist jedoch nicht identisch mit den Hotels Wolpertinger oder Andree's Berg; an deren Stelle steht nur noch eine Ruine. Er schildert, dass er mit Deters II Namen und Pass getauscht sowie dessen Aufzeichnungen erhalten hat, die er als »sozusagen Korrektor « $(W B, 724)$ oder »Überautor « $(W B, 907)$ bearbeitet und umgeschrieben habe. Da die Ebenen in komplexer Weise in mehreren Schleifen zusammenhängen und erzählt werden, wobei vor allem von der zweiten Erzählebene quasi als `Hauptebene aus zeitlich nach hinten und nach vorn erzählt wird (was später noch genauer zu analysieren ist), findet sich für den Protagonisten der dritten Erzählebene die auf der zweiten Erzählebene verwendeten Bezeichnungen »der Dritte« oder eben »Überautor«. Er steht jedoch in Zusammenhang mit Deters und Deters II, die alle mehr oder weniger die gleiche Person in verschiedenen Zeit- und

6 Dies geschieht zur leichteren Identifizierung. Ich folge dabei der Anregung von Ursula Reber in Formenverschleifung, die dadurch im Vergleich zur früheren Sekundärliteratur erstmals größere Klarheit bei der Figurendifferenzierung geschaffen hat. Ist im Folgenden von Deters die Rede, so ist also der Deters der ersten Ebene gemeint. 
Wesenszuständen sind. Auf der dritten Ebene ist zudem noch eine weitere Instanz dieses Personengeflechts angesiedelt, die sich Eckhard Cordes nennt.

Es kommt schließlich zu einer Verbindung der verschiedenen Ebenen durch ein Fest der Geister, das auf allen drei Ebenen gleichzeitig stattfindet. Verschiedene Motive und Handlungsstränge werden hier zusammengeführt, was in einem veritablen (und brutalen) `Showdown k kulminiert. In einem dreiteiligen Epilog werden verschiedene Ausgangsmöglichkeiten präsentiert: Deters ist vermutlich bei dem Fest getötet worden, der $>$ Dritte $<$ hat die virtuellen Geister (ihrem Plan folgend) auf einer Diskette aus dem Wolpertinger gerettet und Deters II hat sich in ein Tier, entweder einen Luchs oder vielleicht aber in das titelgebende Fabelwesen Wolpertinger verwandelt.

Schließlich sei noch der Prolog als Ausgangssituation erwähnt. Ein Ich-Erzähler, der später als der `Dritteく identifiziert werden kann, sitzt an seinem Küchentisch und beginnt zu schreiben. Durch das Formulieren wird er aus seiner Wirklichkeit herausgezogen und erlebt phantastische Szenen, die bereits auf spätere Motive und Teile der Handlungen verweisen.

\subsection{Mythologische Identitäten}

Das in der Einleitung genannte Zitat - „Es ist immer das gleiche." $(W B, 909)$ bezeichnet die Ähnlichkeit, wenn nicht gar Identität von Gestalten verschiedener Mythologien. Wie auch die mythologischen Anspielungen im Allgemeinen nimmt dieses Motiv in $W B$ einen großen Raum ein, es wird immer wieder explizit angesprochen oder in der Bezeichnung der Figuren deutlich, wie gleich näher zu zeigen sein wird. Auf der ersten Seite des Prologs wird durch Wagner-Zitate und urban legends auf Mythen angespielt und sogar der Mythos-Begriff direkt ins Spiel gebracht. Explizit thematisiert wird die Verwendung von Mythen später auch in den Gesprächen zwischen Deters II und Alda, die sich in ihrer gemeinsamen Konstruktion des Fortgangs der Handlung auf verschiedenste Mythologien beziehen. Schließlich spricht Cordes dies in einer der typischen verwirrenden Wendungen an, als er gleich bei seiner Selbsteinführung zugibt bzw. erläutert, nicht Deters II und Alda hätten die Bezüge auf die "sogenannten nordischen Mythologien « eingebaut, vielmehr seien diese aus seiner eigenen »Vorgeschichte hergeleitet« $(W B, 561)$. Der >Autor (Deters II) habe sich vermutlich "mit europäischer Mythologie kaum beschäftigt: Erst was ihm widerfuhr, machte Recherchen meinerseits nötig und also, meine Ergebnisse dem Texte heute (1989) einzufügen « $(W B, 562)$. Alban Nikolai Herbst stellt selbst mehrfach solche Recherchen als einen der Ursprünge seiner Arbeit an diesem Roman dar. In einem Kommentar im Weblog schreibt er darüber:

Mit dem WOLPERTINGER kam der Mythos in meine Arbeit, auch das war wieder in der Konkretion begründet. Das Hotel, worin der Roman zu weitesten Teilen spielt, stand in Hannoversch Münden auf einem Questenberg. Ich recherchierte `Queste und gelangte in die europäische Mythologie. Die Recherche ging bis in die Edda zurück, parallel recherchierte ich die Geschichte des Hotels im Stadtarchiv usw. Handwerk halt. ${ }^{7}$

7 URL-8, 23. Mai 2009. 
Schon wesentlich früher hatte er in einem Interview die Ergebnisse dieser Recherchen zusammengefasst und an Beispielen verdeutlicht:

Die Mächte der Phantasie [...] sind bei mir ja schlicht Geister, und sie stammen aus ganz Europa. Andererseits haben sie in bestimmten Ländern bestimmte Ausprägungen. Der vorgeblich so deutsche Alberich ist ja nichts anderes als eine Abspaltung von Shakespeares Oberon, und der ist aus dem südfranzösischen Auberon assimiliert, der wiederum Gatte der Esclarmonde de Foix war, die in den Pyrenäen den matriarchalen Gral, also die göttliche Fruchtschale, hütete und ihren päpstlichen Häschern als weiße Taube nach Asien entkam. Sie sehen: Hier durchdringen einander teils identische, teils völlig widersprechende Motivstränge. ${ }^{8}$

Schon hier spricht er die Ambivalenz an, die der Beobachtung zugrunde liegt. Einerseits gibt es Übereinstimmungen, scheinen Figuren oder Motive identisch, andererseits widersprechen sie sich wieder. Im eben zitierten Weblog-Kommentar stellt er im Weiteren dann diese Ambivalenz in den Mittelpunkt seiner Betrachtung:

Mir fiel für die Mythen auf, daß ein- und dieselben Figurationen rein und selbr gar nicht waren, sondern daß sich, je nach Zeiten und Gebieten, dieselben Figuren leicht veränderten, verschoben, schließlich aufspalteten in Charactere [sic!], die zueinander sowohl zeitlich als auch nach ihrer Funktion in scharfem Widerspruch standen, also erzählerisch fehlerhaft waren, wenn man sie denn als identische nahm. Nahm man sie aber $\mathrm{n}$ i $\mathrm{cht}$ identisch, waren sie, weil ohne Geschichte, nicht mehr zu verstehen. ${ }^{9}$

Auffällig, wenn auch nicht erstaunlich, ist, dass Herbst die mythischen Gestalten sogleich in ihrer erzählerischen Einbettung und Funktion sieht, die sich, was ein Kennzeichen von Mythos ist, der wiederholten poetischen Bearbeitung anbietet. Die Fülle an Geschichten der sich überschneidenden mythologischen Traditionen bietet sich dem Autor als poetischer Ideenfundus an. Zudem passt die Thematik der ambivalenten mythischen Identität denn auch sehr zu dem bereits etablierten herbstschen Motiv ambivalenter personaler Identität.

\subsubsection{Dr. Elberich Lipom}

Das zentrale Beispiel für die mythologisch geprägten Identitäten ist die Figur Dr. Lipom. Zunächst ist er der stark übergewichtige, Gedichte vor allem von Gottfried Benn deklamierende Arzt Dr. Elberich Lipom, den Deters auf der Zugfahrt nach Hannoversch Münden kennenlernt und der sich dort als ein Mitglied der ATG herausstellt. Gleichzeitig ist er jedoch der Elbenfürst Alberich, der nicht nur der eigentliche Wortführer der ATG ist, sondern später auch dem Thing der Geister vorsteht, zu dem Hunderte von Elben, Geistern und Phantasiewesen zusammengekommen sind. Die Lipom-Identität ist als eine Fassade zu sehen, eine Maskerade wie der dazugehörige Körper. ${ }^{10}$ Als vermeintlicher Mensch Lipom hat er keinerlei Funktion, die entspre-

8 Faure: ») Jetzt hab ich Metall im Mund««, 13.

9 URL-8, 23. Mai 2009.

10 Vgl. dazu WB, 94: "In Wahrheit bin ich nämlich gar nicht fett< [...] >Denn es ist doch so, daß ich nicht mein Körper bin.« 
chende Vorgeschichte und der aktuelle Stand wie die frühere Assistenzzeit bei Benn sowie die jetzige Rente werden weder bestätigt noch spielen sie eine weitere Rolle. Bedeutung hat ausschließlich die Identität als Alberich, selbst wenn auch diese dadurch relativiert wird, dass er entweder eine von Daniello programmierte virtuelle Gestalt oder aber das Phantasieprodukt von Deters II (oder dem ersten Deters) ist. In beiden Fällen bleibt die Elbenidentität in der jeweiligen entworfenen Welt als Hauptidentität bestehen.

Entscheidend für die Erzählkonstruktion ist die verzögerte Identifizierung der Figur. ${ }^{11}$ Zunächst wird er zwar als Dr. Lipom identifiziert, da dies aber nicht seine eigentliche Identität ist, ist die Identifizierung als Alberich verzögert. Seine explizite Benennung als solcher erfolgt erst im letzten Drittel des Romans. Erst durch seine ausführliche Eigenvorstellung zu Beginn des Things gibt Lipom/Alberich seine wahre Identität preis. Davor gibt es zwar viele Hinweise, die auf diese Identifizierung hindeuten bzw. eine solche wahrscheinlich machen, doch können sich weder Deters noch mit ihm der Leser wirklich sicher sein. Dabei hat der Leser jedoch zumindest die Möglichkeit, verschiedenen Hinweisen nachzugehen, die Deters zu übersehen oder aber nicht zu verstehen scheint. Der Vorgang der Identifizierung soll im Folgenden genauer dargestellt werden.

Als sich Lipom Deters im Zug mit seinem vollen Namen als »Lipom, Dr. Elberich Lipom« $(W B, 92)$ vorstellt, ist der Verweis auf die mythische Figur Alberich noch keineswegs eindeutig. Erst seine wenig später folgenden eigenen Hinweise auf seine Tarnkappe, die mit seinem Vornamen zusammenhänge, ermöglichen dem Leser, den Bezug zur Nibelungensage herzustellen. Durch den Vornamen Elberich ist schon die Zugehörigkeit zum Volk der Elben bzw. Elfen angedeutet, zusätzlich wird jedoch auch der Bezug zur Sagengestalt Alberich aufgespannt. Dieser ist in mehreren europäischen Mythologien unter verschiedenen Namen bekannt. In der Form Alberich kommt er im Nibelungenlied und in der Folge dann auch in Richard Wagners Der Ring der Nibelungen ${ }^{12}$ als Zwergenkönig vor, der im Besitz einer Tarnkappe bzw. -mantels ist und den Nibelungenhort bewacht. Außerdem findet er sich in der Sage von Ortnit, die in das Wolfdietrich-Epos aus dem 13. Jahrhundert eingebettet ist. In der französischen Form Auberon findet er sich in Huon de Bordeaux, einer altfranzösischen Chanson de geste aus dem 13. Jahrhundert, die dem Sagenkreis um Karl den Großen angehört. ${ }^{13}$ Sowohl das Ortnit-Epos als auch Huon de Bordeaux haben weiteren Figuren die Namen geliehen. In der englischen Form Oberon ist er schließlich in der Komödie $A$ Midsummer Night's Dream (1595/96) von Shakespeare zu finden und in der Folge in Christoph Martin Wielands Versepos Oberon (1780).

11 Vgl. zu dem Begriff Jannidis: Figur und Person, 147ff. Später kann zusätzlich noch von einer gestörten Identifizierung gesprochen werden.

12 Aus diesem, genauer gesagt aus Siegfried $(2,3)$, wird bereits auf der ersten Seite des Prologs und später in mehreren Wiederholungen zitiert. Das Zitat (»Lustig im Leid [...].«, WB, 17) ist jedoch unmarkiert.

13 Vgl. dazu Michael Heintze: »Huon de Bordeaux«, in: Rolf Wilhelm Brednich u. a. (Hg.): Enzyklopädie des Märchens. Handwörterbuch zur historischen und vergleichenden Erzählforschung, Bd. 6, Berlin / New York 1990, 1400-1407. 
Im Laufe der Gespräche der ATG wird Lipom ganz nebenbei und unerläutert vor allem von Murnau mit verschiedenen Namen angeredet oder mit Bezeichnungen versehen. So wird er als »Andwari« (WB, 169, 173, 197, 627), der als Zwerg im Völuspà aus der Liederedda dem Alberich der Nibelungensage entspricht, »Herr Twer « (WB, 173, 733) oder "Gerdsohn (Wyllt)« $(W B, 662,679,698,884)$ bezeichnet, die auf Deters' Nachfrage als "Spitznamen « $(W B, 173)$ abgetan werden. Außerdem wird er mehrfach ein "Sìdhe " genannt, der Name für die keltischen Elfen. Er selbst sagt Deters gegenüber, er sei eine Zeit lang bei ihnen zu Besuch gewesen (vgl. WB, 318), ohne jedoch zu erklären, um wen es sich dabei handelt; später bemerkt Ortnit nebenbei, Lipom sei von diesen adoptiert worden (vgl. WB, 708). Deters erschließt sich über diese Anspielungen die eigentliche Identität Lipoms jedoch keineswegs, da ihm die Begriffe nichts sagen und er im Gegensatz zum vielleicht ebenfalls unwissenden Leser keine Möglichkeit hat, sie nachzuschlagen. Ihm können sie lediglich ein weiterer Hinweis darauf sein, dass Lipom und die anderen keine normalen Menschen sind, der Leser kann so bereits zusätzlich zu den zuvor beschriebenen Deduktionen erfahren, dass weitere mythologische Namen auf die Figur Lipom bezogen werden.

Bei seiner eigenen Vorstellung zu Beginn des Things expliziert Lipom seine eigene Benennung, indem er die verschiedenen Formen des mythischen Namens Alberich als seine Namen nennt. Er sei der Elbenfürst »Alberich von Niflheim, genannt Auberon de Foix und Oberon von den Düften « $(W B, 803)$. Klar wird beim Thing dann auch, dass Anna seine Gattin, die Elfenkönigin Titania, ist. Außerdem fügt Lipom noch Myrddin Wyllt und Anfortas an, die aus der keltischen Mythologie bzw. der Gralssage stammen, sowie diverse Bezeichnungen durch Titel oder Eigenschaften. Die Bezeichnung mit Namen sind denn auch im gesamten Text der deutlichste und auch wesentliche Hinweis auf die mythischen Vorlagen. Auch wenn die Namensnennung eins der "[b]esonders geläufige[n] Verfahren zur Identifizierung « ${ }^{14}$ einer Figur ist, ist jedoch auffällig, dass die Verbindung zu den Mythologien fast ausschließlich über die Namen hergestellt wird. Die Strukturen und Handlungen spielen bei der Identifizierung der mythischen Figur eine untergeordnete Rolle, da beispielsweise die eigentliche Handlung um Oberon und Titania nur angedeutet wird und damit einen geringen Platz im Roman einnimmt.

Diese Zusammensetzung von Lipoms Identität aus verschiedenen Mythologien bedeutet dabei eine Uneindeutigkeit, eine Aufsplitterung, die sich gleich auch in der benannten Herkunft fortsetzt. Was Lipom in einem Gespräch mit Deters schon früher angedeutet hat, als dessen Verdacht allzu stark geworden ist, dass es sich bei der ATG nicht um Menschen handelt - er sei »wenigstens dreimal gezeugt, aber nur zweimal geboren« $(W B, 645)$-, führt er nun genauer aus: er sei »Erstgeborener des Thor von Asgard und der Frouwe Gerd [...] « sowie »Zweitgeborener des Gaius Julius Caesar von Rom und der Morgana, Frouwe de la rosche bîse, die man auch Fee Morgan nennt $[\ldots]$ « (WB, 803, vgl. auch 667). Diese Angaben fügen zusammen, was in verschiedenen Überlieferungen über die mythische Figur Alberich bekannt ist. ${ }^{15}$

14 Jannidis: Figur und Person, 111.

15 Vgl. Bernd Steinbauer: »Oberon«, in: Rolf Wilhelm Brednich u. a. (Hg.): Enzyklopädie des Märchens. Handwörterbuch zur historischen und vergleichenden Erzählforschung, Bd. 10, Berlin / New York 2002, 173-176. 
Durch die Zusammenführung wird jedoch gerade die Diversität und die eigentliche Undenkbarkeit mehrfacher Zeugung und Geburt betont. ${ }^{16}$ Herbst übergeht also gerade die Unterscheidung zwischen verschiedenen mythologischen bzw. literarischen Überlieferungen, auf die Wieland in seiner Vorrede `An den Leser`(des Oberon) aufmerksam macht:

Aber der Oberon, der in diesem alten Ritterromane [Huon de Bordeaux] die Rolle des Deus ex machina spielt, und der Oberon, der dem gegenwärtigen Gedichte seinen Namen gegeben, sind zwei sehr verschiedene Wesen. Jener ist eine seltsame Art von Spuk, ein Mittelding von Mensch und Kobold, der Sohn Julius Cäsars und einer Fee, der durch eine sonderbare Verzauberung in einen Zwerg verwandelt ist; der meinige ist mit dem Oberon, welcher in Chaucers Merchant's-Tale und Shakespeares Midsummer-Night's-Dream als ein Feenoder Elfenkönig (King of Faeries) erscheint, eine und eben dieselbe Person[.. ${ }^{17}$

Im Prolog, der sowohl von der Handlung als auch von den Figuren her zunächst kaum Verbindungen zu den anderen Teilen zu haben scheint, finden sich jedoch Übereinstimmungen wieder über angedeutete mythische Identitäten. Die einzige zu Handlung und Gespräch beitragende Figur außer dem Erzähler (dem `Dritten`) ist ein dicker Herr, der sich als Goldemar Marduk zu erkennen gibt. Wie in fast allen anderen Fällen ist auch dies ein verweisreicher Name. Goldemar ist der Name des Königs der Zwerge in einem zur Dietrichsepik gehörendem Fragment und wird auch als Elbenkönig und Bruder von Alberich genannt. ${ }^{18}$ Marduk hingegen war die Hauptgottheit der babylonischen Religion. ${ }^{19}$ Während der namentliche Bezug zum Zwergenkönig Goldemar bereits eine später erst über den Alberich-Bezug zu erschließende Identität mit Lipom insinuieren kann, wird eine solche schon früher und deutlicher durch andere Merkmale nahegelegt. Neben der Körperfülle und der Beschreibung als »der dicke Herr « ist es vor allem die Sprechweise mit ständiger Unterbrechung der Sätze durch ein »hä«, die später als die für Lipom kennzeichnende kennengelernt wird. Außerdem wird in die Problematik eingeführt, dass die Elben aus ihren angestammten Aufenthaltsorten durch verschiedene Mächte, u. a. die formale Logik, vertrieben werden. Er teilt mit, dass seine Frau (und damit er vermutlich auch) eine Elfe ist, dass die beiden zerstritten sind und dass er wieder in Besitz eines ominösen Beutels, den seine Frau hat, gelangen möchte. Dafür benötigt er die Hilfe des Erzählers, dem er dies als Bitte bzw. Aufgabe anträgt. Der Streit und die Beutel sind auch später immer wieder in den Äußerungen Lipoms präsent, wohingegen die Aufgabe zumindest in den

16 Im Gespräch mit Deters fügt er auch an, dass es sich einmal um eine Fehlgeburt gehandelt habe. Dies deutet daraufhin, dass es sich bei den Geistern (die Unterscheidung zwischen Geisterwesen und Elben wird nicht gemacht) zumindest teilweise um gestorbene Menschen handelt. Weitere Beispiele dafür sind Ortnit, der als Frühgeburt gestorben ist (vgl. WB, 653), sowie Bertrecht, dessen Ermordung und `Geistwerdung`direkt geschildert werden (vgl. WB, 661ff.).

17 Christoph Martin Wieland: Oberon [1780], in: Ders.: Werke, hg. v. Fritz Martini / Hans Werner Seiffert, Bd. 5, München 1968, 162-381, hier: 162.

18 Vgl. Joachim Heinzle: Einführung in die mittelhochdeutsche Dietrichepik, Berlin / New York 1999, 106f., sowie Wilhelm Wägner: Nordisch-germanische Götter und Helden, 4. Aufl., Leipzig / Berlin 1887, 44ff. Im Fragment wird zudem der Erlkönig mit Oberon, Laurin und Goldemar gleichgesetzt.

19 Nebenbei sei bemerkt, dass Marduk auch der Name eines Tyrannen in Alfred Döblins Berge Meere und Giganten ist, von Herbst immer wieder als wichtiger Bezugstext seines Werks genannt. 
Gesprächen mit Lipom nicht mit dem späteren Protagonisten Deters zusammenhängt. Trotz dieser recht eindeutig erscheinenden Hinweise in der Beschreibung auf die Identität Marduks mit Lipom wird diese wieder hinterfragt. Die eindeutige Identität Lipoms mit der mythischen Alberich-Figur kann nicht auf eine ebenso eindeutige Identität mit Marduk ausgeweitet werden. An verschiedenen Stellen verfällt dieser nämlich ins Wienerische oder verwendet zumindest das Wort »Hobera $(W B, 23,25$, 27). Beides sind später die Kennzeichen von Daniello bzw. Mallebron. Dies könnte als Andeutung weniger einer Identität von Daniello und Lipom verstanden werden denn als Hinweis darauf, dass zumindest die Figur Marduk von Daniello programmiert ist.

Die individuelle Ausgestaltung der Figur erfolgt über die Fassade als Dr. Elberich Lipom. Obwohl die mythische Vorlage Alberich ein Zwergenkönig ist, wird Lipom als eine riesige, immer wieder als $>$ fett $<$ bezeichnete Person geschildert, die gerade eingangs bei der Zugfahrt Schwierigkeiten hat, sich überhaupt zu bewegen. Wie bereits erwähnt, sieht er sich selbst als nicht identisch mit seinem Körper an, dieser ist nur eine Täuschung, was auf die Wandlungsfähigkeit der Elben zurückgeht. Weitere individuelle Kennzeichen, die wie in Bezug auf Marduk bereits erwähnt, Lipom auch innerhalb des Buches erkennbar machen, sind seine sprachliche Angewohnheit, ständig Wörter durch ein »hä«, wohl eine Form von Stöhnen oder Schnaufen, zu unterbrechen sowie seine Vorliebe, Gedichte zu zitieren, die vornehmlich von Benn stammen. Dadurch bietet sich die Möglichkeit, intertextuelle Bezüge direkt zu platzieren. Der Bezug zu Benn könnte auch die diesmal nicht mythologische Namensgebung als Lipom, der medizinischen Bezeichnung für ein Fettgeschwulst, bestimmt haben, da Benn in seinen Gedichten immer wieder auch in medizinischen Ausdrücken auf seine Erfahrungen als Arzt rekurriert hat. Der Name spielt aber auch eine Rolle in der später genauer zu betrachtenden Diskussion über das Denken in Begriffen und ihre Wirkung: Murnau weist Deters darauf hin, dass jeder sich Lipom als einen fetten Menschen vorstelle, »weil er wie einer heißt« $(W B, 173)$.

\subsubsection{Anna als Titania}

Wie bereits erwähnt stellt sich Anna schließlich beim Thing als die Elfenkönigin Titania heraus. Durch ihren verspäteten Auftritt wird zwar bereits ihre herausgehobene Stellung deutlich, doch erst die leise Frage von Lipom (»>Titania? [...] Wir müssen doch abstimmen.«", $W B, 831$ ) identifiziert sie dem Leser als Titania. Als sie sich daraufhin zu einer eigenen Ansprache erhebt, bezeichnet sie sich, wie es Lipom zu Beginn seiner Rede gemacht hatte, mit etlichen ihrer Namen: »[...] Ceridwen, Rhiannon, Arianrhod, Ishtar und Cybele, Königin der Bienen und Sonne [...]« $(W B, 831)$ Ebenfalls wie Lipom wird sie mehrfach nebenbei mit anderen Namen angesprochen, beispielsweise als Brawen oder Beltis (beide $W B, 733$ ), was weitere mythologische Bezüge auf die nordische Mythologie hinzufügt. ${ }^{20}$ Die Annahme, Anna sei zudem

20 Durch die genannten Namen wird sie als Muttergöttin, als magna mater ideae eingeordnet, was später noch von Bedeutung ist: Bra(n)wen ist »unschwer als Muttergöttin zu erkennen, oder besser, als eine ihrer drei Erscheinungsformen «, Sylvia Botheroyd / Paul F. Botheroyd: Lexikon der keltischen Mythologie, München 1995, 47; Ceridwen ist der »Prototyp[] der großen walisischen Muttergöttin « (ebd., 55); Rhiannon ist eine walisische Göttin (ebd., 276), Arianrod eine Sagengestalt in der Nähe der dreifachen Muttergöttin (ebd., 22f.); alle diese sind keltischen Ursprungs; Ishtar 
noch mit Marduks Frau, der Elfe aus dem Prolog, identisch, wird nicht wie bei Lipom über Äußerlichkeiten wie Sprache oder Aussehen hervorgerufen, sondern entsteht durch zwei Aspekte. Zum einen durch die Schlussfolgerung, dass bei der Annahme, Lipom sei mit Marduk identisch, auch seine Frau Anna/Titania mit Marduks Frau identisch sei; zum anderen durch die Verbindung von Anna bzw. vor allem Alda mit dem erwähnten, im Besitz der Elfe sich befindenden Beutel.

Soweit greifen die Prinzipien, die bereits an Lipoms Beispiel verdeutlicht wurden auch hier. Anna ist jedoch - nicht wie Lipom, eher wie Deters - noch auf einer anderen Ebene gespiegelt. Dabei handelt es sich um die später als Alda oder Aldona von Hüon identifizierte Frau, mit der Deters II sich auf der Ebene von 1985 unterhält. Er formt Anna in seiner Vorstellung zunehmend nach der äußeren Erscheinung seiner Reisegefährtin und macht sie mit ihrer Erlaubnis zu seiner »Romanheldin« $(W B, 251)$. Er will als Spiel begriffen wissen, dass er von nun an ihre Geschichte erfindet, gerade ohne etwas von ihr zu wissen; ein Spiel, auf das sie bereitwillig eingeht. Nun nennt er sie auch Anna, was vorsätzlich zur Verwirrung beiträgt (wie auch der oben behandelte Umstand, dass sie ihn Hans Deters nennt). ${ }^{21}$ Zunächst wird Alda als eine scheinbar normale Frau eingeführt, bei der lediglich auffällt, dass sie sehr interessiert an Deters' Ring ist, wird in ihren immer vertrauter und intimer werdenden Gesprächen verschiedene Andeutungen gemacht, dass sie entgegen anfänglicher Wahrscheinlichkeit etwas mit den Abenteuern der ersten Erzählebene zu tun hat. Der Clou an der Sache ist nun, dass Deters II sie erfindet, was zwar eigentlich nur auf der ersten Erzählebene geschehen soll, doch möglicherweise (nach der Erzähllogik, die auch anderweitig deutlich wird) auch wieder Auswirkungen auf seine eigene Ebene hat. Es ist jedoch nicht auszumachen, ob dies durch das Erfinden kommt oder ob sie eben zufällig 'wirklich identisch mit Anna ist, da sich Hinweise auch schon vor der Abmachung (des Erfindens) finden. Diese Eigentümlichkeiten an Alda und weitere Hinweise werden jedoch zunehmend deutlich. So fallen Deters ihre Augen auf, mit denen etwas nicht zu stimmen scheint (vgl. $W B, 247)$, die paradoxerweise quittegrün $(W B, 248)$ sind, und deren Pupillen nicht rund, sondern oval und senkrecht in der Iris zu stehen scheinen (vgl. $W B, 284)$. Ihre Erscheinung scheint sich manchmal auch für Momente auf unschöne Weise zu verändern (vgl. $W B, 339,740)$. Bei Ausrufen der Verwunderung oder des Erstaunens ruft sie ebenso wie Anna die Göttin Hulda an (vgl. WB, 247, 533, 728 resp. 204). ${ }^{22}$ Auf das Spiel mit dem Erfinden wird mehrfach vor allem von Alda wieder Bezug genommen (vgl. WB, 257, 351, 533). Beide verhalten sich im Gespräch (und im zunehmend gemeinsamen Erfinden oder Erzählen der Geschichte)

ist eine babylonische Liebesgöttin und Cybele die ursprünglich phrygische Muttergöttin und die magna mater ideae schlechthin.

21 Im Folgenden wird diese Figur in Abgrenzung von Anna Häusler durchgängig als Alda bezeichnet, um die Orientierung zu erleichtern.

22 Für eine `mythische` Identität gibt es auch Hinweise: die Erle, ein weiterer wichtiger Baum der keltischen Mythologie, heißt auf englisch >Alder Verbindung gebracht, womit wiederum, wie oben erwähnt, Anna gelegentlich bezeichnet wird. Auch die Verbindung mit der Farbe grün ist durch die Erle gegeben, deren Blüten grüne Farbe lieferten. Vgl. James MacKillop: A Dictionary of Celtic Mythology, Oxford / New York 1998, 12 und 52, und Robert von Ranke-Graves: Die weiße Göttin. Sprache des Mythos [1948], übers. von Thomas Lindquist, Reinbek 1988, 195-199. 
so, als wenn Anna Alda sei, auch wenn die Annahme durch die Bezugnahmen auf das Erfinden wieder gebrochen wird. Schließlich verwechseln sie gar öfter ihre Identität über die Ebenen $(W B, 305,686)$, korrigieren sich gegenseitig (»Wieso ich? Deters doch.«", $W B, 823$ ) oder Alda insinuiert kokettierend ihre Identität mit Anna (bspw. $W B, 703)$. Auch wird insinuiert, Anna erfahre - obwohl Deters es ihr verschweige etwas, weil Deters II es Alda mitteilt (vgl. WB, 909).

Resümierend vermerkt Alda an einer Stelle, es gebe schon zwei Partnerinnen Lipoms, Anna und sie selbst. Das tut Deters ab mit dem Hinweis: $»$ Das ist identisch... Wie der Dicke und sein Professor... - Prinzipien in wechselnder Gestalt. Nicht mehr und nicht weniger. « $(W B, 659)$ Auf das zugrunde liegende Prinzip ist später einzugehen, ${ }^{23}$ an dieser Stelle ist die Konstatierung einer völligen Identität zu vermerken. Was eingangs als Spiel begonnen hatte und lediglich als ein solches gemeint war, wird schließlich als Fakt konstatiert. Zwar bezeichnet Murnau Alda einmal (als das Verhältnis der Ebenen sich wieder einmal verkehrt und Deters von der zweiten Erzählebene berichtet) treffend als »eine poetische Symbolisierung " $(W B, 798)$ von Anna, was wenig reale Bezüge impliziert; die erfundene Identität der beiden Frauen hat jedoch Auswirkungen. Diese zeigen sich in der Parallelführung der Hieros gamos, der angestrebten rituellen Vereinigung. Auf der ersten Ebene soll diese zwischen Anna und Deters, auf der zweiten Ebene zwischen Alda und Deters II während des simultan auf beiden Zeitebenen verlaufenen Festes geschehen. Die Hieros gamos sind ein aus dem alten Orient stammender ritueller Brauch, die symbolische Vereinigung von menschlichem Priester und weiblicher Gottheit. Dies wird aber - wie viele andere Hinweise auch - kaum im Buch selbst erläutert. Der Ritus soll hier eine Verbindung zwischen den Menschen und den Geisterwesen oder Elben, eine Art Pakt zwischen ihnen schaffen, der ihr Verhältnis neu konstituiert. ${ }^{24}$

\subsubsection{Zusammenfassung}

Wie am Beispiel von Lipom und Anna gesehen werden kann, und was auch für Murnau gilt, der im nächsten Kapitel näher beschrieben wird, sind die Figuren, die Geisterwesen oder Elben sind, von mythischen Vorbildern aus verschiedenen nordischen Mythologien bestimmt. Dabei wird der Bezug zu den Vorbildern vor allem durch die explizite Bezeichnung mit entsprechenden Namen hergestellt. Insofern sind sie keine individuellen Gestalten des Wolpertinger-Kosmos, sondern durch Bezüge auf Mythen vorgebildet. Auf der anderen Seite sind vor allem ihre äußerliche Beschreibung sowie ihr Verhalten und ihre Meinungen in den Gesprächen nicht durch die mythischen Vorbilder bestimmt, sondern die individuelle Ausgestaltung originärer Figuren. Es wird auf eigentümliche Weise kein Unterschied gemacht zwischen dieser individuellen humanoiden Fassade als Mitgliedern der ATG, für deren Aufrechterhaltung auch keine Begründung geliefert wird, und ihren eigentlichen Identitäten als Elben. Außerdem werden die Ausprägungen ihrer Vorbilder in den verschiedenen, wenn auch verwandten Mythologien, die sich jedoch wiederum lediglich in

23 Siehe Abschnitt 3.3 auf Seite 132.

24 Vgl. dazu genauer Abschnitt 3.3.2 auf Seite 156. 
unterschiedlichen Namensgebungen ausdrücken, nebeneinandergestellt, als wären sie gänzlich kongruent.

Schließlich werden weitere Figuren auf anderen Ebenen eingeführt, mit denen ebenfalls eine Identität insinuiert oder gar spielerisch angenommen wird. Der Charakter dieser nahegelegten Annahmen ist ein spielerischer, da er sich auf kleine Hinweise stützt und nicht gänzlich aufgelöst bzw. bewiesen werden kann. Am deutlichsten kann man am Verhältnis der Figuren Anna und Alda sehen, dass sie als beides gedacht werden, als identisch wie als nicht identisch. Einerseits werden beide Figuren parallelisiert, sind Symbolfiguren, eine Identität wird nicht nur spielerisch angenommen, sondern auch stark insinuiert durch Hinweise, die aber widersprüchlich sind. Sie scheinen einer Überlegung zu unterliegen, die Alda gegenüber Deters II anstellt, als sie über die Konstruktion der Erzählebenen nachdenken. Dort sagt sie über eine potenzielle dritte Ebene: »'Es wäre allerdings [...] ein bißchen öd', alles einfach hochzukopieren. Das sollte dann schon anders sein.« $(W B, 786)$ Eben dieses trifft schon auf ihr Verhältnis zu Anna und der ersten Ebene zu. Sie sind gespiegelt, werden parallel erzählt, verhalten sich ähnlich, sind jedoch auch wieder zu unterscheiden. Cordes fasst die dieser Beobachtung zugrunde liegende Überlegung im Gespräch wiederum mit Deters II zusammen: »)Jedes Ding ist nämlich in Wahrheit mehrere Dinge auf einmal. Aber wir betrachten und schneiden die Dinge zurecht nach jeweils nur einer Funktionsweise.« $(W B, 718)$ Damit ist eine Auffassung von Identität benannt, die in kulturwissenschaftlichen Untersuchungen mythischen Denkens als ein Kennzeichen mythischer Identität beschrieben wird. Als Veranschaulichung dient in diesem Kontext die Beschreibung mythischer Rituale. ${ }^{25}$ Nach moderner Auffassung könnte man sagen, dass dort der Tänzer oder Priester, der beispielsweise die Maske einer Gottheit trägt, diese Gottheit im Ritual symbolisiert. Nach mythischer Denkweise ist er aber nicht nur Symbol, sondern er ist die Gottheit. Das Ritual ist eine konkrete Wiederholung der mythischen Handlung. Der Tänzer oder Priester ist damit gleichzeitig er selbst und auch die Gottheit, eine Vorstellung, die dem modernen Menschen wohl kaum begreifbar ist. Für diesen gilt der Satz vom Widerspruch, der eine Aussage und ihr Gegenteil nicht gleichzeitig zulässt, bzw. der Satz vom ausgeschlossenen Dritten (tertium non datur, Ein Drittes ist nicht gegeben). Der Tänzer kann nicht gleichzeitig er selbst und nicht er selbst, also etwas Drittes, eben die Gottheit sein. Auf den Satz vom ausgeschlossenen Dritten wird in WB immer wieder angespielt. Ihn haben laut Deters II »die Sìdhe erfolgreich bis weit ins dreizehnte Jahrhundert hinein [attackiert] « $(W B, 655)$ und eben dies soll durch $W B$ wiederaufgenommen werden. Diese Zusammenhänge führen zu einer Mythenverwendung, die im folgenden Abschnitt genauer betrachtet wird.

\subsection{Prinzipien in wechselnder Gestalt‘}

Bereits erwähnt wurde die Entgegnung von Deters II auf eine Frage Aldas, ihre Identität mit Anna betreffend: » Das ist identisch... Wie der Dicke und sein Professor...

25 Vgl. dazu Thorsten Wilhelmy: Legitimationsstrategien der Mythosrezeption. Thomas Mann, Christa Wolf, John Barth, Christoph Ransmayr, John Banville, Würzburg 2004, 39-47. 
- Prinzipien in wechselnder Gestalt. Nicht mehr und nicht weniger.« $(W B, 659)$ In diesem Abschnitt sollen die nicht explizit genannten Prinzipien genauer betrachtet werden. Lipom und Murnau sind dabei recht einfach der aus der Mythosforschung bekannten Dichotomie Mythos vs. Logos zuzuordnen. Das Verhältnis von Anna zu Alda ist etwas anders geartet, schon da die beiden Figuren auf verschiedenen Erzählebenen platziert sind, und auch das zuzuordnende Prinzip ist ungleich schwerer begrifflich zu fassen. Sie stehen für Formen von Weiblichkeit, die in einem größeren thematischen Zusammenhang zu verorten sind, der als `Geschlechterkampf` (vgl. $W B, 574$ ) bezeichnet werden soll und in den nicht nur die beiden Figuren einbezogen sind, sondern vor allem auch Oberon/Lipom und die verschiedenen Deters-Figuren.

Lipom und Murnau verkörpern Mythos und Logos insofern, als sie vor allem in den ausladenden Diskussionen der ATG sowie während des Things für die jeweilige Position argumentieren. In ihrem Verhalten spiegelt sich dies auch; da sie jedoch nicht allzu viel `handeln`, die Rede also überwiegt, spielt das Verhalten eine eher untergeordnete Rolle. Bei Anna und Alda verhält es sich zumindest teilweise eher umgekehrt. Gerade Anna, die sich an den Diskussionen inhaltlich kaum beteiligt, verkörpert am ehesten das, wofür sie steht. Bei Alda ist es ähnlich, doch vertritt sie in den Gesprächen mit Deters II zudem noch als feministisch bezeichnete Positionen (vgl. WB, 566). Wie im vorigen Abschnitt bezüglich der Prägung der Figuren durch mythische Vorbilder wird hier gezeigt, dass die Figuren in ihren Identitäten von den Prinzipien abhängen, die sie verkörpern. Es ist jedoch auch hier zu konstatieren, dass es sich bei den Figuren keineswegs um eindimensionale Figurentypen handelt. Dafür ist ihre individuelle Ausprägung zu stark betont, zudem sind sie bereits durch verschiedenartige Funktionen und Vorprägungen mehrschichtig angelegt.

Zur Dichotomie Mythos und Logos ist anzumerken, dass ihre Verwendung in WB zwar an moderne Mythentheorien anschließt, jedoch keinesfalls als eine Darstellung der fachlichen Diskussion um die Begriffe anzusehen ist. Die Begriffe selbst sind daher in ihrem Bedeutungsspektrum erst aus dem Text zu destillieren und können so von ihrer Verwendung in einschlägigen Theorien abgegrenzt werden.

Beide Themengebiete, die durch die personifizierten Prinzipien aufgebracht werden, sind durch ihren Mythosbezug bestimmt. Die Art und Weise, wie der Bezug hergestellt wird, kann nach einer Typologie von Peter Tepe klassifiziert werden. Tepe unterscheidet zwischen drei Typen:

Typ a: Texte, die mythische Erzählungen oder Elemente aus solchen Erzählungen verarbeiten.

Typ $b$ : Texte, die Strukturen mythischen Denkens oder Elemente dieser Denkform verarbeiten.

Typ c: Texte, die Mythostheorien oder Elemente aus ihnen verarbeiten.

Die drei Typen mythoshaltiger Literatur können, aber müssen nicht miteinander verschränkt sein. ${ }^{26}$

26 Peter Tepe: Mythos \& Literatur. Aufbau einer literaturwissenschaftlichen Mythosforschung, Würzburg 2001, 80 . 
Dies ist insofern interessant, als er auch den »Typ c « zur `mythoshaltigen Literatur rechnet. Abgesehen davon, dass sich in WB insgesamt gesehen alle drei Typen mischen, kann die Verwendung bezüglich der Verkörperung der Prinzipien Mythos und Logos diesem Typ zugeordnet werden. Es werden Elemente von Mythostheorien behandelt und diskutiert, die in dieser abstrakten Form in den Mythen selbst nicht vorkommen. Andererseits werden sie zumindest teilweise - nämlich bezüglich der Personifikation, nicht in den Diskussionen - wieder an die narrative Darstellungsform der Mythen herangeführt. Das `Geschlechterkampf`-Thema dagegen ist den Typen a und $\mathrm{b}$ zuzuordnen. Zum einen handelt es sich um die Wiedererzählung eines bzw. Anlehnung an ein Mythologem, zum anderen werden Elemente mythischer Denkformen aufgenommen.

\subsubsection{Mythos vs. Logos}

Wie bereits einleitend vermerkt verkörpert Lipom einen Aspekt, der hier unter dem Begriff `Mythos`subsumiert wird. Demgegenüber steht Murnau für den diesem entgegengesetzten Begriff 〉Logos`. Ihre Verkörperung drückt sich zunächst gar nicht als eine solche aus. Die mit diesen Begriffen mythentheoretisch verbundenen Positionen vertreten sie mehr oder weniger theoretisch argumentierend oder aber unsachlich streitend in den Diskussionen im Wolpertinger. Dabei ist anzumerken, dass die beiden Begriffe ihnen nicht explizit zugeordnet werden. Begrifflich sind sie zwar etwas vereinfachend, ihre diesbezügliche Bedeutung kann aber kontextuell genauer erläutert werden. Sie vereinen jedoch umfassend, was die beiden unterschiedlichen Positionen ausmacht. Die eigentliche Verkörperung wird erst in den Reden vor dem Thing deutlich, als aufgedeckt wird, dass Murnau eine Abspaltung von Lipom selbst ist, ein noch sehr junger »Spaltgeist « $(W B, 806)$. Diese Identität der beiden Geister spiegelt die Begriffsgeschichte wider, an deren Anfang zwischen Mythos und Logos nicht unterschieden wurde, als sie noch nicht in dem späteren Gegensatzverhältnis zueinander bestanden. ${ }^{27}$

\section{Die Entzauberung der Welt}

Bevor näher auf die Verbindung von Figuren und Begriffen eingegangen wird, ist es für das Verständnis nötig, die Problemlage zu benennen, die durch diese Begriffe aufgespannt wird und die eine zentrale Stelle im Roman einnimmt. Gleich mit den »manierierten Zeilen $[\ldots]$, mit denen dieses Buch beginnt $«(W B, 17)$ wird die Thematik angesprochen:

Von den großen Gespensterwesen, die Jahrtausende überdauerten, kam Nachricht zuletzt mit dem Sieg des Automobils, dessen Zeit bereits eine so hektische

27 Sowohl Mythos wie Logos bedeuteten ursprünglich das Wort, sie waren »nahezu austauschbar und unterscheiden sich weniger durch ihre Referenz als durch die Redeform. Logos ist eher die sinnerfüllte, vernünftige Rede, Mythos die unverbürgte.« (Ernst Müller: »Mythos/mythisch/Mythologie«, in: Karlheinz Barck (Hg.): Ästhetische Grundbegriffe. Historisches Wörterbuch in sieben Bänden, Bd. 4, Stuttgart / Weimar 2002, 309-346, hier: 311.) Zum Beginn der Trennung von Mythos und Logos bei Platon siehe Christoph Jamme: »Mythos und Wahrheit«, in: Monika Schmitz-Emans / Uwe Lindemann (Hg.): Komparatistik als Arbeit am Mythos, Heidelberg 2004, 39-54, v. a. 4 of. 
war, daß die Geister sich in die letzten Winkel verkriechen mußten und allmählich erst, als nämlich auch diese unter den Schlagbohrern fielen, zu lernen begannen, sich dort zu zeigen, wo niemand ihren Aufenthalt wähnte. Damit erst fanden sie zu sich, - in den Fragen der Psychologie. $(W B, 17)$

Da die ersten Absätze sich von der folgenden Handlung abheben und auch die zugehörigen Ausführungen Marduks im Prolog sehr elliptisch sind, fällt es zunächst schwer, die Bedeutung oder auch den Inhalt der Thematik zu umreißen. Mit der Erkenntnis, dass es sich bei den ATG-Mitgliedern um Elben bzw. Geister handelt, spätestens aber in der expliziten Thematisierung in den Thing-Reden ist zu verstehen, dass es um die Vertreibung der Geister aus der Lebenswelt der Menschen geht.

Dabei handelt es sich um einen bekannten Topos moderner Gesellschaftstheorien, an den in $W B$ angeschlossen wird. Max Weber hat eine solche Entwicklung im Kontext von Reflexionen über die rationale Wissenschaft beschrieben. Bei ihm verweist das Schlagwort von der »Entzauberung der Welt ${ }^{28}$ auf die »intellektualistische Rationalisierung durch Wissenschaft und wissenschaftlich orientierte Technik «29. Die Beherrschung der Geister mit magischen Mitteln durch den `Wilden` wird ersetzt durch die Beherrschung der Dinge durch Technik. In den Sozialwissenschaften fungiert diese Phrase als ein Passepartoutbegriff, um »die komplexen Prozesse der Säkularisierung und Marginalisierung des Religiösen in Europa auf den Begriff zu bringen « ${ }^{30}$. Im wörtlichen Anschluss an Weber, freilich ohne ihn jedoch zu erwähnen, wird die Wendung von Max Horkheimer und Theodor W. Adorno in Dialektik der Aufklärung ${ }^{31}$ (1947/1969) gebraucht. Sehr deutlich wird das berühmte Werk, das angesichts der Erfahrung des deutschen Faschismus entstand, gleich eingangs als Bezugspunkt etabliert. Der in $W B$ direkt auf die eben zitierte Passage folgende Satz "Gerade das aufgeklärte Denken gewährt dem Mythos Raum " $(W B, 17)$ präsentiert Horkheimers und Adornos zentrale These »des Rückfalls von Aufklärung in Mythologie $(D d A, 3)$ in im Wesentlichen nur sprachlich abgewandelter Form. Dieser eindeutige Verweis ermöglicht, weitere kleine Hinweise vor allem terminologischer Übereinstimmung in einem Kontext zu verorten, der das geschichtstheoretische Bild von $D d A$ als Grundlage der in $W B$ aufgespannten Thematik aufzeigt.

Webers Begriff findet sich gleich eingangs, in der `Entzauberung der Welt « sehen Horkheimer und Adorno das »Programm der Aufklärung « (DdA, 9). Sie setzen in ihren Überlegungen voraus, dass eine Entwicklung von einem ursprünglichen frühen Zustand in der Menschheitsgeschichte zu einem aufgeklärten Denken stattgefunden hat. Dieser Urzustand wird in nicht eindeutiger Weise unter dem Begriff Mythos

28 Am bekanntesten ist die Verwendung der Metapher in dem Vortrag »Wissenschaft als Beruf«. Vgl. Max Weber: »Wissenschaft als Beruf« [1917/19], in: Ders.: Gesamtausgabe, hg. v. Wolfgang J. Mommsen / Wolfgang Schluchter, in Zsarb. mit Birgitt [sic!] Morgenbrod, Abt. I, Bd. 17, Tübingen 1992, 71-111, hier: 87, 109. Zu Entstehung des Begriffs und seinem Kontext im Werk von Weber vgl. Hartmut Lehmann: Die Entzauberung der Welt. Studien zu Themen von Max Weber, Göttingen 2009, 9-20.

29 Weber: »Wissenschaft als Beruf«, 86.

30 Lehmann: Die Entzauberung der Welt, 125.

31 Max Horkheimer/Theodor W. Adorno: Dialektik der Aufklärung. Philosophische Fragmente [1944/1969], Frankfurt am Main 1988 (im Folgenden zit. als $D d A$ ). 
gefasst. Aufklärung ist dabei nicht als historischer Epochenbegriff zu verstehen, sondern wird »im umfassendsten Sinn fortschreitenden Denkens« $(D d A, 9)$ gesehen. Der Mensch strebt durch seinen Verstand nach vollständiger Erkenntnis, die ihm die Furcht vor der äußeren Natur sowie allgemein die metaphysische Furcht nehmen soll und ihn in eine überlegene Position versetzt, die sich in der Beherrschung der Dinge bzw. der Natur im Allgemeinen ausdrückt. Es geht um die Erzeugung und Ansammlung von Wissen durch die moderne Wissenschaft, wodurch dem Menschen Macht verliehen wird. Zum einen geschieht dies durch die Weiterentwicklung von Technik mit Hilfe des vermehrten Wissens, zum anderen liegen abstraktere Entwicklungen im menschlichen Denken zugrunde. Diese manifestieren sich vor allem in der Trennung von Subjekt und Objekt, von Begriff und Sache, also der Verdoppelung der Natur, die der ursprünglichen Verbundenheit und der allgemeinen Verkettung der Zusammenhänge entgegengesetzt ist. Die Abfolge historischer Phasen, die hier insinuiert oder vorausgesetzt wird, ist jedoch lediglich aus Hinweisen herauszulesen. Auch findet sich in $D d A$ keine genaue Definition oder zumindest Erklärung der verwendeten Begriffe. ${ }^{32}$

Die Geschichte des Mythosbegriffs ist auch im Allgemeinen sehr heterogen. Im Laufe der Zeit haben sich viele unterschiedliche Formen des Mythenverständnisses etabliert. ${ }^{33}$ Zunächst standen Fragen der Entstehung, der Ursachen und Bedeutung der Mythen im Vordergrund, was allgemein als ihre aitiologische Funktion bezeichnet werden kann. Auch ging es um Mythenkritik und um ihr poetisches Potenzial, ihre »narrative Disposition «34. Es war Rousseau, der »die geschichtsphilosophischpolitische Frage nach dem Ursprung menschlicher Kultur und deren Verhältnis zur Natur « ${ }^{35}$ an Stelle dieser Aspekte rückte. Der in zeitgenössischen Reiseberichten idealisierte `bon sauvage`, der `gute Wilde`, regte die Vorstellung eines Ursprungsmythos an, eines Ursprungszustands der Menschheit, der von der Einheit von Mensch und Natur geprägt ist. Die Kritik von Rationalität und Zivilisation rückte in den Mittelpunkt des Interesses. Damit einher ging die Sehnsucht nach einem möglichen Anschluss an den Urzustand, nach der Erfahrung von Einheit mit der Natur. Begrifflich liegt hier ein »polemischer« Mythenbegriff zugrunde, der sich auf Mythos »als ein überwundenes Stadium kulturhistorischer Entwicklung $«^{36}$ bezieht.

32 »Auskunft darüber, was Mythos sei, auch nur was er unter diesem Begriff verstanden wissen wolle, wird man bei Adorno kaum im Sinne einer Verbaldefinition finden und angesichts seines bekannten Mißtrauens gegen den Wert von Definitionen auch nicht erwarten.« (Rolf Tiedemann: ")Gegenwärtige Vorwelt . Zu Adornos Begriff des Mythischen (I)«, in: Frankfurter Adorno Blätter 5 (1998), 9-36, hier: 14.) Vgl. auch Günter Figal: „Über das Nichtidentische. Zur Dialektik Theodor W. Adornos«, in: Wolfram Ette / Günter Figal / Richard Klein / Günter Peters (Hg.): Adorno im Widerstreit. Zur Präsenz seines Denkens, Freiburg / München 2004, 13-23, hier: $13 \mathrm{f}$.

33 So unterscheiden Aleida und Jan Assmann in einem systematischen Überblick sieben verschiedene Verwendungsweisen des Mythosbegriffs, vgl. Aleida Assmann / Jan Assmann: »Mythos«, in: Hubert Cancik u. a. (Hg.): Handbuch religionswissenschaftlicher Grundbegriffe, Bd. 4, Stuttgart u. a. 1998, 179-200, 179ff. Einen historischen Überblick bietet Müller: »Mythos/mythisch/Mythologie«.

34 Wilhelmy: Legitimationsstrategien der Mythosrezeption, 47.

35 Müller: »Mythos/mythisch/Mythologie«, 317.

36 Assmann / Assmann: »Mythos«, 179. 
Diese Annahme bestimmt auch das Mythosverständnis in $D d A$. Hier zeigt sich die Ambivalenz zwischen Historizität und ahistorischem philosophischen Denken. Die skizzierte Entwicklung stellt keine vollständige (oder historisch korrekte) Rekonstruktion der menschlichen Frühgeschichte dar. ${ }^{37}$ Das Interesse gilt jedoch auch nicht einem »historischen Phänomen, nicht dem Mythos [...], wie er Gegenstand von Prähistorie, Religionsgeschichte oder Ethnologie ist $^{38}$. Die Zielrichtung von Horkheimer und Adorno ist ihre Gegenwart, der Ausgangspunkt ihrer Überlegungen war die Suche nach einer Erklärung für die Entwicklung, die zu den Gräueln der deutschen Nationalsozialisten führte. Mythos und Mythologie wird also als scheinbar überwundener Urzustand dem Projekt der Aufklärung gegenübergestellt, die sich in Opposition zu diesem erst gebildet hat. Die Entzauberung der Welt ist äquivalent mit "Entmythologisierung " $(D d A, 13)$. Die Rede ist sogar davon, die »Mythen zu zerbrechen« $(D d A, 10)$, sie also gänzlich zu überwinden. Dennoch ist die Kontrastierung schon begrifflich keinesfalls eindeutig. Es lassen sich zwei Verwendungsweisen von Mythos finden. Der ursprüngliche Zustand wird verschiedentlich mit »dem älteren mythischen Glauben, [der] Volksreligion « $(D d A, 17)$, sowie mal mit Präanimismus mal mit Animismus in Verbindung gebracht. Abgelöst wird er aber vom »solare[n], patriarchale[n] Mythos « $(D d A, 17) .{ }^{39}$ Dieser ist selbst mit Aufklärung im gebrauchten Sinn verschränkt, da er ebenfalls eine ordnende, erklärende und damit Angst überwindende Funktion hat. ${ }^{40}$

Wenn man von der historischen Dimension abstrahiert und Mythos und Aufklärung als Prinzipien auffasst, so lassen sich aus den verstreuten Hinweisen in $D d A$ bestimmte Vorstellungen destillieren. Das wichtigste Bezugselement des Mythos ist die Natur, womit zunächst die räußere Natur, die den Menschen umgebende gemeint ist. Die mythische Denkform bannt die unbekannten Schrecknisse der Natur in die Vorstellung von Dämonen und Geistern, errichtet die »Illusion waltender oder innewohnender Kräfte $(D d A, 12)$ der Materie. Im Mythos ist die Natur also eine belebte, die wiederum durch magische Rituale, durch Zauberei beeinflusst werden kann. Abstrakter gesehen steht sie für »die Welt als das Chaotische, Vielseitige, Disparate ( $D d A$, 46), sie ist »undifferenziert« ( $D d A, 21)$, die »guten und schlechten Mächte [sind] nicht eindeutig voneinander geschieden« (ebd.). Oppositionen werden noch nicht als solche begriffen, sondern sind miteinander verkettet. Aus der für später konstatierten "Entfremdung von der Natur« $(D d A, 55)$ kann der zuvor geltende Einklang mit der Natur geschlussfolgert werden.

Der Mythos ist [...] die Natur in allem, worin sie ungeordnet, unbekannt und unbegriffen ist; das Weltalter des Vielen, als welches Natur den in ihr befangenen

37 Vgl. Christoph Jamme: Einführung in die Philosophie des Mythos. Neuzeit und Gegenwart, Bd. 2, Darmstadt 1991, 115f.

38 Tiedemann: „Gegenwärtige Vorwelt«, 15.

39 Ähnliche Nachweise, zusätzlich auch aus Adornos Spätwerk Negative Dialektik (1966), führt Rolf Tiedemann an, siehe ebd., 25.

40 Zur sich wechselseitig bedingenden Ambivalenz der Begriffe Mythos und Aufklärung in DdA siehe auch Georg Dörr: Muttermythos und Herrschaftsmythos. Zur Dialektik der Aufklärung um die Jahrhundertwende bei den Kosmikern, Stefan George und in der Frankfurter Schule, Würzburg 2007, $155 f$. 
Menschen gegenüber- und entgegensteht; ein undurchdringliches Unbestimmtes, das in Stummheit verharrt, vorzeitliches Grauen verbreitend. ${ }^{41}$

Die bei Horkheimer und Adorno als Aufklärung bezeichnete Gegenposition ist die des sich ausbildenden logischen Verstandes. Der Vielfalt und dem Chaos der mythischen Natur wurde durch Vereinheitlichung und Abstraktion, durch Entwicklung der formalen Logik begegnet. Gekennzeichnet ist der aufgeklärte Zustand durch Wissen, die Entstehung der Wissenschaften, die Entwicklung der Technik. Diese ermöglichten die Beherrschung der Natur. Wiederum auf abstrakter Ebene ist die Verwendung des $>$ Begriffs $<$ kennzeichnend, der distanziert und der Kenntlichmachung des »Bekannten, Einen, Identischen « $(D d A, 46)$ dient. Ihm vorher geht die Trennung von "Zeichen und Bild«, eben von "Anschauung und Begriff" $(D d A, 24)$ oder, weiter abstrahiert, von Subjekt und Objekt. Aus der Beschreibung der Entwicklung zur Aufklärung lässt sich auch auf den mythischen Zustand rückschließen. So ist von der »Unterdrückung « oder "Fixierung der Instinkte« $(D d A, 42)$ die Rede, von der Verkümmerung der Phantasie (ebd.) und der Trennung von Denken und »Erfahrung der sinnlichen Welt» (ebd.). Der Naturzustand ist also durch Instinkte und Sinnlichkeit bestimmt, aber wird auch mit der kreativen Produktivität des Geistes, der Phantasie, in Verbindung gebracht.

In $D d A$ ist die primäre Opposition Mythos versus Aufklärung. Wenn in der langen Mythosdiskussion der Mythos immer den Platz gegenüber einer Position der Vernunft besetzt, wird diese begrifflich verschieden gefasst, sei es eben als `Aufklärung`, als Moderne oder als Wissenschaft. In der Mythosforschung ist diese Gegenüberstellung aber vor allem in der Dichotomie Mythos versus Logos gefasst. Die Eindeutigkeit einer Entwicklung, wie sie von dem Altphilologen Wilhelm Nestle in der Formel "Vom Mythos zum Logos" geprägt und in dem gleichnamigen Buch Vom Mythos zum Logos. Die Selbstentfaltung des griechischen Denkens von Homer bis auf die Sophistik und Sokrates (1940) beschrieben wurde, ist jedoch immer wieder hinterfragt worden..$^{42}$ Schon die Bewertung differiert, wenn die Moderne den Mythos "als das Andere ihrer selbst unterstellt, von dem sie sich abgrenzt oder nach dem sie sich romantisch zurücksehnt, [der] ihre eigene Entdeckung, wenn nicht Konstruktion ist, die erst in der Polarität zu Vernunft und Rationalität Kontur gewinnt «43. Nachdem dann Horkheimer und Adorno auf die Verschränkung der vermeintlichen Gegenpole hingewiesen hatten - in ihrer titelgebenden Grundthese von der Dialektik der Aufklärung, die das Umschlagen von Aufklärung in Mythos wie die Existenz aufklärerischer Strukturen im Mythos bezeichnet -, stellte Hans Blumenberg die Verbundenheit der Phänomene in Arbeit am Mythos (1979) noch deutlicher heraus. Er bezeichnet die "Grenzlinie zwischen Mythos und Logos « ganz direkt als »imaginär« und spricht gar vom »Unfug jener sinnfälligen Geschichtsformel «44. Die Begründung ist hier eine ähnliche wie in $D d A$, da seiner Darstellung nach der Mythos ähnliche Funktionen erfüllt wie der Logos. Durch verschiedene Aspekte schafft er eine Distanz zur

41 Tiedemann: »Gegenwärtige Vorwelt«, 26.

42 Vgl. dazu ausführlicher Wilhelmy: Legitimationsstrategien der Mythosrezeption, 68-8o.

43 Müller: »Mythos/mythisch/Mythologie«, 309.

44 Hans Blumenberg: Arbeit am Mythos, Frankfurt am Main 1979, 18 und 34. 
Wirklichkeit und bewirkt dadurch die Bewältigung der Urangst: »Der Mythos selbst ist ein Stück hochkarätiger Arbeit des Logos. «45 Dennoch bleibt festzuhalten, dass eine bestimmte Art von Entwicklung bei aller Relativierung der Beschreibung prinzipiell vorausgesetzt wird. Der von Horkheimer und Adorno beschriebene Rückfall von Aufklärung in Mythos "spielt sich [...] nur auf der Ebene der Beziehung auf unhinterfragbare, absolute Gültigkeiten ab, nicht aber auf der Ebene einer Entdifferenzierung « ${ }^{46}$. Etablierte Denkformen wie die Trennung von Subjekt und Objekt können nicht zurückgenommen werden. Auch für Blumenberg ist es nicht möglich, hinter die Vorstellung moderner Wirklichkeitsstruktur zurückzufallen, indem an mythische Vorstellungen angeknüpft wird: »Mit dem Gedanken, daß Götter erscheinen könnten, ist im Horizont des neuzeitlichen Wirklichkeitsbegriffs nicht einmal mehr zu spielen.«47 Es handelt sich bei der Gegenüberstellung von Mythos und Logos also um eine Opposition, »die sich nicht aufrechterhalten [lässt] und mit [der] doch operiert werden kann $\ll^{48}$.

\section{Lipom und Murnau}

Vor diesem Hintergrund entfalten sich die von Lipom und Murnau vertretenen Standpunkte. Das 'polemische « Mythosverständnis herrscht auch in WB vor. Es wird nicht die Frage verfolgt, die Entstehung, Ursachen oder auch die Bedeutung von Mythen darzustellen oder zu reflektieren. Es wird eine Entwicklung vom Mythos zum Logos insofern vorausgesetzt, als sie bildhaft in der Vertreibung der Geister aus der Welt bezeichnet ist. Sie ist jedoch nicht als endgültig zu betrachten, da die Geister bislang nicht vernichtet worden sind, sondern sich lediglich zurückgezogen haben. Es handelt sich um eine gleichzeitig historische wie ahistorische Vorstellung, die die Auffassung von Mythos und Aufklärung in $D d A$ spiegelt. So wie diese »logische und historische Gegensätze zugleich «49 bilden, der Mythos in den Phänomenen des aufklärerischen Projekts erhalten geblieben ist, so symbolisieren die Geister einerseits einen früheren Naturzustand, andererseits eine weiter existierende untergründige Welt, zu der nur wenige Zugang haben. Die Ambivalenz der Dichotomie, die in der Mythosforschung aufgezeigt wurde, wird auch in der Personifikation in den Figuren Lipom und Murnau gespiegelt. Scheinen sie als eindeutig zu identifizierende und damit voneinander zu unterscheidende Personen zu bestehen, die vehement die jeweilige Position vertreten, so stellt sich die Autonomie Murnaus als gar nicht so eindeutig heraus. Der Zusammenhang ihrer Identität wird während des Things offenbart. Die Aufgabe des Things, während dessen so viele zentrale Dinge angesprochen und aufgedeckt werden, ist die Gerichtsbarkeit, es soll ein Urteil über Murnau gefällt werden. Lipom selbst hat

45 Ebd., 18.

46 Wilhelmy: Legitimationsstrategien der Mythosrezeption, 77.

47 Hans Blumenberg: »Wirklichkeitsbegriff und Wirkungspotential des Mythos«, in: Manfred Fuhrmann (Hg.): Terror und Spiel. Probleme der Mythenrezeption, München 1971, 11-66, hier: 41. Vgl. in $W B$ die Äußerung Lipoms, sie, die Geister, seien »undenkbar geworden« (WB, 809).

48 Volker C. Dörr: Mythomimesis. Mythische Geschichtsbilder in der westdeutschen (Erzähl-)Literatur der frühen Nachkriegszeit (1945-1952), Berlin 2004, 10.

49 Tiedemann: »Gegenwärtige Vorwelt«, 25. 
wohl genug von seiner Aufgabe als Elbenfürst, wie er mehrfach betont, ist müde und möchte nur noch schlafen (vgl. WB, 646). Außerdem entgleitet ihm die Welt, er verliert den Bezug zu ihr, da die Geister wie eben beschrieben durch die Menschen aus ihrer gewohnten Umgebung vertrieben werden und sie keine Zufluchtsorte mehr haben. Außerdem hat er Schuld auf sich geladen, indem er als »Fürsprecher eines Dritten Reiches « $(W B, 803)$ aufgetreten ist, das er unterschätzte. Diese kurze Anspielung auf das `Dritte Reich ` der Nationalsozialisten könnte eine Verbindung zur Mythenkonjunktur der Nazizeit darstellen, wahrscheinlicher ist aber eine Bezugnahme auf Gottfried Benns zeitweiliges Bekenntnis zum Nationalsozialismus..$^{50}$ Lipoms letzte politische Tat, nach der er dem Thing am Folgetag Rechenschaft über seine Schuld geben und dann von seinen Ämtern zurücktreten will, war der Versuch, ein Gleichgewicht wiederherzustellen, das Leben zu versöhnen und den Geistern wieder einen Heimstätte zu verschaffen. Um dies zu erreichen, hatte er Murnau geschaffen, der mit dem Denken der Menschen begabt als Unterhändler mit diesen fungieren sollte. Murnau habe jedoch zunehmend wie die Menschen gedacht, sich in der Folge auf ihre Seite geschlagen und ihre Sache vertreten. Lipom sieht dies als Verrat und Überläufertum an und hat daher das Thing einberufen, um über Murnau zu richten und ihn zurückzuschicken »in das, was man den Äther nannte« $(W B, 807)$.

Murnau ist also eine Abspaltung von Lipom, ein junger Geist, der aus einem alten entstanden ist. Lipom hat ihn aus seinem »eigen Fleisch und Geist und aus einer Birke $^{51}$ und zu Euerer Wohlfahrt « $(W B, 803)$ geschaffen. Da Murnau seiner Meinung nach versagt hat, erfolge die Intention der Menschen, die Geister auszurotten, mit seiner »eigenen Hilfe« $(W B, 804)$. Während Murnau so als ein Wesen dargestellt wird, das zwar mit Lipom in Zusammenhang steht (der letztlich auch die Verantwortung für dessen Handlungen übernimmt), aber eigentlich autonom ist, weist Murnau in Gesprächen mit Deters auf ihre gemeinsame Identität hin. ${ }^{52}$ Kurz nachdem Lipom Deters von seiner Herkunft erzählt hat, erbittet Murnau Deters' Hilfe, um der bevorstehenden Verurteilung und Vernichtung durch das Thing zu entgehen. Die Anklage des Things wird hier vorwegnehmend angedeutet. Murnau erklärt, er sei das schlechte Gewissen Lipoms, " [s] ozusagen hat sich, was er nicht denken will, in mich abgespalten " $(W B, 646)$. Diese beiden aufeinander folgenden Gespräche thematisieren zunächst jeweils die Identität von Lipom und Murnau durch Deters' direkte Nachfragen in der Form der einfachen, aber klassischen Identitätsfrage, wer sie (eigentlich) seien (vgl. $W B, 645$ f.). ${ }^{53}$

50 Diese Annahme bietet sich an, da Lipom immer wieder mit Benn in Zusammenhang gebracht wird. Vornehmlich durch das ständige Zitieren seiner Gedichte, dann aber auch durch den Hinweis, er sei bei Benn Assistent gewesen. Das bedeutet jedoch nicht, dass Lipom auch eine Benn-Figuration ist. Er wird lediglich neben den anderen Bezügen auch etwas an diesen angelehnt. Für weitere Anspielungen auf die Mitschuld im >Dritten Reich`vgl. WB, 319, 385.

51 Mit der Birke sind etliche Assoziationen und Sagen in der keltischen Mythologie verbunden, u. a. die Liebesassoziation, vgl. MacKillop: A Dictionary of Celtic Mythology, 42. Für den Zusammenhang mit Murnau vgl. weiter unten auf Seite 142 und später Abschnitt 4.3.2 auf Seite 223.

52 Möglicherweise sind die Beiden aber auch nach wie vor körperlich miteinander verbunden: Nach einem Spaziergang »stülpt[] « Lipom Murnau »aus sich heraus» $(W B, 376)$.

53 Auch gegenüber Anna hatte Deters die Frage schon formuliert: »Wer seid ihr denn nun?« (WB, 463) 
Schon vorher, direkt nach der Szene in dem Wirtshaus Winkelmanns Schänke, in der sich Lipoms magische Fähigkeiten gezeigt hatten, hatte Deters diese Frage gestellt. Lipom hatte Murnau und Anna vorgeschlagen, nun mit offenen Karten zu spielen und ihre Identität den Anwesenden Deters, Hüon und Dr. Weigan zu verraten. Vorher verlangt er jedoch die Zusage, freiwillig einer der Ihren zu werden (ohne jedoch genau zu wissen, was das bedeute). Während Hüon verneint - als `Gegner selbstverständlich, wie später deutlich wird -, erwidert Deters, er habe sich noch nicht entschieden, jedenfalls, so deutet er an, nicht ohne Genaueres zu wissen. Dies bringt er dann in der Frage zum Ausdruck: »Wer sind Sie, Herr Dr. Lipom?« (WB, 635) Lipom scheint erfreut und beeindruckt vom Mut oder der Standfestigkeit von Deters und erwidert »Nun sag' mir eins, man soll kein Wunder glauben!« (ebd.) Diese Worte sind direkt aus Faust I (V. 2336) übernommen und müssen durch den Konstruktionscharakter der Szene als Abschluss des Kapitels erscheinen, wie es in Faust den Abschluss der Szene in Auerbachs Keller bildet. ${ }^{54}$ Es lässt im WB-Kontext die Frage durch Deters aber wie eine Schlüsselfrage, eine Frage wirken, die ihm den Respekt und die Anerkennung durch Lipom verschafft. Die Frage nach der Identität des Anderen wird für Deters zur Initiation, um von den Geistern ernstgenommen zu werden. Zumindest durch Murnaus Antworten im etwas späteren Gespräch (vgl. WB, 646f.), die auch deren Geschichte einschließen, werden sowohl die Identität als Geister als auch die numerische Identität von Lipom und Murnau bereits angesprochen, doch bleibt sie sowohl Deters als auch dem Leser bis zur klaren Benennung während Lipoms Thing-Rede nicht ganz verständlich. Bis dahin wird niemals eindeutig ausgesprochen, um was für Wesen es sich bei ihnen handelt.

An dieser Stelle ist wieder der Anschluss an die begrifflichen Personifikationen Lipom und Murnau zu finden. Die Begriffsopposition ist in WB nicht direkt in Entsprechung zur Debatte in der Mythosforschung zu finden. Die Themen ebenso wie die Begriffe ähneln jedoch in großem Maße vor allem denen in DdA. Gerade Murnaus Position ist geprägt durch die Begriffe, die in $D d A$ mit der Aufklärung verbunden

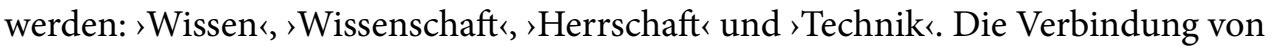
Lipoms Position mit Mythos oder Mythologie geschieht vor allem ex negativo. Wenn Murnau davon spricht, den Mythen ein Ende bereiten zu wollen (vgl. WB, 701), geschieht dies immer in Opposition zu Lipom, dem mithin die Mythen zugeschlagen werden. Er vertritt den Ursprung, die Zeit der mythischen Verbundenheit. Da jedoch gerade der Mythosbegriff in beiden Werken nicht eindeutig verwendet wird, kann er auch nicht als deckungsgleich bestimmt werden. WB ist also keinesfalls als eine Form literarischer >Veranschaulichung « der Philosophie von Adorno und Horkheimer zu sehen. Von Veranschaulichung kann, wie bereits angesprochen, auch nicht die Rede sein, da die Themen mehr diskutiert als in der Handlung gezeigt werden. Dennoch ist der Anschluss auffällig und in den Figurenpositionen sind Bezüge auf die Mythos/Logos-Debatte und vor allem auf $D d A$ mitzudenken. Im Folgenden sollen nun die Standpunkte von Lipom und Murnau genauer aus dem Text heraus charakterisiert werden.

54 Die Szene in Winkelmanns Schänke ist an die Szene »Auerbachs Keller in Leipzig « aus Goethes Faust I angelehnt. Der Text wird von dort fast vollständig entlehnt und auch die Struktur übernommen. Vgl. dazu genauer Abschnitt 4.3.1 ab Seite 214. 
Murnau selbst fasst nach seinem begrifflich differenzierenden Naturell die Unterscheidung der Prinzipien am prägnantesten: »Er [Lipom] aber will, mit einem Wort, Natur. [...] Ich dagegen, Wilfried Murnau, will den Geist!« (WB, 647) Gerade Lipoms Position wird nicht nur von ihm und zudem sehr ungenau formuliert. Murnau präzisiert sie abgrenzend von seiner eigenen und auch andere tragen zur Bestimmung bei. Dies sind vor allem Geister, da es sich bei Lipoms Position auch um die ursprüngliche Anschauung und Lebenswelt der Geister handelt. Als Elbenkönig ist er Symbolfigur für alle Geister. Die in $D d A$ verwendeten Begriffe beziehen sich (mit den oben genannten Einschränkungen) natürlich auf die historische Entwicklung der Menschen, in $W B$ wird der Ur- oder Frühzustand von Geistern symbolisiert. Auch wenn die Elben als menschenähnlich beschrieben werden, so ist doch ihre Identität und Entwicklung nicht ohne Reibungen auf die historische der Menschen übertragbar, wie im Folgenden zu sehen sein wird.

\section{Natur vs. Geist}

Das Schlagwort »Natur« wird auch von Lipom verwendet, er gibt vor: »Prämisse ist und bleibt, hä, Natur!« $(W B, 178)$ Die Dichotomie Natur vs. Geist ${ }^{55}$ kann als Ausgangspunkt in der näheren Bestimmung der beiden personifizierten Personen gesehen werden. Was jedoch mit den Begriffen alles gemeint ist, ergibt sich durch Verkettungen von Themen, die durch das Nebeneinander der Begriffsverwendungen und das Ineinander der Argumentationen die Positionen genauer formen. Eine Bedeutung von `Natur $\triangleleft$ ist die einer Eigenschaft oder verkürzend eines Naturzustands, eines Zustands von Natürlichkeit und Ursprünglichkeit. Für die Elben bedeutet dieser eine Verbundenheit mit der Natur, die soweit gehen kann, dass sie eine Identität bedeutet. Deutlich werden diese Zusammenhänge in Lipoms Rede vor dem Thing. In der Begrüßung wendet er sich an »Euch Blumenkinder, Euch, Birken, Erlen, Eichen, Euch, Eiben, Weiden, Koniferen, Euch, die Ihr in den Pinien lebt und sie beseelt und rauschen laßt des Nachts, Euch Tannen, Fichten, Euch Buchen, Euch aus den Gräsern $[\ldots]$ « $(W B, 802)$, eine Reihe, die noch lange fortgesetzt wird. Später in der Rede resümiert er:
Wir sind immer vieles gewesen, waren der Baum und der Strauch, waren ein Wassertropfen, der aus einer fehlerhaften Dichtung tropfte, [...] ein aus dem Höhenweg sprießendes Gras auf der Straße zwischen Erice und Tràpani, eine Palme in Felanix, [...]. Waren ein Wind, der durch die Fenster drückt [...], waren Süden und Norden, Mistral und Fön, waren Meeresstille [...] (WB, 806)..$^{56}$

Auch Murnau erklärt Deters die Zusammenhänge in gleicher Weise; sie seien mit den Kartoffeln, sonst aber »mit den Gemüsen, Bohnenblüten, Senfsamen, als Motten und Spinnweben unter die Leute« $(W B, 647)$ gekommen. Mit dem Zusatz $»$ Auch als $[\ldots]$ Birken« verweist er auf seine eigene Identität als aus einer Birke entstandener Geist,

55 Auch Alda fügt sie einmal prägnant zusammen, als sie Deters II vor die Entscheidung zwischen beiden stellt: »Natur oder Geist. «(WB, 975)

56 Dass er in dieser Aufzählung über die `Natur $\prec$ hinausgeht, soll etwas später erörtert werden. Die Geister sind in allem, auch schon in Technik, was Murnau und Deters dann noch zu verstärken fordern. 
weswegen er von Lipom auch immer wieder als Betula oder Birkensohn angeredet wird. Die Geister sind also die Natur oder sind in der Natur, beseelen sie und sind mit ihr in Einklang. Deters selbst erlebt diese Verbundenheit bei einem Tanz mit Anna. Sie leitet ihn an, auf die Umgebung, die Farne und die Vögel zu hören, die Augen zu schließen, bis er die Herrschaft über seine Sinne verliert (vgl. WB, 476).

Dass es ein Leben im Einklang mit der Natur auch für den Menschen gegeben hat, wird mehrfach thematisiert. Zunächst ist es Alda - obwohl auf der zweiten Ebene angesiedelt, ist sie auch dem Geisterreich zugehörig -, die gegenüber Deters II auf das ursprünglich harmonische und sich in einem Kreislauf ergänzende Verhältnis zwischen Mensch und Natur hinweist. Die Geister werden in diesem Fall als identisch und damit synonym mit der Natur gesehen.

Als die Pflanzen noch Lebendes waren und in jeder von ihnen sich das Gesamte gleichsam elementar zusammenzog, waren Geister und Menschen ineinander verschlossen. Brauchten diese Bauholz, so entschuldigte man sich beim Baum, der zu fällen war, und schenkte sich nach dem Tode dem Wald. Andere Pflanzen grub man nur rituell aus. $(W B, 730)$

Auch Deters bezieht sich auf diesen früheren Zustand, als er zu Anfang seiner spontanen Rede in Verteidigung Murnaus vor dem Thing die Aufmerksamkeit und das Wohlwollen der zuhörenden Geister gewinnen will. Er schildert seine mangelnde Verbundenheit mit Natur und Umgebung, weitet seine Überlegungen auf das mangelhafte menschliche Erinnerungsvermögen und damit das Verhältnis zur Geschichte aus, kontrastiert diese eigenen menschlichen Eigenschaften mit den >intakten $<$ der Geister und verweist auf die Zeit seiner Urgroßeltern, als diese in Einklang sowohl mit dem Acker und den Jahreszeiten als auch mit den Geistern lebten (vgl. WB, 822ff.).

Hier deutet sich bereits das an $D d A$ orientierte geschichtliche Modell an, das dann an zentraler Stelle in Murnaus Ansichten steht. Dieser setzt dem von Lipom als positiv und erstrebenswert angesehenen Naturzustand die geschichtliche Entwicklung, den Fortschritt entgegen. Damit wird ein Zustand der Moderne bezeichnet, der durch die menschliche Entwicklung der »Wissenschaft $(W B, 733)$ gekennzeichnet ist. Die Wissenschaft wird dabei angedeutet als Mittel der Differenzierung, das eine Ordnung in das vorher bestehende Chaos bringt. Der geschichtliche Begriff der "Aufklärung" $(W B, 314)$ wird von Alda in einer eng mit einem ATG-Gespräch verzahnten Szene aufgebracht. An die positiv konnotierte Naturverbundenheit glaubt Murnau nicht, tut sie als "Naturmythik« $(W B, 195)$ ab. Er sieht die Natur nicht als gerecht an, spricht vielmehr von »dem wahrhaft rücksichtslosen, dem brutalen Naturprinzip« ( $W B, 214$, vgl. auch 146f.), dem ein Riegel vorgeschoben werden müsse. Schlussfolgerung ist jedoch nicht nur die Abwendung der Natur, die nach zwischen ihm und Lipom übereinstimmender Ansicht (mit unterschiedlicher Bewertung) schon erfolgt ist; er geht sogar noch darüber hinaus und beschwört den Niedergang der Natur, der aufgrund der eigenen Aktivitäten in Kauf genommen $(W B, 214)$ oder sogar forciert wird $(W B, 167,195,398)$. Sie soll dabei durch »Technik« $(W B, 515)$ ersetzt werden, die die weiter unten zu beschreibenden >Simulationen` ermöglicht. Wissenschaft und Technik sind allerdings kein Selbstzweck, sein Ziel ist ein moralisches, das zwar auch nur in Schlagworten bezeichnet wird, aber als ein schemenhaftes in seinen Äußerungen mitschwingt. Immer wieder ist von der Entwicklung einer »Moral« die 
Rede, »nach der wir hungern « $(W B, 195)$, »von der wir seit Jahrhunderten... was sag' ich?!: seit Jahrtausenden träumen!« (WB, 214, vgl. auch 385). Ebenso vage wie der Begriff der Moral bleibt der der »Freiheit $(W B, 195)$, den er in diesem Zusammenhang nennt und die es wohl zu erreichen gilt.

\section{Sexualität}

Ein wichtiges Charakteristikum des Naturzustands ist für Lipom wie für Murnau die >Lust $`$ und der $>$ Trieb $<$, jedoch unterscheiden sich wieder die Wertungen. Lipom sieht sie positiv, tritt ein für eine Sexualität, die ausschweifend und orgiastisch ist. Dies zeigt sich zunächst in einer Betonung von Körperlichkeit und des sexuellen Triebs, für den »Schweiß«, »Geruch «, die »Säfte« $(W B, 524)$, »das Geschlecht, [...] die Flüssigkeiten und Sekrete, die Düfte des Unterleibs« ( $W B, 808)$, also alles sogenannte Unreine, Unsterile stehen. Dies kulminiert in der Eigencharakterisierung (die Elben und Menschen gleichermaßen miteinschließt): »Wir aber sind Ferkel! Lustbolde, Freund!« $(W B, 318)$ Lipom vertritt jedoch nicht einseitig eine körperliche, sexuelle Haltung, sondern spricht auch von Liebe, die er zusammen mit der Poesie als Gegenposition zur Vernunft nennt (vgl. WB, 167). Als Elbenkönig hat er zudem besondere Möglichkeiten, sich in Liebesangelegenheiten der Menschen einzumischen. Durch seinen »Zaubertrank« $(W B, 840)$, der vermutlich durch »Stiefmütterchen $(W B, 12$, 345) wirkt, kann er die Gefühle von Menschen beeinflussen, was er zu seinem eigenen Vergnügen (und ohne größere Folgen) auch bei der Rezeptionsdame Fräulein Piggi anwendet. Diese verfällt der »Liebeswut « (ebd.) zum Portier, aus der die beiden erst durch einen Hinweis von Deters erlöst werden. Auch die Liebeswirren Hüons auf der Suche nach seiner Geliebten Rezia sind auf Lipom zurückzuführen (vgl. WB, 345, 698); ein weiteres Eingreifen untersagt ihm jedoch Anna, die erbost auf solche Überlegungen reagiert. Der Zusammenhang erschließt sich durch weitere Hinweise auf den jahrhundertealten Streit des Elbenpaares, der mit Fragen von Liebe und Treue zusammenhängt (vgl. dazu weiter unten Abschnitt 3.3.2 auf Seite 153.) Im extremen Maß zeigt sich Lipoms diesbezügliche Macht jedoch in der Szene in Winkelmanns Kneipe, in der er in Übersteigerung von Goethes Mephistopheles die Mündener Bürger völlig zügellos zu einer Orgie treibt (vgl. dazu genauer Abschnitt 3.5.2 auf Seite 168). Er beklagt den Mangel an solch zügellosem Verhalten, es gebe »ja keine wirklichen Ge,hä,lage mehr«, dagegen beschwört er die »Orgien Cotyttos« (WB, $590)^{57}$, da fühle man noch Leben. Zudem verbinden sich für ihn Lust auch mit Leiden und Schmerz. Damit gehören auch Gewalt und sogar Vergewaltigung zu seiner Vorstellung von Sexualität (vgl. WB, 515 und 523f.). In einem Ausruf schließt er an die von Nietzsche vertretene Unterscheidung zwischen dem Dionysischen und dem Apollinischen an, wobei er sich natürlich Ersterem zugehörig fühlt. Die Lehrer im Wolpertinger bezeichnet er als »Phi,hä,lister«, ohne dass sie ihn jedoch hören könnten. Sie wüssten nichts mehr von Dionysos; mit dem Seufzer »Ach Nietzsche!« $(W B, 219)$ beschließt er seinen kleinen Ausbruch. Die Unterscheidung zwischen Lipoms und

57 Die Orgien fanden im Alten Griechenland zu Ehren der thrakischen Göttin Cotytto oder Kotys statt. 
Murnaus Position hat auch tatsächlich leichte Anklänge an die bekannte Dichotomie. Sie können jedoch nicht gleichgesetzt werden. ${ }^{58}$

Murnaus Position ist wieder etwas schwerer zu fassen, entgegen seiner sonstigen Anlage ist seine Position nicht schlüssig. Zwar »wär' er der letzte, das Lustprinzip zu hintertreiben« $(W B, 687)$, wie er vehement versichert, aber mit keinem Wort erläutert, doch argumentiert er eindeutig von einem sexualitätsfeindlichen Standpunkt. Vor allem ist dies die Gegenposition zu Lipoms gerade geschilderter Favorisierung von Ausschweifung und Körperlichkeit. So ist ihm jede körperliche Form von Sexualität zuwider, wie ihm jedoch vor allem von Lipom zugeschrieben wird (vgl. $W B, 808$, aber auch 647, 687). Murnau möchte die Sexualität, wie alles, »was bisher Natur geheißen hat « $(W B, 398)$, in computergenerierte Simulationen verlegen. Poesie, Liebe, Sexualität - alle Gefühle, die Lipom vertritt, sieht Murnau als sowieso rein geistige Konstruktionen an, die er gänzlich vom Körper trennen will. Nun sollen sie ausschließlich im Kopf entstehen und durch technische Mittel simuliert werden (vgl. WB, 167, 398, 523f., 687). Das von Bertrecht eingebrachte Stichwort der »Medientotale« $(W B, 515)$, die Murnau erreichen wolle, wird von diesem begeistert aufgenommen. Er sieht die »totale Automatisierung « $(W B, 385)$ als notwendig an. Allerdings bleiben seine Beweggründe widersprüchlich oder zumindest vage. Denn einerseits will er auch die von ihm verabscheuten körperlichen »Säfte« $(W B, 524)$ - Schweiß, Geruch etc. - simulieren, andererseits geht es ihm gerade darum, »keimfrei«, ohne "physiologische[n] Schmutz« $(W B, 687)$ auszukommen. Die einzige Art von Begründung, die er in dieser Hinsicht gibt, ist die Frage, wozu der Aufwand betrieben werden solle, wenn es denn auch schlichter gehe (ebd.). Seine eigentliche Zielrichtung scheint sich gegen die Emotionen im Allgemeinen zu richten. Diese will er »neutralisieren" $(W B, 175)$, sie »stören« $(W B, 300)$ und die Moral ist davon »freizuhalten" $(W B, 195)$. An ihre Stelle sollen komplett der Geist und die Logik treten. Konstruiert ist dies in Anlehnung an das Menschenbild, das in WB mitschwingt. Deters beschreibt Murnaus >Entstehung` und seinen daraus resultierenden Charakter in seiner Thing-Rede so, dass er von Lipom ausgeschickt wurde, »um zu helfen, [wofür er] zu sehen lernen mußte, wie es die Meinen tun. Weil diese nur im Denken fühlen, durfte auch der

58 Nietzsches Formulierungen rekurrieren eher auf weiter unten behandelte Aspekte in den Positionen Murnaus und Lipoms - diese passen jedoch genau überein. Er stellt am Dionysischen den Drang zur Einheit [...] ein verzücktes Jasagen zum Gesammt-Charakter des Lebens« heraus, beim Apollinischen dagegen den »Drang zum vollkommenen Für-sich-sein, zum typischen `Individuum<, zu Allem, was vereinfacht, heraushebt, stark, deutlich, unzweideutig, typisch macht (Friedrich Nietzsche: »Nachgelassene Fragmente. Anfang 1888 bis Anfang Januar 1889«, in: Ders.: Werke. Kritische Gesamtausgabe, hg. v. Giorgio Colli / Mazzino Montinari, Bd. 3, Berlin / New York 1972, 16). Peter Pütz betont diese Erläuterung: "Das Dionysische drängt zu einer Universalität, die alle Extreme umfaßt und alle Grenzen überspielt. [...] Auch das Apollinische drängt zur Einheit, aber nicht zur umfassend totalen des Dionysischen. Das Apollinische erreicht sie vielmehr durch Vereinfachen und Herausheben aus der Fülle des Ganzen. Durch einen Akt der Beschränkung wird die Zweideutigkeit beseitigt, die Unterordnung unter ein Gesetz führt zum Einfachen, Individuellen.« (Peter Pütz: »Der Mythos bei Nietzsche«, in: Helmut Koopmann (Hg.): Mythos und Mythologie in der Literatur des 19. Jahrhunderts, Frankfurt am Main 1979, 251-262, hier: 261). Interessant ist in diesem Zusammenhang auch der Hinweis von Tiedemann auf die Ähnlichkeit dieser Kategorien mit der Dichotomie des Mythischen und der Aufklärung bei Adorno, vgl. Tiedemann: "Gegenwärtige Vorwelt«, 25. 
Professor nur denken. Sowie er's aber tat, konnte er nicht bleiben wie ihr und fühlte, weil er dachte.« $(W B, 827)$ Murnau ist also an die Art der Menschen angepasst (im Gegensatz zu den Elben) und da diese nur noch Denken und nicht mehr Fühlen, gilt dies auch für ihn. Warum Murnau jedoch die Emotionen (oder zumindest die körperlichen `Säfte`) nicht abschaffen will, wie er es für die `Natur` auch fordert, sondern sie ebenso wie alles andere auch simulieren will, wird nicht angesprochen.

\section{Mehrdeutigkeit und Begriff}

Lipoms Position geht jedoch über den Bezug auf die Natur hinaus. Verbindungen zwischen Begriffen entstehen dabei vor allem dadurch, dass Lipom selbst sie nebeneinander verwendet. So entsteht ein Netz von Begriffen, die miteinander korrespondieren und damit die Position etablieren, und anderen, von denen sie sich abgrenzen. In Erwiderung auf Murnau ruft Lipom einmal aus: „Vernunft zerstört den Frühling, hä! Zerstört die Poesie, die Liebe!« $(W B, 167)$ Die Abgrenzung erfolgt von Murnaus Vernunftposition, dieser wird jedoch nicht die Natur entgegengesetzt. Dennoch passen alle drei Begriffe. Frühling und Liebe schließen an die Präferenz von Trieb und (ausschweifender) Sexualität an. Poesie wird in gleicher Weise der kalten, logischen Vernunft entgegengesetzt, deutet aber auch bereits auf einen weiteren Aspekt hin, der zu Lipoms Position gehört. Dabei geht es um die Ablehnung dualistischer Entgegensetzungen und die Präferenz von Vielfalt und Mehrdeutigkeit. Poesie in ihrem bildlichen, metaphorischen und damit geradezu prototypisch mehrdeutigen Charakter wird zum einen als Schlagwort verwendet (mehrfach auch noch verstärkt als »esoterische Poesie", vgl. WB, 147, 227, 341), ist zum anderen aber auch in der 'Zitierwut Lipoms zu finden, der ständig Verszeilen vor allem von Gottfried Benn deklamiert. Betont wird der Kontrast zu Murnau dabei, als dieser einmal ebenfalls einen Vers zitiert und Lipom ihm dies wutentbrannt verbietet (vgl. WB, 550). Dabei handelt es sich jedoch lediglich um einen `Ausrutscher`, der auch auf die Ambivalenz in der Abgrenzung zwischen den beiden hinweist, denn Murnau wendet sich eigentlich eindeutig gegen Poesie (vgl. $W B, 306,341$ ). Für Lipom ist die Sprache an sich Poesie, deren Charakteristikum an dieser Stelle ist, dass sie niemals "Zweiwertig" $(W B, 165)$ sei.

Damit ist ein weiterer Aspekt der Diskussionen ins Spiel gebracht, der durch die Begriffe »Dualismus«, »das Binäre« und den »Begriff« als solchen gekennzeichnet ist. Diese beschreiben Murnaus Vorlieben, sie schwingen mit, wenn er Deters gegenüber sagt, er wolle die »Distinktion, $[. .$.$] den Geist (W B, 647)$. In seiner Vorstellung ist alles durch Logik und Wissenschaft erklärbar, auf- und einteilbar in Gegensätze, die sich eindeutig gegenüberstehen und voneinander abzugrenzen sind. Dieser Auffassung folgt auch die Kontrastierung von Lipom und Murnau. Für Murnau ist "[a]lles eine Frage des Begriffs" $(W B, 173)$. Dies hängt mit seiner Überzeugung zusammen, dass alles nur gedacht und konstruiert ist. Durch das Einsetzen eines Begriffs sei das Denken bereits vorherbestimmt. Diese Überlegungen schließen an Gedanken aus $D d A$ an. Dort ist >Begriff< eines der zentralen Schlagwörter. Er wird dargestellt als »Urform objektivierender Bestimmung " $(D d A, 21 \mathrm{f}$.), die für das Auseinandertreten von Begriff und Sache, allgemeiner für die Unterscheidung zwischen Subjekt und Objekt und 
damit für die Abstraktion stand. Als Beispiel für die das Denken bestimmende Qualität des Begriffs führt Murnau ausgerechnet Lipoms Namen an, der wie bereits erwähnt ein Fettgeschwulst bezeichnet. Man halte Lipom »für einen fetten Menschen, weil er wie einer heißt« $(W B, 173)$. Diese Überlegung rekurriert jedoch auf den Diskurs, dass Lipom eigentlich gar nicht dick sei, sondern diese Gestalt nur äußerlich angenommen habe, und damit auf seine mehr oder weniger heimliche Elbenidentität. In dieser Hinsicht charakterisiert Lipom Murnau in seiner Rede vor dem Thing auch als einen Geist, der sich von den anderen abgesetzt hat und nicht wie diese ist. Murnau wolle das werden, "was niemals einer von uns gewesen ist [...], nämlich: einzig, begrenzt und erhoben « $(W B, 806)$. Auch dies charakterisiert Murnaus Bestreben treffend. Er, der von Lipom lediglich abgespalten ist, möchte sich gänzlich »emanzipieren « ( $W B$, $647)$, spricht von der »Autonomie des Geistes« (WB, 195). Zwar sieht er sich schon als Geist, nicht als Mensch, was sich in seinen abschätzigen Bemerkungen gegenüber Deters immer wieder ausdrückt, doch teilt er die Ansichten und das Lebensgefühl der Geister nicht. ${ }^{59}$ Die Vielfalt, die sich schon in der Verbundenheit mit der Natur gezeigt hat, gilt auch für ihr Verhältnis untereinander. Ein weiblicher Geist, Glaistik, bringt dies auf den Punkt: »Uns langweilt die Einigkeit. Wir schließen uns zusammen nicht aus Eintracht, sondern aus Vielfalt. Wir sind nicht gut und sind nicht böse, und ihr seid gut oder seid böse.« $(W B, 818)$ Die Geister wünschen sich keine Harmonie, sondern das Nebeneinander, auch die Spannung und sogar das Leiden. Dies wird ihnen auch als Präferenz von »Verwirrung « und »Chaos« $(W B, 175)$ vorgeworfen oder, wie Gangolf es ausdrückt, sie »haben bereits alles durchvirt und zerstören jede Klarheit« $(W B, 510)$.

Auch die begriffskritische Position der Elben rekurriert auf das ungleich komplexere Denken Adornos. Die Kritik an der Vereinheitlichung des philosophischen Denkens durch das Denken in Begriffen bildet ein zentrales Thema in Adornos Werk. Zusammengefasst sind diese Überlegungen in seinem Spätwerk Negative Dialektik $(1966){ }^{60}$

\section{Zusammenfassung}

Insgesamt kann also konstatiert werden, dass die beiden Positionen von Mythos und Logos durch die Standpunkte von Lipom und Murnau in groben Zügen deutlich werden. Lipom vertritt die Verbundenheit mit der Natur, einen ursprünglichen Naturzustand, der gekennzeichnet ist durch wahres Erleben, durch körperliches Fühlen im Gegensatz zum Denken, durch ausschweifende Sexualität, die Propagierung von Trieb und Lust. All dies ist gekennzeichnet durch die Präferenz von Mehrdeutigkeit und Vielfalt, wovon Chaos und Verwirrung die implizierte Kehrseite sind. Murnau dagegen lehnt die Natur ab, er steht für den Fortschritt der Wissenschaft, für den

59 Auch hier ist eine Ambivalenz zu konstatieren. Die Geister sind den Menschen in manchem überlegen, werden jedoch dennoch zurückgedrängt. Eine Verhältnis wie es in der Realität dem von Natur und Mensch entspricht. Aus diesem Überlegenheitsgefühl heraus verachtet Murnau die Menschen, auf der anderen Seite teilt er ihre Denkweise und will deshalb sogar lieber ein Mensch sein, vgl. $W B, 701$.

6o Vgl. dazu kurz und prägnant Figal: »Über das Nichtidentische«. 
Siegeszug der Technik. Er propagiert die Abschaffung von Emotionen und die Verlagerung aller körperlichen Wahrnehmung in technische Simulation. Abstrahiert drückt sich diese Position im >Begriff`aus, in der formalen Logik sowie in den Schlagworten des Binären und des Dualismus. Wie an den Zitaten des letzten Abschnitts ersichtlich wird, ist der Leser darauf angewiesen, sich aus weit verstreuten Äußerungen ein Bild der gegenübergestellten Anschauungen zu machen. Die Diskussionen werden nie vollständig ausgeführt, eher angedeutet, da sie der strukturellen Anlage des Romans gemäß immer durch Wechsel zu anderen Erzählebenen unterbrochen werden. Beide Positionen sind dabei relativ vage konturiert, da sie weitestgehend in Schlagworten verhaftet bleiben. Genauere Ausführungen und Begründungen verlieren sich in den fragmentierten Auseinandersetzungen der beiden Widersacher.

\section{Die Kehrseite des aufklärerischen Geistes: der `Dunkle` und seine Gehilfen}

Doch nicht nur Lipom und Murnau versinnbildlichen den Gegensatz zwischen Mythos und Logos. Gerade die Position des Logos hat neben Murnau noch weitere Vertreter, die einen anderen Aspekt beitragen. Während Murnau eine harmlose Stellung einnimmt, da er zwar viel redet und diskutiert, aber letztlich in jedem Gedanken von Lipom abhängig ist (der ihn dennoch durch das Thing richten lassen will), wird der ausführend destruktive Aspekt seiner Anschauung von einer ominösen Entität eingenommen, die als >der Dunkle bezeichnet wird. Zieht man noch einmal $D d A$ als Stichwortgeber heran, sind an dieser Stelle Parallelen zur eigentlichen, hier bisher kaum beachteten Grundthese zu erkennen. Die scheinbar paradoxe These - »schon der Mythos ist Aufklärung, und: Aufklärung schlägt in Mythologie zurück« ( $D d A$, 6) - wird vor allem in Bezug auf das Fortbestehen des Mythos in der Aufklärung behandelt. Dabei zielen die historischen Exkurse auf die Gegenwart ab. Die Erfahrung des deutschen Faschismus war für Horkheimer und Adorno der Anstoß für ihre Untersuchungen, er präsentierte das Umschlagen von Aufklärung in Barbarei in aktuellster Form, der ihren Betrachtungen zufolge jedoch kein zufälliges Ereignis, sondern in den Strukturen der zivilisatorischen Entwicklung angelegt war.

Der deutsche Faschismus wird in $W B$ wenig thematisiert. Als Hintergrund von Deters' Identitätsflucht sowie in einigen Anspielungen bei Lipom und in der Szene in Winkelmanns Kneipe spielt er eine Rolle. Das Umschlagen modernen wissenschaftlichen Denkens in Barbarei sowie die mit absoluter Gewalt durchgesetzte Naturbeherrschung wird aber in den Handlangern des unbestimmt bleibenden `Dunklen<, Hüon und Rascher gezeigt.

Die beiden Figuren sind als Parallelfiguren auf zwei verschiedenen Erzählebenen angelegt. Hüon ist auf der ersten Ebene angesiedelt und nimmt als sehr naiv wirkender Gast an dem Treffen der ATG teil. Von Lipom protegiert und von Anna umworben, ist er vermeintlich auf der Suche nach seiner abhanden gekommenen Geliebten Rezia. Er trägt ein Album bei sich, das er immer wieder vorzeigen will, was aber immer wieder, zumeist von Lipom, verhindert wird. Es stellt sich schließlich als eine Sammlung von Popeln berühmter Leute heraus, ${ }^{61}$ eine $»$ kleine Sensation $«(W B, 565)$, die keine ist, wie

61 Diese sind in einer langen Aufzählung aufgeführt (vgl. $W B, 720 f$.$) . Ihre Namen sind als die von$ berühmten Schriftstellern sowie von Leuten des politischen und kulturellen Lebens der Entste- 
der Erzähler der dritten Ebene entschuldigend zugibt. Die etymologische Herleitung von »Poplig, Pöbel, also das Volk [...] In diesem Sinne sammelt Hüon Leute» (WB, 728) wird nebenbei von Deters II geliefert, jedoch nicht weiter verfolgt. Das Album stellt sich schließlich als Tarnung Hüons heraus, ebenso wie seine seltsame Sprache. Er ersetzt dabei Lexeme der deutsche Sprache durch entsprechende französische und baut sie, falls nötig morphologisch angepasst, an der korrekten Stelle des deutschen Satzes ein. ${ }^{62} \mathrm{Im}$ Kontext dieses Abschnitts ist es wichtig, dass er sich nur getarnt hat, letztlich aber »den Mythologien ein Ende [machen] $(W B, 958)$ will. Dies soll durch die Zerstörung von Daniellos Computer erfolgen, dem Biocomputer, von dem er durch Gangolf erfährt (vgl. WB, 853). Obwohl es auf den ersten Blick nicht so aussieht, erfolgt auch hier der Anschluss an die obigen Mythosüberlegungen. Hüons Gedanken in Reaktion auf Gangolfs Informationen werden wiedergegeben: "Die kybernetische Schöpfung emanzipierte sich. Wieviel Leid hatte es gebraucht, den Mythos auszurotten? Wieviele Millionen von Toten, wieviel Demütigungen, wievielen Irrsinn? Das sollte alles umsonst gewesen sein? « $(W B, 854)$ Der zweite Satz schließt wieder direkt an Gedanken aus $D d A$ an, wo immer wieder auf die Härte hingewiesen wird, die nötig ist, um das mythische Stadium zu überwinden. ${ }^{63}$ Die Verbindung von der Zerstörung des Computers zur angenommenen Unterdrückung der Natur in den Mythostheorien ist der Hinweis auf die »kybernetische Schöpfung «. Damit wird auf die schöpferische Funktion des Computers verwiesen. ${ }^{64}$ Hüon stellt sich mehrfach als Vertreter der >Vernunft<-Position, des Logos, dar. Daniello mit seinem Computer bezeichnet er als »Terrorist gegen jede Vernunft « $(W B, 854)$. Er selbst »rette la raison « $(W B, 882)$, da die durch den Biocomputer erzeugten Geister gegen alle Naturgesetze verstoße und jede wahre Aussage durch ihre Existenz verhindert würde. Ein (realer) zeitgenössisch-politischer Bezug wird dadurch aufgemacht, dass er sich in eine Reihe stellt mit Institutionen, die diese »letzte Bastion der Undenkbarkeit« nicht zulassen könnten: »Sie [Deters], ich, Claudia Weigan, ${ }^{65}$ das Max-Planck-Institut, die KWU [Kraftwerk Union als Kernkraftwerkbetreiber] und der Bundeskanzler « (WB, 882). Diese der komischen Anlage der Figur entsprechende überspitzte Auflistung

hungszeit des Romans zu erkennen, deren Vor- und Nachnamen wild untereinander vertauscht sind.

62 Als Beispiel eine seiner ersten Äußerungen: »Soviel je sais steht er noch in Verhandlungen concernant des Aufgebots." $(W B, 250)$ - Dies sind Kennzeichen makkaronischer Dichtung, einer Gattung des Komischen. Vgl. dazu Hermann Wiegand: »Makkaronische Dichtung«, in: Harald Fricke (Hg.): Reallexikon der deutschen Literaturwissenschaft, 3. Aufl., Bd. 2: H-O, Berlin / New York 2000, 527-530. Hüons Sprachweise ist nicht die des Riccaut de la Marlinière aus Lessings Minna von Barnhelm, wie Scherer inkorrekt schreibt (Scherer: »Die Metamorphosen des Wolpertingers«, 179), bei dem französische Wörter und Sätze in schlechtes Deutsch eingestreut sind.

63 Vom Denken, das sich Gewalt antun muss, um »die Mythen zu zerbrechen« $(D d A, 10)$ über die »Ausrottung des Animismus« $(D d A, 11)$ bis zu dem berühmten `Furchtbaren«, das sich die Menschheit zur Schaffung ihres modernen Charakters hat antun müssen (vgl. DdA, 40).

64 Siehe unten, Abschnitt 4.2 auf Seite 207.

65 Nebenbei sei angemerkt, dass Claudia Weigan auch zur Logos-Seite zu zählen ist. Als Psychologin nimmt sie an den Treffen aus wissenschaftlichem Interesse an den Geisterphänomenen teil. Auch wenn ihre Absichten nicht eindeutig geklärt werden, so widerspricht sie zumindest nicht eindeutig Murnaus Unterstellung, sie wolle Lipom vernichten (vgl. WB, 701). Andererseits scheint sie auch eine gewisse Sympathie für die Geister zu haben. 
repräsentiert die wissenschafts- und technikorientierte Vernunftsposition, die von den historisch vagen Umschreibungen in $D d A$ in aktuelle konkrete Beispiele transformiert ist.

Hüon wird mehrfach als Projektion oder Parallele Raschers bezeichnet ( $W B, 843$, 565), wobei bewusst unklar bleibt bzw. infrage gestellt wird, ob dies nicht vielmehr andersherum konstruiert ist. Auf jeden Fall sind sie als Parallelfiguren zu sehen, die eine ähnliche Funktion ausüben. Rascher findet sich auf der zweiten Ebene und ist ein Bekannter Aldas. Auch er positioniert sich als eine weitere Variante der Antimythenfraktion. Gegenüber Deters II fängt er ein Gespräch mit der Bemerkung an, sie schafften es schon, die Mythen kleinzumachen (vgl. WB, 707). Als Neonazi mit Anspielungen auf den realen Neonazi Michael Kühnen angelegt (siehe unten Abschnitt 4.3.1 auf Seite 219), stellt er den deutlichsten Bezug zu nationalsozialistischen Anschauungen her. Damit ist er weniger eindeutig der >Vernunftposition` zugehörig, steht aber letztlich für das Umschlagen der Aufklärung in Barbarei. In Parallele zur Mythophilie der Nazis, gibt er zu, anfangs positiv über die Elben gedacht zu haben. »Ich habe gedacht, die Geschöpfe seien uns zu Diensten. Nibelungen und so. Sind sie aber nicht. Sind in allem auf ihrer eigenen Seite. Fürs Vaterland kein Herz.« (WB, 707) Der Hinweis auf die Nibelungen deutet auf die nationalsozialistische Vereinnahmung der nordischen Mythologie hin, eine bestehende Verbindung, die wohl als möglicher Vorwurf von Herbst antizipiert wurde. ${ }^{66}$ Die wiederum in ihren überdeutlich vorgebrachten faschistischen Ansichten überspitzt angelegte Figur, die in Kombination mit esoterisch-kosmologischen Neigungen zusätzlich ins Lächerliche gezogen wird, sollte wohl dazu dienen, angesichts der reichlichen Bezüge auf nordische Mythologien den erwarteten Nazivorwurf deutlich zu entkräften. Die Beschreibung Raschers im kommentierten dramatis personae deutet auf eine solche Lesart hin: „Das ist ein Kühnen, den der Roman unbedingt braucht, um nicht mißverstanden zu werden." $(W B, 12)$ Die Natur ist bei ihm im Gegensatz zu Murnau positiv besetzt, jedoch in der sozialdarwinistischen Lesart, nach der das Schwache ausgerottet wird und nur die Starken überleben.

Außerdem zugehörig ist wohl der Agent Baumwolle (vgl. indirekt $W B, 866$ ). Auf der Zugfahrt beauftragt er Deters, Anna und Bertrecht zu folgen, was sich jedoch als bloßer Scheinauftrag herausstellt. Es geht ihm nicht um Bertrecht als Terrorist Weisgeld, sondern um die Anna-Figuren. Eine eindeutige Zugehörigkeit zu einer Ebene ist bei ihm nicht auszumachen. Bei der Zugfahrt spricht er mit Deters (also auf der ersten Ebene), später trifft er sich mit dem >Dritten $•$. Auch Mallebron wird als Agent des `Dunklen` verdächtigt (vgl. WB, 994). Dieser ist aber wesentlich deutlicher als Doppelgänger von Daniello auf der zweiten Ebene erkennbar. Sieht man die Helfer des `Dunklen $`$ in einem Zusammenhang und beachtet, dass Hüon Daniellos Computer zerstören will, macht eine Verbindung zwischen Mallebron und dem `Dunklen $<$ keinen wirklichen Sinn. ${ }^{67}$ Eine eindeutige Klärung ist hier wohl nicht möglich.

66 Vgl. Herbsts Äußerungen dazu im Interview: Faure: »Jetzt hab ich Metall im Mund «", 13 und 14.

67 Aus diesem Grund halte ich die Ineinssetzung von Daniello, Mallebron und Baumwolle als zusammengehörige Figuren auf verschiedenen Ebenen durch Moosbach für nicht haltbar. Sie wird allerdings auch nicht genauer und damit potenziell nachvollziehbar begründet, vgl. Moosbach: "Das Ribbentrop-Rhizom«, 52. 
Beim `Showdown` während des Festes treten Hüon und Rascher parallel auf der jeweiligen Ebene als Verfolger von Anna/Deters und Alda/Deters II auf. Beide versuchen, die Computer zu zerstören. Hüon verwendet zusätzlich ein Pflanzenschutzmittel, um die Elben damit zu vernichten. ${ }^{68}$ Deters wird von Hüon zumindest niedergestreckt, wenn nicht gar getötet, wie Moosbach vermutet. ${ }^{69}$ Rascher ist es schließlich, der die zum Luchs verwandelte Alda erschießt. Dabei wird er als Symbol moderner menschlicher Barbarei und Ungeheuerlichkeiten stilisiert, indem er die Leiche zu schänden versucht. Dies schließt an die Entsetzensthematik in VG an, die auch einen Bezug zum Umgang mit der Erfahrung des Nationalsozialismus hat, und damit zusammenhängend auch an das vielbeschworene, auch in WB erwähnte Massaker von My Lai im Vietnamkrieg (vgl. WB, 411), das metonymisch für die moderne Brutalität jenseits des scheinbar unerklärlichen oder einmaligen deutschen `Sonderfalls« steht.

Der so nebulös scheinende Dunkle, der immer wieder von Lipom als Angstphänomen der Geister heraufbeschworen wird, ist eine Figur, die aus verschiedenen religiösen und mythologischen Überlieferungen zusammengesetzt ist. Während andere Figuren, wie an Lipom oben beispielhaft aufgezeigt, vor allem durch mehrere Namen auf verschiedene Mythenüberlieferungen rekurrieren, die miteinander eng verbunden sind, bietet der Dunkle kein schlüssig scheinendes Bild. Er tritt noch nicht einmal als eine Figur auf, lediglich seine Handlanger oder »Agent $[\mathrm{en}] \ll(W B, 883)$ wie Hüon und Rascher werden als Personen erkennbar. Folgerichtig stellt Deters ihn in seiner Thing-Rede auch als bloßes Angstkonstrukt der Geister dar und fordert sie auf, sich ihm zu stellen. Auf jeden Fall eigen ist ihm eine negative Bewertung, eine Aura von Undurchsichtigkeit und Angst. Eine Teufelsfigur ist er jedoch eher nicht. In den Metaüberlegungen von Deters II und Alda wird dies als eine Möglichkeit insinuiert, aber auch nicht direkt bestätigt; er wird vielmehr als Rachegott Jahwe, dem Gott des Alten Testaments gesehen (vgl. WB, 574). Als »Vatergott[]«, dessen Welt (im Gegensatz zu Annas gynaikokratischer) autoritär organisiert ist, ist er Teil der >Geschlechterkampf<-Thematik. In einem späteren Gespräch nehmen die beiden die mythologische Einordnung noch einmal auf. Deters II bringt als weitere Interpretation die eines gefallenen Engels ins Spiel, die der christlichen Überlieferung zugeordnet wird, stellt aber wieder die » Racheseite Jahves« [sic!] $(W B, 655)$ in den Mittelpunkt. Der Zusatz »der die Erde formte aus dem Satz vom ausgeschlossenen Dritten« bringt den Anschluss an die Thematik von Vielfalt und Einheit. Damit wird auf die Bedeutung hingewiesen, die die monotheistische jüdisch-christliche Religion für die Entwicklung begrifflichen Denkens einnimmt. Im zugrunde liegenden Geschichtsbild wird die jüdisch-christliche Tradition der Logos-Seite zugeschlagen, was sich auch in etlichen kritischen Äußerungen Lipoms ausdrückt. Lipom gibt in seiner Rede vor dem Thing auch weitere Hinweise auf ein heterogenes Bild des `Dunklen`. Er stellt ihn dar als ehemals den Elben zugehörig, der sich jedoch von diesen abgewendet hat wie es später dann Murnau intendiert. Als »Hexenjäger« $(W B, 805)$ hat er sich auf die menschlich-

68 Dadurch kommt das die 1980er Jahre stark bewegende Umweltschutzthema in den Roman, vgl. auch $W B, 808$ f.

69 Vgl. Moosbach: »Das Ribbentrop-Rhizom«, 53. 
christliche Seite geschlagen und die frühen Missionare in den nordischen Ländern im Kampf gegen den Glauben an die Elben und anderen Naturwesen geholfen. Es folgen weitere Hinweise auf die geschichtliche Entwicklung, in der Lipom ihn als dunklen Verführer charakterisiert, der in Richtung der gekennzeichneten Logos-Position agiert. Bezeichnend ist die kurze Anmerkung, die einen Bezug zur Technik herstellt, er sei der, »der aus Menschen Automaten werden ließ und sich auf das Haupt die Krone der Mechanik setzte« (ebd.). Damit zeigt sich, dass der `Dunkle« weniger als eine kohärente Figur und Person aufgefasst wird, sondern vielmehr als diffuses Bild für die destruktive Seite des Logos, das verschiedene Aspekte in sich vereinigt, ohne sie zu einem kohärenten Zusammenhang zu vereinigen. Der `Dunkle « steht damit umfassender für die nicht genauer zu fassende Macht des Logos als Murnau, der jedoch eher als Personifikation bzw. als konkrete Person fungiert, die für den Logos einsteht und zudem nicht wirklich als böse gekennzeichnet wird. ${ }^{70}$

Deters schließlich vermittelt in seiner Thing-Rede im Konflikt zwischen den Parteien. Die Murnau verteidigende >Lösung`schließt jedoch kaum die Logosseite und schon gar nicht den >Dunklen und somit die destruktive Seite des Logos ein. Sie ist auch eher als eine Art Lösung für das Problem der Elben zu sehen, aus ihren Lebensräumen vertrieben zu sein. An Murnau schließt er insofern an, dass er die moderne Entwicklung zur Technik akzeptiert, er nimmt die Realität wie sie ist und will den Geistern nicht darin zustimmen, diese Entwicklung zu beklagen oder die moderne Welt zu zerstören. Auch Murnau wollte einen Weg finden, mit den Menschen auszukommen und zu kommunizieren. Er selbst meint, diesen Kommunikationsweg im Computer, also in der Technik, gefunden zu haben (vgl. WB, 732). Kurz zusammengefasst besagt nun also Deters `Lösung ‘, dass es keinen Sinn mache, »die Bäume zu besingen, wenn es keine mehr gibt, und ebenso wenig, die Technik nicht zu besingen, wenn sie überall ist « $(W B, 828)$. Damit greift er den Gegensatz von Natur und Technik auf und bringt eine neue Denkrichtung ins Spiel. Er fordert die Geister auf, aus ihren natürlichen Schlupfwinkeln zu kommen und in die technischen Geräte, »die Maschinen [...], in die Hochhäuser, in die Kanalisation « (ebd.) etc. zu gehen, nur dadurch bekäme »die Natur eine Chance« (ebd.). Damit deutet er die Natur um, sieht sie als ein Prinzip, dessen Bedeutungsnuancen in Lipoms Position vereinigt ist. Murnau verteidigt er nur scheinbar, da er seine Position nicht in ihrem Kern, nur an der Oberfläche aufnimmt. Auch wenn Lipom seufzt, sein Ding wäre, »was Sie fordern « $(W B, 829)$ nicht, ist es dessen Naturposition, die Deters an die Erfordernisse der Zeit anzupassen versucht. ${ }^{71}$

\subsubsection{Männlichkeit vs. Weiblichkeit: der 'Geschlechterkampf‘}

Das diesen Abschnitt einleitende Zitat von den »Prinzipien in wechselnder Gestalt« $(W B, 659)$ bezieht sich im Text lediglich im Vergleich auf Lipom und Murnau, eigentlich sind Anna und Alda der Ausgangspunkt des Gedankens. Noch weniger als

7o Erstaunlicherweise wird auch Lipom mit dem >Dunklen $>$ in Verbindung gebracht, vgl. WB, 105 und 812, er scheint sogar auf diesen zu hoffen, vgl. WB, 294f. Möglicherweise ist dies ein weiterer Hinweis auf Lipoms dunkle Seite, vgl. dazu Abschnitt 3.5.2 auf Seite 168.

71 Vgl. auch Abschnitt 4.2 auf Seite 207. 
beim vorigen, durch das Begriffspaar Mythos/Logos charakterisierten >Prinzip ‘findet sich eine vorgegebene griffige Bezeichnung. Thematisch geht es um Sexualität, womit generell eigentlich die menschliche gemeint ist. Die der Elben ist dabei als Spiegelung der menschlichen zu sehen, zu der sie auch `kompatibel ist. Als das `Prinzip $\prec$, das Deters II anspricht, kann begrifflich am ehesten ein weibliches Prinzip als Bezeichnung für Weiblichkeit an sich angenommen werden, dem im Kontext natürlich ein männliches Prinzip entgegengesetzt ist. Der Kontext ist hier auch weit gefasst, in den ATG-Diskussionen, den Gesprächen zwischen Alda und Deters II, in den ThingReden wie in verschiedenen zentralen Handlungssträngen werden dieser Dichotomie weitere an die Seite gestellt. Es geht dabei um Dominanz und Unterwerfung, Patriarchat und Matriarchat und schließlich auf abstrakter Ebene wieder um den Gegensatz von Dualismus und Pluralismus. Als Oberbegriff dient der des "Geschlechterkampfes" $(W B, 574)$, der die zugrunde liegenden geschichtsphilosophischen Vorstellungen in sich repräsentiert.

\section{Lipom und Anna}

Lipom und Anna bilden diejenige Paarkonstellation, die an zentraler Stelle in der Veranschaulichung der `Geschlechterkampf $\triangleleft$-Thematik steht. Ebenso wie ihre Identität als Elbenkönigspaar Oberon und Titania zunächst nicht ersichtlich ist, so sind in den Diskussionen im Wolpertinger die Andeutungen der Beziehung so gering, dass der Leser nicht auf eine Verbindung zwischen Lipom und Anna kommen würde. Die als naiv und ebenso naiv-lustorientiert sowie flatterhaft dargestellte Anna scheint gar nicht im Interessenfeld Lipoms zu sein, geschweige denn, dass sie ihm überlegen wäre bzw. ihn in der Hand hätte. Vielmehr ist er derjenige, der insgesamt in der Runde den Ton angibt. Verschiedentlich wird dies jedoch anders dargestellt. Im Gespräch mit Dr. Weigan gibt Murnau die Abhängigkeit Lipoms von Anna zu verstehen: „Ohne sie ist er nichts. Eine Nullstelle, wenn Sie so wollen. Ein Loch in der Realität.« $(W B, 701)$ Beim Thing wird diese Einschätzung bestätigt. Zwar setzt sie sich nach ihrem verspätetem Erscheinen zu Lipoms Füßen nieder, nachdem sie sich vor ihm verneigt und ihn als »Mein Fürst « angesprochen hat, doch ist ihrer Erscheinung hier schon »Ironie beigemischt « $(W B, 801)$. Bei den späteren Wortwechseln werden die Verhältnisse dann auch deutlich. Nach Lan-an-Sìdhes Appell an Lipoms Männlichkeit, als dieser kurz versucht ist, Titanias Bedingung eigenmächtig aufzuheben, geht Anna keifend dazwischen: »Ich entlasse ihn nicht! [...] er kann nicht fort, solange ich ihn nicht lasse!« $(W B, 815)$ Lipom lässt daraufhin »ergeben« die Arme hängen, fügt sich und lässt sich auch ohne Protest das Wort entreißen. Als er nach Deters' Einschreiten von den Geistern kaum noch beachtet wird, wendet er sich gar »wieder etwas hilflos[] zu Anna, die ihm nicht nur metaphorisch über den Kopf hinausgewachsen war ( $W B$, 831). Auf der anderen Seite ist wiederum zu vermerken, dass Anna durchaus auch auf Lipoms Anweisungen reagiert, ihnen sogar gehorcht (vgl. WB, 168).

Der Konflikt zwischen Anna/Titania und Lipom/Oberon, auf den hier angespielt wird, ist Wielands Oberon entlehnt. Der Bezug ist zwar deutlich, doch wird er keineswegs eins zu eins übernommen. Vielmehr werden fast alle Elemente umgedeutet und erhalten andere Vorzeichen. In der in Oberon eingebetteten Erzählung von Gangolf 
und Rosette entzündet sich der Streit des Elbenpaares am Ehebruch der jungen Frau an ihrem greisen Gatten. Während Titania die Frau verteidigt und ihr beisteht, ist Oberon über diesen Vorfall so erzürnt, dass er mit seiner eigenen Gattin bricht. Er schwört, sich nicht mit ihr zu versöhnen,

Bis ein getreues Paar, vom Schicksal selbst erkoren,

Durch keusche Lieb in Eins zusammen fließt,

Und, probefest in Leiden wie in Freuden,

Die Herzen ungetrennt, auch wenn die Leiber scheiden,

Der Ungetreuen Schuld durch seine Unschuld büßt. (VI, 101) ${ }^{72}$

Zum einen ist es also Oberon selbst, der die Bedingung stellt und den Konflikt so eskalieren lässt (Titania ruft ihm sogar hinterher), zum anderen sind es eigentlich zwei Bedingungen in einer. Zur Grundvoraussetzung der unverbrüchlichen Liebe kommt auch noch die Bedingung der (vorehelichen) Keuschheit. In WB wird die Konfliktkonstellation etwas anders dargestellt. Im Prolog eröffnet der mit Lipom weitgehend identische Marduk dem Erzähler, seine Frau - die Elfe - gebe nach dem nicht näher bezeichneten Streit erst Ruhe, »wenn ich ihr zwei Leute präsentiere, die sich ständig untreu sind, doch einander lieben bis in den Tod« $(W B, 32)$. Die Bedingung, die für eine Versöhnung erfüllt werden muss, ist demnach gegenüber der Vorlage entscheidend verändert. Geht es zwar in beiden um die beständige Liebe, ist die Forderung nach Keuschheit in $W B$ in ihr Gegenteil verkehrt, sie müssen sich gegenseitig betrügen. ${ }^{73}$ Zwar wird keine Begründung dafür gegeben, doch fügt sich diese amoralische Wendung zum oben beschriebenen Eintreten Lipoms für die triebhafte (naturhafte) Sexualität, die nicht den einschränkenden moralischen Gesetzen der Menschen folgt. Es ist jedoch Anna/Titania, die die Bedingung gestellt hat, und auch die eben beschriebene Thing-Szene zeigt sie im Licht der dominanten Position. Der Bezug zu Wieland ist demnach nur eine Anlehnung, gerade die Figurencharakterisierung ist zwar nicht gänzlich ins Gegenteil verkehrt, wird jedoch keineswegs vollständig übernommen: »In der fast allegorischen Symbolik des >Feenmärchens« scheint Oberon das Prinzip der Männlichkeit und des Sittlichen, Titania das der Weiblichkeit und der Natur zu vertreten. ${ }^{74}$ Die Geschlechterprinzipien sind hier noch anders belegt; die Sittlichkeit, um die es bei Wieland bei allem Verständnis für die menschlichen Schwächen vor allem geht, wird in WB dann keinem der beiden Pole zugeschrieben. Lipom ist in dieser Hinsicht wie bereits beschrieben kaum mit Wielands Oberon zu vergleichen. Dieser macht eine Entwicklung vom »rigoristischen Moralapostel und Misogynen

72 Wieland: Oberon, 271.

73 Schon bei Wieland handelt es sich jedoch um eine Umdeutung der Vorlage Huon de Bordeaux, da das Paar eben die Keuschheitsforderung nicht erfüllt. Oberon muss jedoch die menschliche Natur akzeptieren; durch die erfolgreiche (harte) Prüfung der wahren Liebe des Menschenpaares löst sich aber der eigene Fluch, und das Elbenpaar kann sich versöhnen. Vgl. dazu Florian Gelzer: ")Oberon««, in: Jutta Heinz (Hg.): Wieland-Handbuch. Leben - Werk - Wirkung, Stuttgart / Weimar 2008, 227-237, hier: 233.

74 Sven-Aage Jørgensen / Herbert Jaumann / John A. McCarthy / Horst Thomé: Wieland. Epoche Werk - Wirkung, München 1994, 114. 
zum weisen und menschenfreundlichen Schutzgeist ${ }^{75}$ durch; beide Beschreibungen treffen wohl kaum auf Lipom zu.

$\mathrm{Zu}$ Anna scheint die explizite Forderung nach Untreue deutlicher zu passen. Sie wird insgesamt als eine zumindest den herkömmlichen moralischen Vorstellungen nicht entsprechende Figur gezeichnet. Über sich selbst sagt sie, sie sei »weder hörig, noch gehörig, niemandem, nicht einmal ihrer eigenen Moral« (WB, 168). Sie vertritt mit ihrem Wesen und Verhalten insofern eine moralisch befreite Sexualität, als sie für promiskuitiven Geschlechtsverkehr eintritt. Andererseits legt sie sich bestimmte Regeln auf, so will sie sich - ohne sich als Prostituierte zu sehen - für einen Kuss oder eben den Beischlaf mit Deters bezahlen lassen. Dabei geht es ihr darum, jeglichen »Bindungsanspruch $«(W B, 344)$ zu vermeiden. Die freizügige Einstellung Annas wird metanarrativ von Deters II dahingehend betont, dass er gegenüber Alda mitteilt, Anna aus diesem Grund erfunden zu haben, eben weil sie auf unbedarfte, spontane Weise mit dem Beischlaf umgehe. Er beklagt, dieser sei »so belastet« $(W B, 297)$, die triebhafte Spontaneität werde von gesellschaftlichen Konventionen unterdrückt. Durch diese Äußerung wird sie eindeutig als Figur männlicher Sexualphantasien kenntlich gemacht. Auch Alda schließt sich dieser Sichtweise an, wenn sie von den "männlichen Prostitutionsfantasien " $(W B, 533)$ spricht. Anna muss auch als konstruierter Gegenentwurf zur »spröden Mütterlichkeit« $(W B, 325)$ der aus $V G$ bekannten Agnes und damit wieder als Symbol sexueller Virilität gesehen werden. Eine weitere Szene bleibt dahingehend nicht bei Formulierungen stehen, sondern veranschaulicht die Sichtweise auf geradezu symbolische Weise. Als Deters in einer von mehreren präsentierten Szenenversionen Anna auf ihrem Hotelzimmer besucht, trifft er sie unbekleidet an. Sie spürt seinen kritischen Blick auf ihren Brüsten und beginnt, sie »wie Plastilin« $(W B, 404)$ zu formen. Er reagiert verblüfft, da sich tatsächlich auch in ihrer Gesamtgestalt ein eklatanter Wandel vollzieht. Sie provoziert ihn etwas, als sie meint, sie habe am vorhergehenden Tag wohl nicht seinem »Ideal«, seiner »Anima« (ebd.) entsprochen. Sie präsentiert sich also als buchstäblich ganz nach seinen Vorstellungen und Wünschen formbar.

Ein weiterer Bezugsraum wird dadurch aufgemacht, dass sie in Andeutungen als Vampirin dargestellt wird. Zwar tritt mit Lan-an-Sìdhe die weibliche Vampirfigur der keltischen Mythologie persönlich und zudem noch im Konflikt mit Anna auf, doch hat auch Anna Züge dieser mythologischen Figur. Diese wählt sich als eine Art von Muse einen menschlichen Geliebten, den sie inspiriert, der aber auch früh in geistiger Umnachtung stirbt. Angedeutet wird dieser Zusammenhang nach dem Tod von Bertrecht, der mit Anna auf ungeklärte Weise zusammenhing und immer wieder Anfälle hatte, während der er im Wahnsinn dichtete. Als sich die Elben seinem Bekannten Karl Polst zuwenden, will Anna diesen beißen und kommentiert dies mit den Worten »Dann würd' auch wieder jemand dichten" $(W B, 662)$. Er soll damit also zum Nachfolger von Bertrecht werden, um letztlich dann das gleiche Schicksal zu erleiden. Der Zusammenhang von Lust und Verderben, der im Vampirmotiv gebündelt ist, schließt an die von Lipom propagierte Auffassung von Sexualität an. Auch dort kann die triebhafte Sexualität mit Gewalt und Leid verbunden sein. Anna

75 Michael Hofmann: Reine Seelen und komische Ritter. Aspekte literarischer Aufklärung in Christoph Martin Wielands Versepik, Stuttgart / Weimar 1998, 307. 
demonstriert dies Deters, als sie ihn schließlich entgegen ihrer sonstigen Forderungen nach Bezahlung küsst. Der Kuss ist gierig und heftig, es ist fraglich, ob er eher "Lust oder Furcht $(W B, 353)$ bringt. Deters reagiert denn auch entgegen der sonstigen Männlichkeitsdemonstrationen. Defensiv bekennt er, ihr nur helfen zu wollen, er sei ein »Mann, der dich liebhaben will« (ebd.). Sie tut dies als kitschig ab, hat hier demonstrativ keine harmonisierende weibliche Rolle.

Es zeigt sich also wieder einmal die ambivalente Figurenanlage. Obwohl Anna nach ihrer mythologischen Figuration für das weibliche Prinzip steht, das durch Liebe, Mütterlichkeit und Fruchtbarkeit gekennzeichnet ist, wird sie mehrfach als reine Projektion männlicher sexueller Wünsche dargestellt, die dem Mutterideal entgegenstehen. $\mathrm{Zu}$ den projizierten Phantasien muss dabei auch gerechnet werden, dass sie sich nicht im devoten Gestus erschöpft, sondern durchaus wehrhaft ihre Einstellung zur Geltung bringt. Die Szene, in der sie ihre Formbarkeit nach männlichen Begierden demonstriert, beendet sie »wie eingeschnappt « mit dem Kommentar, ihre »eigenen Leute« möchten sie, »ohne daß ich erst groß an mir rumkneten muß» $(W B, 405)$. Auch verwahrt sie sich Deters gegenüber vehement davor, lediglich als Agnes-Ersatz $\mathrm{zu}$ fungieren (vgl. $W B, 352 \mathrm{f}$.).

Im Konflikt zwischen Lipom/Oberon und Anna/Titania wird in den vielfältigen, die Ebenen überspannenden Diskussionen weniger die im Prolog benannte Bedingung thematisiert, als zunehmend von einem `Nachfolger ‘ für Lipom im Kontext der Hieros gamos geredet. Wie die meisten mythologischen Anspielungen wird der Ritus der >Heiligen Hochzeit in den lediglich drei vorhandenen wörtlichen Erwähnungen nicht erläutert. Ursprünglich als Bezeichnung für den in Homers Odyssee geschilderten Geschlechtsverkehr zwischen der Göttin Demeter und dem Menschen Iasion verwendet (siehe Odyssee, Buch 5, V. 125-128), wurde er später auf ähnliche Riten in Griechenland und im Alten Orient übertragen. ${ }^{76}$ Das von Menschen durchgeführte Zeremoniell war das sichtbare Gegenstück der Vereinigung von Mensch und (weiblicher) Gottheit. Es wurde zum Symbol von Fruchtbarkeit, der Erneuerung allen Lebens. Die »heilige Hochzeit zwischen Himmel und Erde [war] der kosmische Vorgang, der alles Leben auf der Erde erweck[te] «77. Letztlich steht sie allgemein für die Vereinigung zwischen Frau und Mann sowie für die Vereinigung von Gegensätzen, speziell der Gegenüberstellung von Himmel und Erde. Dieser Aspekt ist auch gemeint, wenn Lipom angesichts eines möglichen Scheiterns des Rituals befürchtet, »Himmel und Erde [seien] auf ewig getrennt $(W B, 688)$. Sieht man Anna in dieser Tradition, so erweist sich ihre Rolle als Liebhaberin im Gegensatz zur Mutterfigur als stimmig: "Contrary to ideas that dominated scholarship for a long time, supreme goddesses are not primarily mothers but lovers. ${ }^{78}$ Annas enge Verbindung, ja geradezu Fixierung

76 Vgl. Beate Pongratz-Leisten:»Hieros Gamos«, in: Hans Dieter Betz (Hg.): Religion in Geschichte und Gegenwart. Handwörterbuch für Theologie und Religionswissenschaft, 4. Aufl., Bd. 3: F-H, Tübingen 2000, 1730-1731.

77 Christoph Türcke: Sexus und Geist. Philosophie im Geschlechterkampf, Frankfurt am Main 1991, 24.

78 Kees W. Bolle: »Hieros Gamos«, in: Mircea Eliade u. a. (Hg.): The Encyclopedia of Religion, Bd. 6: God-Ichi, New York / London 1987, 317-321, hier: 320. Auch im Hinblick auf die keltische Kultur (die durch die Anspielungen auf die keltische Mythologie in WB relevant ist) finden sich solche 
auf die Sexualität wird auch betont durch ihre mehrfach gestellte Frage »Wie ist es eigentlich mit dem Sex?« $(W B, 168)$. Diese ist durchgehend >gegen` Murnau und seine sexualitätsfeindliche Haltung gerichtet und wird von ihr unvermittelt in die Diskussionen eingeworfen, um die Aufmerksamkeit darauf zu richten und gerade Murnau zu zwingen, Position zu beziehen (vgl. auch $W B, 815$ ). Deters ist nun in dieser mythisch-rituellen Konstellation als `Nachfolger Lipoms vorgesehen (vgl. WB, 646). Eine Erklärung findet sich für diese Notwendigkeit nicht. ${ }^{79}$ Die Hinweise deuten jedoch darauf hin, dass Deters zum einen wohl seltsamerweise mit Anna selbst die Bedingung erfüllt, die ihren eigenen Streit mit Lipom (bzw. Titanias mit Oberon) konstituiert. Beide haben sich ineinander verliebt bzw. lieben sich, soweit dies bei der flatterhaften Natur Annas glaubhaft ist. Eben diese Anlage, aber auch Deters' kurze sexuelle Verbindung mit der Mündener Lehrerin Claudia Deutsch zeigen den Teil der Bedingung, dass sie sich >untreu< sein müssen. Es wird jedoch explizit angesprochen, dass Deters die Verbindung erfüllt hat (vgl. WB, 923, 997). Dies zeigt sich vor allem darin, dass er bereit ist, die Heilige Hochzeit, also die Vereinigung mit Anna, zu vollziehen. Zum anderen wird Deters zum Nachfolger Lipoms, indem er eben die "Primizien « besteht, die wohl seine Weihung als eine Form von Priester im Kontext der Hieros gamos bezeichnen könnten, und die er ebenfalls durch die Vereinigung mit Anna erlangt. ${ }^{80}$

\section{Deters II und Alda}

Bevor noch einmal näher auf das Ritual selbst und seine Störung, sozusagen den >Showdown « des Romans eingegangen werden soll, ist auf die Parallelführung dieser Thematik auf der zweiten Erzählebene hinzuweisen. Alda und Deters II scheinen sich zunächst zufällig im Zug getroffen zu haben. Weder das Treffen, noch die weitere Entwicklung der Beziehung zwischen den beiden ist jedoch zufällig. Alda weist darauf hin, dass sie den Ring an seinem Finger gesehen hat und in den Gesprächen über die erste Erzählebene wird immer wieder eingeflochten, dass die `Liebesgeschichte $<$ zwischen Anna und Deters durch sie beide parallel geführt wird. Deters II will zunächst lediglich mit Alda schlafen, hat also ein ausschließlich sexuelles Interesse. Die gleichen

Hinweise. Dort gab es ebenfalls Riten nach dem Prinzip der Hieros gamos und in Bezug auf die zentralen keltischen Muttergöttinnen galt: »Kaum ein anderes Volk hat die göttliche Mutter mit soviel Inbrunst verehrt wie die Kelten. [...] aber die Kelten sahen in allen Göttinnen, als Vertreterinnen des weiblichen Prinzips, zuerst einmal die Mutter, selbst wenn die mütterlichen Eigenschaften ins Gegenteil verkehrt waren, wie bei den Kriegsgöttinnen, die töteten, statt Leben zu geben, verhungern ließen, statt zu ernähren, bedrohten, statt zu beschützen.« (Botheroyd / Botheroyd: Lexikon der keltischen Mythologie, 244)

79 Ein kleiner, wenn auch nicht wirklich erklärender Hinweis ergibt sich durch einen Blick auf die Originalgeschichte in Huon de Bordeaux. Dort wird der Titelheld am Ende Nachfolger von Auberon im Elfenreich (vgl. Heintze: »Huon de Bordeaux«). In WB hält Anna Deters zunächst für Hüon und wendet sich ihm deshalb zu.

80 Moosbach/Patorski weist auf eine solche Lesart hin, die sich über die Bedeutung des Wortes Primizien als erste Messe eines neugeweihten Priesters herleitet, vgl. Moosbach: »Das Ribbentrop-Rhizom «, 52. Von Priester ist in $W B$ selbst nicht die Rede, Deters erhält aber den Lilienstabring der Elben als Symbol und führt schließlich auf der Diskette das Volk in eine neue Sphäre. Der Lilienstab ist wiederum von Wieland entlehnt, vgl. Oberon VI, 88 (Wieland: Oberon, 267). 
mythologischen Regeln und Vorgaben, die für Anna und Deters gelten, etablieren sich jedoch zusehends auch für sie, was durch die oben dargestellte weitgehende Identität jeweils zwischen den Figuren auch logisch erscheint. Auch sie müssen sich lieben, Alda muss sich ihm jedoch aus eigenem Willen hingeben.

Laut Aussage von Deters II kommt durch Alda die Thematik als eine neue in sein »Erzählsystem«, wobei er sie als »ihre feministische Mystik« $(W B, 566)$ bezeichnet. $\mathrm{Zu}$ finden ist sie vor allem in ihren Anmerkungen über die nun immer deutlicher in Koautorschaft entstehende erste Erzählebene. Sie führt seine mythologischen Konstruktionen mehrfach zurück auf weibliche Ursprungserzählungen und Mythen und führt damit die Thematik von Matriarchat und Patriarchat, von Muttergottheiten und späterem Vatergott ein, die sich dann auch wieder in den Diskussionen der ATG auf der anderen Erzählebene wiederfinden. Ähnlich und zusammenhängend mit der geschichtlichen Vorstellung einer Entwicklung vom Mythos zum Logos scheint in verschiedensten Andeutungen die Annahme einer kulturellen Entwicklung vom Matriarchat zum Patriarchat durch. Die matriarchale Entwicklungsstufe wird wieder mit einem Urzustand gleichgesetzt, der durch den Einklang mit der Natur sowie die Betonung der Vielfalt ausgezeichnet ist. Der oben beschriebene >Dunkle steht nicht nur für den Logos, sondern ist auch versammelnder Ausdruck für patriarchale mythische Figuren und Götter. Der jüdisch-christliche Jahwe ist als Vatergott deutliches Zeichen dieser Entwicklung. In Aldas mythologischer Auslegung des $>$ Dunklen betont sie diese Ausrichtung, wenn sie meint, Fuvarra, der irische Elbenkönig (also der König der mehrfach erwähnten Daoine Sìdhe, auch unter verschiedenen anderen Schreibweisen, u.a. als Finn Bheara oder Fionnbharr bekannt), habe sich mit Jahwe verbündet, um »Gewalt über das gynaikokratische Knockma« (WB, 655), den Hügel, in dem die Elben wohnen, und damit über deren Gesellschaft zu bekommen.

Interessanterweise erhält Fuvarra Gewalt über die gynaikokratische Gesellschaft und über seine Frau, indem er sich selbst kastriert. Ergänzt wird dies durch die Aussage, damit habe er »sein Weib [betrogen]. Das hat die Königin geschwächt, und die christlichen Horden brachen ein « $(W B, 655)$. Es stellt sich also weniger die Frage, ob die Kastration in den Mythen wörtlich auftaucht und in der erzählten Geschichte einen Sinn macht. Vielmehr bedeutet sie im skizzierten Kontext, dass der matriarchalen Ursprungsgesellschaft, in der Sexualität offen gelebt wurde, das lustfeindliche Christentum entgegengesetzt und sie durch dieses ersetzt wurde. Die kurze Andeutung der Selbstkastration erläutert auch die Bedeutung des schon im Prolog erwähnten >Beutelchens`. Dadurch dass hinzugefügt wird, Fuvarra habe Titanias Ring genommen und ihre Macht mit seinem Beutel gebannt, den sie seither um den Hals trägt (ebd.), wird nahegelegt, dass es sich um seinen Hoden handelt (was schon vorher durch Alda indirekt ausgesprochen wird, vgl. $W B, 532$ ).

Damit ist eines von mehreren Symbolen genannt, die bezüglich der `Geschlechterkampf $\_$-Thematik im Roman eine Rolle spielen: das Beutelchen, der Ring und, mit letzterem verbunden, der Speer oder Stab. Der Beutel ist in der Handlung auf der ersten und zweiten Ebene von Bedeutung, wie erwähnt vom Prolog ausgehend bis zum Finale des Festes. Der Ring dominiert als Symbol im Erzählstrang, der die Geschichte von Hüon präsentiert. Der Speer kommt als Gegenstand erst bei den `Primizien` vor, als Lipoms Gehstock als »Eschenstab» $(W B, 997)$ im Ritual verwendet wird. In den 
Gesprächen zwischen Alda und Deters II werden diese Gegenstände dann wieder in psychoanalytischer Manier als mythologische Symbole interpretiert. Der Speer bezeichnet dabei als Phallussymbol die männliche Macht. In Parallele zur eben erwähnten Selbstkastration Fuvarras in der keltischen Mythologie wird hier auf den Gralsmythos verwiesen. Der Zauberer Klingsor »entmannt «sich dort ebenfalls, um, wie hier hinzugefügt wird, »den Speer zu objektivieren« $(W B, 532)$. In ihrer Deutung geht diese Symbolik durch das Christentum verloren und wird durch die des Rings ersetzt, der an verschiedene andere ähnliche runde Symbole anschließt. Als »Gegensymbol« zum Speer wird auf der tiefenpsychologischen Deutungsebene die Vagina gesehen, die wiederum mit dem Gral in Verbindung gebracht wird. Schlusspunkt der Deutung ist die Aussage, Parsifal habe »in Wahrheit den Uterus der Alten Göttin wiederfinden wollen « (ebd.). Deutlich wird, dass sämtliche Gegenstände psychoanalytisch mit geschlechtlichen Bezügen gedeutet und in einem mythologischen Netz von Beziehungen platziert werden, das jeweils nur angedeutet wird, aber als Zentrum die Annahme eines mythologisch repräsentierten `Geschlechterkampfs hat. $^{81}$

Über den Inhalt des Beutels werden widersprüchliche Informationen gegeben. Während Alda einmal sagt, darin sei die Asche Oberons (vgl. WB, 887), wird an anderer Stelle mitgeteilt, es enthalte "pulverisierte Traumpartikel«, »Albenpulver « oder aber einfach »Koks« (WB, 932). In jedem Fall soll es Halluzinationen hervorrufen. Später finden sich dann zwei der Beutelchen. Alda verbindet die Frage von Deters II nach dem Inhalt mit seiner Entscheidung für oder gegen die Geister, also auch seiner Entscheidung für oder gegen die Heilige Hochzeit. Ausgedrückt ist es jedoch in der Auswahl »Natur oder Geist « (WB, 975). In dem einen scheint tatsächlich Koks zu sein, als »[r]einste Biologie « bezeichnet, im anderen ist möglicherweise etwas anderes, etwas »ähnliches«, etwas das entweder Halluzinationen hervorruft, ${ }^{82}$ oder aber wirklich die Gestaltänderungen und Lähmungserscheinungen in Gang setzt, die in der Folge beschrieben werden.

In ihren Gesprächen kommt es noch mehrfach zu nicht näher ausgeführten Bezügen auf Geschlechtersymbolik in der Mythologie (vgl. WB, 569f., 582 f.). Auch die Begriffe Matriarchat bzw. Gynaikokratie und Patriarchat werden ins Spiel gebracht, finden sich aber auch bei Lipom und Anna wieder. ${ }^{83}$ Durch Alda wird die Thematik jedoch zudem noch mit den oben genannten Aspekten von Natur und Sexualität sowie von Begriff, Mehrdeutigkeit und Vielfalt verbunden. »Dann trennte der Vater Trieb von

81 Dass diese Verbindungen keine ausschließlich eigenen Schlüsse von Herbst sind, zeigt ein Blick in die religionswissenschaftlich umstrittene Matriarchatsforschung der 1980er Jahre, vgl. beispielhaft Heide Göttner-Abendroth: Die Göttin und ihr Heros. Die matriarchalen Religionen in Mythos, Märchen und Dichtung, München 1980, 190-197.

82 Dies ist eine mögliche >realistische< Lesart, die vorher schon genährt wurde, als Dr. Weigan »voll bis zum Hals mit einer modischen Spielart von Koks $(W B, 967)$ verhaftet wird. Weigan ist zwar nicht bei der Beutelchen-Szene dabei (und zudem auf einer anderen Ebene), aber sie erlebt das Fest ebenfalls und durch das Koks wird eine Verbindung gezogen.

83 Die Anspielungen sind wie immer auch im Detail zu finden; so entdeckt Deters II im Gang des Andree's Berg im Rahmen eines Bildes ein Paßfoto, das mit dem Schriftzug >Bachofen versehen ist, womit der Name Johann Jakob Bachofens ins Spiel gebracht ist, der in seinem Werk Das Mutterrecht (1861) den Begriff Gynaikokratie prägte und am Anfang der Matriarchatsforschung steht, vgl. WB, 580. 
Liebe und Besamung von Lust. Der Geist ließ die Geister zurück." (WB, 730) Es wird wieder der (patriarchale) Vatergott angesprochen, der Körper und Geist voneinander scheidet. Die Differenzierung löst einen harmonischen Urzustand ab. Alda schafft die Verbindung zur Begriffsthematik in einem ausführlicheren Passus, der sich gegen die zentralistische Gottesvorstellung der monotheistischen Religionen wendet:

Da der Begriff [...] sich in hierarchische Systeme einfügen muß, damit man mit ihm praktizieren kann, braucht er ein Zentrum. Dies ist Gott. Wenn der gut ist, muß Materie schlecht sein. So einfach ist das. Aus der Ekstase, die sich durchaus sexuell und vielleicht nur so ergibt, wurde die abstrakte Gottesschau. Es ist die Niedermetzelung des Einzelnen zugunsten eines Allgemeinprinzips. $(W B, 567)$

Die Verbindung der Geschlechterthematik zur Behandlung der genannten Themen bei Lipom und Murnau wird durch den einzelnen Gott hergestellt. Im Kontext der vorangegangenen Gespräche ist klar, dass hier vom Vatergott die Rede ist, der wiederum dann im Kontrast zu Matriarchat und den alten Muttergöttinnen steht. ${ }^{84} \mathrm{Sie}$ fügt die Begriffe noch deutlicher zusammen, als sie sagt, der »Vater [habe] Angst vor den Frauen. Sie nehmen auf und trennen nicht « $(W B, 731)$. In diesen Bemerkungen festigt sich die Vorstellung der oben beschriebenen geschichtlichen Entwicklung. Die Natur- oder Mythosposition wird mit Weiblichkeit und die Geist- oder Logosposition mit patriarchaler Männlichkeit verbunden. ${ }^{85}$

Wie bereits erwähnt unterliegen auch Alda und Deters II den mythologischen Zielen, die nach alten rituellen Vorgaben erfüllt werden müssen. Alda begründet ihr Treffen und ihre nötige Verbindung damit, dass sie (als Geist/Elbe) wie alle ihre >Artgenossen « sich »an der Materie " erneuern muss. »Wir müssen uns mit realen Geschöpfen auffüllen wie Sie sich mit fiktiven. Darum stehlen wir euch die Kinder, und ihr stehlt uns die Inspiration.« ( $W B, 730)$ Die Beschreibung des Verhältnisses zwischen Menschen und Geistern, die auch dafür gilt, dass sich die ATG mit Menschen wie Bertrecht >versorgt‘, ist zudem als partielle Begründung für die Hieros gamos zu sehen. Die gegenseitige Abhängigkeit ist der Grund, warum die Erneuerung der Verbindung zwischen den beiden Welten nötig ist.

\section{Das Fest, die Bedingung und die Hieros gamos}

Der Akt der Heiligen Hochzeit findet auf allen drei Ebenen parallel während des ineinander gedachten Festes statt. Die Verschränkung der Ebenen bezieht sich dabei nicht nur auf das Erzählen, das es dem Leser nicht mehr möglich macht, die Figuren eindeutig auseinanderzuhalten. Auch für die Personen selbst ist dies nicht mehr möglich. So ist die häufig wiederholte suchende Frage nach Alda des umherirrenden Deters II nicht mehr eindeutig ihm zuzuordnen. Denn er vermutet, »nicht der Autor [zu sein], für den ich mich hielt, sondern der Dritte, und [ich] suchte nicht Alda, sondern das Mädchen« $(W B, 987)$. Eigentlich waren zuvor die drei parallelen Paare

84 Männlichkeit und Götterfigur werden auch in Daniello verbunden (zu seiner 〉Göttlichkeit` siehe das nächste Kapitel). Er trägt an seinem Revers eine Brosche mit einem Widder. Die symbolische Verbindung zur Männlichkeit wird mehrfach herausgestellt (vgl. WB, 507, 577).

85 Vgl. dazu Türcke: Sexus und Geist, 9-109. 
so angeordnet, dass Deters mit Anna verbunden war, Deters II mit Alda und der `Dritte mit einem neu hinzugekommen `Mädchen`, die als Berta Gert benannt wird. Diese Figur offenbart durch ihren Namen die mythologische Vorlage. Schon Jakob Grimm hat die Verbindungen verschiedener mythologischer und Märchenfiguren nachgewiesen, sodass Berta oder Perchta mit der aus dem Märchen bekannten Frau Holle oder Hulda (oben bereits als häufiger Ausruf von Anna und Alda vermerkt) und womöglich auch mit der nordischen Göttin Frigg gleichzusetzen sind. Außerdem findet sich hier schließlich auch die Verbindung und Erklärung der bereits in VG vorkommenden Spinnenfrau. ${ }^{86}$ Als solche taucht sie in einem späten Rückgriff auf die Zugfahrt wieder auf. Sie lässt den Erzähler zu sich rufen, wird als Frau Gert vorgestellt und gibt sich als Mutter von Alda zu erkennen (vgl. WB, 964f.). In den Überlieferungen ist Ber(h)ta oder Perchta oft verbunden mit Sagen um Spinnerinnen, als Göttin ist sie für diese zuständig. Die verschiedenen mythologischen Figuren werden auch als drei miteinander verbundene drei Frauen gesehen, die auf gewisse Weise wieder identisch sind, aber auch verschiedene Altersstufen symbolisieren, das junge Mädchen, die erwachsene und die alte Frau. Ähnlich, wenn auch nicht gleich scheint es sich auch in $W B$ zu verhalten. Das Mädchen wird auch mit der alten Spinnenfrau verwechselt (vgl. WB, 978), eine Identität wird also insinuiert, und ebenso wird eine Verbindung oder gar Identität mit Alda angedeutet (vgl. $W B$, 994). Eindeutig dargestellt wird keine der Identitäten und auch die Abläufe bleiben im Unklaren. Berta führt ihren nicht zu identifizierenden Begleiter in eine Kartoffelkiste, wo sie zusammen in einer Art Nährlösung landen, während andere Elben auch zugegen zu sein scheinen. Die Unauflösbarkeit der Verschränkung und Verwirrung der Ebenen wird deutlich an einem Satz wie: »Wie nun ich mit Berta in der Nährlösung lag und alle die Hände spürte, die zahllosen Zungen, Lippenpaare, stand ich vor Lipom, so tief gefallen, hinuntergeschluckt.« (WB, 996f.) Es wird also eine Gleichzeitigkeit verschiedener Handlungen ausgedrückt. Von nun an steht Anna im Mittelpunkt. Wenig später wird jedoch geschildert, dass Berta und das erzählende Ich die Geschehnisse in einem Monitor sehen und weiter auf der Flucht sind. Dem Szenengewirr entnehmbar ist jedoch, dass es zu einer Vereinigung eines Paares kommt, wodurch die Bedingung erfüllt wird. Der Abschnitt schließt mit der bereits erwähnten Beschreibung der Kopulation der zum Luchs gewordenen Alda vermutlich mit Deters II, die von Rascher gestört wird, der Alda auch tötet. In der Parallele störte Hüon vorher schon auf der anderen Ebene.

Eine komplette Entschlüsselung des Geschehens ist nicht möglich. Verschiedene Aspekte werden jedoch immer wieder angesprochen und so in ihrer Bedeutung hervorgehoben. Bei der Bedingung geht es darum, dass sich das Paar bis in den Tod lieben muss. Deters und Deters II sind die männlichen Partner in dieser Konstellation und ihnen wird mehrfach die Frage gestellt, ob sie lieben. Bis zuletzt können sie dies nicht eindeutig positiv beantworten. Dennoch wird die Bedingung erfüllt, auch wenn nicht ganz klar wird, warum nun, zumal hinzugesetzt wird, dass sie »sich erfüllte schon seit je« $(W B, 997)$. Angesprochen wird aber auch zumindest in Bezug auf Alda,

86 Vgl. Marianne Rumpf: „Berta«, in: Kurt Ranke u. a. (Hg.): Enzyklopädie des Märchens. Handwörterbuch zur historischen und vergleichenden Erzählforschung, Bd. 2, Berlin / New York 1979, 155-162. 
dass sie nicht besiegbar ist. Sie kann bloß erobert werden, indem sie sich dem hingibt oder schenkt, der sie liebt (vgl. WB, 839, 919, 923). Die Eroberung wird dann in der abschließenden Szene angedeutet. Hatte Deters II sich vorher mehrfach ängstlich angesichts von Aldas Veränderung gezeigt, wird er hier als der sie dominierende gezeigt. In gewandelter Gestalt ist sie dann jedoch für andere angreifbar und wird von Rascher getötet.

\section{Menschlicher Bezug und Ausblick}

Im obigen einleitenden Zitat bezieht sich die Prinzipienhaftigkeit auf Anna und Alda, Lipom und Murnau, bei denen es sich alles um Elben handelt. Dementsprechend beziehen sich die bisherigen Ausführungen auf mythische Verweise, auf Riten und historische Konflikte in der Welt der Elben. Deters und Deters II werden schließlich mit hineingezogen in die Zusammenhänge. Die Elbenwelt fungiert hier jedoch wieder als Spiegel der menschlichen. Doch auch auf der menschlichen Ebene wird der `Geschlechterkampf` aufgegriffen. Wie bereits erwähnt hat Deters ein kurzes Verhältnis mit der Lehrerin Claudia Deutsch. Dieses kulminiert (und endet) in einer Sexszene, die die finale Szene des Festes vorwegnimmt. Es ist die Beschreibung eines Kampfes, indem sich beide als ebenbürtige Gegner erweisen. Gewalt und Lust werden als ineinander übergehend gezeigt. Schließlich gewinnt er jedoch die Oberhand, die männliche Dominanz siegt. Ambivalent wie das Geschlechterverhältnis auf allen Ebenen gezeichnet wird, ist jedoch auch dieser 'Sieg`. Er zeigt sich gar nicht mehr als der Macho, als der er bezeichnet wird, versucht, sich um ihre Verletzung zu kümmern, sie wirft ihn jedoch fluchend und schimpfend hinaus, sich gedemütigt und traurig fühlend.

Dieser explizit vorgeführte `Geschlechterkampf $\prec$ knüpft an den oben beschriebenen Diskurs um Sexualität und darin an Lipoms Position an. Er hatte für eine rausschweifende`Sexualität plädiert und auch Lust und Gewalt in Verbindung gebracht. Dieser Diskurs zieht sich von $V G$ an durch Herbsts gesamtes Werk und findet seinen Ausdruck in zunehmend expliziten Beschreibungen. Alda sagt einmal zu Deters II: »Erzähle niemals, wie sie sich liebten. Verschweig es. Über solche Wunder spricht man nicht.« $(W B, 833)$ Diese romantisierende Sichtweise trifft anscheinend schon auf die rein sexuelle Beziehung von Deters und Claudia Deutsch nicht zu. Später in Meere gilt dies auch für die Beschreibungen der Liebesbeziehung nicht mehr, was dann rechtliche Konsequenzen (bis zum Buchverbot) nach sich zog.

Bezogen auf $W B$ kann konstatiert werden, dass insgesamt kein `Sieger im $>\mathrm{Ge}$ schlechterkampf festzustellen ist. Die Figuren ebenso wie die Verhältnisse sind ambivalent belegt. Zudem wird auch dieser Aspekt rückgebunden an die Alternative von Dualismus und Vielfalt. Türcke stellt in dieser Hinsicht nach seinen philosophiegeschichtlichen Ausführungen fest: »Versöhnung der Geschlechter setzt nicht nur voraus, daß weiblich etwas irreduzibel Anderes als männlich ist, sondern auch Geist etwas irreduzibel Anderes als beide: das Dritte, worin einzig ihre zwanglose Übereinstimmung gelingen kann. ${ }^{87} 7$ Dabei kontrastiert er Aristoteles’ Satz vom zu vermeidenden Widerspruch mit der Dreifaltigkeit sowohl der Großen Mutter als

87 Türcke: Sexus und Geist, 108. 
auch der christlichen (männlichen) Trinität. Eine ähnliche Konsequenz zieht auch Lipom. Als es bei einer der ATG-Diskussionen wieder einmal um Matriarchat und Patriarchat geht (und Murnau sich gegen das Matriarchat wendet), flüstert Lipom: »Ein Drittes, ein Drittes! $(W B, 676)$ Er nimmt Bezug auf einen schon vorher (WB, 665) genannten berühmten Ausspruch von Cato, die Frauen seien, wenn sie den Männern gleichgestellt wären, diesen überlegen. Lipom geht es, wie er durch seinen Kommentar deutlich macht, eben nicht um Kampf oder zumindest nicht um Sieg. Wie auch sonst geht es ihm um eine möglicherweise undenkbare dritte Möglichkeit.

\subsection{Virtualität und `allegorische` Figurenidentität}

In einer Lesart des Romans sind die Mitglieder der ATG virtuelle Gestalten. Programmiert sind sie von dem immer mal wieder anwesenden Broker Daniello, der Deters bei seiner Ankunft als der Besitzer des Hotels Wolpertinger sowie als Finanzier der ATG-Treffen beschrieben wird. Scheinen die Elben demnach gänzlich programmiert zu sein, so sind selbst die Menschen Deters und vermutlich auch Bertrecht und die Psychologin Dr. Weigan sowie das Hotelpersonal unter dem Einfluss von Daniellos "Biocomputer $(W B, 853)$. Dass diese Lesart nicht als Alternative dazu zu sehen ist, dass es sich bei Lipom und den anderen um Elben handelt, lässt sich daran sehen, dass die ATG ihre Abhängigkeit von Daniello erkennt.

Deutlich wird dies in einem längeren Gespräch zwischen Lipom und Daniello, das die Stelle eines vierten Blumenstückes einnimmt. Die Blumenstücke sind eine Kapitelform, die in Anlehnung an Jean Pauls Siebenkäs (1796/1818) gebildet sind, das diese schon im vollen Titel trägt (Blumen-, Frucht- und Dornenstücke oder Ehestand, Tod und Hochzeit des Armenadvokaten F. St. Siebenkäs). Jean Pauls Roman enthält mehrere, wie auch in $W B$ nummerierte, aus dem Kontext der anderen Kapitel herausgehobene Abschnitte. ${ }^{88}$ Der Unterschied dieses Pseudo-Blumenstücks zu den anderen besteht darin, dass es zwar ein wenig aus dem Handlungsverlauf herausgerückt ist, aber stärker etwas mit diesem zu tun hat als bei den anderen, außerdem keine kurze Geschichte erzählt, sondern ein Gespräch wiedergibt, und schließlich, dass statt Nebenfiguren Hauptfiguren die zentralen Akteure sind. Lipom soll Daniello die `Exodus`-Pläne der ATG unterbreiten, die aus Daniellos Einflussbereich ausbrechen und auf einer Diskette über die Einspeisung in einen Zentralcomputer in Frankfurt am Main in die Welt gelangen möchten. Im Gegensatz zu Lipoms selbstbewusstem und autoritärem Auftreten in den meisten anderen Situationen (bis auf die Szene mit Anna nach dem Thing), wirkt er hier als kleinlauter Bittsteller, als spreche, wie sogar vom Erzähler vermerkt wird, »ein sehr Kleinwüchsiger zu einem Hünen« $(W B, 895)$. Während Lipom sich in dieser neuen Rolle erst zurechtfinden muss und dennoch versucht, auf Augenhöhe zu verhandeln, stellt Daniello gleich anfangs seine Überlegenheit

88 Der Bezug auf Jean Paul hinsichtlich der Konstruktion und der Bezeichnung der größeren Abschnitte als Septoren wird im Gespräch zwischen Deters II und Alda direkt hergestellt, siehe WB, 315, vgl. dazu auch Scherer: »Die Metamorphosen des Wolpertingers«, 181, und Reber: Formenverschleifung, 305 FN 24. Interessant wäre hinsichtlich des Einflusses von Jean Paul auch der intertextuelle Bezug auf Siebenkäs' Namens- und Identitätstausch mit seinem Freund Leibgeber sowohl in Siebenkäs als auch fortgesetzt in Titan (1800-1803). 
aus und bestimmt entschieden das Gespräch. Er gibt eindeutig zu verstehen, dass Lipom sich lediglich in seinem, also Daniellos Kopf befinde, ${ }^{89}$ bzw. ist zu erschließen, er sei erst dort und dann durch Daniello computergeneriert. So ist die Virtualität der Geisterwesen eindeutig benannt, die vorher wiederum fast immer nur durch Andeutungen erfahrbar war und am deutlichsten im Gespräch zwischen Hüon und Gangolf angesprochen wurde (vgl. WB, 852ff.).

Gleich eingangs benennt Daniello auch die Funktionen, die er für Lipom vorgesehen hat und als was er sich sieht: Lipom ist der Teufel und Daniello der Gott der virtuellen Wolpertinger-Welt. Daniello stellt eindeutig klar, dass in dieser alles von ihm abhängt, jeder, sogar Deters denkt das, was Daniello will, dass er denkt. Beispielsweise ist Lipoms Meinung, jederzeit abreisen zu können, nur ihm einprogrammiert. ${ }^{90}$ Daniello hat Lipom geschaffen, der die anderen geschaffen hat: »I hoab Ihna g'schoffan uand Sie hoam die ondern g'schoffen. Dös iis Ihr Progromm. ( WB, 896) Lipom versucht verschiedentlich, dagegen zu argumentieren und sogar Daniello einzuschüchtern, wird aber immer wieder von diesem in seine Schranken verwiesen. Schließlich wechselt Lipom die Strategie und versucht, Daniello durch List zu seinem Ziel zu bewegen. Er fordert ihn als Spieler und in seiner göttlichen Allmacht heraus. Zudem bezeichnet er ihn als »autoritär « $(W B, 900)$ und »egoman « $(W B, 902)$ und argumentiert dadurch mit dem Ziel, ihn als einen bösen Gott darzustellen. Daher bringt er auch die Theodizeefrage auf, wie die Wolpertinger-Welt gut sein könne, wenn »wir sterben müssen« (ebd.). Daniello scheint auch erst auf diese Appelle vor allem an seine Allmacht anzuspringen; so greift er noch einmal erklärend auf, dass er Lipom als Teufel sieht, weil dieser »net zuge'm [will], doaß ois guat oang'richtet iis« (ebd.). Lipom vertritt hier die Position des Teufels, der Gott herausfordert. Er ist jedoch im eigentlichen Sinn nicht erfolgreich, denn Daniello ist keine guter, wohlwollender Gott. Ihm ist tatsächlich egal, was mit seinem Geschaffenen passiert, ${ }^{91}$ die geschaffene Welt ist nur zu seiner Entspannung da. Die `Erlaubnis«, Deters könne es ja einmal versuchen, die ATG auf einer Diskette mitzunehmen, gibt er schließlich aus reiner Langeweile, da er des `Schachspiels gegen sich selbst ` doch manchmal müde wird.

Die Idee für den Exodus der ATG aus dem Machtbereich Daniellos kommt bezeichnenderweise Murnau, in einem Gespräch mit Deters. Murnau spricht immer wieder davon, dass er am Leben bleiben, sich »emanzipieren« $(W B, 647)$ will, mehrfach benutzt er die Formulierung, ein rautonomes Ich $($ vgl. bspw. WB, 732) sein zu wollen. Zunächst bezieht sich das auf seine oben beschriebene Abhängigkeit von Lipom, doch in Verbindung mit der Disketten-Idee wird auch die Alternative vom autonomen Selbst gegenüber der Abhängigkeit von Daniello als Programmierer-Gott etabliert.

89 Diese Äußerung spiegelt ironischerweise ein Chanson, das in der Szene in Winkelmanns Schänke zitiert wird. Es handelt sich dabei um das Lied »Die wahren Abenteuer sind im Kopf» des Chansonniers André Heller. Zitiert werden die Verse: »Sie alle, alle sind in meinem Kopf, und sind sie nicht in meinem Kopf, dann sind sie nirgendwo.« ( $W B, 624)$

90 Auf Daniellos Allmacht wird bereits frühzeitig angespielt, als Anna Deters sagt, Daniello könne, wenn er wollte, »die Sonne aufgehen lassen « $(W B, 412)$. Die naive Anna scheint dies jedoch als gegeben zu sehen und thematisiert es nicht weiter.

$91 »$ Woann's z'samm'brechat, bau i hoalt woas oandres. Iis egol.« $(W B, 901)$. 
Durch die metanarrativen Gespräche vor allem auf der zweiten Ebene wird an dieser Stelle eine weitere Parallelsetzung nahegelegt, die die totale Abhängigkeit wieder relativiert. Wird das Verhältnis der Wolpertinger-Gäste zu Daniello im PseudoBlumenstück mit dem Verhältnis von Menschen zum allmächtigen Gott in eins gesetzt, so kann als weitere, allerdings nicht unbedingt identische Parallele das Verhältnis literarischer Figuren zu ihrem Autor gesehen werden. Diese Verbindung erfolgt durch ähnliche Betrachtungsweisen. Daniellos Lipom- bzw. Wolpertinger-Programm scheint so beschaffen zu sein, dass Daniello bzw. selbst der programmierte Daniello (ein Avatar, der reigentlicher sitzt in seinem Computerraum und schreibt die Szene vor) Lipom oder seine Zauberfähigkeiten nicht immer sehen kann. Auch ist das Programm wohl so autonom, dass Daniello nicht alles über die Geschichte weiß, beispielsweise kennt er den alten Andree, den ersten Besitzer des Wolpertinger, nicht. Ebensolches wird auch mehrfach für Deters II und seine Figuren formuliert. So wird angesprochen, dass eine Figur auch mehr wissen kann als ihr Autor (vgl. WB, 113, 563). Oder Alda weist ihn darauf hin, er unterschätze seine Figuren, weil er davon ausgeht, dass Anna etwas nicht weiß, obwohl er (Deters II) es Alda gesagt habe. Diese Bemerkung legt ein Eigenleben der Figuren nahe, das sogar ebenenübergreifend wirkt.

Durch die Lesart der ersten Erzählebene, die die Virtualität einiger Figuren und Beeinflussung der anderen Figuren durch den Biocomputer annimmt, ergibt sich eine allegorische Auslegung ihrer Figurenkonstitution. Daniello ist nicht nur individuelle Figur, sondern verkörpert auf allegorische Weise gleichzeitig auch eine allmächtige Gottesposition; parallel dazu ist Lipom an dieser Stelle eine Figuration des Teufels.

Gleichzeitig verkörpert Daniello auch die Position eines literarischen Autors, da dieser gegenüber der fiktiven Welt eine göttliche Allmachtsposition einnimmt. Ebenso wie göttliche Allmacht die Geschicke der Menschen bestimmen kann und ein Autor die seiner Figuren, kann Daniello die Wolpertinger-Figuren bestimmen. In diesem Sinn sind sie nicht autonom, nicht einmal Subjekte, da sie vollständig prädisponiert sind. Sie haben jedoch einen freien Willen und freie Entwicklungsmöglichkeiten, solange Daniello nicht eingreift. Außerdem haben sie die Möglichkeit, sich Autonomie vorzustellen und zu wünschen, und streben sie durch die Disketten-Idee an.

In diesem Motiv bringt Herbst mehrere Aspekte zusammen. Er bringt das Thema der Virtualität ein, auf deren Bedeutung jenseits von Identitätsaspekten noch zurückzukommen ist. ${ }^{92}$ Zudem wird die angenommene Determiniertheit des Menschen veranschaulicht, indem die Figuren als >programmiert ` vorgeführt werden. Durch die metafiktionalen Überlegungen in Bezug auf die Parallelsetzung von Gott, Autor und Programmierer wird dies noch einmal im Fiktionsdiskurs gespiegelt.

92 Vgl. Abschnitt 4.2 auf Seite 207. 


\subsection{Intertextuell geprägte Identitäten}

$W B$ ist durch eine Vielzahl intertextueller Bezüge geprägt, wie durch einige Belege in den bisherigen Ausführungen bereits angedeutet worden ist. Den literarischen Vorlagen sind Personal und Motive entlehnt, die der eigenen Konzeption angepasst und ineinandergefügt sind. Auch die Figurenidentitäten sind durch die Intertexte bestimmt. Dabei sind die Mechanismen ähnlich wie bei den oben beschriebenen mythischen Bezügen und von diesen nur teilweise abzutrennen. Da auch die mythischen Vorbilder immer durch die literarische Aufbereitung der Mythen bekannt sind ${ }^{93}$ und gerade in $W B$ die literarischen Vorlagen der Mythen deutlich werden, geht hier mythologische Bezugnahme in Intertextualität über. Dennoch kann eine feine Abgrenzung gemacht und muss auch vorgenommen werden. Diese liegt vor allem ex negativo, nämlich da vor, wenn eine Verbindung zu literarischen Texten vorhanden ist, die eindeutig nicht mythologisch geprägt sind. Etliche Figuren sind ziemlich direkt aus den Intertexten entlehnt, ein in der Literaturgeschichte sehr häufig und auf vielfältige Weise gebrauchtes Verfahren. Wolfgang G. Müller hat hierfür den Begriff Interfiguralität geprägt und verschiedene Erscheinungsformen beschrieben. ${ }^{94} \mathrm{Als}$ offensichtlichstes und häufigstes Merkmal der Verbindung von Figuren verschiedener Texte nennt er die Übernahme von Namen in identischer oder veränderter Form. Dies gilt auch für $W B$, wo in den meisten Fällen die Namen direkt übernommen werden. Meist bestimmt die Vorlage zudem die Handlungsweise der Figuren, diese sind also nicht autonom in ihrem Handeln. Dennoch sind die Übernahmen nicht vollständig. Gerade die äußerliche Erscheinungsform der Figuren ist individuell ausgestaltet und an die besondere Konstruktion des Textes angepasst. Ihre Gesamtanlage ist jedoch durch das Netz der Bezüge determiniert und entweder durch ihre eigentliche Vorlage bestimmt oder aber durch andere, die einen Handlungsstrang bestimmen, in den sie hineingewoben sind.

Angesichts der Fülle an intertextuellen Bezügen ist es hier lediglich möglich, diese Mechanismen an einigen Beispielen aufzuzeigen. Das soll an besonders wichtigen und augenfälligen Bezügen geschehen. Dabei handelt es sich um die Intertexte Oberon von Wieland, Faust I von Goethe sowie A Midsummer Night's Dream von Shakespeare.

\subsubsection{Wielands Oberon und Huon de Bordeaux}

Bei Wielands Oberon handelt es sich um einen der deutlichsten und auch in der Menge der Bezüge wichtigsten Vorlagen für WB. Dabei sind selbst die teils strophenlangen Zitate $(W B, 32,190)$ nicht explizit zugeordnet und auch der Name Wieland wird lediglich mit anderem Vornamen in der Namensliste von Hüons Album aufgeführt (vgl. $W B, 720$ ). Neben dem oben bereits beschriebenen zentralen Konflikt zwischen Oberon und Titania, dient Wielands Werk aber auch für andere Motive als Vorlage und vor allem für andere Figuren als Namensgeber. Die ebenfalls bereits erwähnte

93 Wie Blumenberg aufgezeigt hat ist Mythos ist immer schon Rezeption des Mythos und daher dem Mythos inhärent, vgl. Blumenberg: Arbeit am Mythos, 240.

94 Vgl. Wolfgang G. Müller: »Interfigurality. A Study on the Interdependence of Literary Figures«, in: Heinrich F. Plett (Hg.): Intertextuality, Berlin u. a. 1991, 101-121, v. a. $102 \mathrm{f}$. 
Ehebruchgeschichte ist bei Wieland der Auslöser für den Elbenkonflikt und verbindet die beiden zentralen Paare der unterschiedlichen Sphären. In WB stellt sie zunächst vor allem die Figuren bzw. die Namen, die mehr oder weniger direkt übernommen werden. Der Alte heißt ganz direkt Gangolf, bekommt aber in moderner Weise einen Vornamen. Aus seiner jungen Frau Rosette wird leicht modifiziert Rosi Gangolf. ${ }^{95}$ Auch ihr Liebhaber heißt wie in der Vorlage Walter, wird durch seinen Nachnamen Sämann aber zudem noch einer Familie und damit einem weiteren Erzählzweig zugeordnet. Das Personenverzeichnis erweist sich wieder einmal als Hinweisgeber. Die knappe Erläuterung zu Rosi - "Sie liebt Walter Sämann im Birnbaum« $(W B, 10)$ greift eine im Haupttext völlig nebensächliche Episode auf (vgl. WB, 559f.), verweist damit aber gleich auf Oberon, wo die entsprechende Szene einen zentralen Platz innerhalb der Gangolf-Erzählung einnimmt. Analog zur Änderung der Versöhnungsbedingung ist aus dem ehebrecherischen Vergnügen der beiden im Birnbaum ein konstantes Verhältnis geworden, von dem Gangolf weiß und unter dem er leidet.

Ähnlich verhält es sich mit weiteren Nebenfiguren. Der Freiherr Klaus von Hüon, oben bereits als Agent des Dunklen beschrieben, ist Wielands Protagonisten entlehnt. Auch hier bleibt wenig mehr als der Name und einige Motive. So ist er in WB keineswegs der schillernde Held. Er ist allerdings wie in der Vorlage auf der Suche nach seiner Geliebten Rezia, die er in der Verkäuferin Katrin Legrand zu finden glaubt. In der Schilderung seiner Familiengeschichte, die sowohl die Auseinandersetzung mit der Zeit des Nationalsozialismus in den Text einflicht als auch das Ringmotiv erzählt, tauchen weitere Namen aus Oberon auf. Hüons `Onkek, der Anwalt seines Vaters mit Verbindungen zu Lipom, heißt Dr. Tobias Scherasmin und teilt sich den Nachnamen mit dem Diener von Wielands Hüon. ${ }^{96}$ Ebenfalls übernommen werden die Namen Angulaffer und Paladin, deren Persönlichkeiten jedoch völlig verändert werden. Während Lipom und Anna sich also tatsächlich als das mythische Elfenpaar Oberon und Titania herausstellen, sind die anderen Figuren zwar durch Namen und Motive direkt mit der Vorlage verbunden, sind jedoch nicht identisch mit diesen.

Dass sich die Bezüge in diesem Umfeld nicht nur auf Wielands Oberon beziehen, sondern auch auf dessen Vorlage Huon de Bordeaux, zeigt sich an der Figur Mallebron. Dieser taucht (in der Schreibweise Malebron, Mallebron wird in der englischen Übersetzung verwendet) dort als Diener Auberons auf, der Huon über das Rote Meer nach Babylon bringt. ${ }^{97}$ Doch hier erschöpft sich der intertextuelle Bezug auf die Übernahme des Namens. Die Figur in WB ist vermutlich eine elektronische Erschei-

95 Hier sind gleich verschiedene Formen von internymischer Veränderung zu erkennen, d. h. Veränderung am Namen der Figurenvorlage (vgl. ebd., 104-107): die Addition (des Vornamens bzw. eines Diminutivmarkers) und die Substraktion (Kürzung des hinteren Teils des Namens).

96 Dass der 〉Onkel Tobias heißt und zudem mit Hüons »Steckenpferd « (WB, 334), dem Popel-Album, in Verbindung gebracht wird, deutet auf Uncle Toby aus Laurence Sternes Tristram Shandy hin. Von hier aus wird der Vorname von Walter Sämann noch ein zweites Mal intertextuell raufgeladen<, da Toby und Walter Shandy Brüder sind und in WB ebenfalls eine Verbindung zwischen Tobias Scherasmin und Walter Sämann besteht. Diese Bezüge sind jedoch nicht handlungskonstituierend, sondern lediglich Teil des intertextuellen Verweisspiels.

97 Vgl. Willem P. Gerritsen / Anthony G. van Melle (Hg.): A Dictionary of Medieval Heroes. Characters in medieval narrative traditions and their afterlife in literature, theatre and the visual arts, Woodbridge 1998, 149. 
nungsform (ein Avatar) von Daniello auf der zweiten Ebene. Er ähnelt diesem sowohl in Erscheinung als auch vor allem durch seinen österreichischen Dialekt.

\subsubsection{Mephistopheles-Parallele}

Das vierte Kapitel des vierten Septors bildet in WB als "Zweite Nachtmusik: Passacaglia « die Szene in »Auerbachs Keller in Leipzig « aus Goethes Faust I nach. In enger Anlehnung an die Vorlage wird zunächst parallel das Geschehen in der Mündener Kneipe Winkelmanns Schänke und ein Terrassengespräch der ATG geschildert. ${ }^{98}$ Deters phantasiert zeitgleich mit dem Gespräch die Kneipenszene bis Lipom ihm »in die Fantasie [fährt] « $(W B, 598)$, wie Dr. Weigan es formuliert. Lipom und Murnau nehmen Deters in Gedanken mit dorthin, so wie sich Mephistopheles und Faust in das Leipziger Gasthaus begeben. Lipom nimmt denn auch Mephistopheles' Rolle ein und offenbart entgegen seinem sonst fast vollständig durch eine ironische Gelassenheit geprägten Charakter seine böse Seite (selbst die heftigen Auseinandersetzungen mit Murnau zeigen lediglich sein aufbrausendes Temperament und haben nichts direkt Böses an sich). Neben dem oben bereits erwähnten Gespräch zwischen Daniello und Lipom nimmt dieser hier zum zweiten Mal die Rolle einer Teufelsfigur ein. Der Typus von Interfiguralität, der hier vorliegt, unterscheidet sich von den bisherigen, vornehmlich durch internymische Beziehungen geprägten. Der Name Mephistopheles wird ebenso wenig übernommen oder genannt wie Goethe oder Faust. Hier handelt es sich, wieder mit Müller gesprochen, vielmehr um eine Überlagerung von Figurenkonstellationen. Lipom ist ja schon durch die Figurenvorlage des Oberon geprägt, was in dieser Szene durch die charakterliche Anlage und die Handlungen von Mephistopheles überlagert oder kontaminiert wird. ${ }^{99}$ Heftiger noch als Mephistopheles provoziert er die Kneipengäste und verwirrt sie durch seine elbische Zauberkunst. Aus den Löchern, die Lipom in den Kneipenboden bohrt, kommt statt des versprochenen Weins, der in der Faust-Szene zunächst auch aus den Bohrlöchern kommt, Brackwasser. Zudem ersticken die Leute fast daran, weil dieses von alleine ihre Münder füllt. Nach einigen Wechseln der Handlung kommt es zu einem orgiastischen Finale. Lipom zeigt sich gänzlich verändert. Beschrieben wird er als »durchaus nicht mehr gutmütig« ( $W B$, 621), Deters scheint es, als sei es »eine Seelenspur dunkler geworden im Raum« (ebd.). Er habe noch nie "ein so böses, ein derart triumphierendes Gesicht gesehen « wie Lipoms, während dessen Augen etwas »Rauschhaftes « $(W B, 625)$ verströmen. Lipom kommentiert das Chaos mit den Rufen »Hinein in die Natur! [...] Hier ist mein Geschenk!« (ebd.). Dadurch wird der Zusammenhang hergestellt zum Prinzip Natur, das er darstellt im Gegensatz zur Kultur des Murnau-Prinzips. Gleichzeitig wird jedoch die Bedeutung der Szene für diese Konzeption deutlich. Deters II begründet sie gegenüber Alda andeutend aufgrund von Überlegungen zur Erzählkonstruktion (WB, 61of.). Er verweist auf das Intermezzo »Walpurgisnachttraum « in Faust, in dem Oberon vorkommt (und das hier kurz zitiert wird) und schafft dadurch die Verbindung zu Faust. Wichtiger ist jedoch, dass hier deutlich die negative Seite des

98 Zur literarischen Konstruktion der Szene vgl. unten Abschnitt 4.3.1 auf Seite 214.

99 Müller spricht von der "superimposition or contamination of different character constellations", vgl. Müller: »Interfigurality«, 115. 
Naturprinzips dargestellt wird. Während Lipom sonst als der Verfolgte auftritt, dessen (Elben-)Volk vertrieben und ausgerottet werden soll, dessen Prinzip der Phantasie und Naturverbundenheit jedoch positiv konnotiert dem Prinzip der Moderne/Kultur/Logos entgegengestellt wird, wird hier die Kehrseite des Prinzips dargestellt, der Umschlag von Mythos in Barbarei. Was in Bezug auf die Logos-Position an Rascher und Hüon als Helfer des >Dunklen s seine Ausprägung findet, wird hier an Lipom in Bezug auf die Naturposition durchexerziert.

Nebenbei sei noch angemerkt, dass die Faust-Figur nicht eindeutig zugeordnet werden kann. Während Deters derjenige ist, den Lipom/Mephistopheles einmal »in lustige Gesellschaft bringen « (WB, 606/Faust, V. 2158) will, sagt Murnau Fausts Satz, es sei Zeit abzufahren (vgl. WB, 627/Faust, V. 2296). Doch kommt es auf diese in der Szene auch nicht an. Zudem sind auch die Namen der schon im Wolpertinger logierenden Lehrer, die auch in dieser Szene wieder auftauchen, aus Faust entlehnt. In ähnlicher Manier wie beispielsweise bei Gangolf aus Oberon haben sie moderne Vornamen erhalten und sind dadurch in die Zeit des Romans angepasst: aus Brander und Altmeyer werden Andreas Brander und Jochen Altmeyer, aus Siebel die Siebelwirtin (die Wirtin der Schänke), nur Frosch ist nicht zu finden (oder aus ihm ist möglicherweise die ebenfalls anwesende Figur Ferdinand Kalb geworden).

\subsubsection{Shakespeares A Midsummer Night's Dream}

Shakespeares Komödie dient in mehrfacher Hinsicht als Vorlage. Auch wenn die Figuren des Oberon und der Titania wohl eher aus Wielands Oberon stammen, so ist das Stück schon dadurch von Einfluss, dass es Vorlage von Wieland war. Zudem ist das Theaterstück Die Winde (WB, 865), das auf der zweiten Ebene aufgeführt wird, vermutlich an A Midsummer Night's Dream angelehnt. Auch der Kellner im Andree's Berg hat seinen Namen Wand daher, da bei der Pyramus und Thisbe-Aufführung im Stück auch eine Wand gespielt wird. Für die Figurenidentität ist es jedoch vor allem für die Figur Ortnit von Bedeutung, der von Alda explizit als eine Puck-Figuration gewünscht wird (vgl. WB, 531). Ganz nebenher bringt sie hier die Interpretation ins Spiel, das Geschehen der ersten Ebene als »eine Art Mittsommernachtstraum " (ebd.) zu sehen. In der Tat hat es auch Züge davon, das Zusammenspiel der Elbenmit der Menschenwelt, die traumhafte Art der Halluzinationen, die Vermischung auch von hochsprachlichen (oder theoretischen) Diskursen mit derber Sprache und Handlung. Die Puck-Figur, die ihr in diesem Treiben noch fehlt, sieht sie gar nicht als Übernahme der individuellen Figur, sondern in ihrer Funktion als Führer durch das chaotische Geschehen. Deters II entwirft ihn denn auch gar nicht in Anlehnung an den Charakter von Puck, sondern auf Grundlage des Sagenkreises von Dietrich von Bern (vgl. WB, 534). Auch wenn er so als Orientierungsfigur geplant sein mag, erfüllt er diese Funktion in der allgemeinen Konstruktion nicht, da diese darauf aufbaut, dass der Leser die Orientierung verliert und immer wieder darin verunsichert wird, was für real oder fiktiv zu halten ist. Das daraus resultierende Realitätsverständnis wird im nächsten Kapitel ${ }^{100}$ beschrieben und analysiert.

100 Siehe Abschnitt 4.1 ab Seite 187. 


\subsection{Das Deters-Netzwerk}

Im inhaltlichen Überblick über die Ebenen ist deutlich geworden, dass es drei miteinander in Zusammenhang stehende zentrale Figuren gibt, die auf den drei verschiedenen Ebenen angesiedelt als Protagonisten des Romans anzusehen sind: Deters, >der Autor` und `der Dritte`. Dieser Eindruck kommt dadurch zustande, dass sie im Fokus des Erzählvorgangs stehen. Wenn sie nicht selbst erzählen, so sind sie größtenteils die fokalisierte Figur. Der Leser erfährt von ihnen am meisten und hat auch an fast ausschließlich ihren Gedanken teil. Auch wenn also beispielsweise Lipom eine wichtige Gestalt ist, so wird er doch immer aus der Distanz betrachtet, lediglich seine Worte oder sein Verhalten, nicht aber seine Überlegungen werden wiedergegeben und zudem wird auf ihn im Allgemeinen nur eingegangen, wenn Deters zugegen ist.

\subsubsection{Hans Deters' Vorgeschichte - Bezüge auf VG}

Nach dem Prolog ist Hans Deters die zweite Figur, die im erzählerischen Fokus steht, und rasch als eine der Hauptfiguren des Romans erkennbar wird. Der Einstieg erfolgt medias in res und die Figur wird als »Deters « bzw. kurz darauf als »Hans Deters" (WB, 37) bezeichnet. Der Name kann dem Leser nicht bekannt sein, weder auf den wenigen vorhergehenden Seiten noch in vorher publizierten Werken von Herbst kommt er vor. ${ }^{101}$ Verschiedene Hinweise legen jedoch schnell einen Anschluss an VG nahe. Während der gefälschte Pass, den er betrachtet, und auch die Notwendigkeit, eine dazu passende Familie zu erfinden, oder die Bezeichnung »Flucht « $(W B, 38)$ für seine Abreise noch keinen zwingenden Bezug darstellen müssen, auch wenn sie eindeutig aus VG stammende Motive sind, so verdichten weitere Details den zunehmenden Verdacht einer Verbindung der beiden Romane: Bremen als Ort der Passausstellung sowie der Name »A. Schulze« als Name des vermeintlichen Beamten; gleich darauf folgt die Nennung von Frau Großwald und ihrem Sohn Robert, der in $V G$ mehrfach, jedoch völlig nebenbei erwähnt wird, sowie die Benennung einer Mitreisenden als Anna. Eindeutig gemacht und schließlich sogar thematisiert wird der Bezug durch die Erinnerung an das Pappbehältnis (in VG der »Pappkarton«) als Sammelort und Aufbewahrung seiner »früheren Aufzeichnungen« $(W B, 40)$, das er zurückgelassen hat und damit sich selbst. Diese Motive stehen in $V G$ an zentraler Stelle. Es sind deutliche Hinweise darauf, dass Deters identisch ist mit dem >Autor<-Erzähler aus $V G$, der derjenige der drei Hauptfiguren war, der am Ende den Pass erbeutet hatte und mit dem Zug abgereist war.

Die Übernahmen aus bzw. Korrespondenzen zu $V G$ sind vielfältig und zu zahlreich, um einzeln aufgeführt zu werden. Sie beziehen sich auf Figuren, Motive oder motivisch aufgeladene einzelne Wörter oder Phrasen (wie >Flucht $`$ oder `Kontakt haben ). Figuren werden auf unterschiedliche Weisen übernommen. Einige Nebenfiguren wie Robert Großwald, Günther Carstens oder Großvater Branske, die in VG nur erwähnt werden, werden auch in $W B$ lediglich namentlich genannt. Die wenig Kontur

101 Dies versteht sich bei Herbst nicht von selbst. Deters ist weiterhin auch eine Figur der Anderswelt-Trilogie und die Figur Arndt kommt beispielsweise auch in Eine sizilische Reise, in Der ArndtKomplex sowie in weiteren kleineren Texten vor. 
erhaltene Nebenfigur Hansen aus $V G$ bleibt Nebenfigur in $W B$, wird hier aber der neuen Figur Oberst Baumwolle zugeordnet. Bruno Pomposiewitz wird als Bruder von Leonore Pomposiewitz und Kamerad von Christoph Sämann genannt, die hier neu eingeführte Figuren sind; außerdem ist er die Hauptfigur des Ersten Blumenstücks. Karl Polst hingegen, der in $V G$ nur beiläufig erwähnt ist, wird zur aktiven Nebenfigur. Entgegengesetzt sind sich die Fälle der weiblichen Hauptfiguren. Agnes ist in VG eine aktive Figur, die in $W B$ nur noch als Name auftaucht, aber für Deters und den 'Autor weiterhin eine wichtige Rolle spielt; die verschiedenen Anna-Figuren, auf die in $V G$ lediglich vorausgedeutet wurde, werden in $W B$ zu Protagonisten. Motive, die übernommen werden, sind Anspielungen auf Vampire, auf die Belastung durch die Nazi-Vergangenheit der Eltern, die Leopardenfrau der Zugfahrt und natürlich das strukturelle Grundmotiv der verschachtelten Erzählung, der Erfindung einer Figur durch eine andere.

Es stellt sich also die Frage, ob es sich bei $W B$ um eine direkte Fortsetzung von VG handelt. $W B$ ist keineswegs als eine solche explizit annonciert, der Vorgängerroman wird weder im Text noch in den Paratexten erwähnt. ${ }^{102}$ Im Text selbst wird diese Frage zunächst eher verwirrend, denn klärend thematisiert. Es könne »nicht eingestanden werden [...], sie [die früheren Aufzeichnungen] seien den jetzigen in einem Sinne vorhergegangen, der diese zu deren Fortsetzung macht « $(W B, 40)$. Sowohl die Verwendung des Verbs »eingestehen«, die nichts über die Faktizität dessen, was eingestanden wird, aussagt, als auch der relativierenden Wendung »in einem Sinne" tragen dazu bei, die Frage, ob es sich um eine Fortsetzung handelt, in der Schwebe zu halten. Zwar wird sie verneint, doch gleichzeitig relativiert und überhaupt angesprochen und damit aufgeworfen. Möglicherweise ist diese Formulierung eine Lossagung davon, eine konsequente Fortsetzung ohne einen Bruch oder Änderungen in der Darstellungsweise zu schreiben. In der Tat ist dies auch nicht der Fall. Das Personal ist größtenteils ein anderes, Handlung und Erzählweise unterscheiden sich deutlich und auch die Thematik, um einmal provisorisch von reiner solchen zu sprechen, ist eine andere.

Ein Blick auf andere »autographic sequels $\aleph^{103}$ - ein von Wolfgang G. Müller eingeführter Begriff für Fortsetzungen, die vom Autor des früheren Textes geschrieben wurden - dient der genaueren Charakterisierung des vorliegenden Falls. Müller führt einige Beispiele aus der Weltliteratur auf und unterscheidet zwischen solchen, die den ökonomischen Erfolg eines Buches ausnutzen (wie bei Defoes The Further Adventures of Robinson Crusoe oder Samuel Richardsons Pamela, Part II) und veritablen zweiten Teilen wie von Cervantes' Don Quixote oder Goethes Faust oder seinem Wilhelm Meister. Weitere Beispiele sind Sherlock Holmes und andere Reihen oder häufig Trilogien um einen Protagonisten bis zu ungewöhnlicheren Beispielen wie James Joyces Portrait of the Artist as a Young Man und Ulysses, in denen Stephen Dedalus von der Hauptfigur zu einer Nebenfigur wird, oder John Barths Roman Letters (1979). Barth

$102 V G$ und $W B$ können in gewisser Hinsicht zusammen mit der Anderswelt-Trilogie als eine Pentalogie gesehen werden; jedoch ist nur letztere explizit als eine Reihe ausgezeichnet.

103 Müller: »Interfigurality«, 110. Als »allographic sequels« bezeichnet er dagegen von anderen Autoren geschriebene Fortsetzungen. 
bezeichnet seinen Roman explizit als eine Fortsetzung, verwendet jedoch Figuren aus verschiedenen seiner früheren Bücher (und fragt sie zudem noch um Erlaubnis).

Der gängige Modus der Interfiguralität in rautographic sequels‘ ist der der Wiederverwendung einer bereits bekannten Figur. Dabei ist es selbst in den zuletzt genannten etwas ungewöhnlicheren Beispielen üblich anzunehmen, »that figures from an earlier work by an author that reappear in a later work by the same author are identical « ${ }^{104}$ Obwohl der Anschluss an die Details der Herkunft und erst kürzlich vergangenen Erlebnisse von Deters sowie an diverse Motive eindeutig scheint, gilt eine solche Annahme nicht für WB. Die üblichen Mechanismen werden unterwandert. Das markanteste Zeichen für die Übernahme einer Figur ist die Wiederverwendung des Namens. Der Name Deters ist wie gesagt aus VG nicht bekannt, was die Schwierigkeiten deutlich macht, ihn überhaupt als Folgefigur der verschiedenen miteinander zusammenhängenden Figurenidentitäten zu erkennen. Scherer verweist in diesem Zusammenhang auf eine Stelle am Schluss von $V G$, wo gesagt wird, es werde »ein anderer sein, ein ganz anderer « $(V G, 325)$. Er leitet über zu $W B$, indem er sagt: »Hans Erich Deters heißt dieser andere [...]. ${ }^{105}$ Scherer insinuiert damit und im Folgenden zwar eine Identität zwischen Deters und den $V G$-Figuren, doch wird auch noch einmal die Aufmerksamkeit darauf gelenkt, dass es sich eben doch um einen anderen handelt, zumal die zitierte Stelle aus einer Passage des >Autor<-Erzählers stammt. Selbst wenn man jedoch annimmt, Deters sei von der Person her vollständig identisch mit dem >Autor-Erzähler, so wird er durch den neuen Kontext und die anders geartete ästhetische Konstruktion des Folgetextes zu einer neuen Figur. Dies kann in Ansätzen mit Müllers Beispiel von Odysseus verglichen werden. Dieser sei in der Odyssee derselbe wie in der Ilias, »but within the Odyssey as an aesthetic construction he is a new figure «; der Fokus liege nun auf ihm als Protagonisten, zudem sei er nicht mehr ein Krieger unter vielen, sondern habe eine andere narrative Funktion, die des zentralen Helden einer Abfolge von Abenteuern, »which prefigures the genre of the novel $[\ldots]$ or, rather, romance ${ }^{106}$. Was jedoch dort eine analytische Erkenntnis ist, die für das unmittelbare Verständnis nicht vonnöten ist, hat bei Herbst einen zentralen Stellenwert. So wie der Roman als Ganzes eine Fortsetzung von $V G$ und gleichzeitig eben keine ist, so ist auch Deters gleichzeitig identisch und nicht identisch mit den in sich schon lediglich mehr oder weniger identischen $V G$-Figuren. Wieder einmal ist dies ein Beispiel für den Versuch, das `Andere ‘ darzustellen, das `Dritte ‘ aus dem 'Satz vom ausgeschlossenen Dritten $\lessdot$ Jürgensen weist daher berechtigterweise darauf hin, dass die Figuren »der Poetik von Herbst entsprechend [...] nicht identisch mit ihren Vorgängern« seien, sondern ihnen lediglich ähnelten: »Markant zeigt sich dies beispielsweise an dem intertextuellen Witz, dass zwar in beiden Texten die Annonce von >Anna der Nutte $(V G, 210 ; W B, 60)$ eingeblendet wird, sich auf den Karten aber unterschiedliche Telefonnummern finden. ${ }^{107}$

104 Müller: »Interfigurality«, 112.

105 Scherer: »Die Metamorphosen des Wolpertingers«, 178.

106 Müller: »Interfigurality«, 113.

107 Jürgensen: »Ich sind auch andere«, 154. Auch Moosbach betont dies: »Die neu entstehende, sich selber erfindende Erfindung namens Deters ist nämlich keine richtige Synthese, keine Verbindung, Vereinigung oder Vermischung zwischen Laupeysser [sic!] und Falbin, die beiden bleiben ja auf 
Die Annahme eines identitären Zusammenhangs zwischen Hans Deters und dem >Autor<-Erzähler bzw. demjenigen, der am Ende von $V G$ schließlich im Zug sitzt, wird im weiteren Verlauf dann durch seine Äußerungen bezüglich der Ereignisse bestärkt, die seiner Ankunft in Münden unmittelbar vorausgegangen sind. Diese werden zunächst vor allem in kleinen Wortwechseln mit Anna angesprochen und rekonstruiert. Dabei werden verschiedene Versionen präsentiert, die sich dahingehend unterscheiden, wann und wo Deters Anna erstmals gesehen hat und vor allem werden zeitliche Differenzen in der Wahrnehmung seiner Ankunft deutlich. Im Gespräch mit Anna und Bertrecht unmittelbar nach der Ankunft gibt Deters zu, Anna sei ihm bereits in Bremen aufgefallen und er sei ihretwegen ebenfalls umgestiegen. Das genannte Datum seiner Abreise, "Sonntag, 23. 8. 81« (WB, 133), schließt dabei an die in $V G$ aus diversen Angaben rekonstruierbare Chronologie an. ${ }^{108}$ Anna und Bertrecht weisen ihn jedoch darauf hin, dass bereits Montag ist, eine zeitliche Verschiebung, die sich Deters nicht erklären kann und die den ersten Hinweis auf die folgenden zeitlichen Verwirrungen darstellt. Die von Deters angedeutete Vorgeschichte lässt jedoch wieder keine eindeutige Identifizierung $\mathrm{zu}$, verweist jedoch vor allem auf die Identitätsproblematik in VG. Wird er durch die Zugfahrt als identisch mit dem >Autor<-Erzähler dargestellt, wird er durch weitere Details sowohl Falbin als auch Laupeyßer zugeordnet: Falbin zugehörig ist die Berufsangabe als »Bürokaufmann, beim Autohaus Schmidt« $(W B, 134)$, sowie der zwanghafte Gang zum Bahnhof $(W B, 137)$; mit Laupeyßer verbunden ist die Erinnerung daran, sich auf der Straße vor seinem Haus wiedergefunden zu haben, ohne sich zu erinnern, wie er dort hingekommen war, Andeutungen der Verwandlung in einen Vampir (WB, 134f.) sowie der Pappkarton $(W B, 137) \cdot{ }^{109}$ Die synthetisierte Identität und gemeinsamen Erinnerungen der drei $V G$-Figuren wird dadurch noch einmal bestätigt. ${ }^{110}$

Die längste Bezugnahme auf die $V G$-Vorgeschichte findet sich im 2. Kapitel des 3. Septors $(W B, 407-416)$. Dort besucht Deters Anna auf ihrem Zimmer aufgrund des nicht weiter kommentierten Bedürfnisses, jemandem den Grund seiner Abfahrt zu erzählen. Was folgt ist eine zusammenfassende Nacherzählung der Ereignisse aus $V G$. Diese beginnt jedoch viel früher als dort, nämlich bereits in Deters' Kindheit und schildert auch Erfahrungen aus der Zivildienstzeit. Der Großteil der Erzählung weckt den Eindruck einer realistischen bzw. auf realistische Ereignisse zurückgeführten Nacherzählung des in VG metafiktional bis phantastisch geschilderten Geschehens. Alltägliche Erfahrungen verbinden sich mit dem Nachdenken über Fragen des Leids und der inhärenten Aggressivität des Menschen; die nicht gelebte Liebe zu Agnes

dem Bahnsteig zurück. sie verbleiben in Die Verwirrung des Gemüts, wohingegen Deters sich per Zug in den Wolpertinger aufmacht." (Moosbach: "Das Ribbentrop-Rhizom», 39).

108 Vgl. VG, 47 und 107. Dort ist dieses Datum als Tag des Verschwindens von Falbin angegeben.

109 Im Folgenden wird Deters außerdem ausschließlich mit Agnes in Verbindung gebracht, nicht aber mit B., die in WB nicht einmal erwähnt wird. Die Verbindung von >Autor/-Erzähler und Agnes wird zwar auch in $V G$ schon angedeutet, eigentlich ist sie jedoch eher mit Laupeyßer verbunden.

110 Die Verbindung zwischen den verschiedenen Deters-Instanzen kann mit Wolfgang G. Müller als intratextuelle Interfiguralität gesehen werden. Diese sieht er als eine Sonderform von Interfiguralität, die die Verbindung von Figuren innerhalb eines literarischen Textes bezeichnet. Sie beruht auf der »intersection or interpenetration of different fictional contexts« (Müller: »Interfigurality«, 118) und ist daher in metafiktional geprägten Texten zu finden. 
scheint einen Ausweg zu bieten, der sich aber nicht erfüllt. Selbst das eben erwähnte Aufwachen auf der Straße wird als ein (wenn auch unerklärlicher) Aussetzer geschildert, ansonsten wird die in $V G$ phantastisch übertrieben wirkende Wandlung Laupeyßers in nüchternen realistischen Worten geschildert. Die dort zentrale Geschichte der erfundenen Figur (Falbin), die er Agnes schildert, werden als Ablenkungsversuch von der Liebe zu ihr eingeordnet. Erst bei der Schilderung eines Selbstmordversuchs scheint die Erzählung ins Phantastische zu kippen. Dabei handelt es sich jedoch nicht um den in $V G$ geschilderten Selbstmordversuch mit dem Auto, sondern um einen Sprung aus dem Fenster. Deters kommt jedoch nicht unten an, sondern landet auf dem Fensterbrett von Agnes in einem entfernten Ortsteil, wo er sie mit einem anderen Mann beobachtet. Er lässt sich wieder fallen und kommt nochmals auf der Straße zu sich. Dies wird jedoch nicht als ein phantastisches Ereignis dargestellt, sondern von ihm als "Halluzinationen« $(W B, 416)$ bezeichnet, was die Phantastik als ein >Antäuschen erkennbar macht und die überraschend realistische Sichtweise noch unterstreicht. Am selben Tag erfolgte dann die Abreise und die erste Begegnung mit Anna, was den Anschluss an WB herstellt. Auffällig ist die Schilderung der Ereignisse in einem Tonfall, der sie durch Tempusverwendung und raffende Erzählweise wie weit in die Vergangenheit zurückreichend erscheinen lässt, obwohl sie sich eigentlich erst in den vorangegangenen Wochen ereignet haben. Dies zeigt einmal die Distanz, die in der Fortsetzungsfrage zum vorhergegangenen Buch aufgebaut wird, und kann außerdem der durcheinander geratenden Zeit zugeschrieben werden, der Herausgehobenheit der folgenden phantastischen Ereignisse aus der Zeit.

Der figürliche Anschluss von Deters an VG ist also als deutlich festzustellen. Die dort geschilderten Ereignisse bilden im beschriebenen besonderen Verhältnis die Vorgeschichte zu WB. Dass Deters' Erzählungen und Erinnerungen sich auf Erlebnisse des >Autor «-Erzählers ebenso wie von Laupeyßer und Falbin - und damit auf unterschiedliche fiktionale Ebenen - beziehen, wird in $W B$ nicht noch einmal thematisiert. ${ }^{111}$ Wenn man die Identität der Figuren in $V G$ einmal unter dem Aspekt einer Unterscheidung von Darstellung und realistischer Grundierung betrachtet, ${ }^{112}$ ergibt sich folgendes Bild: die Darstellung ist extrem verschachtelt und zeichnet die Erlebnisse mehrerer Figuren nach; der realistischen Grundlage nach sind dies aber lediglich die Ereignisse einer Person. Die Andeutungen in WB stützen eine solche Interpretation, wobei eben diese eine Person Deters wäre. In der an die beiden Romane anschließenden Anderswelt-Trilogie sieht Deters den Sachverhalt erstaunlicherweise viel einfacher, bestätigt die Überlegungen aber auch. Mit einem Perspektivenwechsel mitten im Satz heißt es dort: »[D]er Pappkarton, in den ich diese Aufzeichnungen stopfte, bevor sich Laupeyßer im Bahnhofsklo mit Claus Falbin zu Hans Deters vereinte.« $(B A, 77)$

111 Lediglich an einer Stelle werden die beiden zusammen noch einmal erwähnt, wobei festgestellt wird, Deters habe keine Ähnlichkeit mehr mit ihnen (vgl. WB, 563). Außerdem fällt der Name Falbin noch zweimal, da Ferdinand Kalb Deters an Falbin erinnert (vgl. WB, 219 u. 456).

112 In Anlehnung an die Unterscheidung von Darstellung und Handlung in der Narratologie. 
Bei der Betrachtung der Übernahme der beschriebenen Motive aus $V G$ stellt sich die Frage, ob ein Wissen um das vorhergehende Buch für ein Verständnis von WB notwendig ist. Dass die Erläuterung der Motive relativ spärlich ist und eher in Andeutungen geschieht und zudem nicht ausgeweitet wird, spricht für einen vorausgesetzten Anschluss. Angesichts der Konstruktion des Romans als Spiel oder Rätsel, bei dem auch bei anderen Aspekten das Wissen oder Unwissen sowie die Aufmerksamkeit und der Leseaufwand des Lesers eine Rolle spielt, kann eine solche Voraussetzung auch wieder infrage gestellt werden und als eine zusätzliche Lesart oder als weiteres mögliches Niveau im Verständnis des Lesers begriffen werden (vgl. dazu unten Abschnitt 4.3.2 auf Seite 221). Im Anschluss an VG kann Deters' Erfinden seiner eigenen Lebensgeschichte und seiner engeren Verwandtschaft als Versuch gesehen werden, eine autonome Identität auszubilden. Eine `Begründung ‘ für dieses Vorhaben durch die Last eines unfreiwillig geerbten nationalsozialistisch belegten Namens fällt hier jedoch weg. Die Thematik der Nachkommenschaft zu nationalsozialistischen Tätern wird in den Seitenstrang der Vorgeschichte des Freiherrn Hüon verlegt und taucht auch in den ATG-Diskussionen auf; sie ist jedoch nicht mehr auf Deters bezogen (auch der gesamte Diskurs aus VG um die Fähigkeit zum Entsetzen fällt weg). Insofern fehlen hier Informationen, was aber auch bedeutet, dass die betroffenen Diskurse in den Hintergrund treten. Entweder kann Deters' Entscheidung für den Identitätswechsel also durch Vorwissen erklärt werden oder aber als kontextlos hingenommen werden. Eine dritte Möglichkeit ist die Annahme eines anderen Kontexts, nämlich die Betonung der Möglichkeit, sich überhaupt eine neue Identität zu imaginieren (aus welchen Gründen auch immer). Dieses Imaginieren und Phantasieren konstituieren schließlich das metafiktionale Spiel, das WB ausmacht.

Interessant ist auch die andere Blickrichtung, vom späteren auf den früheren Roman. Einige Motive in $V G$, die, wie oben dargestellt, dort einen mysteriösen Charakter haben und meines Erachtens nur sehr begrenzt innerhalb einer stimmigen Interpretation erklärt werden können, werden im Folgeroman erläutert oder wiederaufgenommen und bekommen so eine Erklärungsgrundlage. Dabei handelt es sich vor allem um die dubiose Frankfurt-Fahrt, bei der nicht klar ist, ob sie stattgefunden hat, was die Anna-Figur für eine Rolle spielt und was es mit der Leoparden- oder Spinnenfrau auf sich hat. An diesen Handlungsstrang knüpft $W B$ an und ermöglicht teils mythologisch grundierte Erklärungen (die weiter oben ausgeführt wurden). Es erfolgt also nicht nur eine Wiederaufnahme, sondern auch eine rückwärtige Erklärung von Motiven. Eine solche Leserlenkung erfolgt auch in der partiellen Bestätigung von bereits aus VG erhobenen Hypothesen. Die angedeutete Verwandlung Laupeyßers in einen Vampir wird - auf Deters bezogen - in WB direkt angesprochen. Auch wenn sie hier ebensowenig > vollzogen ‘ wird, so wird das Motiv doch in einem größeren Zusammenhang bestätigt. In ähnlicher Weise wird, wie eben bereits angesprochen, eine schon in VG mutmaßliche Identität von Laupeyßer, Falbin und dem >Autor`-Erzähler durch die Zusammenführung ihrer Erfahrungen und Handlungen in der Folgefigur Deters bestätigt oder nahegelegt und unterstützt. Es ist jedoch wiederum nicht nur Deters, der als Folgefigur zu sehen ist. Denn auch Deters II, der >Autor « der zweiten Erzählebene, berichtet Alda vom Irregehen zum Bahnhof (was in VG Falbin zuzuordnen ist), von der `Kloszene $\prec$ mit dem Kampf um den Pass und der darauf erfolgten Abreise aus 
Bremen, sowie dass er 1983 in Frankfurt am Main begonnen habe, die Geschichte des Passes zu schreiben (vgl. WB, 303f.). Dadurch wird zwar die eben konstatierte Identität von Deters und dem >Autor «-Erzähler aus $V G$ nicht infrage gestellt, allerdings sind die Zusammenhänge wieder bezeichnend für das Verhältnis zwischen Deters auf der ersten und dem >Autor $<$ der zweiten Ebene.

\subsubsection{Die erste Ebene: Hans Deters}

Das Verhältnis zwischen allen drei Ebenenprotagonisten ist insgesamt anders geartet als das zwischen den drei Hauptfiguren in VG. Dort habe ich die Vervielfältigung der Figuren vornehmlich psychologisch gedeutet, als eine Aufspaltung einer Person in mehrere Figuren, die zwar nicht in rein schematischer Weise eins zu eins auf reale Entsprechungen zurückzuführen waren, aber doch mit einer gewissen poetischen Unschärfe bzw. poetischen Mehrwert verschiedene Aspekte eines Charakters darstellten. Zugrunde liegt bei dieser Interpretation ein sozialpsychologischer Begriff von Identität. In $W B$ tritt ein solcher in den Hintergrund. Bis auf die eben beschriebenen, aus VG übernommenen Aspekte spielt er keine Rolle mehr. ${ }^{113}$ Die Gründe für die gegenseitige Erfindung ebenso wie für ihre Zusammenhänge können als metanarrativ bezeichnet werden. Sie ergeben sich durch die konstruierte Anlage des Romans und die innerhalb dieser Ontologie wie innerhalb der erzählten Geschichten entwickelten Erfordernisse. Im Folgenden sollen nun die drei Figuren charakterisiert und dabei ihre Funktionen sowie die Verhältnisse zueinander bezeichnet werden.

Deters ist wie gesagt der Protagonist der Zugfahrt und damit der ersten Erzählebene, die später in Hannoversch Münden vor allem im Hotel Wolpertinger angesiedelt ist. Zu Beginn der Zugfahrt betrachtet er seinen neuen Pass und erfindet sich seine Familienkonstellation und -geschichte. Im Gegensatz zu den teils sprechenden Namen anderer Figuren und auch der Vorgängerfiguren Ulf Laupeyßer und Claus Falbin und zu den teils von realen Persönlichkeiten entlehnten Namen ist der Name Hans Erich Deters als unauffälliger deutscher Durchschnittsname, als »Telefonbuchname[] «114 anzusehen. Lediglich ${ }^{115}$ dem mittleren Namen wird ein »Eigensinn « zugeschrieben, da im gefälschten Pass zwischen dem $r$ und i ein Leerraum stehengelassen wurde, der die Personalpronomen Er und Ich kenntlich macht: »Darüber kann einer ins Meditieren geraten, durchaus." $(W B, 38)$ Dies kann als Hinweis auf die folgende >Aufspaltung ‘ in weitere Personen gesehen werden, wie Reber das macht, ${ }^{116}$ vor allem jedoch als bildlicher Hinweis auf die Erzählhaltung insbesondere der ersten Erzählebene. Diese wechselt vornehmlich zwischen Außenschilderung (»Er«) und

113 Ein psychologischer Aspekt findet sich bei der im Roman selbst aufgebrachten Lesart von Wahnzuständen. Dabei geht es jedoch weniger um Identität als um die Erklärung der Imaginationen. Siehe unten Abschnitt 4.1.2 auf Seite 204.

114 Reber: Formenverschleifung, 303 und 362.

115 Die Idee, den Nachnamen Deters auf das englische »to deter someone« (jemanden hindern, abschrecken) zurückzuführen, halte ich für weit hergeholt und höchst spekulativ, vgl. Moosbach: "Das Ribbentrop-Rhizom«, 31. Passend wäre es angesichts von Deters' Zugfahrt und mäandernden Imaginationen allerdings und wohl weder zu beweisen noch zu widerlegen.

116 Vgl. Reber: Formenverschleifung, 317. 
Innenschilderung (»Ich«). Längere Abschnitte mit einem heterodiegetischen Erzähler und Deters als fokalisierter Person wechseln unmarkiert zu anderen, die er als Ich-Erzähler schildert. Doch auch der heterodiegetische Erzähler ist nicht konsistent auf das Geschehen gerichtet, so wird auch der Leser angesprochen oder der Erzähler spricht in Wir-Form, was entweder als pluralis majestatis gesehen werden kann oder den Leser miteinschließt. Zudem finden sich in den Abschnitten in Außenperspektive auch Halbsätze, die als innerer Monolog gedeutet werden können. Eine allgemeine, für den gesamten Roman geltende narratologische Aussage zur Erzählsituation ist somit nicht möglich; zum einen ist oft nicht eindeutig bestimmbar, wer wie spricht, zum anderen wäre in den Fällen, in denen es vielleicht möglich wäre, ein Kommentar Satz für Satz vonnöten, der jeden Rahmen sprengen würde.

Eine eindeutige Zuordnung ist auch nicht gewollt, wird sie doch immer wieder unterwandert und hinterfragt, indem jede Ebene als eine in Entstehung begriffene Erzählung inszeniert wird, als ein work in progress, bei dessen Entstehung der Leser in statu nascendi zugegen ist. Gerade während der Zugfahrt wird die Erzählung durch Meta-Kommentare als Imaginationen von Deters kenntlich gemacht:

Wie aber nun Frau Pomposiewitz aus dem Abteil kriegen? Daß sie plötzlich Lust auf einen Stadtbummel bekommt, will Hans Deters nicht plausibel werden. Eine Erklärung nach der anderen streicht er aus seinem Kopf. Er hat Skrupel. Das wundert um so mehr, als er ja Autor all dieser Wägungen ist [...]. (WB, 112)

Die Fragen nach erzählerischen Problemen lassen die Leser direkt an den Überlegungen teilhaben. Andererseits wird er auch gleich wieder verunsichert durch den Zusatz, er sei nur

möglicherweise [der Autor], denn ähnliches ließe sich von jeder anderen Person behaupten, - mit Ausnahme Dr. Lipoms, der resolut die Meinung vertritt, er schaffe Hans Deters auch als Person und den Leser in einem Aufwasch gleich mit. Daß eine Figur ihren Schöpfer erfinde, ist eine informelle, informale und informationsdienstliche Verkehrung, die nicht ernst genug genommen werden kann. (ebd.)

Diese hier nur als Möglichkeit aufgebrachte Volte der Erfindung eines Schöpfers (Autors) durch seine eigene Figur, ist bereits aus $V G$ bekannt, wo Falbin als erfundene Figur Ereignisse seines Schöpfers Laupeyßer erfindet und so auf diesen Einfluss nimmt. Diese Wendung wird nun in WB zentral.

Deters ist zunächst derjenige, der sich das Geschehen im Zug ausdenkt und in ein Notizbuch schreibt. Abgesehen von den genannten Überlegungen zum Aufbau der Erzählung, die in diese selbst eingestreut sind, und von verschiedenen Stilen, die ausprobiert werden, ${ }^{117}$ wird auch durch deutliche Unterbrechungen auf diesen Umstand hingewiesen. Immer wieder kommt der Schaffner oder Kellner der Zugbar und unterbricht Deters' Imaginationen. Auch später, als die Handlung weit fortgeschritten ist, wird darauf hingewiesen, dass Deters sich die Geschehnisse entweder

117 Beispielsweise die Beschreibung eines Toilettenbesuchs in satirischer Manier à la Laurence Sterne oder Jean Paul ( $W B, 48 f f$.) oder Schilderung des Lebens einer Figur im filmischen Zeitraffer ( $W B$, $113 \mathrm{ff}$.$) .$ 
im Zug oder aber im Wolpertinger, in dem er alleiniger Gast ist, ausdenkt und ihm dies »in klaren Zuständen « $(W B, 578)$ auch bewusst ist (vgl. auch $W B, 159,169 f$., 232f., 651, 935). Schon im gefälschten Pass ist als besonderer Vermerk »Träumer« $(W B, 37)$ eingestanzt. Deters wird wichtiger Teil der Handlung. Dabei vermischen sich wieder die verschiedenen Lesarten. Einerseits webt er sich selbst in die Handlung hinein, da sie ja vollständig seine Imaginationen sind. Andererseits wird er von Lipom und Anna aufgrund einer Verwechslung in ihren Kreis hineingezogen. Sie sehen ihn als ein mögliches Objekt innerhalb ihres ehelichen Konflikts und als potenziellen Nachfolger Lipoms in der Konstellation der Hieros gamos, der Heiligen Hochzeit, auf die sich Deters schließlich auch einlässt. ${ }^{118}$ Weitere Funktionen zeigen sich in den früh eingeführten Antonomasien `Lauscher $\triangleleft$ und `Husar , mit denen Deters teils vom Erzähler, teils von Lipom oder anderen benannt wird, als »ein Spielchen nur, zwischen dem Doktor und mir « (WB, 328), wie er selbst einmal bemerkt. Der Begriff \Lauscher wird deshalb verwendet, weil in der immer wieder verwendeten umgangssprachlichen Redeweise anfangs gesagt wird, Deters stelle seine Lauscher auf (vgl. $W B, 43$ f.), wenn er den Gesprächen der ihn umgebenden Reisenden zuhört. Diese Redeweise verselbständigt sich soweit, dass er pars pro toto mit diesem Begriff benannt wird. Später bekommt der zunächst merkwürdig wirkende Name eine gewichtigere Erläuterung im Kontext des Konflikts zwischen Elben und Menschen, ${ }^{119}$ in dem Deters auf dem Thing als Mittlerfigur auftritt. In seiner Rede erklärt er den Elben die beschränkte Weltwahrnehmung der Menschen (im Vergleich zu den Elben) und weist auf seine mangelnde Kenntnis seiner Vorfahren hin: »Weil dies so ist, habe ich nichts im Ohr, was war, obgleich man mich den Lauscher nennt. Was ich höre, bin ich selbst, und wenn ich zurückdenke einhundert Jahre, zweihundert Jahre, sehe ich nichts als meine Fantasie.« $(W B, 823)$ Auch wenn er die Bezeichnung hier als Widerspruch verwendet, deutet sie auf seine Fähigkeit hin zuzuhören und sich Sachen vorzustellen, zu phantasieren, auf die Sphäre der Elben zu horchen. ${ }^{120}$ Dies befähigt ihn dazu, in Kontakt mit diesen zu treten (vgl. auch den Hinweis, die Geister »nähr[t]en sich von Fantasten « $[W B, 883]$ wie Deters). Wichtiger fast noch ist die weitere Bezeichnung als Husar. Entstanden wohl aus einem Frau Pomposiewitz, einer Beifahrerin im Zug, zugeschriebenen Gedanken, Deters habe »ein richtiges Husarengesicht, der wäre früher bestimmt Ulane geworden. Attila.« (WB, 52), nimmt Deters auch diese Bezeichnung in seiner Rede wieder auf. »[I]ch, auch Husar geheißen, weil ich gegens Vergessen ritt, bin also der, von dem ihr als einem Vergesser sprechen sollt" $(W B, 823)$. Auch dieses Zitat entspringt dem Kontext der Gegenüberstellung von Menschen und Elben. Er charakterisiert sich damit als ein Besonderer unter den Menschen, der sich gegen die moderne Bewusstseinsentwicklung der Menschen seit der Industrialisierung anstemmt. Gleichzeitig stellt er sich jedoch auch als einen typischen Menschen dar, der im Gegensatz zu den Elben steht. Durch diese Doppelcharakterisierung, die in beiden `Spitznamen $\prec$ bzw. in ihrer Erläuterung durch ihn enthalten ist, stellt er sich

118 Vergleiche dazu genauer oben Abschnitt 3.3.2 ab Seite 153.

119 Vgl. dazu Abschnitt 3.3.1 auf Seite 134.

120 Auch wenn einmal gesagt wird, er schaffe es nicht, »in den Lauscher zurückzusinken« $(W B, 132)$ halte ich es nicht für fraglich, dass es lediglich eine Bezeichnung für Deters ist und keine weitere personale Aufspaltung, wie Reber insinuiert, vgl. Reber: Formenverschleifung, $315 \mathrm{f}$. 
als geeignet dar, um für die Menschen zu sprechen und gleichzeitig mit den Elben einen Weg zu deren Rettung zu finden.

\subsubsection{Die zweite Ebene: Deters II oder der sAutors}

Deters II, der >Autor ${ }^{121}$ auf der zweiten Ebene, fährt »simultan « $(W B, 303)$ mit Deters ebenfalls auf der gleichen Zugstrecke - nur genau vier Jahre später. Ist zunächst nicht genau zu unterscheiden, wer von den beiden im Speisewagen aus seinen Imaginationen geschreckt wird, so wird spätestens mit Erscheinen von Alda am Ende des ersten Septors die zweite Ebene erkennbar, als der Ich-Erzähler mit den seufzend gesprochenen Worten "Vor vier Jahren... « $(W B, 234)$ den zeitlichen Abstand zur randeren zwischen Alda und Deters II, der ihr die Ereignisse der ersten Ebene erzählt. Zunehmend greift sie dann in die Gestaltung der Erzählung ein und wird zur Koautorin. Das Verhältnis zwischen Deters und Deters II ist dabei nicht eindeutig zu bestimmen. Wie oben bereits angerissen, haben sie gewisse Übereinstimmungen in ihren Erlebnissen. Auch lässt Deters II sich von Alda, die er anfangs Anna nennt in Anlehnung an seine erfundene Anna der ersten Ebene, Hans Deters nennen. Ihr wahrer Name wird durch den Göttinger Zimmerwirt Karlsson offenbart. Wenn es jedoch um den wahren Namen von Deters II geht, weicht er aus (vgl. $W B, 315,924)$. In ähnlicher Weise wie Anna und Alda zusammenhängen, ${ }^{122}$ sind auch Deters und Deters II miteinander verbunden. Beim Erfinden der Figuren habe er »[e]her bei Deters « $(W B, 283)$ an sich selbst gedacht (als bei Bertrecht); später bemerkt Alda, die beiden seien eins, aber auf einer anderen »Sphäre $(W B, 693)$. Auffällig ist auch, dass Deters II keinen eigenen Eintrag im Personenregister hat, im Gegensatz zu Cordes und auch zu Anna und Alda, die beide verzeichnet sind. Durch die Gespräche auf der zweiten Ebene, die sowohl die erste erzählt als auch Kommentare über ihre Konstruktion enthält, wird eine eigenständige metanarrative (und metafiktionale) Dimension eingeführt. Dies ist auch die Hauptfunktion von Deters II im Gesamtgefüge. Ähnlich wie beim >Autor--Erzähler in $V G$ wird so ein mögliches Verhältnis eines empirischen Autors zu seinem Protagonisten abgebildet, der diesen nach seinen Erfahrungen und sich selbst ähnlich darstellt. Während das Mitverfolgen des poetischen Erfindungsvorgangs auf der ersten Ebene nach und nach in den Hintergrund tritt und nur noch ab und zu durch metafiktionale Unterbrechungen auf die Fiktivität der Ereignisse hingewiesen wird, übernimmt eben diese Darstellung des literarischen Produktionsprozesses die zweite Ebene. Es wird jedoch mit der Frage gespielt, was - über eine reale Autor-FigurKonstellation hinausgehend - passiert, wenn die Ebenen durcheinander geraten bzw. wenn die Richtung, >in der e erfunden wird, sich umkehrt und die Figur Einfluss auf den Schöpfer nimmt.

121 Wie bereits erwähnt wird er im Text wirklich so genannt.

122 Vgl. dazu genauer Abschnitt 3.2.2 auf Seite 129. 


\subsubsection{Die dritte Ebene: der \Dritte` und Eckhard Cordes}

Die dritte Ebene erscheint insgesamt durch die spärliche Figurenausstattung ebenso wie durch die kaum vorhandene Handlung als eine erzählerische Hilfskonstruktion. Es scheinen hier gleich zwei >Deters-Instanzen $\triangleleft$ angesiedelt zu sein: der >Dritte $<$ und Eckhard Cordes. Diese sind als Figur(en) nur schwer bestimmbar, was sich schon darin zeigt, dass in der bisherigen Sekundärliteratur erst bei Ursula Reber zwischen ihnen unterschieden wird. ${ }^{123}$ Das Verwirrspiel wird auf dieser Ebene also noch einmal in weitere Höhen getrieben. Die Verwirrung entsteht dadurch, dass der \Dritte sich zunächst als anonymer Ich-Erzähler einführt (vgl. $W B$, 56 off.) und später für beide Figuren derselbe Name gewählt wird (vgl. WB, 679f.).

Der `Dritte $<$ spricht im Passus, in dem er sich selbst einführt, von sich lediglich als "Ich«, bleibt also anonymer Ich-Erzähler, und differenziert sich von den bisherigen Figuren dahingehend, dass er "weder Deters noch eigentlich sein Autor « $(W B, 560)$ sei. Vielmehr gibt er sich als Ich-Erzähler des Prologs zu erkennen $(W B, 561)$, der dann später den >Autor`, also Deters II getroffen habe. Dieser hat mit ihm im Frankfurter TAT-Café die Identität getauscht, das heißt seinen Namen, den Pass und die Schlüssel zu seiner Wohnung, also sein gesamtes Leben. Zudem hat dieser ihm seine Aufzeichnungen überlassen. Er selbst war wohl unzufrieden mit seinem bisherigen Leben, wieder einmal betrunken und wusste nicht recht, wie ihm geschieht und auf was er sich dabei einlässt. Diese Vorfälle schildert er an zwei verschiedenen Stellen (WB, 562 und 724f.). Scheint in der späteren, genaueren Beschreibung vieles wie ein zwar reichlich seltsamer, aber durchaus möglicher Vorgang, kippen beide jedoch schnell ins Phantastische, wenn ihn beispielsweise eine Freundin nicht mehr erkennt (vgl. WB, 725). Auch seine Bestimmung des Verhältnisses zwischen ihm und Deters II ist hier einzuordnen. Dieser sei »tatsächlich [...] nach Frankfurt weitergereist, und zwar, um ich zu werden. Ich bitte das wörtlich zu nehmen. Nur dann erfaßt man den Umfang meines Problems." $(W B, 562)$ Wie so etwas vorzustellen ist, wird kaum geklärt. Er sei durch diesen Vorgang »das Produkt einer sehr eigenartigen und anthropologisch untypischen Fortpflanzung, einer Spaltung « $(W B, 724)$. Wenn Deters II jedoch auf irgendeine Art der `Dritte geworden wäre, dann ist nicht nachvollziehbar, warum er »höchst trickreich durch ein Hintertürchen entschlüpft» (ebd.) sei und auch an der früheren Arbeitsstelle des `Dritten $\prec$ zu sehen war $(W B, 725)$. Wie genau die Identität zwischen den Figuren bestimmbar oder vorstellbar sein soll, ist also nicht genauer festzustellen. Er beschreibt sich selbst als »eine Hilfskonstruktion, die ihm [dem >Autor`] erlaubt, sich zu sehen. [...] Daraus erhellt ebenfalls unschwer, daß wir nicht identisch sein können, und zwar so wenig, wie Hans Deters noch Ähnlichkeit mit Ulf Laupeyßer oder Claus Falbin hat.« $(W B, 563)$ Das Verfahren ist damit ähnlich wie bei $V G$, auf das hier Bezug genommen wird. Die Schilderung der Treffen und Ereignisse erfolgt in realistischer Art, dann wird jedoch in einem Kommentar ein Vorgang behauptet, der in seiner Vagheit und Phantastik nicht vorstellbar wird. Da

123 Vgl. Reber: Formenverschleifung, 322, wobei sie die beiden auf S. 320 auch verwechselt. Vgl. jedoch die fehlende Unterscheidung bei Scherer: »Die Metamorphosen des Wolpertingers«, 182, Moosbach: "Das Ribbentrop-Rhizom«, 51, und Jürgensen: »Ich sind auch andere«, 155. Bei Kühlmann fehlt der Hinweis auf diese Figuren ganz. 
dies ja, wie durch das ständige Hinterfragen der `wirklichen` Abläufe und Zusammenhänge deutlich wird, beabsichtigt ist, bleibt die Konstatierung und Aufführung sowie Sammlung der Hinweise auf die solcherart behaupteten Vorgänge.

Der $>$ Dritte $<$ ist noch deutlicher als Deters II durch die narrative Funktion innerhalb der metafiktionalen Gesamtkonstruktion bestimmt. Seine Selbsteinführung erfolgt bezeichnenderweise über den längsten metanarrativen Diskurs des Buches. Er räsoniert über die Authentizität des ihm überlassenen Berichts. Wie später durch die Schilderung des Identitätstauschs klar wird, handelt es sich um die Aufzeichnungen von Deters II. Durch das Motiv des vorgefundenen Manuskriptes und seine daraus resultierende Rolle als Redakteur und Korrektor bis hin zum umschreibenden CoAutor reiht er sich ein in die lange Tradition der vor allem in der Romantik beliebten Herausgeber-Fiktion. ${ }^{124}$ Seine Rolle bei der Umarbeitung der Erzählung bleibt vage, lediglich einige Andeutungen weisen auf die Größe der Eingriffe hin. ${ }^{125}$ Wie er sich selbst als strukturell nötige Hilfskonstruktion als »Meta-Erzähler[] « ${ }^{126}$ von Deters II sieht, so wird er zudem auch von diesem und Alda geschaffen, wodurch wiederum seine Glaubwürdigkeit unterwandert wird. Auf einen Vorschlag von Alda und einen dubiosen Hinweis auf weitere Zahlenspiele fügen sie noch die dritte Ebene in ihre Konstruktionen ein. Auf dieser soll aber nicht noch eine weitere simultane Parallelhandlung ablaufen, da es "ein bißchen öd' [wäre], alles einfach hochzukopieren " ( $W B$, 786). So wird nicht noch einmal eine Zugfahrt oder eine Gesprächsrunde in einem weiteren parallel zu sehenden Hotel geschildert. Er verbleibt eher handlungsarm auf der dritten Ebene, wird jedoch etwas konturierter als Person, wenn er schließlich doch nach Münden kommt und sich im Jagdhaus Heede einquartiert (das jedoch nicht am selben Platz steht wie die anderen Hotels und damit keine zeitüberschreitende Identität mit diesen hat). Lediglich der Agent Baumwolle nimmt Kontakt zu ihm auf, wie er es mit Deters auf der Zugfahrt gemacht hat. Da sich dieser von ihm abgewendet (und den Elben zugewendet) hat, will er nun über den `Dritten` an Anna/Alda gelangen. Auch wenn der >Dritte $<$ nicht nur Baumwolle gegenüber - an Max Frischs Stiller gemahnend - vehement abstreitet, Deters zu sein (vgl. $W B, 789,951,961)$, ist dieser wohl doch so etwas wie sein »vorheriges Ich « $(W B, 875)$. Wie auch immer die identitären Zusammenhänge vorzustellen sind, ${ }^{127}$ in der Handlungsstruktur ist der >Dritte< vor allem eine Hilfskonstruktion. Er ist ein »Joker auf der Hinterhand, der ausgespielt wird, wenn's an der Zeit ist « $(W B, 840)$. Da Baumwolle als Vertreter des Dunklen das Fest und die Primizien stören will, schlägt Murnau in einer Szene, in der sich die Ebenen gehörig ineinander verwickeln, vor, das Fest zur Sicherheit in die Zukunft zu

124 Vgl. dazu die Studie von Uwe Wirth, in der u. a. mit Wieland und Jean Paul wichtige Intertexte von WB im Mittelpunkt stehen: Uwe Wirth: Die Geburt des Autors aus dem Geist der Herausgeberfiktion. Editoriale Rahmung im Roman um 180o: Wieland, Goethe, Brentano, Jean Paul und E. T. A. Hoffmann, München 2008.

125 So gehen angeblich die mythologischen Bezüge auf ihn zurück (vgl. WB, $561 \mathrm{f}$.) ebenso wie die Figur Klaus Hüon (vgl. WB, 565). Da beide Komplexe von zentraler Bedeutung sind, aber lediglich nebenbei erwähnt werden, werden jegliche Annahmen über Zusammenhänge ein weiteres Mal hinterfragt.

126 Reber: Formenverschleifung, 323.

127 Oder wie Baumwolle es formuliert: »Es ist doch ganz gleichgültig, ob Sie er sind oder nicht.« (WB, 789) 
verlegen. Die Frage geht an Deters, ob er seinen Autor, also Deters II, dazu bringen kann, dies zu erreichen. Dieser will mit Alda nun durch den >Dritten $<$ Baumwolle austricksen (vgl. WB, 867). Geschehen soll dies über seine Eigenschaft als Meta-Autor. $\mathrm{Da}$ alles von der Phantasie- und literarischen Schreibleistung der Ebenen-Autoren abhängt, soll sich der $>$ Dritte « nun die Feste der verschiedenen Ebenen »ineinander verschränkt« $(W B, 918)$ vorstellen. Durch seine poetische Kraft zur Veränderung der Geschehnisse, soll er eine Verformung der Zeit schaffen, die es ermöglicht, die Angreifer zumindest zu verwirren. So wie Deters II der >Autor $>$ von Deters ist, wird er zum scheinbar mächtigen Meta-Autor, was sich in den Bezeichnungen als »unsrem projektiven Autor « $(W B, 874)$, »unser letzter, oberster Autor « $(W B, 840)$ oder »unser Überautor « $(W B, 907)$ ausdrückt. Das Besondere an der Konstruktion ist nur, dass die Macht, die ihm zukommt, von einer hierarchisch niedrigeren Ebene zugeschrieben wird.

Auf welcher Ebene die Figur Eckhard Cordes angesiedelt ist und als was er bestimmt werden kann, ist noch schwerer zu sagen als beim `Dritten . Er scheint weniger funktional konstruiert zu sein als dieser und tritt sehr überraschend als sehr konkrete Figur in Erscheinung. Scheinbar erfolgt dies auf der zweiten Ebene, da Deters II ihn im Andree's Berg trifft. Einiges ist jedoch merkwürdig und zeigt Deters II, dass Cordes in eine andere Zeitschicht gehört. Sie haben dasselbe Zimmer, jedoch sehen sie verschiedene Zimmernummern; Cordes tritt auf einen Balkon, den Deters II aber nicht sehen kann, weswegen er nur sieht, wie Cordes durch die Wand verschwindet. Auch sehen ihn andere Leute nicht. Bemerkt wird, dass Deters in der Erzählung auch einen Balkon hat und zudem hält Cordes das Hotel für das Wolpertinger. Dennoch gehört er, wie später festgestellt wird, der Zeitschicht von 1989 an (vgl. WB, 923). Weiterhin ist merkwürdig, dass er weder Lipom kennt noch irgendetwas von den Geschehnissen im Wolpertinger weiß. Andererseits wird er ganz direkt als »späteres Ich « $(W B, 923)$ von Deters II bezeichnet (als das er eigentlich Bescheid wissen müsste). Bei der nächsten Begegnung hat sich eine Veränderung ergeben, Cordes hat Verletzungen am Kopf und reagiert anders als vorher. Er weiß vieles über die mystisch-mythische Bedeutung der Dinge, kennt Ortnit/Ramon-Roger und fängt an, Deters II zu beraten und ihm Tipps zu geben. Er ist also in das Geschehen hineingezogen worden, hat "viel gelernt in den kommenden vier Jahren " $(W B, 717)$ und greift aus der Zukunft in das Geschehen ein (ohne jedoch Deters II etwas vollständig zu erklären).

Ausgehend von seinem Namen kann der Versuch unternommen werden, Cordes' Identität zu bestimmen. Als ursprünglicher Namensbesitzer ist der `Dritte zu identifizieren: »Er selbst, der Dritte, war ja der wirkliche Cordes. ( $W B, 924)$ Untermauert wird dies an mehreren Stellen, wenn der Namenstausch (durch den Passtausch) in die Überlegung miteinbezogen wird. Demnach heißt der ursprüngliche Cordes (der `Dritte $<$ ) nun Deters und dieser (d. i. Deters II) nun Cordes. Nach dem Tausch erkundigt sich der $>$ Dritte auf seiner ehemaligen Arbeitsstelle entsprechend nach Herrn Cordes $(W B, 692)$. Auch kommentiert er erschreckt die Verwendung `seines` Namens für die Figur Cordes ( $W B, 679 f$.). Andererseits ist die Figur Cordes wiederum eindeutig vom $>$ Dritten $<$ zu unterscheiden. Dies zeigt sich spätestens, wenn die beiden aufeinandertreffen und Cordes auf den davon genervten >Dritten $<$ einredet (vgl. WB, 950f.). Dies besagt bislang erst, was Cordes nicht ist, nur woher der Name stammt. 
Als `späteres Ich ` von Deters II hängt Cordes enger mit diesem zusammen und auch die weiteren Hinweise gehen in diese Richtung. Er selbst spricht von einer Veränderung, dass er ein Mensch gewesen ist, nun seinen Ort aber nicht mehr verlassen kann, da er geworden ist `wie die anderen . Ausgeführt wird dies nicht, aber einzige Auslegungsmöglichkeit ist, dass auch er ein Geist geworden ist (vgl. WB, 718 und 913). Metanarrativ bestätigt wird dies von Alda, die ihn als "Gespenst vom Andree's Berg", als einen »Hans Deters, der hiergeblieben ist « $(W B, 702)$ sieht, was Deters II als interessante Überlegung aufnimmt. Auch der $>$ Dritte $<$ bezeichnet Cordes einmal im Gespräch als »Sie Gespenst « $(W B, 951) .{ }^{128}$ Aus diesen Andeutungen kann gefolgert werden, dass Cordes einerseits während der Primizien, also des Vollzugs der Heiligen Hochzeit, entstanden ist, erst danach trat er sein »Amt « $(W B, 913)$ an; andererseits greift er von der Zukunft aus in das Geschehen ein und übergibt Deters II eins der Beutelchen, was die Voraussetzung für die Heilige Hochzeit erst zu sein scheint. In einer kausal absurden Schleife macht er die eigene Entstehung aus einer Form seiner selbst heraus erst möglich. Die Zentralität dieser Zusammenhänge zeigt sich darin, dass Cordes zur Beschreibung seines identitären Verhältnisses zu Deters II das von Lacan stammende Motto, das dem gesamten Roman vorsteht, nur leicht abwandelnd aufgreift:

Gewissermaßen sind wir identisch... und doch nicht. Ich bin die Zweite Zukunft dessen, was Sie gewesen sein werden, für das, was Sie dabei sind zu werden. $(W B, 718)$

\subsubsection{Die Bedeutung des Figurengeflechts}

Diese Schleifen sind wie insgesamt für die Konstruktion des Romans auch für das Verhältnis aller Deters-Instanzen untereinander kennzeichnend. Wurden sie bislang (bis auf die Figur Cordes) alle in ihrer Autor-Funktion beschrieben, als eine sich potenzierende Hierarchie von Autoren auf einer Struktur von Meta-Ebenen, so bleibt wie mehrfach angedeutet auch diese Hierarchie nicht bestehen. So wie Deters II entgegen herkömmlicher Richtungen schon seinen Überautor erfindet, so erdenkt sich auch Deters nicht nur seine Geschichte, sondern auch seinen ihn erfindenden >Autor<, wie zwischendurch wieder eingeflochten wird (vgl. $W B, 767,786,834,873$ u. ö.). Das Verhältnis dieser vier Instanzen ist also mit herkömmlichen Denkvorstellungen nicht zu vereinbaren. Zwar sind sie auch »zeitliche Aufspaltung[en] « ${ }^{129}$ einer Person, doch sie lediglich als solche zu sehen, greift zu kurz. Sie hängen miteinander zusammen, sind identisch und doch wieder nicht. Sie sind Aufspaltungen einer Person, die sich

128 Eine andere Andeutung, Cordes sei ein Vampir, wird noch weniger ausgeführt und ist zudem widersprüchlich. Alda spricht diese Vermutung als Warnung aus und bezieht sich dabei auf die Zugfahrt (vgl. WB, 704). Dort ist das fehlende Spiegelbild, ein typisches Vampirkennzeichen, aber eindeutig Deters zugeschrieben (vgl. WB, 89). Dieser hat aber andererseits an anderer Stelle wieder ein Spiegelbild, obwohl er gleichzeitig eine Veränderung seiner Zähne bemerkt (vgl. WB, 161). Auch in Bezug auf Deters bleibt die Andeutungen einer Verwandlung problematisch, da er sich vermutlich am Ende dann nicht in einen Vampir verwandelt, sondern in einen Luchs. Reber hält das Motiv daher für ein »interpretatorisches 〉Dead End « (Reber: Formenverschleifung, 408 FN 169). Ein Anschluss an die zugehörige Symbolik aus $V G$ ist jedoch anzunehmen.

129 Scherer: »Die Metamorphosen des Wolpertingers«, 180. 
jedoch weder zeitlich-räumlich noch von ihrem Persönlichkeitsumfang zu dieser wieder zusammenfügen lassen.

Als Bild zur Veranschaulichung ist das eines Netzwerks dienlich, möglicherweise eines "Ego-Netzwerk[s] « ${ }^{130}$ von Figuren, die zeitlich voneinander unterschiedene Entwicklungsstufen eines Ichs sind. Als weiteres Bild wurde mehrfach das eines Rhizoms vorgeschlagen. Ein erster jedoch kontextloser Hinweis findet sich bei Scherer ${ }^{131}$, Moosbach/Patorski baut seine gesamte Arbeit auf den Begriff nach dem Verständnis von Deleuze und Guattari auf, ${ }^{132}$ und auch Reber bezieht sich auf dem Rhizombegriff verwandte Konzepte von ihnen wie `Fluchtlinien $`$ oder $`$ Werden ${ }^{133}$. Neben Zweifeln an der Schlüssigkeit der Übertragung von recht willkürlich gewählten philosophischen Modellen auf Herbsts Werke, stellt sich die Frage, inwieweit solche Bilder wirklich hilfreich sind. Sie können zwar versuchen, die Zusammenhänge zu veranschaulichen, indem sie ein griffiges Bild zur Verfügung stellen. Das Deters-Netzwerk als einen "Block des Werdens ${ }^{134}$ zu sehen oder von einer »dynamischen Konsistenzebene eines Dreiergefüges ${ }^{135}$ zu reden, sagt aber wenig aus über die Funktion dieser Konstruktion.

Hinweise auf die Funktion ergibt ein kontrastierender Vergleich mit $V G$. Wie im zugehörigen Abschnitt bereits angesprochen, hat die Figurenaufspaltung dort die psychologischen Züge klassischer Doppelgänger, die Veranschaulichung verschiedener charakterlicher Aspekte einer Person in der Aufspaltung in zwei oder mehr. Dies trifft in WB nicht zu. Über das natürlich durch die romantischen Vorbilder als intertextueller Bezugspunkt mitzudenkende Doppelgängermotiv geht diese Konstruktion hinaus. ${ }^{136}$ Zum einen sind die Deters-Instanzen zeitlich voneinander getrennt und treffen sich (teilweise) erst in einer merkwürdigen Verschlingung der Zeitebenen, zum anderen stellen sie keine sich entgegenstehenden oder ergänzenden charakterlichen Züge dar. Im Rahmen ihrer Übertragung bachtinscher Überlegungen auf WB kommt Reber zu der Aussage, dass »den menschlichen Figuren, so wie sie geschildert sind, $[\ldots]$ außerhalb ihrer jeweiligen Rollen kein Sein zukommt. Der Wechsel der Rolle geht stets mit dem Wechsel der >Identität $`$ im engeren Sinne einher ${ }^{137}$. Wie weiter oben dargestellt, gilt dies auf unterschiedliche Weise für alle Figuren des Romans. Die Deters-Figuren sind allerdings das deutlichste Beispiel nicht unbedingt für die Rollenhaftigkeit, sondern für den Rollen- und Identitätswechsel selbst. ${ }^{138}$ Dies

130 Reber: Formenverschleifung, 320.

131 Scherer: "Die Metamorphosen des Wolpertingers", 180.

132 Moosbach: »Das Ribbentrop-Rhizom «.

133 Vgl. Reber: Formenverschleifung, 318 und passim.

134 Moosbach: »Das Ribbentrop-Rhizom«, 54.

135 Reber: Formenverschleifung, 337.

136 Vgl. auch ebd., 33of.

137 Ebd., 353.

138 Dass von »Bertrecht dem Dichter und Bertrecht dem Terroristen, von Katrin Legrand der CoopVerkäuferin und Katrin-Kybele als nicht nur chronologisch und phantasmatisch, sondern als tatsächlich und radikal geschiedenen Personen gesprochen werden kann « (ebd.), wird in der Handlung nicht weiter ausgebaut. Zwar gibt es Hinweise darauf im Text (vgl. $W B, 715)$, doch sind sie so marginal, dass ein Vergleich mit der Aufspaltung der Deters-Figuren keineswegs möglich ist. 
macht den Unterschied zu der eigentlich ähnlichen Konstruktion in $V G$ aus: Ihre Rollen definieren sich durch die Funktionen, die ihnen in bestimmten Kontexten zugeschrieben werden. Innerhalb der oben beschriebenen, immer miteinander verwobenen Motivkomplexe wird ihnen dann sogar eine aktive Rolle zugeschrieben. Im `Geschlechterkampf $\triangleleft$ müssen sie den männlichen Part und in den Hieros gamos die diesem zugewiesene Rolle übernehmen. Im Kampf der gegeneinanderstehenden Positionen Mythos vs. Logos bzw. Elben vs. moderne Menschen kommt ihnen die Vermittlerrolle zu. Insgesamt stellen sie wichtige, da aktive Teile innerhalb der metanarrativen Gesamtkonstruktion dar, haben Funktionen innerhalb des metanarrativen Spiels. Sie sind die Aktivpunkte, die das Spiel am Laufen halten. Die personale Aufspaltung ist daher im Wesentlichen nicht psychologisch, sondern metanarrativ begründet. 



\section{Zwischen Mythos und Virtualität}

\subsection{Alles ist fiktiv: die Infragestellung der Wirklichkeit}

Wolpertinger ist in hohem Grade ein metafiktionaler Roman. Metafiktionale und metanarrative Aspekte und Kommentare finden sich in unterschiedlicher Erscheinung; neben impliziten Formen wie (intendierten) Widersprüchen oder Wiederholungen reicht das Spektrum der expliziten Formen von eher unscheinbar und punktuell eingestreuten Erzählerkommentaren bis zu ausführlichen Diskussionen verschiedener Figurenkonstellationen. Um die metafiktionalen Aspekte - besonders den fictum-Aspekt, die "Bezugnahme auf den Wahrheitsstatus $\aleph^{1}-$ und um die Frage, wie die Welt (sei es die fiktive oder die reale) wahrgenommen wird, die durch die metafiktionalen Diskussionen thematisiert wird, geht es im folgenden Abschnitt.

In der in der Einleitung genannten Definition von Metafiktionalität wird betont, dass durch sie die Fiktionalität eines Textes »zu Bewußtsein « gebracht werde. ${ }^{2}$ Der Rezipient wird also durch den Text veranlasst, über Aspekte der Fiktionalität des Textes nachzudenken. Patricia Waugh betont in ihrer Pionierarbeit über Metafiktion darüber hinaus den Bezug zur Unterscheidung von realer und fiktiver Welt. Die Fiktionalität werde thematisiert, »in order to pose questions about the relationship between fiction and reality « ${ }^{3}$. Sie geht noch darüber hinaus, wenn sie sagt, metafiktionale Literatur würde »the possible fictionality of the world outside the literary fictional text ${ }^{4}$ zum Bewusstsein bringen. Verbindendes Merkmal der Autoren metafiktionaler Literatur sei die Erkundung einer »theory of fiction through the practice of writing fiction «" . Diese Aussagen gelten auch für WB. Aus den selbstreflexiven Diskussionen der Fiktionalität des Textes lassen sich die Postulierung bestimmter Vorstellungen von Wirklichkeit und von Fiktion erkennen. Dabei handelt es sich jedoch weder um eine ausformulierte noch um eine kohärente Fiktionstheorie, auch wenn Aspekte inzwischen genauer ausgeführter Fiktionstheorien erkennbar sind. Trotz expliziter Thematisierung sowohl auf der Ebene des discours als auch der histoire geht es um die praktische Erkundung der mit der Unterscheidung von Fiktion und Realität zusammenhängenden Phänomene; epistemologische Fragestellungen sind damit eng verbunden mit fiktionstheoretischen Überlegungen.

1 Wolf: »Metafiktion «, 430.

2 Vgl. ebd., 429. Auch bei Tilmann Köppe: »Der Konjunktiv in Andreas Maiers Roman Wäldchestag und die Theorie der Metafiktionalität«, in: J. Alexander Bareis / Frank Thomas Grub (Hg.): Metafiktion. Analysen zur deutschsprachigen Gegenwartsliteratur, Berlin 2010, 115-133, hier: 119.

3 Patricia Waugh: Metafiction. The Theory and Practice of Self-conscious Fiction, London / New York 1984, 2.

4 Ebd.

5 Ebd. 
Zunächst kann jedoch aus pragmatischer Perspektive festgehalten werden, dass Herbst nicht den Geltungsanspruch vertritt, in WB reale Sachverhalte darstellen zu wollen oder auch nur faktuales Erzählen vorzutäuschen. Durch die paratextuelle Bezeichnung als Roman ist der Text hinreichend als fiktional gekennzeichnet. Gewöhnlich wird jedoch angenommen, dass Aussagen über die fiktive Welt innerhalb dieser einen Wahrheitsanspruch haben. ${ }^{6}$ Was beispielsweise ein Erzähler über sie aussagt, wird als wahr aufgenommen. ${ }^{7}$ In $W B$ sind alle Ebenen nicht nur fiktiv - das sind sie als Elemente eines Romans -, sondern auch fiktional; das bedeutet, dass jede Ebene von einer anderen aus erzählt wird, was nur durch die unmögliche Konstruktion eines narrativen Zirkels oder Schleife erzählbar ist. Das Grundprinzip besteht in der Unterwanderung jedes Versuchs des Lesers, eine feste und konsistente Grundlage auszumachen, von der erzählt wird bzw. die einen Wahrheitsanspruch vertritt. Schon die jeweilige Ausgangssituation von Prolog und Erster Abteilung weist auf die metafiktionale Struktur hin. In beiden Fällen wird eine Figur (der Ich-Erzähler des Prologs bzw. Deters als fokalisierte Figur) als Schreibender und damit als Erzeuger von Imaginationen eingeführt.

Das primäre Erzählprinzip ist das der literarischen Imagination, die als solche kenntlich gemacht wird. Von vornherein ist dies am Aufbau der Ebenen abzulesen. Deters auf der ersten Ebene wird als Schreibender eingeführt, der sich zwar auf einer Zugfahrt zu befinden scheint, aber durch explizite metafiktionale Kommentare wird auch gesagt, dass er zumindest Teile seiner Erlebnisse nur imaginiert. Da er jedoch nicht als Ich-Erzähler fungiert, sondern heterodiegetisch erzählt wird, ist gleich durch die Erzählsituation eine Distanz aufgebaut: wo ein heterodiegetischer Erzähler vorhanden ist, muss eine übergeordnete Ebene existieren, auch wenn sie nicht als solche dargestellt sein muss. Durch die zweite Ebene wird eine solche WB sogar aufgeführt und in Deters II der Autor der ersten Ebene kenntlich gemacht. Anfangs schreibt er Deters' Erlebnisse auf, später erzählt er sie Alda (die dann auch beginnt, als Koautorin mitzuerzählen). Genau diese Konstellation ergibt ein erzählerisches Problem, das auch thematisiert wird. Es ist nämlich daran zu zweifeln, dass Deters II den Text aufschreibt, während er sich mit Alda unterhält bzw. ihr die Geschichte erzählt, andere zeitliche Möglichkeiten sind jedoch kaum gegeben. So wird der mögliche Einwand aus >realistischer Perspektive selbst im Roman vorgebracht, denn Deters II erzähle »so wahnsinnig viel [...], daß alleine dieses skeptisch stimmt « $(W B, 560)$. An dieser Stelle kommt dann der `Dritte ins Spiel, der wiederum der Autor des >Autors $`$ von Deters ist. Die Grundkonzeption ist also die Abbildung des literarischen Entstehungsvorgangs auf mehreren Ebenen.

Die zweite Ebene scheint sich zunächst als die zentrale Ebene zu etablieren, von der aus erzählt wird. Während Deters und die Diskussionen und Ereignisse auf der ersten Ebene zwar wohl den meisten Raum einnehmen, wird durch die Bestimmung von Deters II als >Autor ein hierarchisches Verhältnis aufgebaut, dass die erste Ebene

6 Vgl. Martinez/Scheffel: Einführung in die Erzähltheorie, 17.

7 Selbst bei einem unzuverlässigen Erzähler wird eine höhere zu entdeckende Wahrheit angenommen: »The reader makes sense of such narratives [unreliable narration] by recontextualizing the discrepancies at progressively higher levels of the text until an authoritative norm is discovered." (Waugh: Metafiction, 102). 
deutlich als Fiktion kenntlich macht. Die erste Ebene wird dabei nicht nur als reinfacher Binnenerzählung bestimmt, was ein gängiges literarisches Muster wäre, sondern durch die metanarrativen Diskussionen und die Präsentation von verschiedenen Möglichkeiten wird in einem deutlichen Maß ihr Konstruktionscharakter kenntlich gemacht. Die zunächst im Vergleich zur ersten Ebene zu konstatierende relative Handlungsarmut und die geringere Anzahl an Figuren lässt die zweite als Ebene erscheinen, die vor allem einen erzählerischen Rahmen für die erste Ebene schafft. Auch als mit der `Dritten Ankunft « eine weitere, eigentlich übergeordnete Ebene - dem Anschein nach eine Metaebene - eröffnet wird, wird die Zentralität und Bedeutung der zweiten Ebene nur bedingt infrage gestellt. Selbst die Zuordnung der dritten Ebene ins Jahr 1989, also chronologisch nachgeordnet auf dem von 1976 über 1981 und 1985 bis dann ins Jahr 1989 reichenden Zeitstrahl der Handlungen, macht eine Hierarchisierung nur zeitweise eindeutig. Schon bald sprechen Deters II und Alda nämlich darüber, eine dritte Ebene einzuführen, sodass sich auch diese als von ihnen erzählt erweist. Damit wäre die zweite Ebene im Jahr 1985 wieder als die Haupt- oder Gegenwartsebene bestimmt, von der aus die Vergangenheit (1981) und die Zukunft (1989) erzählt wird. ${ }^{8}$

Mit der eben erwähnten Einführung der dritten Ebene durch Deters II und Alda kommt jedoch eine weitere Schleife hinzu, die in der Folge ihren hierarchischen Status viel deutlicher unterwandert. In der Erzählung von Deters sagt dieser nämlich auf einmal - abgetrennt durch einen Gedankenstrich: »Das will ich den Autor seiner [sic!] Partnerin sagen lassen.« $(W B, 786)$ Durch einen sofortigen Wechsel der Ebenen folgt ein Kommentar von Alda, es käme ihr unwahrscheinlich vor, dass Deters sie beide erfinde. Als Gegenvorschlag folgt der Einfall, eine dritte Ebene einzuführen. Was an dieser Stelle noch als unsinnige Idee abgetan wird, kommt nur wenig später bei einem der plötzlichen Wechsel zum Tragen. Eine kurze Beschreibung, die eindeutig der zweiten Ebene zugeordnet ist, wird mit abschließenden Anführungszeichen beendet, gefolgt von einem Kommentar von Lipom (vgl. WB, 834). Die zweite Ebene wird zumindest an dieser Stelle nun von Deters erzählt. Die hierarchische Ordnung der Ebenen gerät durcheinander. Schon kurz vorher passiert Ähnliches, jedoch innerhalb der ersten Ebene. Diese wird quasi in sich verdoppelt. Die Schilderung des Things, das durch die teilnehmenden Figuren der ersten Ebene zugeordnet ist (Dr. Weigan und Deters beobachten die Geister, die Mitglieder der ATG ebenso wie weitere Geister), wird mehrfach unterbrochen und so als Erzählung von Deters gegenüber den ATGMitgliedern selbst dargestellt. Es wird also als Erzählung ihrer eigenen Erlebnisse präsentiert. Somit wird der fiktionale Status des Ereignisses angesprochen; dass es sich überhaupt ereignet hat, wird fraglich. Wenn Lipom aber fragend kommentiert, "So souve,hä,rän hab' ich gesprochen? « $(W B, 814)$, so impliziert er wiederum, dass es sich tatsächlich so zugetragen hat. Gleichzeitig weisen weitere Unterbrechungen es jedoch auch als Teil der Erzählung von Deters II und Alda aus. Eine Bestimmung, welche Ereignisse >tatsächlich`stattgefunden haben und wer erzählt, ist nicht möglich.

8 So auch die Beschreibung bei Scherer, die er vorsichtiger- aber auch korrekterweise mit dem Zusatz versieht, "ausgemacht [sei] das bei Herbst nie« (Scherer: »Die Metamorphosen des Wolpertingers", 182). 


\section{Möbiusschleife und Rhizom als Veranschaulichung der Erzählstruktur}

Der eben bereits beiläufig verwendete Begriff der Schleife deutet auf verschiedene mögliche Bilder, die das Ineinander der Ebenen veranschaulichen können. Brian McHale verweist in seiner durch viele Beispiele sehr anschaulich gestalteten Gesamtschau postmoderner Prosa in Bezug auf hierarchisch geschachtelte Erzählungen zunächst auf »Chinese boxes or Russian babushka dolls «?. An fiktionstheoretische Begriffe angepasst bezeichnet er entsprechend konstruierte Welten als "Chinese-box worlds" und ebensolche Romane als »Chinese-box novels«. Diese Art von rekursiver Struktur habe den Effekt "of interrupting and complicating the ontological `horizon` of the fiction, multiplying its worlds, and laying bare the process of world-construction ${ }^{10}$. McHale unterscheidet verschiedene Ausformungen dieses Prinzips, die sich auch in älteren Romanen und anderen literarischen Formen schon finden lassen. Kennzeichnend für seine postmodernen Beispiele sei ganz einfach die Frequenz solcher Unterbrechungen einer Erzählung durch Hinzufügung weiterer, untergeordneter Erzählungen und Welten.

McHale verweist in seinen Ausführungen wiederholt auf den Naturwissenschaftler Douglas R. Hofstadter, der sich in dem populärwissenschaftlichen Buch Gödel, Escher, Bach (1979) mit rekursiven Folgen beschäftigt hat. Ein zentraler Begriff ist dabei die sseltsame Schleife`. Sie tritt »immer dann ein, wenn wir uns durch die Stufen eines hierarchischen Systems nach oben (oder nach unten) bewegen und uns dann unerwartet wieder genau an unserem Ausgangspunkt befinden ${ }^{11}$. Ein System, in dem eine seltsame Schleife vorkommt, nennt er »verwickelte Hierarchie«. McHale sieht diese Phänomene als äquivalent mit Genettes Bezeichnung Metalepse. Doch ist diese Gleichsetzung etwas verkürzend; sie funktioniert nicht in allen Fällen. Bei der Metalepse kann es sich auch nur um eine eigentlich logisch nicht mögliche Überschneidung zweier (hierarchischer) Ebenen handeln, wenn beispielsweise eine Figur der einen Ebene mit der Figur einer anderen zusammentrifft. Daraus resultiert jedoch noch keine Schleife. Das narrative Äquivalent dazu ist vielmehr eine prototypische mise-en-abyme, bei der das Ende einer Erzählung in einer metaleptischen Grenzverletzung der Erzählebenen wieder in den Anfang derselben Erzählung mündet. Diese Konstruktion wurde in der Forschungsliteratur mehrfach mit einer Möbiusschleife verglichen. ${ }^{12}$ Auch Hofstadter findet auf abstrakterer Ebene zu diesem Vergleich und beschäftigt sich mit den Bildern des niederländischen Künstlers M. C. Escher als einer bildlich sehr anschaulichen Entsprechung. Die Holzschnitte Möbiusstreifen I (1961) und Möbiusstreifen II (1963) $)^{13}$ sind dafür die strukturell klarsten Beispiele, es finden

9 Brian McHale: Postmodernist Fiction, London / New York 1987, 112.

10 Ebd.

11 Douglas R. Hofstadter: Gödel, Escher, Bach. Ein Endloses Geflochtenes Band [1979], 5. Aufl., Stuttgart $1985,12$.

12 Vgl. Werner Wolf: Ästhetische Illusion und Illusionsdurchbrechung in der Erzählkunst. Theorie und Geschichte mit Schwerpunkt auf englischem illusionsstörenden Erzählen, Tübingen 1993, 369, der wiederum auf den Schriftsteller und Theoretiker Jean Ricardou verweist.

13 Hofstadter: Gödel, Escher, Bach, 34 und 296. Die Struktur basiert auf der mathematischen Beschreibung durch August Ferdinand Möbius und Johann Benedict Listing. 
sich in Eschers Werk aber noch viele andere, optisch komplexere. Ein bekanntes, sehr einfaches Bild ist die Lithographie Zeichnen (1948), die zwei Hände darstellt, die sich gegenseitig zeichnen. Abgesehen von dem zusätzlichen trompe-l’eil-Effekt, der die Illusion erzeugt, dass die Hände aus der zweidimensionalen Ebene des Papiers heraustreten und dreidimensional werden, ist an dieser Stelle vor allem die unendliche Schleife interessant. Zwar handelt es sich hier um ein eher einfaches Beispiel, da nur zwei Hände sich gegenseitig erschaffen, doch stellt es gerade durch den fiktional schöpferischen Aspekt des Zeichnens das Prinzip dar, nach dem die Ebenen in WB generiert werden: Autor I erfindet Autor II, der wiederum Autor I erfindet. In WB ist die Konstruktion noch komplexer, da es sich um (mindestens) drei Ebenen handelt, sodass sich mehrere Schleifen ergeben, je nachdem, welche Ebene welche generiert. Es wird jedoch noch einmal bildlich deutlich, dass keine Ebene ausgemacht werden kann, die hierarchisch einer anderen jederzeit überlegen wäre; es handelt sich also um eine verwickelte Hierarchie oder um eine Heterarchie. Dieser Begriff entstammt der Computerwissenschaft und bezeichnet ein Programm mit einer Struktur, in der es keine `höchste Stufe gibt. ${ }^{14}$ Obwohl es auch einige Anzeichen dafür gibt, die zweite Ebene in $W B$ als Hauptebene zu sehen, kann eine solche Aussage nicht eindeutig vertreten werden, da beide anderen Ebenen auch wieder sich als übergeordnet bzw. in der Schleife als vor- wie nachgeordnet erweisen. Die Schleife(n) sind nicht auflösbar.

Ein anderes Bild zur Veranschaulichung der Erzählstruktur von WB ist das mehrfach in der Forschungsliteratur vorgebrachte Rhizom. Wie bereits erwähnt ist es Scherer, der in Bezug auf WB erstmals den Begriff Rhizom vorbringt, wenn er von den »verschiedenen Fiktionsebenen, die [...] wie ein Rhizom auswuchern ${ }^{15}{ }^{15}$, spricht. Er führt dieses Bild jedoch nicht näher aus, es bleibt bei der Erwähnung. Der Begriff Rhizom stammt ursprünglich aus der Botanik, wo er ein sich verzweigendes Sprossachsensystem bezeichnet, das Wurzeln und Blätter bestimmter Pflanzen miteinander verbindet. Gilles Deleuze und Félix Guattari überführten diesen Begriff als Metapher in Philosophie und Wissenschaftstheorie. Bei ihnen ist das wichtigste Kennzeichen eines Rhizoms das Fehlen einer hierarchischen Ordnung; im Gegensatz zu klassischen Baumstrukturen, die sich immer weiter aufteilend verzweigen, sind hier Querverbindungen zwischen den Elementen möglich. Ein Hauptzweig ist nicht auszumachen und zirkuläre Strukturen im Ganzen oder in Teilabschnitten können entstehen. Diese Kennzeichen finden sich wie beschrieben wiederum in der Ebenenkonstruktion von WB. Moosbach/Patorski nutzt den Begriff mit direktem Bezug auf die Verwendung durch Deleuze/Guattari. Er sieht jedoch stärker Herbsts Gesamtwerk als ein »Ribbentrop-Rhizom ${ }^{16}{ }^{16}$, als dass er den Begriff auf mikrotextuelle Strukturen anwendet. Insgesamt versucht er verschiedene andere Begriffe der

14 Vgl. ebd., 145.

15 Scherer: »Die Metamorphosen des Wolpertingers«, 180.

16 So der Titel der Arbeit. Vgl. auch Patorski / Moosbach: »Die Anderswelt als Rhizom«. 
Deleuze/Guattari-Terminologie zur Beschreibung der Erzählstrukturen zu nutzen, die dann auch narratologische Analysekategorien weitgehend ersetzen. ${ }^{17}$

\subsubsection{Illusionsdurchbrechung und Kohärenzverweigerung}

In der Abbildung des poetischen Schöpfungsprozesses durch die Darstellung von Autoren im Vorgang des Erzählens oder Schreibens auf allen Ebenen zeigt sich die metafiktionale Gesamtkonstruktion des Romans. In Bezug auf Metafiktionalität wird im Allgemeinen auf den Aspekt der Illusionsdurchbrechung bzw. der Störung des mimetischen Effekts hingewiesen. ${ }^{18}$ Diese Annahme kann auch angezweifelt werden, ${ }^{19}$ doch übernehme ich sie, da sie in $W B$ thematisiert wird.

Schon bei einer hierarchisch geschachtelten Erzählung mit einer Binnenerzählung, wo die Fiktionalität der diegetischen Ebenen herausgestellt wird, kann der reale Autor als eine weitere Metaebene mitgedacht werden, die damit die Fiktivität selbst der hierarchisch höchsten Ebene offenbart. In WB wird eine solche Vorstellung schon textintern durch die eben beschriebene Schleife bewirkt. Jeder der auf den Ebenen konstruierten Autoren ist von einem oder mehreren der anderen erdacht, wodurch das eingangs postulierte Prinzip erfüllt wird, alles sei fiktiv.

Die metafiktionalen Kommentare sind jedoch nicht nur als verspielter Selbstzweck anzusehen, auch wenn sie sicherlich ein wichtiger Aspekt in dem Spiel sind, als das $W B$ gesehen werden kann (worauf später noch genauer einzugehen ist). An sich sagt Metafiktionalität oder eine metafiktionale Erzählkonstruktion auch noch nichts aus über die zugrunde liegende Vorstellung von Realität noch wird eine Aussage über den Fiktionsstatus hergestellt. ${ }^{20}$ Durch die Demonstration der Prämisse der vollständigen Fiktivität der erzählten Welt wird jedoch die Zuverlässigkeit bzw. der Wahrheitsstatus der Erzählungen hinterfragt. Der Leser auf der Suche nach festen Bezugspunkten, letztlich nach Kohärenz des Textes bzw. zunächst der fiktiven Welt wird dadurch verunsichert. Denn selbst in einer phantastisch anmutenden Welt mit vielen offensichtlich erfundenen Figuren, Gegenständen oder Zusammenhängen gilt dies: die Regeln, die in einer solchen Welt gelten, unterscheiden sich zwar von denen der realen Welt, sie werden jedoch im Laufe der Lektüre erlernt und normalerweise kann so eine kohärente Weltsicht hergestellt werden. ${ }^{21}$ Auch im WB-Text wird in

$17 \mathrm{Zu}$ meinen Einwänden gegen die starke Anlehnung an Deleuze/Guattari siehe den Überblick über die Sekundärliteratur zu Herbst auf Seite 31.

18 Vgl. Nünning: "Mimesis des Erzählens«, 33; Dirk Frank: Narrative Gedankenspiele. Der metafiktionale Roman zwischen Modernismus und Postmodernismus, Wiesbaden 2001, 16; Fludernik: "Metanarrative and Metafictional Commentary«, 29; und die große Monographie von Wolf: Ästhetische Illusion und Illusionsdurchbrechung in der Erzählkunst.

19 Tilmann Köppe unternimmt eine interpretationstheoretische Annäherung an den Metafiktionsbegriff und wendet sich dabei gegen die Annahme eines Illusionsbruchs, da er davon ausgeht, dass bei fiktionaler Literatur keine Täuschung vorliegt, die folglich auch auch nicht aufgehoben werden könne. Zudem würde der kompetente Leser durchgängig um die Fiktionalität des Textes wissen. Vgl. Köppe: »Der Konjunktiv in Andreas Maiers Roman Wäldchestag«, $123 \mathrm{f}$. Auch Wolf vermerkt, dass Metafiktion nicht auf Illusionsdurchbrechung zu reduzieren sei, vgl. Wolf: »Metafiktion«, 430.

20 Vgl. Bunia: Faltungen, 141.

21 Vgl. Umberto Eco: Nachschrift zum >Namen der Rose` [1983], übers. von Burkhart Kroeber, München $1986,33 \mathrm{f}$. 
gewissem Sinn die Suche des Lesers nach Kohärenz nahegelegt, beispielsweise wenn Alda und Deters II über die Stimmigkeit der Zusammenhänge ihrer Konstruktion diskutieren (vgl. WB, 701-704). Auch wenn sie teils so reden, als wäre die fiktive Welt real (auch wenn sie andererseits wieder auf die Fiktionalität der Erzählung verweisen), nehmen sie mit ihren Überlegungen Lektürevorgänge eines möglichen Lesers und seine vielleicht vorgebrachten Einwände gegen die Logik der Zusammenhänge vorweg.

Eine Vorannahme dieser Überlegungen zur Kohärenz ist der kooperative Charakter von Kommunikation. Als Kooperationsprinzip vor allem in Anschluss an Paul Grice bekannt, überträgt Jannidis es auf die literarische Kommunikation. ${ }^{22}$ Die Personen, die an der Kommunikation beteiligt sind - im Falle der besonderen (da in einer Richtung erfolgenden) literarischen Kommunikationssituation sind es Autor und Leser - bemühen sich kooperierend um das Erreichen des gleichen Ziels, das jedoch sehr vage sein kann. Grice nimmt als Ziel in der Gesprächsanalyse den maximal effektiven Austausch von Informationen an, »in der narrativen Kommunikation könnte ein solches Ziel darin bestehen, interessant über ein Geschehen zu informieren und dies so effektiv wie möglich zu tun $\ll^{23}$. Hinzuzufügen wäre - um die Seite des Lesers miteinzubeziehen - als weiteres Ziel bzw. Teil dieses Ziels das Verständnis der Informationen und die zugehörige Bedeutungskonstitution. Interessanterweise wird hier von der Effektivität und damit vom allgemeinen Funktionieren dieser Kommunikation ausgegangen. Doch schließt das Verständnis des Kooperationsprinzips ein, dass die Gültigkeit immer vorausgesetzt wird, auch wenn offensichtliche Verstöße vorliegen. Diese erzeugen lediglich den Auftrag an den Leser, nach einem anderen Verständnis des Textes zu suchen, das sich mit dem Kooperationsprinzip deckt.

Es kann also der gegenseitige Wille sowohl des Autors als auch des Lesers angenommen werden, zu einer funktionierenden Kommunikation beizutragen. Es stellt sich jedoch die Frage, ob in WB das ebenfalls angenommene Bedürfnis des Lesers nach Herstellung von Kohärenz das Ziel der vom Autor vorgegebenen Kommunikation ist, da dieses konsequent hintergangen und seine Erfüllung verweigert wird. Wie in der Beschreibung der Ebenen bereits angedeutet, wird selbst die mögliche und durch viele Hinweise naheliegende Interpretation der zweiten Ebene als Hauptebene wieder durch die Darstellung weiterer Lesarten und möglicher Konstruktionen hintergangen. Der Leser wird in seiner Kohärenzsuche konstant düpiert und daran gehindert, die ineinander verflochtenen Ebenen und Motivstränge zu entwirren. Der Leser bleibt verwirrt. Zunächst werden im Folgenden beispielhaft die Verfahren vorgeführt, die die Suche nach Kohärenz unterwandern, danach ist zur Frage zurückzukehren, welches Ziel die Verwirrung des Lesers erreichen soll.

Eine solche Verwirrung kann entweder durch mangelhafte oder verzögerte Informationsvergabe oder durch sich widersprechende Aussagen erzeugt werden. In $W B$ finden sich verschiedenste Arten an Techniken der Verwirrung. Neben der bereits oben beschriebenen verzögerten Identifizierung der Figuren erschweren wohl die nicht gekennzeichneten Ebenenwechsel das Verständnis am meisten. Zudem sind es die 
elliptischen und andeutungsreichen Gespräche, die weniger erläutern als verwirren. Kennzeichnend ist dies schon für die Diskussionen der ATG, mehr noch aber für die Gespräche zwischen Alda und Deters II, die als metanarrative Kommentare am ehesten die Möglichkeit bieten würden, helfende Hinweise zu geben und zu erläutern, dies jedoch gerade nicht bieten.

Bereits in $V G$ war die Identifizierung der Ebenen nicht leicht, da sie weder explizit eingeführt noch - beispielsweise durch Zwischenüberschriften - als solche kenntlich gemacht wurden. Dort waren sie jedoch konsequent einzelnen oder auch aufeinander folgenden Absätzen zuzuordnen. Die Absätze des >Autor`-Erzählers waren sogar durch Kursivierung besonders abgesetzt. Auffällig und schnell zu verstehen war der Übergang mitten in einem Satz, der Absatz- und Erzählerwechsel nach einem Komma durch Einfügung einer Leerzeile. In $W B$ sind die dort bestehenden Ansätze, die Identifizierung zu erschweren, weitergetrieben und ungleich wirksamer. Auch hier werden die Ebenen kaum als solche eingeführt, sondern müssen nach und nach identifiziert werden. Vor allem durch die Ähnlichkeit der ersten und zweiten Ebene, was Situation und Namen angeht, ist dies nicht einfach. Die dritte Ebene, die als einzige als solche gleich mit ihrer Einführung kenntlich gemacht wird, trägt, wie oben beschrieben, durch die Anonymität des Dritten auch nicht zu einer Klärung bei. Typisch für WB sind jedoch die Wechsel zwischen den Ebenen von Satz zu Satz, also mitten in Absätzen, die nicht als solche ausgewiesen werden. Zudem kann nach einem Satz der anderen Ebene wieder ein Wechsel zur zuvor verfolgten Ebene erfolgen. Die Erzählung der Ebenen ist also eng ineinander verflochten. Zudem sind die Gespräche meist aufeinander bezogen, wodurch die Verbindung noch enger wird. Die Wiedergabe der Gespräche erfolgt oft im dramatischen Modus. Etliche Äußerungen werden daher ohne den Sprecher identifizierende verba dicendi angegeben. Da der Wechsel jederzeit erfolgen kann, kann er erst durch den inhaltlichen Kontext erschlossen werden. Anfangs sind die Wechsel noch eher eindeutig als metafiktionale `Erinnerungen $`$ an eine Form von Rahmenerzählung zu erkennen. So kann der Leser durch verschiedene Hinweise davon ausgehen, die Diskussionen der ATG fänden bloß in der Vorstellung von Deters (oder Deters II) statt, der sich noch im Zug befinde. Da jedoch lange Passagen das Geschehen im Wolpertinger beschreiben, tritt die Zugsituation in den Hintergrund. Sehr plötzlich wird dann wieder daran erinnert. Ein Ausschnitt aus einer Diskussion, der sich passenderweise auch noch um Fragen der Realitätswahrnehmung dreht, verdeutlicht dies beispielhaft:

[Lipom zu Murnau:] »Sie dekuvrieren sich immer, hä, mehr, Sie begründungsloser Rationalist! Ich kenne Sie! Ich kenne Sie gut!« Sein Stock fuchtelte über den Köpfen.

»Wieso `begründungslos`? « fragte der kleine Professor, strich gleichsam den Ton glatt.

»Weil Sie Ihrer Erfahrung glauben, Ihr glauben müssen!« »Aber Herr Dr. Lipom«, versuchte Deters es freundlich. »Welche Kriterien hätte man sonst? «

»Kriterien?!« rief Dr. Lipom. »Er fragt mich nach Kriterien? Sie werden doch nicht Skeptiker, hä, sein?!« Empört blickte er den Lauscher an. »O über den Relativismus! Den mach' ich Ihnen kaputt!«

»Mögen Sie noch etwas? « fragte der Speisewagenkellner. 


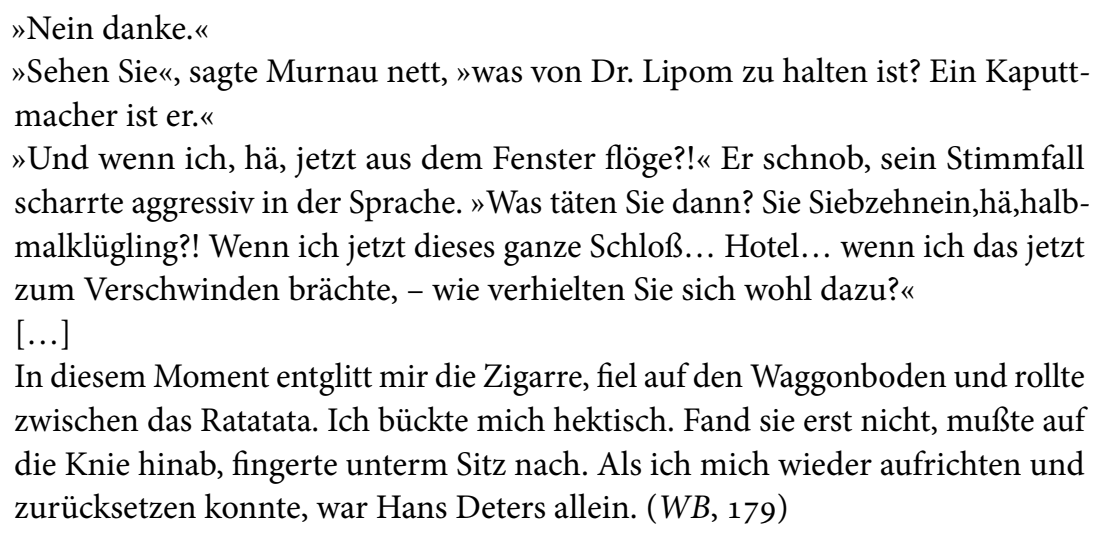

Mitten in der Diskussion, die hier abwechselnd in fast jeder Zeile bzw. in sehr kurzen Absätzen eine Aussage von Murnau oder Lipom wiedergibt, findet ein Wechsel statt. Die Bezeichnung Speisewagenkellner macht deutlich, dass der Schauplatz wieder der Zug ist. Nach der Erwiderung, die nicht gekennzeichnet und nur durch das Vorwissen Deters zuzuordnen ist, wird die Diskussion kommentarlos fortgeführt. Wenige Zeilen weiter ist durch den Begriff Waggonboden wieder der Wechsel des Schauplatzes klar. An dieser Stelle sind die Wechsel durch die Signalwörter deutlich zu erkennen. Dennoch ist die Störung des Leseflusses eindeutig. Der Leser wird wieder einmal daran erinnert, dass es sich bei dem Erzählten um Träumereien bzw. literarische (aufgeschriebene) Imagination von Deters im Zug handelt. Diese Erinnerungen werden immer seltener, vor allem die Unterbrechungen der ersten durch die zweite Ebene dagegen häufiger. Der letzte Satz im Zitat ist zudem ein typisches Beispiel für einen Perspektivwechsel mitten im Satz. Er trägt auch zur Unauflösbarkeit der Zuordnungen bei. Das `Ich im Satz, das sich im Zug befindet, kann weder als Deters noch als Deters II eindeutig bestimmt werden, da beide sich anfangs in einem Zug befinden und beide sich dieselbe Geschichte ausdenken. Mit Hans Deters im zweiten Satzteil wird jedoch vermutlich jemand anders bezeichnet, nämlich der imaginierte Deters im Wolpertinger, da dort die Beschreibung (ohne die ATG) fortgesetzt wird. Es handelt sich also nicht um einen bloßen Perspektivwechsel im Satz von der Ichzur Er-Perspektive.

Ähnliche Mechanismen werden bei den Wechseln zwischen der ersten und der zweiten Ebene in Bezug auf Anna und Alda angewendet. Da Alda vor ihrer Identifizierung als Alda ebenfalls Anna genannt wird, fallen Ebenenwechsel erst durch inhaltlich anders orientierte Aussagen oder die Bezeichnung anderer Gesprächsteilnehmer auf. Ein weiteres Beispiel beginnt auf der ersten Ebene und wechselt dann auf die zweite:

Anna zögerte, dann wandte sie sich zur Tür.

"Ach so, eines noch", sagte ihr die Psychologin hinterher.

Anna dreht sich in der Taille zurück und rümpfte enorm die Nase.

»Lassen Sie Ihre Hände von ihm... und auch von Bertrecht. Eines versprech' ich Ihnen: Wenn Sie denen was antun, kriegen Sie’s mit mir zu tun."

»Aber wieso denn? Was mache ich denn? Die sind's doch, die immerzu von mir was wollen! Mir ist das egal, wirklich! - Pah!« machte sie zum Schluss noch und huschte von dannen.

»Schlafen Sie, Hans? « fragte Dr. Weigan und war ebenso beruhigt wie verunsichert über seinen gleichmäßig tiefen Atemgang. 
»Einer fehlt noch«, sagte Anna.

»Nun?«

»Eine amüsante Figur, die Ihre Leser bei der Stange hält. Das ist ja wohl alles eine Art Mittsommernachtstraum.«

»Puck? « fragte ich.

Anna nickte. $(W B, 531)$

Auch hier erfolgt der Wechsel unkommentiert. Zwar ist Anna 1 gerade gegangen, als die Äußerung einer weiteren Anna wiedergegeben wird. Ein plötzliches Verschwinden und Wiederkommen ist jedoch auch nicht ungewöhnlich in WB. Hier offenbart jedoch erst der metanarrative Inhalt der Überlegungen sowie das Auftauchen des Erzähler-Ichs, dass es sich wieder um Alda und die zweite Ebene handelt.

Während in diesen isolierten Beispielen die Identifizierung der jeweiligen Ebene relativ eindeutig wirkt, auch wenn sie teils um wenige Zeilen verzögert ist, so ist doch anzumerken, dass die Wechsel ständig erfolgen und nicht abzusehen ist, zu welchem vermeintlichen Ausgangspunkt sie zurück- oder hinspringen. Der Leser kann dabei nur den Überblick verlieren, da ein solcher systematisch unterlaufen wird. Dabei ist anzumerken, dass Herbst dies nicht unbedingt so sieht, sondern sogar Hinweise für den Leser eingebaut zu haben glaubt, wie das wiederkehrende Motiv »Hell lachte die Sonne«:

Es ist ein klangliches Ironisches Leitmotiv, das ich meines Wissens im Dritten Septor anschlug, so, daß ich im Sechsten nur noch $d$ a s schreiben mußte, und jeder Leser weiß sofort, wo er ist, nämlich auf der Terrasse. Meine Idee war, solche Bildleitmotive als Grundierung von Tableaux zu verwenden. ${ }^{24}$

Dass nicht jeder Leser >sofort ‘ weiß, wo er ist, zeigt sich auch bei Thomas Malsch, der in diesem Motiv einen anderen Sinn zu sehen versucht. ${ }^{25}$

Zudem gilt, dass je mehr Ebenenwechsel und Wechsel von Schauplätzen oder Perspektiven innerhalb der Ebenen dazukommen, desto fragmentierter der Zusammenhang der einzelnen Erzählstränge wird. Gerade für die Diskussionen bedeutet dies, dass Argumentationsketten auseinandergebrochen werden oder aber gar nicht vollendet werden.

Ihren Höhepunkt an Verwirrung erreichen die Ebenenwechsel in der Schilderung des Festes oder der Primizien, das parallel auf allen drei Ebenen geschildert wird. Die Erzählung ist hier vollständig ineinander verwoben, Wechsel finden selbst innerhalb eines Satzes statt. Zudem wird das Geschehen durch mehrere Ich-Erzähler wiedergegeben, die den einzelnen Deters-Instanzen kaum noch zuzuordnen sind. Einige Ausschnitte sollen auch dies wieder veranschaulichen:

Wie nun ich mit Berta in der Nährlösung lag und alle die Hände spürte, die zahllosen Zungen, Lippenpaare, stand ich vor Lipom, so tief gefallen, hinuntergeschluckt. $(W B, 997)$

24 URL-9, 19. Juli 2010.

25 Vgl. Thomas Malsch: „Vom Wiedereintritt des Autors in seine Geschichte. >Buenos Aires. Anderswelt , ein kybernetischer Roman von Alban Nikolai Herbst«, in: Thomas Kron / Uwe Schimank (Hg.): Die Gesellschaft der Literatur, Opladen 2004, 45-80, 54 FN 7. 
Nach der Schilderung des Rituals, in dem das Ich mit Anna verbunden ist, was es als Deters identifiziert, folgt dieser Satz, der dem eben zitierten logisch widerspricht:

Dies alles konnte ich in einem der Monitore sehen, bevor ich Berta in den Barraum folgte. (ebd.)

Zwischenzeitlich wurde keine weitere Information darüber mitgeteilt, dass das Ich mit Berta die Nährlösung verlassen hätte. Der Fortgang legt jedoch eine mögliche Interpretation nahe:

»Weiter!« Das war Berta. Sie gab mir einen rohen, derben Stoß. Ich kippte nach vorn. »Zieh den Kopf ein, Mensch!«

Schon waren die schweren Stiefelschritte nah.

»Spring!« fauchte Alda. (WB, 997f.)

Hier wird erzählt, als seien Berta und Alda in der selben Situation. Angesichts der oben dargelegten Überlegungen zur Identität der Frauenfiguren Anna, Alda und Berta sowie der Deters-Instanzen Deters, Deters II, dem >Dritten $<$ und Cordes ist die ineinander verzahnte Schilderung der Ereignisse nur folgerichtig. Die Figuren sind eben gleichzeitig identisch miteinander und nicht identisch. Die Zeiten sind auf phantastische Art miteinander verknüpft, sodass die Ereignisse nicht nur gleichzeitig ablaufen, sondern auch auf dieselbe Art wie die Figurenidentität ineinander übergehen. Die drei Epiloge, die verschiedene Ausgänge bieten, zeigen jedoch auch, dass das Fest verschiedene mögliche Ereignisse neben- und miteinander schildert.

Neben den nicht gekennzeichneten Ebenenwechseln finden sich weitere Techniken, die systematisch die Verwirrung des Lesers betreiben bzw. Hilfen zur Kohärenzherstellung andeuten, dann aber gerade nicht bereitstellen. Kennzeichnend sind sie für die ATG-Diskussionen sowie vor allem für die Gespräche zwischen Alda und Deters II. Auf der ersten Ebene ist es Deters, der als Neuankömmling viele Zusammenhänge und Andeutungen in den Gesprächen der vermeintlichen Gruppenmitglieder nicht versteht. `Natürlich $\measuredangle$ ist dies allerdings nur, wenn er in der Diegese als Neuankömmling betrachtet und von seiner gleichzeitigen Einordnung als Erfinder der gesamten Gespräche abgesehen wird. Typisch für seine Rolle des Unwissenden ist die kurze Nachfrage »Bitte? «, die Unverständnis andeutet und die Bitte nach Erläuterung impliziert. Dadurch böte Deters sich als eine Identifikationsfigur für den Leser an, der sich ebenfalls in der dargestellten Welt (noch) nicht auskennt, aber verstehen und die Regeln und Zusammenhänge dieser Welt erkennen will. Umberto Eco hat gerade diese Technik genutzt, um im historischen Roman Il nome della rosa (1980, Der $\mathrm{Na}$ me der Rose) geschichtliches Detailwissen, das dem heutigen Leser normalerweise nicht bekannt ist, zu vermitteln. Die Erzählerfigur Adson von Melk nimmt als junger Mönch, der noch nicht über das nötige Überblickswissen verfügt, diese Rolle ein: "Alles begreiflich machen durch einen, der nichts begreift. ${ }^{26}$ Bei Deters wird genau diese Rolle angedeutet, dann jedoch nicht erfüllt. Seine eben erwähnten Nachfragen werden übergangen, eine Erläuterung bleibt aus (vgl. bspw. $W B, 717$ ). An anderen Stellen wird er wegen seines Nichtverstehens und Unwissens sogar als ungebildet 
geradezu beschimpft. In einem Gespräch mit Murnau, als Deters wieder einmal nach der Identität der ATG-Mitglieder fragt, deutet Murnau die Verbindung der Geister mit bestimmten Pflanzenarten, vor allem den Kartoffeln, an. Ihre Identität als Geister oder Elben bleibt weiterhin unausgesprochen, sodass Deters weiterhin nicht folgen kann. Er nutzt jedoch die Chance, um weitere Fragen zu stellen:

"Und die Egel?»

»Das Gegenstück halt! Die Sekrete. - O weh!« Er schlug sich mit der Handfläche vor die Stirn.

"Und wer ist die Frau?

»Thor! So dumm kann keiner sein! - Das ist doch nicht möglich!« $(W B, 647)$

Eine Erläuterung folgt nicht mehr, vielmehr findet wieder ein Wechsel statt, Murnau ist verschwunden und das Gespräch abrupt beendet. Ähnlich verhält es sich bei den Gesprächen zwischen Alda und Deters II. Dieser hat die meiste Zeit eine andere Rolle als Deters. Er ist vor allem der Autor-Schöpfer der ersten Ebene und bestimmt, was dort passiert, welche Mythologien und intertextuellen Anspielungen er in den Text einbaut und welche Zusammenhänge er konstruiert. Dies erfolgt in zunehmendem Maß im Austausch mit Alda. Die metanarrativen Gespräche der beiden geben auch viele Hinweise für das Verständnis; diese Funktion wird jedoch auch wieder dadurch konterkariert, dass die Hinweise immer nur in Andeutungen erfolgen. Vielfach sind solche Andeutungen zudem so elliptisch, dass der Leser nur mit großer Mühe oder aber gar nicht folgen kann. Typisch ist dabei folgendes Gespräch:

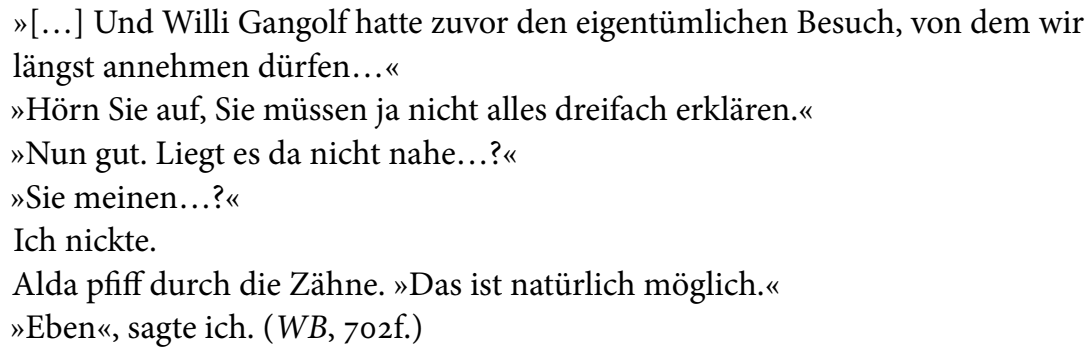

Während Deters II etwas genauer erläutern will, unterbricht ihn Alda sogar, wobei sie mit ihrer Aussage übertreibt. Auch bisherige `Erklärungen` waren nur Hinweise und auch hier folgen nur elliptische Andeutungen. Der Leser kann zwar Annahmen treffen und verschiedene Möglichkeiten durchspielen, bleibt jedoch immer im Ungewissen, ob diese auch wirklich zutreffen. Doch auch Deters II ist nicht nur der sallwissende Autor, der dem Leser lediglich Informationen vorenthält. Er ähnelt Deters darin, dass auch er Zusammenhänge seiner eigenen Geschichte nicht versteht. Noch einmal kann hier auf Eco zurückgegriffen werden, der das Schaffen einer fiktionalen Welt als einen Vorgang beschreibt, bei dem der Autor durch einige Entscheidungen Regeln über diese Welt aufstellt, die dann aus sich heraus andere Regeln ergeben. ${ }^{27}$ Damit ist der Autor mit Vorgaben aus seiner erschaffenen Welt konfrontiert. Die Zusammenhänge der erzählten Welt erhalten einen scheinbar autonomen Charakter. Bei Deters II wird diese wohl für literarische Welten allgemeingültige Annahme veranschaulicht und übertrieben. Er steht seiner eigenen Schöpfung als Interpret gegenüber, der selbst 
nur Vermutungen und Annahmen über die Zusammenhänge anstellen kann. Einmal äußert Deters II folgende Vermutung gegenüber Alda:

Der Grund für diese ja sehr plötzliche Hellsichtigkeit, besonders Karlebachs, ist nicht recht zu bestimmen«, sagte ich erklärend. »Womöglich hängt's mit dem Kontakt zu Bertrecht zusammen. Denn am Montag abend [sic!] hatte der Pferdeschwanz die ATG-Leute ja noch keineswegs sehen können. [sic! $]^{28}$ (WB, 606)

Diese Passage stellt die Zusammenhänge als ambivalent dar. Einerseits präsentiert er sich als wissend, da er seine Äußerung als >erklärend bezeichnet. Andererseits könnte er den dargelegten Zusammenhang auch als Tatsache und nicht als Vermutung präsentieren. Dass jedoch lediglich eine Vermutung ausgesprochen wird, deutet darauf hin, dass stringente Schlüssigkeit gar nicht gewollt ist, dass seine Konstruktion der Zusammenhänge gar nicht so kohärent ist, wie der Leser durch seine Vorannahmen erwartet. ${ }^{29}$

\subsubsection{Formen von Realitäts- und Wirklichkeitsverständnis}

Es wird klar, dass durch die beschriebenen Techniken dem Leser unmöglich gemacht wird, die Zusammenhänge der Konstruktion vollständig zu entwirren. Selbst die beteiligten Figuren, die dazu beitragen, die Zusammenhänge überhaupt erst zu konstruieren, sind nicht in der Lage, sie vollständig zu verstehen. An ihnen wird also bereits in Teilen der Lektürevorgang des Lesers und der darauf folgende Versuch der Kohärenzherstellung vorweggenommen und ihre Unmöglichkeit dargestellt. Es hat also nichts damit zu tun, dass der Leser noch aufmerksamer sein müsste, seine Lektüre noch genauer, um sämtliche Zusammenhänge herzustellen. Er kann damit den Text nicht herkömmlich erschließen, es ist eher so, dass »der Text vielmehr seinen Leser beherrscht « $^{30}$. Auch wenn Scherer in diesem Zusammenhang einen »Eindruck des Beliebigen ${ }^{31}$ moniert, implizieren diese Techniken doch ein bestimmtes Realitätsverständnis.

\section{Wirklichkeitswahrnehmungen}

Die Darstellung aller Wirklichkeitsebenen als fiktive zusammen mit der absichtlichen Verwirrung des Lesers beim Versuch, zu differenzieren und eine reale Ebene auszumachen, zeugt vom Verständnis, alle Wirklichkeitserkenntnis sei fiktiv und unzuverlässig, ein Erkennen von Realität, das Feststellen, was wahr und was falsch ist, sei nicht möglich. Deters schließt in seiner Rede vor dem Thing an ein solches Verständnis an. Er schildert den Geistern die Form der Wirklichkeitswahrnehmung

28 Es fehlen hier die schließenden Anführungszeichen, was in WB mehrfach vorkommt. Entweder ist dies ein bloßer Flüchtigkeitsfehler oder aber es deutet an, dass das Folgende wieder Teil der gerade mündlich erzählten Geschichte ist.

29 Vgl. auch WB, 695, wo Deters II Alda ganz unverblümt sagt, dass er »[k]eine Ahnung « habe, wie ein bestimmter Handlungsstrang weitergehe und nicht einmal daran gedacht habe.

30 Scherer: »Die Metamorphosen des Wolpertingers«, 172.

31 Ebd., 171. 
der Menschen und führt dadurch die vorher in metafiktionaler Konstruktion eher abstrakt bleibende Vorstellung auf real grundierte, $d$. h. auch für die Leserwirklichkeit geltende Überlegungen zurück. Auf diese Passage ist oben bereits in Bezug auf Deters' Bezeichnung als Lauscher und Husar eingegangen worden. Er versucht, den Geistern die Denkweise der Menschen zu erklären. Dabei gibt er implizit Hinweise auch auf das Denken und das Wesen der Geister, was an dieser Stelle jedoch weniger relevant ist. Ausgangspunkt seiner Ausführungen ist der Umgang mit der Geschichte. Da er lediglich seine Eltern und höchstens seine Großeltern erlebt hat, seine Erinnerung also schon zeitlich durch seine kurze Lebensspanne eingeschränkt ist, ist er bei der Vergegenwärtigung der vornehmlich auch fremden Vergangenheit auf "nichts als [s] eine Fantasie« $(W B, 823)$ angewiesen. ${ }^{32}$ Er geht in seinen Erklärungen jedoch über die Fiktionalität des nicht selbst Erlebten hinaus.

Wenn ich einen beliebigen Gegenstand vor mich stelle, eine Tasse etwa, so habe ich, anders als ihr, keine Erinnerung an die, die sie formten. Will ich wissen, wie es zur Tasse kam, muß ich mir ausdenken, wie es zu ihr gekommen sein könnte. Das nennen die Meinen Wissenschaft. [...] Denn wir müssen, um sie zu erfassen, die Dinge erfinden. (WB, 823)

Das Schlüsselwort ist in allen Fällen `Erinnerung`. Dass selbst die eigene Erinnerung nicht ausreicht, eine wirkliche Vorstellung zu bekommen oder besser zu behalten, verdeutlicht sein Beispiel über körperliche Schmerzen:

[A]nders als Ihr kann ich mich stoßen, mir wehtun, mich verletzen, kann verkrüppeln, aber wenn der Schmerz vergangen ist, vergesse ich es wieder, und wenn ich ein Krüppel bin und ich das wissen will, muß ich es abermals denken. $(W B, 824)$

Alles, was er wahrnimmt, muss also gedacht werden. Damit ist auch das, »was Realität ist für mich, gedacht« (ebd.). Der Mensch vergisst sehr viel und ist daher auf die Ergänzung seiner Erinnerung durch denkende Erfindung angewiesen. ${ }^{33}$ Mit diesen Ausführungen vertritt Deters eine konstruktivistische Weltsicht. Mit seiner Selbstbeschreibung »als der, der nur weiß, daß er ist, weil er denkt« (ebd.) geht er gar auf Descartes' berühmtes, konstruktivistisch deutbares Diktum zurück. Deters selbst verwendet nicht den Begriff Fiktion oder verwandte Begriffe; er spricht vor allem vom Erfinden. Doch von der Erfundenheit ist es nicht weit zur Fiktion. Zwar kann Erfundenheit nicht mehr als Kriterium für Fiktion angeführt werden, doch bleibt sie weiterhin ein prominentes Indiz. In älteren Fiktionstheorien wurde zwischen Erfundenheit und Fiktion nicht unterschieden. ${ }^{34}$ Unter Verwendung des Fiktions-

32 Deters' Ausführungen in der Thing-Rede erinnern an die durch den Historiker Hayden White angestoßene Debatte um die Entstellung von Fakten als Fiktionalisierung in der narrativen Historiographie, vgl. Zipfel: Fiktion, Fiktivität, Fiktionalität, 172-179.

33 Die Erinnerung spielt eine wichtige Rolle in der Kontinuitätsfrage der individuellen Identitätskonstruktion. Vgl. dazu Marion Gymnich: »Individuelle Identität und Erinnerung aus Sicht von Identitätstheorie und Gedächtnisforschung sowie als Gegenstand literarischer Inszenierung «, in: Astrid Erll / Marion Gymnich / Ansgar Nünning (Hg.): Literatur - Erinnerung - Identität. Theoriekonzeptionen und Fallstudien, Trier 2003, 29-48, v. a. 33-39.

34 Vgl. Bunia: Faltungen, 136-140. Es gibt fiktionale Literatur ohne oder mit wenig Erfindung wie bei Rainald Goetz' Abfall für alle oder bei Alexander Kluge. Auch ohne ausgefallene Beispiele zu 
begriffs ist Deters' Ansicht von der stets 'gedachten Realität ‘ daher zugespitzt als Gleichsetzung von Realität und Fiktion zu sehen. Mit Peter Blume (im Anschluss an Gottfried Gabriel) kann diese Position als Panfiktionalismus bezeichnet werden. Für den Panfiktionalismus gilt dabei folgende Grundthese:

Da Wirklichkeit für den Menschen stets nur als wahrgenommene und damit durch den Wahrnehmungsapparat konstruierte Wirklichkeit existiert, lassen sich alle Perzepte und damit auch alle Wirklichkeitsmodelle des Menschen in gewisser Hinsicht als Fiktionen betrachten[.] ${ }^{35}$

Dass diese Position inzwischen als widerlegt betrachtet wird, ${ }^{36}$ spielt an dieser Stelle keine Rolle. Blumes Definition fasst ziemlich genau zusammen, was als eine fundamentale Position in WB festgestellt werden kann. Sie bildet die Grundlage ebenso für die Parallelsetzung von Autor und Schöpfer-Gott, auf die später noch einmal eingegangen wird, wie für das Erfinden der eigenen Geschichte, das in $V G$ an zentraler Stelle stand und in $W B$ bei Deters weiterhin zu finden ist. Keine der in $W B$ präsentierten Formen des Verständnisses von Wirklichkeit ist jedoch mit dem Panfiktionalismus gleichzusetzen. Es scheinen immer wieder andere Vorstellungen durch, die dieser Position widersprechen.

\section{Die `Agnes-Realität` und Imaginationen als positiver Gegensatz}

Weit vor der Thing-Rede deutet Deters II im Anschluss an VG eine realistische Position an: die Vorstellung einer tatsächlich auszumachenden, einer unhintergehbaren Realität. Wie in $V G$ ist es die Freundin Agnes, die für diese Realität steht. Wie dort ist sie auch in $W B$ die Mutter, die an die drängenden Bedürfnisse ihres Kindes gebunden ist, an »Lebensnotwendigkeiten « $(W B, 411)$ und »Sachzwang « $(W B, 532)$. Dadurch wird sie als »real " gesehen, als eine Person, deren tatsächliche Existenz seltsamerweise nicht hinterfragt wird (vgl. WB, 352, 330). Auf den ersten Blick ist es seltsam, dennoch besteht eine Parallele, wenn festgestellt wird, der »vom Hof durch die gekippten Fenster hereinwehende Abgasgeruch garantierte Realität« $(W B, 352)$. Auch hier ist es eine letztlich körperliche Konsequenz, die einen Bezug zur Realität herstellt. Körperlichkeit kann jedoch nicht als Anzeichen von Realität gewertet werden. Denn auch in den Imaginationen werden körperliche Reize geschildert, was sich vor allem in der Schilderung des Festes und der Primizien zeigt. Eine wahre Realität wird schließlich auch angenommen, wenn Deters aus seinen Imaginationen erwacht und sich dessen

bemühen gilt dies, wenn man bedenkt, dass sich in jeder Fiktion Nicht-Erfundenes und Erfundenes in unterschiedlichem Maße mischen; dabei ist an das sogenannte Napoleon-Problem zu denken, das Vorkommen einer auf den historischen Napoleon referierenden Figur.

35 Peter Blume: Fiktion und Weltwissen. Der Beitrag nichtfiktionaler Konzepte zur Sinnkonstitution fiktionaler Erzählliteratur, Berlin 2004, 12.

36 Blume führt zwei Gegenargumente aus (vgl. ebd., 12-16) und Jannidis fasst die Gegenargumentation (ohne den Begriff Panfiktionalismus zu erwähnen) prägnant zusammen: »Die Konstruktion von `Realität unterliegt anderen Einschränkungen und gehorcht anderen Anschlußgesetzen als das, was wir herkömmlich als >Fiktion • bezeichnen. Nicht zuletzt ist die Konstruktion der gesellschaftlichen Wirklichkeit ein kollektiver Prozeß, dessen Freiheitsgrade auch von biologischen und physikalischen Gegebenheiten bestimmt werden.« (Jannidis: Figur und Person, 66 FN 117). 
bewusst wird. Diese Bewusstseinsphasen nehmen jedoch ab und werden zudem durch die beschriebenen Verfahren infrage gestellt.

Im Gegensatz zu dieser tatsächlichen Realität stehen die Imaginationen von Deters und Deters II. Durch die Gegensätzlichkeit sind die Imaginationen ambivalent konnotiert, teils werden sie negativ gesehen, vor allem wenn sie als Wahngebilde erscheinen, teils werden sie als positiv gesehen. Die positive Konnotation erfolgt vor allem durch die Geister, die für das phantasierende Erfinden stehen. Durch die Sympathielenkung des Lesers, die die Geister zumeist als positiv darstellt (wenn sie nicht gerade ihre böse Seite herauskehren), wird gleichzeitig auch die Imagination positiv konnotiert. Während das (alltägliche) Erfinden der wahren Wirklichkeit durch Erinnern in Deters' Äußerungen in seiner Thing-Rede eher negativ wirkt, da er als Mensch sich als defizitär gegenüber den Geistern darstellt und zudem eine quasi demütige Haltung ihnen gegenüber einnimmt, um ihre Gunst zu gewinnen, ist der gleiche Vorgang im Kontext der Geistergespräche naturgemäß ein positiver. Einerseits sind die Geister ein Produkt dieser Imagination (sei es die von Deters, die von Deters II oder aber die von Daniello, der sie programmiert), andererseits wird das Phantasieren als ein Charakteristikum, als konstituierende Eigenschaft von ihnen dargestellt. Im Anschluss an Überlegungen zu Benn und der Romantik spricht Lipom beispielsweise von dem »Versuch, die Imagination vor der Wirklichkeit zu bewahren« $(W B, 100) .{ }^{37}$ Die Wirklichkeit wird hier als etwas geradezu Feindliches dargestellt, das es abzuwehren gilt. Durch den Gegensatz erhält die Imagination eine positive Konnotation und wird zudem als wichtiger als die Wirklichkeit bestimmt.

Bei einem weiteren Gespräch über die bereits aus $V G$ bekannte Thematik der Bewältigung von Vergangenheit, die man selbst nicht erlebt hat (für die man aber dennoch Verantwortung verspürt), bezieht Deters eine Position, die für die Fiktion eintritt. Er wirft die Frage auf, wie man etwas verarbeiten könne, »das man nur vom Hörensagen, aus Büchern und Filmen kennt « $(W B, 450)$. Unter der Voraussetzung, eine solche Aneignung von geschichtlichem Wissen als Fiktion zu sehen, stellt er die These auf: »Um eine Fiktion zu verarbeiten, muß ich sie erst ... begehen. (ebd.) Deters will also die eigentlich nicht selbst erlebten Ereignisse imaginieren und konstruieren, um sie in der Phantasie zu erleben. Entscheidend ist aber vor allem Murnaus Reaktion. Er ist ganz verzückt von diesen Eingaben und kommentiert sie dahingehend, dass Deters gelernt habe, zur Einsicht finde, »er fängt mitzuspielen an « $(W B, 450)$. Murnau wählt den Begriff des Spiels, es geht jedoch an Ernsthaftigkeit darüber hinaus. Die konstruierende Imagination ist die Wirklichkeitssicht der Geister. Wie sie sie ausüben, wird in verschiedenen Szenen beschrieben, am deutlichsten wohl im Gedankenausflug von Lipom, Murnau und Deters in Winkelmanns Schänke, wo sie eine Orgie unter den Bewohnern auslösen. Zudem wird die reigentliche Wirklichkeit desavouiert, so beispielsweise in einer Formulierung Annas, Claudia Weigan täte Deters nicht gut, »sie würde [ihn] nur an das Gestell Wirklichkeit schnallen « $(W B, 537)$. In diesem Zusammenhang wird immer nur der undefinierte Begriff `Wirklichkeit ‘ benutzt. Es deutet jedoch alles darauf hin, dass weniger eine objektive Realität als Feindbild ge-

37 Scherer sieht in der Folge den ganzen Roman als einen solchen Versuch, vgl. Scherer: »Die Metamorphosen des Wolpertingers«, 179. 
meint ist als die alltägliche oder naive Vorstellung des Menschen, eine solche objektive Realität zu erkennen.

\section{Die metafiktionale Bestätigung der Erfindungen}

Im Zusammenhang mit dieser positiven Bewertung der Imaginationen muss das Spiel mit Vorstellungen von Wirklichkeit gesehen werden, das sich im Kontext der metafiktionalen Konstruktion zeigt. Der metafiktionale Aufbau des Buches müsste an sich noch keine Auswirkungen auf die bei den Figuren vorhandenen Vorstellungen von Wirklichkeit haben. In WB ist jedoch kennzeichnend, dass eben dies passiert. Die Metafiktionalität selbst wird als konstituierend angenommen. Die Vorstellung, Phantasie beeinflusse und werde die Wirklichkeit, wird für allgemeingültig genommen und in ihren Konsequenzen durchgespielt. Die Fiktionen erhalten dadurch einen quasi autonomen Status. Sie sind nicht mehr gänzlich von ihrem Schöpfer abhängig, sondern können auch für diesen Konsequenzen haben bzw. weiß er selbst oftmals nicht wirklich Bescheid.

Dieser Aspekt zeigt sich an verschiedenen Stellen. In den Gesprächen zwischen Alda und Deters II findet sich teils eine eigentlich absurde Logik. Der Zusammenhang der Erzählung, in die sie selbst verstrickt sind, wird nicht über die Darstellung dieser Zusammenhänge hergestellt, sondern über ihre eigenen Fiktionen. Wie bereits dargelegt, bleibt die Art der Erfüllung der Bedingung im Elbenpaarstreit im Dunklen. Auch den beiden Koautoren sind die Zusammenhänge diesbezüglich nicht mehr klar:

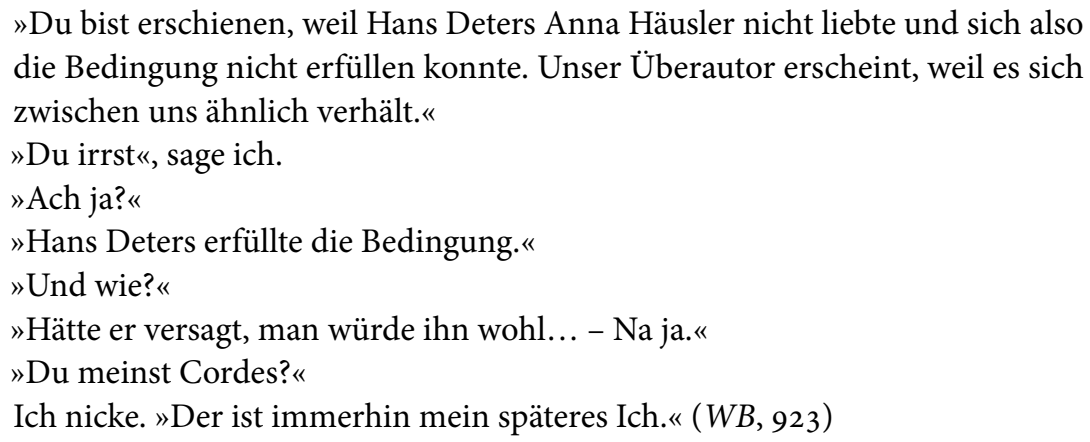

Zwar präsentiert sich Deters II als wissend, erklärt die Bedingungserfüllung jedoch nicht. Ex negativo wird aus dem Vorhandensein einer von ihm erfundenen Figur geschlussfolgert, dass die Bedingung erfüllt ist. In anderen Fällen werden scheinbare Fakten präsentiert, die auf ihrer Ebene als real dargestellt werden. Im Nachhinein bestätigen sie Ausgedachtes, das vorher als solches markiert war, als wahr. Wieder aus einem Gespräch zwischen Deters II und Alda:

»Warum haben Sie mir verschwiegen, daß Sie eine Hüon sind?»

»Warum haben Sie den Freiherrn Hüon genannt? $(W B, 570)$

Der Freiherr von der ersten Ebene ist durch die Erzählsituation als Erfindung von Deters II markiert. Dass Alda den selben Namen hat, verbindet die Ebenen auf eine nicht bestimmbare, aber selbst den Autor verwirrende Weise. Ähnlich ist seine Bemerkung, als Alda ihm eines der Beutelchen zeigt: »Da fantasier' ich die ganze Zeit von so 'nem Ding, und Sie verschweigen mir, daß Sie eins haben?!« (WB, 656, vgl. auch 566) Auch 
auf der ersten Ebene ist der gleiche Mechanismus zu finden, wenn Deters die Frau, der er seit Bremen gefolgt ist, für sich Anna nennt und dann mitbekommt, dass sie wirklich Anna heißt, wodurch »seine Erfindung Bestätigung erfuhr» $(W B, 65)$.

Es kann jedoch auch eine teils gegenteilige Reaktion erfolgen. Als Deters II sein erfundenes späteres Ich trifft, bemerkt dieser, »das meiste dessen sei falsch, was ich mir ausgedacht hätte über ihn« $(W B, 717)$. Hier wird an verschiedene Diskurse angeschlossen. Einerseits wird durch die Metalepse eine realistische Weltsicht unterwandert, andererseits erfährt eben dadurch die Erfindung der Figur Bestätigung. Jedoch gerade dieser Mechanismus, der in den eben genannten Beispielen sich als ein häufiger findet, wird hier wieder selbst gebrochen. Denn es zeigt sich, dass der Autor/Schöpfer nicht Herr über seine eigenen Erfindungen ist, sie teilweise autonom sind. Er erfindet sie zwar, aber er stößt die Schöpfung gleichsam nur an, sie hat ihre eigene Wahrheit oder Wirklichkeit, die ihm nicht vollständig bekannt ist (bzw. einen Meta-Autor erfordert). Es gilt hier gerade nicht, was Eco an seinen eigenen Erfahrungen mit Il nome della rosa verdeutlicht:

Doch als ich Jorge in die Bibliothek setzte, wußte ich noch nicht, daß er der Mörder war. Er hat das Ganze sozusagen auf eigene Faust getan. Und man halte das nicht für einen `Idealismus` wie die Behauptung, Romanpersonen hätten ein Eigenleben und der Autor lasse sich, wie in Trance, ihr Handeln von ihnen eingeben. Dummheiten für Abituraufsatzthemen. Nein, die Personen sind gezwungen, nach den Gesetzen der Welt zu handeln, in der sie leben. Anders gesagt, der Erzähler ist der Gefangene seiner eigenen Prämissen. ${ }^{38}$

Nun behauptet nicht der Autor Herbst hier das Gegenteil, vielmehr wird in WB genau mit der Idee gespielt, was wäre, wenn die Figuren ein Eigenleben hätten bzw. nicht gezwungen seien, sich an die intratextuellen Weltgesetze zu halten. Natürlich kann von einer Meta-Ebene aus behauptet werden, sie hielten sich an die Gesetze der geschaffenen Welt, nur stimmten diese Gesetze nicht mit denen einer konventionellen Geschichte überein. Dies bringt jedoch keinen größeren Mehrwert, da solche vermeintlichen Gesetze nur schwer unter einen regelmäßigen Nenner zu bringen wären.

\section{Krankheit- bzw. Wahndiskurs}

Die positive Konnotation der Geister wird (neben der Darstellung ihrer bösen Seite) durch eine weitere Lesart hinterfragt. Was schon in $V G$ durch Hinweise auf einen Klinikaufenthalt nach dem Selbstmordversuch des `Autor--Erzählers als Möglichkeit aufgeworfen wurde, findet sich in Andeutungen auch in WB: die Erklärung der Imaginationen als halluzinatorische Wahnzustände mit pathologischem Charakter. Ein erster Hinweis kann gleich im ersten Absatz des Prologs entdeckt werden. Die Geister hätten nach der Durchsetzung der Dominanz der Technologie »in den Fragen der Psychologie« $(W B, 17)$ zu sich gefunden. Herbst hat diese Lesart im Interview bestärkt, wenn er sagt: "[S]ämtliche Geschehnisse und Wahrnehmungen in meinen Büchern lassen sich zugleich als geistespathologische Phänomene lesen, ja mitunter 
sogar als psychologische Fallstudien. « $^{39}$ Doch auch der Konstruktion des Romans entsprechend, mit seinen metanarrativen Kommentaren in konstituierender Funktion, wird die Lesart im Text selbst immer wieder aufgebracht und thematisiert.

Zunächst geschieht dies tatsächlich in Bezug auf VG. Als Deters von seinen früheren (in $V G$ geschilderten) Erlebnissen berichtet, spricht er davon, dass er nicht wusste, »ob es nur Wahnbild war « $(W B, 314)$. Er spricht von »Halluzination « und »Depression« und hat wegen dieser immer »ein Röhrchen Lexotanil« $(W B, 328)$ dabei, ein Psychopharmakon. Die Verbindung mit den Ereignissen um Agnes insinuiert eine >reale ‘ Grundierung der Imaginationen als Halluzinationen, so wie auch Agnes (wie bereits erwähnt) eine auf gewisse Weise unhinterfragt reale Konnotation hat.

Die ambivalente Deutbarkeit seiner Imaginationen als Wahnbild oder kreative Schöpfung geht auch in WB weiter. Deters ist abgesehen vom Hotelpersonal allein im Hotel Wolpertinger und zunächst scheint klar, dass er sich die Geschehnisse mit den Geistern nur ausdenkt. Er tut dies, um »seine Isolierung aufzulockern« und meint, bis zum dritten Tag habe er »Wirklichkeit und Fantasma trennen können« (WB, 888). Zum Zeitpunkt der Äußerung erwacht er jedoch nicht mehr aus seinen Träumereien und niemand weckt ihn mehr daraus. Der Hinweis auf sein Alleinsein und die Imaginationen ist bislang lediglich als metafiktionales Signal und Erinnerung an die Fiktionalität der Teilebene beschrieben worden. Seine Entwicklung wird jedoch auch anders charakterisiert:

Immer wieder erwacht er aus seinen Imaginationen, kommt zu sich, - aber indes er im Feld seiner Fiktionen allmählich kräftiger und selbstbewußter wird, schwächt sich seine Konstitution in der Realität, hier also, im Wolpertinger. Er liefert sich zusehends seinen Geistern aus, wird schweigsamer zugleich, gegenüber der Rezeptionsfrau, gegenüber dem Portier. Es käme ihm nicht mehr in den Sinn, seine Erfindungen an der, will ich einmal sagen, Natur zu prüfen. Er verliert den Kontakt. Man könnte sagen, er werde allmählich wahnsinnig. $(W B, 651)$

Auch hier ist also die Ambivalenz zu verzeichnen. Das kreative Potenzial der Imaginationen ist erkauft durch den Verlust des Kontaktes zur Realität. Relativiert wird die hier nur vermeintlich festzustellende Realität und damit auch der gesamte Krankheitsdiskurs jedoch durch die zweite Ebene.

Weiter fortgeschritten in der erzählerischen Spirale ist der >Dritte`, der bei der >Dritten Ankunft‘ von seinem Treffen mit Deters II berichtet. Er übernimmt die Aufzeichnungen, damit dessen Identität und dadurch das damit zusammenhängende Anliegen, sich seine eigene Geschichte zu erfinden. Das sei für ihn zu einem realen Problem geworden, »dem kein innerer Zwang korrespondiert«; für Deters II sei dies jedoch ein "neurotisches, allenfalls psychotisches Problem gewesen « $(W B, 562)$. Die Figuren sind bereits in den Erzählschlaufen gefangen, die oben wenn nicht zu entwirren, so doch zu erklären versucht wurden. Dennoch wird der Anschein von Anschluss an eine realistische Grundierung versucht, indem auch hier auf Krankheitsbezeichnungen zurückgegriffen wird. Angespielt wird ebenfalls auf die aus VG

39 Faure: »)Jetzt hab ich Metall im Mund««, 13. 
bekannte Vorgeschichte und ein weiteres Mal wird sie nicht phantastisch, sondern realistisch gedeutet.

Doch dem allgemeinen Kreislauf der Verunsicherungen entsprechend wird auch der Krankheitsdiskurs zusätzlich in die phantastische Welt verwoben. Im Grunde wird nie richtig geklärt bzw. ist sogar unter ihren Mitgliedern strittig, um was für eine Gesellschaft es sich bei der ATG handelt, was ihre Ziele sind und was sie eigentlich macht. Eine der Andeutungen über ihre Tätigkeiten abseits der Diskussionen stammt von Bertrecht, der zunächst (als Mensch) nur teilnehmender Gast ist. Er bemerkt Deters gegenüber, die ATG kaufe Menschen, es müssten "aber kranke Menschen sein " $(W B, 245)$. Der Kaufvorgang wird nicht näher erläutert, spätere Ereignisse lassen aber vermuten, dass es sich weniger um ein Kaufen mit Geld handelt, sondern um das Hineinziehen der Menschen in ihren Kreis. Dies erfolgt bei Bertrecht selbst und gleichzeitig auch bei Polst. Auch Deters ist ein Kandidat, dem jedoch die Entscheidung selbst zugestanden wird und der diese lange Zeit nicht trifft. Bertrecht und Deters sowie gewissermaßen auch Weigan werden jedoch als Menschen dargestellt, die in den Bann der Geister gezogen werden. Neben dem Personal des Hotels, die aber nicht als Mitglieder der ATG gehandelt werden, sind es nur diese drei, die die Geister $\mathrm{zu}$ sehen vermögen. Zusammen spekulieren sie über Gemeinsamkeiten, die ihre Wahrnehmungen möglich machen. In diesen Zusammenhang gehört auch der Grund, warum der Agent Baumwolle Deters ausgewählt hat, sich unter die Geister zu mischen und für ihn zu spionieren. Seine Fähigkeit, "sich Zusammenhänge zu erschwindeln" sei »schon pathologisch» $(W B, 68)$. Die Andeutungen ergeben den Zusammenhang, dass die >Betroffenen ‘ die Fähigkeit zum kreativen Spiel mit dem Erfinden besitzen, dass sie also Phantasie besitzen. Dies entspricht auch den Anleihen an die keltische Mythologie, in der die Elben besonders Dichtern erscheinen und diese in ihre Welt hineinziehen. Die Krankheit ist damit wieder doppelt besetzt. Durch die Bezeichnung als Krankheit oder damit zusammenhängende Begriffe wie Wahnbild, Halluzination oder Depression sind sie als Abweichung vom Normalen und Gesunden als defizitär negativ konnotiert; durch die Sichtweise als Fähigkeit oder besondere Disposition zu kreativer Imagination erhalten sie eine positive Konnotation.

Die Psychologin Claudia Weigan sieht darin das Interessante an der ATG und ihren Einflüssen und verwissenschaftlicht den Krankheitsdiskurs. Die Zusammenhänge zu untersuchen, ist der Grund, warum sie immer wieder zu den Treffen kommt. Der wissenschaftlich geprägte Zugang ist vermutlich der Grund für ihre Konflikte mit Anna, die wie oben dargestellt gerade nicht rational-analytisch, sondern körperlich-instinktgesteuert handelt. Deters wendet sich wegen seiner Vermutung, dass es sich um krankhafte Halluzinationen handelt, selbst an Weigan als Expertin. Sie relativiert jedoch die Krankheitsdiagnose und versucht, das Phänomen relativ neutral als psychologisches zu beschreiben und dadurch zu entschlüsseln. Ein Krankheitssymptom wären die Erscheinungen nur, wenn Deters sie nicht als solche mitteilen könnte; da er jedoch mit Bertrecht und ihr darüber reden könne, wäre es etwas anderes (vgl. $W B, 380$ ). Durch die vergleichenden Erzählungen der drei, findet sie zu mehreren Begriffen, um mit dem Phänomen zusammenhängende Aspekte zu beschreiben. Weigan konstatiert eindeutig, dass es die Geistergesellschaft nicht gebe, Lipom, Murnau 
und Anna seien lediglich »Intersubjektivismen « (ebd.), d. h. intersubjektive Erscheinungen zwischen Bertrecht, Deters und ihr. Sie seien jeweils auf etwas andere Art >betroffen<, die Wahrnehmungen seien jedoch teils identisch. Sie selbst seien in einem »Kollektivwahn« befangene »reinste[] psychische[] Kippfiguren« $(W B, 459)$, da sie während ihrer gemeinsamen Halluzinationen gleichzeitig an verschiedenen Orten seien. Damit findet sie jedoch eindeutig zu klinischer Sprache und der Erkenntnis, das es sich um eine Krankheit handeln müsse (vgl. WB, 469), die zudem ansteckend sei (vgl. WB, 380,460$)$.

An dieser Stelle sei schon einmal darauf verwiesen, dass der Krankheitsdiskurs in $T A$ wiederaufgenommen wird. In ähnlicher Weise, wie in $W B$ die Ereignisse aus $V G$ eher realistisch gedeutet werden und als pathologische Halluzinationen bezeichnet werden, so wird in TA vornehmlich darauf hingewiesen, dass Deters (bei dem nicht mehr zwischen den verschiedenen Identitäten differenziert wird) nach den Ereignissen in Hannoversch Münden längere Zeit in einer Klinik verbracht hat und immer wieder >Flashbacks` erlebt. Zunächst wird also auch hier eine realistische Lesart stark gemacht; erst die immer wiederkehrende Diskette stellt den Bezug auf die phantastischen Aspekte von $W B$ wieder eindeutig her.

\subsection{Virtualität}

Die Virtualität der Wirklichkeit rückt als Thema in den Fokus durch die Aufdeckung des Hotels Wolpertinger als Bio-Computer. Im Keller befindet sich ein Computerraum, von dem aus Daniello die Geschehnisse steuert. Die Geister sind nach dieser Lesart lediglich von ihm konstruierte Programme, die nach seinen informatischen Vorgaben handeln. Technisierung und Computer werden in Herbsts Werk erst in $W B$ thematisiert, ${ }^{40}$ in $V G$ war das Thema noch gar nicht vorhanden. Anzumerken ist, dass es sich in $W B$ zwar lediglich um eine mögliche Lesart der ersten Ebene handelt, doch sind Computer und damit zusammenhängend auch Film und Fernsehen durch einige Erwähnungen und Anspielungen auffallend präsent. Doch erst in TA rückt das Thema prominent in den Vordergrund.

Im Wesentlichen lassen sich zwei Aspekte des Themas ausmachen, die sich ungefähr den oben dargestellten Positionen Lipoms und Murnau zuordnen lassen. Entsprechend sind sie ineinander verwoben und lassen sich nicht gänzlich differenzieren. Die Schöpfung der Geister durch Daniello als Programmierer betont die schöpferische (poietische) Seite der Technik und ist damit der Mythosposition von Lipom zuzuordnen. Die Nähe von programmierter Schöpfung zur poetischen Fiktion wird herausgestellt. Die zunehmend sich vollziehende Technisierung und Computerisierung der modernen Welt kommt Murnaus Logos-Position entgegen.

40 Allerdings wird der »Konflikt zwischen Geist und Maschine« sowie die die Rolle des Computers in der Entstehung von Literatur (»Der Computer wird Partner und Miturheber des Werkes.«) schon in der Zeitschrift Dschungelblätter thematisiert, vgl. Alban Nikolai Herbst (Hg.): Dschungelblätter. 3/7 (Floréal 1986/87), besonders Abschnitte II und VI. 


\subsubsection{Programmierung als Fiktion}

Die Auffassung, Computern (die pars pro toto für das gesamte Phänomen von Programmierung und Virtualität stehen) ein poetisches Potenzial zuzusprechen, verblüfft zunächst. Mehr oder weniger ist dies metaphorisch aufzufassen. Es lassen sich jedoch zwischen der Programmierung virtueller Welten und poetischer Fiktion Verbindungen sehen. Fiktion kann dadurch definiert werden, dass sie eigenständige Welten schafft. ${ }^{41}$ Gleiches gilt auch für die Programmierfähigkeiten Daniellos. Er gibt, soweit aus dem Text zu erschließen ist, bestimmte Vorgaben und Regeln, nach denen die Welt rund um das Wolpertinger-Hotel funktioniert. In diese Welt schreibt er die Geisterfiguren als selbst handlungsfähige Programme, die im Rahmen der Vorgaben in der Manier ausgereifter künstlicher Intelligenz eigene Gedanken entwickeln und Entscheidungen treffen, jedoch immer abhängig von ihrem Schöpfer ${ }^{42}$ und seinen Eingaben und Begrenzungen bleiben. Dies entspricht der oben mit Verweis auf Eco angesprochenen Auffassung der Funktionsweise des literarischen schöpferischen Prozesses. Die in WB beschriebene Schaffung virtueller Welten, die auch einen nicht geklärten Einfluss auf als real angenommene Menschen wie Deters hat und als BioComputer eine Verbindung von Technik und lebendigem Material bildet, geht über die Möglichkeiten der Computertechnik der aktualen Welt hinaus (sei es zum Veröffentlichungszeitpunkt 1993 oder auch heute). Doch im Prinzip ist die Analogie zwischen literarischer fiktionaler Welt und einer programmierten virtual reality auch in Bezug auf die eingeschränkten tatsächlichen Möglichkeiten bereits gegeben.

In Bezug auf diese Zusammenhänge ist der Computer der Mythos-Position Lipom zuzuschlagen, insofern diese für die poietische Schöpfung steht. Diese Zuordnung findet sich angedeutet auch im Text, erfolgt jedoch nicht über den prinzipiell technikfeindlichen Lipom selbst, sondern durch Deters. Während einer der Diskussionen spekuliert er, der Computer sei vielleicht »eine Erscheinung der Poesie« und zwar "[w] egen der Fiktion« $(W B, 341)$. Er spricht damit erstmals gerade im Gegensatz zur vernunftfreundlichen und daraus abgeleitet technikfreundlichen Murnau-Position die mögliche schöpferische Dimension von Technik an. Durch den zusätzlichen Kommentar wird die Parallele zur Welten schaffenden Fiktion angedeutet. Im hinterhergesetzten Kommentar, dem aber niemand aus der Runde Beachtung schenkt - »Vielleicht kommen im Computer Mythologie und Technik zueinander« (ebd.) erfolgt die `Zuordnung zu Lipoms Position. Mythologie ist hier im Sinne der obigen Ausführungen als Oberbegriff für die schöpferische Imagination des Menschen zu verstehen. Herbst hat den Zusammenhang zwischen Computern und Fiktion bzw. Literatur im Interview noch einmal hervorgehoben, wenn er die »Kompilationsfähigkeit von Großrechnern« und den «desinformierenden Geheimdienst für echt literarisch « 43 hält.

41 Vgl. Bunia: Faltungen, 84.

42 Die Parallelisierung von Daniello als Schöpfer/Gott und als Autor ist oben betont worden, vgl. Abschnitt 3.4 auf Seite 164.

43 Faure: »Jetzt hab ich Metall im Mund««, 13. Der Geheimdienst tritt in dieser Funktion durch den Agenten Baumwolle in Erscheinung. 


\subsubsection{Programmierung als Manipulation des Menschen}

Die Rolle des Computers reiht sich in Murnaus Position nahtlos in seine Überlegungen ein. An dieser Stelle wird die mechanisch rechnende Seite des Computers betont. Murnau favorisiert die Wissenschaft und lehnt die Natur (im Menschen) ab, möchte sie vernichten. Daher tritt er für eine Technisierung der Welt und eine Mechanisierung des Menschen ein. Er will die Triebe in den Menschen unterdrücken bzw. durch technischen Schein befriedigen, sie programmieren und ihre Gedanken kontrollieren durch »Computerisierung « (WB, 387, vgl. auch 398). Die einzige Möglichkeit, die Welt »moralisch zu gestalten« sieht er in der «totale[n] Automatisierung « $(W B, 385)$.

Die immer wieder durchscheinende Ambivalenz der entgegengesetzten Prinzipien findet sich auch im Computer-Zusammenhang. Eigentlich lehnt Murnau Daniello und seinen Computer ab, ${ }^{44}$ bringt jedoch Sympathien für ihn auf, wenn er Parallelen zu seinen eigenen Zielen erkennt:

In einem gewissen Sinn könnte ich mich für die Annahme erwärmen, was Daniello veranstaltet, komme dem glückhaften Zustand bereits nah, in den die Maschinen uns eines Tages versetzen werden. $(W B, 398)$

Sowohl werden bei Daniello beide Aspekte angedeutet, der schöpferische wie der des dem Natürlichen entgegengesetzten Scheins, als auch bei Murnau das Entgegenkommen gegenüber Daniellos Machenschaften.

Murnau ist es auch (im Zusammenspiel mit Deters), der den Computer bzw. die Technik als neuen Zufluchtsort der Elben vorschlägt: »Der Computer doch, Husar, der Computer! Ich haben den Einschlupf gefunden!« $(W B, 732)$ In dieser Hinsicht kann er seine Herkunft nicht verleugnen oder unterdrücken, er ist noch mehr Geist als Mensch. In der Folge soll Deters die programmierten Geister auf einer Diskette in einen Zentralcomputer in Frankfurt einschleusen, was er zumindest durch Raub der Diskette vorbereitet (die dann in TA wieder vorkommt und in Argo motivlich abgeschlossen wird). Wie oben dargestellt, kommt dies jedoch eher Lipoms Position zugute, da die phantasiebegabten Geister in der Welt bleiben sollen und nicht vermenschlicht bzw. rationalisiert und mechanisiert werden, wie Murnau es vorhat, sondern als phantastischer Störfaktor gerade die technische Welt des Menschen wieder etwas entrationalisieren wollen.

Durch Murnaus Ausführungen zum technischen Schein als »Glücksmanipulation « $(W B, 388)$ wird der Computer mehrfach auch mit Fernsehen, Film und Video in Verbindung gebracht. Murnau stellt die Entwicklung vom Kino, über Fernsehen zum Computer als eine lineare Entwicklung in Richtung der totalen Simulation dar (vgl. WB, 928), die er jedoch entgegen möglicher anzunehmender negativer Konnotation begrüßt. Herbst folgt dieser realen technischen Entwicklung, indem er diese Themen zunehmend in seine Texte einbaut. Im Prolog wird viel mit Fernsehund Filmreferenzen gearbeitet. Dem Ich-Erzähler des Prologs wird die Elbenwelt auf

44 Hüon als Abgesandter des >Dunklen`, der wie oben dargestellt in gewissem Sinn der MurnauPosition zuzuordnen ist, versucht, Daniellos Computer zu zerstören. 
einem Bildschirm gezeigt, worauf er dahingehend reagiert, es als Computerspiel zu betrachten und die Elben abschießt. Zudem werden die Bilder, die er sieht wie ein Film präsentiert, sogar mit Filmterminologie wie »SCHNITT«, »TOTALE« oder »CLOSE $\mathrm{UP}$ « $(W B, 28 \mathrm{f}$.), und als » Montage [...] fantastischer Filme, der Sechziger, der Siebziger, auch einiger neuerer Produktionen « $(W B, 31)$, unter anderem Dracula-Filmen.

Während der Computer und das Virtualitätsthema in WB noch keine zentrale Rolle spielt und mehr als weiteres Beispiel im Kontext der zentralen Themen zu sehen ist, tritt es in TA in den Mittelpunkt des Geschehens. Mag dies einerseits der Verortung in einer zukünftigen Welt und den Anleihen an das Genre Science-Fiction zuzuschreiben sein, kann die zunehmende Bedeutung des Themas für Herbst andererseits vielleicht gerade der Grund für die Platzierung in der Zukunft sein. Bereits jetzt sei darauf hingewiesen, dass das Thema vor allem Anschluss in Bezug auf die sogenannten Holomorfen findet. Während in WB der Bio-Computer nur kurz angesprochen, aber nicht näher erläutert wird, wird die Vorstellung einer »Holomorfie«-Technologie in TA genau geschildert, die nicht nur die in der Anderswelt alltäglichen Holomorfen als künstliche Menschen hervorbringt, sondern auch die Illusion von städtischer Umgebung und Landschaft erzeugt. Außerdem stellt die Diskette, auf der sich die elbischen Mitglieder der ATG als Programme befinden und die Deters Daniello entwendet, die (abgesehen von Deters als Hauptfigur) wesentliche Verbindung zwischen den Romanen dar. An einer Stelle wird sogar mit der Möglichkeit gespielt, die erst in $T A$ vorkommende Holomorfie als Erläuterung für $W B$ zu nutzen. Deters schaut die Diskette an und denkt: »Holomorfenstruktur [...]; sei so etwas abgespeichert auf dem Ding? Dergleichen hatte er ja immer geahnt, doch war es natürlich erleichternd, endlich ein Wort dafür gefunden zu haben.« $(T A, 244)$ Dass die Geister als Programme wirklich Holomorfen sind, ist damit jedoch nicht gesagt; aber der Anschluss zwischen den beiden Büchern wird in Bezug auf dieses Thema hergestellt und die Entwicklung deutlich.

\subsection{Alles ist konstruiert: Mythologie und Intertextualität}

Neben der metafiktionalen Komponente im Sinne der Anregung, über den Fiktionalitätsstatus der Erzählung und damit das Verhältnis von Fiktion und Realität nachzudenken, gibt es noch eine starke metanarrative Komponente. In diesem Abschnitt soll die Thematisierung der narrativen Konstruktion in den Gesprächen zwischen Alda und Deters II behandelt werden. Damit geht es um die Frage, wie die fiktive Welt aufgebaut ist und sowohl wie als auch dass im Text selbst über diesen Aufbau diskutiert wird. Zunächst wird also der fictio-Aspekt ${ }^{45}$ des Romans behandelt, der die Gemachtheit und Konstruiertheit ohne Bezug auf einen Wahrheitsstatus herausstellt. Auf ein bestimmtes Realitätsverständnis wird damit nur mittelbar Bezug genommen, doch hängen die Fragen nach dem Aufbau der fiktiven Welt schließlich auch mit Referenzen auf die aktuale Welt zusammen, die den Wahrheitsstatus wieder ins Spiel bringt.

45 Vgl. Wolf: Ästhetische Illusion und Illusionsdurchbrechung in der Erzählkunst, 38f., und Wolf: "Metafiktion", 430. 
Die Gespräche zwischen Alda und Deters II sind bereits mehrfach als metanarrativ bezeichnet worden, da sie sich vor allem um den Aufbau der Erzählung, seine Quellen und auch die Bedeutung drehen. Der Erzählvorgang selbst wird sowohl vorgeführt als auch explizit thematisiert. Mit Fludernik ${ }^{46}$ könnten die Gespräche der zweiten Ebene zudem genauer als metadiskursiv und/oder metakompositional bezeichnet werden, da sie sich vor allem um die Konstruktion der Erzählung und die Intentionen des Autors Deters II drehen. Da primär von der zweiten Ebene aus erzählt wird, wird durch die Thematisierung der Konstruktion deutlich, dass alle anderen Ebenen nicht nur fiktional, sondern auch nach bestimmten Vorbildern konstruiert sind. Da weiterhin die zweite Ebene im oben geschilderten bestimmten Identitätsverhältnis zur ersten Ebene steht, was vor allem die Figurenidentität und bestimmte Motive betrifft, ergibt sich im Rückschluss auch der Konstruktionscharakter der zweiten Ebene selbst. Die Strukturen, die die Handlung und zentrale Motive prägen, sind wie bei den Figurenidentitäten durch mythologische und intertextuelle Vorbilder vorgegeben. Durch die Gespräche wird der Konstruktionscharakter zwar immer wieder thematisiert und damit offengelegt, andererseits werden die Bezüge jedoch nur in geringem Umfang und dann auch nur in Anspielungen benannt. Der volle Umfang der Konstruktion ist daher wohl nur einem »kumulativen Erkenntnisprozeß « 47 vorbehalten, sei es durch Literaturwissenschaftler oder engagierte Leser.

Anfangs ersinnt Deters II die Geschichte der ersten Ebene im Zug und schreibt sie wohl auch auf. Als Alda hinzukommt, fängt er an, ihr die Geschichte zu erzählen und in Göttingen liest sie die bisherigen Aufzeichnungen. Von Anfang an kommentiert sie die Erzählung, entdeckt als Leserin die eingebauten Bezüge, sie diskutieren über die Erzählung. Vermehrt erzählt dann auch Alda und schließlich entdeckt sie sogar Bezüge, die Deters II nicht bewusst sind. Dies ist Teil des Ineinandergreifens der Ebenen der fiktiven wie realen Kommunikationssituation. Die Bezüge können zwar nicht von Deters II intendiert sein, sind jedoch vom Über-Autor eingebaut, sei dies der `Dritter, der sie nachträglich zusammen dann mit der Reaktion Aldas hineingeschrieben hat, oder aber Herbst als realer Autor. Immer wieder wird in den Diskussionen explizit der Begriff >Konstruktion` verwendet:

Übrigens versteckt sich hier eine völlig andere Schwierigkeit, eine, die meine Konstruktion anlangt. $(W B, 303)$

Meine Konstruktion mußte hermetisch werden. $(W B, 506)$

Es war nicht leicht, bei allem Trubel in der Konstruktion zu bleiben. (WB, 873)

Der fiktionstheoretischen Vorstellung von möglichen Welten folgend wird jede fiktional erzählte Welt konstruiert. ${ }^{48}$ Das kontinuierliche Thematisieren des Konstruktionscharakters und zusätzlich die Betonung des Drucks der Bildung einer kohärenten Komposition deutet jedoch auf einen besonderen Stellenwert in WB hin. Der Konstruktionscharakter wird eingebunden in die Erzählung selbst und von der Einhaltung

46 Vgl. Fludernik: »Metanarrative and Metafictional Commentary«, 23f. und 26.

47 Jannidis: Figur und Person, 136.

48 Vgl. bspw. Martinez/ Scheffel: Einführung in die Erzähltheorie, 124, und Umberto Eco: Lector in fabula. Die Mitarbeit der Interpretation in erzählenden Texten, München 1998, $166 \mathrm{ff}$. 
der Vorgaben hängt der Fortgang der Geschichte ab. Dies hängt mit dem Meta-Aufbau als Schleife zusammen, da Deters II und Alda als Autoren selbst nicht unabhängig agieren, sondern von anderen Instanzen abhängen und gelenkt werden. Nach Nünnings Typologie der Formen von Metanarration sind die Diskussionen zwar einerseits als isoliert in Bezug auf die erzählte Geschichte zu betrachten, da sich die Diskussion auf einem anderen Erzählniveau befindet, andererseits sind sie aber auch integriert, was eben durch das besondere Verhältnis der Erzählebenen zueinander begründet ist. ${ }^{49}$ Da Deters II und Alda wie bereits dargestellt vor allem durch die `Geschlechterkampf - Thematik mit den anderen Ebenen verbunden sind, ist nicht verwunderlich, dass dies auch das Verbindungsglied in Bezug auf die Konstruktion ist. Die eben zitierte Bemerkung von Deters II, seine Konstruktion müsse hermetisch werden, setzt er fort, er dürfe sich nicht verraten: "Nur so ließ sich die Balance austarieren im Zweikampf zwischen Anna und mir.« $(W B, 506)$ Der `Geschlechterkampf findet einen zentralen Kampfplatz im Zweikampf der Koautoren um die Dominanz in der Bestimmung des Fortgangs der Erzählung.

Egal von welcher Ebene aus betrachtet, ist der Roman eine große Konstruktionsleistung. Die Konstruktion besteht ja nicht nur im Aufbau einer oder mehrerer fiktiver Welten und der dazugehörigen Planung, sondern in der Zusammensetzung aus verschiedensten Versatzstücken, die im Einzelnen durch Ähnlichkeiten eine gewisse Art von Identität aufweisen und zwischen denen Verbindungen hergestellt werden können, wie sie Herbst in Bezug auf die verschiedenen Mythologien aufgefallen sind. Das Zusammenspiel der gesamten mythologischen wie intertextuellen Vorlagen erzeugt auch Konflikte, da die Identität teils nur eine vage ist, teils nicht tatsächlich besteht, sondern von Herbst an die Versatzstücke herangetragen ist. Diese Konflikte werden jedoch von Deters II im Text thematisiert und wenn er sie mit Alda bespricht, muss er teils zugeben, dass er keine Lösung für sie hat, dass er also teilweise auch nicht weiß, was sich aus der Konstruktion ergibt. Dies zeigt wieder die Veranschaulichung des Entstehungsprozesses literarischer Arbeit, da solche Konstruktionsschwierigkeiten normalerweise ausgeräumt werden, insofern sie dem Autor bewusst sind.

\subsection{1 »Ist das eine Anspielung oder ein Kalauer? «" ${ }^{50}$ Die Referenzfrage}

In der folgenden, genaueren Untersuchung der einzelnen Versatzstücke geht es um deren Herkunft, d. h. aus welchen Kontexten sie der Autor Herbst entnommen hat. Aus dem entgegengesetzten Blickpunkt, d. h. worauf sie verweisen, stellt sich die Frage nach ihrer Referenz. In den modernen Fiktionstheorien stellt die Frage nach der Bedeutung von Referenz eine wichtige Debatte dar. Die auf Gottfried Gabriel zurückgehende These der mangelnden Referenzialisierbarkeit versteht die Fiktionalität literarischer Werke »in dem Sinne, daß sie grundsätzlich keinen Anspruch auf unmittelbare Referenzialisierbarkeit, d.h. Verwurzelung in einem empirisch-wirklichen Geschehen erheben ${ }^{51}$. Im Gegensatz zur faktualen Darstellung wird danach also kein real existentes Geschehen mimetisch abgebildet, sondern ein erfundenes Ge-

49 Zur Terminologie vgl. Nünning: »On Metanarrative«, 26.

$50 W B, 309$.

51 Martinez / Scheffel: Einführung in die Erzähltheorie, 13. 
schehen ohne vordergründigen Bezug zur realen Welt erzählt. In dieser oder einer ähnlichen Formulierung können viele offenkundige Überschneidungen zwischen fiktiven und realen Welten jedoch nicht erklärt werden. Referenzfeindliche Positionen, vor allem in ihrer poststrukturalistischen Ausprägung, sind daher auch vielfach kritisiert worden. ${ }^{22}$ Selbst wenn bei einer fiktionalen Darstellung die Fiktivität des Erzählten angenommen wird, also die Darstellung von Sachverhalten ohne die direkte Entsprechung in der Wirklichkeit, so gilt doch immer, dass fiktive Welten in der einen oder anderen Weise auf die reale Welt bezogen sind. »Geschichten, die in keiner Relation zu unserer Wirklichkeitskonzeption stehen, könnten wir weder erzählen noch verstehen, wir können sie uns nicht einmal vorstellen. «33

Interessant in $W B$ ist nun, dass verschiedene Referenzformen eindeutig ausgemacht oder sogar als solche explizit benannt werden. Die Frage des Wirklichkeitsbezugs und anderer Formen von Referenzierung wird also direkt im Text aufgebracht. Im Folgenden sollen verschiedene Bezüge genauer dargestellt und eingeordnet werden. Dies gibt schließlich Aufschluss über das zugrunde liegende Realitätsverständnis.

\section{Referenzen auf Fiktion}

Die Referenzierung der fiktiven Objekte erfolgt auf verschiedene Bereiche. Zwar gibt es auch Verweise auf die aktuale Welt, jedoch nehmen solche auf andere fiktive Welten den größeren Anteil ein. Im Vordergrund stehen Bezüge auf mythologische Figuren sowie intertextuelle und intermediale Verweise. Das bedeutet zunächst, dass wenig von Personal, Schauplätzen und selbst von den Ereignissen wirklich original ist im Sinne von neuer Erfundenheit. Die Mythologiebezüge sind bereits im Zusammenhang mit den Identitätsfragen ausführlich dargestellt worden und auch die intertextuellen Bezüge kamen zur Sprache. Beispiele für letztere sollen jedoch noch einmal genau dargestellt werden, um die strukturelle Übernahme der Intertexte zu verdeutlichen. Danach erfolgt die Darstellung der Referenzen auf die aktuale Welt.

Schon die Makrostruktur ist durch Verweise geprägt. So beträgt die Dauer des Aufenthalts von Deters im Wolpertinger sieben Tage und entsprechend ist die Kapiteleinteilung der Zweiten Abteilung, die auf der ersten Ebene im Wolpertinger spielt, in sieben »Septoren « eingeteilt. Zwar gerät die Wahrnehmung der Zeit bei Deters durch den Eintritt in die andersartig geprägte Welt (sei es durch die Elben oder durch Daniellos Programmierung) durcheinander und er scheint nie genau zu wissen, welcher Tag gerade ist. Dennoch entsprechen die Abschnitte grob den jeweiligen Tagen des Aufenthalts. Bereits angesprochen wurde der Bezug des Begriffs 'Septoren auf die Einteilung der Romane Jean Pauls in `Sektoren . Weiterhin kann es auch als Verweis auf den siebenjährigen Sanatoriumsaufenthalt Hans Castorps in Thomas Manns Der Zauberberg gesehen werden. ${ }^{54}$ Im Text selbst wird jedoch vor allem auf die Konstruktion nach verschiedenen religiösen und mythischen Vorlagen verwiesen, vor allem aber auf die sieben Tage der Schöpfungsgeschichte. Deters II

52 Vgl. zu dieser Debatte Zipfel: Fiktion, Fiktivität, Fiktionalität, 50-56, und Bunia: Faltungen, $51 \mathrm{f}$.

53 Zipfel: Fiktion, Fiktivität, Fiktionalität, 82.

54 Scherer verweist darauf (Scherer: »Die Metamorphosen des Wolpertingers«, 190 FN 73) ebenso wie Kühlmann: »Postmoderne Phantasien«, 504. 
fragt Alda, was ihr zum zweiten Tag der Schöpfungsgeschichte einfällt und erläutert kurz seine diesbezüglichen Pläne (siehe $W B, 247$ ). Als er über den dritten Tag der Schöpfungsgeschichte nachdenkt, schlussfolgert er aufgrund der zugehörigen mythologischen Symbolik, dass Daniello nun vorkommen muss (vgl. WB, 507). Die gewählte makrostrukturelle Konstruktion gibt damit Vorgaben für den Ablauf des Geschehens.

Auch in kleineren Einheiten finden sich solche Vorlagen. So sind Teile des Wolpertinger-Geschehens nach der 6. Sinfonie (F-Dur, op. 68) von Ludwig van Beethoven gestaltet. Die Überschrift des vierten Kapitels des Zweiten Septors enthält dafür den deutlichsten Hinweis, da »dem Lauscher ein eigensames Andante molto mosso geschieht $(W B, 324)$. Das »Andante molto mosso« bezeichnet den 2. Satz der Sinfonie, die eine Szene am Bach wiedergibt, was auch im entsprechenden Kapitel geschieht. Ebenso wie bei Beethoven ruft mehrfach ein Kuckuck und andere Motive werden aufgenommen (vgl. WB, 336f.). Ohne Beethoven namentlich zu nennen, thematisieren Deters II und Alda den Bezug (zudem mit dem Hinweis auf die "Konstruktion", vgl. $W B$, 337). Auch weitere Satzbezeichnungen können als Vorlagen für Szenen in $W B$ identifiziert werden. Der erste Satz »Erwachen heiterer Gefühle bei der Ankunft auf dem Lande « korrespondiert mit den verschiedenen Ankünften in Hannoversch Münden und auch das "Lustige[] Zusammensein der Landleute« und »Gewitter und Sturm« aus dem dritten und vierten Satz werden als Ereignisse genutzt.

Neben ähnlichen Korrespondenzen und Verweisen auf Bram Stokers Dracula (vor allem im Prolog), wie bereits beschrieben auf die Geschichten von Oberon und Huon sowie die motivisch passend eingestreuten Zitationen von Benn-Gedichten, ist es vor allem der bereits erwähnte Faust-Bezug, an der der Umfang der Verwobenheit zwischen Wolpertinger-Handlung und Intertext dargestellt werden kann. ${ }^{55}$ Im Fall der Szene in Winkelmanns Schänke ist das gesamte Kapitel durch den Bezug zur Szene in "Auerbachs Keller in Leipzig " aus Goethes Faust I bestimmt. Dabei wird die Handlung in der prinzipiellen Struktur übernommen und lediglich an den Aufbau, die Zeit und die Handlung von $W B$ angepasst. Auch die Figurennamen der `Zeche lustiger Gesellen werden übernommen. Brander und Altmayer sind Teil der Lehrergruppe aus dem Wolpertinger, wobei die Herkunft der Namen sich erst jetzt eindeutig erschließt, da sie in dieser Szene die Hauptakteure der auch sonst größtenteils anwesenden Lehrer sind. Aus Siebel wird die Siebelwirtin, lediglich Frosch ist nicht zu finden. Das Besondere dieses intertextuellen Bezuges ist die fast vollständige Übernahme des Textes, der in die Szene eingebaut wird. $\mathrm{Zu}$ einem beträchtlichen Teil geschieht dies in vollständig übernommenen Phrasen. Größtenteils werden jedoch einzelne Worte in Sätze und Beschreibungen eingebaut. Dies erfolgt jedoch streng nach der in Faust zu findenden Reihenfolge. Das Kapitel in WB wird eingeleitet mit Lipoms Ausruf »Will keiner trinken? Keiner lachen?« $(W B, 587)$, der mit V. 2073 auch in Faust der vollständige erste Vers der Szene ist. Ebenso schließt das Kapitel mit einer Äußerung Lipoms "Nun sag' mir eins, man soll kein Wunder glauben!« $(W B, 635)$-, die den letzten Vers (2336) der Szene aus Faust wiederum vollständig zitiert. Dazwischen werden die Verse teils umgeformt, teils `aufgefüllt‘. Die zwei Verse von Mephistopheles - »Gib

55 Als ein weiterer Text ist das Gedicht »Lenore« von Gottfried August Bürger zu nennen, das im Prolog die Geschichte um Lenore Pomposiewitz strukturiert und ihr auch den Vornamen verleiht. 
nur erst Acht, die Bestialität / Wird sich gar herrlich offenbaren.« (V. 2297f.) - werden zu einem kleinen Absatz ausgebaut, der sich vor allem am Wort `Bestialität $`$ orientiert, das ins Positive gewendet Lipoms Prinzipien aufgreift:

»Geben Sie nur erst acht, Herr Husar«, sagte befriedigt Dr. Lipom. »Das ist Natur, Natur! Die herrlichste Bestialität, Pan, Dionysos, zeigt eure Hörner! Pukas herbei! Heran, ihr Gwyllions, Kelpies, Peggy Powler, kommt! Der Hof der Unseelie wird sich öffnen! Gar herrlich ist die Jagd, in der sich Geister offenbaren!« $(W B, 627)$

Alle Wörter der Verse sind vorhanden (lediglich die Anrede ist an das `Sie angepasst), doch sind Bezüge und Intention leicht verändert. Bezieht sich die Bestialität in Faust auf die Menschen, sind es hier die Geisterwesen, die ihre Bestialität ausleben (jedoch wohl in den Menschen). Außerdem bezieht sich das "herrlich" bei Mephistopheles in schadenfroher (böser) Weise auf die Offenlegung der wahren Natur des Menschen; Lipom freut sich jedoch an der positiven Tierhaftigkeit der Geisterwesen und der Natur, für die er als Prinzip steht. Die Unterscheidung ist nur eine feine, denn ein boshaftes Schadenfrohsein gegenüber den Menschen ist auch bei ihm vorhanden.

Auffällig sind die wenigen Abweichungen vom Goethe-Text. Lieder der Faust-Szene (das Rattenlied etc.) werden gänzlich nicht übernommen, sondern durch zeitgenössische Texte ersetzt. Dafür werden Lieder und Schlager der in den 1970er und 1980er Jahren sehr bekannten Liedermacher Wolf Biermann, Konstantin Wecker, Hannes Wader, Reinhard Mey und Cat Stevens sowie der Schlagersänger und Chansonniers Freddy Breck, Freddy Quinn, André Heller und Caterina Valente verwendet. Die Ersetzung begründet Deters II mit »Zeitkolorit« $(W B, 599)$, eine Übernahme auch der Lieder wäre allzu auffällig gewesen. Es soll durch zeitgenössische Anspielungen, die sich vor allem im Lied »Trotz alledem! « von Hannes Wader finden (»in den Sechzigern «, »Pop«, »SPD«; WB, 613f.), doch eine möglichst realistische Beschreibung einer zeitgenössischen Kneipenszene entstehen, wie auch durch den Versuch einer Verwendung von mündlicher Rede wie oft bei Herbst deutlich wird. Außerdem wird auch hier das Neben- und Ineinander von hoher Literatur (Goethe, außerdem wieder etliche Benn-Zitate) und volkstümlicher bzw. sogar trivialer Kultur praktiziert. Die markanteste Änderung im Goethe-Text auf Wortebene ist jedoch die Ersetzung von »Der Kerl ist vogelfrei!« (V. 2312) zu »Der Kerl ist ein Jude, ein Jude!« (WB, 629). Vorher ist bereits dieser Bürger als »deutschtümelnd[] $(W B, 625)$ dargestellt worden und in der Folge ruft er im orgiastischen Rausch zudem noch »Es lebe Deutschland! Heil Hitler!« (WB, 630). Hier wird das Motiv des latenten Nazismus im deutschen Bürgertum wieder aufgegriffen und dargestellt, dass es in einer entzügelten, rauschhaften Situation sofort wieder durchbricht.

Ebensowenig wie Faust als Intertext werden die Lieder und Schlager genau benannt. Die Bezüge werden jedoch in Anspielungen auf der 2. Ebene im Gespräch zwischen Deters II und Alda thematisiert. So fragt er immer wieder, ob sie die Szene bereits erkenne und - wie bereits erwähnt - begründet er die Ersetzung der Lieder damit, dass er sie so im Roman nicht bringen könne. Wie mit vielen weiteren beiläufig gebrachten Bezügen und Zitaten im Buch (im Gegensatz zu den meist von Benn stammenden 
Gedichtzitaten, die als solche zu erkennen sind, wobei auch Benn gleich eingangs genannt wird), wird hier in extremen Maß die intertextuelle Collage praktiziert. ${ }^{56}$

\section{Referenzen auf die aktuale Welt}

Es ist jedoch nicht alles aus bereits vorliegenden fiktionalen Elementen neu konstruiert und zusammengesetzt. In $W B$ finden sich auch verschiedene Elemente, die auf reale Gegebenheiten referieren. Die fiktiven Personen oder Ereignisse stehen dabei nicht direkt für die realen Entsprechungen, vielmehr werden diese verformt und in der Fiktion funktionalisiert. Es kann zwischen verschiedenen Formen von Referenzen unterschieden werden, zwischen mutmaßlichen Erlebnissen des Autors selbst, autofiktionalen Verweisen auf mit Herbst verbundene zeithistorische Personen und Ereignisse sowie Verweisen auf zeitgenössische Künstler (vor allem Schauspieler) in ihren typischen Rollen oder ihrer öffentlichen Erscheinung.

Autofiktion Autofiktionale Bezüge finden sich wesentlich geringfügiger und subtiler untergebracht als in VG; sie spielen also keine entscheidende Rolle. Eine direkte namentliche Anspielung auf Herbst findet sich nicht, ${ }^{57}$ doch gibt es einige Übereinstimmungen. Im Wesentlichen sind es anfangs aus $V G$ übernommene Übereinstimmungen zwischen Deters und Herbst wie die Herkunft aus Bremen und die Übersiedlung nach Frankfurt am Main, denen jedoch nur durch die Einbeziehung des Vorgängertextes und seiner Hinweise eine autofiktionale Komponente zugeschrieben werden kann. Dem heutigen Leser kann zudem eine kleine Übereinstimmung auffallen, die jedoch keinerlei Auswirkungen hat. Der Brief von Dr. Gustav Grote, dem Vater von Klaus von Hüon, der diesem als Säugling beigelegt ist und in der ATG-Runde von Lipom vorgelesen wird, ist mit der Orts- und Datumsangabe »Bremen, 7. Februar 1955 (WB, 263) gekennzeichnet. Dabei handelt es sich um Alban Nikolai Herbsts eigenes Geburtsdatum, wenn auch nicht den Geburtsort. ${ }^{58}$ Daraus ergeben sich jedoch keinerlei Anschlüsse. Von Hüon ist wohl kaum als ein Alter ego von Herbst zu sehen und auch sonst lassen sich keine sinnvollen Verbindungen beispielsweise von inhaltlichen Aussagen oder der Sympathielenkung zwischen den beiden herstellen.

Der wesentliche Hinweis auf die autofiktionale Verarbeitung eigener Erlebnisse findet sich als metanarrative Reflexion. Deters II reflektiert über die »reale Grundierung « $(W B, 507)$ einiger Schilderungen, angestoßen durch das Nachdenken über die erzählerische Einordnung der Terroristengruppe um Karl Polst und den Dichter Bertrecht. Die Bemerkung des örtlichen Bürgermeisters »Nicht einmal die Amerikaner haben unsere Brücke sprengen können« (WB, 435f.), die Polst dann auf die Idee

56 Auch mehrere Gedichte von Erich Fried und eins von Friederike Roth werden ohne namentlichen Nachweis zitiert, in diesen Fällen jedoch mit der Zielsetzung, diese lächerlich zu machen, wie aus dem Kontext deutlich wird, vgl. WB, 302, 406.

57 Die diesbezüglichen Überlegungen von Scherer halte ich für überinterpretiert, für eine intentionale Platzierung finden sich keinerlei Hinweise. Vgl. Scherer: „Die Metamorphosen des Wolpertingers", 181.

58 Das ist Refrath, vgl. Scherer: »Alban Nikolai Herbst [KLG]«, und Munzinger Online: »Herbst, Alban Nikolai«, Stand: 3. April 2012, Personen - Internationales Biographisches Archiv, URL: http://www.munzinger.de/document/00000023007. 
bringt, diese Brücke wirklich zu sprengen, bezeichnet Deters II als authentisch, als wirklich erlebte Äußerung des Bürgermeisters. Hier vermischen sich wieder einmal die Ebenen, doch diesmal nicht nur innerhalb des Textes, sondern der gesamten Kommunikationssituation (also unter Einbeziehung des realen Autors). Der Satz »In Wahrheit hatte ich selbst die unsägliche Rede des Bürgermeisters gehört." $(W B, 506)$ ist im Text Deters II zuzuschreiben, was sich aus dem weiteren Kontext (Bezüge auf Alda, Agnes und Göttingen, wo sich Deters II gerade befindet) ergibt. Es gibt jedoch Anzeichen dafür, diese Passage gleichzeitig auch Herbst selbst als realem Autor zuzuschreiben. Beschrieben wird ein Empfang und ein Hotelaufenthalt. Verschiedene real bzw. historisch existierende Namen werden genannt, die der Schriftstellerin Angela Hoffmann und der Schriftsteller Asmus Petersen und Detlef (»Dele«) Michelers sowie (Hugo) Dittberner. Als zeitliche Angabe wird das Jahr 1976 genannt. Ausgesprochen wird es nicht, aber es scheint sich um ein Schriftstellertreffen bzw. eine Preisverleihung, Lesung oder ähnliche literarische Veranstaltung zu handeln. Der Empfang und die Erlebnisse während des Hotelaufenthalts geben die Inspiration für verschiedene Szenen und Konstellationen im Text. Die Nennung der Namen deutet auf die Schilderung einer tatsächlichen Entstehung erster Ideen, Skizzen oder Entwürfe für WB hin. Herbst spielt hier mit zwei Phänomenen. Zum einen schafft er Authentizität in zwar eher nebensächlichen Handlungssträngen, aber gerade in einem, der als einer der wenigen politisch ist (neben der Handlung um die Terroristen). Mehrfach werden den Mündener Bürgern nationalistische, teils nazistische Positionen zugeschrieben und gerade eine davon wird durch den Hinweis auf die historische Realität untermauert und als nicht fiktiv dargestellt, was die Konnotation von Wahrheit mit sich bringt. Diese als real markierte Schilderung ist in einem Roman keineswegs automatisch verifiziert, doch entscheidend ist hier die Textstrategie, die auf den Hinweis auf Authentizität abzielt. Zum anderen wird der Leser auf eine weitere Art desillusioniert, indem ein menschliches Vorbild für Lipom geschildert wird, das Hotel Wolpertinger ein mögliches reales Vorbild erhält und auch die Konstellation Deters, Anna und Hüon beschrieben wird. Auch hier kommt es nicht auf die Verifizierung der historischen Tatsachen an, sondern auf die Textstrategie, die schon durch die Beschreibung deutlich wird. Insofern wäre die Nennung der realen Namen nicht `nötig‘, durch sie wird jedoch der reale Schriftsteller und die historische Realität in die Imagination des Lesers einbezogen. Herbst erwähnt das Treffen dann später tatsächlich im Blog als sein erstes Treffen im Verband Deutscher Schriftsteller und bezeichnet es explizit als "Quelle des Wolpertingers « $\$ 9$.

Reale Orte und Schauspieler Neben den autofiktionalen Bezügen auf den realen Autor Herbst finden sich weitere Referenzen auf die (historische) aktuale Welt. Diese sind sehr vielfältig und können nur exemplarisch angesprochen werden. Zum einen sind dies die Orte wie die Zugstrecke von Bremen über Hannover nach Göttingen, dann die Stadt Göttingen sowie der Ort Hannoversch-Münden. Die Beschreibungen der Orte beziehen sich dabei einerseits auf die realen Lokalitäten, andererseits sind fiktive Elemente hinzugefügt. Das Hotel Wolpertinger basiert zwar wohl auf einer 
realen Vorlage ${ }^{60}$ ist jedoch eindeutig als fiktiv anzusehen. Weitere Bezüge fallen bei den Figuren ins Auge. Ähnlich wie oben beschrieben bei den Elben der Bezug zu den mythologischen Vorbildern vor allem über den Namen hergestellt wird, werden einige Nebenfiguren durch den Namen als Referenzen auf historische Personen gekennzeichnet. Diese fallen schon im Personenverzeichnis auf, da es sich ausschließlich um bekannte Persönlichkeiten aus dem zeitgenössischen Theater- und Filmgeschäft handelt: die Schauspieler Klaus Maria Brandauer, Klaus Kinski, Gudrun Landgrebe, Bernhard Minetti, Hanna Schygulla und der Regisseur Claus Peymann führen das Theaterstück auf der zweiten Ebene auf (vgl. WB, 772 ff.). Diese sprechen sich auch gegenseitig mit diesen Namen an, sodass angenommen werden kann, sie verwiesen tatsächlich auf die realen Personen. Es handelt sich damit um nicht erfundene fiktive Figuren. ${ }^{61}$ Anders verhält es sich mit dem Namen Depardieu, mit dem der Portier des Wolpertingers bezeichnet wird. Zwar handelt es sich um einen Hinweis auf den französischen Schauspieler Gerard Depardieu, die fiktive Figur steht jedoch nicht wirklich für ihn. Der Name dient vielmehr lediglich dazu, die Figur zu beschreiben, unter Verzicht auf eine ausführliche Beschreibung eine bildliche Vorstellung im Leser zu erzeugen. Dies zeigt sich an der Verballhornung des Namens als »Deppi« sowie an der Variation mit dem Namen »Lundgren" (WB, 518, 541 u. ö.), einer Anspielung auf den schwedischen Action-Darsteller Dolph Lundgren.

Die Figur Armin, Kritiker Eine Nebenfigur der Ersten Abteilung (der Zugfahrt) ist der Kritiker Armin. Bei dieser Figur handelt es sich um eine zwar erfundene Figur, die jedoch durch eine Referenz zur aktualen Welt gekennzeichnet ist. Der Mann, der sich als Kritiker vorstellt, wird eingeführt als ein sich unhöflich gegenüber seinen Mitreisenden gebärdender Mensch und er wird in satirisch überzeichnendem Gestus beschrieben, was zusammenfassend in der Formulierung »[k]leines bissiges Nagetier « $(W B, 53)$ gipfelt. Nach einem kalauerigen Gespräch über Literatur, in dem er sich der ihm gegenübersitzenden Frau Pomposiewitz gegenüber arrogant gibt, bekommt er noch einen unerklärlichen Wutanfall. Auf dem Weg zur Zugtoilette trifft er auf Anna Häusler, die er zu kennen scheint und der er sich auf karikatureske Weise anbiedert. Gänzlich bloßgestellt wird die Figur durch die später folgende Beschreibung seines Toilettenaufenthalts. In Kontrastsetzung von dreckigem Ort und sogenannt niederen Körperfunktionen zu vorgeblichem Feingeist wird beschrieben, wie er dort das Buch für eine Rezension liest. In einer Mischung aus Kalauer, manierierter Schreibweise - durchsetzt mit philosophischen Ausdrücken und Verweisen - und Fäkalsprache wird die arrogante, aber letztlich ihrem Anspruch nicht gerecht werdende Haltung des Kritikers und zudem insgesamt das Rezensieren von Büchern vorgeführt und lächerlich gemacht. Der Kritiker wird als jemand entlarvt, der das Buch, über das er schreibt, nicht versteht und nicht würdigt oder respektiert, und es dennoch verreißt. Schon die Beschreibung ist als offensichtliche Abrechnung mit dem Umgang der

6o Vgl. URL-11, 20. Jan. 2006, sowie URL-8, 23. Mai 2009.

61 Zudem kommt es zu einer weiteren Vermischung der Ebenen, wenn neben der nach der realen Schauspielerin benannten Figur Gudrun Landgrebe auch das Wort »flambiert« $(W B, 776)$ verwendet wird, womit auf einen ihrer bekanntesten Filme, Die flambierte Frau (1983), angespielt wird. 
Zeitungen mit Autoren und ihren Büchern zu sehen. Die namentliche Bezeichnung ebenso wie die Zuordnung des Kritikers zur FAZ stellen einen autofiktionalen Bezug her, insofern mit hoher Wahrscheinlichkeit ein Erlebnis des realen Autors Herbst verarbeitet wird. Die erste wirklich schlechte Kritik, die Herbst erhalten hat, stammt von Armin Ayren und war ein in der FAZ veröffentlichter Totalverriss von VG. ${ }^{62}$ Die persönliche Verletzung, die daraus resultierte, kommt immer wieder im Weblog zur Sprache. ${ }^{63}$ Es ist also anzunehmen, dass es sich hier um eine "subversive Bestrafung " $(W B, 54)$ des Kritikers handelt. Die Referenz wird dabei wieder über den Namen hergestellt.

Die Figur Rascher Während der Nachname der Figur Klaus von Hüon wie bereits beschrieben auf die mittelalterliche Dichtung Huon de Bordeaux zurückgeht, hat seine Parallelfigur Alfred Rascher verschiedene Bezüge zur historischen Realität. Im Personenverzeichnis wird dieser beschrieben als »ein Kühnen, den der Roman unbedingt braucht, um nicht mißverstanden zu werden « $(W B, 12)$. Durch diesen Hinweis wird der Bezug zu Michael Kühnen (1955-1991) aufgemacht, einer führenden Gestalt der deutschen Neonazi-Szene der 1970er und 1980er Jahre. Leichter nachzuverfolgen ist der Bezug durch eine Beschreibung Raschers, der am Revers das Signum ANS trägt (vgl. WB, 712), der >Aktionsfront Nationaler Sozialisten«, die 1977 von Kühnen gegründet wurde. Der Name Alfred Rascher selbst hat einen allerdings recht indirekten Bezug zur NS-Thematik, worauf Patorski/Moosbach hinweist; Rascher sei ein Zürcher Buchhändler gewesen, der während der Querelen um das Erscheinen von Walter Matthias Diggelmanns Roman Die Hinterlassenschaft (1965) diesem vorwarf, Mitglied der Waffen-SS gewesen zu sein. ${ }^{64}$ Der Zusatz zur Beschreibung im Personenverzeichnis deutet vermutlich auf die satirische Überzeichnung der Figur Rascher hin. Herbst hat im Interview auf politische Reaktionen auf WB verwiesen, die er wohl schon im Voraus erwartet hatte:

Daß jemand es wagt, vom Nationalsozialismus okkupierte Figurationen wieder aufzugreifen, hat natürlich besonders bei der Linken zu Gesichtszuckungen geführt. Und die Konservative, geschweige Rechte, mußte besonders auf Dis$\operatorname{tanz} .^{65}$

Mit den vom Nationalsozialismus okkupierten Figurationen sind die >nordischen Mythen gemeint. Die überdeutlich lächerliche Charakterisierung der Rascher-Figur deutet darauf hin, dass es sich beim befürchteten `Mißverständnis` um den NaziVorwurf handelt.

Die Figur Baumwolle Diese durch mehrere Beispiele veranschaulichte Art von Inspiration, die durch reale Personen, Ereignisse oder Gegenstände ebenso - oder sogar gleichzeitig - wie durch fiktionale hervorgerufen wird, wird in der fiktiven Welt des

62 Vgl. Ayren: »Die Verwirrung der Grammatik«.

63 Vgl. URL-12, 30. März 2007, und URL-13, 28. Okt. 2006.

64 Siehe Moosbach: »Das Ribbentrop-Rhizom«, 52 FN 218.

65 Faure: »)Jetzt hab ich Metall im Mund ««, 13. 
Textes auch im Kleinen veranschaulicht (ebenso wie der reale Erzählakt mehrfach gespiegelt wird). Die Zugfahrt wird immer wieder durch metanarrative Kommentare und metafiktionale Erinnerungen daran unterbrochen, dass Deters sich zumindest Teile der Geschehnisse imaginiert. Kurz nach dem Gespräch mit dem Agenten Jeremias Baumwolle sitzt Deters wieder in seinem Abteil und starrt auf das Schildchen, das in den Kragen des Mantels geheftet ist, der ihm auf den Schenkeln liegt. Mehrfach wird das Schildchen mit dem Text »Pure Cotton « und einer Umrandung abgebildet $(W B, 73,79,82,85,108)$. Einerseits kann nun festgehalten werden, dass der Agent mit dem Namen Baumwolle »aus dem Stoffschildchen 'pure cotton`seines [d. i. Deters'] Wollmantels auferstanden ${ }^{66}$ ist; die Inspiration für eine Figur bzw. den Namen einer Figur wird als eine zufällige, auf die unmittelbare Umgebung zurückzuführende aufgezeigt. Andererseits ist die Nennung der englischen Übersetzung von Baumwolle ein deutlicher Hinweis, im deutschen Namen den englischen Jerry Cotton zu erkennen - der Name der bekannten Figur aus den Serienromanen gleichen Titels. Jeremias Baumwolle war sogar der ursprüngliche Name der Figur, den sein Erfinder Delfried Kaufmann zunächst als Parodie auf Agentenfiguren geplant hatte. ${ }^{67}$

Dieses recht simple Beispiel veranschaulicht noch einmal in kompakter Weise die Verbindung von realen Inspirationen oder Bezügen mit intertextuellen (oder eben fiktionalen). Beim Umgang mit den Referenzen wird dabei kein deutlicher Unterschied zwischen Fiktion und Realität gemacht. Der Verweis auf die reale Person Karin Anselm bezieht sich - da die Figur eine Kommissarin ist - auf deren Fernsehrolle als Tatort-Kommissarin; daneben steht gleichwertig der Verweis auf die reale politische Person Michael Kühnen; die originäre Figur Deters kommt ebenso vor wie die rentliehene< Figur Leo Brosamer ${ }^{68}$. Für Herbst sind die Figuren irreal und real zugleich, weil sie damit »vollständig unserer Wirklichkeit ${ }^{69}$ entsprechen, in der die Wirkung von literarischen und Fernsehfiguren neben der von realen Personen besteht.

Dies führt im Grunde genommen wieder - wie oben ausgeführt - zu einer Einordnung der in $W B$ teils vertretenen Position als Panfiktionalismus, da sich Peter Blume bei der Definition des Begriffs auch auf die Referenzialisierung bezieht: »[E]ine Abgrenzung fiktionaler Texte von nichtfiktionalen aufgrund eines angenommenen unterschiedlichen Wirklichkeitsbezugs ist daher nicht haltbar. "70 $^{70}$ Herbst unterscheidet wie gesehen nicht im Wirklichkeitsbezug, er geht sogar noch darüber hinaus und behandelt Bezüge zur Wirklichkeit in gleicher Weise wie Bezüge auf fiktive Welten (und vice versa). Auch wenn es Herbst nicht um die Abgrenzung fiktionaler Texte von nicht fiktionalen geht (seine Texte sind eindeutig als fiktional markiert), so ist die Unterscheidung der diesbezüglichen Positionen, die Blume vornimmt, doch

66 Scherer: »Die Metamorphosen des Wolpertingers«, 179.

67 Vgl. dazu Jörg Weigand: »Jerry Cotton - endlich enttarnt«, in: Die Welt, 6. Mai 1998. Den Hinweis darauf verdanke ich Jannidis: Figur und Person, 247.

68 Die aus dem Roman Die verborgenen Gärten (1982) von Martin R. Dean stammt, wie auch angemerkt wird, vgl. $W B, 10$.

69 Faure: ») Jetzt hab ich Metall im Mund««, 13.

70 Blume: Fiktion und Weltwissen, 12. 
hilfreich, da in beiden Fällen Wahrheitsfragen berührt werden. Auf der einen Seite ist nämlich eine panfiktionalistische Position in WB zu finden: begrifflich wird die Wirklichkeit infrage gestellt, womit entweder eine objektive Realität oder aber die intersubjektiven Übereinstimmungen in der Wahrnehmung der Wirklichkeit gemeint ist. In der Erzählkonstruktion, die in der Andeutung eines infiniten Regresses in Form einer Schleife die Kommunikationssituation einer literarischen Produktion abbildet, wird die Fiktionalität aller Ebenen deutlich. Die Analogie zu einer entsprechenden Wahrnehmung der aktualen Welt bzw. zu einem entsprechenden Umgang mit ihr wird durch den Anschluss an $V G$ hergestellt. Deters ist als Synthese der Vorgängerfiguren weiterhin dabei, sich seine eigene Geschichte zu erfinden. Ausgehend davon, dass es keine objektive Realität oder Geschichte gibt, sondern nur die (kollektive) subjektive Wahrnehmung und Überlieferung, geht er davon aus, dass der Wahrheitsstatus einer Geschichte eben nicht anhand der Realität überprüfbar ist, sondern nur von der Wahrnehmung der Beteiligten abhängt. Auf der anderen Seite wird der panfiktionalistischen Position auch wieder widersprochen. Die sogenannte Agnes-Realität, die körperlich drängenden Notwendigkeiten, die anhand der Freundin Agnes mit ihrem Kind, das sie zu versorgen hat, exemplifiziert werden, und auch zusätzlich mit dem Verweis auf lebensbedrohlichen Hunger und andere existenzielle Situationen untermauert wird, ist der Hinweis auf eine objektive, nicht hintergehbare Realität. In Bezug auf Blumes Einteilung sprechen diese Hinweise für die Annahme eines Kompositionalismus. Dieser besagt, dass fiktionale Texte Mischungen aus "fiktionalen und nichtfiktionalen Elementen ${ }^{71}$ seien. Diese auf John Searle zurückgehende und auch bei Eco zu findende Position, bezieht sich wieder zunächst auf die Unterscheidung fiktionaler und nichtfiktionaler Texte. Sie geht damit aber von einer Unterscheidung zwischen Fiktion und Nichtfiktion (Wirklichkeit) aus. Durch die Annahme einer >Agnes-Realität erfolgt dies auch in WB und die explizite Vermischung der Referenzen auf fiktionale wie reale Gestalten und Ereignisse in der Fiktion entspricht der kompositionalistischen Position. Dies zeigt, dass in $W B$ beide Positionen nicht unterschieden werden und, sich eigentlich ausschließend, nebeneinander stehen.

\subsubsection{Leserwissen}

Angesichts der vielschichtigen und komplexen Konstruktion des Romans als ein metanarratives Rätsel stellt sich die Frage nach dem für die Lektüre des Romans erforderlichen Wissen und der Aufmerksamkeit des Lesers. Bevor auf konkrete Beispiele eingegangen werden kann, muss geklärt werden, nach welchem Leser überhaupt gefragt wird. Wie immer kann der reale Leser nicht oder höchstens exemplarisch angeführt werden; die Frage nach dem intendierten Leser kann nur der Autor selbst beantworten. Aus dem Text selbst können Hinweise auf einen Modell-Leser erschlossen werden, der die Fertigkeiten repräsentiert, die ein Leser haben muss, um den Text zu verstehen. ${ }^{72}$ So problematisch die Rekonstruktion des Modell-Lesers üblicher-

71 Ebd., 23.

72 Wie bereits erwähnt verwende ich den Terminus Modell-Leser im Sinne von Jannidis: Figur und Person, 30-33, 237, 254, der basierend auf Wolfgang Iser, Umberto Eco und Peter J. Rabinowitz eine funktionale Verwendungsweise beschreibt. Danach ist der Modell-Leser der vom Autor intendierte 
weise sein mag, so werden in $W B$ durch die metanarrativen Äußerungen hilfreiche Hinweise an die Hand gegeben, da im Zusammenhang der fiktionalen Abbildung von Kommunikationsstrukturen und ihrer Diskussion auch - fast ohne den Begriff auch nur des Lesers zu erwähnen - über fiktive Modell-Leser gesprochen wird.

Dass es sich nicht um einen einfach zu lesenden Roman handelt, ist inzwischen klar geworden. Die Vielzahl an mythologischen und intertextuellen Anspielungen sowie die Konstruktion nach musikalischen Vorlagen erfordert vom Leser ein immenses Wissen. Doch selbst wenn ein enzyklopädisches Wissen vorhanden wäre, verlangt die Komplexität und Fragmentiertheit des Erzählens eine ebenso große Aufmerksamkeit des Lesers. Dies wird schon im Text anhand von Deters II und Alda aufgezeigt. Alda scheint zwar sämtliche zumindest mythologischen Anspielungen von Deters II zu verstehen, da sie als Elbin selbst alles erlebt hat bzw. kennt, bei intertextuellen Anspielungen wie der Wirtshausszene aus Faust scheint sie dagegen Verständnisschwierigkeiten zu haben (vgl. WB, 599). Anders ergeht es Deters II. Als Alda anfängt, stärker ihre Rolle als Koautorin wahrzunehmen, kann er mit ihrem mythologischen Wissen nicht mithalten (vgl. WB, 909). In einigen oben bereits zitierten Passagen wird damit geradezu kokettiert, dass nicht zu viel (und im Grunde genommen damit zu wenig) Erläuterungen ausgesprochen werden (vgl. $W B, 703$ ). Daran zeigt sich die Strategie, dem Leser zwar teils Andeutungen zu geben, aber ihn im Nachvollziehen der Konstruktion und Implementierung der Verweise zu fordern. Auf der zweiten Ebene wird die erste Ebene als ein work in progress dargestellt, das Alda immer wieder kritisiert (und auch mit erfindet). Als sie einmal nicht zufrieden mit den Begründungen von Deters II ist, meint sie: »Trotzdem klappert und rasselt es in Ihrer Konstruktion. Schlafen kann ein Leser dabei nicht.« (WB, 703) Gemeint ist zuvorderst, dass etwas nicht logisch konstruiert ist, doch das Bild des schlafenden Lesers besagt auch, dass es keine einfache Lektüre sein kann (die quasi auch im Schlaf zu verfolgen ist). Gefordert ist ein extrem aufmerksamer Leser, der extrem viel Wissen und womöglich Arbeit in die Lektüre einbringt. Es gilt, was Jannidis für einige Texte der Moderne konstatiert, dass sie »in ihren zahlreichen intra- und intertextuellen Verweisen und Mustern eine unrealistisch hohe Präsenz des Textes im Gedächtnis des Lesers voraussetzen, also eher für den kumulativen Erkenntnisprozeß der Literaturwissenschaft als für die einfache Lektüre geschrieben zu sein scheinen " 73 Andere vorstellbare Varianten wären, dass solche Texte für den ebenfalls kumulativen Erkenntnisprozess eines Mehrfachlesers geschrieben seien, oder aber auch, dass sie für solche Lektüren besser geeignet (nicht explizit dafür geschrieben) seien, was die intentionale Komponente aus der Einschätzung abschwächt.

$W B$ ist stärker als alle anderen Texte von Herbst auf eine mehrschichtige Lektüre hin angelehnt. Selbst die verschiedenen Ebenen und die jeweils zugehörige Handlung auseinanderzuhalten erfordert höchste Aufmerksamkeit. Zusätzlich erfordern ande-

Leser als anthropomorphes Konstrukt, soweit er sich aus dem Text erschließen lässt. Mit Rabinowitz können dabei noch der auktoriale und der narrative Leser unterschieden werden; der auktoriale ist der vom Autor intendierte Leser, der um die Fiktionalität des Textes weiß, der narrative akzeptiert die fiktive Welt als wahr. Vgl. Peter J. Rabinowitz: »Truth in Fiction. A Reexamination of Audiences«, in: Critical Inquiry 4/1 (1977), 121-141, hier: 1266 .

73 Jannidis: Figur und Person, 136. 
re Anspielungsebenen weitere Spezialkenntnisse, die im Normalfall erst zusätzlich erarbeitet werden müssen. Dass wohl immer nur eine selektive Lektüre möglich ist, zeigt sich selbst in der Literaturwissenschaft. So geht Reber, die die bislang ausführlichste Untersuchung zu $W B$ vorgelegt hat, kaum auf die eigentlich sehr zentralen mythologischen Vorlagen ein. ${ }^{74}$ Stattdessen beleuchtet sie andere Aspekte und Bedeutungsschichten des Buches und geht dabei weitestgehend textimmanent vor (bis auf die Anwendung verschiedener theoretischer Konzepte). Anhand eines Kommentars in Herbsts Weblog kann noch das Beispiel einer realen Leserin angeführt werden, das dieser mehrschichtigen Lektüre entgegenkommt, aber gerade das Gegenteil des angenommenen Lesers darstellt, der Kohärenz und Verständnis sucht. Unter dem Pseudonym MelusineB sagt diese Leserin: »Ich bin aber die Sorte Leserin, die sich während des Lesens nie fragt: Was bedeutet das? Ich lasse mich einfach hineinziehen in einen `Sound o d e r eine Geschichte. $\aleph^{75} \mathrm{Ihr}$ komme es bei einer solchen Lektüre vor allem auf die sprachliche Darstellung an, andere Aspekte des mehrschichtigen Aufbaus könnten also weitgehend unbeachtet bleiben.

Es gibt jedoch auch Anspielungen in WB, die nicht verstanden werden können. Ein Beispiel soll dies aufzeigen. In einem der vielen Streite beschimpft Lipom Murnau:

Schauen Sie nur, Sie spinniger Birkenfinger, was Sie angerichtet haben! Unser Husar ist ganz gefühlig von Ihren Quasseleien! Ham ihn wohl an der Stirne berührt? [...] Hat er schon gar den weißen Fleck? $(W B, 321)$

Herbst kommt darauf im Austausch mit einem Leser im Weblog zu sprechen. Dort verweist er auf das Buch Fairies (1978) von David Larkin, Brian Froud und Alan Lee. Er zitiert nach der deutschen Übersetzung von Renate Reimann: „Der Geist der Birke hat weiße Spinnenfinger. Wen er am Kopf berührt, der behält ein weißes Mal und verliert den Verstand. Wen er am Herzen berührt, der muß sterben. ${ }^{76}$ Herbst fügt als Erklärung noch hinzu, dass er diese Vorlage jedoch verdrehe, denn Murnau stehe bei ihm ja für den Verstand. Selbst enzyklopädisches Wissen reicht wohl nicht aus, um zu verstehen, was es mit dem weißen Fleck auf sich hat. Dafür ist ein Zufallsfund oder ein direkter Hinweis vonnöten, doch selbst die Erklärung ist sehr speziell, da sie nicht auf dem Original, sondern auf der Übersetzung fußt. Im Original kommt der Begriff Verstand nicht vor, es ist von Verrücktheit die Rede: »If the hand touches a head it leaves a vivid white mark and inflicts madness [...].«77 Angesichts eines solch komplizierten Zusammenhangs bleibt nur die Schlussfolgerung, Herbst habe es darauf angelegt, dass der Leser nicht alles versteht und womöglich auch auf diese Art absichtlich verwirrt wird.

Wie bereits gesagt, lässt sich die Frage nach dem intendierten Leser nur durch Äußerungen des Autors selbst erschließen. Herbst erörtert sie im Zuge von in Kom-

74 Vgl. Reber: Formenverschleifung, 300 und 314.

75 URL-14, 16. Juni 2010.

76 Brian Froud / Alan Lee: Das große Buch der Geister. Von Elfen, Nixen, Gnomen, Irrwischen und anderen geheimnisvollen Wesen, übers. von Renate Reimann, Oldenburg u. a. 1979 zit. nach URL-9, 19. Juli 2010.

77 David Larkin (Hg.): Faeries. Described and illustrated by Brian Froud and Alan Lee, New York u. a. 1978, keine Seitenzählung. 
mentaren des Weblogs erfolgten Gesprächen über WB. Angestoßen wurden sie durch einen Leser unter dem Pseudonym NO und seine WB-Lektüre im Juni und Juli 2010. In Kommentaren unter einem Eintrag des Arbeitsjournal begann er, seine Lektüre zu kommentieren und Herbst Fragen zu stellen. Er präsentiert sich als aufmerksamer und gebildeter, belesener Rezipient, teilweise aber auch als naiver Leser (d. h. kein >professioneller L Leser). Er verweist auf etliche Anspielungen, die er erkannt hat, spekuliert über andere und fragt Herbst, ob er richtig liege. Zwischendurch fragt er auch direkt, »ob denn eigentlich auch der Leser Spaß an dem Buch [habe], der das alles nicht sehen « könne, wobei mit `das alles` die Anspielungen gemeint sind, und ob die »Vielzahl und Vielheit des Zugrundeliegenden nicht übertrieben« sei. Herbst geht direkt darauf ein:

Ich hoffe: ja. Einfach deshalb, weil auch ich Spaß an Büchern hatte, bei denen ich längst nicht alles sah, beileibe nicht. Die für mich so wichtigen »Die Dämonen« habe ich mindestens dreimal gelesen im Abstand von Jahren, und immer war da etwas Neues zu finden. Wobei ich alles, was einem Leser nötig ist, um die Zusammenhänge zu verstehen, ja noch eigens hinzuerzähle, bzw. die Romanfiguren erzählen lasse. Um der Handlung zu folgen, die ja auch Spannung hat oder witzig ist (»Deppi! Deppi!), braucht es nicht mehr. ${ }^{78}$

Abgesehen von der etwas gewagten Einschätzung, dass alles, was für das Verständnis nötig sei, gesagt werde, kann gerade der Autor die Frage nach dem Spaß des Lesers wohl kaum beantworten. Deutlich wird dennoch das Bild einer mehrfachen Lektüre, das Herbst als Autor des Buches im Sinn hat. Dies setzt einen entsprechend interessierten und engagierten Leser voraus. An anderer Stelle setzt er weniger Erwartungen in den Leser:

Zur »Bildung«. Zur»Voraussetzung«. Was Ihnen manchmal zuviel sei. Wissen Sie, ich kann das nicht wissen und will es auch nicht wissen. Ich kann mich nicht hinsetzen und darüber nachdenken, ob nun weite Leserkreise dieses und jenes als Vorwissen mitbringen oder nicht. I $\mathrm{ch}$ bringe es mit. Das muß genügen. Alles andere wäre Literaturpädagogik. Vieles weiß ja auch i $\mathrm{ch}$ nicht - weshalb auch i $\mathrm{ch}$ bestimmte Texte gar nicht verstehen kann, bzw. nicht in sie hineinkomme. Das betrifft den ganzen Zusammenhang des Pops. Ich $\mathrm{k}$ a $\mathrm{n} \mathrm{n}$ die meisten Texte, die in seinem Lebensgefühl leben, weil sie seine Erfahrung haben und wollen, nicht verstehen; das bedeutet aber nicht, daß ich den Autoren vorwerfen dürfte, sie nähmen keine Rüchsicht [sic!] auf meine völlig andere Sozialisation; es wäre einfach dumm, es ihnen vorzuwerfen. Ich kann als Lesender nur versuchen, mich der fremden Erzählung zu öffnen, um vielleicht auf meinem Weg hineinzufinden. Dies ist umgekehrt auch von meinen Lesern zu erwarten, bzw. zwingt sie ja niemand, meine Bücher auch nur zur Hand zu nehmen. ${ }^{79}$

Der Leser, den Herbst als eine Art idealen Leser im Sinn hat, ist im Grunde genommen jemand, der ihm selbst als Leser ähnelt: ${ }^{80}$ Jemand, der versucht, auf den Text

78 URL-15, 23. Juni 2010.

79 URL-8, 23. Mai 2009.

8 Manfred Günter Scholz und Nikolas Immer definieren den intendierten Leser als »ideale[n] Leser, dessen Kompetenz sich mit der des Autors decken sollte, [was] eine real nicht völlig einlösbare 
zuzugehen, sich seiner Machart zu öffnen und auch bereit ist, Zeit in diesen zu investieren. Dass es nicht immer passt zwischen Text und Leser ist ihm klar, im Sinne seiner abwehrenden Trotzhaltung gegenüber fehlender Anerkennung stellt er es sogar heraus.

Auf das mögliche Bedürfnis der Leser auf konventionellere Erzählhaltungen, beispielsweise einen linearen Erzählverlauf wird wiederum in WB durch den Vorschlag von Alda eingegangen, die Blumenstücke einzufügen. In diesen solle sich der Leser ohne »Bildungsballast [...] einmal frei bewegen dürfen«: »Man mag sich ja nicht gern den Gürtel zu eng um die Fantasie schnallen lassen und hat ein Anrecht auf Feier und Abend. Und wie feiert so ein Leser? Indem er eine richtige Geschichte liest.« $(W B, 314)$ Es wird also wieder einmal gespielt mit dem Bewusstsein um die besonderen Eigenschaften des eigenen Textes. Und selbstverständlich fallen auch die Blumenstücke nicht ganz aus dem Rahmen. So nimmt das Zweite Blumenstück Motive aus dem Roman Ljudi sa četiri prsta (1975, Die Daumenlosen, dt. 1975) des serbischen Schriftstellers Miodrag Bulatović auf, was später auf der zweiten Ebene auch wieder thematisiert wird (vgl. WB, 544) und womit weitere Vampir-Traditionen ${ }^{81}$ eingebracht werden.

\subsubsection{Der Roman als Spiel}

Auch wenn beispielhaft an verschiedenen Strukturen, Motiven und dem Nachweis von Intertexten aufgezeigt wurde, wie der Aufbau beschaffen ist, so sagt dies nur begrenzt etwas aus über die Funktion der Zusammenstellung und Übernahme dieser Versatzstücke aus. Zum einen wird diese, wie gezeigt wurde, genutzt, um Fragen der Abhängigkeit des Subjekts zu veranschaulichen, und auch, um eine bestimmte Form von Identität darzustellen zu versuchen, nämlich die Möglichkeit, zugleich das eine und etwas anderes zu sein. In Fragen der Wirklichkeitswahrnehmung wird durch das Nebeneinander unterschiedlicher Referenzialisierung eine Nivellierung der Wahrnehmung zwischen Fiktion und Realität erreicht.

Ein Begriff, der die Verweise zusammenbringt und in der intertextuellen Determiniertheit sogenannter postmoderner Prosa auch immer wieder als Vorwurf zu hören war, ${ }^{82}$ wird im Text von $W B$ selbst häufig eingebracht: der des Spiels. In gewisser Weise ähneln sich die Konstellationen von Lipom und Murnau und Alda und Deters II als Gesprächspartner. Die Diskussionen sind in beiden Fällen eher kämpferisch. Bei den als Selbstgespräche einzuordnenden Diskussionen zwischen Lipom und Murnau prallen recht heftig zwei Positionen aufeinander. Die Heftigkeit der Konfrontation erklärt sich durch die Aufspaltung sich entgegenstehender Positionen, die oben als

Fiktion« bedeutet. Siehe Manfred Günter Scholz / Nikolas Immer: »Leser«, in: Dieter Burdorf/ Christoph Fasbender / Burkhard Moennighoff (Hg.): Metzler Lexikon Literatur. Begriffe und Definitionen, 3., völlig neu bearbeitete Auflage, Stuttgart / Weimar 2007, 432-433, hier: 432. Herbst geht es hier weniger um die Kompetenz im Sinne von Wissen, sondern um eine ähnliche Einstellung dem Lektüregegenstand gegenüber.

81 Neben der keltischen mit der mythologischen Figur Lan-an-Sìdhe, der westlichen Literatur mit Bram Stokers Dracula nun die serbische.

82 Vgl. z. B. Hanns-Josef Ortheil: »Das Lesen - ein Spiel. Postmoderne Literatur? Die Literatur der Zukunft«, in: Die Zeit, 17. Apr. 1987. 
Mythos- und Logos-Position beschrieben wurden, in verschiedene Personen. Dennoch beruhigen sich beide nach erhitzter Debatte immer wieder sehr schnell und kennzeichnend ist die Formulierung, die Lipom verwendet, als er Murnau einmal vorwirft, dieser klaue seine Argumente: »Scheren Sie sich auf Ihre Seite des Spielfelds zurück! $(W B, 207)$ Bis zum Thing, als die Konfrontation ernst wird, da Lipom Murnau verurteilen und damit vernichten lassen will, ist damit der Charakter der Auseinandersetzung bezeichnet: das spielerische Ausloten zweier Ansichten, das trotz kämpferischem Duktus auch wieder freundschaftliche Versöhnung und gegenseitige Anerkennung andeutet.

Auch für das Verhältnis von Deters II und Alda ist der Spiel-Begriff wichtig. Gleich im ersten Gespräch verwendet ihn interessanterweise Alda. Zwar ist es Deters II, der ihr im Grunde genommen verkündet, dass er sie in seine Geschichte einbauen und sie damit quasi erfinden will. Doch sie reagiert sehr offensiv:

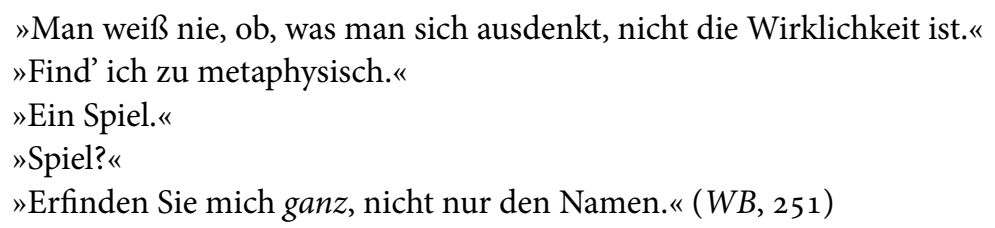

Eigentlich ist es seine Sichtweise, die er hier als zu metaphysisch abtut. Ihr Kommentar »Ein Spiel.« kann dabei im Kontext als mehrdeutig verstanden werden. Auf der einen Seite versteht sie seine Kontaktaufnahme als Flirtversuch, auf den sie entsprechend reagiert. Der Charakter ihres Umgangs ist durchgehend dadurch geprägt. Das Flirten als eine Form der sexuellen Annäherung wird später durch das Motiv des `Geschlechterkampfs` grundiert. Wie im kämpferischen Verhältnis von Lipom und Murnau ist auch hier gleichzeitig das spielerisch-provokative Moment enthalten. Auf der anderen Seite ordnet sie sehr offensiv seine spielerisch-phantasierende Absicht als ein solches ein. Sie stellt damit klar, dass sie sich auf das Spiel mit der Phantasie einlässt und bestimmt aber von Anfang an die Regeln mindestens mit. Dieser Zusammenhang wird auch noch mehrfach betont:

»Ich hab' ja nichts dagegen, daß Sie mich als Anna erfinden, aber dann muß ich mich auch benehmen wie sie.«Immerhin blieb sie im Spiel. $(W B, 351)$

»Ich verlange von Ihnen, daß Sie unser Spiel ernst nehmen, wenn Sie mich lieben wollen. Denn das, geben Sie's zu, ist seit allem Anfang unser gemeinsames Ziel.« $(W B, 730)$

Auch hier findet sich wieder des Aspekt des Changierens zwischen Spiel und Ernst. Einerseits wird das phantasierende Verbinden von den beiden mit der erzählten Geschichte als Spiel betrachtet, was eine Ziel- bzw. Zwecklosigkeit insinuiert. Andererseits verliert es durch die Determiniertheit, der sie durch die mythischen Strukturen des `Geschlechterkampfs` unterliegen und die sie das Ziel der (göttlichen) Vereinigung verfolgen lässt, gerade den spielerischen Charakter und wird zu einer ernsten Angelegenheit.

Es kann jedoch auch eine Relativierung der Bedeutung konstatiert werden, die dem fiktionalisierenden Umgang mit der eigenen Identität in VG und auch bei Deters 
noch zugemessen wird. Ist dort das Erfinden einer anderen eigenen Vergangenheit eine essenzielle Angelegenheit, die einerseits befreiend wirkt, andererseits an den Rande des Wahnsinns zu führen scheint, so hat es bei Deters II und Alda durch den spielerischen Zug eine gewisse Leichtigkeit. Diese trägt dazu bei, dass nicht die gravierende Trennung zwischen realer (`Agnes - ) Wirklichkeit und verschiedenen veränderbaren subjektiven Wirklichkeiten im Vordergrund steht, sondern das schillernde Unvermögen zu unterscheiden, was wahr ist und was falsch. Alda beginnt schließlich ein ebenenübergreifendes Gespräch mit Lipom und den anderen Elben, das anfangs eindeutig als Simulation gekennzeichnet ist. Deters II, der von ihrer konsequenten Imitation einer Redesituation irritiert und eher genervt ist, weigert sich, dabei mitzumachen. Alda stellt wieder die Regeln klar: "»Nun spiel doch mit<, sagt Alda, indem sie sich vom Nichts weg- und mir zuwendet. ,Sonst funktioniert das nicht. Antworte ihm.« $(W B, 915)$ Damit ist deutlich gemacht, dass es sich um ein Spiel handelt, das nur funktioniert, wenn alle Mitspieler so tun, als ob es sich um eine reale Situation handelt. Im Weiteren zeitigt dieses Vorgehen seine Wirkung, da nicht mehr eindeutig ist, ob Lipom und die anderen nun nicht da sind oder doch.

Der Begriff Spiel wird auch mehrfach in Zusammenhang mit Daniellos Aktivitäten gebraucht. Zuerst ist es Murnau, der ihn verwendet, als er mit Deters über den Keller des Hotels spricht. Der dort befindliche Computerraum sei »das Denkzentrum des Spiels« $(W B, 398)$. Was er damit meint, bleibt unklar, da er einerseits von der Verantwortung Daniellos in Zusammenhang mit `dem Kapitalı spricht; dies deutet auf Daniellos Finanzierung der ATG-Treffen hin und insinuiert eher die Auffassung der Treffen als Spiel. Andererseits bettet er seine Andeutungen in Ausführungen zu seiner technikfreundlichen Position ein, die im Nachhinein auch als Hinweis auf die eigentliche Tätigkeit Daniellos (der Simulation des Ganzen) verstanden werden kann. Bezogen auf diese ist es dann Daniello selbst, der sehr offensiv den Begriff Spiel verwendet. Es gibt drei zentrale Gespräche Daniellos und in allen drei bringt er das Motiv an, so wird es als das zentrale ihn beschäftigende Thema etabliert. Deters erfährt von Daniellos Aktivitäten im Computerraum in einer Art Audienz. Er erkennt, dass das gesamte Geschehen im Wolpertinger nur virtuell inszeniert ist und bringt wie bereits geschildert das Motiv der Gott-Analogie auf. Als er Daniello Anmaßung vorwirft, reagiert dieser eben mit dem Hinweis: »'s blabt soa oda soa an Spüü. Nur dös i selbst dauernd oam Zug bin, doa gibt's so goa koane Gegner.« $(W B, 580)$ Auch das große >Teufel-Gott-Gespräch zwischen Lipom und Daniello schließt daran an. Daniello lamentiert wieder, das Ganze sei wie Schach gegen sich selbst zu spielen (vgl. $W B, 899$ ), und dass es so langweilig sei (vgl. WB, 902). Die Überlegung, das Spiel einfach zu beenden, da es ja sowieso langweilig sei, demonstriert dabei seine Überlegenheit und Allmacht. Die Bedrohung, die damit für die `Existenz` der Wolpertinger-Besucher entsteht, zeigt, dass es sich nur für ihn um ein Spiel handelt, für die anderen ist es Ernst. Die Analogie zum Verhältnis von Gott und Mensch noch weitertreibend, wird beim `Showdown « noch die Diskussion um den vermeintlich freien Willen des Menschen angesprochen. Als Deters während des Festes zu Daniello in den Computerraum vordringt, kommt es zu einem weiteren aufklärenden Gespräch. Daniello meint dabei, dass Deters sich selbst entscheiden müsse, ob er im 
Computerraum bleibe oder sich wieder in das Chaos des Festes (und die Verfolgung durch die Abgesandten des >Dunklen`) begeben wolle. Deters erkennt jedoch, dass es sich nicht um eine Entscheidung aus freiem Willen handelt, die wirklich etwas bewirken würde, sondern um die Aufforderung zu einer Art Spielzug. Darum fragt er auch noch einmal explizit, da er es wohl trotz des vorherigen Gesprächs noch nicht wahrhaben wollte: »Das ist nur ein Spiel? « Und Daniello bestätigt ein weiteres Mal diese Erkenntnis: „Ois iis on Spüü.» (WB, 991) Zwar ist Deters selbst nach den Aussagen in diesen Zusammenhängen ein Mensch und keine >Datei<, er wird jedoch in seinem Denken und selbst seinen Erinnerungen durch die Programmierung von Daniello beeinflusst. Er identifiziert sich inzwischen mit den Elben, >glaubt‘ sozusagen an ihre Existenz, auch wenn sie nur virtuell ist, und stiehlt schließlich die Diskette. Ebenso wie der Programmierer Daniello Schöpfer der virtuellen Welt des Wolpertinger ist und die `Schöpfung ein Spiel für ihn ist, so kann per Analogie auch der Roman als ein Spiel des Autor-Schöpfers gesehen werden (je nach Standpunkt der Betrachtung Deters, Deters II, der >Dritte oder der reale Autor Herbst). Auch er hat die Macht, die Figuren und das Geschehen so zu lenken, wie er es will. Im Grunde bildet Daniello im Computerraum sogar viel stärker die Situation des realen Autors ab, als dies bei den als Schreibende oder Fabulierende geschilderten Deters-Figuren der Fall ist. Er ist als einziger wirklich getrennt von seinen Figuren, die scheinbar metaleptische Grenzüberschreitung im Gespräch mit Lipom wird der Situation entsprechend erklärt, dass der Daniello, den Lipom sieht, lediglich ein programmierter Avatar ist, während sich der richtige Daniello im Computerraum befinde. Ungeklärt ist dabei die Frage, auf welcher Ebene sich der Daniello im Computerraum befindet. Aber selbst die Avatar-Original-Konstellation entspricht den realen Möglichkeiten. Sogar wenn sich ein realer Autor selbst in eine Geschichte hineinschreibt und sich mit dem realen Namen bezeichnet, ${ }^{83}$ kann er dies lediglich über eine literarische Figur, die einem Avatar entspricht, tun. Die Analogie zum Spiel gegen sich selbst ist bei der Konstruktion der Geschichte auch sehr stimmig, da er sämtliche Vorgaben selbst bestimmt. Es ist gerade die Frage nach dem zum Verständnis nötigen Leserwissen, die die Möglichkeit eröffnet, das Spiel nicht nur gegen sich selbst zu spielen, sondern Mitspieler zu ermöglichen. Deters fragt Daniello nach seiner eigenen Existenz, doch dieser verweigert die Aussage: »I konn Ihna jo neet ois verroaten, sunst hätt' i jo schoa wieder g'wunna.« $(W B, 580)$ Ebenso kann auch die Konstruktion und Figurenanlage nach diversen intertextuellen Verweisen, die in den wenigsten Fällen explizit benannt ist, gesehen werden. Der Leser wird zum Mitspieler, der die Verweise zu erkennen sucht. Der Autor hat sie also nicht nur im Spiel gegen sich selbst lediglich für sich platziert. Die Andeutungen vor allem in den metanarrativen Diskussionen dienen als Hinweise zum Auffinden; viele nicht benannte bleiben den meisten Lesern dabei vermutlich verborgen.

83 Diese Form von Autofiktion findet sich immer wieder in der Literaturgeschichte, bei Herbst selbst in Eine Sizilische Reise sowie in Buenos Aires. Anderswelt. 


\section{Teil III}

\section{Die Anderswelt-Romane}





\section{Identität zwischen Körperlosigkeit und Körperlichkeit}

\subsection{Einleitung}

Der Roman Thetis. Anderswelt ${ }^{1}$ ist auf zweierlei Weise im Werk von Herbst zu verorten. Einerseits ist er der dritte Teil der losen Pentalogie, die mit $V G$ beginnt. Andererseits ist TA als erstes Buch einer Trilogie, der Anderswelt-Trilogie ${ }^{2}$, zu sehen. Thetis erschien 1998, Buenos Aires. Anderswelt ${ }^{3} 2001$ und Argo. Anderswelt im Herbst 2013. ${ }^{4}$ Der Zusammenhang der gesamten Pentalogie ist ein loser, sie ist auch beispielsweise in den üblichen Paratexten nicht als eine solche annonciert. Der Zusammenhang besteht im Anschluss an Motive der vorhergehenden Romane, die Übernahme bzw. den Anschluss an Figuren, in Verweisen und Anspielungen. Die anderen, skleineren Bücher von Herbst, die neben der `Pentalogie` als Hauptwerk das Nebenwerk bilden, sind nicht in diesem Maß einbezogen, auch wenn sich auch dort teilweise Verweise und Anspielungen finden. Im Wurm Vorsatz, einem Faltblatt, das $B A$ beiliegt, und die wichtigsten Figuren und Gruppierungen enthält, werden $V G$ und $W B$ schließlich als Vorgängerromane aufgeführt. ${ }^{5}$ Die $A W$-Trilogie ist schon durch den jeweiligen Untertitel Anderswelt als zusammengehörig erkennbar und wird auch im Klappentext zu $B A$ als Trilogie bezeichnet (ebenso dann auf der Impressumsseite von Argo). Auch die Übergänge und der Anschluss an die beschriebene Handlung und die eingeführten Figuren machen die Bücher leicht als zusammengehörig identifizierbar. Insgesamt sollen alle Bücher der Pentalogie für sich lesbar sein (vgl. $W V$, ii). Sie seien jedoch nicht »voraussetzungslos«, sondern mit den anderen Büchern und zudem auch mit denen anderer Autoren sowie Filmen, Geschehnissen und Personen verknüpft. Die Bücher stehen vielmehr in »einem außergewöhnlich engen Verhältnis zueinander « ${ }^{6}$, sodass einige Motive und Anspielungen nicht verständlich sind, wenn der Gesamtzusammenhang nicht bekannt ist. ${ }^{7}$ Dies gilt sowohl für die späteren als auch für die

1 Alban Nikolai Herbst: Thetis. Anderswelt. Fantastischer Roman, Reinbek 1998.

2 Wird auf die Trilogie insgesamt verwiesen, wird sie mit der Sigle $A W$ abgekürzt.

3 Alban Nikolai Herbst: Buenos Aires. Anderswelt. Kybernetischer Roman, Berlin 2001.

4 Argo ist erst nach Fertigstellung dieser Arbeit erschienen und wurde daher kaum thematisiert.

5 Vgl. Alban Nikolai Herbst: WurmVorsatz, Beilage zu Buenos Aires. Anderswelt, 2001 (im Folgenden zit. als $W V$ ), ii.

6 Jürgensen: »Unwirkliche Städte, unwirkliches Ich«, 100.

7 Dies zeigt sich beispielhaft bei Judith Leiß, die von dem in TA wiederkehrenden Satz »Blut und Hirn verspritzten sich rings um die Wände« irritiert ist (vgl. Leiß: Inszenierungen des Widerstreits, 231). Diese Wiederholungen sind jedoch eine Anspielung auf WB und stellen >Flashbacks « von Deters dar, der als durchgehende Figur wesentlich für die Verbindung der Romane sorgt. Mit dem 
früheren Bücher, das heißt, einige Zusammenhänge werden erst durch die späteren Bücher verständlich bzw. wird einigen Motiven eine Erklärung beigegeben.

Thetis ist wesentlich einfacher strukturiert als $W B$, die einzelnen Ebenen und Handlungsstränge sind bis auf kleinere Ausnahmen klar auseinanderzuhalten. Generell gibt es hier nur zwei Fiktionsebenen bzw. zwei Welten, die zunächst eindeutig voneinander geschieden werden können. Die Ausgangssituation ist wieder ähnlich wie in beiden Vorgängerromanen: eine in einer mehr oder weniger der aktualen ähnelnden Welt lebende Figur sitzt in einem Café (bzw. in $W B$ ist es zunächst ein Zug) und denkt sich eine Geschichte sowie eine zugehörige fiktive Welt aus. In TA ist es der bereits bekannte Hans Erich Deters, der sich in der »Realwelt« $(T A, 727)$ befindet, die als Berlin erkennbar wird. Deters ist ein Aktienbroker, der für die Firma Evans Sec. arbeitet (vgl. TA, 248, 315), was Herbst in der bereits erwähnten Fußnote in die Taschenbuchausgabe von $W B$ eingearbeitet hat (vgl. WB, 726 FN 1). Deters sitzt im Café Silberstein und denkt sich eine Parallelwelt aus, die sogenannte >Anderswelt Dabei wartet er auf eine Frau, die er in der U-Bahn getroffen hat, die - wie sich später herausstellt - ein Teil der von ihm erfundenen Welt ist. Diese beiden Welten sind trotz späterer metaleptischer Grenzüberschreitungen eindeutig voneinander zu unterscheiden.

Die >Anderswelt $<$ ist einerseits eine Parallelwelt zu Deters' Realwelt, andererseits eine zukünftige Entwicklung dieser Welt. Nach dem Dritten Weltkrieg und anderen politischen Krisen folgt die Klimakatastrophe und die sogenannte Große Geologische Revision: innerhalb von hundert Jahren vollziehen sich erdgeschichtliche Umbrüche in der Landschaft, Europa wird größtenteils durch das Thetismeer überflutet, neue Gebirge entstehen und Vulkane brechen aus. Es schließen sich Völkerwanderungen, apokalyptische Tierplagen und Krankheitsepidemien an. Eine riesige Mauer wird gebaut, die das Thetismeer abhalten soll, Europa ganz unter sich zu begraben.

Die Handlung spielt in Europa, das ein vereinigter Staat ist, der jedoch in drei sehr heterogene Bereiche aufgeteilt ist: den heruntergekommenen Osten, in dem 400 Millionen Menschen leben und als Arbeiter für die anderen Teile missbraucht werden; das Zentrum Buenos Aires, eine technisch hoch entwickelte, riesige Stadt, in der 60 Millionen der `Bourgeoisie leben; schließlich eine kleine Stadt der Reichen, der >Westen , mit lediglich 450 Bewohnern. Die Zentralstadt Buenos Aires, die sich Deters imaginiert, ist »eine Legierung aus allen Großstädten und damit gleichsam die Megalopolis schlechthin ${ }^{8}$. Er denkt sie sich aus den verschiedenen realen Städten Buenos Aires, Paris, Rom, Prag, Belgrad, London werden anfangs genannt - zusammen und »fehlt [etwas], denk ich's aus den Geschwistern hinzu« $(T A, 9)$. Diese Idee wird schon in $V G$ genannt:

»Vierte[n] Nachspiel« am Ende von TA (878-887), der an die Epiloge von WB direkt anschließt, ist ohne das Wissen um den Vorgängerroman wohl kaum etwas anzufangen.

8 Vgl. Jürgensen: »Unwirkliche Städte, unwirkliches Ich«, 104. Jürgensen beschäftigt sich in diesem Aufsatz mit der »Kopplung von Ich- und Stadtentwurf« (ebd.) und der Tradition des Großstadtromans. 
Frankfurt: Alle Städte zu einer zusammenlegen, die Ortseigenschaften miteinander verschmelzen, den Eiffelturm auf die Kaiserstraße pflanzen, über den Main gespannt die Golden Gate Bridge. (VG, 32)

In den Anderswelt-Romanen wird die Idee wieder aufgegriffen, »entfaltet und ausgeführt « ${ }^{9}$. Naturwissenschaftliche Entdeckungen bewirken grundlegende Veränderungen in der Anderswelt: etliche der reichen Bewohner des Westens sind unsterblich, gentechnische Veränderungen werden an Menschen vorgenommen, außerhalb des Ostens ist die Ernährung auf künstliche Nahrung umgestellt, Westen und Zentrum sind quasi hygienisch rein: es herrscht eine große Angst vor Ansteckungen, weswegen die Leute kaum aus dem Haus gehen, auch und gerade sexuelle Aktivitäten sind in simulierende Geräte, die Infomaten, ausgelagert. Die Energie wird durch Wasserkraft mittels des Thetismeers gewonnen. Eine neue Energieform, das sogenannte Hodna, ermöglicht einen Schutzschirm über Zentrum und Westen, der ein energetisches Kraftfeld erzeugt. Innerhalb dieses Bereichs ist auch die Technik der Holomorfie ermöglicht: ganze Umgebungen und Landschaften können ebenso materiell simuliert werden wie androide Roboter, die Holomorfen, die vom bloßen Anschein nicht mehr von Menschen unterschieden werden können und für diese alle Arbeiten erledigen.

Diese Entwicklung betrifft jedoch nicht den Osten. Dieser »verrottet im kontaminierten Dreck des Zivilisationsmülls. Hier vegetiert der Abschaum: vierhundert Millionen Arbeiter, als bloße Körper verwertet, indem sogar die Scheiße als Heizmaterial kapitalisiert wird. ${ }^{10}$ Es entstehen neue, doch atavistische Religionen mit Kinderopfern zur Besänftigung des Thetismeers (das gleichzeitig eine Göttin ist); eine Richtung besteht aus Frauengruppen, die Devadasis ${ }^{11}$ genannt werden, andere aus Männergruppen, den Schänderpriestern.

\section{Handlungs- und Figureneinführung}

\section{Thetis}

Drei Handlungsstränge können in $T A$ identifiziert werden und als heuristische Unterscheidung den drei geographischen Regionen zugeordnet werden. Zunehmend überschneiden sie sich jedoch und hängen immer mehr miteinander zusammen.

Im Osten ist die Hauptfigur der Arbeiter Achilles Borkenbrod, ein Außenseiter, der sich auf den Weg nach Leuke oder Levkás macht, einen paradiesischem Sehnsuchtsort, der sich im Osten des Thetismeers befinden soll. Die Amazone Meroë hilft ihm scheinbar, nach Landshut zu kommen, bringt ihn dort aber zu den Myrmidonen, weiblichen Kämpferinnen um die >Mongolin` Lykomedite Zollstein. Er wird gezwungen, mit dieser ein Kind zu zeugen. Dieses Kind ist Niam Goldenhaar, die die Tochter von Thetis und auf nur im mythischen Denken mögliche Weise zugleich diese selbst. Sie hat ungewöhnliche Eigenschaften: Sie kann bereits kurz nach der Geburt sprechen und handeln, sie ist zwar klein, aber quasi wie ein ausgewachsener Mensch. Borkenbrod soll nach vollbrachter Leistung hingerichtet werden, doch Niam

\footnotetext{
9 Patorski / Moosbach: »Die Anderswelt als Rhizom«, 16.

10 Scherer: "Alban Nikolai Herbst $[K L G]$ «.

11 Historisch eine Bezeichnung für indische Tempeltänzerinnen.
} 
verhindert dies und bringt ihn bei den Konkubinen unter. Dort wird er als Frau versteckt, die meisten wissen jedoch Bescheid und erfreuen sich heimlich daran, einen Mann als Konkubine zu haben. In der Zwischenzeit macht sich Poseidon, ein Freund, auf die Suche nach Borkenbrod. Meroë wurde erschossen und ihr Geist wurde ihm eingepflanzt. Er landet bei den Schänderpriestern und wird dort in sunappetitlichen< Szenen verstümmelt und zu einem >Propheten` gemacht.

Bereits an den genannten Namen zeigt sich die vor allem im Osten verortete Verbindung zu griechischen, keltischen und auch anderen Mythologien. Achilles, Poseidon und Odysseus (der Anführer der Schänderpriester) verweisen auf die homerischen Epen. Thetis ist in der griechischen Mythologie Achilles' Mutter. Nach seinem Tod wird Achilles auf die Insel Leuke, die Insel der Seeligen gebracht, die sich an der Mündung der Donau im Schwarzen Meer befinden sollte. ${ }^{12}$ Darauf weist Herbst auch im WurmVorsatz zu BA hin. Dort setzt er nach seinem aus WB bekannten Mythenverständnis Leuke aus der griechischen Mythologie mit Tir na nOg, der Jenseitsinsel der keltischen Anderswelt, gleich. ${ }^{13}$ Während Meroë vermutlich Kleists Penthesilea entnommen ist, wo sie eine der Amazonen ist, bezieht sich der Vorname von Lykomedite Zollstein wiederum auf die griechische Mythologie und den König Lykomedes, bei dem Achilleus von seiner Mutter Thetis versteckt wurde, was in TA travestiert wird. Herbst rät dem Leser im WurmVorsatz: »Wegen ihres Namens sieh nach bei Homer. Das kann sowieso, für das gesamte AndersweltProjekt [sic!], nicht schaden. ${ }^{14}$ Abgesehen davon, dass diese Information nicht bei Homer, sondern bei Apollodor zu finden ist, wird die Verbindung deutlich. Vorausblickend ist bereits die Achilleis von Goethe als wichtige Grundlage des dritten Bandes Argo zu nennen. ${ }^{15}$ Mit der Figur Niam wird die Verbindung zur keltischen Mythologie deutlich gemacht, die in WB bestimmend war. Der Mythen-Mix, der dort schon zu finden war, wird in der $A W$-Trilogie noch wesentlich auf die griechische Mythologie ausgedehnt.

Der zweite Handlungsstrang spielt im Zentrum, der Zentralstadt Buenos Aires. In der dortigen Gesellschaft gibt es drei `Klassen`, die "phylogenetische Kategrie[n] « darstellen: "holomorph, real oder Klon" $(B A, 90)$. Die Kategorie `real bezeichnet die Menschen. Die Holomorfen werden als genügsamer und praktischer Arbeitsersatz für die Menschen genutzt, werden im Normalfall auch als solcher gesehen und abschätzig behandelt. Die Klone sind sogar noch geringer geachtet als die Holomorfen, da diese "dienstbar $(B A, 119)$ sind. Im Mittelpunkt des zweiten Handlungsstrangs stehen die Holomorfen ${ }^{16}$. Der Holomorfe Herr Drehmann kann sich ungewöhnlicherweise an bereits in seiner Programmierung gelöschte Ereignisse erinnern und wird dadurch zu Überlegungen zu seiner Identität als Holomorfer gebracht. Er bekommt Kontakt zu einer Rebellenorganisation der Holomorfen, die beginnen, sich von den Menschen autonom zu machen. Gegenspieler ist Markus Goltz, der Chef der Sicherheitszentrale

12 Nicht so bei Homer. Für Nachweise vgl. Preußer: »Achilles als Barde«, 86 FN 52.

13 Vgl. $W V$, ix und xiv.

14 Ebd., $x v$.

15 Vgl. Schnell (Hg.): Panoramen der Anderswelt, $97 \mathrm{f}$.

16 Ich halte mich an diese in $T A$ vorherrschende Schreibweise. In $B A$ werden sie teils als $>$ Holomorphe bezeichnet, ein Bedeutungsunterschied ist aber nicht ersichtlich. 
von Europa, der sowohl die Holomorfenrebellion bekämpft und zerschlägt, als auch durch Intrigen gegenüber dem Westen seine Machtposition auszubauen sucht.

Der dritte Handlungsstrang ist im Westen angesiedelt. Hier ist die zentrale Figur der `Tycoon` Toni Ungefugger. Er ist zunächst Chef der Firma EWG (Europäische Wirtschaftsgesellschaft, die eigentlich in fast allen Bereichen - Wirtschaft, Finanzen, Arbeit, Absicherung, aber auch Sicherheit, Militär, Technik - für Europa zuständig ist). Selbst unglaublich reich, konnte er sich eine medizinische Behandlung leisten, die Unsterblichkeit verleiht. Er bekämpft die Welt der Dinge und des Körpers und versucht alles durch Simulationen zu ersetzen und zum reinen Bewusstsein zu werden. Hier einzuordnen ist auch noch Elena Goltz, geb. Jaspers, die im Zentrum für die EWG arbeitet und eine ehrgeizige Anhängerin Ungefuggers ist, sowie die aufeinanderfolgenden Sicherheitsberater Jensen - der alte Jensen und der junge -, die Vater und Sohn sind.

Die Handlungsstränge kommen auf verschiedene Art und Weise zusammen. Schon innerhalb der Anderswelt kreuzen sich die Handlungen. Odysseus, der die Schänderpriester anführt, verbündet sich mit den Myrmidonen, um gegen das Zentrum und den Westen zu kämpfen. Dabei spielt auch Niam und die Prophezeiung von der Thetis-Flut eine Rolle. Es findet ein sofort niedergeschlagener Ein-Tages-Krieg statt und später noch einmal ein Aufstand, der jedoch auch nicht erfolgreich ist. Der Osten wird bezwungen, Ungefugger wird Präsident des Staates und Elena Goltz EWG-Leiterin. Doch auch durch Deters gibt es Verbindungen. Er begibt sich immer wieder in die Anderswelt und hat dort Kontakt zu Elena Goltz, Herrn Drehmann und den Holomorfenrebellen sowie Achilles Borkenbrod. Markus Goltz versucht herauszufinden, was es mit Deters auf sich hat und nimmt ihn sogar einmal gefangen. Der Roman endet damit, dass Deters, der - wie sich herausstellt - im Café auf Niam gewartet hat - in die Anderswelt hinein- und nicht mehr hinausgelangt.

Zwei Teile sind etwas aus dem Rest der Handlung herausgehoben. Ein >Intervallo<, das den Weltraumflug eines Raumschiffs (Mayflower II) darstellt, in der eine schlafende Mannschaft testweise in unendliche Weiten geschickt wird. Vom Computer als gottgleichem Bewacher angeleitet, wird sowohl Erd- und Menschheitsgeschichte rekapituliert sowie die Entwicklung eines Kindes aus der Mannschaft und ganzer nachfolgender Generationen in der Isolation geschildert. Die Reise stellt sich schließlich als ein Simulationsexperiment in der Anderswelt heraus, das fehlschlägt. Der zweite, wesentlich stärker herausfallende Teil wird kurz vor Ende des Romans eingeschoben. Dieses »Vierte[] Nachspiel: Quasi ein zweiter Prolog« (TA, 878-887), schließt unvermittelt an $W B$ an und bietet zu den dortigen drei bereits vorhandenen Epilogen eine weitere Version. Es wird angedeutet, dass Niam den Ich-Erzähler (Deters II) vor Rascher rettet und diesen tötet. ${ }^{17}$

Thetis ist insgesamt von einer für Herbst ungewöhnlich übersichtlichen, wenn auch keineswegs unterkomplexen Erzählstruktur. Die verschiedenen Handlungsstränge sind die meiste Zeit gut auseinanderzuhalten, die Plot-Orientiertheit einer auch auf Science-Fiction-Literatur referenzierenden Erzählweise wird deutlich. Bis auf die von

17 Diese Figuren werden im obigen Teil zu WB eingeführt und erläutert. 
Herbst bekannten abrupten Sprecherwechsel ist die Erzählweise eher konventionell, als Eigenart sticht die kommalose asyndetische Reihung von Substantiv-Dreiergruppen hervor. ${ }^{18}$

\section{Buenos Aires}

Buenos Aires ist dagegen fragmentierter, was sich schon auf der Textoberfläche zeigt. »Eingeblendete Fotographien (sichtlich digitalisiert), [...] musikalische Noten und eine variable Typografie durch Kursiv-, Fettdruck und verschiedene Schrifttypen [...] neben handschriftlich eingefügten Sätzen (die Graffitis [sic!] des Untergrundkämpfers Borkenbrod) und ganzen Schaltplänen unterwandern die visuelle Homogenität des Blocksatzes ${ }^{19}$; des Weiteren gibt es Fußnoten, Motti zwischen den größeren Abschnitten, Lücken im teils fragmentierten Text sowie konfuse Zeichenfolgen als Indikatoren des Wechsels zwischen verschiedenen Welten. Angesichts dieser Zersplitterung konstatiert Scherer: »Man kann für >Buenos Aires [ [...] kaum mehr eine Handlung wiedergeben. $\aleph^{20}$ Einige Handlungsstränge aus TA lassen sich jedoch durchaus nachverfolgen (im Folgenden keineswegs vollständig wiedergegeben), außerdem kommt einer neu hinzu.

Bei Letzterem handelt es sich gleich um eine komplett neue Erzählebene bzw. eigenständige Welt, deren genaues Einfügen in den Weltenaufbau der Gesamtkonstruktion weiter unten dargestellt wird. Die Anderswelt stellt sich ebenso wie die $>$ Welt $<$, Deters' Realwelt, in einer Lesart als Computersimulationen einer weiteren Welt heraus. In dieser, Garrafff genannt, sind die Hauptfiguren ein Programmierer namens Alban Herbst, seine Chefin Sabine Zeuner sowie der >fiese Kollege Lerche. Während in der Anderswelt Borkenbrod als Graffito-Rebell im Untergrund wirkt, Deidameia die vereinigten Myrmidonen- und Holomorfenrebellen anführt, denen ebenso wie dem in der Anderswelt gestrandeten Deters Goltz auf der Spur ist, manipulieren die Programmierer in Garrafff die Geschehnisse der simulierten Welten. Borkenbrod knüpft Kontakt mit Carola Ungefugger, der Ehefrau des Präsidenten, die ihm aus Vernarrtheit in seinen Sohn Jason ein Schiff zur Verfügung stellen will, die »Argo«. Auch Garrafff stellt sich als ein »bedingtes System " $(B A, 114)$ heraus, das in einer >seltsamen Schleife $<$ wiederum vom Wissenschaftler Beutlin und Goltz in der Anderswelt beobachtet und kontrolliert wird. Deters wird schließlich nach neun Jahren in der Anderswelt vom Programmierer Herbst gelöscht bzw. zwischengespeichert,

18 Als Beispiel: „Dann seh ich nur noch Wand Denkmal Bäckerei und weiß eben nicht mehr: Osten Westen Lohnniveau.« $(T A, 13)$ - Was Katharina Döbler als »kunstschreiberische Mätzchen« in die Nähe »Höhere[r] Deutsche[r] Jungliteratur « (Katharina Döbler: »Delirium und Moralium «, in: Neue Zürcher Zeitung, 6. Okt. 1998) rückt, versucht Brittnacher einerseits als »sprachliche Marotte» abzutun, andererseits als »lückenloses Inventarisieren des Moments« zu interpretieren, das »an das Verfahren einer Wackelkamera« erinnert (Brittnacher: »Der verspielte Untergang«, 40). Die Wirkung einer überbordenden Darstellungsweise ist damit ganz gut beschrieben; anzunehmen ist jedoch auch, dass das Stilmittel als Hommage an Döblins Berge Meere und Giganten (1924) gedacht ist, das für Herbst ganz allgemein und aufgrund der Überschneidungen in der Situierung bei TA im Speziellen ein wichtiges Referenzbuch ist, und in dem das Stilmittel von Döblin ebenfalls - und schon im Titel - verwendet wird.

19 Scherer: »Alban Nikolai Herbst $[K L G]$ «.

20 Ebd. 
wobei Herbst sich an seiner Stelle in die Anderswelt einschleust. Damit endet $B A$ ähnlich wie auch der Vorgängerroman damit, dass sich eine Figur in einer von ihr geschaffenen Welt wiederfindet.

\subsection{Holomorfenidentität: Autonomie und Originalität}

Insgesamt kann in Thetis eine Rückkehr zu psychologischen bzw. sozialpsychologischen Identitätsaspekten konstatiert werden. Diesmal geht es jedoch nicht wie in beiden Vorgängerromanen um aufgespaltene Identitäten. Hier werden der Science-Fiction-Situierung gemäß die menschlichen Identitätsfragen auf die Holomorfen übertragen und veranschaulicht.

Die Holomorfen sind Roboter ${ }^{21}$ in der Zentralstadt von Buenos Aires. Sie sehen den Menschen täuschend ähnlich, wobei die neueste Generation nur noch durch ein spezielles Gerät, ein Biometer, als nicht menschlich identifiziert werden kann. Technisch gesehen können sie als eine »Materie-Energie-Legierung " $(T A, 238)$ gesehen werden. Sie sind also programmiert, können durch die Datenleitungen woanders hingeleitet werden und über diese auch umprogrammiert werden. Zeitweise sind sie nur eine holographische Projektion. Sie können aber auch materialisiert werden. Insgesamt sind sie auf die Energie des Hodnaschirms angewiesen, der über dem Westen und Buenos Aires errichtet wurde. Die Technik, die die Materialisierung ermöglicht, wird dabei in verschiedenen Science-Fiction-typischen, technisch klingenden Begriffen beschrieben, die eine ungefähre Vorstellung vermitteln. Sie seien »selbstreflexive[] Feldstärkenwesen« $(T A, 265)$ oder aber "gescannte FeldPhotonenEmissionsholografien im hodnagravatischen Raum, worin sich elektromagnetische und energetische Felder als synthetische Materie bilden « ( $W V$, vii). Kennzeichnend für sie ist die Selbstreflexivität, das Vorhandensein eines Selbstbewusstseins. Dies bedeutet jedoch noch nicht, dass sie in jedem Fall wissen, dass sie Holomorfe sind. Herr Drehmann, der der Protagonist dieses Handlungsstrangs ist, ist sich seiner Herkunft klar und hat auch kein Problem damit, als Holomorfer den Menschen zu dienen (vgl. TA, 277). Die Anführerin der Holomorfenrebellen, Frau Tranteau, berichtet jedoch, dass sie erst zufällig entdeckt hat, kein Mensch zu sein (vgl. TA, 241).

21 Der Begriff $>$ Roboter $\triangleleft$ wurde von dem tschechischen Künstler Josef Čapek erfunden und von dessen Bruder, dem Schriftsteller Karel Čapek, in seinem Theaterstück R. U. R. - Rossum's Universal Robots (1920/21) bekanntgemacht. Interessanterweise werden in diesem Stück bereits etliche Themen eingeführt, die bis heute mit Robotern verbunden sind und auch in TA eine Rolle spielen: der Roboter als Arbeitssklave des Menschen, das daher von Pflichten und Zwängen befreite Leben der Menschen, die Auflehnung des Geschöpfs gegen seinen Schöpfer und auf abstrakterer Ebene der Konflikt zwischen Natur und Technik. Vgl. dazu Bianca Westermann: Anthropomorphe Maschinen. Grenzgänge zwischen Biologie und Technik seit dem 18. Jahrhundert, Paderborn 2012, 83-91. Die Kulturgeschichte des künstlichen Menschen geht jedoch viel weiter zurück: ausgehend von Prometheus als Menschenbildner, der Erschaffung der Pandora durch Hephaistos und den Pygmalion-Mythos über Homunculi, Golem, Frankenstein und die Automaten, die in der Literatur um 1800 eine bedeutende Rolle spielten, bis zu den Androiden, den menschenähnlichen Robotern der Science-Fiction. Vgl. dazu Klaus Völker: Künstliche Menschen. Dichtungen und Dokumente über Golems, Homunculi, Androiden und liebende Statuen, München 1976, 333-388, speziell zu den Automaten Westermann: Anthropomorphe Maschinen, 17-81. 
Herr Drehmann, der wie jeder Holomorfe keinen Vornamen besitzt, ist ein sogenanntes >Maultier`, das anstelle seines Besitzers zur Arbeit geht. Sein Besitzer ist Dr. Jaspers, der als Vater von Elena Jaspers auch anderweitig mit der Handlung verbunden ist. Die `Maultiere ähneln teilweise ihren Besitzern sowohl charakterlich als auch körperlich, wobei sich der eher hagere Dr. Jaspers Herrn Drehmann eher gemütlich und füllig hat gestalten lassen (vgl. TA, 276). Die Menschen lassen sich ihre >Maultiere nur selten als perfekte Roboter gestalten, sondern eher als »behinderte, irgendwie gemütlich mißratene, altsofa-artig defekte« $(T A, 796) .{ }^{22}$ Zum einen ist dies Teil der weitgehenden Simulation von Welt in der Zentralstadt, wo die Roboter ebenso die Menschen simulieren wie die Dingwelt (wie Wände, Häuser und andere Erscheinungen) holographisch dargestellt wird. Zum anderen sind die Holomorfen Abbildungen der Menschen und nicht perfekte, den jeweiligen Zweck viel besser erfüllende Wesen. Die Menschen können sich dadurch gut und sicher gegenüber den dienstbereiten Robotern fühlen.

Auch vom Bewusstsein sind die Holomorfen auf die perfekte Simulation hin programmiert, was in der Praxis auch eigentlich unperfektes Verhalten bedeuten kann. Herr Drehmann will so perfekt wie möglich als Abbild bzw. Vertreter seines Besitzers sein und geht deshalb auch wie ein Mensch zur Arbeit anstatt sich auf dem Datenwege zu transferieren (vgl. TA, 73). Er identifiziert sich völlig mit den Menschen, was auch körperliche Symptome nach sich zieht und ihm den Vorwurf der Rebellen einträgt, er sei »völlig vermenscht « ( $T A, 228$, vgl. auch 221). Ihm gefällt es, nicht als Holomorfer erkannt zu werden $(T A, 75)$, und er ist schließlich sogar glücklich, als er sich wie ein Mensch fühlt (TA, 218).

Dieser vorgefertigten Anlage entsprechend verstehen sich Herr Drehmann und Dr. Jaspers auch beim ersten Treffen sofort (vgl. TA, 275 und 526). Dr. Jaspers lässt den Holomorfen sogar als seinen Schwager eintragen, seine Frau Gisela ist also dessen "virtuelle Schwester « $(T A, 67) .{ }^{23}$ Holomorfe haben keine Geschwister, sie können »Angehörige nur nach $\mathrm{Pa}_{\text {« }}(T A, 67)$ haben. Wie immer bei Herbst, ist der Pass auch hier ein Bild für die Identität als solche. So wird auch erwähnt, dass die Holomorfen Identitätsnummern haben oder sich über ihren Handabdruck in einem Scanner ausweisen und bezahlen können $(T A, 69,217)$. Die Definition einer Verwandtschaftsbeziehung über den Pass erinnert dabei an die Thematik in $V G$ (die auch in $W B$ zumindest erwähnungsweise fortgeführt wird), wo Laupeyßer sich seine Verwandtschaft selbst erfinden will, da er unter der unfreiwilligen tatsächlichen Verwandtschaft leidet.

Die Ähnlichkeit mit den Menschen wird bis zuletzt fortgesetzt. Ebenso wie diese altern sie und werden schließlich pensioniert. Danach werden sie jedoch gelöscht $(T A, 68)$. In allen anderen Holomorfen werden ihre Spuren, also die Erinnerungen an sie, gelöscht und das System neu konfiguriert. Die Illusion der Menschenähnlichkeit ist damit allein für die Menschen bestimmt, für die eine solche Anpassung angenehm zu sein scheint.

22 Sogar »Desperados Gauner Totschläger « $(T A, 570)$ werden programmiert, wie Deters in Ingolstadt feststellt.

23 Später kommt jedoch heraus, dass solch ein Vorgehen keineswegs normal ist; es handelt sich vielmehr um die Idee von Frau Jaspers, die als zweite Frau von Dr. Jaspers die Tochter Elena ausstechen will. 
Herr Drehmann ist damit also ein dem Menschen dienender Roboter, der sich dessen auch bewusst ist, aber gänzlich auf den Menschen und die Identifikation mit diesem bezogen. Lediglich ein Aspekt steht dieser Identifikation zu diesem Zeitpunkt entgegen: die Emotionen des Menschen und die damit verbundene Sprunghaftigkeit ist ihm suspekt. Zwar scheinen bestimmte Gefühle vorhanden zu sein, doch sind sie begrenzt. Im Normalzustand des Holomorfen können die Emotionen damit als Unterscheidungsmerkmal des Menschen bestimmt werden.

\subsubsection{Die Identitätskrise des Herrn Drehmann}

Der eben beschriebene Normalzustand und die Funktionsweise der Holomorfen werden nebenbei erklärt und teils auch als Kontrast zu der eigentlich im Mittelpunkt der Erzählung stehenden Veränderung, die an Herrn Drehmann vor sich geht. Die Probleme, die diese Veränderung erzeugt, wachsen sich zu einer Krise aus, die Aspekte der Holomorfenidentität besonders herausstellt und auch die Beziehung zu realen menschlichen Identitätsfragen herstellt. Der im Folgenden dargestellte Ablauf der Veränderungen entspricht nicht der Präsentation im Text, sondern der zu rekonstruierenden Chronologie. Dabei werden zunächst die von Herrn Drehmann selbst induzierten Veränderungen beschrieben und dann die mit den Holomorfenrebellen in Zusammenhang stehenden.

Die auffallendste Absonderlichkeit, die sich bei Herrn Drehmann entwickelt, ist die banal wirkende Tatsache, dass er gerne isst. Er gehört zur weit entwickelten sogenannten `Mönchs- bzw. Nonnenreihe`, der organische Fähigkeiten einprogrammiert sind (vgl. TA, 70). Diese etwas despektierliche Bezeichnung erklärt sich daher, dass die Generation von Holomorfen anstrebe, »sich durch Dienstbarkeiten von ihrer Digitalität zu läutern« (TA, 273); kennzeichnend ist also die oben beschriebene dienende Identifikation des Holomorfen mit den Menschen. Holomorfe wie Herr Drehmann können demnach Stoffwechsel simulieren, was sie vor allem zu perfekten Begleitern beispielsweise bei Empfängen machen kann. Die Besonderheit bei Herrn Drehmann ist nun, dass sich diese Fähigkeit verselbständigt. Er entwickelt eine Vorliebe für gutes Essen, wodurch die Fähigkeit ihre reine Zweckmäßigkeit verliert. Dies geht soweit, dass er die Vorliebe tagsüber unterdrückt, um nicht aufzufallen, für sich die ansonsten verkümmerte Esskultur der Menschen wiederentdeckt und alleine auslebt (vgl. TA, 69f.). Dadurch gewinnt er an Eigenständigkeit, seine Zielsetzung ist nicht mehr allein der Dienst für den Menschen. Gleichzeitig wird er im Grunde menschlicher als die Menschen, da er die ursprüngliche menschliche Kultur eher lebt als die sich weitgehend künstlichen ernährenden Menschen selbst.

Auslöser der `Krise`selbst ist jedoch die verbliebene Erinnerung an seinen ebenfalls holomorfen Kollegen Herrn Hausmann. Dieser war anscheinend wegen auftretender Probleme gelöscht worden. Wie bereits erwähnt werden die Spuren eines gelöschten Holomorfen ebenfalls entfernt, sodass andere Holomorfe keine Erinnerung an diese haben. Menschen erinnern sich natürlich an sie, es ist jedoch normal, nicht weiter darüber nachzudenken oder diese zu erwähnen. Herr Drehmann erinnert sich jedoch weiterhin an Herrn Hausmann. Als Ersatz wurde eine weibliche Holomorfe 
eingesetzt, Frau Dr. Doradin. Außerdem scheint Herr Drehmann auf einmal eine Ehefrau zu haben. ${ }^{24}$ Die Erinnerungen an Herrn Hausmann sind unregelmäßig und ihm fallen erst nach und nach Details ein. Ihm ist dabei klar, dass er sich eigentlich nicht erinnern dürfte und die fehlerhafte Erinnerung eigentlich melden müsste. Ihm ist seine "Gemütsverstimmung " $(T A, 71)$ also bewusst und auch, dass eine solche für Holomorfe eigentlich unmöglich ist. Eine mögliche technische Erklärung wäre ein Virus im System, was er jedoch auch nicht meldet, da er nicht riskieren will, abgeschaltet zu werden.

Der >Auslöser ‘ der Krise, die fehlerhafte Erinnerung, zieht weiteres Nachdenken nach sich. Dabei geht es um die Frage, welche Aspekte an ihm bzw. welche seiner Handlungen »datisch erzeugt, also hinzuprogrammiert « $(T A, 76)$ sind und welche selbstorganisierend verursacht und damit quasi von ihm kreiert sind. Dies zeigt sich auch in der Überlegung, die ihn beschäftigt, ob elektronische Bestellung und Geldtransfers wirklich stattfinden oder ob die Vorstellung davon ihm lediglich einprogrammiert ist. Die Formulierung, die Frage habe "von seinem Denken Besitz ergriffen « $(T A, 69)$, deutet an, dass er sich die Veränderungen nicht erklären kann und sie womöglich von außen an ihn herangetragen sind. Stoßrichtung seiner Zweifel ist damit die Frage nach der eigenen Autonomie. Er fühlt sich wie ein »Versuchstier (TA, 77), das von der Stuttgarter Computerzentrale verändert wird. Die Verunsicherungen erzeugen in ihm ein Gefühl, das so sein müsse, als würde »einer bei hellem Bewußtsein umprogrammiert « $(T A, 71)$. Er ist daher so verunsichert, dass er einerseits eine elektronische Manipulation von außen vermutet, andererseits aber sich die Frage stellt, ob er tatsächlich ein Maultier oder gar überhaupt ein Holomorfer sei (vgl. TA, 80 und 123).

Herr Drehmann scheint jedoch tatsächlich von verschiedenen Parteien beeinflusst zu werden. Die offiziell für ihn als Holomorfen zuständige Computerzentrale versucht, ihn erst zu reparieren, später dann zu löschen. Gleichzeitig manipulieren ihn die Ingolstädter Holomorfenrebellen um Frau Tranteau. Es stellt sich schließlich heraus, dass die Erinnerung an Herrn Hausmann ihm durch sie zugespielt wurde. Ebenso träumt er mehrfach von der Begegnung mit Frau Tranteau, die ihm vermutlich auch >datisch zugespielt wird, da sie schließlich genau so abläuft wie geträumt (vgl. TA, 71, 126, 236). Durch die Manipulationen verirrt er sich auch mehrfach bei Spaziergängen und findet einmal eine Adresse, wo befreundete Menschen wohnen, die sich zusammen mit ihm und Herrn Hausmann regelmäßig zu einer Spielrunde trafen. Später dann landet er beim früheren Haus von Herrn Hausmann selbst, wo ihn dieser erwartet und zu den Rebellen bringt. Herr Hausmann wurde also nicht gelöscht, sondern ist Mitglied der Rebellen. Der scheinbar unbewusste, von außen erzeugte Drang, zu einem bestimmten Ziel zu gehen, erinnert dabei an Falbins `Irregehen in VG. Auf diese Weise wird die Identitätsthematik des Holomorfen Herrn Drehmann mit der der Menschen verbunden.

24 Die Verunsicherung bekommt fast paranoide Züge, als ihm auffällt, dass seine Frau und seine Kollegin sich anscheinend absolut ähneln, vgl. TA, 127f. Später stellt sich jedoch heraus, dass er wohl gar keine Ehefrau hat, diese Vorstellung ihm auch nur zugespielt wurde, vgl. TA, 243. 


\subsubsection{Ansichten der Rebellen und autonome Holomorfenkultur}

Die Holomorfenrebellen sind eine Gruppierung von Holomorfen in Ingolstadt, die alle an sich Veränderungen festgestellt haben und ihre Selbstreflexivität über das normale Maß hinaus entwickelt haben. Individuell dargestellt werden sie durch die beiden Figuren Herr Hausmann, der wie Herr Drehmann ein `Maultier` war und eine Leidenschaft für Telefonkarten entwickelt hat, und Frau Tranteau, die die Anführerin der Rebellen ist. Beide sind im Vergleich zu Herrn Drehmann schon fortgeschritten in ihren Überlegungen und wesentlich radikaler; sie gehen in den Konsequenzen, die sie aus den beobachteten Entwicklungen ziehen, deutlich über Herrn Drehmanns Absichten hinaus. Wohl selbst am weitesten entwickelt, stellen Frau Tranteaus Ausführungen die am deutlichsten ausgearbeitete Position der entwickelten Holomorfen dar.

Das wichtigste Kriterium für die Bedeutung der Entwicklung der Holomorfen, das sie zu wirklichen »Geschöpfe $[n]$ « $(T A, 242)$ macht, ist die Unvorhersehbarkeit, mit der die Entwicklung vonstatten geht. Ursprünglich war die Weiterentwicklung der Holomorfentechnologie aus praktischen Gründen angestoßen worden; die vom Energieschirm über der Zentralstadt abhängigen Roboter sollten auch außerhalb, vor allem an der Mauer zum Thetismeer, eingesetzt werden. Für die Entwicklung von Selbstprojektoren, die die nötige Energieform in mobiler Version zur Verfügung stellen sollten, war Frau Tranteau zuständig. Der verantwortliche Sicherheitschef Klaus Gerling bemerkte die aus dem Ruder laufende Entwicklung, unternahm aus einer gewissen Lust an Chaos und `natürlicher oder ursprünglich scheinender Unkontrollierbarkeit jedoch nichts dagegen. Die Menschen haben die Holomorfen-Entwicklung also eher als eine Form von Experiment beobachtet und die dem Zufall unterliegende Veränderung interessiert verfolgt. Das plötzliche Auftreten von Neigungen und Lüsten ist dabei nicht durch Besonderheiten der Programmierung zu erklären, sondern unterliegt einzig dem Zufall. Damit haben die Holomorfen nach Frau Tranteaus Ausführungen individuelle Besonderheiten und damit eine Form von Charakter entwickelt, der sie eben zu Geschöpfen macht. Die durch die spezifische, ursprünglich vom Kunden bestellte und bestimmte Programmierung lässt sie schon von vornherein zu Originalen mit eigener Signatur werden. Die selbstkodierende Veränderung verstärkt nun noch die Individualisierung.

Die Ansichten und Forderungen der Holomorfen haben dabei generell einen Bezug zu den Menschen, auch wenn sie sich von diesen abzugrenzen versuchen. Im Normalzustand ist es ihre Funktion, den Menschen behilflich zu sein und zu dienen, weshalb sie sich den Menschen so weit wie möglich angleichen. Die Rebellen sind - als sich ebenso erst neu definierende Individuen wie als formierende `Gattung « bemüht, sich mit den Menschen zu vergleichen und sich von ihnen abzugrenzen. Aus dem Vergleich resultiert zunächst die Ansicht von der Überlegenheit der Holomorfen. Schon der die Entwicklungen anstoßende Gerling sieht sie »an Schlagkraft wie vor allem Belastbarkeit« $(T A, 161)$ den Menschen überlegen, wobei sich an den Kategorien schon die Zielsetzung eines Kampf- oder Arbeiterroboters ablesen lassen, der die Nachteile eines Menschen technisch ausgleicht. Außerdem spricht in solchen Überlegungen natürlich der bis zu den unvorhergesehenen Entwicklungen geltende 
Fakt eine Rolle, dass sie `seelenlose und damit austauschbare Roboter sind, die im Gegensatz zu den Menschen keinen wirklichen Wert haben und daher verschlissen werden können. In diesen Planungen ebenso wie im in der Anderswelt erreichten Alltag zeigt sich die Überlegenheit der Technik für spezifische Aufgaben gegenüber dem durch seine Natur sprunghaften und eingeschränkten Menschen. Holomorfe sind als Arbeitsersatz (als >Maultier ) auch darum so geeignet, weil sie nicht lernen oder sich einarbeiten müssen, da sie ans Netz (Euroweb genannt) angeschlossen sind und dadurch immer auf dem neuesten Stand der Informationen gehalten werden (vgl. $T A$, 406). Zudem können sie zwar materialisiert werden, brauchen aber im Grunde die Körper nicht. In Gebieten, wo fast nur Holomorfe sind, bleiben sie reine Projektionen ohne materielle Substanz. ${ }^{25}$ Die Schlussfolgerung aus diesen Überlegungen wird von Herrn Hausmann in radikaler Manier zusammengefasst durch den Ausruf: »Denen sind wir überlegen!» $(T A, 235)$ Eine solche Vorstellung stützt sich nicht nur auf den Vergleich in einigen Punkten, an denen technische Vorzüge die Überlegenheit beweisen, sondern basiert zunächst erst einmal auf dem Versuch, die beiden `Gattungen`gleichzustellen, indem scheinbar offensichtliche Nachteile oder Mängel der Holomorfen relativiert werden. Frau Tranteau argumentiert in dieser Hinsicht in Bezug auf die Entwicklung eines eigenständigen Selbstbewusstseins. Sie gesteht den Illusionscharakter der Holomorfen aufgrund ihrer Programmierung und Projektion ein. Im Gegensatz zu einem Tisch als realem Ding schienen sie zunächst nur Illusion. Durch die spezielle Technik, die ihre Materialisierung ermöglicht, seien sie jedoch mit der Dingwelt sogar verzahnt. Ihr neu entdecktes >Fühlen` sei damit gleichzeitig Illusion und real, ebenso wie das Fühlen des Menschen auch nur Illusion sei (vgl. TA, 238). An dieser Stelle wird wieder der für Herbst kennzeichnende Realitäts- und Wirklichkeitsbegriff angewandt. Die Realität ist nur eine Illusion und die Wirklichkeit ist durch die tatsächliche Wirkung bedingt. Da die Holomorfen auch `wirken`, seien sie und ihre Gefühle auch wirklich. Ein ähnlicher, aber einfacherer Vergleich zwischen Menschen und Holomorfen ist der spezifische Nachteil der Holomorfen, auf den Hodnaschild angewiesen zu sein (weswegen auch die Selbstprojektoren entwickelt werden sollten). Der direkte Vergleich ergibt jedoch wieder eine Gleichstellung, da auch die Menschen auf eine spezifische Atmosphäre angewiesen sind (vgl. TA, 240).

Frau Tranteau baut die Überzeugung von der Überlegenheit der Holomorfen in einen geschichtsphilosophischen Horizont ein. Sie sieht die Holomorfen als Teil einer geschichtlichen Entwicklung bzw. als Ausdehnung der Theorie biologischer Evolution. Zweimal werden dabei wieder Vergleiche mit der Entwicklung der Menschheit bemüht, die beide jedoch nur entfernt eine Begründung liefern. Zum einen wird eine Parallele zur Befreiung farbiger Menschen aus der Sklaverei der Weißen aufgemacht. Auch in diesem Falle hätten viele der Unterdrückten anfangs nicht die Zusammenhänge der Unterdrückung und den Sinn einer Befreiung gesehen (vgl.

$25 \mathrm{Vgl}$. TA, 569. An einigen solchen Stellen werden die Begründungen für logische Zusammenhänge der fiktiven, in der aktuellen historischen Zeit aber unmöglichen technischen Entwicklungen etwas dünn, wie dies vielleicht immer in reich ausgestatteten fiktiven Welten der Fall ist. Warum sollten die Holomorfen an dieser Stelle beispielsweise dann überhaupt als Projektionen durch die Gegend laufen und nicht reine Rechenprozesse bleiben? Für die Ausarbeitung der Fragen nach Problemen der Identität ist dies jedoch nebensächlich. 
$T A$, 237). Grundlage des Vergleichs ist die Vorstellung von einem geschichtlichen Fortschreiten von Unterdrückung zu einer Befreiung und Gleichstellung aller. Zum anderen wird noch eine geschichtsphilosophische Perspektive aufgemacht, die jedoch über das real-historische hinausgeht und die Mythologie mit einbezieht. »Hatten mythisch die Götter die Riesen gestürzt und die Menschen die Götter, so stiege geschichtslogisch nun der Holomorfe auf.« $(T A, 523)$ Diese Entwicklung sei in der Geschichte so angelegt und Teil einer »informatischen Evolution« (ebd.); die Holomorfen seien insgesamt höher entwickelt als die Menschen und Ziel der Evolution (vgl. TA, 239). Hier liegt ein teleologisches Weltbild zugrunde, wobei jedoch nicht näher auf die dahinterliegende Macht, sei sie göttlich oder eine Art von Schicksal, eingegangen wird.

Unabhängig vom Überlegenheitsdiskurs kann festgehalten werden, dass der Unterschied zum ^Vorher ` der plötzlichen Entwicklung, also zum geplanten Normalzustand der Holomorfen, darin besteht, dass sie ein eigenes Selbstbewusstsein sowie die Fähigkeiten entwickelt haben, Gefühle zu haben. Die Förderung dieser Fähigkeiten und die Befreiung der Holomorfen aus ihrer (nicht selbstgewählten) Bevormundung oder gar Unterdrückung durch die Menschen wollen sie durch die Weiterentwicklung der Selbstprojektoren erreichen, durch das Projekt, an dem Frau Tranteau federführend gearbeitet hat. Dies ist jedoch lediglich die technische Seite der angestrebten Unabhängigkeit. Die Notwendigkeit der Entwicklung einer eigenständigen Identität unabhängig vom Menschen ist den Rebellen durchaus bewusst. Dem sehr nah an den Menschen orientierten Herrn Drehmann sind die Kriterien für das Menschliche und das Holomorfe noch sehr nahe beieinanderliegend. So verwechselt er sogar in seinem Denken die Begriffe >menschlich und `holomorf^, da ihm die Kriterien für die Unterscheidung durcheinandergehen (vgl. TA, 225). Die Rebellen sind daher bemüht, neue spezifisch holomorfe und damit nicht menschliche Kategorien des Denkens und Fühlens zu entwickeln (vgl. TA, 227). Offensichtlich scheinen sie jedoch darin noch nicht sehr weit fortgeschritten zu sein, da wie bereits beschrieben alles in Bezug auf die Menschen oder in Abgrenzung von ihnen geschieht.

Frau Tranteau fordert daher ein »holomorfe[s] Klassenbewusstsein « $(T A, 521)$ ein, das jedoch erst dabei ist, sich zu entwickeln. Die Holomorfen sollen bewusst dem Unterdrückergeist der bisherigen Beziehung zum Menschen folgende Gedanken und Sprache vermeiden oder jegliche Anpassung an die Menschen auch in der Übernahme von Angewohnheiten wie dem Essen oder gar der völlig unnötigen Einnahme von Ernährungspillen aufgeben. In gewisser Hinsicht stellt dies jedoch wiederum eine zwangsweise Gängelung der Holomorfen dar. Insbesondere bei Herrn Drehmann ist gerade das Besondere, dass er gerne isst; dies ist es, was ihn zum individuellen Holomorfen macht, auch wenn es den typischen Anforderungen oder Bedürfnissen der Holomorfen widerspricht. Abgesehen von der Möglichkeit, hierin eine Inkonsistenz im narrativen Aufbau der fiktiven Welt zu sehen, kann sich daran auch die Schwierigkeiten der Holomorfen zeigen, sich wirklich unabhängig vom Menschen zu definieren und eine spezifisch eigene Identität aufzubauen.

Dass sich in dieser Hinsicht schon einiges abseits der Bemühungen der Rebellen getan hat, ist an der Entwicklung holomorfer Subkulturen im Raum Ingolstadt zu sehen. Dort leben Holomorfe in friedlicher Koexistenz mit Menschen bzw. haben 
teilweise sogar deren Sympathien. Dort entsteht Holomorfenmusik, -dichtung und -malerei auf der einen Seite; aber auf der anderen auch die dunkleren Seiten einer sich entwickelnden Gesellschaft, Vergnügungsviertel, Bars und heruntergekommene oder verbrecherische Holomorfe (vgl. TA, 521 f. und 569f.). Auch das spiegelt jedoch wieder die menschliche Natur und Gesellschaft, da die Holomorfen zunächst einmal von Menschen so bestellt und programmiert wurden. Vorgeführt wird die immer vorhandene negative Seite des Menschen, die selbst auf die eigentlich neutralen Holomorfen abfärbt.

\subsubsection{Veränderungen an Herrn Drehmann nach dem Kontakt mit den Rebellen}

Herr Drehmann ist zunächst sehr skeptisch gegenüber den Einwürfen seines früheren `Freundes` Herrn Hausmann und den Ausführungen von Frau Tranteau. Die selbstinduzierten sowie die von außen applizierten Veränderungen hatten bei ihm bislang nur Verwirrung, aber noch keine Veränderung im Denken gebracht. Diese vollzieht sich erst nach und nach, als er in sein normales `Leben` zurückgeschickt wird. Vor allem beschäftigt ihn der Aspekt der Individualität, die Idee, ein eigenständiges Wesen zu sein. Für ihn, der seine Existenz bislang nur als Diener seines Besitzers begründet sah, ist es etwas besonderes, "für sich genommen etwas zu sein« (TA, 267) Zwar unterscheidet er sich äußerlich von Dr. Jaspers, ist aber von diesem in seinen Grundzügen bestimmt und dessen Vorstellung angepasst; nun entdeckt er, dass er »nicht nachgemacht sein« $(T A, 268)$ will. Zunächst geht er noch von der Angleichung an den Menschen aus und hat ein Problem damit, sich ja doch von diesen fundamental zu unterscheiden. Doch beginnt er, die diesem zugrunde liegende Wertung zu hinterfragen: »War einer denn schlechter, bloß weil er sich unterschied?« $(T A, 265)$ In dieser Frage steckt jedoch ganz vehement der Gedanke, eben kein gleichförmiger Roboter zu sein, sondern ein Individuum, ein sich von allen anderen unterscheidendes Wesen. Aufgrund der Zurückweisung durch seine menschlichen `Freunde` fühlt er sich ausgeschlossen, beginnt jedoch auch hier, die Bewertung zu verändern. Ist seine gewohnte erste Schlussfolgerung, er gehöre nicht dorthin oder dazu, folgt nun erstmals die gedankliche Umkehrung, vielleicht gehörten die Menschen nicht in diese Welt, was impliziert, dass die Welt für die Holomorfen da sei (vgl. TA, 218). Die individuierende Abgrenzung von den Menschen führt also auch bei ihm zu Überlegenheitsgedanken. Er bewertet die Fakten noch einmal neu: die Menschen seien angewiesen auf Nahrung und materielle Bewegungsmittel, wohingegen sich Holomorfe allein durch Gedankenkraft »Räume Orte Kontinente schaffen und also wechseln« $(T A, 265)$ könnten. ${ }^{26}$ Zudem könnten die Menschen eigentlich überallhin gelangen, doch würden sie (die Menschen der Zentralstadt und des Westens zumindest) diese Möglichkeit nicht ergreifen (vgl. TA, 269), sie würden die Welt lediglich in Simulationen wahrnehmen und erleben.

Ein im Kontext des Identitätsdiskurses bei Herbst wichtiger Aspekt ist die Bedeutung des Körpers für die Identität. Bei den Holomorfen und gerade bei Herrn

26 Den Beweis zu erbringen, dass dies auch Menschen können, ist allerdings Deters ureigenste Aufgabe. 
Drehmann wird auch dies wieder thematisiert. Schon die Bestellung von Dr. Jaspers ist durch besondere Aufmerksamkeit dem Körper gegenüber gekennzeichnet, insofern er eher füllig und in Einklang mit dem gemütlichen Temperament gebildet wird. Zudem gehört er der Generation von Holomorfen an, die den menschlichen Stoffwechsel simulieren können. Die Anpassung an den Menschen zeigt sich also auch im Körperlichen. Insofern wählt er auch meist den beschwerlichen Weg zu Fuß und nicht den datischen Transferweg, um nicht als Holomorfer aufzufallen und den menschlichen Besitzer perfekt zu simulieren. Nach dem Kontakt mit den Rebellen behält er diese Angewohnheit bei, jedoch wechselt die Bewertung entscheidend: er macht dies nun nicht mehr aus Anpassung, sondern aus (stillem) Protest. Er wählt nicht den für Holomorfe vorgesehenen Weg, sondern aus freien Stücken die Art von Fortbewegung, die ihm passt. Die Auflösung von Identität wird an ihm ganz plastisch vorgeführt, wenn er die Grenzen seines bisherigen möglichen Wirkungskreises austestet. Nach dem Treffen mit Frau Tranteau geht er ziellos durch die Gegend bis an den Rand des Hodnaschirms, wo sein Projektionssignal nur undeutlich ist. Ihm wird leicht übel, seine Gliedmaßen werden durchsichtig und verlieren an Kontur oder verschwinden ganz, was jedoch keine Schmerzen verursacht. Er zieht sich jedoch wieder in den sicheren Bereich zurück und sein Körper wird wieder ganz fest und präsent (vgl. TA, 267). Ähnliches fällt Deters an Herrn Hausmann auf, als dieser ihn zu Frau Tranteau bringt. Im Gleiter wird Herrn Hausmanns Handgelenk durchscheinend, was auch ihn nicht schmerzt und was er auf den Einfluss der Sicherheitszentrale zurückführt (vgl. $T A, 566 f$.). Auf diese Weise wird sehr deutlich die Bedeutung, aber auch die Fragilität des Körpers für die Holomorfen veranschaulicht. In den Holomorfen wird eine Entwicklung vorweggenommen und auf die Spitze getrieben, die sich bei den Menschen vollzieht und deren Vorreiter der Unsterbliche und spätere Präsident Europas Toni Ungefugger ist. Er hat eine starke Abneigung gegen alles Natürliche und propagiert die Entkörperlichung, sein Ziel ist die Existenz als reines Bewusstsein. In diese Überlegungen fügen sich die Holomorfen perfekt ein, worauf später zurückzukommen ist (vgl. Abschnitt 5.4.2 auf Seite 256.).

Die Entwicklung im Zeitraum der Handlung von TA ist noch einmal folgendermaßen zusammenzufassen: der Normalzustand der Holomorfen ist die weitgehende Emotionslosigkeit. Emotionalität ist menschlich und für die Holomorfen suspekt, da sie sprunghaft und daher nicht vorhersehbar ist. Nach der Entwicklung individueller Leidenschaften ist jedoch das Kennzeichen der fortgeschrittenen Holomorfen das Fühlen und Erleben von Emotionen. Die Rebellen wollen sich von den Menschen abgrenzen, entwickeln sich jedoch (unbeabsichtigt) in genau ihre Richtung. Die Pointe dabei ist, dass gerade Frau Tranteau sich letztlich als menschlicher als die Menschen (der Anderswelt) erweist und dadurch untergeht. Der Sicherheitschef der EWG, Markus Goltz, der auch im Konflikt mit Deters steht, beobachtet die Rebellen und plant einen Überfall auf die Rebellenzentrale und die Zerschlagung der Rebellion. Gerade Herr Drehmann ist es, der unbeabsichtigt Signale an die Sicherheitszentrale übermittelt. Dies ist Frau Tranteau bekannt, doch kann sie sich »aus Menschlichkeit« $(T A, 524)$ nicht dazu entschließen, ihn um der Sicherheit der anderen willen zu eliminieren. Diese Gegenüberstellung und Umkehrung der eigentlich zu erwartenden Verhält- 
nisse funktioniert nur durch eine die Menschen von Buenos Aires kennzeichnende Gegenentwicklung, die später beschrieben werden soll.

\subsubsection{Parallelen und Differenzen zur menschlichen Identität}

Die genauere Untersuchung der Passagen, die von den Holomorfen handeln und sich vor allem um ihre individuelle wie gruppenspezifische Identitätsfindung drehen, zeigt die Übertragung von realen menschlichen Identitätsfragen auf und ihre repräsentative Darstellung an den Holomorfen. Herbst führt die Beschäftigung mit Identitätsfragen, die an ähnlichen Aspekten schon in $V G$ zu finden sind, fort, überträgt sie jedoch auf eine technisierte Umgebung der möglichen Zukunft.

Ganz konkret können verschiedene Kategorien realer (historischer) Identitätstheorien im Holomorfendiskurs festgemacht werden. Die »Qual der Selbsterkenntnis« (TA, 218), die Herr Drehmann durchleiden muss, verdeutlicht die Schattenseiten, die Probleme der Identitätsfindung auch von Menschen. Dabei werden implizit verschiedene bekannte Aspekte sozialpsychologischer Theorien appliziert. Die Störungen, die Herrn Drehmann aus seiner eigentlich gefestigten Identität als ein Wesen reißen, das seinen Wert aus der Verbindung zum Menschen zieht, thematisieren die Kontinuitätsproblematik. Für die Konstruktion eines stabilen Ichs ist die kontinuierliche Betrachtung der eigenen Handlungen und ihre Einordnung nötig. Unabdingbar ist dafür die Leistung der Erinnerung, da nur sie Kontinuität gewährleisten kann. ${ }^{27}$ Die Störung der Erinnerung wird an Herrn Drehmann sehr plastisch vorgeführt. Dabei ist weniger das vollständige Fehlen der Erinnerung ein Problem, wie es bei der ınormalen` Löschung eines Holomorfen vorläge, da dieses per se nicht bewusst wäre, sondern die gestörte Erinnerung, das Bewusstsein, sich nicht auf die Erinnerung verlassen zu können und damit die Unsicherheit über die eigene Verortung.

Ein weiterer Aspekt ist der der Individualisierung, der Bewusstwerdung der eigenen Individualität durch die Abgrenzung von anderen. Herr Drehmann stellt dies für sich persönlich fest, nachdem die Begegnung mit den Rebellen und ihre Ansichten auf ihn zu wirken beginnen. Er möchte nicht ein lediglich dem Menschen nachempfundener Roboter sein, vielmehr gefällt ihm der Gedanke, eigenständig für sich etwas zu sein und einen eigenen Wert zu haben. Die kollektive Identitätsbildung der Holomorfen fällt dahingehend jedoch etwas komplizierter aus. Sie sind `natürlicherweise auf den Menschen bezogen, da sie von diesen hergestellt, programmiert und nach individuellen Wünschen bestellt werden. Durch die zufällige sprunghafte Entwicklung von Eigenheiten stellen sie die Individualität für sich fest und wollen sich auch als Gruppe, `Gattung` oder `Spezies` von den Menschen abgrenzen. Dieser Vorgang ist jedoch schwieriger als von Frau Tranteau erhofft oder überhaupt erkannt. Die vollständig von den Menschen geprägten Holomorfen, die selbst in ihren neu entwickelten Eigenheiten den Menschen ähneln, wollen eigene Denk- und Fühlkategorien entwickeln, doch worin sollen diese bestehen? Abgesehen von kleinen, eigentlich technischen Unterschieden werden solche nicht dargestellt oder auch nur angedeutet.

Interessanterweise wird hier eine selbst für die menschliche Identitätskonstruktion wichtige Unterscheidung der sozialwissenschaftlichen Identitätsforschung angewen-

27 Vgl. Gymnich: »Individuelle Identität und Erinnerung«, v. a. 33-39. 
det und veranschaulicht, die Unterscheidung zwischen Innen- und Außenperspektive, deren Relation das Realitätsproblem beschreibt. Herr Drehmann, dessen Andeutungen über seine Probleme an der neu hinzuprogrammierten Kollegin Dr. Doradin verständlicherweise abprallen, da sie eine ‘funktionierende` Holomorfe ist, ist in dieser Zeit gänzlich auf seine Innenperspektive, auf sich selbst zurückgeworfen. Er braucht jedoch die Reaktion und Bestätigung von außen, um die Störungen überhaupt einordnen zu können. Diese erhält er schließlich auf eher unangenehme Art durch seine menschlichen >Freundeく sowie später dann durch Herrn Hausmann und Frau Tranteau.

Die Parallelisierung der Holomorfen mit der menschlichen Situation findet sich konkret angesprochen in einer Überlegung von Deters, die jedoch - soweit das überhaupt zu trennen ist - stärker den Realitäts- und Fiktionsdiskurs betrifft, als Fragen der Identität. Deters denkt, dass es ihm wie Herrn Drehmann gehe. »Alles ist simuliert. Ich selbst bin Simulation in einem Gehirn.« $(T A, 380)$ Im Umfeld dieses Zitats finden sich Bezüge auf $V G$ und $W B,{ }^{28}$ die auf die sich ähnelnde Erzählkonstruktion aller Romane der Pentalogie anspielen, wo eine Figur eine andere erfindet. Dies sagt auch etwas über die Annahme fehlender Autonomie und damit über die Identität aus; hier ist der Gedanke jedoch vor allem als deutlichster Bezug auf die Parallelisierung von Holomorfen und Menschen zu sehen.

Gerade die Frage der Autonomie ist eine weitere Parallele, die nicht nur für Herrn Drehmann, sondern vor allem auch für die Rebellen gilt. Das wichtigste Ziel der rebellierenden Holomorfen, das Ziel, das eigentlich erst die Rebellion ausmacht, ist der Wille, unabhängig von den Menschen und ihrer Programmierung zu werden. Hier wird die historische Parallele zur in der realen Geschichte der Menschen immer wieder auftretenden Entwicklung von Unterdrückung bzw. Dienerschaft zu Freiheit und Selbstbestimmung deutlich. Auch hier gilt jedoch die Begrenztheit in der Ausführung bzw. Ausschmückung der fiktiven Welt. Zwar wird der Frage nachgegangen, wie die Holomorfen die Selbstprojektoren unabhängig betreiben sollen, da sie immer wieder davon abhängen, dass ein Mensch oder ein anderer (eingeschalteter) Holomorf den Selbstprojektor in Gang setzt. Die Frage der Reproduktion wird jedoch nicht angesprochen. Wie entstehen neue Holomorfe? Werden sie von anderen programmiert? Wären sie dann wiederum abhängig von diesen und müssten sich von diesen emanzipieren?

Abgesehen von den Parallelen zwischen Identitätsproblemen der Holomorfen und denen der Menschen, wirft die durch ihre Revolte Beachtung findende Entwicklung der Holomorfen auch Fragen bei den Menschen auf. Dies wird beispielhaft an Goltz veranschaulicht.

Wegen Deters kommt Goltz immer wieder ins Grübeln, da er dessen ontologischen Status nicht versteht. Obwohl er als \Polizeichef Europas « sehr mächtig ist und ihm alle Fahndungsmöglichkeiten offenstehen, gelingt es Deters immer wieder, seine Verfolger abzuschütteln. Dadurch, dass dieser unbewusst die Welten wechselt, löst er sich für die Beobachter in der Anderswelt scheinbar in Luft auf. Goltz wendet sich an den 
Wissenschaftler Beutlin (vgl. BA, 99ff.), um Genaueres über die Möglichkeiten zu erfahren, wie Holomorfe aufgespürt und identifiziert werden können. Dieser berichtet von den Experimenten mit Modellwelten, die rein virtuell verschiedene Szenarien durchspielen, und die Verbindung zwischen den Welten. Da sie alle als Computersimulationen gleich aufgebaut sind, lassen sich Fragmente der Welten und auch die >datischen Geschöpfe` zwischen ihnen hin- und herkopieren. Menschen sollen sich eigentlich nur über ihr Bewusstsein in diese Welten einklinken können, während ihre Körper an »Infoskope und Simularmaschinerien angeschlossen " $(B A, 150)$ sind (wie in den Filmen eXistenZ (1999) von David Cronenberg und der Matrix-Trilogie (1999/2003) der Wachowski-Geschwister). Es gibt nun aber auch Experimente, rechte Menschen zu `sampeln $\triangleleft$ quasi elektronisch nachzubauen. Diese Experimente sind dabei aus dem Ruder gelaufen, da die gesampelten Personen ein Eigenleben begonnen haben und ihren eigentlich noch zu programmierenden `Charakter eigenständig mit aus der Umgebung >aufgesogenen $<$ Daten gefüllt haben (vgl. BA, 98-101).

Unter dem Aspekt der Identität geht es hier noch einmal aus menschlicher Sicht um die Frage, was einen Menschen ausmacht. Goltz geht in seinen Überlegungen als >Polizeichef` zunächst von juristischen Aspekten aus; angesichts der Strafverfolgung überlegt er, ob es möglich wäre, Verbrecher zu holomorfisieren und dadurch körperlos einsperren zu können (vgl. BA, 99). Bereits vorher hatte Goltz die Idee einer »datischen Kopie« seiner selbst fasziniert, um angesichts holomorfer Rebellen und elektronischer Überwachungsmöglichkeiten in gleicher Form interagieren zu können. ${ }^{29}$ Nun erschrecken ihn die Erläuterungen von Beutlin aber gleich in doppelter Hinsicht. Zum einen beginnt er die Pläne von Ungefugger zu erahnen, der die heimliche Holomorfisierung der Menschheit anstrebt; zum anderen stellt sich ihm selbst die Frage der eigenen Betroffenheit. "In Goltz' Fragen schwelte das Feuer der Identität oder, um es kunsttheoretisch auszudrücken, des Originals." $(B A, 101)$ Was er vorher als eine Möglichkeit erachtet hat, seine eigenen Zwecke besser verfolgen zu können - die eigene Kopie -, erscheint ihm angesichts von außen bestimmter Durchführung als ein Schrecken. Während die Holomorfen versuchen, ihre eigene Identität in Anlehnung und Abgrenzung von den Menschen zu bilden, stellt sich angesichts der zunehmend näherrückenden Möglichkeit, Menschen zu holomorfisieren, die Frage, was die Menschen als die `Originale` gegenüber den Holomorfen als Nachbildungen auszeichnet.

An dieser Stelle drängen sich Vergleiche mit Ridley Scotts Film Blade Runner (1982) sowie seiner literarischen Vorlage, Philip K. Dicks Do Androids Dream of Electric Sheep (1968, dt. Träumen Androiden von elektrischen Schafen?) auf. ${ }^{30}$ In der fiktiven Welt sind die Unterschiede zwischen Menschen und den sogenannten

29 »Man müßte sich, dachte er, dazuschalten können. Abermals lockte ihn die Idee einer datischen Kopie seiner selbst. Man sollte als erkennungsdienstlichen Simulationsraum ein kybernetisches Modell Europas erschaffen und dorthinein alle verfügbaren Daten projizieren.« (TA, 590) Aus Sicht von Garrafff ist dieser Schritt bereits vollzogen.

30 Es finden sich auch zwei kleine Bezüge auf den Film in BA. Sabine Zeuner überlegt, dass Deters »seinen Vater [seinen Programmierer Herbst] töten wollen « (161) könnte, was der Replikant Roy Batty im Film tatsächlich macht. Auf derselben Seite findet sich dann noch ein nicht gekennzeichnetes Zitat, das der Sterbeszene von Batty entnommen ist. Zu Herbsts Einschätzung von Blade Runner vgl. URL-16, 16. Jan. 2012. 
Replikanten, künstlichen Menschen, nur mit einem aufwendigen Test herauszufinden, das angebliche Unterscheidungsmerkmal soll ein Mangel an Empathie sein. Wie die Holomorfen auch entwickeln sie nun aber gerade Gefühle und Einfühlungsvermögen und setzen sich eher dadurch noch von den Menschen ab. Der Test erinnert an den Turing-Test, der 1950 von dem Informatiker Alan Turing ersonnen wurde, um festzustellen, ob eine Maschine ein dem Menschen gleichwertiges Denkvermögen hat. Diesen historischen Test würden die Holomorfen »ohne weiteres bestehen « $^{31}$, er sagt jedoch nichts über die Unterscheidung aus. Im Grunde geht es jedoch um die klassische Identitätsfrage, - positiv formuliert - wie viele Übereinstimmungen es geben muss, um identisch zu sein. ${ }^{32}$ Was schließlich im Film erst in der Director's Cut-Version von 1992 wirklich angedeutet wird, dass nämlich die Hauptfigur, der Replikantenjäger Rick Deckard, ebenfalls ein Replikant sein könnte, ohne es zu wissen, ähnelt nun auch der Frage, die sich Goltz stellt. Nur besteht hier die Möglichkeit, noch im Nachhinein holomorfisiert zu werden.

Eben dies muss Goltz schließlich feststellen, nämlich dass die geplante Holomorfisierung bereits vonstatten gegangen ist. In den ganz alltäglich verwendeten Lappenschleusen, ${ }^{33}$ die eine Verbindung zwischen zwei weit entfernten Orten erlauben, werden Fahrzeuge und Menschen bereits kopiert und über elektronische Leitungen befördert, ohne diesen technischen Schritt zu bemerken. In der Angst, bereits holomorfisiert und damit potenziell durch Programmierung fremdbestimmt zu sein, macht er sich auf die Suche nach einem Original und stellt dabei fest, dass Borkenbrod einer der wenigen Menschen der Anderswelt ist, die noch nie eine Lappenschleuse benutzt haben und damit noch nicht kopiert wurden. Von ihm will Goltz nun erfahren, ob er real sei (vgl. $B A, 235)$. Als Borkenbrod ihm diese Frage auch nicht beantworten kann, verlangt er ein Treffen mit der Rebellenführerin Deidameia, was Borkenbrod auch arrangiert. Der vorher so stringente und über Systemzweifel erhabene Goltz kommt nun offensichtlich durch diese Entdeckungen ins Zweifeln. Weder verhaftet er den lange gesuchten Borkenbrod noch plant er eine Konfrontation beim Treffen mit Deidameia. Ihm geht es jetzt um die Suche nach Gewissheiten. »Die alten monotheistischen Fragen kehrten zurück, lächerlich zugleich, doch von enormer Virulenz." $(B A, 219)$ Was macht den Menschen aus? Was unterscheidet kopierte Programme von »Wesen« $(B A, 217)$ ? Ist der Mensch autonom in seinen Gefühlen und Entscheidungen oder fremdbestimmt? Goltz spürt in sich einen neuen »rebellische[n] Impuls« $(B A$, 219) und fragt sich, ob und warum ihm ein solcher einprogrammiert sein könnte.

Deidameia und die Rebellinnen haben diese Fragen gleichsam schon hinter sich gelassen und die Möglichkeiten der Technik für ihren Kampf genutzt. Der Sozioniker ${ }^{34}$

31 Malsch: »Vom Wiedereintritt des Autors in seine Geschichte«, 55.

32 Vgl. dazu das anschauliche Paradox vom Schiff des Theseus bei Plutarch und Thomas Hobbes, das in der Einleitung auf Seite 20 dargestellt wurde.

33 Für genauere Erläuterungen dazu vgl. Abschnitt 6.1.4 auf Seite 288.

34 Sozionik ist ein interdisziplinäres Forschungsfeld zwischen Soziologie und Informatik, genauer gesagt der Künstlichen Intelligenz. Dabei geht es um die Frage, was die Technik von der Gesellschaft lernen kann. Vgl. Thomas Malsch / Michael Florian / Michael Jonas / Ingo Schulz-Schaeffer: "Sozionik. Expeditionen ins Grenzgebiet zwischen Soziologie und Künstlicher Intelligenz«, in: Thomas Malsch (Hg.): Sozionik. Soziologische Ansichten über künstliche Sozietät, Berlin 1998, 9-24. 
Thomas Malsch spricht hier unter Hinweis auf real existierende Systeme vom "Entwurf einer Agentengesellschaft [...], die auf Verteiltheit und Mobilität beruht« ${ }^{35}$. Das Boudoir, ihre Zentrale, existiert nun 105-mal, Deidameia selbst ist 106-mal vorhanden (vgl. $B A, 222)$. Durch ihre eigene Multiplikation ist es kaum noch möglich, alle Entitäten auf einmal zu kontrollieren oder gar zu vernichten, da »jede auf unverwechselbare Persönlichkeitsmerkmale [...] abstellende Rasterfahndung ausgehebelt wird, sobald Agentenprogramme beliebig kopiert und vervielfältigt werden können « ${ }^{36}$. Individuelle Identitätsfragen wie Goltz scheint Deidameia sich nicht zu stellen. Dass diese jedoch nicht ganz ausgeklammert werden können, zeigt sich dennoch am Rande: »So lebte [Deidameia] mehrfach, Borkenbrod einzig. Beide waren sich ihres Unterschieds bewußt, das ging wie ein Riß durch ihre Beziehung.» $(B A, 232)$ Sie gibt auch bei der Überlegung, dass die Kopien zerstört werden könnten, zu, an ihrem Körper zu hängen (vgl. $B A, 222$ ). Nicht aufgeworfen wird jedoch die Frage, in welcher der Kopien ihr "wahres Ich $\ll^{37}$ stecke. Vielmehr stellt sie gerade der ungefuggerschen Vision einer Welt, die "asexuell und von allem Organischen frei, abstrakt und logisch, kurzum binär« $(B A, 220)$ sei, eine radikal pluralistische entgegen: "Wir hingegen wollen so viel Welten wie möglich.« $(B A, 223)$ Dass sie dabei Wert auf die »Unantastbarkeit des einzelnen ... egal ob Bit oder Zelle« (BA, 227), legt, also sowohl von Mensch als auch Holomorfen, und damit doch wieder den Fokus auf das Individuum bringt, ist kein Widerspruch. Vielmehr drückt sich gerade darin die Gleichzeitigkeit von Pluralität und Individualität, und damit von Identität und Diversität aus.

\subsection{Klonidentität: Individualität}

Eine weitere Besonderheit bei den Identitätsfragen findet sich in einer Randepisode, die hier kurz behandelt werden soll. Hierbei handelt es sich um die Identität der Klone. Die Technik des Klonens ist in der Anderswelt bereits weiter fortgeschritten und auch bei Menschen möglich. Hier stellen sich erwartungsgemäß Fragen der Individualität, die am Beispiel der Klonin Dorata Spinnen vorgeführt werden.

Dorata Spinnen lässt sich selbst Dolly nennen, was naheliegenderweise auf das Klonschaf Dolly verweist, das (in der realen Welt) 1996 als erstes Säugetier geklont wurde. Sie ist die Tochter des Wissenschaftlers Dr. Spinnen ${ }^{38}$, der aus einer Zelle seiner Frau bereits 15 identisch aussehende Töchter geklont hat. Dr. Spinnen entwickelt chemische Kampfstoffe für den Kampf gegen den Osten und ist an der Entwicklung lebender Organspenderkörper durch Klonen beteiligt. Seine Töchter sind sozusagen nur Nebenprodukte. Die eigentliche Geschichte um Dolly wird durch die zufällige Begegnung mit dem (dem Leser bereits vorher bekannten) John Broglier angestoßen.

35 Malsch: »Vom Wiedereintritt des Autors in seine Geschichte«, 61.

36 Ebd., 71.

37 Ebd.

38 Der Name verweist auf den Schriftsteller Burkhard Spinnen. Dabei handelt es sich um einen »Freundschaftsdienst « von Herbst, da Spinnen wohl gerne einmal ein Bösewicht in einem seiner Romane sein wollte. Vgl. URL-17, 26. Jan. 2006, und URL-18, 7. Jan. 2006. Dort ist diese >Bitte ebenfalls auf 1996 datiert, sodass angenommen werden kann, die Klon-Episode sei auch erst 1996 also eher spät im Entstehungsprozess, eingefügt worden. 
Dieser `Gigolo < verliebt sich in sie und sie werden ein Paar. Identitätsfragen werden aufgebracht, als er Bilder ihrer Schwestern in ihrer Wohnung bemerkt und sie anfänglich für Bilder von Dolly selbst hält. Erst dann erfährt er, dass sie geklont ist. Seine Reaktion ist Erschrecken, aber auch Neugier. Sie dagegen reagiert defensiv: er solle das »häßliche[] Wort « $(T A, 471)$ nicht aussprechen und einfach nicht daran denken, dass sie geklont sei. Im späteren Telefonat mit dem Vater kommt heraus, dass sie schlechte Erfahrungen gemacht hat, da sie zuvor von Verehrern verlassen wurde, die von ihrer Herkunft erfahren hatten (vgl. TA, 475).

In der Terminologie sozialpsychologischer Identitätstheorien geht es hier um die Frage, wie ein Mensch sich von den anderen als Individuum abgrenzt. Bei den mindestens fünfzehn identischen Schwestern ist dies wieder auf die Spitze getrieben. Eine reale aktuelle Entwicklung wird in erwartbarer zukünftiger Realisierung vorgeführt und mit anderen Themen des Herbst-Kosmos verbunden (dem Natur vs. Geist-Diskurs aus WB). Dolly scheint jedoch selbst keinerlei Probleme mit der Vielzahl ihrer Schwestern zu haben, es wird jedoch aufgezeigt, dass es ein gesellschaftliches Problem ist, ein Problem aus der Außenperspektive. Dem `Original, Dr. Spinnens Ehefrau Beate (die nicht als Mutter bezeichnet wird), sind die "Selbstkopien« (TA, 474) nicht geheuer; sie vermeidet daher jeden Umgang mit ihnen. Am Beispiel von Broglier wird angedeutet, dass es für andere ein Problem sein kann, dass der Partner oder ein anderes Gegenüber ein Klon ist. Damit wird auch hier die Frage nach Kopie, Original und >Echtheit gestellt, die auch schon bei den Holomorfen und - wie am Beispiel von Goltz zu sehen - auch bei den Menschen virulent ist.

\subsection{Menschliche Identität in der Anderswelt}

Die menschliche Identität wird in den $A W$-Romanen nicht nur als Gegenbewegung zum Autonomiestreben der Holomorfen thematisiert, sondern kann als Diskurs auch innerhalb der menschlichen Figuren identifiziert werden. Hier spielt vor allem die Körperlichkeit eine Rolle, sodass drei größere Komplexe im Folgenen näher betrachtet werden:

- die Gegenbewegung der Menschen zum Autonomiestreben der Holomorfen, die sich in einer Abwendung von natürlicher Körperlichkeit und ihrer Virtualisierung ausdrückt,

- das Streben Ungefuggers nach völliger Körperlosigkeit, das auf der genannten Gegenbewegung aufbaut und diese zuspitzt, sowie

- die dazu im Gegensatz stehende Betonung und Verteidigung von Natürlichkeit und Körperlichkeit, die sich vor allem im Osten bzw. den von dort stammenden Figuren findet.

\subsubsection{Gegenbewegung zum Autonomiestreben der Holomorfen}

Wie bereits erwähnt lässt sich zum Autonomiestreben der Holomorfen eine Gegenbewegung bei den Menschen feststellen. Die menschliche Gesellschaft der Anderswelt entwickelt sich so, dass die Menschen immer mehr sowohl in ihren äußeren Strukturen als auch bis in die Gefühle hinein von anderen bestimmt und gelenkt werden. Die 
individuelle Selbstbestimmung und -ausrichtung wird dabei aufgegeben. Anzumerken ist die Ambivalenz dieser Entwicklung. In der Abgrenzung von den Holomorfen zeigt sich das fortbestehende Bewusstsein von Selbstbestimmung und der Geltungsanspruch, im Gegensatz zu diesen ein Individuum zu sein und dadurch mehr wert als sie zu sein. Zudem gilt die Entwicklung nicht für alle, bei Einzelnen wie Toni Ungefugger und auch nahen Gefolgsleuten wie Jens Jensen bleibt es undenkbar, sie nicht als selbstbestimmte Subjekte zu denken, da es gerade sie sind, die die Leitlinien für die anderen bestimmen. Die zu beschreibende Gegenentwicklung gilt also für die Arbeitnehmer der Zentralstadt, vor allem die Mitarbeiter der von Ungefugger aufgebauten und zunächst auch geleiteten EWG, der Europäischen Wirtschaftsgesellschaft. Paradebeispiel für den Menschentypus dieser Entwicklung ist Elena Jaspers (später Elena Goltz), die Tochter von Dr. Jaspers, die zum Ende von TA die Leitung der EWG übernimmt.

Den Mitarbeitern der EWG werden die äußeren Strukturen vollständig vorgeschrieben, die Kleidung und die Sprache werden bestimmt. Sie sollen gänzlich abhängig von der Firma gemacht werden. Über die privatesten Angelegenheiten muss sie informiert sein, sodass auch diese bestimmt werden können. Dies geht soweit, dass Ungefugger darüber bestimmen kann, wer wen heiratet und welches Paar sich trennen muss. Elena Jaspers hat daher auch Markus Goltz zu heiraten, wobei die beiden Führungsfiguren als »Referenzpaar $(T A, 320)$ dienen sollen. Mitarbeiter der EWG werden beliebig versetzt, wodurch alte Beziehungsnetze gekappt und soweit überhaupt vorhanden der Eigensinn gebrochen werden. Auf diese Art und Weise sollen die Mitarbeiter auch sozial an die Firma gebunden sein; nicht ein privates Umfeld soll sie auffangen, vielmehr soll die Firma dieses ersetzen - "private und berufliche Bindungen [werden] identisch $(T A, 313)$. Eine solche Vermischung setzt sich auch im allgemeinen Geschäftsmodell der Firma fort. Sie ist zunächst vor allem für die soziale Absicherung der Menschen zuständig. Mitarbeiter, die kündigen, würden vielleicht gleichzeitig ihre Altersversorgung verlieren. Nicht zuletzt machen sie jedoch auch mehr oder weniger freiwillig mit aus Angst, in den Osten abgeschoben zu werden.

Elena Jaspers und Markus Goltz sind herausgehobene Beispiele für den neuen Typus Mensch, der von der EWG geprägt ist und nach ihren Vorstellungen geformt wurde. In dieser Hinsicht ähneln sie den Holomorfen, die nach den eigenen Vorstellungen programmiert sind, die neuen Menschen sind jedoch nach den Anforderungen und Werten der Firma erzogen. Jensen junior beschreibt dieses Ansinnen den Musterbeispielen Elena Jaspers und Markus Goltz denn auch, ohne dass diese protestieren oder ins Nachdenken kommen:

[W]ie wir die Stadt gebaut haben - wir, Sie hören ganz recht - so auch die Städter. Sie sind nach unseren Lebensprinzipien erzogen [...]. Wenn ich aber swir sage, dann meine ich Werte, Wertvorstellungen. Wir haben aus Vorstellungen Realitäten gemacht: gänzlich ideologiefreie ökonomische Kraftgeschöpfe wie Sie, Frau Jaspers, ideologiefreie Strategen wie Sie, Herr Goltz. Sie sind unsentimental, praktisch, intelligent. Berechenbar.« $(T A, 319)$

Dass es gerade in Ungefuggers Firma zur Unterordnung des Individuums unter die Ziele der Firma kommt, hängt mit seinem Gesamtziel der Körperlosigkeit, der Existenz als reinem Bewusstsein zusammen, das im nächsten Abschnitt thematisiert werden 
soll. Symptomatisch dafür ist jedoch schon die Beschreibung von Elena Jaspers und einer Versammlung der EWG, auf die sie Deters mitnimmt. Dieses ausführlich geschilderte Treffen wird aus der kritischen Sicht von Deters erzählt. Es präsentiert sich ihm wie einheitliche Parteiveranstaltungen realer totalitärer Staaten. Bei der Veranstaltung denkt er an einen »Parteitag « $(T A, 614)$, auf einem Banner ist zu lesen »EWG EUROPA - GEMEINSAM ZUM SIEG« (TA, 615), Elena Jaspers beschreibt er als »jungmädchenhaft" (ebd.). Deters' Sicht auf die Versammlung und speziell auf Elena ist situiert in den Diskurs um Männlichkeit und Weiblichkeit, auf den später genauer einzugehen ist. An dieser Stelle ist lediglich der Bezug auf die Unternehmenskultur und das diesbezügliche Verhalten Elenas zu betrachten. Zusammenfassend bemerkt Deters: »Völlig körperlos. Es war eine Orgie der Geschlechtslosigkeit.« (TA, 615) Entsprechend beschreibt er die anwesenden »[r]einliche[n] Mädchen« (ebd.) oder »Reinlichkeitsmädchen « $(T A, 617)$, die einheitlich gekleideten »schwarzgekleidete[n] Männer« wie auf einer »Massenbeerdigung« $(T A, 614)$. Die Reden erst von Jensen und dann von Ungefugger selbst lassen das Spektakel zu einer quasi-religiösen Veranstaltung werden. Deters gibt seinen Eindruck durch seine spöttischen Kommentare wieder (vgl. TA, 616), später wird der messianische Auftritt von Ungefugger beschrieben, der erst mitleidserheischend seine Lebensgeschichte vorträgt, um dann eine Art Verfassung der Firma zu präsentieren, die in ihren Formulierungen in satirischer Deutlichkeit an die Zehn Gebote angelehnt sind. Hier werden die Wertvorstellungen der EWG prägnant präsentiert; der Kunde und vor allem die Firma sind das Wichtigste, unbedingtes Gehorsam wird gefordert. Gerade das Individuum soll in den Hintergrund rücken, was positiv formuliert sich im Bild des einen Körpers ausdrückt.

Jetzt steht ihr wie in Mann, eine Frau. So will ich euch und so soll unsere Kundschaft euch sehen: als einen einzigen Leib! Ihr seid die Hände des Unternehmens, die Arme, die Füße, der Bauch und die Brust, die Nase, die Augen, die Ohren! $(T A, 626)$

Ungefugger sagt den verzückten Mitarbeitern direkt, dass sie nichts seien ohne den ganzen Organismus, für den sie Sorge zu tragen hätten. Während bislang die Absage an jeglichen Individualismus lediglich implizit war, gipfelt sie nun deutlich zugespitzt in der Aussage: »Ihr seid identisch!« (ebd.) Aus Sicht des Unternehmens ist der einzelne Mitarbeiter zwar wichtig als Teil des als Gesamtorganismus gesehenen Unternehmens, er stellt jedoch kein handelndes Subjekt dar. Der den Menschen (in der Anderswelt im Gegensatz zum Holomorfen) kennzeichnende freie Wille wird hier unterdrückt.

Die EWG und ihre Werte und Selbstpräsentation lassen sich als lediglich etwas zugespitzte Beschreibung aktueller Tendenzen in kapitalistischen und totalitären Systemen der aktualen Welt lesen. Die Zentralstadt ist das Zentrum der Banken, Versicherungen und Makler. Eine Verbindung zur Finanzwelt wird auch durch Deters aufgemacht, der in der scheinbar >realen ' Gegenwelt in Berlin selbst Broker ist und auch dort die Unbarmherzigkeit dieses Systems erlebt. Hier können also sozialkritische Tendenzen ausgemacht werden, wie sie bislang in solcher Breite nicht in Herbsts Werk zu finden war. Dies ist eher verwunderlich, da Herbst sich auch immer wieder gegen die Politisierung von Literatur ausgesprochen hat. Doch auch 
in $T A$ ist gesellschaftliche Sozialkritik nicht der zentrale Aspekt der Darstellung. ${ }^{39}$ Die anhand des Wirtschaftskonzerns beschriebene Gleichschaltung der Menschen ist vielmehr im Kontext einer Dichotomie angesiedelt, deren Pole als Vergeistigung und Körperfeindlichkeit gegenüber einer teils atavistisch dargestellten Körper- und Naturposition gefasst werden können. Diese bereits ähnlich aus WB bekannte Gegenüberstellung kann an den Ansichten und Zielen der Figur Toni Ungefugger genauer herausgearbeitet werden.

Vorher sei noch darauf hingewiesen, dass sich in gewissen Aspekten vergleichbare Entwicklungen nicht nur auf das Zentrum beziehen. Im unterentwickelten Osten werden die einzelnen Menschen aufgrund ihrer Chancenlosigkeit als wertlos angesehen. Diese Ansicht gilt sowohl für die Bewohner des Ostens selbst als auch noch verstärkt aus Sicht der Einwohner der Zentralstadt, die wie bereits erwähnt ihre Freiheiten aufgeben, um nicht in den Osten abgeschoben zu werden. Deutlichstes Beispiel für die Menschenverachtung, die der Westen dem Osten entgegenbringt, ist das neue `Geschäftsmodelk , das Jensen Elena Jaspers vorschlägt. Statt ihr bisheriges sozial orientiertes Projekt weiterzuverfolgen, jedem Einwohner der Zentralstadt einen Holomorfen zu verkaufen, soll sie in den Organhandel einsteigen. In großem Stil sollen Ostbewohner gegen geringfügige Bezahlung Körperteile für Patienten der Zentralstadt zur Verfügung stellen (vgl. TA, $321 \mathrm{ff}$.). Auch hier greift Herbst Entwicklungen der aktualen Welt, den Organhandel mit der >Dritten Welt $>$ auf, um sie in das Gesellschaftssystem der Anderswelt zu integrieren.

\subsubsection{Ungefugger und der Weg zur Körperlosigkeit}

Toni Ungefugger ist die wohl mächtigste Person in ganz Europa. ${ }^{40}$ Als einer der wenigen Unsterblichen in der Weststadt lebend, ist seine Firma EWG vor allem für die Zentralstadt wirtschaftlich und sicherheitstechnisch von großem Einfluss, aber auch für den Osten hat er große Bedeutung, da er sich immer wieder für die Ostbewohner einsetzt und selbst den Kontakt zu ihnen aus Werbezwecken nicht scheut. Als Gründer und Firmenchef der EWG und später als Präsident von Buenos Aires hat Ungefugger die Macht, seine Ziele und Vorstellungen zu verwirklichen und auch für andere Menschen relevant zu machen. Zunächst handelt es sich tatsächlich um persönliche, individuelle Vorlieben oder besser Abneigungen. Er selbst sieht dies freilich nicht so, denkt vielmehr, dass er einer Sache und dem Allgemeinwohl dient, das zufälligerweise auch seiner eigenen Firma wieder zugute kommt (vgl. TA, 844ff.). Diese etwas verquere Einschätzung ist im oben beschriebenen Zusammenhang zu sehen, dass er sich zwar für die Entindividualisierung, also die Unterordnung des Individuums unter die Belange der Firma einsetzt, dabei aber sich selbst weitgehend ausschließt, da seine Ansichten die Belange der Firma vollständig bestimmen.

In Bezug auf den Körper schließt er sich jedoch gerade nicht aus; die Abneigung gegen alles Körperliche, die er als eine menschliche Zielrichtung zu etablieren ver-

39 Vgl. dazu später Genaueres in Abschnitt 6.1.1 auf Seite 282.

40 Döbler beschreibt ihn als »ein aus Dr. No, J. R. Ewing [aus der Fernsehserie Dallas] - und einer Prise Bill Gates - sowie reichlich amerikanischem Sektenchef zusammengerührter Manager« (Döbler: »Delirium und Moralium«). 
sucht, geht gerade vom eigenen Gefühl aus. Der Körper ist ihm lästig, menschliche Fortpflanzung und natürliche Sexualität sieht er als »schleimig und infektiös« (TA, $851)$ an. Damit einhergehend verdammt er auch den Sexualtrieb und Gefühle. Seinen eigenen kann er mehr oder weniger (dazu später mehr) selbst unterdrücken und unter Kontrolle halten, seiner Frau dagegen mit ihren »ordinäre[n] Reproduktionswünschen « $(T A, 163)$ lässt er wie etwa einer Katze oder anderen Tieren eine Spritze geben, wenn sie »heiße Zeiten« $(T A, 111)$ hat. Den persönlichen Umgang mit der Unterdrückung jeglicher Gefühle und körperlicher Triebe überträgt er auch auf seinen Wirkungsbereich, wodurch sich die Gesellschaft von Buenos Aires in eine ähnliche Richtung entwickelt. Ungefugger lässt `Kreuzzüge` der »Sexualhygiene« (TA, 163) und »moralische Reinigungsaktion[en] « (TA, 830) durchführen, später lässt er die Prostitution gänzlich verbieten. Entsprechend entwickelt sich das Verhältnis der Bewohner zu ihrem Körper. Natürlichen Geschlechtsverkehr gibt es nicht mehr, dieser findet (obzwar zusammen) im Infomaten statt. Selbst im Osten wird aus Angst vor Ansteckung Verzicht geübt (vgl. TA, 43, 62). ${ }^{41}$ In diesen Kontext gehört auch die bereits im Zusammenhang mit Herrn Drehmann angesprochene Umstellung von natürlichen Nahrungsmitteln auf Pillen als Nahrungsersatz, die die menschliche Kulinarik fast vollständig verdrängt hat. Beispielhaft wird der Umfang dieser Entwicklung anhand von Dr. Jaspers angedeutet. Er hatte sich ja Herrn Drehmann als >Maultier angeschafft und war seit dieser Anschaffung nicht mehr aus seiner Wohnung gekommen. Wie alle anderen Menschen auch, hatte er sich auf Unterhaltung im Infomaten beschränkt. Als er dann nach der Löschung von Herrn Drehmann gezwungen ist, wieder ins Büro zu gehen, kostet es ihn größte Überwindung. Er gerät in Panik bei der Vorstellung, Bakterien, Viren oder auch nur Blütenpollen schutzlos ausgesetzt zu sein. Selbst sich bewegen zu müssen hält er für eine Zumutung; vor dem Ausmaß an Wirklichkeit, dem er draußen ausgesetzt ist, ekelt er sich sogar (TA, 40of., 403, 518f.).

Das Ziel, das Ungefugger zu erreichen sucht, ist es, die Gesellschaft körperlos zu machen. Ihm geht es um vollständige Kontrolle und die lässt sich seiner Ansicht nach über Gefühle und Triebe nicht gut gewinnen. Die einzige Möglichkeit, dies zu erreichen, sieht er in der Abschaffung des Körpers. Natürlich setzt er die Aufrechterhaltung von »Erkenntnisvermögen und Handlungsfähigkeit« $(T A, 401)$ voraus. Dazu baut er auf Entwicklungen seiner Forschungsabteilungen, die mit Gehirnbänken ${ }^{42}$ und mit Holomorfien experimentiert. Auch hier sieht er die Forschung und sein Streben als Dienst an anderen, sogar den Armen, da er durch die Abschaffung des Körpers auch die des »körperlichen Elends « $(T A, 402)$ beabsichtigt. Sein persönliches Ziel ist die »Existenz als reines Bewußtsein « (ebd.). In dieser Hinsicht schließt Ungefugger deutlich an Murnau und die zugehörige Geist- bzw. Anti-Natur-Position aus WB an.

41 Welche Krankheit(en) speziell diese Angst hervorrufen, wird nicht thematisiert, in $B A$ wird lediglich einmal das Schlagwort »Aidsbefall« $(B A, 198)$ genannt. Vgl. ähnlich Alban Nikolai Herbst: »Das Flirren im Sprachraum«, in: Zettelkasten 23 (2004), 11-35, hier: 23.

42 Vgl. TA, 401. Dieser Hinweis wird nicht weiter verfolgt, bildet aber den einzigen Hinweis auf eine Erklärung für eine kurze Passage über Elena Jaspers: »Dann schlug ein herbeigeschossenes Graupelkörnchen gegen das Glas, worin ihr Gehirn schwamm.« $(T A, 529)$ Hier wird angedeutet, dass ihr Gehirn und ihr Restkörper getrennt sind, der Körper vielleicht sogar holomorf ist. Auch auf diese Möglichkeit wird in den bisherigen Anderswelt-Romanen nicht weiter eingegangen. 
Er kann geradezu als derjenige Vertreter dieser Position gesehen werden, dem schon einiges dahingehend gelungen ist, sie umzusetzen und der dabei ist, sie vollständig zu verwirklichen. Murnau nimmt sich dagegen nur als theoretischer Vorreiter aus, der gegen die übermächtige Parallel- bzw. Gegenfigur Lipom nicht ankommt. Was in $W B$ als theoretische Positionen präsentiert wurde, die sich aus Tendenzen realer Vergangenheit und Gegenwart speisten und gegeneinander um die Vorherrschaft diskutierten, wird in den Anderswelt-Romanen als fortgeschrittene Entwicklung und realer Widerstreit aufgezeigt. Die Position der Vergeistigung ist dabei vorherrschend. Goltz gegenüber gerät Ungefugger einmal in die Defensive und legt schließlich etwas unbeherrscht seine Ansichten und Ziele dar. Er geht zunächst von seiner Kritik am Individuum aus; stärker als bei Murnau wird jedoch an gesellschaftliche und wirtschaftliche Modelle angeschlossen:

Der Virus der Selbstsucht, Herr Goltz, Individualismusbakterien ... Persönlichkeit ist ein Sarkom. - Der Kommunismus hatte schon recht, nur eben nicht in den Mitteln: Ein Volk wird am perfektesten genormt durch Konsum. Zu normen heißt zu leiten, Herr Goltz. (TA, 846)

Wir beide sind Feinde der Barbarei, hassen beide die Materialität. [...] Ich werde also erst das Zentrum synthetisieren, und dann, Herr Goltz, werde ich auch den Osten synthetisieren. [...] Wir brauchen kein Natursurrogat! Wir sind über Natur hinaus und werden diesbezüglich Gesetze erlassen. [...] Wir werden eine Kunstwelt schaffen ... (TA, 847)

Ungefuggers Ziele sind so klar gesteckt wie umfassend. Sein Plan ist die Synthetisierung der Welt, die Bezwingung der Natur. Mit dem Naturbegriff schließt er direkt an die Formulierungen von Murnau an. In den Worten von Jens Jensen, der zumindest nach außen die Politik von Ungefugger vertritt, wird dies noch deutlicher: er spricht von der gleichmachenden Erziehung der Mitarbeiter und muss dennoch zugeben, sie hätten »die Natur noch immer nicht im Griff» (TA, 319, vgl. auch 851).

War der Aspekt der Entkörperung bei Murnau jedoch noch mehr in der körperfeindlichen Haltung zu finden und ließ eher futuristisch wirkende Ausblicke auf die Ersetzung der körperlichen Triebe durch elektronische Mittel zu, ${ }^{43}$ erlaubt das in der Zukunft angesiedelte Geschehen in den Anderswelt-Romanen die Beschreibung einer Vision, das Vorhaben auch wirklich auszuführen. Ungefugger begeistert sich für die Holomorfie und die Entwicklung der Selbstprojektoren, die diese unabhängig machen können. Ihm geht es natürlich nicht um die Holomorfen, sondern um die eigene Unabhängigkeit vom Körper. Durch die Speicherung der eigenen DNA-Struktur auf einer Diskette ist es ihm möglich, eine Kopie seiner selbst zu projizieren. Die Entwicklung geht ihm jedoch noch nicht weit genug, da ihm in seinem Streben nach völliger Unabhängigkeit schon bewusst ist, dass die Holomorfien vom Selbstprojektor abhängen und zudem nur Kopien sind. Er selbst will jedoch keine Kopie sein, sondern ein souveränes, autonomes, aber eben datisches Original. Das lässt ihn zunächst auch selbst vor dem Gedanken an einen solchen Schritt zurückschrecken. »Ungefugger

43 Zwei Beispiele: »Sexualität findet simuliert statt« $(W B, 524)$; »Also sollte man die Hirnaffektionen bezapfen!« $(W B, 687)$. 
war einzig. Daran ließ er nicht rühren.« (TA, 724) Auch hier wird wieder der Widerspruch zwischen kollektivierenden Entwicklungen und dem Bestehen auf der eigenen Subjekthaftigkeit deutlich. Das Problem der Unterscheidung zwischen Kopie und Original lässt selbst die zukünftig situierte Anderswelt daran scheitern, einen >wirklichen ‘ technischen Ausweg zu weisen. Ungefugger sieht sich jedoch schon in einer Übergangszeit, die Menschen sieht er als »halb noch Tiere, halb aber Götter « $(T A, 852)$. Dass er bei einem Attentat angeschossen wurde und ein Ohr verloren hat, macht ihm seine bislang trotz seiner Unsterblichkeit fortbestehende Verletzbarkeit und damit Abhängigkeit vom Körper bewusst.

Die Möglichkeit der Übertragung eines Menschen in elektronische oder holomorfe Form wird durch das sogenannte >chuting`von Dr. Jaspers vorgeführt, womit die Holomorfenrebellen sich als technisch weiter fortgeschritten als die ursprünglichen Auftraggeber erweisen. Dr. Jaspers wird von den Rebellen auf eine Weise in eine elektronische Form überführt, die kaum bestimmbar ist, da möglicherweise etwas schiefgelaufen ist. Er behält sein Bewusstsein und verliert sein »leibliches Leitbild « $(T A, 519)$, verschmilzt zeitweise mit Herrn Drehmann und verändert schließlich im Euroweb ständig seine Identität bzw. fällt er mit verschiedenen anderen Personen zusammen (vgl. TA, 518f., 475-485, 525, 527).

Ungefuggers Vorhaben der allgemeinen Entkörperung hat auch eine religiöse Dimension bzw. ist eingebettet in religiöse Bezüge. Diese kamen schon in der Schilderung der EWG-Versammlung zum Vorschein und wurden durch syntaktische Parallelen zu den Zehn Geboten stilistisch deutlich gemacht. Im Gespräch mit Goltz stellt sich Ungefugger als Erlösergestalt dar.

Ich werde $[\ldots]$ als Befrieder des Ostens in die Geschichte eingehen. Einen Kreuzzug werden wir führen, Herr Goltz! Macht euch die Erde Untertan! Wir werden ein Neues Christliches Weltreich errichten! Und ich ... ich werde über mich selbst in hundert, in zweihundert, fünfhundert Jahren alles nachlesen können, ich werde, Herr Goltz, die Geschichte sein! $(T A, 851)$

Auch hier sind wieder die Anspielungen auf Bibel und christliche Religionsgeschichte zu finden. ${ }^{44}$ Deters sieht Ungefuggers Bezug zum Christentum vor allem in der puritanischen Körperfeindlichkeit und der Präferenz für den Geist und sieht ihn daher als "zutiefst religiösen, monotheistischen Menschen « $(T A, 402)^{45}$ und sieht zudem Ähnlichkeiten mit Religionsstiftern und Propheten. Ungefuggers Formulierung vom Neuen Christlichen Weltreich ist daher auch weniger auf andere zentrale Themen wie die Nächstenliebe bezogen, auf die nirgends hingewiesen wird, sondern auf den assoziierten puritanischen und asketischen Charakter. Auch hier wird deutlich, dass Ungefuggers und Murnaus Positionen deckungsgleich sind.

44 Auch bei dem eben erwähnten `chuting` von Dr. Jaspers, seiner Verwandlung in elektronische Form, werden christliche Begriffe wie `Transsubstantiation « und `Konsekration` verwendet (vgl. $T A, 476$ ), die die Wandlung von Brot und Wein in Leib und Blut Jesu während des Abendmahls bezeichnen.

$45 \mathrm{Zu}$ Herbsts wiederkehrender Kritik am Monotheismus siehe Abschnitt 7.3.2 auf Seite 354. 
Die Gegenposition zu Ungefuggers Streben, die sich gezwungenermaßen oder aber bewusst und freiwillig den Bedürfnissen des Körpers ergibt und damit für eine ursprünglichere Natur steht, wird durch verschiedene Diskurse und (Gegen-)Figuren vertreten. Erst einmal gibt es eine unfreiwillige Kehrseite des Reinheitsstrebens, wenn selbst bei Ungefugger der Geschlechtstrieb sich entgegen seiner eigenen Annahme nicht unterdrücken lässt und er diesen ausleben muss. Ausgerechnet er geht daher in das >Boudoir , die als Stripclub oder Bordell getarnte Zentrale der Myrmidonen. " $[$ S $]$ o verfiel der Reine [...] dem Schmutz« und vergnügt sich mit einer »schlimm heruntergekommenen Vettel [...], ließ sich schlagen von ihr und anpinkeln und suhlte zurück « $(T A, 433)$. Auch wenn seine heimlichen Eskapaden damit einigen Leuten bekannt sind, so scheint er doch weiter an seine eigentlichen Ziele zu glauben und gesteht sich seine Bedürfnisse in geradezu schizophrener Weise nicht ein. Aufgrund der scheinbaren Bigotterie wird er abermals in den religiösen Kontext eingeordnet: "Solange Biologie nicht restlos domestiziert ist, verlangt sie nach Opfern auf dem Altar der Physiologie." (TA, 432) Deters stellt ihn auch daher in einer Reihe mit Religionsstiftern und Propheten. Alles deutet jedoch tatsächlich darauf hin, dass er am Ziel der Körperlosigkeit und der restlosen Ausrottung der Triebe festhält und sofern überhaupt eingestanden, die in TA beschriebene Phase als einen Übergang ansieht.

Ansonsten sind auch in seinem eigenen Lager Figuren zu finden, in denen eine unbewusst lenkende Kraft wirkt; es sind immer seine Vertrauten wie Klaus Gerling sowie der alte und der junge Jensen. In ihnen 'gärt ‘ der Osten (vgl. TA, 812), der für eine mit dem Mythos und damit mit Natürlichkeit und Körperlichkeit verbundene Position steht. ${ }^{46}$ Die dem Osten direkt zugehörigen Figuren sind eher als Gegenfiguren im eigentlichen Sinn anzusehen, da sie von vornherein auf der anderen Seite stehen. Am deutlichsten wird dies an Borkenbrod und Deters zu sehen sein.

Im Zusammenhang der Gegenpositionen ist ein weiterer Diskurs zu verzeichnen, der als eine Reaktion der Menschen der Anderswelt auf Ungefuggers Körperablehnung zu sehen ist. Hier handelt es sich um die zwar nebenbei, aber immer wieder in verschiedenen Kontexten auftauchende Thematisierung des Körpers durch Piercings und ähnliche Techniken der Körpermutilation. Bereits Deters zeigt noch in seinem srealen` Berlin seine Abneigung gegenüber solchen Praktiken.

Direkt vor mir [...] eine junge Frau. [...] Beide Ohrränder, wie eine Wundnaht, durchlöchert. Behängt mit Kinkerlitzchen. Einen Ring durch die Nasescheidewand [sic!] gestochen. Das Ziel der Frauenemanzipation restlos erreicht. Da baumelt es nun, dieses Ziel, unter den hübschen Nüstern und wartet auf Erfüllung. (TA, 13f.)

Er befestigt im Vorübergehen eine Metallkette an ihrem Nasenring und zieht sie dabei mit sich fort. Schließlich befestigt er die verzweifelt Schreiende mit einem Schloss an einer Halterung. Bereits in der Wortwahl wird die Ablehnung deutlich, überdeutlich dann in seinem Handeln (oder seiner Imagination, was nicht völlig klar wird). Deutlich ist an dieser Stelle der Kontext des `Geschlechterkampf $\_$-Diskurses. Durch den ironischen Kommentar zur Emanzipation wird dieser bereits aufgemacht. Der dann 
folgende Aufbau von (männlicher) Dominanz wird durch einige kleinere Signale etwas ironisch als eine Art von sadomasochistischem Beziehungsspiel dargestellt (er »schnalzt« mit der Zunge, um sie zu kommandieren, der Park ist »besinnungslos und geil nach Erde riechend «, die junge Frau bezeichnet er als seine »Freundin«, er macht sie an einem Ring für Hundeleinen fest). Der Körperbezug und genauer der unnatürliche Umgang mit dem Körper wird hier lediglich durch den Vergleich mit einer medizinischen Operation angesprochen. Auffällig ist die frühe Platzierung des Piercingdiskurses im Text.

Deutlicher benannt wird der Körperbezug in der Übertragung auf die Anderswelt. Herr Drehmann, der sich auch körperlich bemüht, die Menschen so perfekt wie möglich zu imitieren, beobachtet deren seltsames Verhältnis zum Körper:

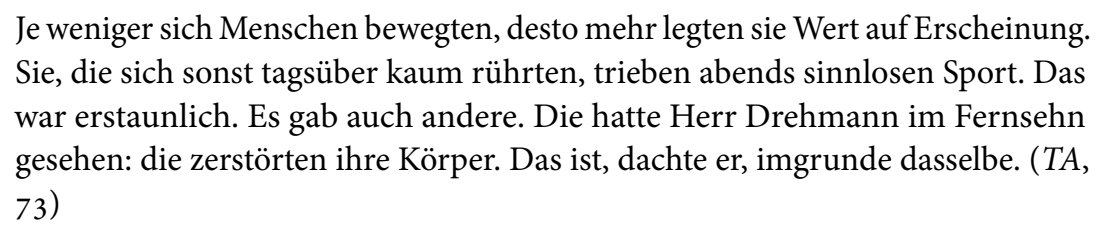
Sie, die sich sonst tagsüber kaum rührten, trieben abends sinnlosen Sport. Das war erstaunlich. Es gab auch andere. Die hatte Herr Drehmann im Fernsehn gesehen: die zerstörten ihre Körper. Das ist, dachte er, imgrunde dasselbe. (TA, 73)

Auch hier geht es um die mutwillige Veränderung des Körpers. Bezeichnend ist, dass diese Beobachtung gerade aus Sicht eines Holomorfen präsentiert wird. Nach einer beiläufigen, aber wieder eindeutig bewerteten Erwähnung bei Deters' Fahrt durch das östliche Zentrum ("gepierct bis zur Unkenntlichkeit«, TA, 231), sind es vor allem die Vorstellungen im >Boudoir , die noch einmal den Umgang mit dem Körper betonen. Dort geht es nicht mehr nur um Piercing, vielmehr werden weitere Varianten präsentiert, die die zukünftige ins Extreme gehende Entwicklung darstellen könnten. Dabei handelt es sich um das `Branding`, eine Art Tätowierung, die als Brandzeichen auf offener Bühne appliziert wird (vgl. TA, 694). Die als satirische Verarbeitung von aktuellen SM-, Gothic- und Homosexuellen-Szenen zu sehenden Beschreibungen der Praktiken und Aufführungen im >Boudoir ‘, die Deters zu sehen bekommt, werden im Körperdiskurs auf verschiedene Weise verortet. Zunächst erinnern Deters die Praktiken der Anderswelt an seine Berliner Erlebnisse, er erklärt sie sich aber in Bezug auf die Anderswelt. Die Piercings bei jungen Müttern, die mit Kinderwagen durch die Gegend schieben, sieht er als "pervertierte Bürgerlichkeit« $(T A, 663)$ und stellt sich in drastischen Bildern die konsequente Fortführung dar.

Deters, widerwillig, stellte sich vor und wollte doch nicht, wie man bereits den Babies Brustgehänge applizierte und mit Nadeln gegen die Schamlippchen vorging, die kleinen Hoden wegband, Stücke aus den Geschlechtsteilchen schnitt. (ebd.)

Die Möglichkeit einer Erklärung, die sich ihm aufdrängt, verweist auf die ungefuggerschen Ziele:

Anders schien seinen Körper niemand mehr spüren zu können. Derart um sich gegriffen und in die Gehirne gefaßt hatte die allgemeine Synthetisierung. Bewies man sich so, kein Holomorfer zu sein? (ebd.)

Die »Verstümmelungskosmetik« (TA, 789), deren Vision er später noch weitertreibt, indem er von der neuesten Mode gefährlicher Körperteilamputationen berichtet, sieht 
er als Reaktion auf die puritanische Körperfeindlichkeit Ungefuggers. Zwar kann dies eigentlich nicht dem Nachweis dienen, kein Holomorfer zu sein, da sie sich körperlich von den Menschen nicht unterscheiden bzw. der Unterschied nur technisch sehr aufwendig nachgewiesen werden kann, doch wird das Unwohlsein der Menschen gegenüber dem >Unechtsein « der Holomorfen immer wieder betont. So wird die absichtliche Modifikation des Körpers durch Piercing, Branding oder Amputation als Teil einer erneuten, wenn auch verqueren Bewusstmachung des Körpers gesehen.

Herbst greift dieses Thema in seinem späteren Vortrag "Die anthropologische Kehre« (2005) wieder auf, wobei jedoch erstaunlicherweise die Veränderung des eigenen Körpers durch `technische`Mittel in genau entgegengesetzter Richtung interpretiert wird. Er beschreibt seine Sicht auf Änderungen im öffentlichen Selbstbild der Menschen durch die Entwicklung der Computer und des Internets. Hier nur anzudeuten ist, dass er die Auflösung des autonomen Ichs, des Ichs als Instanz konstatiert. Damit einhergehend sieht er die Aufgabe des Körpers als Repräsentant des Ichs, der Körper wird »disponibel ${ }^{47}$. Dabei geht er nicht nur von theoretischen und spekulativen Überlegungen über zukünftige Entwicklungen einer Schnittstelle zwischen Mensch und Maschine aus - in der Science-Fiction-Literatur als Cyborg bekannt -, sondern sieht schon das Piercing als Symptom dafür. »Jedes Piercing bereitet den Bioport vor: eine Schnittstelle an unserem Körper für einen Chip. $^{48}$ Als weitere Beispiele führt er aktuelle Nachrichten über medizinische Erfolge der Verwendung von Chips in der Behandlung Querschnittsgelähmter sowie die zeitweise Mode, in Diskotheken über implantierte Chips zu bezahlen, an. Während also in der Anderswelt die `körperliche Mutilation als mehr oder weniger unbewusste Gegenreaktion auf die Abschaffung des Körpers gesehen wird, als Bewusstmachung des Körpers, sieht Herbst sie hier als Symptom der Abschaffung des Körpers.

\subsubsection{Das 'Wesenhafte ${ }^{49}$ des Körperlichen}

Auch in den $A W$-Romanen spielt die Sexualitätsthematik für die menschliche Identität wieder eine wichtige Rolle. Während die spezifische Ausformung der Thematik dem veränderten Genre der Bücher angepasst ist, bleibt die generelle Ausrichtung dieselbe. In WB waren Männlichkeit und Weiblichkeit als Prinzipien in verschiedenen Figurenkonstellationen personifiziert. Die sexuellen Prinzipien bestimmten damit ihre Figurenidentität. In den $A W$-Romanen wird die Sexualität als gesellschaftliches Konfliktfeld vorgeführt. Da die verschiedenen Fiktionsebenen sich schließlich deutlich vermischen und sich daher auch die Themen der verschiedenen Bereiche als für andere ebenfalls relevant herausstellen, ist auch die Sexualitätsthematik auf allen

47 Alban Nikolai Herbst: »Die anthropologische Kehre. 42 Partikel«. Vortrag im Rahmen der Tagung >Medienkonzepte und Medieninnovation 1950-2000<, Universität Siegen, 16. Dezember 2005, URL: http://www.die-dschungel.de/ANH/txt/pdf/anthropolog_kehre.pdf, Abschnitt 26.

48 Ebd., Abschnitt 31. Herbst übersieht dabei oder geht zumindest nicht darauf ein, dass es sich beim Piercing um eine sehr alte Kulturtechnik handelt. Dieser Einwand wurde auch schon im Blog vom Leser >Randolph Carter ` vorgebracht, Herbst bleibt jedoch bei seiner Meinung: URL-19, 23. Juli 2004-26. Juli 2004.

49 [Herbst:] »Du hältst den Körper für wesenhaft? « [Broglier:] »Ich glaube, ja.«»Soll ich dir etwas verraten?« Er hob eine müde Braue. »Ich auch.« $(B A, 158)$ 
Ebenen und in allen geographischen Bereichen (bzw. Welten) zu finden. Auf der einen Seite steht die Regulierung der individuellen sexuellen Bedürfnisse durch gesellschaftliche und staatliche Vorgaben und damit der Zugriff auf und die Bestimmung wichtiger Teile der persönlichen Identität der Individuen. Dies ist Teil der Kampagne von Ungefugger zur Entkörperlichung und Hygienisierung der Gesellschaft. Auf der anderen Seite steht die Verteidigung der individuellen Triebe durch sexuelle Praktiken und damit ihre Bedeutung als Widerstand gegenüber den Übergriffen auf die persönliche Identität. Was in WB als `Geschlechterkampf` bezeichnet wurde, die Verbindung von Sexualität und Natur durch Darstellung animalischer und daher ursprünglich wirkender Sexualität, wird hier noch einmal deutlicher herausgestellt. Jegliches direkte körperliche Ausleben von Sexualität wird als `natürliche`Sexualität gesehen, da sie in der Anderswelt keineswegs normal ist und zudem das Natürliche negativ konnotiert und gesellschaftlich verpönt ist. Natürlicher Geschlechtsverkehr bedeutet, sich Krankheiten auszusetzen und wird daher mindestens in der West- und der Zentralstadt nicht ausgelebt und ist, wie bereits erwähnt, durch die virtualisierte sexuelle Stimulation im sogenannten Infomaten ersetzt. Zwar verfolgt Ungefugger seine Ziele sehr stringent und mit immer umfassenderen Kampagnen, dennoch ist auch die Freiwilligkeit bzw. die Bereitwilligkeit der Bevölkerung zu betonen, diese Entwicklung zu unterstützen. ${ }^{50}$ Die Technisierung der Sexualität ist ein beliebtes Motiv im Science-Fiction-Genre. Die in $B A$ auch verwendete alternative Bezeichnung für den (wohl nur für sexuelle Bedürfnisse vorgesehenen) Infomaten, `Orgasmatron` (vgl. $B A, 127)$, verweist auf eine ähnliche Vorrichtung mit demselben Namen in Woody Allens Science-Fiction-Parodie The Sleeper (1973, Der Schläfer) und auf weitere vergleichbare Geräte in anderen bekannten Science-Fiction-Filmen. ${ }^{51}$ Das Kennzeichnende von Herbsts Text ist jedoch die Auflehnung einiger Figuren gegen solche Entwicklungen und die Entgegensetzung von natürlicher Sexualität, womit vor allem eine triebgesteuerte, nicht von rationalen Erwägungen geleitete gemeint ist, eine "animalischerseits bestimmte Richtung" $(B A, 130)$. Sexualität steht damit als wichtiges Symbol für die unkontrollierbare Natur im Gegensatz zum Versuch weitestgehender Kontrolle durch die hochentwickelte Technik. ${ }^{52}$ Das Sexuelle ist damit ein Definitionsraum der individuellen Identität. Durch die Betonung und Erkundung des Körperlichen soll ein natürlicher Bezug zu den eigenen Bedürfnissen hergestellt werden. Zwar wird damit auch die `Fremdbestimmtheit $\triangleleft$ durch die eigene Triebhaftigkeit festgestellt; diese natürliche Fremdbestimmtheit ist aber gegenüber der Fremdbestimmtheit durch Ungefugger und die Firma positiv besetzt.

50 Vgl. TA, 37: »Versklavung der Lust aus Freiwilligkeit, uniforme Exzesse der Vorsicht«, oder den Verkaufserfolg der Infomaten, deren Erfindung »mit großer Erleichterung, wie eine Erlösung fast, angenommen worden« $(T A, 327)$ war.

51 Vgl. den Artikel »Orgasmatron« in Wikipedia (Englisch): »Orgasmatron«, 20. Jan. 2015, URL: http://en.wikipedia.org/wiki/Orgasmatron.

52 Dies ist die generelle Ausrichtung. Unterschieden wird zusätzlich zwischen triebgesteuerter Sexualität und ihrer Ausformung in der Erotik. Für Deters sind Natur und Erotik nämlich »Erzfeinde $[\ldots]$ wie Elternschaft und Geschlechtsliebe«, $B A, 138$. Im Großen und Ganzen kann allerdings eine Gleichsetzung von Sexualität und Natur angenommen werden. 
Im Folgenden soll nun an drei thematischen Komplexen, die jeweils mit bestimmten Figuren verbunden sind, das Wesenhafte des Körperlichen skizziert werden: am Männlichkeitsdiskurs um Deters, Elena und Goltz, am Diskurs um die Ambivalenz der Geschlechterrollen, für die Achilles paradigmatisch steht, und am Diskurs um die ursprüngliche Natürlichkeit des Körperlichen, die mit dem mythischen Osten verbunden ist.

\section{Deters, Elena und Goltz: Dominanz, Männlichkeit und Macht}

Deters steht in seinem Umgang mit verschiedenen Frauenfiguren am deutlichsten für die `natürliche`Sexualität und damit zusammenhängend für stereotype Männlichkeit oder das `männliche Prinzip`. An zentraler Stelle steht dabei die Beziehung zu Elena Jaspers bzw. später Goltz. ${ }^{53}$ Dabei ist zu beachten, dass sowohl Elena als auch Goltz Deters' Erfindungen sind und demnach seine eigenen Vorstellungen und Stereotype widerspiegeln.

Von Anfang an ist das Verhältnis zwischen Deters und Elena sexuell geprägt. Er begegnet ihr das erste Mal, als sie gerade mit ihrem späteren Mann Markus Goltz ein Restaurant besucht. Zwar ist Deters' Annäherung eher unbeholfen, doch wird auch hier die Ausrichtung deutlich. Das erfolgt vor allem durch den Vergleich mit Goltz. Dieser wird als »bubige[r] Freund « $(T A, 307)$ mit einer allzu hohen Stimme (»Knabensopran kurz vorm Stimmbruch «, TA, 309) beschrieben, der beim eleganten Abendessen Hagebuttentee trinkt. Er scheint offensichtlich homosexuell zu sein, was später auch bestätigt wird (vgl. $T A, 317,320$ ), Berührungen sind ihm überaus unangenehm $(T A, 165,308)$. In all diesen überspitzten Beschreibungen wird er als >unmännlich 〈 dargestellt, schließlich sogar als »Unmann « $(T A, 308)$ bezeichnet. Deters stellt in der Beschreibung schon seine Sicht der Verhältnisse klar, wenn er beobachtet, es wäre »selbst Außenstehenden auffällig und hätte die Frau zutiefst beleidigen müssen, wie dieser Unmann jeder körperlichen Berührung auswich « (TA, 308). In diesem überdeutlichen Kontrast zu Goltz präsentiert sich Deters geradezu als Prototyp von Männlichkeit. Seine ungeschickte Annäherung wird von Elena sofort positiv aufgenommen, wodurch die nachfolgenden Telefongespräche und Treffen erst ermöglicht werden. Ihr vorläufiges Urteil über Deters ist daher bezeichnend: »Hübscher Kerl. Jedenfalls Kerl.« (TA, 312)

In den folgenden Gesprächen und Treffen bestätigt er dann eher den Eindruck männlicher Bestimmtheit. Er führt ihre Unterhaltungen sehr direkt auf eine sexuelle Ebene und zeigt sich dabei dominant.

»Haben Sie mit Özban geschlafen? "54 $^{54}$ "Ich bin liiert, das wissen Sie.»

53 Im Folgenden wird sie als Elena bezeichnet, da der Nachname im Laufe des Textes wechselt. Markus Goltz wird wie im Buch als Goltz bezeichnet.

54 Özban ist ein Broker-Kollege von Deters wohl in Deters' eigener Welt, der jedoch ebenfalls mit Elena anbandelt. Die Zugehörigkeit zu den verschiedenen Welten wird hier etwas unklar (eine logische Lesart wäre, dass Elena hier gar nicht Elena ist, sondern ihr sreales` Vorbild Clara Witten, dazu später mehr). Özban steht ähnlich wie Deters für eine leicht chauvinistische Attitüde, vgl. TA, 384ff. und 503-506. 
»Sie würden auch mit mir nicht schlafen?«

"Sollte ich das?"

»Das sollten Sie.« $(T A, 501)$

Seine Selbstsicherheit und Dominanz speisen sich dabei vor allem aus seinem Status als Autor, der sich Elenas Welt ausdenkt und in die er dennoch eindringt. Er weiß somit alles über die Vorgänge und ihr Verhalten und weiß auch, dass ihm selbst Goltz letztlich nichts anhaben kann. Dass er vor diesem nicht `kuscht $\iota$, hat ihm aber gerade »ihr Begehren eingetragen « $(T A, 503)$. Die sexuelle Komponente wird später dann deutlicher in den Dominanz-Spielen, in denen er ihr Anweisungen gibt, was sie zu tun hat (dass sie beispielsweise in der Öffentlichkeit heimlich die Unterwäsche ausziehen soll, vgl. auch $T A, 563$ ) und in denen er die Vorgehensweise vorgibt und sie in ihrer Erregung zappeln lässt. Diese Andeutungen von BDSM-Spielen ${ }^{55}$ erschöpfen sich zwar lediglich in der Anregung von Vorstellungen, es kommt also zu keinem direktem körperlichen Kontakt zwischen den beiden; insofern unterscheiden sie sich kaum von den sexuellen Praktiken der Zentralstadtbewohner im Infomaten. Doch letztlich geht es hier um den absichtlichen Umgang mit grundlegenden Trieben und vor allem um ihre (eigene) Unkontrollierbarkeit bzw. eben das Ausgeliefertsein einem Fremden gegenüber. Deters ist sich darüber bewusst, wenn er ihr sagt, er »verkörpere - für Sie, wohlgemerkt - etwas wahnartig Fremdes, fieberig Duftendes. Ich errege Sie, aber gefährde Sie auch.« $(T A, 506)$

Parallelisiert auf einer anderen Erzählebene wird dieses Verhältnis durch das Verhältnis von Deters und Clara Witten. Das ist auch nicht verwunderlich, da Clara in der >Welt $<$ (Deters' Realwelt) die »reale[] Vorlage « $(T A, 563)$ für Elena ist. In $B A$ ist bei einem Treffen auch nicht mehr zwischen ihnen und damit zwischen ihren Welten zu unterscheiden, beide Möglichkeiten werden als gleichberechtigt nebenbzw. nacheinander präsentiert. Dort erinnert sich Clara an ihre Beziehung zu Deters, die durch die gleichen sexuellen Spielchen geprägt war und auch dadurch, dass sie nie miteinander geschlafen haben (vgl. $B A, 136-139$ ).

Im Verhältnis von Deters und Elena sind schließlich jedoch zwei Volten zu verzeichnen. Zuerst ist da Deters' Abwendung von ihr im Laufe der bereits beschriebenen 'geschlechtslosen EWG-Versammlung. Durch ihre Verzückung und, wie er bemerkt, geradezu hündische Hingabe an Ungefugger begebe sie sich aller Erotik und wird damit für ihn vollständig uninteressant (vgl. TA, 615ff., 754). Es scheint eine Übertragung der Triebe auf die Ungefugger-Verehrung stattzufinden. Ihre Begeisterung zeigt sich dabei in einem ekstatischen Verhalten: als Deters aufgerufen wird, bestätigt sie ihm das mit einem Ja, als »hätte sie >fester! fick mich fester! ‘ gestöhnt « (TA, 617). In $B A$ erfolgt dann die überraschende Parallele, als Deters sich in einem Café in Hannover mit Elena bzw. Clara Witten trifft. Nach den neun Jahren in der Anderswelt hat er

55 BDSM ist die heute übliche Bezeichnung für verschiedene Formen von Sadomasochismus. Die Abkürzung setzt sich aus den Anfangsbuchstaben von »Bondage \& Discipline, Dominance \& Submission, Sadism \& Masochism« zusammen. - Der Zusammenhang zu BDSM wird hier in dem kurzen Wortwechsel hergestellt: [Elena:] »Berühren Sie mich.« [Deters:] »Noch nicht. »Sie quälen mich.«»Ja.«»Quälen Sie mich.« $(T A, 511)$ BDSM-Assoziationen sind typisch für Herbst. Wird in $V G$ die Entdeckung dieser Leidenschaft beschrieben, so finden sich auch in WB solche Anklänge vor allem in den Dialogen zwischen Alda und Deters II. 
seine männliche Dominanz verloren und ist zu einem weinerlichen »WeichEi« $(B A$, 75) geworden. Auch Clara erkennt Deters nicht als Deters wieder, sieht ihn nicht mehr als Mann mit Ausstrahlung, Witz und Haltung, sondern »wie Tausende anderer ein mißhandeltes Mensch, das man bemitleiden, aber ganz sicher nicht begehren konnte« $(B A, 139)$. Dieser Niedergang als Mann geht einher mit dem Bedeutungsverlust von Deters in der Gesamtkonstruktion; in $B A$ spielt seine Funktion als Autor und damit Schöpfer einer der Welten keine Rolle mehr, er ist lediglich ein Avatar unter anderen und wird schließlich von einem seiner Schöpfer, dem Programmierer Herbst, gelöscht, der sich an seiner Stelle in die Anderswelt einschleust.

Am Beispiel von Goltz wird auf etwas verquere Art die Verbindung von Sexualität und Macht verdeutlicht. Goltz wird zwar als `Unmann « beschrieben und selbst seine homosexuelle Neigung wird erwähnt, doch scheint sie kaum eine Bedeutung für ihn zu haben, geschweige denn, dass er sie auslebe - vielmehr erscheint er geradezu als asexuell. Hier wird auch wieder mit der scheinbaren Unabhängigkeit literarischer Figuren von ihrem Autor gespielt, da Deters, der ihn sich ja erdenkt, erstaunt über sein Aussehen und Wesen ist, als er ihm begegnet. Deters hat ein Bild von einem "Ideal-Goltz« $(T A, 583)$, das wie der Schauspieler Jürgen Prochnow aussieht, eben mit einer »vernarbte[n] Prochnow-Visage« (ebd.). Der `tatsächliche` Goltz sei dagegen für einen Mann mit einer solchen Macht eine »alberne Fehlbesetzung « (TA, 309). Goltz hat jedoch die Macht nicht nur äußerlich, also von Amts wegen, sondern scheint trotz seiner >Bubihaftigkeit und der hohen Stimme auch eine solche Ausstrahlung zu haben. Die Verbindung von (männlicher) Macht und unmännlich hoher Stimme ist als wiederkehrendes Motiv zu verzeichnen, denn Jens Jensen hat diesbezüglich auffallende Ähnlichkeiten mit Goltz. Auch er wird einerseits als geradezu skrupelloser Machtmensch dargestellt, als »Prototyp eines selbstsüchtigen Pragmatikers« (TA, 164), und ist zudem (im Gegensatz zu Goltz) ein großer bulliger Typ. Doch spricht auch er, »als wäre er nie in den Stimmbruch gekommen « (ebd.). Goltz’ Ausstrahlung von Macht wirkt wie der Ersatz für die ansonsten fehlende (körperliche) Männlichkeit. Sie ist es, die auch Elena an ihn bindet. Die Wirkung seiner Machtausstrahlung wird denn auch in ähnlichen Worten wie die sexualisierten Treffen von Deters und Elena beschrieben: „Goltzens Macht [...] hatte sie [...] mit einem gleichermaßen kräftigen wie zärtlichen Griff zwischen die Beine gepackt.« $(T A, 311)$

In verschiedenen anderen Konstellationen, die hier kurz angerissen werden sollen, wird diese Thematik ebenfalls behandelt. Die bereits erwähnte Beziehung der Klonin Dolly zum Gigolo Broglier beleuchtet dabei die Verbindung von Sexualität und Natürlichkeit auf eine besondere Weise. Das Verhältnis der beiden ist gekennzeichnet durch Unverklemmtheit und natürlichen Sex, d. h. nicht im Infomaten. Gerade durch sie, die künstlich geschaffene, ${ }^{56}$ kommt Broglier zur natürlichen Art zurück, durch sie, die »keine Geschichte» hat, bricht geradezu »eine frühe Kulturstufe durch» $(T A, 470)$.

56 Das Klonen kann sogar als »asexuelle Reproduktion« bezeichnet werden, vgl. Joachim Kalka: "Körperphantasien. Von Schafen und Menschen «, in: Kursbuch 128 (Juni 1997): Lebensfragen, 1-14, hier: 5. Dort findet sich auch der Hinweis, dass der Begriffs des Klonens ursprünglich aus der Landwirtschaft stammt und dort u. a. das Pfropfen von Pflanzen bezeichnet. 
Auch hier findet sich wieder der Hinweis von >unverklemmtem` Geschlechtsverkehr und Ursprünglichkeit, der die Unterdrückung animalischer Triebe im Menschen als (negative) Entwicklung der Zivilisationsgeschichte impliziert.

In der Episode von der Flugsimulation der Mayflower 2 nimmt die Beschreibung der Sexualitätsentwicklung des einzigen wachen Passagiers Enzo, eines anfangs fünfjährigem Jungen, den meisten Raum ein. Als er in die Pubertät kommt, führt ihm der gottgleiche Rechner Holomorfe als Sexualpartner zu. Schließlich erkennt er jedoch die Künstlichkeit der Partnerinnen und gerade ihre vollständige Bereitwilligkeit zeigt ihm die Unechtheit seiner Umgebung. "Niemand ist wie ich bin. Niemand schwitzt. Niemand hat irgendwelche Gerüche. Mach mir eine wie mich. Mach mir eine richtige Frau.« $(T A, 195)$ Auch hier liegt die Betonung auf der Körperlichkeit; Schweiß und Gerüche stehen dabei symbolisch für die natürliche Sexualität und Triebe und weniger für imaginierte oder virtualisierte Erotik.

Ein weiteres Beispiel ist in $B A$ Deters' Beziehung in seinen neun Jahren in der Anderswelt zu Els (Elizabeth Siddal ${ }^{57}$ ), die von sexuellen und beziehungstechnischen Dominanzfragen (vgl. BA, 29ff., 5of.) geprägt ist. Schließlich findet sich Ähnliches auch auf der Ebene von Herbst in Garrafff wieder. Die Beziehung von Elena und Deters stellt sich als eine Spiegelung des Verhältnisses von Herbst zu seiner Chefin Sabine Zeuner heraus. Er flirtet eher erfolglos mit ihr, findet jedoch ihre (auch körperlich geäußerte) Anerkennung, als er den Avatar Broglier verändert und sich im Konkurrenzkampf mit dem Kollegen Lerche als gewitzter herausstellt (vgl. $B A, 153$ f.). Später wird dann der flirtende Kampf um die Dominanz der Beziehung, die bislang von Zeuner dadurch bestimmt wird, dass sie eine solche ablehnt, von ihnen beiden im Verfolgen der Entscheidungen von Deters in der Anderswelt ausgetragen. Dass Deters dort zwischen zwei Frauen steht, zwischen Elena und der bereits in TA als Nebenfigur eingeführten Corinna Frieling, hat vor allem Auswirkungen auf die Beobachter. Der in der Anderswelt in Vertretung geführte `Geschlechterkampf` verwirklicht sich schließlich auch bei Herbst und Zeuner.

Als der Programmierer Herbst am Ende von $B A$ schließlich an Deters' statt in der Anderswelt gelandet ist und sich dort zurechtzufinden versucht, während sich sogar die Sätze der Erzählung auflösen, hält er sich an einem Gedanken fest: »Das einzige was mir helfen kann. Frauen. Er kennt ja genug.« $(B A, 268)$ Gänzlich klar wird nicht, was er damit meint. Malsch spekuliert:

Für Deters heißt sie Elena Jaspers. Für Herbst heißt sie Sabine Zeuner. Für Broglier heißt sie Dorata Spinnen. Und für Borkenbrod heißt sie, wen wunderts, wiederum Elena Jaspers. Damit schließt sich der Reigen. [...] Was für Deters das Heimweh nach der Dunckerstraße, das ist für Broglier und für alle anderen männlichen Konfigurationen des gespaltenen Ichs unseres Fiktionärsduos

57 Der Name stellt einen Bezug zur englischen Malerin und Dichterin gleichen Namens aus dem 19. Jahrhundert her, der Ehefrau von Dante Gabriel Rossetti und Modell verschiedener Präraffaeliten. Die Bedeutung des Bezugs wird jedoch nicht recht deutlich, möglicherweise war lediglich die äußerliche Erscheinung Vorbild für die Figur, die als »schmale Präraffaelitin« $(B A, 18)$ beschrieben wird. 
Herbst \& Deters die unstillbare Sehnsucht »zurück zu seiner Dorata zu finden« (BAA: 158$). .^{5}$

Angesichts der obigen Ausführungen und im Hinblick auf entsprechende Diskurse in den Vorgängerromanen könnte eine Lesart sein, dass der Kontakt zu den Frauen und damit die Sexualität bzw. der sexuelle Akt und die Körperlichkeit die letzte Möglichkeit zur Selbstvergewisserung und zur Wirklichkeitserfahrung bleibt (vgl. Laupeyßers Herstellung von Nähe durch Beischlaf in $V G$ ).

\section{Achilles Borkenbrod und Weiblichkeit}

Zwar wird bei der Darstellung der identitätsstiftenden Bedeutung von Sexualität mit der entsprechenden Dichotomie der Geschlechter gearbeitet; vor allem die Bedeutung der Männlichkeit wird in stereotyper Weise betont. Es ist jedoch schon in den eben beschriebenen Konstellationen auffällig, dass Stereotype zwar verwendet, aber andererseits auch immer wieder hinterfragt bzw. ambivalent dargestellt werden. So ist Deters nicht durchgängig oder eindeutig in der Rolle des Machos und Goltz füllt die stereotyp männliche Dominanz- und Machtposition auf körperlich ungewöhnliche Weise aus. Auch steht Deters in Elena keineswegs das traditionelle Frauenstereotyp entgegen. Auch sie ist sehr durch Ehrgeiz und Machthunger geprägt und wird vor allem durch den Bezug zur Macht bestimmt. Hier zeigt sich die Ambivalenz schon in den sexuellen Dominanzspielchen. Zwar nimmt sie teilweise die ihr zugedachte submissive Rolle an; doch ist es eben Teil des noch ungeregelten Spiels, dass auch sie Vorgaben gibt und den Fortgang der Beziehung sogar stärker in der Hand hat als Deters.

Diese Ambivalenz der Geschlechterrollen wird deutlicher dargestellt anhand der Figur Achilles Borkenbrod. Der Vorname verweist wieder in eindeutiger Weise auf die mythologische Vorlage, Homers' Achilles. ${ }^{59}$ Bei dem Gedanken an den männlichen ,Superhelden der Ilias ist der Bezug zur Weiblichkeit zwar erstaunlich, doch speist sich auch dieser aus dem mythologischen Kontext. ${ }^{60}$ In verschiedenen Varianten des Mythos wird er von seiner Mutter Thetis als Mädchen verkleidet und unter den Töchtern des Königs Lykomedes versteckt. Von einer der Töchter, Deidameia, bekommt er einen Sohn. ${ }^{61}$ Auf diese Varianten wird in TA Bezug genommen und alle genannten Elemente tauchen auch hier auf.

Zunächst wird auch Borkenbrod in ähnlicher Weise wie Deters als ursprünglich-männlich präsentiert. Er stellt sich selbst als Außenseiter dar, der nicht dem

58 Malsch: »Vom Wiedereintritt des Autors in seine Geschichte«, 78.

59 Der Nachname ist dagegen kein mythologischer Bezug, sondern verweist auf Sibelius' 4. Sinfonie, die nach ihrer Erstaufführung in Finnland wegen ihrer Kargheit Borkenbrot-Sinfonie genannt wurde (vgl. URL-20, 12. Sep. 2012). Die Sinfonie soll zu Beginn den `Soundtrack Erschaffung der Anderswelt und der Figur Borkenbrod, vgl. TA, 20.

6o Bei Preußer findet sich diesbezüglich eine relativ ausführliche Darstellung der Überlieferung des Achilles-Mythos in der Antike sowie in Bezug auf Christa Wolf, vgl. Preußer: »Achilles als Barde«, 73-75.

61 Vgl. Apollodor: Die griechische Sagenwelt. Apollodors Mythologische Bibliothek, übers. von Christian Gottlob Moser / Dorothea Vollbach (Sammlung Dieterich 354), Köln 1997, III 171-174. 
Osten wirklich zugehörig ist, da er auf mysteriöse Weise als Kind aus Schweden über das Meer gekommen ist. Außerdem ist sein großes Ziel, an den Sehnsuchtsort Leuke zu gelangen. Er ernährt sich nicht von dem halbsynthetischen Essen, sondern halbwegs `natürlich . Schon hier wird er deutlich auf die Ungefugger entgegengesetzte Position verwiesen, wenn er bemerkt, dass das Essen »körperlos« $(T A, 55)$ schmeckt. Wichtiger noch ist sein vorauseilender Ruf, dass er tapfer sei und keine Angst vor "der Ansteckung " $(T A, 62)$ habe. Damit steht er für die ursprüngliche `natürlicher Sexualität. Aus diesem Grund wählt ihn seine Bekannte Meroë für die Myrmidonenführerin Lykomedite Zollstein aus, die jemanden sucht, sie zu befruchten, um ein Kind zu zeugen, das Thetis geopfert werden soll.

Die Myrmidonen, in der Ilias eigentlich die Bezeichnung für das von Achilles angeführte Heer (bzw. die Volksgruppe), sind in der Anderswelt eine Frauenarmee. Sie sind dem Kampf gegen den Westen verschrieben und vereinigen sich später nach ihrem Wechsel in die Zentralstadt mit den Holomorfenrebellen. Wie auch bei der offensichtlichen mythologischen Vorlage, den Amazonen, fällt vor allem die Umkehrung stereotyper Geschlechterbilder auf. Die Myrmidonen bilden sich aus ausschließlich weiblichen Kämpferinnen, die jedoch die traditionell männlichen Werte wie Disziplin und kämpferische Härte vertreten. Eine Gruppe ebenfalls weiblicher Konkubinen, die sogenannten Harines, steht zu ihrer Pflege und Lustbefriedigung zur Verfügung. Diese sind jedoch wiederum deutlich nach traditionell weiblichen Werten modelliert, die den militärischen entgegenstehen, sie sind schön, zart und empfindlich. Borkenbrod, der als männlicher Repräsentant zu den Myrmidonen gebracht wird, vor allem auch in der Funktion, ein Kind zu zeugen, wird jedoch gleich in die weibliche Umgebung eingepasst. Er wird in Vorbereitung der von ihm verlangten Zeugung mit Frauenkleidern versehen, gewaschen und gekämmt, außerdem werden ihm die Fingernägel lackiert (vgl. TA, 10of., 103f.). Die Zeugungsnacht mit der als verwachsenes Monster beschriebenen Zollstein (auch Mandschu oder Mongolin ${ }^{62}$ genannt) verändert weiteres für ihn. Entgegen jeglicher Erwartungen wird der Geschlechtsakt ein geradezu zärtlicher Umgang der beiden, die eigentlich Häßliche erscheint ihm sogar als schön. Die Beschreibung der Nacht (vgl. TA, $285 \mathrm{ff}$.), die nur in seiner Erinnerung erfolgt, wird sprachlich durch die verwendeten Worte und gewählten Bilder religiös überhöht. Seine Selbstbezeichnung als Frühlingskönig und ihre als Frühlingsprinzessin gemahnt an den aus WB bekannten Kontext der `Heiligen Hochzeit‘, der Hieros gamos. Der Geschlechtsverkehr bewirkt an den beiden eine Verwandlung ihrer vorher scheinbar festgefügten Rollen und Identitäten. Zollsteins durch traumatische Erfahrungen ${ }^{63}$ verhärtete Persönlichkeit bricht in diesem Akt auf, ihr Entschluss, Borkenbrod töten zu lassen, setzt sie aus plötzlich auftretendem Mitleid nicht um. Wieder wird dabei eine Verbindung hergestellt zwischen dem Sexualitäts- und Geschlechterkontext und der Dichotomie von Gefühl und Geist (oder Mythos und Logos).

62 Hans Richard Brittnacher bringt diesbezüglich den interessanten Hinweis, dass der vom Westen errichtete Laserzaun »kaum dauerhaft dem Mongolensturm wird widerstehen können « (Brittnacher: »Der verspielte Untergang «, 35) und verweist damit auf die ansonsten kaum aufkommende Assoziation der Mauer gegen das Thetismeer nicht mit der innerdeutschen Mauer, sondern mit der Chinesischen Mauer.

63 Vgl. TA, 555-559. 
Ebenfalls stimmte, daß sie sich verwandeln sollte zur Frühlingsprinzessin. Konsekration. Und als die Mandschu wieder zu sich gekommen war und sich Struktur und Willen zurück um den Geist gepanzert hatten, da war es, ihn zu töten, zu spät gewesen. Da hatte er sie gedauert [...]. $(T A, 287)$

Während des Akts schreit und wimmert sie vor Lust und das Ungewöhnliche daran, wie sich ihre verstandesmäßig absolute Härte in Lust und Mitleid verwandelt, versucht Borkenbrod gar nicht erst zu begreifen, sondern zu fühlen. Ausdruck findet dies in Worten, die die Thematik aus WB direkt wieder aufgreift: "In diesem Bett war für Begriffe kein Platz.« $(T A, 286)$ Und auch später noch einmal greift er diese Formulierungen auf: »Von alledem, das begriff er, begriffe man nichts, und strengte sich einer noch so sehr an." $(T A, 295)$ Doch auch bei Borkenbrod findet eine Verweichlichung statt, er begegnet ihrem Vertrauen mit eigenem Vertrauen und lässt sich derart fallen, dass er zu einem »sabbernd zerbrechliche[n] Mannskind « $(T A, 287)$ verkommt, eben die verletzliche Rolle eines Kindes annimmt und damit gerade das Gegenteil der männlichen Stärke darstellt.

Als Lykomedite Zollstein ihn später dann doch noch hinrichten lassen will, ist es Niam, die inzwischen geborene Tochter, die wundersamerweise gleich nach der Geburt sprechen kann, die ihn rettet. Sie versteckt in bei ihrer Ziehmutter, der Anführerin der Konkubinen, Deidameia. Er wird nun nicht nur wie eine Frau gekleidet, sondern als Frau verkleidet. Die Konkubinen wissen von seinem wahren Geschlecht, verraten ihn aber nicht. Als Niam ihn zu ihnen bringt ist er vielmehr deshalb eine Sensation. Deidameias Furcht und Zweifel wird von den anderen Frauen der Hinweis auf Liebe entgegengesetzt. »Wir wollen lieben«, sagten die Frauen. »Lieben? «»Lieben. « noch gibt.« $(T A, 299)$ Wenig später im Gespräch mit Borkenbrod ist auch Deidameia erstaunt: »Männer waren ihr selten begegnet, einer aber, der liebte, noch nie.« (TA, 301) Beide Hinweise zusammengenommen ergeben wieder eine Gegenüberstellung der Geschlechter: »solche wie uns« bedeutet in der größeren Gruppe der Myrmidonen die >weiblichen` Frauen, die lieben können und wollen und nicht verhärtet sind. Männer dagegen werden normalerweise als nicht zur Liebe fähig angesehen. Borkenbrod, der seine Vaterliebe zu Niam entdeckt und eingesteht, ist dahingehend eine Ausnahmeerscheinung. Auch in der Verkleidung bleibt er jedoch Mann. ${ }^{64}$ Schon Meroë hatte die beiden Seiten in ihm erkannt, als sie ihn folgendermaßen beschrieb: "Er ist ein Träumer und hat Kraft. Es gibt nicht viele Träumer da draußen.« (TA, 102) Mehrfach wird diese Aufhebung bzw. Relativierung der zuvor etablierten bzw. impliziten Dichotomie von weiblicher Liebe und männlicher Härte noch vorgebracht. Einerseits wandelt er sich, wird zu einem »rosigen Hetärenmännchen « $(T A, 594)$, er lernt die weibliche Zärtlichkeit kennen, die ihm bis dahin nicht bekannt war, weil er ohne Mutter aufgewachsen ist. Hier wird sehr deutlich der Aspekt der Mutterliebe als urweibliche Eigenschaft ins Spiel gebracht (die sich bei ihm dann in die Vaterliebe

64 Dieses Motiv wird noch weitergesponnen. Später meint Deters nämlich im $>$ Boudoir $\triangleleft$ Borkenbrod als `Tunte $<$ zu identifizieren (vgl. $T A, 664)$. In $B A$ wird dies jedoch als eine Verwechslung entlarvt (189). 
wandelt). ${ }^{65}$ Andererseits wird doch auch die Betonung seiner Männlichkeit aufrechterhalten; als die Soldatinnen, die in der Myrmidonen-Gruppe den Part der verhärteten >Männer einnehmen, dies entdecken, genießen sie das Unerwartete heimlich und verraten ihn ebenfalls nicht an ihre Anführerin.

Wesentlich später wird er von Odysseus, dem Anführer der Schänder-Heere, der mit Zollsteins Myrmidonen paktiert, enttarnt - in Anlehnung an die List, mit der in der mythologischen Überlieferung Odysseus den versteckten Achilles unter den Mädchen enttarnt (vgl. TA, 594-597). Als daraufhin der gemeinsame Kampf gegen den Westen geplant wird, ist auch das Einschleusen der Konkubinen als Rebellinnen in den Westen ein Teil des Plans. Die Zollstein lässt Borkenbrod zu sich rufen und verlangt von ihm überraschenderweise nicht wie von ihren ja weiblichen Soldatinnen die völlige Verhärtung, sondern im Gegenteil die Bewahrung seiner Weichheit.

Bewahr dir was von dem, das du bist. [...] Ich will nicht, daß du wirst wie [Odysseus]. [...] Er wird euch über die Grenze führen, aber dann ... dann wirst du führen. Er liebt nicht, wen er führt, er liebt die Führung. Ich will, daß du niemals die Führung liebst. $(T A, 639)$

[...] dann wirst du weitertrainieren, wirst dich härten lassen, aber bitte ... bleib weich! (TA, 640)

Wieder wird mit Kontrasten gearbeitet. Odysseus steht als harter und skrupelloser Kämpfer für die alte Zeit. Borkenbrod steht dagegen für eine neue Umgangsform, er kann bereits lieben. Die Führung wird er tatsächlich auch nicht übernehmen, denn Deidameia ist im Westen dann die Führerin der Rebellen. Die Zollstein gibt ihm in diesem Gespräch den Auftrag, als Geschichtenerzähler, als Poet zur Rebellion beizutragen. Sie macht ihn zum >Graffito-Rebellen ${ }^{66}$, als der er in $B A$ dann auftritt.

Die beiden häufigsten Graffiti stellen gleichzeitig Leitmotive der $A W$-Romane dar. Deters entdeckt das erste gleich eingangs im Café Silberstein, wo er wartet:

Three things that enrich the poet Myths, poetic power, a store of ancient verse (u. a. $T A, 30,86,364, B A, 62 f ., 118$ )

Das andere scheint noch rätselhafter:

Über wen lächeln die Rinder des Tethra? (u. a. TA, 30, 177, 245)

Entgegen der Verwirrung etlicher Kritiker und Interpreten führen diese »teils rätselhaften Sätze « jedoch nicht ins »Nichts ${ }^{67}$. Bei dem ersten Zitat handelt es sich um die poetischen Prinzipien keltischer Minnesänger, die im Llyfr Coch Hergest, dem

65 Vgl. TA, 592: »Er war früher nie gestreichelt worden. Schon der Gedanke, daß es ein Streicheln gab, hatte ihm ferne gelegen. Er hatte keine Mutter gehabt, es ihn zu lehren. Aber das wußte er nicht."

66 Preußer verweist in diesem Zusammenhang auf Jean Baudrillard, der in seinem Aufsatz »Kool Killer oder Der Aufstand der Zeichen« (1978) das revolutionäre Potenzial von Graffiti beschrieben hat. Ein direkter Einfluss auf Herbst wird jedoch nicht deutlich.

67 Reber: Formenverschleifung, 408. Vgl. auch Maike Albath: »Der götterhaften Giftbrühe entstiegen «, in: Der Tagesspiegel, 31. Okt. 1998. 
Roten Buch von Hergest aufgeführt sind, wie Robert von Ranke-Graves ausführt ${ }^{68}$ und auch in TA angedeutet ist (vgl. TA, 244). Das zweite entstammt dem »Lied von Amergin «, einem Barden der frühen irischen Mythologie (vermutlich 1268 v. Chr.). >Tethra` war »der König des Untermeer-Landes, [...] möglicherweise eine Maskulinierung von Thetys, der peslasgischen Meeresgöttin, auch als Thetis bekannt ${ }^{69}$ und mit den $>$ Rindern des Tethra $<$ sind demnach Fische gemeint. Die Frage hat vermutlich die Bedeutung >wer Glück beim Fischen hat.$^{70}$ Dies serklärt ‘ die Sprüche nun nicht unbedingt, stellt aber den Zusammenhang zu Herbsts Mythenverwendung her, die stark von Ranke-Graves beeinflusst ist. ${ }^{71}$ Es ist ein Bezug auf die in verschiedenen Gestalten und Bedeutungen auftretende Thetis und eine weitere Verbindung zwischen den klassisch-griechischen und den keltisch/nordischen Mythen. Im ersten Spruch findet sich das selbsternannte poetische Arsenal der herbstschen Poetik: die Verwendung mythischer Strukturen, die Fabulierlust und der intertextuelle Bezug auf bzw. das Zitat älterer Literatur, denen er »subversives Potential $\aleph^{72}$ zuspricht.

Am Ende von $B A$ findet sich schließlich noch eine Wende in Bezug auf Borkenbrod und den Männlichkeitsdiskurs. Abseits des Treffens zwischen Goltz und Deidameia verfolgt Borkenbrod Elena und vergewaltigt sie. Zum einen ist dieser Gewaltausbruch und gegenseitige Kampf eher untypisch für das von ihm gezeichnete Bild und stellt damit eine auffällige Besonderheit dar. Der »Zorn« des Achilles ist aber seit dem ersten Vers der Ilias das kennzeichnende Merkmal dieser mythischen Figur. ${ }^{73}$ Genau dies wird auch explizit vermerkt: »erst alles das machte ihn zu dem Heros, der er seit je, seit Troja, war« $(T A, 253)$. Mit >Heros` ist damit nicht ein moralisch bewertetes Heldenhaftes gemeint, sondern die Kehrseite, die im Mythos auch besteht und auf die bereits oben hingewiesen wurde: die homerischen Helden sind gleichzeitig auch »blutigste Schwerverbrecher « $(B A, 209)$. Elenas Reaktion ist dabei gewissermaßen ambivalent. Erst wehrt sie sich aus rationalen Gründen nicht, dann packt sie doch Wut und Hass und es kommt zu einem Kampf, der als eine ins Brutale gesteigerte Form des `Geschlechterkampfs` gesehen werden kann; die Rede vom »Machtspiel « $(B A, 252)$ unterstützt dies. Schließlich wandelt sich ihr Hass in Verwunderung, da sie die sich bei ihm bildenden Schuppen, seine atavistische Mutation, bemerkt. Wie sie sie anfasst, wirkt es auf ihn wie eine Liebkosung, die ihn >überwindet ‘ und schwach macht. Es ist nun das, »was es schien: [eine] banale Vergewaltigung « $(B A, 254)$, und Elenas passive und sogar ihm gegenüber positive Gedanken können als männliche Vergewaltigungsphantasien gesehen werden. Zum anderen deutet die Ungewöhnlich-

68 Vgl. Ranke-Graves: Die weiße Göttin, 20.

69 Ebd., 241f.

70 Vgl. ebd., 251.

71 Vgl. u. a. Kühlmann: »Postmoderne Phantasien«, 502 FN 8, oder URL-21, 20. Aug. 2004.

72 Friedmar Apel: »Täglich sieben trockene Martinis«, in: Frankfurter Allgemeine Zeitung, 6. Okt. 1998.

73 Vgl. dazu noch einmal Preußer: "Achilles als Barde«, besonders 83. 
keit der Brutalität Borkenbrods und die Ambivalenz der Gefühle von beiden ${ }^{74}$ auf die Zielgerichtetheit der mythischen Vorlage. Borkenbrod will Elena nach Leuke bringen und ohne, dass sie weiß was das ist, steht ihr "ein Meer vor Augen ... zumindest hätte sie weglaufen können, doch dieses Meer, das M e e r! $(B A, 255)$ Auch sie unterliegt also den mythischen Vorgaben. Elena ist also "Die schöne Helena "75, die in manchen mythologischen Überlieferungen nach Achilles' Tod mit ihm auf Levkas vereint wird. Gleichzeitig ist die Szene auch eine Parallele zu Kampf, Überwindung und Hochzeit zwischen Peleus und Thetis, den Eltern des Achilles sowohl in der Mythologie ${ }^{76}$ als auch in TA (vgl. 354ff.). Gerade in der Szene in TA wird die Ambivalenz von Macht und Gewalt zwischen den Geschlechtern - der mächtigen Göttin bzw. Midgardschlange und dem sterblichen Mann Peleus - deutlicher herausgestellt.

\section{Der mythische Osten}

In der Anderswelt ist innerhalb der Dreiteilung Europas die deutlichste Abgrenzung die zwischen dem Zentrum und dem Osten. Zwar ist der Westen wenigen Reichen vorbehalten und für die Bewohner der Zentralstadt kaum erreichbar, doch sind beide Teile unter dem Hodna-Schirm und damit Teil der allgemeinen Synthetisierung. Ungefugger übt dabei vom Westen seinen großen Einfluss aus. Zwar hat er auch Einfluss auf den Osten, dennoch kann der Osten als Gegenbild zu den westlichen Teilen der Anderswelt und vor allem zu den Vorstellungen und Idealen von Ungefugger gesehen werden.

Der Osten steht dabei für den Mythos. Diese Zuordnung ergibt sich teilweise durch die Beschreibungen, teilweise durch den Gegensatz zu Ungefugger, durch die Gegenüberstellung ideologischer Positionen. Sehr deutlich sind die Übernahmen von Namen und Geschichten besonders der griechischen, aber auch der keltischen Mythologie. ${ }^{77}$ Dabei sind die mythologischen Verweise strikt auf die Sphäre des Ostens beschränkt. Erst durch die spätere Infiltration der Zentralstadt durch die Myrmidonen kommt es zu einer Vermischung der Sphären; vorherige mythologische Bezüge in der Handlung der Zentralstadt oder des Westens beziehen sich immer auf auswärtige Figuren (bspw. die Verbindung des Präsidenten mit Eris, dem Achäer, vgl. TA, 353). Die Zuordnung ist Teil der Gesamtanlage des Anderswelt-Projekts, die Herbst vorweg in einer "Schreibauskunft» formuliert hat. Auch die Sprache der einzelnen eigentlich

74 Vgl. bspw. »[A]uch er schlug, man kann nicht sagen, es machte ihm Freude, aber es gehörte zum Mauernschleifen dazu.« $(B A, 253)$

75 Vgl. TA, 305, auch $B A, 235$, wo eins von Borkenbrods Graffiti der Vers 419 aus dem 3. Gesang der Ilias ist, der Helena beschreibt. Diese Verflechtung muss Herbst jedoch recht spät eingearbeitet haben, da die Figur noch 1996 den Namen Sibylle Jaspers trug, vgl. Alban Nikolai Herbst: "Schreibauskunft. Zum Roman >Anderswelt «, in: Neue Deutsche Literatur 44/5 (1996), 83-87, hier: 84 .

76 Vgl. Apollodor: Die griechische Sagenwelt, III 170.

77 Nicht nur die Hauptfiguren sind entsprechend genannt, es wird auch berichtet, dass allgemein mythologische Namen verwendet werden wie Medea, Jason, Pan, Lilith, Klytemnästra, Edda, Medusa etc., außerdem auch Bezeichnungen von Geschlechtsteilen wie Clitoris, Vagina, Phallus, die sich klanglich unauffällig einreihen (vgl. TA, 42). Clitoris als Frauenname ist ein Verweis auf Arno Schmidt, den Herbst schon in $V G$ bringt $(V G, 185)$. 
geographisch gegliederten Teile soll den Zuordnungen entsprechen. Die Sprache des Ostens beschreibt er als »überwiegend mythisch, so auch sind es die Namen ${ }^{78}$. Damit bezeichnet er einen »mitunter schludrige[n] Ton «, die absichtliche Verwendung von "Fäkalsprache « ${ }^{79}$, in denen Geschichten aus dem heruntergekommenen Osten erzählt werden, die teils die Ekelgrenze deutlich überschreiten. Dies gilt vor allem für den Erzählstrang um Borkenbrods Freund Poseidon, der diesem ins Ungewisse folgt, um ihn zu beschützen. Er gerät dabei in die Hände marodierender Schändertruppen. Bei den Schändern oder Schänderpriestern handelt es sich um eine radikale Sekte, die sich aus genetisch mutierten Menschen zusammensetzt (aus "Mutanten Bastarden Abgestückelten Gefundenen «, TA, 49). Sie ziehen zusammen mit sogenannten Heiligen Frauen und Hundsgöttern (Kreuzungen aus Kampfhunden und Heiligen Frauen) durch den Osten, richten Massaker an und opfern Kinder. Poseidon wird zum Oberhaupt der Schänderpriester gebracht, Dagda, eigentlich einer Gottheit der irischen Mythologie. ${ }^{80}$ In einer merkwürdigen Zeremonie wird er gequält und >gemolken «, verschiedene Flüssigkeiten sowie eine Unmenge von Spinnen kommen aus seinem Körper. Im Laufe der Prozedur scheint er Visionen zu haben, wird daher als Prophet angenommen und geblendet, um seine Seherkraft zu verstärken. Diese sowohl durch ihre Brutalität als auch durch ihre detaillierte Beschreibung körperlicher Folterreaktionen die Grenzen der Zumutbarkeit des Lesers austestenden Passagen haben auch am deutlichsten das Unverständnis der Literaturkritik hervorgerufen. ${ }^{81}$ Über die geschmacklichen Grenzen lässt es sich dabei streiten, die >Ekelpassagen erhalten ihre Bedeutung ${ }^{82}$ jedoch im Kontext einer Verortung des Ostens als Gegenposition zur entkörperlichten Welt Ungefuggers im Westen bzw. der Zentralstadt. Der Osten wird dominiert durch die allgegenwärtige Gefährdung durch Thetis, das Meer und zugleich die Göttin. Es ist abzusehen, dass die große Mauer, die das Meer abhalten soll, nicht mehr lange hält. Die Schänder und die Heiligen Frauen hängen der Überzeugung an, dass Kinderopfer die Göttin beschwichtigen. Sie glauben, dass Thetis »die Reinheit $(T A, 49)$ hasse. Dies ist auch die Begründung dafür, die Kinder zu schänden, bevor sie getötet werden. Sie selbst lassen sich »taufen mit Urin und weihen in Lymphe«, Mütter, die ihre Kinder nicht herausgeben, werden "gepfählt und von den Priestern gegessen « (ebd.). Alle Handlungen und Beschreibungen deuten auf die größtmögliche Körperlichkeit, auf Dreck, Körperflüssigkeiten und körperliche Gewalt. Immer wieder wird die Verbindung von Osten und Unreinheit aufgemacht. Der Präsident vermisst die »unreine Welt« $(T A, 362)$, die vor der allgemeinen Synthetisierung bestand und im Osten weiter besteht, ohne sie zu vertragen. Er lässt sie nur an sich heran durch die Erzählungen des entführten Eris. Als die Myrmidonen

$\mathbf{7 8}$ Herbst: »Schreibauskunft«, 83.

79 Ebd., $85 f$.

80 Vgl. MacKillop: A Dictionary of Celtic Mythology, $125 \mathrm{f}$.

81 Vgl. vor allem Döbler: „Delirium und Moralium«; Wörtche: »Pusteln und Pickel«; Albath: »Der götterhaften Giftbrühe entstiegen«; Burkhardt Lindner: »Krise der Phantasie«, in: Frankfurter Rundschau 13.3.1999.

82 In $B A$ stellen sich diese Szenen als sich selbstentwickelnde Mechanismen, d. h. automatische Regressionen im Zusammenhang der simulierten Welten heraus, wodurch eine weitere Lesart gegeben wird, dazu später Genaueres. 
in der Zentralstadt angekommen sind und Deters verwirrt über die Entwicklungen seiner selbst geschaffenen Welt sinniert, stellt er fest, dass es plötzlich »um Mythen [ging], deren Einbruch in den Zentralpragmatismus für jede Reinheit vernichtend ist « $(T A, 378)$. Die Reinheit bzw. eben gerade die Unreinheit oder Vernichtung der Reinheit ist das wiederholte Schlagwort, das mit dem Osten verbunden ist. Auch in der Charakterisierung von Jens Jensen und seinen heimlichen Leidenschaften, auf die noch zurückzukommen ist, taucht es wieder auf:

Imgrunde gärte der Osten in ihm. Der Westen war auf seine Haut nur gehaucht. [...] Und [...] wie der Vater [...], wollte nun der Albino ebenfalls etwas Östliches haben, ungereinigt und furchtbar irdisch. Es war dieses Brutale in ihm, das dem allen entsprach. $(T A, 812)$

Auch die Beschreibungen des Organhandels gehen in diese Richtung. Im Osten werden Kinder großgezogen, lediglich um als `Ersatzteillager $\triangleleft$ für Menschen in der Zentralstadt oder im Westen zu dienen. Ganze `Organfarmen « entstehen so. Die Ostler dienen der Produktion von Buenos Aires also nicht nur körperlich wie Borkenbrod und Poseidon in der Fabrik, sondern stehen "auch als Körper zur Verfügung « ${ }^{83}$. Herbst betont in der »Schreibauskunft» den Begriff des Körpers, die Reduktion auf den Körper. Dabei ist anzumerken, dass der Bezug auf den Körper hier vor allem in Gegenüberstellung zur zunehmenden Körperlosigkeit des Westens zu sehen ist; die reine Reduktion auf den Körper erlaubt auch keine Ausbildung einer individuellen Identität.

Die in TA etablierte Gleichung von Osten und Mythos sowie die Zuordnung von Unreinheit und Körperlichkeit zu dieser Position sollte deutlich geworden sein. Der Künstlichkeit der synthetisierten Welt stehen diese Kennzeichen als Symbole von ursprünglicher Natürlichkeit gegenüber. Damit wird eindeutig an das Verständnis des Mythosbegriffs in WB angeknüpft, an das durch Lipom personifizierte MythosPrinzip, das eng mit dem Begriff der Natur verbunden ist. Im Folgenden werden weitere Aspekte dieser Position in TA aufgezeigt, immer in Abgrenzung zu Ungefuggers Ansichten.

Dem Aspekt der Körperbeherrschung in Ungefuggers Zielen, die Kontrolle sowohl über Triebe als auch über Krankheit und Vergänglichkeit des Körpers, steht der Osten als Bild völligen Ausgeliefertseins gegenüber. An den individuell dargestellten Figuren wie Borkenbrod und Niam wird exemplarisch die Fremdbestimmung aufgezeigt. Beide unterliegen den Zwängen, die in Zusammenhang mit Thetis stehen. Zwar wird einerseits die Geschichte der Anderswelt als eine Mischung aus Geschichtsschreibung und Mythen, Sagen oder Legenden berichtet ${ }^{84}$ und auch die Darstellung der ThetisForderungen als Glaubensinhalte der Schänder-Sekte stellen ihren Wahrheitsgehalt infrage; andererseits wird Borkenbrod als Thetis-Sohn und Niam als Thetis-Tochter bzw. als Thetis-Erscheinung selbst präsentiert. Die als geplantes Thetis-Opfer gezeugte Niam lehnt sich einerseits gegen die Pläne der (biologischen) Mutter Lykomedite

83 Herbst: »Schreibauskunft«, 83.

84 Vgl. TA, 35-51. Vor allem immer wieder verwandte Formulierungen wie »so sagt man« (48) und »es hieß«(50) stellen die Geschichten als Mythen heraus. 
Zollstein auf, andererseits wartet sie auf die Erfüllung der Prophezeiungen ${ }^{85}$. Durch die Präsentation solcher Zusammenhänge als Tatsachen wird damit innerhalb der Erzählung bestätigt, dass diese Geltung besitzen.

Neben den körperlichen Trieben wird auch die Existenz von Gefühlen betont. Das ist in der Anderswelt keineswegs selbstverständlich. Grundlegende Gefühle wie Liebe und Trauer gibt es im synthetisierten Westen nicht mehr. Als Poseidon, der nicht nur ein Freund von Borkenbrod, sondern ihm auch in heimlicher Liebe zugetan ist, bemerkt, dass dieser verschwunden ist, bewegt ihn ein aussterbendes Gefühl:

Trauer war etwas, das das Zentrum fast vergessen hatte und der Westen längst nicht mehr kannte. Sie war Seelenteil des Ostens, auch wenn man für sie keinen Begriff mehr hatte: Immer wieder, in den Liedern, quoll sie auf. (TA, 137)

Später wird das Trauern in Zusammenhang mit Poseidon noch einmal aufgegriffen. Als er längst als verstümmelter Prophet bei den Schändern lebt, verschwindet Meroë aus ihm, deren Erinnerungen und damit quasi ihre Seele oder eben das, was von ihr übrig geblieben ist, ihm vor seinem Aufbruch ins Hirn transplantiert wurde (vgl. TA, 146ff.). Dies erfolgt durch Tränen, die aus Poseidons Augenwunden kommen; sie verdunstet auf mysteriöse Weise. Borkenbrod begreift von alledem nicht viel, bemerkt jedoch eine Änderung. Durch seine Fähigkeit zur Trauer und implizit vorausgesetzt zur Freundschaft überhaupt, entsteht ein Gefühl der Gemeinschaft.

Auch die Gemeinschaft im Zelt war still. Denn Gemeinschaft war man. Das hatte hier bislang noch keiner erlebt. Odysseus nicht, die Devadasi nicht, nicht einmal die Priester waren je Gemeinschaft gewesen. Jetzt erst, als einer so trauerte und weil man ihm Zeit ließ dafür gegen jedes Gesetz, wurden sie es. (TA, 651)

Auch wenn die Gemeinschaft von mordenden Schändern und rasenden Heiligen Frauen etwas merkwürdig anmutet, so ist sie doch wieder im Kontrast zu Buenos Aires zu sehen, wo die Entwicklung hin zum konformen Individualismus geht. Selbst die am ehesten vergleichbare Beschreibung von Gemeinschaft in der Zentralstadt, die EWG-Versammlung, wird nicht als gefühlsmäßige Zugehörigkeit präsentiert, sondern als induzierte Manipulation.

Wichtiger noch als Trauer und Gemeinschaftsgefühl ist jedoch die Liebe. Sie erscheint keineswegs als zentrales Motiv, das in den Vordergrund sticht, findet sich aber in verschiedenen Figurenkonstellationen. Vorweggenommen sei diesmal der Kontrast der Zentralstadt und des Westens. In der Familie Ungefugger ist das Fehlen von Liebe deutlich; mit dem Unterdrücken des sexuellen Triebs seiner Frau geht auch die Ignoranz gegenüber ihren Gefühlen und Bedürfnissen einher. Die Verbindung zwischen Elena und Markus Goltz ist von außen an diese herangetragen und zwischen ihnen höchstens durch die Anziehung von Macht begründet. Zuneigung ist vielleicht in der Familie Jaspers zu ahnen, ist jedoch höchstens ex negativo aus den im Mittelpunkt stehenden Querelen zwischen Frau und Stieftochter zu erahnen.

85 Vgl. TA, 388. Die legendenhafte Prophezeiung selbst findet sich in TA, 461:»[...] das Thetisopfer eines Heiligen Kindes, welches, der Meeresgöttin dargebracht, Unsterblichkeit erhielte und - so wollte es die Schänderlegende - zurückkehrte dann, um die Europäische Stadt und alles Leben in ihr ein- für jedesmal und allen Willen auszulöschen; auf daß Ruhe werde auf Erden und sämtliches Leiden verwische.« 
Einziges Positivbeispiel bleibt die Zuneigung zwischen Dolly Spinnen und ihrem Vater und dann die Liebe zu Broglier. Wie bereits beschrieben ist dieses Verhältnis jedoch gerade paradoxerweise durch die `Ursprünglichkeit` von Dolly geprägt. Dies ähnelt der Ausprägung der Liebe im Osten. Dort ist sie eng mit körperlichen Trieben verbunden und stellt sich als eine Art von Urkraft dar.

In Bezug auf Borkenbrod ist sie bereits angesprochen worden. Zwar wird nicht genauer erläutert, warum die Liebe so wichtig ist, aber ihre Bedeutung wird als gegeben angenommen. Die Harines halten es wie bereits erwähnt für wichtig, dass es solche `wie uns`, die durch die Fähigkeit zu lieben gekennzeichnet sind, auch in Zukunft geben wird. Auf Wunsch der Zollstein soll Borkenbrod als liebender Vater und Mann in der Rolle des Poeten an der Rebellion teilnehmen. Bei den Schändern löst er einen großen Konflikt im Machtgefüge aus, die in der Tötung eines vorher mächtigen Götzen gipfelt. ${ }^{86}$ Er wird jedoch selbst nicht angegriffen, da er wohl durch seine Fähigkeit zum Mitleid eine beruhigende Wirkung auf die Heiligen Frauen hat. ${ }^{87}$ Auch hier findet sich das Signalwort der Liebe. »Das ist ja furchtbar. Alles, was euch fehlt, ist doch Liebe.« (TA, 654)

Die eigentliche Bezugsfigur für den Liebesdiskurs ist jedoch Borkenbrods Tochter Niam Goldenhaar. Sie zieht die Liebe von so vielen Personen auf sich wie keine andere Figur, zudem in unterschiedlichen Formen. Zunächst wird sie als Kind von ihren diversen Elternfiguren geliebt, was für diese nicht selbstverständlich ist: von Borkenbrod, von der Ziehmutter Deidameia, von der Wirtsmutter Zollstein (vgl. TA, 761). Und doch wird an ihr die allgemeine Ambivalenz deutlich, die auch die Darstellung von Liebe (und zugehörig dem Geschlechtstrieb) bestimmt. Einerseits ist auch Niam ein $>$ Monster $<$ oder $>$ Ungeheuer ${ }^{88}$. Sie kommt vollentwickelt und sprechend, bloß von kleiner Statur und doch irgendwie kindlich, zur Welt. Sie hat einen einklappbaren Giftzahn, den sie nicht wirklich unter Kontrolle hat und dem sowohl Odysseus als auch Jensen zum Opfer fallen. Zudem fordert sie kaltblütig die Opferung weiterer Unmengen von Kindern, die zusammen in eine Grube geschüttet werden sollen, um Thetis zu beruhigen. Auf der anderen Seite ist sie gefühlvoll, bemerkt die Probleme ihrer Gesprächspartner, sie ist voller Liebe zu ihrem Vater, für dessen Rettung sie sich sogar selbst gefährdet (vgl. TA, 536). Schließlich wandelt sie sich zur einer ausgewachsenen Schönheit. Dieser Widerspruch wird von Odysseus erkannt, aber nicht gelöst.

[Odysseus'] Gedanken waren um die bestialische Kleine gekreist, die irgendwo da draußen für totgeglaubt warte. Und sinne. Was war ihm Niam unheimlich! Und derart unangenehm! Und doch. Und doch! Er liebte sie. $(T A, 671)$

86 Dieser ist mitsamt der Forderung nach Menschen- und besonders Kindsopfern der mexikanischen Mythologie entlehnt, worauf Preußer hinweist, vgl. Preußer: »Achilles als Barde«, 78, Nachweise ebd. Das Opfern von Kindern findet sich aber auch direkt in den Mythen von Thetis und Achilles, vgl. Ranke-Graves: Die weiße Göttin, $146 \mathrm{f}$.

87 Preußer weist in Hinblick auf $B A, 63$, darauf hin, dass Odysseus für »den Effekt der domestizierenden Kulturleistung Gesang « mit Orpheus überblendet wird, vgl. Preußer: »Achilles als Barde«, 78. Hier gilt Ähnliches auch für Achilles, der selbige Wirkung erreicht.

88 Vgl. $B A, 66$, vgl. auch $W V$, vi: »Wie alle Feen und alle Erlöser ist sie monströs.» 
Vorher behauptet er gegenüber der Zollstein, er liebe Niam wie ein eigenes Kind (vgl. $T A, 605 f$.). Dies kann sich jedoch nur auf ein frühes Stadium ihres Kontaktes beziehen, denn später stellt sich dies anders dar.

In der wachsenden Niam wird die Verbindung des Gefühls Liebe und des Sexualtriebs (sowie des `Geschlechterkampfs $`$ ) besonders deutlich. $\mathrm{Zu}$ Jensen sagt sie, als sie eigentlich die Gefangene und damit in einer defensiven Position ist: »Ich will lieben, und du bist mir nicht gewachsen.« $(T A, 802)$ Hier wird deutlich mit der Doppelbedeutung von >lieben` gespielt; einmal dem Gefühl und einmal der Ausübung des Geschlechtsaktes. Eine eindeutige Zuordnung, was an dieser Stelle gemeint ist, kann nicht vorgenommen werden. Vielmehr ist im Kontext der verschiedenen Diskurse beides impliziert. An Niam wird mythisch verkleidet Erwachsenwerden dargestellt. Sie ist kein normaler Mensch, aber die sie kennzeichnenden Entwicklungsschübe müssen als Parallelen zu menschlichen Entsprechungen gesehen werden. So häutet sie sich mehrfach, was mit ihren Schuppen zu tun hat, die sie wie ihr Vater Borkenbrod teilweise am Körper hat oder temporär bildet; diese stammen wohl von ihrer beider Herkunft von Thetis her, die in TA als identisch mit der Midgardschlange gesehen wird. Die erste von den Häutungen wird als »ihre erste Periode« $(T A, 760)$ bezeichnet. ${ }^{89}$ Gleichzeitig ist es aber auch eine »minutenlange Selbstgeburt, die das alte Ich, ein das neue Ich Gebährendes, zurückläßt« (ebd.). Zum einen sind die Häutungen also Entwicklungssprünge, die für sie eine neue, jeweils etwas erwachsenere und entwickeltere Identität bilden. Diese Entwicklungssprünge entsprechen der manchmal ebenfalls sprunghaften, manchmal kontinuierlichen Identitätsentwicklung der Menschen. Zum anderen ist es eben auch die geschlechtliche Entwicklung, die bei Frauen durch das Einsetzen der Periode gekennzeichnet ist. Bezeichnend ist daran, dass Identitätsentwicklung selbst in der bildhaften Darstellung eng mit der geschlechtlichen Entwicklung verknüpft wird.

In Niams Verhältnis zu Odysseus wird auch die Verknüpfung von Liebe und Trieb und die Wandlung in ihrer Bedeutung vorgeführt. Erst ist es die Kindesliebe, wenn er von seiner Liebe zu Niam spricht. Später ist es dann eindeutig das sexuelle Begehren gegenüber der schönen Jugendlichen. Nachdem sie ihn bereits gebissen hat, überkommt ihn die sexuelle Erregung und der Impuls, sie zu berühren. Sie merkt dies jedoch und schmettert es gleich ab. Sie weiß, dass er ihre Liebe (oder ihre Lust) nicht überleben würde und das auf eine grausame Art (vgl. TA, 762). Ihr Lusttrieb ist ebenso wie der Biss mit ihrem Giftzahn etwas, was sie nicht kontrollieren kann. Sie meint, nicht sie habe Odysseus gebissen, »es hat dich gebissen« $(T A, 761)$. Wieder einmal wird die Unkontrollierbarkeit von körperlichen Trieben demonstriert und ein weiteres Beispiel angeführt.

Ähnlich wie das entwickelte Verhältnis von Niam zu Odysseus ist das zu Jens Jensen. Er ist jedoch zudem mit ihr verwandt, er ist ihr Onkel, was sie jedoch erst erfahren, kurz bevor sie aufeinandertreffen. Er ist fasziniert von den Beschreibungen, die Odysseus ihm mitteilt. Ein Teil ihrer Vereinbarung ist dann die Überstellung von Niam, die er in einem Labor gefangen hält und untersuchen lässt. Wie bereits in einem Zitat zu Jensen angedeutet wurde, hängt dieses Interesse mit vererbten Ähnlichkeiten mit sei-

89 Die Bildung der Schuppen tritt bei Borkenbrod vermutlich nur beim Sex auf (vgl. TA, 593, 645, $B A, 254 \mathrm{f}$.), was in beiden Fällen die Verbindung von Sexualität und Atavismus betont. 
nem Vater zusammen..$^{90} \mathrm{Da}$ beide pikanterweise engste Gefolgsleute von Ungefugger sind bzw. waren, sind sie Gegenfiguren zu diesem innerhalb seines eigenen Systems, die damit (wie bei ihm selbst auch) die Unmöglichkeit des Systems angesichts der nicht zähmbaren animalischen Natur des Menschen vorführen. Vom alten Jensen wird ganz explizit gesagt, er habe »eine eigenartig gegenläufige Bewegung zu den Neigungen des Unsterblichen ausgebildet « $(T A, 152)$. Er wird begierig auf den direkten Kontakt zu den Dingen, auch `dreckigen`, auf »Schlamme Steine Pilze« (ebd.). Von »direktem körperlichen Kontakt« (ebd.) ist er geradezu besessen, ernährt sich auf (eigentlich) natürliche Weise und raucht sogar. Während Ungefugger den Kontakt zum Osten nur aus Werbezwecken über sich ergehen lässt, sucht Jensen senior diesen geradezu. In seiner gegenläufigen Entwicklung lehnt er sogar die ihm von Ungefugger angebotene Unsterblichkeit ab und stirbt an einer Verstrahlung, die er sich im Gefecht zugezogen hat. Ungefugger ist von dieser »Verleiblichung " $(T A, 157)$ und dem seiner Ansicht nach unsinnigem Tod persönlich verletzt. Er nimmt sich des Sohns vom alten Jensen an, weiß allerdings nicht, dass auch dieser einer "schwelenden Leidenschaft" $(T A, 164)$ verfallen ist. Diese stellt sich zwar lediglich als Sammelleidenschaft für die Bilder moderner Meister heraus (vgl. TA, 783, 811), ist jedoch Symptom für die unterschwellige Gegenrichtung seiner Ansichten. Noch deutlicher wird sie durch die Betonung ihres unbewussten Charakters, ihre Beschreibung als Prädisposition, die bei ihm durchbricht, und die der weitgehenden Reflexion und Logikverfallenheit Ungefuggers umso mehr entgegensteht.

Eine Prägung war da durchgebrochen, das hatte in seinem Vater gelebt, war vererbt auf ihn und wischte Ungefuggers Prägungen weg. Niam hatte es leicht mit ihm, weil die Lust des alten Jensens am Osten Greifbaren Schmutzigen sich durch den Albino in die Welt zurückpreßte. $(T A, 767)$

Und das Zitat von oben noch einmal ausführlicher:

Längst war er bereit. Doch schon früher war er's gewesen, insgeheim, ohne etwas zu ahnen. [...] [D] as Widerspenstige [lebte sich] durch ihn hindurch. Dabei hatte er sich noch lange für treu gehalten. [...] Imgrunde gärte der Osten in ihm. Der Westen war auf seine Haut nur gehaucht. [...] Der alte Jensen, sein Vater, war auferstanden in ihm. Aus ihm aufgestanden war der. Und so, wie der Vater sich seinerzeit die Asiatin gewonnen hatte, wollte nun der Albino ebenfalls etwas Östliches haben, ungereinigt und furchtbar irdisch. Es war dieses Brutale in ihm, das dem allen entsprach. (TA, 811f.)

Jensens Neigung oder Leidenschaft hat er nicht selbst gewählt, vielmehr ist es eine Art von geradezu mystisch anmutender natürlicher Kraft, die durch ihn hindurch wirkt. Sie wird jedoch nicht klar benannt, findet vielmehr verschiedene Bezeichnungen (die >Lust`, der `Osten`) und drückt sich durch die aktiven Abstrakta aus. Diese Kraft ist die Kraft des Mythos, der triebhaften ursprünglichen Natur. Die Jensens sind jedoch sehr ambivalente Figuren. Zwar bricht sich in ihnen die Kraft des Ursprünglichen, des Ostens Bahn, doch sind sie im Großen und Ganzen getreue Gefolgsleute von Ungefugger. Und das nicht von ungefähr: denn der Unsterbliche braucht ironischer-

90 Vgl. Abschnitt 5.4.3 auf Seite 273. 
weise gerade solche Männer, die selbst nicht seine Ziele verkörpern, um diese Ziele überhaupt gegen die natürlichen Triebe und Gewalten durchsetzen zu können.

Als Jensen nun Niam gefangen hält und sie wissenschaftlich untersuchen lässt, um ihre Identität zu enthüllen, reagiert sie wie bereits erwähnt in gleicher Weise auf seine sich entwickelnde sexuelle Begierde wie bei Odysseus - sie schmettert ihn ab und sieht ihn als ihm nicht gewachsen an. Dabei bemerkt sie diese Entwicklung in ihm sofort, während ihm die Veränderung seiner Gefühle nicht klar wird. Er beobachtet sie monatelang in ihrem Gefängnis und schickt schließlich die »Laboranten « weg, um sie für sich zu haben. Er »[m]erkte zu spät, daß er liebte« (TA, 755). Während er seine eigenen Gefühle nicht erkennen kann, hat er jedoch ein Gespür für ihre.

\begin{abstract}
Er spürte, die will einen Mann. [...] Welche eine Kraft! Er war voller Mitleid! Was hätte er das Geschöpf gern in die Arme genommen! [...] Seine Liebe war so erglüht, nein brannte [...]. [...] Er blieb sitzen, blieb noch stundenlang sitzen. Und weinte. Sie lehrte ihn weinen durch ihren Anblick. Er weinte in der Folgezeit oft. Öfter. Zu oft. Diese Schwäche! Es war, als saugte Die mit dem Goldhaar ihm das Mark aus der Haltung. (TA, 768f.)
\end{abstract}

Auch in diesen Zitaten fällt die Verwendung des Begriffs Liebe auf, zudem im letzten wiederum in Kombination mit Mitleid. Obwohl es in diesen Begegnungen sehr eindeutig um das sexuelle Begehren geht, ist dennoch immer auch von Liebe und anderen verwandten Gefühlen die Rede.

Die bislang vorgestellten Charakteristika der Mythos-Position sind als Kontrast zu sehen zu dem Aspekt in Ungefuggers Ziel der Entmachtung des Körpers (und damit gleichbedeutend der Natur). Eine weitere eng damit zusammenhängende Gegenüberstellung ist jedoch ebenfalls von Bedeutung. Ungefugger ist nicht nur feindlich gegenüber den körperlichen (natürlichen) Trieben eingestellt und versucht, sie zu unterdrücken, sondern plant auch, sowohl den menschlichen Körper als auch die natürliche, materielle Umgebung durch technische Simulation zu ersetzen. Technische und naturwissenschaftliche Entwicklungen sind ihm Mittel, die Natur zu unterdrücken und Identitäten zu bestimmen. In TA werden Ungefuggers Ansichten in dieser Hinsicht vorgeführt, die virtualisierte Welt des Westens beschrieben. Erst in $B A$ erfolgt jedoch die diesbezügliche begriffliche Gegenüberstellung zum Mythos. Am prägnantesten ist dies in der Formulierung des Schwurs ausgedrückt, den jeder Rekrut zu leisten hat, nachdem Ungefugger die Armee übernommen hat. Wieder in Erinnerung an Darstellungsformen totalitärer Regime wird der Schwur während Feiern in Fußballstadien im Chor geleistet und lautet: „Den Mythos entmachten / Der Klarheit das Licht« $(B A, 129)$ Das gewählte Wortfeld von >Klarheit` und >Licht birgt deutlich die Assoziation von Aufklärung, von modernem aufgeklärtem Denken. Der Bezug auf die Verwendung des Mythos-Begriffs in WB und die dortige Gegenüberstellung der Lipom- und Murnau-Position im Anschluss an die Dichotomie Mythos vs. Aufklärung in Bezug auf Horkheimer und Adorno wird damit deutlich gemacht. Dem wissenschaftlichen Denken, das die Welt erklären und über die Technik auch verändern kann, steht das Ungeheuerliche des Ostens gegenüber. In $B A$ wird dies noch einmal in den Formulierungen deutlich, die den Niedergang des Mythischen beschreiben. Alles Unerklärliche, das Mythische und Ungeheuerliche gilt 
als überwunden, die Schänder sind in entlegene Gebiete vertrieben, die "Ausrottung der letzten Ungeheuerlichkeiten « $(B A, 66)$ steht unmittelbar bevor. ${ }^{91}$ Aus dem Osten kommen nun gerade keine »mythischen Nachrichten « mehr und selbst das Wunder von Lough Leane - ein heiliger See, der durch einen Mauerdurchbruch durch Thetis entstanden ist und wundersamerweise salzloses Meer enthält - ist fast vergessen, das vorher ein Zeichen dafür war, »daß es weiter Naturgewalt gebe« $(B A, 65)$. Auch in dieser Formulierung sind Natur und Mythisches identisch, wie dies auch in $W B$ der Fall war und oben ausführlich behandelt wurde.

Der Diskurs um die Dialektik der Aufklärung taucht auch in $B A$ in der Metaperspektive bei der plötzlichen (technischen) Multiplikation der Welten wieder auf. Der Programmierer Herbst räsoniert über die Zusammenhänge der verschiedenen virtuellen Welten und die Beobachtungen, die er und seine Kollegen dabei gemacht haben.

Weniger anfangen ließ sich mit den eigentümlich mythischen Erscheinungen und Strukturen; es war gewesen, als wäre das gesamte System exponenziell sowohl re- wie progrediert: Der notwendig gewordene technische Fortschritt schien einen mythischen Regress zu erzwingen. $(B A, 95)$

Weder die Midgardschlange noch die Hundsgötter der Anderswelt seien programmiert worden, sondern im selbstgenerativen System von allein entstanden. Noch einmal gespiegelt auf einer untergeordneten Ebene findet sich ein ähnliches Phänomen während der simulierten Fahrt der Mayflower 2 innerhalb der Anderswelt. Auch dort läuft eine Computersimulation ab und mythologische (bzw. biblische) Strukturen bilden sich von alleine. Herbst sieht daher einen unausweichlichen Zusammenhang zwischen technischem Fortschritt und mythischem Regress. In dieser Formulierung scheint das Ergebnis der Beobachtung der Weltensimulationen identisch mit den Überlegungen Horkheimers und Adornos.

Im oben erläuterten Zusammenhang von Mythos mit nicht binärem Denken kam auch immer wieder der Satz vom ausgeschlossenen Dritten zur Sprache. Auch in BA wird er in Verbindung mit dem Mythos gebracht, wenn auch indirekt. Die Poesie wird an einer Stelle als "Komplott gegen den Satz vom ausgeschlossenen Dritten « $(B A, 209)$ bezeichnet; die an dieser Stelle konstatierte Ambivalenz sei die gleiche wie bei Helden Homers, die gleichzeitig (neben ihrem Heldentum) auch »meuchelbereite Piraten waren, blutigste Schwerverbrecher zur See« (ebd.). Die homerischen Helden stehen hier für den Mythos; die Ambivalenz ihrer moralischen Bewertung exemplifiziert das Charakteristikum des mythischen Denkens, das darin besteht, nicht binär unterscheidend zu sein, sondern mehrdimensional.

Ungefugger hat es geschafft, die offensichtlichen Vertreter des Mythischen und des mythischen Denkens zu verdrängen, und Goltz ist fest davon überzeugt, man habe »den Mythen noch die dürrsten Haarwurzeln verätzt« $(B A, 245)$. Doch gilt in den Anderswelt-Romanen nicht nur, dass die technische Entwicklung immer mit einem mythischen Regress einherzugehen scheint, sondern auch, dass die Vertreter des wissenschaftlichen Denkens von der Überwindung des Mythischen zu früh überzeugt

91 Gemeint sind Niam, der man als einziger nicht habhaft wird, vgl. $B A, 66$, und die "politischen Monstren« $(T A, 870)$ : der alte und der junge Jensen, Odysseus und die Zollstein, die alle tot sind. 
sind. Jedes Mal, wenn die Ausrottung der früheren Ungeheuer behauptet wird, kommt der Nachsatz, es schlafe die Midgardschlange im Thetismeer vor der Großen Mauer (vgl. TA, 770, 871). Zudem sind mit Niam und Borkenbrod noch Wesen in der Anderswelt, die - deutlich an ihrer atavistischen Verschuppung erkennbar - zum Bereich des Mythischen gehören. 


\section{Multiplikation der Welten}

\subsection{Anderswelt: Autonomisierung einer Fiktion}

\subsubsection{Verhältnis von Realwelt und Anderswelt}

Im Gegensatz zu den vorhergehenden Romanen können in Thetis zwei relativ eindeutig voneinander unterschiedene Welten ausgemacht werden. Die Figur Hans Deters schließt an den Vorgängerroman $W B$ an. Während er in $W B$ im Zug saß und sich von dort die Erzählebenen vervielfachten und immer komplizierter und phantastischer wurden, sitzt er in TA nun in Berlin im Café Silberstein (das es in den 1990er Jahren - zur Zeit der Entstehung des Romans [November 1993 bis Juni 1998] ${ }^{1}$ - wirklich gab) und erdenkt sich eine distinkte >Anderswelt ‘. Durch den Namen wird sowohl die Andersartigkeit der fiktionalen Welt als auch überhaupt erst ihr eigenständiger Weltencharakter betont.

Dabei ist jedoch anzumerken, dass dieser Name nicht nur wörtlich zu nehmen ist und ganz einfach eine sandere bezeichnet. Wie schon viele weitere Begriffe und Anspielungen in $W B$, aber auch weiterhin in den $A W$-Romanen ist dies ein Bezug zur keltischen Mythologie. Dort ist die Anderswelt die »Welt der Toten und Geister ${ }^{2}$, nicht eine reine Jenseitswelt, sondern eine Parallelwelt, die zu bestimmten Zeiten auch von lebenden Menschen betreten werden kann. Wie Herbst im WurmVorsatz zu $B A$ hinweist, verläuft die Zeit dort viel schneller: verbringt ein Mensch dort wenige Stunden, sind in seiner Realwelt Jahre oder Jahrzehnte vergangen. ${ }^{3}$ Diese Merkmale gelten auch für die herbstsche Anderswelt, die aber keineswegs identisch mit der keltischen Vorstellung ist; sie teilt lediglich einige Aspekte und ist damit mit dieser verbunden. Im übrigen gilt dies auch schon für die Geisterwelt in $W B$, auch wenn dort der Begriff Anderswelt in diesem Zusammenhang nicht vorkommt.

Die Trennung der Welten scheint zunächst sehr deutlich durch eine fiktive Situierung in der Zukunft, wobei ein spezifisches Jahr (im Gegensatz zur exakten Einordnung der Welten in $B A$ ) nicht genannt wird. Es wird jedoch eine umwelt- und erdgeschichtliche Entwicklung beschrieben, die an Merkmale der heutigen Welt anschließt und an einer Stelle zumindest als Teilstück auf »einhundert Jahre« $(T A, 35)$ beziffert wird. Zudem wird im Abschnitt »Intervallo« eine Auflistung erd- und kulturgeschichtlicher Stationen aufgeführt (vgl. TA, 176-189) - ein »chronikalische[r] Parforceritt durch die Menschheitsgeschichte« als literarisches Gegenstück zu Stanley Kubricks Sprung vom fliegenden Knochen zum Raumschiff in seinem Film 2001:

1 Vgl. TA, 895 .

$2 W V$, iii.

3 Vgl. auch MacKillop: A Dictionary of Celtic Mythology, 360. 
A Space Odyssey (1968, 2001: Odyssee im Weltraum $)^{4}$-; der letzte Eintrag aus der historisch belegten oder mythologisch überlieferten Geschichte ist die Ermordung Rabins 1995. Danach finden sich u. a. die "Sprengung des World Trade Center ( TA, 188; im Nachhinein erstaunlich, da 1998 geschrieben, wobei es schon 1993 einen Bombenanschlag im World Trade Center gab) sowie der Dritte Weltkrieg, die Große Geologische Revision, die Grundlage des geographischen Aufbaus der Anderswelt ist, und die Erfindung der Holomorfie. Auch hier wird ersichtlich, dass die Anderswelt im Vergleich zur realen Welt als zukünftig verortet wird. Als Deters später die Grenze zwischen den Welten überschreitet, wird dies bestätigt: »Mußte sich klarmachen, wo er war. Daß er in der Zukunft war." $(T A, 441)^{5}$

Für Scherer sind die Beschreibungen der Anderswelt die "gesteigerte und doch wiedererkennbare Realität« der Zukunft, »durchaus realistisch ausgemalt[] « ${ }^{6}$. In $T A$ selbst spielt Deters mit einer solchen Sichtweise, wenn er sich in seinen Imaginationen unterbricht und meint, das wäre »alles noch viel zu gegenwärtig, zu heutig, das könnte ja alles morgen früh schon sein« $(T A, 326)$.

Die Anspielungen auf die reale Welt des zeitgenössischen Lesers sind vielfältig. Die Aufteilung der Anderswelt in die großen, sehr unterschiedlichen Gebiete Westen und Osten sind zwar geographisch nicht mit den entsprechenden deutschen Regionen identisch; die Assoziation wird jedoch durch Ausdrücke wie »Wessi« oder "AufbaU OsT « $(B A, 129)$ unterstützt. Ebenso ist der Bau und der bevorstehende `Fall $<$ der Staumauer gegen das Thetismeer ein Hinweis auf die deutsche `Wende`-Zeit um 1989. Die Jugoslawienkriege bzw. der Balkankonflikt der 1990er Jahre findet nicht nur indirekt seinen Niederschlag in den Greueln des Romans, ${ }^{7}$ sondern wird auch mehrfach erwähnt (TA, 463, $B A, 96,265)$. Allgemeinere aktuelle Themen sind drohende Umweltkatastrophen, die Weiterentwicklung von Technik bzw. Technisierung der Welt, die Angst vor HIV- und anderen Infektionen sowie »transplantationsmedizinische Abschöpfung der Dritten Welt « ${ }^{8}$.

Judith Leiß leitet aus den Schilderungen zukünftiger technischer, sozialer und umweltbezogener Entwicklungen eine gegenwartskritische Lesart ab und ordnet TA dem theoretischen Untersuchungsgegenstand ihrer Studie Inszenierungen des Widerstreits. Die Heterotopie als postmodernistisches Subgenre der Utopie gemäß als Utopie bzw. genauer als eine >Heterotopie ein..$^{9}$ Sie sieht im Roman »angesichts der Fülle von

4 Vgl. Scherer: »Alban Nikolai Herbst $[K L G]$.

5 Eindeutig ist dies jedoch nicht; denn als er ganz in der Anderswelt landet, heißt es: »Eine Zukunftsstadt war das nicht. Sondern eine andere Gegenwart.« (TA, 895)

6 Scherer: »Alban Nikolai Herbst $[K L G]$ «. Vgl. auch Döbler: »Delirium und Moralium«: »Die Anderswelt $[\ldots]$ ist im Grunde nichts anderes als eine imaginierte Extrapolation unserer gegenwärtigen Realität."

7 Vgl. Alban Nikolai Herbst: »Rede aus Anlaß der Verleihung des Phantastik-Preises der Stadt Wetzlar zum 16. September 1999 gehalten von einem Feinde«, 1999, URL: http://www. die dschungel.de/ANH/txt/pdf/phantastik_rede.pdf, 4, sowie URL-22, 11. Sep. 2012.

8 Brittnacher: „Der verspielte Untergang «, 35. Weitere Teile dieser Auflistung sind dort entnommen. Vgl. auch Döbler: "Delirium und Moralium «.

9 »Als >Heterotopie wäre demnach ein utopischer Roman zu bezeichnen, der die Rezipienten durch die spezifische Gestaltung der fiktionalen Welten W1 und W2 beziehungsweise des Verhältnisses 
Problemen sozialer, politischer und ökologischer Art « »sozialkritische[s] Potential $\aleph^{10}$, will ihn »als ästhetisch-literarisches Plädoyer für eine ethisch fundierte, radikalpluralistische Haltung verstanden« wissen, das »ihn möglicherweise gesellschaftlich wirksam werden lässt ${ }^{11}$.

Auch wenn Leiß durchaus stichhaltige Einwände gegen die gegenteilige Argumentation von Kühlmann ${ }^{12}$, Preußer ${ }^{13}$ und Döbler ${ }^{14}$ vorbringt, scheint sie mir den Roman doch allzu sehr auf ihr Interpretationsschema (den Nachweis eines >Widerstreits ) hin zu lesen. Der abgeschwächten Formulierung, der Roman habe »durchaus eine gesellschaftskritische und politische Dimension ${ }^{15}$ ist wohl kaum zu widersprechen. ${ }^{16}$ Sie liest jedoch TA isoliert, nicht im Kontext der Trilogie oder sogar der Pentalogie (was - wie oben in der Einleitung dargestellt - meines Erachtens zwingend ist). Unter anderem dadurch gewinnt der utopische Aspekt in ihrer Interpretation einen hohen Stellenwert. Andererseits muss festgehalten werden, dass in $T A$ als einzigem Roman die scheinbar sozialkritischen Aspekte eine Rolle spielen (selbst in $B A$ treten sie wieder weiter in den Hintergrund).

Ohne nun in den Diskurs um die Gattungszugehörigkeit als Utopie einsteigen zu wollen, ist ihre Argumentation einmal nachzuverfolgen. Für die Zuordnung eines literarischen Textes zur Gattung Utopie ist für sie ein »sozialkritisch-didaktischer Impetus konstitutiv ${ }^{17}{ }^{17}$. Ein solcher wird jedoch nicht recht deutlich. Am Beispiel der Technisierung und zunehmenden Virtualisierung der Gesellschaft verdeutlicht: zwar werden Fragen nach Identität und realem Empfinden aufgeworfen angesichts von künstlichen Menschen, menschlichen Kopien und virtuellen Landschaften. Es werden die Probleme beschrieben, die die Leute teilweise damit haben. Explizit als negativ wird die Technik jedoch nicht bezeichnet, die »Simulationsmedien [...] sind eine aktuelle

zwischen W1 und W2 mit Widerstreitssituationen konfrontiert und ihnen somit Gelegenheit gibt, sich der Irreduzibilität radikaler Pluralität zu stellen und sich im Aushalten des Widerstreits zu üben.« (Leiß: Inszenierungen des Widerstreits, 126) Der Widerstreit muss dabei nicht unbedingt auf der Handlungsebene erfolgen.

10 Ebd., 234.

11 Ebd., 237.

12 Kühlmann: »Postmoderne Phantasien«, 499, 504, 512.

13 Preußer: »Die Pluralität der Untergänge«, $16 f$.

14 Döbler: »Delirium und Moralium«.

15 Leiß: Inszenierungen des Widerstreits, 237.

16 Kurz, knapp und vage formuliert es Michalzik: »Irgendwo steckt wie in jedem Mythenbastler also der Moralist.« (Peter Michalzik: »Phakten oder Fantasie«, in: Süddeutsche Zeitung 12.11.1998) Auch Preußer gesteht ein, Herbst schreibe an bestimmten Punkten »moralisierende Warnliteratur «, relativiert dies aber damit, es ging ihm nicht »um die Zukunftstauglichkeit seiner Entwürfe« (Preußer: »Die Pluralität der Untergänge«, 16). Brittnacher relativiert diese Aussagen noch weiter, wenn er im Rahmen seiner Verortung von TA im Apokalypse-Diskurs schreibt, Herbsts Erzählen sei die "Absage an eine geschichtsphilosophische Dimensionierung seines Romans, daran, einen weiteren Beitrag zu `moralisierender Warnliteratur` zu liefern « (Brittnacher: "Der verspielte Untergang «, 37); »endzeitliche[] und heilsgeschichtliche[] Implikationen « (ebd.) der Apokalypse bestünden nicht länger, da es den Untergang in der Anderswelt schon gegeben habe, er aber auch noch einmal bevorstehe.

17 Leiß: Inszenierungen des Widerstreits, 237. 
Tatsache im Leben der meisten Menschen, es gibt sie, und sie haben bestimmte, ästhetisch verwendbare Wirkungsweisen ${ }^{18}{ }^{8}$, worauf Reber hinweist. Daher gibt auch Leiß selbst zu:

Herbsts Roman ist also tatsächlich nicht didaktisch, politisch, gesellschaftskritisch oder utopisch in dem Sinne, dass der Text mit Bezug auf ein konkretes gesellschaftliches Problem als Handlungsanweisung verstanden werden könnte. ${ }^{19}$

Ein Signal wird schließlich auch gleich anfangs im Kontext politischer Bezüge auf die aktuale Welt gesetzt, als sich Deters die Anderswelt ausdenkt: »Dann seh ich [Deters] nur noch Wand Denkmal Bäckerei und weiß eben nicht mehr: Osten Westen Lohnniveau. Dann erst bin ich in Buenos Aires angekommen." $(T A, 13)$ Durch die Zusammenstellung der Wörter »Osten Westen Lohnniveau« ist der zeitgenössisch politische Bezug eindeutig und erfolgt hier, bevor der Bezug auf den >realdeutschen Osten und Westen in der Anderswelt etabliert ist; doch gleichzeitig wird der Bezug eben relativiert. Die Verbindung zur Anderswelt - hier im Sinne der ausgedachten Welt, die bei Herbst auch immer für das Phantasieren steht - wird erst möglich, wenn man von allzu festen realen Referenzen absieht. Es ist ein kleiner Hinweis, doch stützt er die allgemeine Tendenz.

Das didaktische Moment ist also bei Herbst nicht auszumachen. Leiß gesteht dies in Bezug auf die "Ebene der Inhalte« dann auch zu, nicht aber auf eine »Meta-Ebene $\ll^{20}$. Damit kommt sie unter Verwendung von nicht ganz stimmigen Bezügen und der Betonung von eher Nebensächlichem zum `stimmigen ‘ Ziel: es scheine die "postmodernistisch-utopische Vision einer Welt auf, in welcher man den Widerstreit inkommensurabler Positionen nicht gewaltsam in eine Einheit zu überführen trachtet, sondern die Existenz des Heterogenen und Inkommensurablen anerkennt ${ }^{21}{ }^{1}$. Hier findet sich wieder der herbstsche Widerstand gegen das Binäre und Homogene. Dies entspricht dann ihrem Interpretationsziel, den Text dem von ihr konstruierten Genre der $>$ Heterotopie` zuzuordnen.

\subsubsection{Aufbau der Welten}

Hilfreich ist an dieser Stelle, auf Leiß' schematisierende Darstellung der Welten zurückzugreifen. Entsprechend ihrem »Prinzip der zwei Welten«, das sie als »Grundstruktur der Gattung 〉Utopie « ${ }^{22}$ aufstellt, geht sie in Bezug auf $T A$ von »der Kontrastierung der Welt des Autors und der zeitgenössischen LeserInnen (W0) mit einer Welt W2 « ${ }^{23}$

18 Reber: Formenverschleifung, 405.

19 Leiß: Inszenierungen des Widerstreits, 240.

20 Ebd., 241.

21 Ebd. Dass sie diese Position der »Idee der Gerechtigkeit« verpflichtet sieht und von einem »ethische[n] und politische[n] Statement « (243) spricht, ist wohl eher eine Frage der Terminologie der Begriff `Gerechtigkeit ist beispielsweise sehr abstrakt, doch ist es sehr fraglich, ob er in Herbsts Texten vertreten wird.

22 Ebd., 47.

23 Ebd., 218. 
aus. Die Anderswelt wird jedoch von Deters erst erdacht; damit sind drei verschiedene Welten zu bezeichnen:

- W0: - aktuale Welt (Welt des Autors Herbst und der zeitgenössischen Leser)

- W1: - Deters' Realwelt

- W2: - Anderswelt

Deters' Realwelt ist eine fiktionale Version der aktualen Welt, d. h. sie orientiert sich an dieser nach dem sprincipal of minimal departure . Sie ist damit eine Fiktion erster Ordnung, während die Anderswelt eine Fiktion zweiter Ordnung darstellt. ${ }^{24}$ So wird deutlich, dass der Aufbau von TA zunächst recht übersichtlich ist. Die Anwendung dieses Schemas auf $B A$ wird später dann die zunehmende Komplexität veranschaulichen.

Im »Vorspiel« (TA, 9-31) wird die Anderswelt erst geschaffen. Es wird der Vorgang beschrieben, wie Deters anfängt, sie sich auszudenken. Dabei gehen die Welten erst einmal durcheinander. Deters muss die Augen wieder öffnen, die er während des Erfindens geschlossen hat, um eine Straße zu überqueren; er denkt, er werde angesprochen, dabei ist es dann schon wieder Borkenbrod in der Anderswelt (vgl. TA, 11). Der Konstruktionscharakter der Schilderung ist durch viele Kommentare unmittelbar präsent: Vom ersten, welterschaffenden Satz »Ich will Dich Buenos Aires nennen. " und dem die realweltliche Referenz noch enthaltenden »Das reizt mich auf, Dich umzuerfinden." $(T A, 9)$ über »Ich gieße einen Liter Neapel hinein.» $(T A, 10)$ zu begleitenden Kommentaren wie »So könnte das gehen. Ja. [...] Dazu muß ich die Stadt in meinen imaginären Zugriff bekommen.« $(T A, 12)$ So ist das Buenos Aires der Anderswelt ganz eindeutig die Stadt seiner »unausgesetzten Erfindung« (ebd.).

Im ersten Teil »Europa « und dem »Intervallo: Nach Centaurus A« (TA, 33-171, 175-211) etabliert sich die Anderswelt in einer heterodiegetischen Binnenerzählung als eindeutig von der Realwelt geschiedene Welt. Von Zeit zu Zeit wird durch metafiktionale Kommentare daran erinnert, dass sie eine Fiktion zweiter Ordnung ist. So wird kurz eingeflochten, dass eine Beobachtung von Deters gedacht wird (bspw. TA, 121, 129, 218) oder seine (gedachte) Erzählung wird in aus WB bekannter Manier durch die Frage des Barkeepers unterbrochen, ob er noch etwas zu trinken haben wolle ( $T A$, 126, 170); auch gibt es weniger klare Hinweise, indem beispielsweise eingeflochten wird, das Geschehen befinde sich auf einer bestimmten »Imaginationsebene» (TA, $572)$.

\subsubsection{Scheinbare Autonomisierung der Anderswelt}

Ganz so eindeutig ist die Trennung der Welten jedoch nicht. Der Übergang vom Aufbau mit Rahmenerzählung und Binnenerzählung zu einer phantastischen und

24 Leiß schaltet noch eine Welt Wo' dazwischen, deren Funktion nicht ganz klar ist. Diese Bezeichnung soll »sowohl die ontologische Differenz zwischen der Welt Deters' und seiner Fiktion [...] als auch die funktionale Identität von Deters' Realwelt mit der bisher W1 genannten Fiktionalisierung von W0 anklingen lassen.« (ebd., 222) Ich halte diese zusätzliche Bezeichnung nicht für nötig, zumal in ihren weiteren Ausführungen die Welt W1 denn auch gänzlich herausfällt und lediglich zwei Bezeichnungen verwendet werden. 
metafiktionalen Erzählung ist fließend. Die Vermischung der Ebenen und die Metalepse, d. h. dass Deters in die von ihm erfundene Anderswelt gerät und auch, dass Personen und Vorgänge aus der Anderswelt Auswirkungen auf ihn sogar in seiner Realwelt haben können, wird durch die graduell sich entwickelnde Autonomisierung der fiktiven Welt ab dem zweiten Teil »Niam Goldenhaar« (TA, ab 213) vorbereitet. Auf der Flucht vor der Polizei geraten Herr Drehmann und Herr Hausmann unversehens ins Samhain, wo sie von Deters und anderen in der Bar angestarrt werden. Deters sitzt im Café Silberstein, das zugleich in der Anderswelt das Samhain ist, und einen Übergang zwischen den Welten darstellt, worauf gleich zurückzukommen ist. Die Autonomie der Fiktion wird jedoch in folgender Passage deutlich:

Dann hörte ich, daß Herr Hausmann etwas zu Herrn Drehmann sagte. Verstand aber im Lärm nicht, was. Der Techno hämmerte wie rhythmisch-mechanisches Rülpsen. Aber ich hatte ja Fantasie und dachte es mir aus: [...]. (TA, 235)

Obwohl Deters sich sowieso alles ausdenkt, wird hier der Eindruck erzeugt, er würde das Geschehen selbst erleben, würde es nur beschreiben und das Erfinden wäre eine Behelfsmaßnahme, um die gestörte Beobachtung auszugleichen. Es ist jedoch der erste kleine Hinweis auf den Übergang von getrennten Welten, die in einem hierarchischen Abhängigkeitsverhältnis stehen, zu zwei mehr oder weniger autonomen, aber miteinander verbundenen Welten. Wenig später kann er die Unterscheidung zwischen den Welten nicht mehr vollständig nachvollziehen (vgl. TA, 244f.). An dieser Stelle ist es noch leicht, die Beschreibung als das getrübte Bewusstsein eines Betrunkenen zu lesen, bald werden die Verschränkungen der Erzählungen und damit die Verbindungen zwischen den Welten jedoch deutlicher gemacht.

Dass sich die Anderswelt unabhängig von Deters entwickelt, wird besonders deutlich, als er sich einmal aus ihr zurückzieht. Da er nicht mehr wirklich durchblickt, den Überblick über seine Phantasie und Konstruktion verloren hat und vor allem die Chronologie nicht mehr versteht, "hatte [er] den Kontakt zur Anderswelt abreißen lassen wollen « $(T A, 726)$. Sich abzulenken gelingt ihm aber nicht und so betritt er die Anderswelt nach kurzer Zeit wieder. Dort ist bereits ein fortgeschrittenes Datum. Gleichzeitig wird aber ganz explizit betont, dass es sich bei der Anderswelt um »seine Imaginationen« handelt, die ihm »lästig geworden« (ebd.) waren.

Bereits vorher geraten Deters die Welten durcheinander, ohne dass er es will. Als er durch die Anderswelt geht, sieht er an unwahrscheinlichen Plätzen in der Zentralstadt in Autos Schänderpriester sitzen, die sonst nur im Osten vorkommen. Er kneift mehrmals die Augen zusammen und die Erscheinungen stellen sich als Einbildung heraus. Doch es passiert immer wieder. »In jedem Wagen saß ein Schänder. Diesmal half es nicht, die Lider zuzukneifen. Jetzt hielten sich die Halluzinationen in der Realität.« $(T A, 431)$ Auch dass Goltz ihn bei den Rebellen festnehmen kann, ohne dass er selbst es verhindern kann, ist ein Zeichen für die Autonomie der Anderswelt (vgl. TA, 580).

An mehreren Stellen wird deutlich gemacht, dass Deters die von ihm selbst erfundene Welt nicht vollständig versteht oder er bestimmte Zusammenhänge gar nicht mitbekommt. Was Goltz fast zur Verzweiflung bringt (und später auch die Tranteau und Deidameia beunruhigt), ist, dass Deters immer wieder einfach verschwindet. Dies 
erfolgt, wenn er in die Dunckerstraße einbiegt, die es in der Anderswelt nicht gibt bzw. die dort Waldschmidtstraße heißt. Er wird dort unsichtbar und ist jeweils ins »reale Berlin« (TA, 266; W1) zurückgekehrt. Dass die Straßen in den verschiedenen Welten auch unterschiedlich aussehen, »war Hans Deters bislang entgangen«. Auch dass sie sich ständig verändern, merkt er nicht oder erst später. »Es konnte vorkommen, daß das Gebäude Nr. 65 mittags renoviert war, aber sich am nächsten Morgen im alten Verfallszustand befand." (ebd.) Oder er bemerkt einen Laden wieder, den er morgens vermisst hatte. All dies sind `Indizien ( (vgl. ebd.), aus denen Deters etwas über seine eigene Welt ableiten kann.

All diese >Indizien` gipfeln in der Feststellung am Schluss von TA, als er sich vollständig in der Anderswelt wiederfindet, er habe "zwar Buenos Aires erfunden, das hieß jetzt aber nicht, daß er sich auskannte drin." $(T A, 895)$ Als zentraler Satz für beide Bücher, findet er sich (umformuliert in Ich-Form) am Anfang von $B A$ ebenfalls wieder (vgl. $B A, 12)$. Der Autor hat die Welt zwar geschaffen, sie entwickelt sich jedoch ohne ihn weiter. Dass er die Vorgaben und Regeln des Weltenaufbaus aufgestellt hat, heißt nicht, dass er sämtliche Details und Zusammenhänge kennt. Dabei hat die Autonomisierung der Anderswelt natürlich mit der Frage zu tun, wer denn eigentlich der Erzähler ist, ob es nicht eine womöglich auktoriale Instanz gibt, die Deters übergeordnet ist. Auf diese Frage ist später zurückzukommen (vgl. Abschnitt 6.3.2 auf Seite 308).

Die Metalepse wird im Vorhinein infrage gestellt:

Doch hatte Deters auch während der knapp viertelstündigen Fahrt den Eindruck gewonnen, zwischen jetzt und heute mittag $[\ldots]$ sei nahezu ein halbes Jahr verstrichen. Tatsächlich befand er sich um vier Tage voraus in der Zukunft. Längst hatte dieses schlimme Zeitverhalten in die Realität hineingefaßt und herumgezerrt an ihr. Aber das wußte Deters, dachte er, nicht. (TA, 247)

Deters scheint die Kontrolle über seine Fiktion zu verlieren. Sein Zugriff auf die fiktionale Welt begründet sich auf Eindrücke, er übersieht Sachverhalte. In dieser Passage scheint dann ein übergeordneter, auktorialer Erzähler ins Spiel zu kommen, der Deters korrigiert und die Wahrheit feststellt ( $>$ Tatsächlich $২$ ). Durch den kleinen Zusatz »dachte er« im letzten zitierten Satz wird Deters selbst jedoch zu einer Figur in seiner eigenen Erzählung. Nicht er selbst verliert die Kontrolle über die Welt, weil die Welt autonom wird, sondern er verschafft sich einen eigenen Avatar. Dies hat in gewissem Sinn seine Parallele später in der realen Kommunikationssituation von $B A$ (und auch in anderen Büchern von Herbst oder bspw. Borges), wenn der reale Autor Herbst eine Figur Herbst erschafft. Zwar wird insinuiert, der Autor fiktionalisiere sich selbst (in einer weiten Definition von Autofiktion) und steige gewissermaßen in die Erzählung ein, doch bleibt er literarische Figur, lediglich alter ego oder Avatar der realen Person. ${ }^{25}$

25 Frank Zipfel gibt jedoch beim diesbezüglichen Autofiktionstypus zu bedenken, dass nicht von einer Annahme von Tatsachenbehauptungen auszugehen ist, sondern von einer poetologischen Funktion, der Reflexion von Literaturauffassungen durch den Autor. Vgl. Abschnitt 8.3.2 auf Seite 387. Malsch bspw. scheint die Unterscheidung zwischen Figur und realer Referenz nicht ganz klar durchzuhalten, vgl. Malsch: »Vom Wiedereintritt des Autors in seine Geschichte«, 76. 


\subsubsection{Metaleptische Verbindungen von Welt und Anderswelt}

Es werden verschiedene Erklärungen gegeben, wie von der Welt in die Anderswelt zu gelangen ist. Diese `erklären $`$ nichts im eigentlichen Sinne, da es sich nicht um aus der Realität übernommene Elemente (immigrant objects $)^{26}$, sondern um Elemente des "naturwissenschaftliche[n] Wunderbare[n] $\aleph^{27}$ handelt - aber sie machen die Verbindung der Welten anschaulicher. Da sind zum einen die sogenannten Lappenschleusen, die einmal technisch, dann phantastisch erklärt werden. Zum anderen gibt es eine snaturwissenschaftliche` Erklärung, die mehr ein Vergleich ist, und an moderne Raum- und Zeitvorstellungen anschließt.

\section{Lappenschleusen}

Zunächst sind die sogenannten Lappenschleusen ein technisch fortgeschrittenes Mittel, um in der Anderswelt - bzw. genauer nur in der entwickelten Zentralstadt große Entfernungen zurückzulegen. Sie werden folgendermaßen erklärt:

Es waren nicht Schleusen in gemeinem Sinn, sondern Straßenzüge, die auf wenigen Metern weit entfernte Stadtbezirke miteinander verbanden. In ihnen wurde sämtliche Hardware weich. Die Räume umlappten einander, daher der Name. Zeit blies wie in Gardinen hinein. Man schritt hindurch, schritt nur die Straße entlang, kam nach zehn Minuten Hunderte von Kilometern entfernt wieder heraus. Sogar an den Anfang der Straße zurückschauen ließ es sich. (TA, 130)

Bereits in dieser recht frühen Erläuterung dieses technischen Phänomens wird sowohl der naturwissenschaftliche Anklang mit der Raumüberlappung angedeutet, als auch eine technische Erklärung (zwar reichlich schwammig) angesprochen, nämlich dass die Hardware weich werde. Dies deutet voraus auf die vor allem in $B A$ virulente Frage, was dort eigentlich genau passiere und welche Auswirkungen das auf den Menschen habe. Genaueres findet sich schon im rauktorialen` WurmVorsatz zu $B A$ :

Eine sozusagen datische Abkürzung von Ort zu Ort. Fahrzeuge und Personen werden an der Einfahrt in Bits (gescannte Atome) zerlegt und an der Ausfahrt wieder zusammengesetzt. So lassen sich weite Strecken ohne wahrnehmbaren Zeitverlust überwinden. Der Name rührt von der Vorstellung einer lappenartig gefalteten Zeit her, der ein ebensolcher Raum korrespondiert. ${ }^{28}$

Diese Erklärung gibt sich einen noch `naturwissenschaftlicheren` Anklang, ohne poetische Bilder zu bemühen.

Im Zusammenhang mit der Verbindung der Welten ist jedoch zunächst wichtiger, dass es Lappenschleusen »offenbar [...] auch im Außenverhältnis mit der Realwelt

26 Vgl. Zipfel: Fiktion, Fiktivität, Fiktionalität, 97f., 102, in Anlehnung an Thomas Pavel.

27 Tzvetan Todorov: Einführung in die fantastische Literatur, München 1972, 53. Todorov merkt an, dass dieses heute Science-Fiction genannt wird und »das Übernatürliche auf rationale Weise erklärt [wird], aber anhand von Gesetzen, die die gegenwärtige Naturwissenschaft nicht anerkennt « (ebd.). Vgl. dazu auch Uwe Durst: Theorie der phantastischen Literatur [2001], 2., aktualisierte, korrigierte und erweiterte Aufl., Berlin 2010, 42.

$28 W V$, ix. 
[gibt]. Das wußte Deters sowenig wie Goltz.« $(T A, 727)$ Weder Deters oder Goltz noch der Leser verstehen bis zu diesem Zeitpunkt das Verhältnis zwischen den Welten in Bezug auf ihre Verbindungsmöglichkeiten. Es gibt demnach aber Orte, an denen sich zwischen den Welten wechseln lässt. In $B A$ wird trotz der Multiplizierung der Welten und ihrer Erklärungen auch dieses Motiv fortgeführt, wenn der »zunehmend deutlicher werdende[] Verdacht [aufkommt], daß auch Garrafff Lappenschleusen kannte $[\ldots] \lll(B A, 158)$.

Die erste dem Leser vorgeführte Lappenschleuse in diesem Sinn ist das Café Silberstein, das bezeichnenderweise in der Anderswelt Samhain heißt. Samhain bzw. Samuin war ein keltisches Fest, dessen mythologische Grundlage war, dass sich am 1. November die Feenhügel öffneten und ein wechselseitiger Zugang zur Anderswelt bzw. zur Menschenwelt ergab. ${ }^{29}$ In der phantastischen Lesart ist dies die ambivalente Erklärung, warum Deters in seinem Café Figuren der Anderswelt erblicken kann; es ist ein mythologisch `begründeter Zugang und eine Lappenschleuse, deren Existenz und Funktionsweise selbst den besser informierten Figuren nicht bekannt ist.

Verschiedene andere Orte werden noch aufgeführt und veranschaulicht für einen Zugang in die Anderswelt, auch ganz >unmythisch im Sinne einer phantasierten Parallelwelt. Anfangs ist es die Kulisse des Berlins der Nachwendezeit, einer Stadt im Umbruch von Renovierung und Neubau. ${ }^{30}$ In der modernisierten Stadt sieht Deters die Baustellen als noch nicht gänzlich geglättete Oberfläche, die den »Einstieg« noch zulassen. "Noch gibt es Löcher in der Realität. Wer sie bemerkt, findet Schleusen.« $(T A, 18)$ Deters bemerkt diese "Schleusen an distinkten Orten, Fahrstühle aus der Fantasie direkt in die Realität.« $(T A, 134)$ Wohlgemerkt dreht er hier die Richtung der 'Schleuse um, was jedoch bezeichnend ist; die Schleusen ermöglichen von beiden Seiten den Zugang zur jeweils anderen Welt.

Neben dem Café ist vor allem das `Boudoir « eine Schleuse - gleichzeitig sowohl ein Bordell und Striplokal als auch die Kommandozentrale erst der Holomorfenrebellen, dann auch der Myrmidonen. Deters selbst - zwar auch im Samhain sitzend - kann auch die Schleuse >repräsentieren` (vgl. TA, 771). Nur angedeutet wird, dass Kinos ebenfalls diese Funktion einnehmen können: »Lichtspielhäuser, die gewöhnlichen Menschen wie Zeitlöcher vorkommen mögen, wenigstens als Ausgänge aus der Realität, lösten ihn [Broglier] aus der Melancholie.« $(B A, 124)$

Die Funktionsweise der Lappenschleusen bleibt jedoch unklar und verwirrt die Beteiligten. Warum Deters manchmal einfach verschwindet, beschäftigt sowohl Markus Goltz als auch die Rebellinnen (vgl. $T A$, 524f., 573, $B A$, 98f.) und stellt für sie ein Gefährdungspotenzial dar. Der Anschlag schließlich auf Deters' Arbeitgeber, den er sich in einer Vermischung der Ebenen ausdenkt, ebnet die Zugänge zwischen den Welten ein: »Die Explosion sprengte die letzte Grenze zwischen beiden Welten weg $[\ldots] . \lll(T A, 748)$ Als es am Schluss von TA dann zur Razzia im Silberstein/Samhain

29 Vgl. dazu MacKillop: A Dictionary of Celtic Mythology, 377f. Samhain galt teilweise auch als Erinnerung an die geschlechtliche Vereinigung des Gottes Dagda mit verschiedenen weiblichen Gottheiten.

30 Herbst beschreibt in seiner Zweiten Heidelberger Vorlesung, dass er diese Phantasien bei Spaziergängen durch das Berlin der 1990er Jahr mit seinen » Brachen und Baustellen « und kombinierten Kinobesuchen absichtlich forciert hat, vgl. $K R, 68$. 
kommt, wird Deters vollends in seine selbsterfundene Welt katapultiert: »Die andere Welt hatte angedockt.« $(T A, 889)$ Als er in der Anderswelt ankommt, fragt er nach dem Datum und es ist der 1 . November. In $B A$ stellt sich dann heraus, dass es wie in einer Zeitschleife immer dieser Tag ist. Damit ist der Übergang zwischen den Welten auch fließend geworden, bestimmte Schleusen scheinen nicht mehr vonnöten zu sein. Veranschaulicht wird dies, indem Deters zwischen den verschiedenen Welten nicht eindeutig zuzuordnenden Orten wie Bombay und Hannover wechseln kann. Möglich wird dies wohl durch ein Zeichen, das eine indische Frau ihm auf die Stirn malt. Er reflektiert bei dieser Gelegenheit auch weiter über die Art, wie er von einer Welt in die andere gelangt:

Wahrscheinlich durfte man nicht gezielt suchen, vielleicht war, um zu wechseln, dieses lockere sehnende Schweifen nötig, das Deters überhaupt erst zu seiner Verabredung im Silberstein SAMHAin hatte kommen lassen. $(B A, 58)$

Der Übergang ist also nicht zu erzwingen, sondern muss wie intentionslos geschehen. Als entscheidend sieht er ein Vertrauen in seine Imaginationen an. »Was konnte man anderes tun, als seinen Imaginationen zu vertrauen? Wenn sie ihn hergeführt hatten, müßten sie ihn auch wieder fortbringen können $[\ldots]$.« $(B A, 60)$ Der Zugang ist damit auch nicht wirklich frei, sondern von der Phantasie des Akteurs abhängig. Es scheint auf einen "Ladungszustand der Fantasie« $(T A, 266)$ anzukommen, ob der Wechsel zwischen den Welten möglich ist. Fraglich bleibt aber, um wessen Phantasie es sich dabei handeln muss.

\section{Anderswelt-Zugänge und der Heterotopie-Begriff}

All die genannten Orte, die die Funktion von Lappenschleusen haben, schließen an ähnliche Beschreibungen in den Vorgängerromanen an. Besonders deutlich wird der Zusammenhang im erläuternden Wurm Vorsatz zu BA hergestellt. Der Zugang zur Anderswelt erfolge 'heutzutage »besonders oft an Schnittstellen von Cyberräumen. Aber auch Kinos, Bahnhofstoiletten oder Striplokale können diesbezüglich äußerst gefährlich sein. $\aleph^{31}$ Ähnlich wie der Begriff »Holomorfenstruktur « $(T A, 244)$ retrospektiv als mögliche Erklärung für Vorgänge in $W B$ eingeführt wird, so bietet der Begriff (Lappen)Schleuse « eine gemeinsame Bezeichnung für vorher nicht begrifflich fixierte Phänomene. In $V G$ saß der `Autor<-Erzähler vor allem im Café, das Kino löste einige Vorgänge aus und auch die Zugfahrt durchs `Niemandsland ‘ hatte phantasieanregende Auswirkungen; auf der Bahnhofstoilette erfolgte die `Fusion` von Laupeyßer und Falbin. In $W B$ hatten ähnliche Funktionen der Zug, in dem Deters anfangs sitzt, und später auch Cafés und Hotels (nicht zuletzt das Wolpertinger), wo Deters und Anna bzw. Deters II und Alda phantasieren.

Dass `Cyberräume a auch Verbindungen zur Anderswelt schaffen, wird in TA gar nicht wirklich thematisiert. In $B A$ stellt die Anderswelt sich in einer Perspektive als 'datische`, also am Computer programmierte Welt heraus; der Zugang selbst erfolgt jedoch nicht auf technischem Weg (bis auf den Programmierer Herbst), sondern ist weiterhin nicht ganz geklärt, ein phantastisches Element. 
Die genannten Orte ähneln interessanterweise den Orten, die Michel Foucault als Heterotopien bezeichnet. ${ }^{32}$ Er versteht darunter "tatsächlich verwirklichte Utopien « oder »Orte, die außerhalb aller Orte liegen, obwohl sie sich durchaus lokalisieren lassen « ${ }^{33}$. Er stellt verschiedene Grundsätze zur Einordnung auf und nennt als Beispiele u. a. eben den Zug als Ort des »Nirgendwo «34, Theater und Kino, ${ }^{35}$ Feste und Bordelle, um nur solche zu nennen, die mit Herbst übereinstimmen. Auch den Spiegel führt er an, der allerdings zwischen Utopie und Heterotopie liege. Foucault beschreibt also Orte, die gleichzeitig andere Orte sind; in denen neben dem Realraum auch ein Illusionsraum geschaffen wird, der auch die Funktion haben kann, die realen Räume als noch größere Illusion zu zeigen. ${ }^{36}$ Bei Herbst verbindet sich diese gesellschaftlich etablierte Funktion vermutlich mit individuellen Sichtweisen oder Vorlieben, sodass auch ein Café - das ja auch als kommunikativer Ort mitten im Leben gesehen werden kann - als >vorübergehender Halteplatz ${ }^{37}$ einen ähnlichen Charakter wie eine Heterotopie bekommt. Außerdem scheint die Gemeinsamkeit der Zugänge zur Anderswelt zu sein, dass sie einen mentalen Zustand ermöglichen, der Realität und Verstand nicht mehr als primäre Weltzugänge sieht. Zu beachten ist, dass der Vergleich der Anderswelt-Zugänge mit der foucaultschen Begrifflichkeit keineswegs eine Beeinflussung impliziert, da kein expliziter Hinweis von Herbst vorhanden ist.

\section{'Naturwissenschaftliche` Erklärungen}

Das Verhältnis der beiden Welten zueinander wird auch versucht, mithilfe von modernen naturwissenschaftlichen Theorien bzw. Vorstellungen von Raum und Zeit zu erklären. Schon bei der Erklärung des Wortes Lappenschleuse (bezogen auf die inner-andersweltlichen Schleusen) wird darauf angespielt: »Die Räume umlappten einander, daher der Name.« (TA, 130) Die aus der Allgemeinen Relativitätstheorie stammende Vorstellung eines gekrümmten Raumes (bzw. der Raumzeit) wird hier auf die Verschachtelung fiktionaler Welten angewandt. In Deters' eigenen Überlegungen finden sich dann Fachbegriffe der Quantenmechanik wie »Wellenfunktion« oder "Zustandsvektor" wieder. Deters stellt sich im Silberstein vor, er warte bereits ein halbes Jahr auf die mysteriöse Frau.

Noch begriff ich [Deters] nicht die unmögliche mögliche Zeit: daß Dinge zu wirken begannen, die erst eintreten werden, als stürbe jemand vor seiner Geburt. Nicht nur existierten die in der Wellenfunktion enthaltenen Möglichkeiten

32 Der oben behandelte Heterotopie-Begriff von Leiß geht zwar auch auf Foucault zurück, hat aber mit diesem kaum noch etwas zu tun und stützt sich mehr auf die "semantische Struktur des Wortes« (Leiß: Inszenierungen des Widerstreits, 21).

33 Michel Foucault: »Von anderen Räumen« [1967/1984], in: Ders.: Schriften in vier Bänden. Dits et Ecrits, Bd. 4: 1980-1988, hg. v. Daniel Defert / François Ewald, unter Mitarb. von Jacques Lagrange, übers. von Michael Bischoff, Leipzig 1992, 931-942, hier: 935.

34 Ebd., 936.

35 Darauf weist auch Reber hin: „Kino und Varieté aber stellen klassische Orte dieses Ambivalenzund Substitutionsphänomens dar, - Orte, an denen sich immer schon mehrere Wirklichkeiten überschneiden« (Reber: Formenverschleifung, 384).

36 Vgl. Foucault:»Von anderen Räumen«, 941.

37 Vgl. ebd., 934. 
tatsächlich, sondern mit einem Mal hatte sich wenigstens zwei von ihnen gegenseitig geöffnet, anstatt füreinander unzugänglich zu bleiben. Als sich dieser Übergang vom quantenphysikalischen zum klassischen Bereich - Kollaps der Wellenfunktion genannt oder Reduktion des Zustandsvektors - in die Wirklichkeit schraubte, war es noch nicht November, sondern ein früher heißer Sommer gewesen. $(T A, 83)$

An dieser Stelle ist und bleibt es noch Sommer für ihn. Er ist noch nicht in einer anderen Welt oder anderen Zeit gelandet. Es wird jedoch vorweggenommen, dass eben dieses kommen wird. >Noch jedoch indikativisch berichtet, dass etwas passiert ist. An anderer Stelle bemerkt Deters zu Elena, dass sie in der Anderswelt keine räumlichen Distanzen kennen würden aufgrund des »so gar nicht mehr newtonschen Raum[es] « $(T A, 381)$. Damit wird wieder auf einen realen physikalischen Begriff zurückgegriffen.

Es werden jedoch auch Begriffe aus anderen Bereichen hinzugezogen und auf physikalische Phänomene bezogen. So erklärt Deters ein anderes Mal wieder Elena (bzw. ihrem realweltlichen Pendant) die räumlichen und zeitlichen Verhältnisse von Welt und Anderswelt. Die Chronologie wirke »nicht kausal, sondern sememisch«. Der aus der Sprachwissenschaft entlehnte Begriff für semantische Grundeinheiten wird selbst nicht erläutert, aber das zugehörige Phänomen angedeutet: »Die Zeiten schließen aneinander, wo sie einander ausschließen müßten.« $(T A, 506)$ Da die phantastischen Ideen, die Deters (bzw. der Autor Herbst) in seiner Erzählung ausprobiert, nur teilweise an moderne Physiktheorien angelehnt sind, ist es also nötig, auch andere Begriffe hinzuzuziehen. Dies ist jedoch im Gegensatz zu den Raumzusammenhängen die einzige (pseudo-)wissenschaftliche Erklärung für die Unstimmigkeiten mit der Zeit. Sonst werden nur die zeitlichen Verschiebungen zwischen den Welten angedeutet und es ist klar: »Irgend etwas stimmte nicht mehr mit der Zeit.« $(T A, 443)$ In $B A$ erlebt Deters schließlich, wie bereits angesprochen, einen kontinuierlichen 1. November $(B A, 42,187)$. Vor allem in Bezug auf die Zeit wird also auf eine bildhafte Sprache zurückgegriffen, die wissenschaftlich unpräzise ist, aber bestimmte Vorstellungen ermöglicht: »Die Chronologie war nach hinten gebeugt, eine Brücke, man spaziert über den Bauch des Romans über den Fluß der Handlung zurück und pflanzt vorne ein, was erst hinten gepflückt war.« $(T A, 247)$

Insgesamt wird mit den Begriffen und Vorstellungen der modernen Physik vor allem gespielt. Dabei scheint nur bedingt ein Anspruch auf Nachvollziehbarkeit oder 'Stimmigkeit zu bestehen. ${ }^{38}$ Selbst Deters denkt darüber nach, ob ein bestimmtes Konzept stimmig ist (vgl. TA, 507). Um die literarische Interpretation physikalischer Theorien darzustellen, ist es nötig, sie sprachlich zu verschleiern. Sie werden in komplizierte Sätzen eingearbeitet, ohne wirklich etwas zu beschreiben. Im oben genannten Zitat stellt sich die Frage: kann sich ein »Übergang vom quantenphysikalischen zum klassischen Bereich [...] in die Wirklichkeit schraub[en] « (TA, 83)? Nimmt man so einmal lediglich die Parenthese weg, wird die verschleiernde Formulierung offensichtlich. Dieser Umgang mit komplizierten und den meisten Lesern wohl kaum verständlichen Begriffen schafft dennoch die Anregung ungefährer Vorstellungen.

38 Der Rezensent Burkhardt Lindner sieht jedoch »die szientifisch versierte Rede [...] der Lächerlichkeit preis[gegeben]«, vgl. Lindner: »Krise der Phantasie«. 
Im bereits genannten Gespräch zwischen Elena und Deters fragt sie, warum sie sich bei einer angenommenen Trennung der Welten unterhalten könnten. Deters antwortet: »Vielleicht lebt man immer in beiden Welten zugleich, kippend, gekippt, eine Frage der Perspektive. [...] Eine permanente und dennoch nicht stetige Reduktion des Zustandsvektors.« $(T A, 507)$ Wieder werden >vielleicht--Überlegungen formuliert und vage Begriffe genannt. Doch genau dies ist, was in $T A$ und später vor allem in $B A$ ausprobiert wird: die Multiplikation der Welten, in denen Figuren gleichzeitig vorkommen können. Das Nebeneinander möglicher Welten und möglicher Zustände, die mit verschiedenen Beobachterperspektiven korrelieren.

\subsubsection{Verschiedene Realitätssysteme}

Die eben dargestellten Aspekte des Zusammenspiels der Welten W1 und W2 - die Metalepse und die Autonomisierung - sind auch Merkmale, die den Roman der phantastischen Literatur zuordnen. Die paratextuell erfolgende Genreeinordnung wird bestätigt.

Folgt man der minimalistischen Definition von phantastischer Literatur, die Uwe Durst auf Todorov aufbauend in seiner umfassenden Untersuchung vertritt, stellen beide Aspekte einen "realitätssystemische[n] Skandal « 39 dar. Das Phantastische ist für ihn eine Abweichung von einem Realitätssystem bzw. der Widerstreit zweier unterschiedlicher Realitätssysteme. Dem Begriff des Realitätssystems ${ }^{40}$ stellt er den für seine Zwecke wenig hilfreichen Begriff der (außertextlichen) Wirklichkeit oder Realität entgegen. Das Realitätssystem ist ein kohärentes System, das im Text als die Realität der Figuren etabliert wird. Diese Realität kann auch eine `wunderbare`, übernatürliche sein und nicht mit der Alltagsrealität des Lesers übereinstimmen. ${ }^{41}$

In $T A$ liegen nun auch zwei zunächst kohärent erscheinende Realitätssysteme vor: W1 ist Deters' Realität und basiert auf der aktualen Welt. W2 ist die Anderswelt, in der viele Sachen möglich sind, die in der aktualen Welt nicht möglich sind. Sie ist jedoch in dieser Hinsicht eine kohärente Science-Fiction-Welt, in der ein technischer Fortschritt viele neue Möglichkeiten geschaffen hat. ${ }^{42}$ Erst als Deters in diese Welt eindringt, passiert etwas, das nicht mit den Regeln dieser Welt übereinstimmt. Sowohl Frau Tranteau als auch Goltz verfolgen Deters' Spuren argwöhnisch, weil sie seinen ontologischen Status nicht einordnen können - es dürfte ihn nicht geben. Das >Wunderbare tritt also in ihr Realitätssystem ein. Ebenso die Autonomisierung der Anderswelt. Deters denkt sie sich in einer Bar aus und gibt die Figuren und die Regeln

39 Durst: Theorie der phantastischen Literatur, 394.

40 Ebd., 92-103 und passim.

41 Auch Herbst ist - wenn auch nicht explizit - ein Anhänger in etwa der minimalistischen Definition, vgl. Alban Nikolai Herbst: ") Dieser mächtige Raum..... Zu einer Poetik des Fantastischen «, in: die horen 50/217 (2005), 13-15, 18-24.

42 Nach der maximalistischen Definition ist schon diese Abweichung von (bisher) bekannten naturwissenschaftlichen Gesetzen ein Merkmal phantastischer Literatur (vgl. Durst: Theorie der phantastischen Literatur, 29-39). Deters formuliert die Gegensätzlichkeit der Welten im Gespräch mit Elena bzw. ihrem realweltlichen Pendant sehr prägnant, ohne auf Phantastikzuordnungen einzugehen: »Was Ihre Realwelt ist, ist meine Anderswelt vielleicht. Möglicherweise umgekehrt. Für Sie stimmt, was für mich unglaublich ist.« $(T A, 507)$ 
vor, wie diese Welt aufgebaut ist. Wie schon bei $W B$ beschrieben, ist dies Eco zufolge der übliche Ablauf der Schaffung einer fiktiven Welt. Aus den Regeln, die der Autor anfangs aufstellt, ergeben sich automatisch weitere, sodass eine scheinbare Autonomie der Welt vom Autor vorliegt. ${ }^{43}$ In TA wird dies jedoch `wörtlich genommen $<$ und die Anderswelt entwickelt sich unabhängig von Deters weiter. Dies ist im Realitätssystem von W1 eigentlich nicht möglich und stellt damit ein phantastisches Element dar. Natürlich lassen sich weitere solche Elemente finden: beispielsweise ist es Deters unmöglich, die aus WB bekannte Diskette loszuwerden. Er versucht mehrfach, sie in den Müll zu werfen oder zu vernichten, doch jedes Mal taucht sie wieder in einer Kommodenschublade in seiner Wohnung auf (vgl. TA, 863-868).

Anzumerken ist, dass diese Vorgänge sich auch in $B A$ fortsetzen. Dort ist jedoch zunächst davon auszugehen, dass W1 und W2 lediglich Computersimulationen in W3 darstellen. Auch hier erfolgt eine selbständige Weiterentwicklung der simulierten Welten unabhängig von den (ersten) Eingaben der Programmierer, es handelt sich um »selbst generative[] [sic!] Systeme[] « $(B A, 141)$. Der Sozioniker Thomas Malsch weist jedoch darauf hin, dass es solche eigenständigen Entwicklungen in Computersimulationen (in gewissem Maß) durchaus gibt, da die Programme dann derart strukturiert sind, dass sie sich nach bestimmten Vorgaben weiterentwickeln. ${ }^{44} \mathrm{Da}$ die Systeme sich jedoch auch unter unerklärlichen Umständen verbinden und vor allem eine Wechselwirkung und Beobachtungsumkehrung erfolgt (auf die später genauer einzugehen ist), finden sich auch hier phantastische Elemente.

Reber sieht die Bezeichnung 'fantastischer Roman « übrigens als »Verkaufslabel « 45 , da sie $T A$ für den eingängigsten und am wenigsten experimentierfreudigsten von Herbsts Romanen hält. Wenn man dazu noch bedenkt, dass dieser Roman auch im bekannten Publikumsverlag Rowohlt erschienen ist, scheint dies eine schlüssige Annahme zu sein. Ich gehe jedoch dennoch nicht davon aus, dass Herbst die Bezeichnung aus Kalkül gewählt hat. Zum einen weist er ein solches Denken im Allgemeinen beispielsweise im Weblog immer weit von sich (weswegen er auch immer wieder damit hadert, dass seine Bücher nicht gekauft werden), zum anderen ist der Begriff der Fantastik auch in seinen poetologischen Texten präsent. ${ }^{46}$

Neben der phantastischen Lesart wird wie in jedem der Romane von Herbst noch eine bzw. mehrere mehr oder wenige realistische Lesarten angedeutet. Es wird ja immer wieder darauf verwiesen, dass Deters eigentlich im Café Silberstein in Berlin sitzt und sich die gesamte Erzählung ausdenkt bzw. in zunehmend betrunkenem Zustand

43 Vgl. Eco: Nachschrift zum >Namen der Rose`, 31-37.

44 Malsch spricht von »mobile[n] Agentenprogramme[n] in einer offenen Systemumwelt « (Malsch: "Vom Wiedereintritt des Autors in seine Geschichte«, 71) bzw. von »distributed artificial intelligence (DAI) (Thomas Malsch: »Naming the Unnamable. Socionics or the Sociological Turn of/to Distributed Artificial Intelligence«, in: Autonomous Agents and Multi-Agent Systems 4 (2001), 155-186, hier: 155).

45 Reber: Formenverschleifung, 377.

46 Zum Beispiel in der Zweiten Heidelberger Vorlesung und im zugrunde liegenden Vortrag Alban Nikolai Herbst: »Fantastische Räume. Vortrag zum Fantastik-Symposion Linz Mai 2004«, 2004, URL: http://www.die-dschungel.de/ANH/txt/pdf/fantastische_raeume_2004_1.pdf, vgl. auch den Aufsatz von Herbst: » Dieser mächtige Raum...««. 
phantasiert. Selbst die Metalepsen sind - wie eben ausgeführt - in dieser Lesart zu erklären, da Deters sich selbst als Figur in die Erzählung hineindenkt.

Zusätzlich kommt er auch auf einen möglichen »Defekt « $(T A, 133)$ zu sprechen, der wohl nach den Erlebnissen in Hannoversch Münden, die die Grundlage von WB bilden, entstanden ist. Ihn hatten nach seinem Entschluss, über die Erlebnisse nicht zu sprechen, zunehmend »Visionen « heimgesucht, die zu einem Zusammenbruch und eine Klinikeinweisung geführt haben (TA, 133f., 854, 856, 864). Die Ärzte stellten bei ihm Symptome fest, die auf früheren, regelmäßigen Konsum harter Drogen und eine damit zusammenhängende Hirnschädigung hindeuteten. Die >Visionen` und >Phantasmen seien »Flashbacks«. Deters verweigert sich jedoch dieser Diagnose, da er - »bis auf dieses eine Mal vor der Hotelruine« $(T A, 854)$ - niemals Drogen genommen habe. Erst als er fälschlicherweise gesteht, regelmäßig Drogen konsumiert zu haben, wird er entlassen. Diese Wendung bringt dabei im Grunde Herbsts Poetik zum Ausdruck, gibt ein reales (bzw. als realistisch gedachtes) Beispiel: »Man muß lügen, um glaubhaft zu sein.« (ebd.)

Das reine, also freiwillige Phantasieren wird aber im direkten Kontext auch als positiv dargestellt, als nicht belastend-krankhaft. Einerseits will er seine Ruhe vor den Phantasmen (»Warum ließ man ihn nicht endlich in Ruhe?! Hatte nicht auch einer wie er das Recht auf ein einfaches Leben?«, TA, 864); andererseits findet er im Phantasieren »Spaß« und »Lust«, die ihm ein lange vermisstes wohliges Gefühl zurückgeben.

\subsection{Virtuelle Realität: Alles ist simuliert}

Während in WB die Computertechnik und damit die Virtualität bestimmter Figuren oder scheinbarer Realitäten nur eine nebengeordnete Rolle spielte und lediglich eine Lesart darstellte, ist in den $A W$-Romanen die Virtualität omnipräsent. Den Begriff Virtualität verwende ich in diesem Zusammenhang nicht im philosophischen, »eigentlichen ${ }^{47}$ Sinn, sondern in der Bedeutung einer computergenerierten Simulation der eigentlichen Realität. Der ursprünglich aus der Optik stammende Begriff, wo das Virtuelle beispielsweise das reflektierte Bild im Spiegel bezeichnet ${ }^{48}$ ist nach Elena Esposito ein modaler Begriff, der innerhalb des kontingent Möglichen den Bereich der nicht aktualisierten Möglichkeiten umfasst. ${ }^{49}$ Dort geht es nicht um ,falsche reale Objekte`, sondern um »wahre virtuelle Objekte, für welche die Frage der realen Realität ganz und gar gleichgültig ist « ${ }^{50}$. Im Kontext der computergenerierten virtuellen Realität wird die »oft vernachlässigte[] Unterscheidung von Virtualität und Simulation ${ }^{51}$ gerade nicht gemacht: virtuelle Realität ist simulierte Realität. Die simulierten

47 Elena Esposito: »Fiktion und Virtualität«, in: Sybille Krämer (Hg.): Medien, Computer, Realität. Wirklichkeitsvorstellungen und Neue Medien, Frankfurt am Main 1998, 269-296, hier: 270.

48 Vgl. ebd., 278.

49 Vgl. ebd., 269.

50 Ebd., 270.

51 Ebd. 
Objekte der Anderswelt sind falsche reale Objekte und die Frage, welche Realität real ist, ist nicht gleichgültig, sondern steht im Mittelpunkt.

In Bezug auf Virtualität ist in den $A W$-Romanen generell zwischen zwei Aspekten zu unterscheiden:

- In der Anderswelt werden - allerdings nur in den technisch fortgeschritteneren Teilen Zentralstadt und Westen - große Teile der Umwelt und der Umgebung simuliert und die Sinneserfahrungen virtuell nachgebildet; auch die künstlichen menschlichen Wesen, die Holomorfen, sind in gewissem Sinn Teil der virtuellen Realität von Buenos Aires;

- In $B A$ erweisen sich die gesamte Anderswelt ebenso wie Deters' Realwelt als virtuelle Welten, die im Computer simuliert sind.

Im Folgenden soll auf den ersten Aspekt eingegangen werden, der zweite wird im nächsten Abschnitt (Abschnitt 6.3) thematisiert.

Bereits im ^Vorspiek lernt Deters die Technik der Holographie kennen bzw. erdenkt sich ihre Anwendung in der Anderswelt. Er wird gegen eine Wand geschleudert und fällt hindurch, da sie nur simuliert ist (vgl. $T A, 28)$. Später wird die Simulation großer Teile der Umgebung in der Zentralstadt Buenos Aires noch einmal anhand einer Wand veranschaulicht. Als Herr Drehmann auf der Suche nach Herrn Hausmann ist, dabei nervös wird und sich verfolgt fühlt, greift er einmal mit der Hand durch eine Wand hindurch: „Eine Simulation. Weshalb simulierten die hier eine Wand? « $(T A, 223)$ Es handelt sich lediglich um eine Wand in der Funktion eines Vorhangs, die Reinigungsgeräte und Putzmittel versteckt. Die Illusion wird jedoch so perfekt ausgeführt, dass sogar ein Geruch mit simuliert wird. Was auf diese Weise nebenbei szenisch veranschaulicht wird, wird ansonsten lediglich erwähnt. Der Blick auf den Ozean beim Präsidenten ist eine »dreidimensionale Filmprojektion « $(T A, 115)$, ein Großteil der Stadt wird als »holomorfes Environment « (TA, 131) simuliert.

Im Westen ist die Entwicklung am weitesten fortgeschritten: »Hier war alles Illusion.« $(T A, 394)$ Als Goltz dort Jensens Anwesen aufsucht, wird die Funktionsweise der holomorfen Umgebung vorgeführt. Die Umgebung des Hauses ist ein »Holomundus" ( $T A, 783)$, ein unabhängig von der Umgebung zu regelndes projiziertes Gebiet. Als Goltz einen Schalter umlegt, `zerflirrt « die »Projektionswelt» $(T A, 782)$. In der Genauigkeit der Projektionen gibt es Unterschiede, bei Jensen musste sie »ein Vermögen gekostet haben, derart detailstrukturiert war sie« $(T A, 783)$. Als es später zu Unruhen und mythisch grundierten Umweltveränderungen kommt, gibt es Schwankungen im für die Projektionen nötigen `Hodnaschild « und die »Landschaftsillusionen« werden lahmgelegt.

Beklommen sahen die Unsterblichen, wie tot um sie her alles war. Seit Jahrzehnten wieder sahen sie das. [...] Die Rosen blühten nicht, es gab keine Rosen, gab Schutt nur Gestänge Gerümpel Müll. An den Schweizergardisten, soweit sie nicht ohnedies Holomorfe waren und platzten, hingen Lumpen herum. (TA, 697)

In $B A$ werden die Arten der Umgebungssimulation im privaten Bereich noch genauer dargestellt. Es gibt eine »Fensterreform» $(B A, 44)$, nach der alle Fenster durch Bild- 
schirme ersetzt werden, die beliebig programmierte Szenen zeigen. In verschiedenen Bautypen wird die Illusion erzeugt, im Freien zu stehen oder das Dach ist als Himmel programmiert (vgl. $B A, 144 \mathrm{ff}$.)

Die Holomorfen sind im Gegensatz zur ebenfalls als holomorf bezeichneten Umgebung nicht projiziert, sondern - obzwar künstlich - doch physische Wesen, die wie bei Herrn Drehmann zu sehen, sogar körperliche Funktionen des Menschen entwickeln können. Ihre Konsistenz wird einmal als »Materie-Energie-Legierung « $(T A, 238)$ erklärt. Einerseits sind sie also programmiert und können auch jederzeit umprogrammiert werden, andererseits haben sie einen materiellen Körper, durch den nicht wie durch eine projizierte Wand hindurchgegriffen werden kann. Dennoch sind Holomorfe nicht auf den Körper angewiesen, können sich durch Datenbahnen bewegen und können auch (mitsamt dem Körper) gelöscht werden. In Ingolstadt, wo fast nur Holomorfe angesiedelt sind, haben sie im Normalfall keinen Körper, weil er dort keinen Sinn macht. Dementsprechend können sie durch Deters hindurchlaufen, als er mit Herrn Hausmann dorthin kommt (vgl. TA, 569). Zudem hängen sie (zum Zeitpunkt des Geschehens) noch vom Hodnaschild über der Zentralstadt und dem Westen ab und damit von einer Energie- bzw. Hodna-Quelle. Sie sind also einerseits körperlich, andererseits nicht körperlich und damit auch im Bereich der virtuellen Realität anzusiedeln.

Die zunehmende Bedeutungslosigkeit der `Dingwelt $`$ wird an den Holomorfen veranschaulicht, wenn sie eben nicht darauf angewiesen sind, als `Körper « beispielsweise von A nach B zu gelangen oder zu kommunizieren: »Er hätte [das Taxi] eigentlich herbeidenken können. Das hätte bei einem Euroweb-Holomorfen vollauf genügt.« (TA, 221) Die Holomorfen können »allein durch ihre Gedankenkraft Räume Orte Kontinente schaffen und also wechseln « (TA, 265). Im Gesamtkontext der $A W$-Romane ist hinzuzufügen, dass dies den Menschen nur durch die Phantasie, die poietische Kraft möglich ist. Deters' fiktionale Erschaffung einer aus vielen Metropolen zusammengesetzten Stadt wird angedeutet als verwirklicht in der Holomorfie-Technik.

Auch bei den Menschen spielt die >Dingwelt eine immer geringere Rolle. »Euroweb « und »New Work « $(T A, 275)$ ermöglichen, die eigene Wohnung nicht mehr verlassen zu müssen und dennoch zu arbeiten und zu leben. Das "Euroweb« ist dabei eine dem realen Internet ähnelnde virtuelle Realität, in dem Informationen ausgetauscht und abgerufen werden können, aber in der auch gearbeitet oder Urlaub gemacht wird. Zudem gibt es Geräte, die »Infomaten«, die vermutlich mit dem »Euroweb« verbunden sind. Urlaub und sogar Sex erlebt man in diesen Geräten, die nicht nur eine andere Realität vorgaukeln, sondern diese auch erleben lassen: »Es gab prinzipiell keinen Unterschied zwischen realdatischer und informatischer Synapsenreizung." $(T A, 393)$ Durch die erweiterten Möglichkeiten ${ }^{52}$ der künstlich erzeugten Erlebnisse erfolgt eine Umkehrung der Empfindung, was wirklich ist und was künstlich. »Das

52 In $B A$ werden weitere Details ausgeführt. Im Infomaten oder »GanzkörperInfoskop« [sic!] kann man sich auch anders >designen`: die Figur Uma Svendson jettet als »fünf Jahre jüngere, hochgewachsene langbeinig Rötlichblondierte [...] informatisch nach Goa« $(B A, 197 \mathrm{f}$.$) .$ 
Euroweb war authentischer als die calle de Preciados, das innere Netz das wirkliche Leben.« $(T A, 131)$

Durch verschiedene kleine Szenen wird anhand der Anderswelt gezeigt, was die Auswirkungen einer bis zur Totalität fortschreitenden Medialisierung sein könnten. Der fast ausschließlich Ersatz der >dinglichen Realität durch Simulation und Projektionen folgt dabei Ungefuggers bereits angesprochener Strategie der Entkörperlichung und der >Verflüssigung ‘ aller Dinge. Alles Konkrete solle abgeschafft werden, ganz Europa flüssig »wie Geld « $(T A, 155)$ werden. Der relativ deutlichen Negativ-Zeichnung Ungefuggers entspricht die Vorführung der Probleme, die eine solche Medialisierung mit sich bringen könnte. Paradoxerweise wird gerade an Herrn Drehmann gezeigt, dass die umfassende Künstlichkeit der Umgebung Angst macht. Seine Menschlichwerdung wird an diesen Gedanken anschaulich gemacht: »Alles war unecht. Und machte dennoch angst.« (TA, 270) Für die >echten` Menschen bestätigt wird diese Empfindung, wenn sie es unheimlich finden, dass eine Stadt oder eine Versammlung nur aus Holomorfen besteht, die von außen zwar nicht zu unterscheiden sind, wo aber die Vorstellung Unwohlsein auslöst, dass es sich um künstliche Wesen handeln könnte (vgl. TA, 329). Im Intervallo, wo zunächst alle außer Herrn T Holomorfe sind, ${ }^{53}$ wird gezeigt, wie ein Mensch, der nie anderes erlebt hat, unglücklich darüber wird, als er die Künstlichkeit der Umgebung erkennt (vgl. TA, v. a. 192-195).

Als schließlich während des `Eintageskriegs` auch Kämpfe in Buenos Aires stattfinden, wird die geänderte Wahrnehmung der Leute gezeigt. »Die Bürger brachten sich nicht in Sicherheit, sondern strömten hin, um das Schauspiel zu genießen. Sie hatten gelernt, alle Realität als Veranstaltung zu begreifen.« (TA, 702) Durch die Gewöhnung können sie nicht mehr zwischen der Simulation und realen Ereignissen unterscheiden.

Dieser naiven Unterscheidungsunfähigkeit wird bei einigen Leuten dann nicht die rational begründete Ablehnung von Technik und Fortschritt entgegengesetzt, sondern eine Hinwendung zu körperlich erfahrener Authentizität, die sich als Sehnsucht bemerkbar macht. Wie oft bei Herbst wird die Authentizität durch Sexualität ermöglicht. Mehrere hohe Mitarbeiter Ungefuggers (Jensen sen. und jr.) wenden sich dem Osten zu und bei Broglier ist es der "aggressive[] Verzicht auf jedes simulative Moment" ( $T A, 470)$, der ihn gerade bei der Klonin Dolly erregt. Der fortgeschrittenen Technik entsprechend wäre ein Unterschied in der körperlichen Wahrnehmung zwar nicht vorhanden gewesen, aber hier ist es wieder die Vorstellung und Bewusstmachung, die den Unterschied ausmacht.

Insgesamt gesehen ist die Unterscheidung von Realität und Simulation in der Wahrnehmung nicht möglich. Projektionen sind aus der Nähe zwar als solche feststellbar, da sie nicht materiell sind, sind aber im Normalfall auch nicht dafür gedacht. Durch die Holomorfen- bzw. Hodnatechnik ist jedoch auch eine Materialisierung der künstlichen Welten möglich. Dass ein Unterschied zwischen Realität und Simulation tatsächlich besteht, wird dabei nicht negiert. Dies wird bei Versagen der Technik deut-

53 Abgesehen davon stellt sich die Raumfahrt der Mayflower 2 im Nachhinein insgesamt als im Computer simuliert heraus. 
lich und vor allem auch darin, dass die Unterscheidung im Bewusstsein der Menschen teilweise wirksam und dadurch auch wichtig ist.

Lediglich an einer Stelle wird in TA mit der Vorstellung gespielt, dass die Abgrenzung tatsächlich überwunden werden kann. Zwar ist im Experiment des Intervallos eigentlich alles nur im Computer simuliert (was dem oben genannten zweiten Aspekt entspricht und damit auf $B A$ vorausdeutet), doch hat die eigentlich nur kurze Simulation Auswirkungen auf die Experimentteilnehmer. Sie verwandeln sich in seltsame `Flatschen $\prec$ die - um sie loszuwerden - über dem Osten abgeworfen werden. Der Experimentleiter Beutlich stellt fest: »Es sieht so aus, als würden Simulationen unter gewissen Bedingungen realitätsfähig werden.« $(T A, 250)$ Die `gewissen Bedingungen bleiben recht unbestimmt; es handelt sich um »Grenzbereiche«, in denen Simulationen wahr werden. Auch dies ist ein Ausblick auf $B A$, wo der Übergang zwischen >datischen`Simulationen und realen Welten auf phantastische Art weiter aufgelöst wird.

\subsection{Multiplikation von Welten und Beobachtern}

Auch wenn sich die Rekonstruktion des Weltenaufbaus in TA nicht als ganz so einfach herausgestellt hat, wie anfangs angenommen, so wird in $B A$ der Aufbau noch einmal verkompliziert. Neben Deters' Realwelt (W1) und der Anderswelt (W2) wird mit Garrafff noch eine weitere Welt (W3) und damit Erzählebene hinzugefügt; zudem wird durch die De-Hierarchisierung der Deters-Ebene das Verhältnis der Welten zueinander noch weiter destabilisiert.

\subsubsection{Weltenmultiplikation}

In $B A$ scheint sich die bislang als Ausgangspunkt der Erzählung erachtete Realwelt von Deters (W1) als eine vollständig im Computer simulierte Welt zu erweisen. Sie ist eine Kopie der ihr hierarchisch übergeordneten Welt »Garrafff« $(B A, 38)$, die damit vor allem geographisch als weitgehend identisch mit der aktualen Welt vorgestellt werden kann (sie ist allerdings offensichtlich technisch weiter fortgeschritten). In dieser Welt sind verschiedene Programmierer bei der Firma Cybergen $(B A, 33)$ in Beelitz, einem Ort bei Berlin, angestellt. Neben Lerche, einem als charakterlich bösartig dargestellten Menschen, und der Vorgesetzten Sabine Zeuner, ist dies vor allem der Programmierer Alban Herbst. Wie die Raumfahrt der Mayflower 2 im Intervallo ist W1 eine »datische Welt« $(B A, 94)$, die für Simulationen politischer Zusammenhänge programmiert wurde $(B A, 94)$; sie wird einfach »Welt« $(B A, 97)$ oder Erde« $(B A$, 156) genannt. Die Anderswelt (W2) ist ebenfalls eine bei Cybergen generierte Welt, die auf einem anderen erdgeschichtlichen und auch technischem Stand ist und für naturwissenschaftliche Modellierungen gedacht ist.

Zunächst ist das Verhältnis zwischen Garrafff und den beiden Welten ein eindeutig hierarisches. W3 ist ihnen übergeordnet, da sie beide nur als Computersimulationen in dieser Welt existieren. Vorzustellen ist dies so, dass die simulierten Welten in der Firma zum einen auf verschiedenen Bildschirmen verfolgt werden kann. Jede mögliche Szenerie und sämtliche Personen können wie mit einer Kamera verfolgt werden. Zum 
anderen können die Welten aber auch als »simulakre Vollprojektion« $(B A, 196)$, also als ${ }_{3}$ D-projizierte virtuelle Realität in den Büroräumen erlebt werden. Sie sind dabei vollständig den Eingriffen der Programmierer ausgesetzt, die im Normalfall eigentlich Forschungsfragen vorbehalten sind. So wird an Corinna Frieling in der Anderswelt ein Medikament getestet, weswegen ihr Brustkrebs einprogrammiert wird $(B A, 116 f$. ) Sie können beispielsweise auch einfach sämtliche Personen wegschalten (vgl. $B A, 27)$, was eine Erklärung im Nachhinein dafür ist, dass Deters in einer Szene auf einmal ganz allein in der Welt ist. Auch den Datenstrom, der Deters immer auf der Netzhaut angezeigt wird, kann Herbst unterbrechen (vgl. $B A, 37$ ). Wie bereits oben erwähnt, spiegelt sich aber auch der `Geschlechterkampf $\triangleleft$ in der Anderswelt (Deters und Elena) im Verhältnis zwischen Herbst und Zeuner, die aus solchen Gründen auch in die Simulation eingreifen (vgl. $B A, 179,153$ f.).

Dieser Zusammenhang der Welten stellt sich wiederum als nicht ganz so einfach, als nicht eindeutig hierarchisch dar. Die Welt W1, Deters' Realwelt, erhält nur scheinbar einen anderen, untergeordneten Status. Dass die Hierarchie der Welten durch verschiedene seltsame Schleifen komplett aufgelöst wird, wird im nächsten Abschnitt gezeigt. An dieser Stelle soll es erst einmal um die weitere Vervielfältigung der Welten sowie die Verbindungen zwischen ihnen gehen.

Es sind die Akteure der verschiedenen Welten, die mit unterschiedlichen Informationsständen die Zusammenhänge zwischen den Welten zu verstehen versuchen. So stellen die Programmierer aus W3 fest, dass Deters in W2 auftaucht. Natürlich versuchen sie, diesen Umstand informatisch-technisch zu erklären. Sie nehmen an, dass eine Verbindung sich über »Web- und Stromleitungen « $(B A, 97)$ etabliert hat. Erst sind sie überrascht und erschreckt, dann aber auch neugierig, sodass sie nichts gegen diese Entwicklungen unternehmen. Alle Entwicklungen gehen für sie darauf zurück, dass es sich bei den Weltensimulationen um selbststeuernde Systeme handelt, die sich nach den Vorgaben entwickeln, nach denen sie anfangs programmiert wurden und nach denen ihre Entwicklung angestoßen wurde. Entsprechend sind die umweltspezifischen Veränderungen, die in der Anderswelt zu der geologischen Umbildung Europas geführt haben, als Auswirkung dieser Modellierung aufzufassen. Das »Städtegemisch « $(T A, 428)$ wird so erklärt, dass sie in die Anderswelt als Experiment auch Daten von W1 eingespielt haben, die sich dann nach »chaotischen Gesetzmäßigkeiten durcheinander mischten « $(B A, 97)$. Dementsprechend wird auch eine Art Erklärung für die in $T A$ den Leser teils verwirrenden mythischen Anspielungen und in der mythischen Ost-Welt lokalisierten Brutalitäten geliefert. ${ }^{54}$

Der notwendig gewordene technische Fortschritt schien einen mythischen Regress zu erzwingen. Die Anderswelt benahm sich wie ein fremdartiger Orga-

54 Diese wurden in den Rezensionen kontrovers betrachtet. Katharina Döbler stellt angesichts der »extrem unappetitlichen körperlichen Vorgängen « die Frage, ob ein Roman `alles` darf, beantwortet sie aber mit »Ja«, auch wenn die Zahl der Leser klein bliebe (vgl. Döbler: »Delirium und Moralium «). Maike Albath hingegen unterstellt Herbst in einem Verriss »viel Gusto fürs Unappetitliche« (Albath: »Der götterhaften Giftbrühe entstiegen«), was ihn sogar zu einer Fußnote in $B A$ veranlasste (vgl. $B A$, 246); Thomas Wörtche beklagt die "Akne-Prosa " (Wörtche: »Pusteln und Pickel«). Es bleibt somit bei der Beschwerde über sunappetitliche`Schilderungen, Interpretationsüberlegungen finden sich diesbezüglich nicht. 
nismus. Kein Mensch hatte so etwas wie eine Midgardschlange programmiert, und wer wäre von sich aus auf Hundsgötter verfallen? $(B A, 95)$

Damit wird ein im Vorgängerroman zentraler Erzählstrang zu einem Nebeneffekt der sich selbst weiterentwickelnden Programmierung deklariert. Zudem war dieser Erzählstrang Teil der Phantasien von Deters. Dieser wird als »Avatar « von W1 zwar von den Programmierern beobachtet und sein Übergang nach W2 aufmerksam verfolgt. Nicht thematisiert wird dabei jedoch, dass die komplette Welt W2 eigentlich von ihm erdacht worden ist. Es wird rein die Perspektive eingenommen, dass es sich um selbstentwickelnde Systeme handelt.

So müssen die Programmierer feststellen, dass entgegen ihrer eigentlichen Versuchsanordnung "Welt und Anderswelt verschmolzen« $(B A, 98)$. In $T A$ wurde dies durch die Explosion im Silberstein/Samhain erklärt, wodurch der Übergang zwischen den beiden Welten geöffnet ist. Deters kann nun frei zwischen Welten und Orten wechseln. Er landet schließlich von Bombay aus in Hannover und ist erleichtert, »realdeutschen Boden « $(B A, 78)$ unter den Füßen zu haben. Die Beschreibungen lassen das "Setting der Jahrhundertwende« $(B A, 79)$ erkennen. An dieser Stelle wird dann einmal zusammengefasst, was vorher nur in Andeutungen und an ungenauen Angaben zu erkennen war. Es gibt nicht nur die drei Welten, sondern auch manche der Welten zu verschiedenen Zeitpunkten.

Damit ergibt sich eine weitere mögliche Aufreihung der Welten, in die die zeitliche Komponente mitaufgenommen werden muss:

- W1: «Welt«; Deters’ Realwelt, 1998

- [W1': Deters als Figur, die eine Verbindung zwischen den Welten ermöglicht]

- $\mathrm{Wlt}_{2}$ : Deters in Hannover/Berlin, 2000

- Wlt 3 : Herbst in der >Welt $\triangleleft$ statt Deters, findet sich im Jahr 2001 wieder

- W2: »Anderswelt«

- $\mathrm{W}_{2} \mathrm{t}_{2}$ : Deters in der Anderswelt 9 Jahre nach den zuerst geschilderten Ereignissen

- W3: »Garrafff«

In Deters Versuch, einen Überblick über seine `Erinnerungen` zu gewinnen, wird dann wieder auf den »Umweg [s] einer Fantasie« $(B A, 77)$ und das, was er sich »zusammengesponnen « $(B A, 79)$ hatte, zurückgegriffen und nicht auf die Erklärung als datische Welten. Die Zeitangaben widersprechen auch der Anordnung der Welten aus Sicht von Garrafff (vgl. $B A, 97$ ). Deters fällt weiterhin eine herausgehobene Position zu. Er ist derjenige, der die Welten »fiktiv immer mit[denkt] und [...] dadurch Realitäten [schafft] « $(B A, 152)$; er ist auch »der einzige, der die Schnittstellen unmittelbar sinnlich erfuhr, indem er Zeitenbrüche und Weltenwechsel bewußt in Gang setzte, wenn auch nicht mehr vollkommen freiwillig« $(B A, 160)$.

Als es dann später erst Deters (vgl. $B A, 38$ ), dann Broglier von der Anderswelt nach Garrafff (vgl. $B A, 122)$ verschlägt, ist nicht nur eine Verbindung zwischen den aus Sicht von W3 rein datischen, simulierten Welten hergestellt, die noch einigermaßen technisch erklärt werden kann; vielmehr findet ein Übergriff von den simulierten Welten auf ihre eigene Welt statt. Spätestens zu diesem Zeitpunkt bleibt dem Programmierer Herbst also nichts anderes mehr übrig, als sich an den »Strohhalm der 
Transzendenz «55 zu klammern. Seine Beobachtungen und Erlebnisse passen nicht mehr zu dem Wissen, die anderen Welten selbst mitprogrammiert zu haben.

Im Grunde gab es Anlass zur Panik. Offenbar hatten wir die kybernetischen Welten nicht geschaffen, sondern es schien sie immer schon, zugleich und neben der Realität, gegeben zu haben; wir hatten lediglich den - oder einen - Zugangscode gefunden. Theoretisch mussten also auch wir sie betreten und mit ihnen verschmelzen können. $(B A, 151)$

So wird Abstand genommen von den technischen Erklärungen. Die unbestimmte "Matrix« hat auch die eigentlich als hierarchisch über den anderen stehende Welt >umschlossen` oder »gesuckt « $(B A, 144)$. Damit sind die Leser wieder auf die Erklärungen von und um Deters zurückgeworfen. Einhergehend geht es nicht mehr darum, ein hierarchisches Verständnis des Weltenaufbaus aus W3-Perspektive zu etablieren, sondern um Vorstellungen, was der Gedanke multipler Welten impliziert. Letztlich geht es so um eher ideologische Vorstellungen, wie gleich zu sehen sein wird.

Die Frage nach dem Zusammenhang multipler Welten wird nun von verschiedenen Akteuren wiederaufgegriffen. Noch auf den >datischen Z Zusammenhang bezogen geht Beutlin auf Nachfrage von Goltz davon aus, dass eine »Unendlichkeit miteinander verschränkter Realitäten « $(B A, 221)$ entstehen können. Dies wird später in zwei Situationen wieder aufgegriffen.

In der ersten Situation spricht Deters, als er von den Rebellen aus den Fängen von Goltz gerettet wird, mit Deidameia über seine Möglichkeiten, wieder in seine eigene Welt zurückzugelangen. Da er in der Lappenschleuse kopiert wurde und sein ’Original gelöscht oder vernichtet wurde, sieht er keine Chance für sich. Deidameia bietet ihm jedoch einen weiterentwickelten Selbstprojektor und den freien Übergang im >Boudoir`. Zum >Tanken` müsste er jedoch ab und zu wieder zurückkehren. Sie vermutet nun, dass es auch möglich wäre, in seiner Welt den Selbstprojektor an die Stelle zu legen, wo in der Anderswelt der Zentralcomputer steht. Genauer erklärt sie den Vorgang nicht, wichtiger ist aber die Feststellung, dass es »starke Indizien « dafür gebe, dass »[j]ede mögliche Welt [...] Elemente aller anderen [enthalte] « $(B A, 225)$. Die bereits angesprochene eigene Vervielfältigung durch Anfertigung von Kopien ihrer selbst und des >Boudoirs sieht sie auch als eine Multiplikation von Welten - auch wenn alles darauf hindeutet, dass sich ihre Kopien alle in derselben Welt befinden. Es zeigt sich jedoch deutlich ihr ideologisches Anliegen, das sich aus dem Kontrast zu Ungefugger speist. Ungefugger wolle alles holomorfisieren und dann aber »alle übrigen Realitäten löschen [...]. Er will eine einzige - ein monogames Paradies. [...] Wir hingegen wollen so viele Welten wie möglich. Wir sind für Willkür, Hans Deters. Wir wollen Ekstase, nicht Ordnung.« $(B A, 223)$ Malsch tut dies als »banal [...] zum Recht auf Devianz herunter gekochte [sic!] Programmatik« und »[banale] anarchistische Utopie ${ }^{56}$ ab. Zwar gehen die Begriffe - Realitäten, Welten - etwas durcheinander; es geht Deidameia jedoch nicht um Devianz, sondern um Vielfalt, um radikale Pluralität. Ihre weiteren Ausführungen klingen tatsächlich etwas banal,

55 Malsch: »Vom Wiedereintritt des Autors in seine Geschichte«, 69.

56 Ebd., 72. 
stellen aber eine Paraphrase des herbstschen Körperlichkeitsdiskurses dar, die etwas simpel geraten ist:

»Wir wollen, Hans Deters, nicht korrekt leben. Wir wollen Risiken. Wollen Rauschgifte nehmen und mit überhöhter Geschwindigkeit fahren. Wollen übernächtigt sein und uns betrinken, wollen leiden, weil das die Lust anfacht." (BA, 223f.)

In der zweiten Situation findet sich Herbst in Deters' Realwelt (eigentlich W1) wieder, doch in einem unerwarteten Jahr $\left(\mathrm{Wlt}_{3}\right)$. Als er sich zu orientieren versucht, reflektiert er über die vielfältigen Welten. Zwar versteht auch er die Zusammenhänge nicht, stellt aber fest, dass immer andere Welten oder gleiche Welten zu anderen Zeitpunkten sich auftun. So fragt er sich, wie viele Welten vorhanden oder möglich sind:

Entspricht jedem Gedanken eine Realität? irgendwo? $(B A, 267)$

Gibt es für jede Sekunde eine eigene Welt? Milliarden Welten, um Sekunden verschoben? Oder gibt es Sprünge, gibt es manche Welten in manchen Zeitzuständen nicht? $(B A, 265)$

Auf diese letzte Überlegung kommt er, da er daran denkt, dass in W1 der Jugoslawienkrieg stattgefunden hat und in der Anderswelt sich entsprechend Monstrositäten ausgebildet haben, in der Welt Garrafff jedoch nicht. Da stellen sich ihm die weiteren Fragen:

Existiert eine Erde, die niemals Konzentrationslager hatte? $(B A, 265)$

bzw.

Irgendwo könnte Milošević ein zweiter Nyerere sein. $(B A, 267)$

\subsubsection{Beobachterpositionen}

Schon in TA wird das Verhältnis der beiden Welten W1 (Welt) und W2 (Anderswelt) als eine Frage der Perspektive sehr anschaulich dargestellt. Dies geschieht über Deters' Begegnungen einmal mit Frau Tranteau und einmal mit Markus Goltz, beides sind Standpunkte innerhalb der Anderswelt, der von Deters aus gesehen ganz wörtlich zu nehmenden >anderen Welt $\ltimes$. Beide beobachten Deters und seine Spaziergänge und Einmischungen in der Anderswelt und verstehen seinen (ontologischen) Status nicht. Das Interessante dabei ist, dass sie erst einmal neutrale Beobachtungen registrieren und sie ihrem Weltbild entsprechend und den Vorgaben der Anderswelt, also ihren Naturgesetzen, folgend, einzuordnen versuchen.

Frau Tranteau lässt Deters zu sich in die Rebellenzentrale bringen und erklärt ihm ihr Unbehagen ihm gegenüber:

Ein eigenartiger Mitspieler sind Sie! Sie haben imgrunde keinen Anlaß, sich zu beteiligen. Ich komme, mit Verlaub, um den Eindruck nicht herum, daß Sie wie soll ich's ausdrücken? - anders woher stammen ... aus einer Anderswelt, um es einmal so zu sagen [...] Sie spazieren durch die Stadt, als müßten Sie sich nicht an Gesetze halten ... ich meine Naturgesetze, Herr Deters. $(T A, 573)$ 
Damit dreht sie die Perspektive um, was durch die Verwendung des besonderen Begriffs Anderswelt (anstelle beispielsweise von »aus einer anderen Welt«) überdeutlich gezeigt wird. Nicht mehr sie als ausgedachte Figur ist Teil einer anderen Welt, sondern Deters. Durch den Verweis auf geltende Naturgesetze macht sie deutlich, dass sie sich nicht als Bewohnerin einer phantastischen Welt sieht, sondern einer konsistenten Realität. Durch den Perspektivwechsel wird veranschaulicht, was in der Fiktionstheorie allgemein für fiktive Welten gilt:

[D]ie fiktive Welt existiert [...] als Welt nicht in der realen Welt und ist daher keine reale Welt; aus Sicht der fiktiven Welt ist natürlich die eigene (von außen fiktive) Welt die reale Welt und die (von außen reale) Welt in keiner Weise vorhanden. ${ }^{57}$

Erst durch Deters Verhalten finden sich unerklärliche Diskrepanzen in diesem Weltbild; letztlich wird so ihre Welt zu einer phantastischen. Im Nachhinein wird dem Leser auch eine andere Anschauung der Anderswelt präsentiert: die Erreichbarkeit eigentlich weit entfernter Bereiche in Buenos Aires, die Deters als dessen Struktur erklärt hat und im Gespräch mit Frau Tranteau als solche verteidigt, stellt sich als eine ihm zugehörige Eigenschaft heraus, die sich zudem auch auf Personen erstreckt, die mit ihm in Kontakt kommen. Auch hier zeigt sich die Verklärung der Zuordnung: Deters weiß nicht alles über die Anderswelt, auch wenn er sie sich eigentlich ausgedacht hat.

Tranteaus Beobachtungen zum Verhältnis der Welten bzw. zum Verhältnis von Deters zu ihrer Welt sind erstaunlich präzise für ihre eigentlich unzureichende Beobachterposition.

Sie müssen nur einen Einfall haben, es braucht das gar keine böse Absicht zu sein, und schon geschieht uns Ihr mentaler Zeitvertreib. Uns, Herrn Deters, geschieht er wirklich. Das macht Sie zu einer heiklen Person. (TA, 575)

Angesichts dieser Erkenntnisse verhält sie sich erstaunlich gelassen. Sie stellt ihn lediglich zur Rede bzw. will die Fronten klären. Sie vermutet also eine »Wechselwirkung« (ebd.) zwischen Deters und seinen Imaginationen, die ja gerade deutlich vorgeführt wird.

Nach dem Überfall von Goltz und der Festnahme von Deters wird dieser an einen "Gehirnstrom-Interpretator " $(T A, 580)$ angeschlossen, durch den Deters' Gehirn auf Bildschirmen abgebildet und dort angesteuert werden kann. Die Gedanken können dabei sowohl graphisch als auch »als interaktive Spielfilmszenen « $(T A, 581)$ dargestellt werden. Goltz will durch die Erinnerungen von Deters Rückschlüsse auf die Rebellen ziehen. Zwei Aspekte werden hier in einer komplexen Konstruktion vorgeführt: zum einen wird die individuelle Interpretation von Wirklichkeit plastisch vor Augen geführt, zum anderen wird wieder das besondere Verhältnis von Deters zur Anderswelt veranschaulicht.

Der erste Aspekt, die subjektive Wirklichkeitsinterpretation, wird gezeigt, indem Goltz sich selbst in Deters' Erinnerungen sieht, er aber aussieht wie der (realweltliche)

57 Bunia: Faltungen, $104 f$. 
Schauspieler Jürgen Prochnow, als den Deters sich Goltz immer vorgestellt hat. Goltz erkennt, dass diese subjektive Erinnerung eine Interpretation darstellt, die jegliche intersubjektive Wahrheit von Erinnerungen infrage stellt. Erzähltechnisch wird die Konstruktion genutzt, um mithilfe der Erinnerungen bzw. Phantasien, die Goltz an den Bildschirmen verfolgt, auch die Geschichte um Odysseus weiterzuerzählen.

Zum anderen erkennt Goltz, dass Deters die Informationen über seine Welt (W2) nicht irgendwo erhält, sondern selbst erzeugt. Zwar kann er dies, da er wie Tranteau auch von einer konsistenten Realität ausgeht, nicht glauben, doch muss er erkennen, dass lediglich diese phantastische Annahme die Widersprüche erklärt, die sich durch Deters' Auftreten in der Anderswelt in seinen Beobachtungen ergeben (vgl. TA, 588). Als er sich schließlich selbst im Bildschirm sieht, wie er in eben dieser Situation vor den Monitoren sitzt, ergibt sich eine mise en abyme: ein Bild, das sich selbst enthält, bzw. eine Erzählung, die sich selbst enthält. Um aus dieser Endlosschleife (einem infinitem Regress) wieder herauszukommen, muss Goltz das Experiment abbrechen. Er erkennt, dass Deters diese Konstruktion herbeigeführt hat, um absichtlich wahnsinnig zu werden und so das Ausspionieren durch Goltz zu beenden. Das durchdrehende Lachen von Deters' kann dabei im Grunde als das Vergnügen des Autors am metafiktionalen Spiel gesehen werden.

In $B A$ wird schließlich der Beobachtungskreis vollständig und übersichtlich dargelegt. Die Programmierer in Garrafff (W3) sind an ihren Computermonitoren deutlich als Beobachter ihrer Simulationswelten W1 und W2 zu erkennen. Deutlich gemacht wird dies durch mehrere Auflistungen, was auf zehn verschiedenen Bildschirmen jeweils zu sehen ist. Zunächst werden Deters in W1 und Corinna Frieling in W2 sowie verschiedene zufällige weitere Perspektiven der zwei Welten gezeigt (vgl. $B A, 180$, 195f.). Auf einmal wird jedoch die gesamte Beobachterkonstruktion und damit auch Hierarchie, die in $B A$ neu etabliert wurde - W1 und W2 sind simulierte Welten in W3 -, komplett aus den Angeln gehoben, indem dieser Auflistung eine weitere zur Seite gestellt wird (vgl. $B A, 196 \mathrm{ff}$.). In dieser beobachten nämlich Goltz und Beutlin (W2) nicht nur Frielings Haus, wo Deters sie gerade besucht und das ebenfalls in W2 ist, sondern auch die Programmierer Herbst, Zeuner und Lerche in W3 (Garrafff). Schließlich wird in einer allerdings als (zukünftige) Möglichkeit kategorisierten Auflistung noch die Perspektive von Deters in W1 ebenfalls als Monitorwand aufgeführt $(B A, 199 f f$.$) : Deters (wenn er denn nicht auch gerade bei Frieling und damit in W2$ wäre) könnte auf seinen Monitoren Goltz und Beutlin, Frielings Schlafzimmer, das BoudoIr sowie Goltz' Einsatztruppe und zudem noch die Myrmidonen sehen - also alles Szenarien von W2.

Durch die zweite Auflistung wird wie gesagt die vorher hergestellte Hierarchie zunichte gemacht. Die Programmierer in W3 haben zwar die Welten W1 und W2 geschaffen, können aber anscheinend von ihren eigenen Simulationen beobachtet werden. Noch einmal etwas übersichtlicher:

- W3 beobachtet W1 und W2

- W2 beobachtet W2 (andere Szenarien derselben Welt) und W3

- W1 beobachtet W2 
Auffällig ist, dass lediglich W1 nicht W3 beobachtet und W2 nicht W1. Dabei wird die Möglichkeit ausgelassen, wieder eine mise en abyme-Konstruktion zu schaffen, indem beispielsweise Deters Goltz dabei beobachtet, wie dieser Herbst dabei beobachtet, wiederum Deters zu beobachten. Die Möglichkeit, dies zu zeigen, wird ausgelassen, doch sie besteht.

\section{Beobachternetzwerke}

Die Frage nach einem solchen Kreislauf wird auch von Thomas Malsch gestellt. Er analysiert dieselbe Konstruktion und unterscheidet dabei nicht nach Welten, sondern nach Beobachtungsmodi. ${ }^{58}$ Die erste Beobachtung bezeichnet er als eine Beobachtungskommunikation erster Ordnung (die Programmierer beobachten Deters und Frieling und kommunizieren darüber); die zweite eine Beobachtungskommunikation zweiter Ordnung (Goltz und Beutlin beobachten die Programmierer beim Beobachten); die dritte eine svirtuelle Beobachtungskommunikation dritter Ordnung (Deters könnte die Beobachter zweiter Ordnung Goltz und Beutlin beobachten).

Malsch erklärt, dass bei Beobachtungskommunikationen eine Asymmetrie zwischen Beobachter und Beobachtetem bestehe: »Ohne Grenzziehung zwischen observans und observandum keine Beobachtung. Das bedeutet: Unbeobachtbarkeit der observierenden durch die observierte Kommunikation. "59 Wird diese Asymmetrie aufgehoben, was tatsächlich geschehen kann - dass also ein Beobachteter anfängt, den Beobachter zu beobachten -, dann ist die Beobachtungskommunikation jedoch keine mehr, sondern geht in den »Symmetriemodus der Normalkommunikation « ${ }^{60}$ über. ${ }^{61}$ Die Schlussfolgerung aus diesen Überlegungen ist bei Malsch die These, es werde durch den Roman gezeigt,

dass die Beobachtungshierarchie eine längst außer Kraft gesetzte Fiktion ist, wenn sie denn jemals funktioniert haben sollte. Beobachtungsverhältnisse sind stattdessen netzwerkartig und zirkulär konstruiert. Um im Modell zu veranschaulichen, wie so etwas geht, stelle man sich vor, dass A von B, B von C und C wieder von $\mathrm{A}$ beobachtet wird. So geht die Hierarchie in einen Kreislauf über. ${ }^{62}$

Malsch fragt nun aber auch nach der nicht ausgeführten mise en abyme-Konstruktion, warum »C, wenn $C$ via B auch A beobachten kann, trotzdem nicht in der Lage sein soll zu beobachten, wen A beobachtet ${ }^{63}$. Beim Erklärungsversuch, dem Verweis auf die den Titel des Aufsatz gebende Formulierung vom »Wiedereintritt des Autors in seinen Roman $\aleph^{64}$, erläutert Malsch leider nicht wirklich, was er meint, und wird zudem recht

58 Vgl. Malsch:»Vom Wiedereintritt des Autors in seine Geschichte«, 74.

59 Ebd., 75.

60 Ebd.

61 Malsch nennt den Klatsch als Beispiel: dieser lebe von der asymmetrischen Situation, es handelt sich nur um Klatsch, solange der Betroffene nicht anwesend ist; wird weiterhin über den Betroffenen gelästert, wenn er anwesend ist, so hört es auf Klatsch zu sein und wechselt den Kommunikationsmodus, wird beispielsweise Konflikt oder Konfrontation, vgl. ebd.

62 Ebd., 76.

63 Ebd.

64 Ebd. 
unklar. Auch hier zeigt sich vermutlich die kleine Schwäche seines Aufsatzes, nicht (literaturwissenschaftlich) eindeutig zwischen dem Autor Herbst und der Figur, also dem Programmierer Herbst zu unterscheiden. Er vernachlässigt an dieser Stelle, was er vorher bereits explizit genannt hat. Als er nach den Gründen fragte, warum die Beobachtung dritter Ordnung einen toten Winkel hat (die Beobachtung erster Ordnung nicht zu sehen), schreibt er:

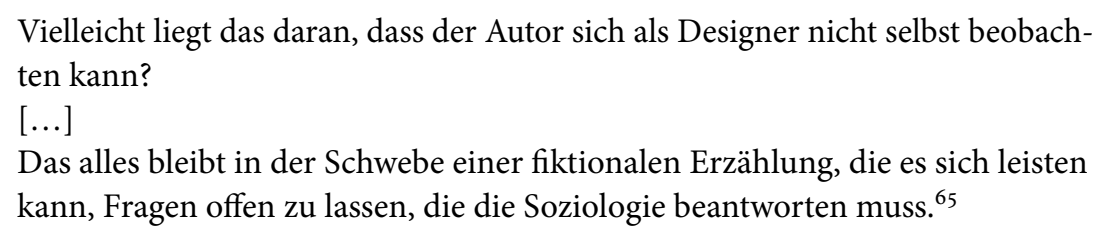

Denn im Grunde konstruiert Herbst hier eine unmögliche und daher mit den Mitteln, die Malsch anwenden will, nicht erklärbare Beobachtungssituation, die nicht zu einer Normalkommunikation wird. Warum Herbst an dieser Stelle nicht die mise en abyme-Konstruktion anwendet, wie er sie in der > Verhörszene r mit Deters und Goltz in TA angedeutet hat, ist wohl textintern nicht zu klären. Er umgeht die Eigenbeobachtung von Deters (abgesehen davon, dass die Beobachtung dritter Ordnung durch Deters sowieso nur als Möglichkeit markiert ist) jedoch literarisch sehr interessant durch einen intertextuellen und metafiktionalen Hinweis. Wohlgemerkt als Möglichkeit könnte sich Deters auf dem Bildschirm im Bett mit Corinna Frieling betrachten, doch wird dies folgendermaßen beschrieben:

Der dem Betrachter seit »Die Verwirrung des Gemüts« eigenwillig bekannte, wenn auch ein wenig in die Jahre gekommene Hinterkopf eines Mannes [...]. ${ }^{66}$ Der Anblick war zu indiskret, als daß ein wohlerzogener Zuschauer nicht hätte den Bildschirm sofort abschalten sollen. $(B A, 200)$

Natürlich wäre auf dem Bildschirm nur der Hinterkopf (bzw. Deters insgesamt von hinten) zu sehen, doch durch den Verweis auf $V G$ werden die zugehörigen Konnotationen aufgerufen (für den kundigen Leser wäre der explizite Hinweis noch nicht einmal nötig): schon dort steht der Hinterkopf als ein komplexes Motiv für die Schwierigkeit, sich selbst zu beobachten. ${ }^{67}$

Die Bewertung dieser Analyse von Beobachtungsnetzen erfolgt bei Malsch wie explizit angekündigt mit soziologischem Blickwinkel, er liest den Roman »als soziologische Aussage ${ }^{68}$. Dementsprechend nimmt er an, dass Herbst »die soziologische Einsicht [radikal ernst nimmt], dass es keine über der menschlichen Gesellschaft stehende Beobachterperspektive geben, dass Gesellschaft nur von innen beobachtet und beschrieben werden kann ${ }^{69}$. Ähnliche Formulierungen in dieser Hinsicht sind, dass Herbst »ernst [mache] mit der Binnenperspektive und [...] sich dem Blick aufs

65 Ebd., 74.

66 Der Satz ist tatsächlich elliptisch, da der Inhalt der `Screens` als Auflistung beschrieben wird.

67 Vgl. Abschnitt 1.3.1 auf Seite 55.

68 Malsch: »Vom Wiedereintritt des Autors in seine Geschichte«, 65.

69 Ebd., 46. 
Ganze ${ }^{70}$ verweigere oder dass es um »verschränkte Beobachtungsverhältnisse [gehe] unter Verzicht auf die Zentralperspektive « ${ }^{71}$.

Zusammenfassend formuliert Malsch seine These in Abgrenzung von ebenfalls möglichen Interpretationen nach »postmodernem Strickmuster «:

Ich lese diesen Roman dagegen als einen Versuch, Gesellschaft als Verschrän-

kung disparater Kommunikationsperspektiven zu dechiffrieren. ${ }^{72}$

Malsch kommt zu dieser Interpretation, da er die technisch erzeugten Welten aus der Sicht seines Forschungsfelds - der Sozionik - betrachtet. Er ignoriert bei all seinen detailreichen Beobachtungen jedoch weitgehend, dass Herbst sich nicht nur mit der realen Gesellschaft und den analog dazu programmierten künstlichen Gesellschaften beschäftigt, sondern dass seine Erzählung auch ganz entscheidend phantastische und mythologische Elemente enthält. So ist Malschs soziologischer Ansatz ein sicherlich sehr erhellender, aber auch stark verkürzender Beitrag. ${ }^{73}$

\section{Die Frage nach der Erzählinstanz}

Die von Malsch auf die Gesellschaft bezogenen Beobachtungsperspektiven und die ausgehebelte Zentralperspektive kann jedoch auch literaturwissenschaftlich betrachtet werden. In gewisser Hinsicht kann Ralf Schnells grobe Verortung der Anderswelt-Romane in seiner Geschichte der deutschsprachigen Literatur seit 1945 (2003) als Anschluss an diese Problematik angesehen werden. Er geht jedoch so weit zu sagen, Herbsts Romane würden »keine Erzähl-Instanz, und sei es nur die zur Reflexion des Erzählvorgangs « ${ }^{74}$, kennen; ein Erzähler (!) sei »nicht erkennbar «. »Keine poetische oder poetologische Instanz gebietet über diesen digitalen Kosmos. « ${ }^{75}$

Richtig ist, dass keine Erzählinstanz allen anderen übergeordnet ist und für Kohärenz sorgt. Es gibt jedoch gerade diverse Erzähler und Erzählinstanzen. Der begrifflich sehr schwammigen Kurzanalyse sind die obigen an Malsch angelehnten Analysen entgegenzuhalten..$^{76}$ Diese Aussagen lassen die Suche nach einem konventionellen personalen oder auktorialen Erzähler erkennen, übersehen wird aber, dass ein Großteil des Textes geradezu konventionell erzählt ist. ${ }^{77}$ Gerade in $T A$ sind fast alle handlungsreich erzählenden Passagen unkompliziert durch eine unpersönliche heterodiegetische Erzählinstanz geschildert, die als vom >Autorく Deters eingesetzt gedacht werden kann.

70 Malsch: »Vom Wiedereintritt des Autors in seine Geschichte«, 46.

71 Ebd., 73.

72 Ebd., 50.

73 Auch Reber betont, ihres Erachtens würden subjektive Schicksale im Vordergrund stehen, vgl. Reber: Formenverschleifung, 401.

74 Schnell: »Prosa der Moderne - nach der Postmoderne«, 604.

75 Ebd.

76 Auch Leiß wendet sich gegen diese Interpretation, indem sie die "[Unvereinbarkeit] der Stimmen und Perspektiven « ihrer Gesamtthese vom Widerstreit folgend als »Widerstreit der Erzählinstanzen« sieht, vgl. Leiß: Inszenierungen des Widerstreits, 231.

77 Vgl. auch Reber: Formenverschleifung, 377: »Thetis weist von allen Bänden die am einfachsten strukturierte Erzählform auf, die auch im Gegensatz zu den restlichen Bänden den zu vermittelnden Plot in den Vordergrund stellt, dem literarische Experimente untergeordnet werden«. 
Andere Passagen sind wieder durch Deters als Ich-Erzähler geschildert. In diesen finden sich auch die für Herbst typischen Sprecherwechsel innerhalb eines Satzes, wie beispielsweise: »Er wäre hingegangen, wäre ich noch Broker gewesen.« $(T A, 231)$ Beide Personalpronomen beziehen sich auf Deters, verweisen jedoch auf verschiedene Möglichkeiten und vielleicht auch verschiedene Welten. Auch werden Deters' Aussagen immer wieder infrage gestellt. Es stellt sich also an vielen Stellen die Frage, wer denn nun eigentlich spricht.

So gibt es Stellen, an denen ein im Grunde genommen auktorialer Erzähler Kommentare macht. Diese Erzählinstanz scheint alles zu wissen, wird aber weder als Instanz offfenbart, noch gibt sie alles preis. Dieser auktoriale Erzähler äußert sich vornehmlich in verbessernden, richtigstellenden und damit scheinbar erläuternden Einlassungen..$^{78}$

Deters ging nämlich nicht an die Bar. Von dort aus beobachtet er sich nur. (TA, 377)

Er hatte geträumt, ja, aber die Wahrheit. Und war dennoch heimgekommen, war wirklich, in des Wortes emphatischer Bedeutung, mit dem ICE von Hannover nach Berlin gefahren, hatte vorher wirklich Clara Witten getroffen, [...] war wirklich am Hackeschen Markt, der wirklich Hackescher Markt gewesen, in die Tram gestiegen [...]. $(B A, 167)$

In beiden Fällen werden die Erlebnisse von Deters kommentiert. Beiläufige Wörter wie `nämlich oder `wirklich zeigen an, dass es eine andere, feste Wahrheit zu geben scheint. Teilweise wird auch durch den Konjunktiv mitgeteilt, dass die vorliegende Erzählung gerade nicht die Wahrheit wiedergibt, sondern eine andere Möglichkeit oder Variation:

Wäre Deters konsequenter gewesen, es wäre ihm die Idee automatisch gekommen, daß es solche Schleusen nicht nur zwischen den Stadtteilen gab. (TA, 134)

Also wenn dies Buenos Aires w a r. Das war es nicht, aber wenn, [...]. (BA, 55)

In all diesen Fällen scheint es jemanden zu geben, der mehr weiß als alle Figuren und auch der Leser. Diese Instanz befindet sich eigentlich auf einer Meta-Ebene wie ein Beobachter zweiter Ordnung. Sie beobachtet vor allem Deters dabei, wie er sich die Anderswelt ausdenkt, und später auch Herbst, wie er sich in der von ihm (mit)programmierten $>$ Welt $`$ zurechtzufinden versucht.

Schließlich sind noch bestimmte textuelle wie paratextuelle Elemente anzuführen, die auch keinem `Urheber` zugeordnet werden können. So werden Erzählpassagen in

78 Schnell hat kürzlich in einem weiteren literaturgeschichtlichen Überblick die oben genannten Beschreibungen etwas modifiziert. Dort schreibt er: "[Die Anderswelt-Trilogie] kennt keine auktoriale Erzähl-Instanz, ihre Orte sind entwirklicht, die Figuren besitzen keine Identität, und die Handlung bietet keinen roten Faden. (Ralf Schnell: »Von 1945 bis zur Gegenwart. Romane der Postmoderne«, in: Volker Meid (Hg.): Geschichte des deutschsprachigen Romans, Stuttgart 2013, 705-734, hier: 734.) Auch diese veränderte Beschreibung ist meines Erachtens zu verkürzt, um aussagekräftig zu sein, und zudem nicht korrekt, wie an den hier folgenden Beispielen deutlich werden dürfte. 
$B A$ immer wieder mitten im Satz oder gar Wort unterbrochen durch anscheinend wirre Zeichenfolgen:

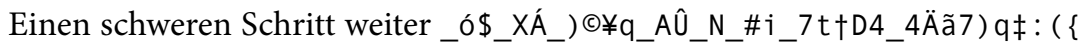

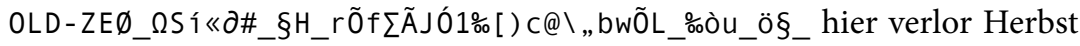
Hans Deters auf seinen Beelitzer Monitoren. $(B A, 16)$

Einer Schilderung von Deters' Erkundungen folgt also die Beschreibung von Herbst. Nach wenigen Zeilen folgt wieder eine ähnliche Zeichenfolge und die Schilderung geht mit Beutlin weiter. Angedeutet wird damit eine Störung in den Vernetzungen zwischen den Welten (vgl. BA, 162). Die Zeichenfolge ergibt vermutlich keinen Sinn, ist aber auch nicht einem "zufälligen Herumtippen auf den Tasten " 79 entsprungen, da die Zeichen teils sehr ungewöhnlich sind. Es erzeugt eher den Anschein eines »Konvertierungsproblem $[\mathrm{s}] \ll^{80}$ von Zeichensätzen und damit eines technischen Problems. Wieder stellt sich die Frage aus welcher Perspektive diese nun aufgezeichnet werden. Gleiches gilt für eine weitere Störung, die sich am Ende des Romans andeutet, wenn Wörter und Sätze immer weiter aufgelöst werden, fragmentarisch wiedergegeben, sodass sogar Lücken im Text stehenbleiben (vgl. besonders $B A$, 266f.). Jürgensen weist zudem auf die vielfältigen paratextuellen Elemente in $B A$ hin - das Gesamtmotto, Zwischenmotti (alles Zitate), Zwischentitel der einzelnen Kapitel, wobei noch die Fußnoten mitangeführt werden könnten -, »die eine Lektürelenkung suggerieren [...], aber bezeichnenderweise bei der Orientierung im Text kaum helfen. ${ }^{81}$

Durch die Auflösung der Beobachtungshierarchie bei der Auflistung der Bildschirme wird eine auktoriale Position zwar nicht direkt, jedoch generell destruiert. Es wird zudem nie deutlich, um was für eine Art von Instanz es sich handelt und wo sie sich befindet (d. h. auf welcher Ebene der Erzählkommunikation). Ihre Auktorialität bzw. >Allwissenheit` wird immer nur angedeutet, die souverän vorgebrachten Behauptungen werden niemals verifiziert. Versucht man, den aus Stanzels Typologie stammenden, umstrittenen Begriff der Auktorialität mit dem Vokabular der modernen Narratologie (in der Folge Genettes) zu fassen, wird das Problem deutlich: es handelt sich bei dem Erzähler sicher nicht um eine Figur der erzählten Welt, folglich ist es ein heterodiegetischer Erzähler. Doch ist er extra- oder intradiegetisch? Sprich: auf welcher Ebene befindet er sich? Nimmt man als Erläuterung für den Begriff »heterodiegetisch « die Formulierung »keine Figur der erzählten Welt « ${ }^{82}$, dann wird angesichts der dargelegten Multiplikation der Welten die Schwierigkeit deutlich, dieses Kriterium anzulegen. Ein auktorialer Erzähler »scheint« - nach Stanzel - »auf den ersten Blick mit dem Autor identisch zu sein ${ }^{83}$. Selbst wenn schon Stanzel gleich auf die Unterscheidung zwischen Autor und Erzähler hinweist, ist dies doch die Erläuterung, die dem Begriff den Namen gibt. In $B A$ wird nun genau damit gespielt. Es wird trotz aller Debatten in der Literaturwissenschaft nahegelegt, dass es sich hier um

79 Reber: Formenverschleifung, 407.

8o Ebd.

81 Jürgensen: »Unwirkliche Städte, unwirkliches Ich«, 111.

82 Martinez / Scheffel: Einführung in die Erzähltheorie, 82.

83 Franz K. Stanzel: Typische Formen des Romans, Göttingen 1964, 16. 
Autorkommentare handelt. In einer Fußnote werden Deters' und Brogliers Gedanken und Überlegungen kommentiert und mit dem Zusatz versehen: »Späte Anm. der Fiktionäre.« $(B A, 152 \mathrm{FN} \mathrm{16})$ Die Fiktionäre werden an anderer Stelle als »Herbst \& Deters « $(B A, 83)$ kenntlich gemacht. Ob es sich dabei um Herbst, den Programmierer, oder Herbst, den realen Autor, handeln soll und wie das Verhältnis zu Deters eigentlich ist, wird offengelassen. Zudem hat der reale Herbst in seiner Wohnung in Berlin angeblich ebenfalls ein solches Schild (auch auf seiner Website) ${ }^{84}$ Durch die autofiktionalen Verweise, also die Verweise auf die Welt des realen Autors Herbst wie, um bei den Fußnoten zu bleiben, der Hinweis auf Maike Albaths Rezension ${ }^{85}$ (vgl. $B A, 246)$-, wird dies noch weiter nahegelegt. Doch eben auch nur das. Ohne dass klar ist, auf welcher Ebene sich der mysteriöse Kommentator befindet, kann er auch nicht als zuverlässig eingestuft werden. Die als `wirklich ‘ dargestellten Umstände sind trotz ihrer Bestimmtheit im Tonfall nicht perspektivisch einzuordnen. ${ }^{86}$

Wie bereits dargestellt ist jedoch anzunehmen, dass die beschriebene Auflösung der Beobachtungshierarchie weniger gesellschaftsbezogen als >erkenntnistheoretisch zu sehen ist. Stärker noch als bei den Metalepsen, bei denen der Schluss naheliegt, sich als Leser zu fragen, wo die Grenzen der eigenen Welt liegen, wird in Bezug auf die Beobachtung eindrücklich gezeigt, dass es keine Zentralperspektive, sondern nur Binnenperspektiven gibt. Das logisch nicht erklärbare Durcheinander an Welten und Perspektiven, das auf phantastische Weise mit realistischen Erklärungsmustern bricht, wird nie aufgelöst. Es wird keine letztgültige Perspektive aufgeführt, die ein kohärentes Ganzes präsentiert. Dementsprechend kann der Umgang mit der angedeuteten Erzählinstanz als ıgnostisch gesehen werden: aus der Sicht der Figuren wie der Leser kann nicht geklärt werden, ob es diese Instanz gibt oder ob es sie nicht gibt. Dass Herbst »alle Standorte des Beobachtens, Subjektivierens und Perspektivierens verlassen $\aleph^{87}$ habe, kann jedoch gerade nicht behauptet werden.

\section{Der Autopoiesis-Begriff}

Schnell setzt der von ihm postulierten `Auflösung $`$ oder `Nicht-Existenz $\triangleleft$ der Erzählinstanz zudem den Begriff der Autopoiesis entgegen.

Die Abgründe und Abstürze [des digitalen Kosmos ohne poetische Instanz] sind autopoietischer Art. Das Erzählsystem generiert sich selbst. ${ }^{88}$

Seine [Herbsts] Erzählinstanz hat sich in der Immanenz simultaner Möglichkeiten aufgelöst. Die Selbstreflexivität ist konstitutiver Bestandteil des autopoietischen Systems geworden. ${ }^{89}$

Angesichts der sehr blumigen und tautologischen Formulierungen könnten diese als unpräzise Verwendung eines Modeworts abgetan werden. Schnell gibt dem Begriff

84 Vgl. URL-23, 22. Sep. 2012, sowie http://www.die-dschungel.de/ANH/main.html.

85 Vgl. Albath: »Der götterhaften Giftbrühe entstiegen«.

86 Vgl. dazu auch Kreknin: Poetiken des Selbst, 368.

87 Schnell: »Prosa der Moderne - nach der Postmoderne $\lll, 605$.

88 Ebd., 604.

89 Ebd., 605. 
jedoch als übergeordneter Bezeichnung für Herbsts Ästhetik (»Digitalismus bzw. Autopoiesis $~^{90}{ }^{\circ}$ ) einen besonderen Stellenwert, den er in eine Reihe mit entsprechenden Bezeichnungen für Ransmayrs, Handkes und Jelineks Schreibweisen als Beispiele für `nach-postmoderne « Ästhetiken aufführt. Zudem wird in der Folge von anderen mehrfach auf diesen Begriff verwiesen, ohne jedoch über die Wiederholung von Schnells Aussage hinauszugehen..$^{91}$ Daher ist kurz darauf einzugehen.

Anfang der 1970er von den Neurobiologen H. R. Maturana und F. J. Varela geprägt, wurde der Begriff Autopoiesis vor allem durch Luhmann zu einem zentralen Begriff in seiner Ausprägung der Systemtheorie. In der Literaturwissenschaft ist er bislang eher als Modewort zu sehen und noch nicht in klarer Verwendungsweise etabliert. Während bei Luhmann das gesamte Sozialsystem `Kunst $`$ ein autopoietisches System ist, ${ }^{92}$ wird das Konzept in der systemtheoretisch orientierten Literaturwissenschaft durchaus auch auf die Analyse von Einzeltexten angewandt. Dabei liegt der Fokus dann vor allem auf innertextlichen Strukturfragen oder solchen der Gattung. ${ }^{93}$ Andere verwenden den Begriff ohne theoretische Fundierung nur aufgrund der wörtlichen Bedeutung - >Selbsterschaffung - des aus griechischen Wortstämmen gebildeten Neologismus. ${ }^{94}$ Insgesamt ist fraglich, worin der Begriff über den der Selbstreferenzialität hinausgeht und ob er einen Mehrwert bringt.

Es stellt sich daher die Frage, was mit Autopoiesis eigentlich gemeint ist und welche Kennzeichen als grundlegend für ein solches System zu gelten haben. Bei Luhmann (im direkten Anschluss an Maturana) steht im Konzept der Autopoiesis beispielsweise die Geschlossenheit des Systems und die Unterscheidung und Abgrenzung von der Umwelt an zentraler Stelle. ${ }^{95}$ Bei der Erzählkonstruktion in $B A$ stellt sich allerdings angesichts ihrer gewollten Unübersichtlichkeit und ihrem paradoxalen Aufbau die Frage, ob es überhaupt einen Systemcharakter hat, ${ }^{96}$ geschweige denn, dass es sich

90 Schnell: »Prosa der Moderne - nach der Postmoderne«, 602.

91 Vgl. Jürgensen: »Unwirkliche Städte, unwirkliches Ich «, 109; Giacomuzzi: »Die ১Dschungel.Anderswelt und A. N. Herbsts >Poetologie des literarischen Bloggens «, 142.

92 Vgl. beispielsweise Niklas Luhmann: »Das Kunstwerk und die Selbstreproduktion der Kunst«, in: Hans Ulrich Gumbrecht/K. Ludwig Pfeiffer (Hg.): Stil. Geschichten und Funktionen eines kulturwissenschaftlichen Diskurselements, Frankfurt am Main 1986, 620-672, hier: 623.

93 Vgl. beispielsweise Thomas Klinkert: "Fiktion und Autopoiesis. Überlegungen zum epistemischen Status der Literatur am Beispiel von Don Quijote«, in: Hartmut Schröder / Ursula Bock (Hg.): Semiotische Weltmodelle. Mediendiskurse in den Kulturwissenschaften, Berlin 2010, 303-325, 320-322, und Thomas Klinkert: »Autopoiesis. Chrétien de Troyes«, in: Niels Werber (Hg.): Systemtheoretische Literaturwissenschaft. Begriffe - Methoden - Anwendungen, Berlin / New York 2011, 59-76.

94 Dies gelingt nur in unterschiedlichem Grade überzeugend: vgl. Hermann Korte: »Schreib-Arbeit. Literarische Autorschaft in Kafkas Tagebüchern«, in: Heinz Ludwig Arnold (Hg.): Franz Kafka, 2., gründlich überarbeitete Aufl. (Text + Kritik-Sonderband), 2006, 254-271, hier: 264, und Nathalie Groß: Autopoiesis. Theorie und Praxis autobiographischen Schreibens bei Alain Robbe-Grillet, Berlin 2008, 15f., 58, 215, 348.

95 Vgl. Klinkert: »Autopoiesis«, 63 f.

96 Dagegen spricht, dass keine Kohärenz vorliegt. In Bezug auf die obige Zuordnung zur phantastischen Literatur in Anschluss an Durst, ist darauf hinzuweisen, dass er diese als »Nichtsystem " definiert. Ein "gültiges Realitätssystem « kann hier »nicht formuliert « werden, da sich (mindestens) zwei Realitätssysteme im Widerstreit befinden. Vgl. Durst: Theorie der phantastischen Literatur, 116f., 100. 
um ein geschlossenes System handelt. Durch die gewichtige Position autofiktionaler Elemente und expliziter Bezüge auf die Realwelt des Autors wird die ausschließliche Selbstreferenzialität infrage gestellt.

Selbst wenn nun abseits von theoretischer Fundierung nur die wörtliche Bedeutung zugrunde gelegt wird, ist ein Mehrwert der Bezeichnung nicht auszumachen: weder erschaffen sich die Welten in $B A$ selbst (sie werden entweder programmiert oder phantasiert), noch erschafft sich das Erzählsystem: in der realen Kommunikationssituation ist es immer noch der reale Autor, der das System zusammensetzt; und innerhalb des Textes sind - wie oben ausgeführt - mehrere Erzähler zu erkennen, nur eben können die Verwicklungen des Systems nicht hierarchisch und kohärent aufgelöst werden. Wie in einer unendlichen Schleife schließen Erzählebenen aneinander an. Damit liegen Selbstreferenzen innerhalb der Erzählung vor, doch wird nichts aus sich selbst heraus geschaffen.

Die Frage, ob ein Mehrwert des Begriffs Autopoiesis für das Verständnis der Erzählweise von $B A$ besteht, setzt meines Erachtens zum einen eine Klärung der Verwendungsweise des Begriffs in der Literaturwissenschaft sowie eine systemtheoretisch fundierte Untersuchung des Textes voraus. In der bisher im Zusammenhang mit Herbst verwendeten Weise wirft er mehr Fragen auf als er beantworten würde.

\subsubsection{Kybernetik im Roman}

Die Terminologie von der Beobachtung n-ter Ordnung, die Malsch ins Spiel bringt, stammt aus der Kybernetik zweiter Ordnung, einer von dem Biophysiker Heinz von Foerster geprägten Ausrichtung von Kybernetik und Systemtheorie, die den Beobachter einschließt. Der Konzentration auf das Zusammenspiel der Beobachterperspektiven folgend, bietet sich eine solche Deutung des Romanuntertitels $B A$ (»Kybernetischer Roman $«)$ an. ${ }^{97}$

Dass Herbst eine solche Deutung intendiert hat, ist jedoch fraglich. Zwar bezieht er sich an einer Stelle in $B A$ auf Begriffe, die mit der Kybernetik (erster Ordnung) in Verbindung gebracht werden können. In einer Fußnote, die sich auf den Begriff >Avatar bezieht, wird auf die Verbindung der verschiedenen Ebenen und ihrer erzählenden und beobachtenden Figuren hingewiesen: In Deters `stecke »nicht nur Herbst (und Beutlin), sondern auch Laupeyßer und Falbin [...]: Netzwerke sind Regelkreise; es realisiert sich in ihnen die newton-physikalisch unmögliche Wechselwirkung." (BA, 33) Der indirekte Hinweis auf die Kybernetik ist an dieser Stelle jedoch aufgrund der begrifflichen Ungenauigkeit ${ }^{98}$ eher unergiebig und eine solche wenn auch indirekte Bezugnahme auf die Wissenschaft singulär. Wichtiger ist an diesem Zitat noch einmal

97 Auch Scherer bezieht sich unter Verweis auf Malsch darauf, vgl. Scherer: »Alban Nikolai Herbst $[K L G] \ll$.

98 Vgl. Genaueres dazu in Abschnitt 7.3 ab Seite 346. Sehr vage ist auch die Überlegung von Jürgensen, es werde durch den Untertitel der "Systemgedanke[] « betont und "ein solches System " solle »der Gattungsbezeichnung zufolge [...] vorliegen beziehungsweise zumindest simuliert werden« (Jürgensen: »Unwirkliche Städte, unwirkliches Ich«, 105). Kritisch sieht die Verbindung Bernd Graff, der als bisher einziger die Verwendung des Begriffs hinterfragt und sie ebenfalls für unpräzise hält, vgl. Bernd Graff: »Aus dem Ruder gelaufene Elementarteilchen «, in: Süddeutsche Zeitung, 16. Nov. 2001. 
die explizite Benennung des Phänomens, dass die Konstruktion der Welten als ein Netzwerk gesehen wird, in dem Wechselwirkungen stattfinden. Es ist keine durchgängig hierarchische Struktur vorhanden. Was geschaffen wurde, kann auch auf den Schöpfer zurückwirken. Welcher Art die Verbindungen sind, über die die Prozesse ablaufen - ob datisch/informatisch oder phantastisch -, wird nicht thematisiert; das Prinzip des Aufbaus aber bestätigt.

Ansonsten ist Herbsts Verständnis des Begriffs geprägt durch die vage Verbindung mit Computern, informatischen Simulationen und Internet. ${ }^{99}$ Die Charaktere oder Figuren in den simulierten Welten sind aus Sicht von W3 »kybernetische Geschöpfe» ( $B A, 114$, vgl. auch 178f.) und Gebäude oder Orte dort »kybernetische Entitäten« ( $B A$, 116); die Arbeit am Computer ist ein »kybernetische[r] Arbeitsplatz« $(B A, 120)$, das Programmieren manchmal ein »kybernetische[r] Trick « $(B A, 149)$ und der Programmierer Lerche wird als »Kybernetiker» $(B A, 201)$ bezeichnet.

Es wird also nicht explizit erklärt und daher auch nicht ganz eindeutig, warum $B A$ nun ein >kybernetischer Roman sein soll. Die phantastischen Elemente des ,fantastischen Romans $T A$ finden sich auch weiterhin in $B A$. Worin sich $B A$ nun vom Vorgängerroman absetzt, sind zum einen die Betonung und Multiplizierung der Beobachterperspektiven, die unter die Bezeichnung Kybernetik gestellt werden könnten, zum anderen das Hinzukommen der Simulation nicht nur in bioinformatischer Weise von Umgebungen und androiden Robotern, sondern ganzer Welten im Computer. Beide Aspekte könnten die Verwendung des Untertitels begründen.

99 Weitere Nachweise auch in den Aufsätzen und im Weblog siehe Abschnitt 7.3 "Der Kybernetikbegriff« ab Seite 345 . 
Teil IV

Die Poetik 



\section{Kybernetischer Realismus}

\subsection{Einleitung}

Herbst entwickelt seine Poetik kontinuierlich seit Jahrzehnten; seit Beginn seines belletristischen Publizierens begleiten öffentliche poetologische Überlegungen sein Schreiben. Trotz zahlreicher Veröffentlichungen ist sie jedoch »keine ausformulierte Poetik ${ }^{1}$, er bezeichnet sie selbst als eine "vorläufige Ästhetik $\aleph^{2}$, die aus ihren eigenen Überlegungen heraus niemals abgeschlossen sein kann. Dadurch ergeben sich auch kleinere Widersprüche, allerdings eher in einzelnen Aussagen. Die übergreifenden Themen sind erstaunlicherweise von Anfang an auszumachen, wie im Folgenden zu sehen sein wird. Einzelne Aspekte sind durch externe historische Entwicklungen wie den Durchbruch von Computer und Internet hinzugekommen und haben sich erstaunlich passend in die bereits bestehenden poetologischen Anschauungen eingefügt.

In den 1990er Jahren waren es zwei Preisreden, in denen Herbst anfing, seine Poetik genauer auszuarbeiten (Grimmelshausen-Preis 1995, Phantastikpreis der Stadt Wetzlar 1999) ${ }^{3}$. Daneben sind auch Radioessays zu von ihm bewunderten oder präferierten Schriftstellern zu nennen, die er auch nutzt, um seine eigenen Positionen darzustellen. Doch erst in den 2oooer Jahren hat er begonnen, programmatische Essays in Folge zu veröffentlichen (v. a. drei größere Aufsätze unter dem gemeinsamen Titel »Poetologische Thesen«, dann »Das Flirren im Sprachraum« sowie »Die anthropologische Kehre «) ${ }^{4}$. 2007 gipfelten diese Bemühungen in den Heidelberger Poetikvorlesungen, die unter dem Titel Kybernetischer Realismus publiziert wurden. ${ }^{5}$ Darin finden sich teils konkreter gefasste oder weitgehender modifizierte Varianten von Thesen und Formulierungen aus den vorherigen Publikationen, weshalb die

1 Schütte: »Erzählen für morgen«, 125.

2 Alban Nikolai Herbst: »Poetologische Thesen III. Intensität oder Die Ambivalenzen«, in: L. Der Literaturbote 18/72 (2003), 40-52, hier: 52.

3 Alban Nikolai Herbst: "Grimmelshausen-Preisrede zum 15. November 1995«, 1995, URL: http: //www.die-dschungel.de/ANH/txt/pdf/grimmelshausen_rede.pdf, Alban Nikolai Herbst: »Rede aus Anlaß der Verleihung des Phantastik-Preises der Stadt Wetzlar zum 16. September 1999 gehalten von einem Feinde«, 1999, URL: http://www.die-dschungel.de/ANH/txt/pdf/phantastik_rede.pdf.

4 Alban Nikolai Herbst: »Poetologische Thesen I. Das realistische Dilemma oder Die `Menschlichkeit «", in: L. Der Literaturbote 18/69 (2003), 34-51; Alban Nikolai Herbst: »Poetologische Thesen II. Das experimentelle Dilemma«, in: L. Der Literaturbote 18/70 (2003), 46-55; Herbst: »Poetologische Thesen III«; Alban Nikolai Herbst: »Das Flirren im Sprachraum«, in: Zettelkasten 23 (2004), 11-35; Alban Nikolai Herbst: »Die anthropologische Kehre. 42 Partikel«. Vortrag im Rahmen der Tagung >Medienkonzepte und Medieninnovation 1950-2000<, Universität Siegen, 16. Dezember 2005, URL: http://www.die-dschungel.de/ANH/txt/pdf/anthropolog_kehre.pdf.

5 Alban Nikolai Herbst: Kybernetischer Realismus. Heidelberger Vorlesungen, Heidelberg 2008. 
Vorlesungen tatsächlich als "zentraler Schritt des work in progress " gesehen werden können und als "Gelegenheit ${ }^{6}$, die verstreuten Überlegungen zu einer Poetik zu verdichten. Entsprechend fasse ich Herbsts Poetik insgesamt den Vorlesungen folgend als eine wenn auch nicht ganz homogene, so doch zusammenhängende Poetik unter dem Begriff >Kybernetischer Realismus`.

Parallel dazu entstanden Überlegungen im Weblog, die sich mit dem Internet als Medium und dem Literarischen Weblog als neuer Form beschäftigen und unter den Titeln »Weblog als Dichtung « bzw. Kleine Theorie des literarischen Bloggens als Aufsatz bzw. inzwischen auch als Buch erschienen sind. ${ }^{7}$

Typisch für Herbst ist die Formenvielfalt der Textsorten, in denen die Poetik präsentiert wird: er stellt sie in Reden, Radioessays, programmatischen Aufsätzen, den explizit dafür vorgesehenen, aber von außen herangetragenen Poetikvorlesungen sowie im Weblog dar; mehr oder weniger implizit ist sie auch in seinen literarischen Texten zu finden, teils über konkrete Hinweise oder theoretische Überlegungen, die den manchmal hybriden Charakter der Erzählweise ergeben. Aber auch die Mikroformenvielfalt ist kennzeichnend: sie erfolgt durch ein Gemisch von systematischem Denken und poetischen Stilmitteln, durch »Begriffdefinierung, Zitatcollage, Essay, Polemik oder persönliches Bekenntnis « ${ }^{8}$ sowie literaturhistorische Übersicht. Je nach Bildhaftigkeit sind sie dabei mehr oder weniger gut verständlich (die Zitatcollagen ohne viel Erklärung beispielsweise im zweiten Teil der Vorlesungen grenzen doch und durchaus beabsichtigt - ans Literarische und werden dadurch wieder interpretationsbedürftig).

Im Folgenden werde ich versuchen, die Grundzüge der Poetik und ihre Grundlagen vor allem auf Basis der Vorlesungen nachzuzeichnen, also weniger die genaue Entwicklung nachzuverfolgen. Wo es nötig ist, greife ich aber auch auf ältere Texte zurück. Eine ausführliche Darstellung der Poetik ist angebracht, da es in dieser um verschiedene Grundthemen aus Herbsts Werk und Denken geht, auch um die Aspekte Identität und Realität, sein Menschen- und Wirklichkeitsbild, wie er es auch in seinen Büchern verwirklicht sieht. Dennoch ist die Darstellung auf diese beiden Aspekte zugespitzt und es wird nicht der Anspruch einer vollständigen Darstellung erhoben.

Insgesamt lassen sich folgende Themen ausmachen, die im Folgenden erörtert werden: Wirklichkeitsbegriff, Sexualität/Sinnlichkeit vs. Entkörperung, Autonomie des Textes vs. Intentionen/Bewusstsein des Autors, Form, Kunst vs. Moral, Gesellschaftsbezug/Autonomie der Kunst, Kampf gegen Realismus, Monotheismus und den Satz vom ausgeschlossenen Dritten, Technik und Internet sowie Körpermutilation.

Herbst tritt in seinen Vorlesungen mit dem Anspruch an, die »Grundzüge einer allgemeinen nach-postmodernen Literaturästhetik« zu entwickeln, wie er sie für unabdingbar hält,

6 Schütte: »Erzählen für morgen«, 125.

7 Alban Nikolai Herbst: »Das Weblog als Dichtung. Einige Thesen zu einer möglichen Poetologie des Weblogs«, in: Markus A. Hediger / Benjamin Stein / Hartmut Abendschein (Hg.): Literarische Weblogs, Bern 2007, 9-30; Alban Nikolai Herbst: Kleine Theorie des Literarischen Bloggens. Die Dschungel. Anderswelt, Bern 2011 (im Folgenden zit. als KTLB).

8 Schütte: »Erzählen für morgen«, 125. 
»wenn vor allem die Prosa-Dichtung nicht restlos den entertainenden Bach hinabgehn und Literatur eine Bedeutung wiedererringen soll, die sie in den letzten drei Jahrzehnten verspielt hat und die über den puren Zeitvertreib einer zunehmend geringeren Leserschaft oder die Bedürfnisse eines, gesellschaftspolitisch gesehen, Orchideenstudiums hinausgeht « $(K R, 5)$.

Abgesehen von dem - wie er eingesteht - „Größenwahn « (ebd.), der dieses Anliegen durch seinen Anspruch auf Allgemeinheit auszeichnet, setzt er hier einige Dinge voraus. Bevor ich also zur eigentlichen Poetik komme, will ich kurz seine Einschätzung der bestehenden Kultursituation sowie seine Ansprüche an Kunst vorstellen. ${ }^{9}$

\subsubsection{Kultursituation}

Die Kultursituation betreffend sind vor allem zwei Themenkomplexe von Wichtigkeit, die Herbsts Ansicht nach gegenwärtig gegeben sind: auf der einen Seite eine Abnahme der Bedeutung von Literatur und - nicht identisch damit, aber doch damit zusammenhängend - der Niedergang des Buches als Medium; auf der anderen Seite die Forderungen des (Buch-)Markts und damit eine Vorherrschaft realistischen Schreibens.

In Bezug auf den ersten Komplex vertritt Herbst mehr oder weniger deutlich die These, dass die Schriftkultur »am Sterben « $(K R, 5$ und 37$)$ sei. Die Literatur verliert demnach ihre Leser und ihre Bedeutung; das Buch ist einerseits nicht mehr geeignet, einer angemessenen zeitgenössischen Ästhetik als Medium zu dienen, und wird andererseits durch andere Medien wie Film oder Internet ersetzt. Herbst hält jedoch trotzdem sowohl an Buch als auch an Literatur fest, dazu später mehr.

Der zweite Komplex umfasst eines von Herbsts großen Themen, den Kampf gegen realistische Literatur. Diese ist eines seiner großen `Feindbilder bzw. anders formuliert: er positioniert sich in Abgrenzung von ihr. Sie kommt als solche denn auch fast in jedem seiner poetologischen Texte vor. Am ausführlichsten sind die Vorbehalte im Essay »Poetologische Thesen I « von 2003 dargestellt, der den Untertitel »Das realistische Dilemma « trägt. Der Begriff Realismus wird insgesamt sehr ungenau verwendet, was Herbst auch eingesteht. Er bezieht sich dabei keineswegs auf den Epochenbegriff und auch nicht auf Sujets. Vielmehr meint er den epochenübergreifenden Stilbegriff bzw. die ästhetische Haltung, die sich auf die künstlerische Darstellung menschlicher Wirklichkeit bezieht. Die zugrunde liegende Vorstellung von Wirklichkeit sieht er als den eines »Konsens-Alltags « ${ }^{10}$. Er fasst dabei auch verschiedenste Genres zusammen, die sich vordergründig gar nicht auf einen solchen menschlichen Alltag beziehen müssen, wie beispielsweise bestimmte Ausprägungen von Science-Fiction, Krimis, den »Agenten- und Abenteuerroman « oder »Blumenromane[] von Verwirrung und Nöten des Herzens ${ }^{11}$. Diesen unterstellt er eine gleiche Auffassung von Wirklichkeit und Identität der Menschen. Vor allem zielt seine Kritik auf einen Großteil der

9 Ich werde im Folgenden nicht immer zwischen Kunst und Literatur differenzieren, da auch Herbst das nicht konsequent macht; die Rede ist aber eher bzw. vor allem von Literatur.

10 Herbst: »Poetologische Thesen I«, 35.

11 Ebd., 48. 
deutschsprachigen Nachkriegs- und Gegenwartsliteratur. Er zitiert diesbezüglich keine Beispielstellen, wie er das mit der von ihm favorisierten Literatur macht, nennt jedoch beiläufig etliche Namen, sodass die Zielrichtung klar wird: darunter sind Burkhard Spinnen, Uwe Timm und Birgit Vanderbeke, etwas früher zu verorten Dieter Wellershoff, Heinrich Böll und Siegfried Lenz, etwas später dann die "jüngste Renaissance ${ }^{12}$, der "Aufschwung, den die deutschsprachige Literatur seit Fall der Mauer nahm, inklusive Fräuleinwunder und sogenanntem ‘amerikanischem`Erzählen « ${ }^{13}$, also auch Pop-Literatur, namentlich nennt er hier Thomas Brussig, Judith Herrmann und Benjamin von Stuckrad-Barre. ${ }^{14}$ Dies ist wohlgemerkt eine ästhetische Positionierung. Zwar polemisiert er sehr verbissen gegen Böll, Lenz und Erich Fried an vielen Stellen; ${ }^{15}$ mit Spinnen ist er jedoch beispielsweise befreundet und hat ihn wie bereits erwähnt sogar auf dessen Wunsch in TA als Figur eingearbeitet; Stuckrad-Barre gesteht er in genanntem Essay zu, ein »hochbegabter Literat $~^{16}{ }^{\mathrm{zu}}$ sein.

An der Literatur, die Herbst unter der Bezeichnung Realismus fasst, kritisiert er mehrere Aspekte: das zugehörige Menschenbild, die Auffassung von Sprache sowie die Kommunikationssituation zwischen Autor und Leser. Der Mensch, aber auch die Sprache, würden nicht als sich entwickelnd, als prozessual aufgefasst, vielmehr erlebe sich der Mensch »in jedem Moment seines Lebens als immer schon >fertig, [...] - sozusagen als ein Auto, das die Zeit wie eine Straße befährt « ${ }^{17}$. Eine Infragestellung dieser gefestigten Selbstbilder werde als Angriff auf die eigene Identität wahrgenommen, das Rühren an diesen Grenzen sei demnach ein Tabu. Die Annahme eines solchermaßen gesicherten Fundaments, eines autonomen Ichs, sieht Herbst als Voraussetzung für das Funktionieren der demokratischen Gesellschaft und ihrer Rechtsfähigkeit. ${ }^{18}$ Demokratie setze die bewusste "Entscheidungsfähigkeit des Einzelnen ${ }^{19}$ in allen Belangen voraus. Das Eingeständnis der Existenz unbewusster Prozesse und damit von Determiniertheit sei gefährlich für das demokratische System und für die (Begründung von) Moral. ${ }^{20}$

Die Sprache wiederum werde in der realistischen Literatur als eine Funktion verstanden. Jedes Wort hat demnach einen definitiven Sinn, es ist die Idee bestimmter unveränderlicher Inhalte. Sogenannte `schöne Sprache` werde allenfalls als Mehrwert angesehen, Klang und Form jedoch eher als störend empfunden, daher die Neigung zu Reduktion und die Forderung von Simplizität. Aufgrund der Idealisierung von Mensch und Sprache tendiere der Realismus »entweder zu Typisierung oder zur psychologischen Erklärung oder positivistisch, `einfach`, zur Schilderung

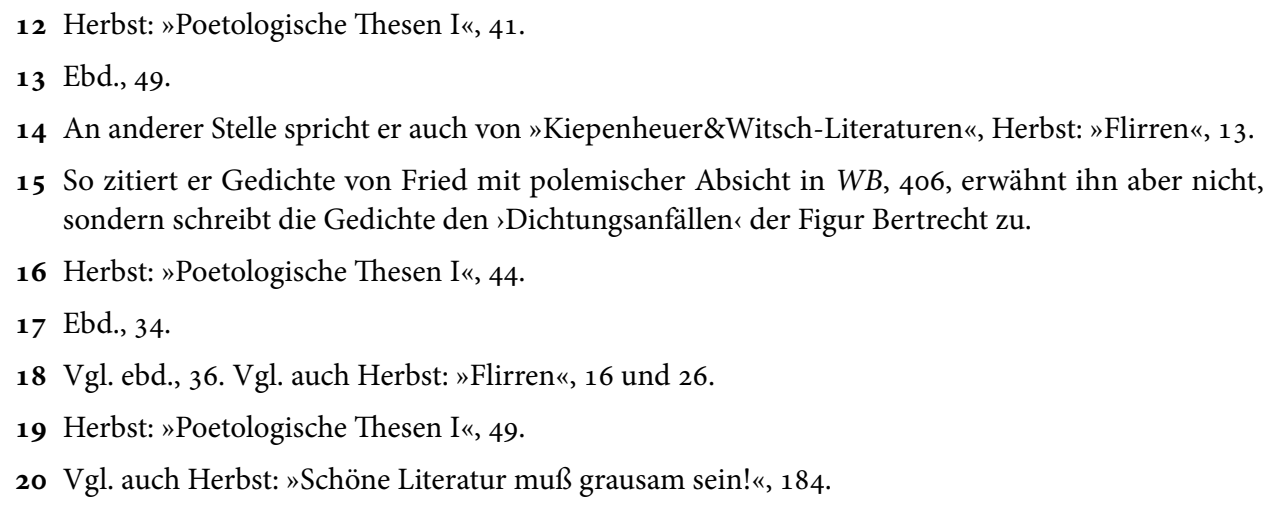


von Phänomenen. Und, versöhnlich ausgleichend, zur Ironie « ${ }^{21}$. Die beiden Aspekte Menschenbild und Sprache bilden die Grundlage für Herbsts Auffassung der Kommunikationssituation realistischer Literatur. Dafür greift er teilweise direkt auf freudsche Begriffe zurück, teils allgemein auf psychologisierende Sprache. Die realistische Literatur bediene das Tabu, das Ich-Ideal des Lesers nicht anzugreifen, sondern würde es gerade bestätigen. Der Leser verlange die literarische Identifikation, das sich Wiedererkennen im Gelesenen. So werde eine frühkindliche Situation wiederhergestellt: die Kompetenz des Autors, über seine Welt zu verfügen, werde vom Leser nicht bestritten. Psychologisierend sei es der Vater (bzw. die Mutter), der erzähle und dem der Leser glaube, ohne zu hinterfragen. Das »Sich-Versenken, das Sich-Überlassen « sieht Herbst als eine Form von Regression.

Man könnte sagen, der Leser möchte regredieren (= >sich wegträumen`), aber dabei `die Mutter`nach eigenen Wünschen bestimmen. Auf diesen Impuls können sich die Autoren verlassen. ${ }^{22}$

Oder als eine Art Bündnis formuliert:

Zwar lieferst du (’lieber Leser`) dich mir aus, aber ich werde alles dafür tun, daß es dir gut dabei geht; weil ich das garantiere, darfst du mich als `Mutterı, die das Regressionsmilieu herstellt, aber auch als $>$ Vater akzeptieren, der dir sagt, wo es langgeht. ${ }^{23}$

Dadurch werde die Botschaft transportiert, dass menschliches Leid eigentlich nicht existieren sollte, aber es ertragbar gemacht werden könne. Das Leid werde als eine äußere Situation dargestellt und der Mensch bzw. der Leser als Opfer bestätigt. Sein Fundament werde jedoch gestützt und damit das autonome Ich des Lesers erst ermöglicht. Die Erwartungen des Lesers seien zudem auf etwas gerichtet, »das sich schwarz auf weiß nachhause tragen läßt, nicht aber auf ein darüber hinausgehendes Staunen und Staunenwollen « $(K R, 13)$. Polemisch spricht Herbst von einem Virus, einem »Virus der Profanität, des etwas sofort Gebrauchen-können-müssen, letztlich der Kalkulierbarkeit von Erfahrung und Erkenntnis« (ebd.). Neu erkannt solle immer nur das werden, was bereits erkannt worden wäre, was wiederum einen Regress darstelle. Für den Leser sei das zwar beruhigend, aber einen Reifeprozess könne es nicht ermöglichen. ${ }^{24}$

Wichtig in der Situationsbeschreibung bzw. -interpretation, die Herbst vorbringt, ist im Anschluss an diese Kommunikationsstrukturen auch das Stichwort des Marktes. Im Rückgriff auf Marx und Adorno sieht er den Markt als vorherrschend in der Festlegung dessen an, was der Kunst möglich ist. Die gerade beschriebene Passivität des Lesers in der Kommunikation des Leseprozesses passt zur von Herbst konstatierten Veränderung der Rolle des Lesers im Markt: er ist nicht mehr ein Empfänger

21 Herbst: »Poetologische Thesen I«, 35.

22 Ebd., 37.

23 Ebd., 38.

24 Herbst konzediert solche Neigungen auch für sich selbst - wenn auch möglicherweise nur argumentativ-ironisch. Das ändert jedoch nichts an seiner Schlussfolgerung: Wer sich als »intakte[] IchPerson[] « sehe und auch über solche lieber lesen wolle, habe "[s]eine Zeit nicht begriffen", Herbst: »Flirren«, 11. 
(oder auch Sender), sondern wird ausschließlich als Käufer von Ware angesehen. Autoren passen sich in ihrem Verhalten und Denken an den zugehörigen Begriff der Zielgruppe an, wodurch ein kreisförmiger Prozess der Bedürfniserhebung und Bedürfniserzeugung entsteht (vgl. $K R$, 9). Statt wie früher Eliten oder Oligarchen zu repräsentieren, bildet Kunst den Durchschnitt des Geschmacks der demokratischen Menge ab, es wird ein Mittelideal gebildet. Aus diesem werden kalkulierte Bestseller geformt. Dabei hat die Orientierung an der Mitte auch Auswirkungen auf die moralische Spannbreite der Möglichkeiten: literarische Veröffentlichungen dürfen nicht den moralischen Rahmen sprengen, der von den Vermarktungsmodalitäten festgelegt ist (vgl. $K R, 32 \mathrm{f}$.).

Auch stilistische Entwicklungen bezieht Herbst auf den Markt. Schreibweisen, die die Sprache beispielsweise Anfang des 20. Jahrhunderts oder auch Ende der 1960er Jahre entschlacken wollten und eine lebendige Alltagssprache verwendeten, eine »der Lebenswirklichkeit der Leser zugewandte Umgangssprache« $(K R, 7)$, hätten sich heute verselbständigt. Sie seien nun »den Interessen eines eben diese Lebenswirklichkeit bestimmenden Marktes zugeneigt« (ebd.) - was progressiv war, sei regressiv geworden.

\subsubsection{Kunstanspruch}

Die Forderungen, die Herbst an Kunst im Allgemeinen stellt, stimmen weitestgehend mit den Bestimmungen für eine eigene neue Poetik, den sogenannten Kybernetischen Realismus, überein. Werden diese Ansprüche nicht erfüllt, fällt es ihm schwer, die entsprechende Literatur überhaupt als Kunst einzuordnen. Es gibt jedoch durchaus auch nach seiner Einschätzung Kunst, die nicht mit dem Kybernetischen Realismus übereinstimmt. Daher soll es in diesem Abschnitt um die Funktionen von Kunst im Allgemeinen gehen, um die Aufgaben, die Kunst für Herbst zu erfüllen hat. Im nächsten Abschnitt sollen dann die grundlegenden Begriffe und Merkmale genauer ausgeführt werden, die den Kybernetischen Realismus selbst ausmachen.

Der Gegensatz zwischen den Ansprüchen, die Herbst von Kunst einfordert, und seiner Sicht auf die heutige Kultursituation ist wohl das widersprüchlichste Element seiner Poetik. Einerseits vertritt er die beschriebene pessimistische und fast schon resignative Sicht auf den Status quo, andererseits setzt er diesem geradezu hoffnungsvoll eine normative Poetik entgegen, die der aktuellen Situation entgegenwirken soll: Sie soll auf den Menschen zugehen und seine eigentlichen Bedürfnisse unterstützen. Auf diese Weise nimmt er für Kunst nach wie vor eine »kulturelle Leitfunktion « (KR, 5) in Anspruch, die entweder überhaupt erst etabliert werden müsste oder aber wiederhergestellt werden soll. In den Vorlesungen geht er davon aus, dass Literatur diese Rolle »in den letzten drei Jahrzehnten $(K R, 5)$ verspielt habe. Vorher konstatiert er jedoch weit pessimistischer, dass er "an die Leitfunktion der Dichtung nicht mehr glaube « und vor allem, dass seine favorisierten Romane »sie ohnedies nie gehabt « $^{25}$ hätten. Auch der bereits zitierte Anspruch an eine zeitgenössische Poetik, über einen "Zeitvertreib einer zunehmend geringeren Leserschaft oder die Bedürfnisse eines [...] Orchideenstudiums ( (ebd.) hinauszugehen, widerspricht der analysierten Entwicklung. Herbst ist sich dieses Widerspruchs bewusst und vertritt ihn auch, er hält

25 Herbst: »Poetologische Thesen III«, 40. 
jedoch trotz allem aus »Überzeugung« $(K R, 19)$ an der Bedeutung von künstlerischer Literatur und auch dem Buch als Medium fest. ${ }^{26}$

In diesem Zusammenhang grenzt Herbst Kunst von Unterhaltung ab, bezieht sich auch auf die Unterscheidung von sogenannten E- und U-Künsten, die er wieder stark macht. ${ }^{27}$ Die kulturelle Leitfunktion von Literatur sieht er als ursprünglich eine zeitliche; früher hätten literarische Avantgarden virulente Themen als erste aufgegriffen, heute hätten diese Aufgabe eher andere Medien wie Film und Internet übernommen. Unterhaltungsliteratur sieht er dagegen gar nicht recht als Kunst, sie würde ihre »widerständige, progressive Kraft unter der Macht der Vermarktbarkeit und des Labelings « $(K R, 6)$ verlieren. Um in Bezug auf Literatur diese Unterscheidung deutlich zu machen, verwendet Herbst bewusst den Begriff der Dichtung als »emphatische[r] Form hoher Literatur « ${ }^{28}$, die seinen Kriterien für Kunstanspruch entspricht.

Die in der im eben angeführten Zitat verwendete Kategorie des Widerstands (>widerständige $\mathrm{Kraft} \iota$ ) nimmt bei ihm bei der Bestimmung dessen, was Kunst ist, einen wichtigen Platz ein. Gegen was der Widerstand dabei genau gerichtet ist, wird nicht klar benannt, er steht zunächst für sich selbst, ist ein "grundwirkende[s] Element aller Kunst « $(K R, 8)$. Die Ausrichtung lässt sich jedoch aus dem Kontext einigermaßen erschließen. Es ist Widerstand gegen leichte Konsumierbarkeit, gegen den Markt und seine rigiden Vorgaben, gegen das regressive Sich-Versenken. ${ }^{29}$ Der Zusammenhang von Regression und (fehlendem) Widerstand findet sich auch bei Horkheimer und Adorno im "Kulturindustrie«-Kapitel von $D d A,{ }^{30}$ doch verweist Herbst hier vor allem auf José Lezama Lima, der im Schwierigen, das Widerstand leistet, die Förderung des Erkenntnisvermögens sah. ${ }^{31}$ Auch innerhalb der Kunst sollen Gegensätze bestehen bleiben und nicht harmonisch angeglichen werden. Deutlich formuliert er: »Es geht um Störung. (32 $^{32}$ Die Forderung nach einem widerständigen Moment in jeder Kunst, ja die Aneinanderkettung der Kategorisierung als Kunst mit dem Aspekt des Widerstands, enthält zwangsläufig den Wunsch, etwas zu verändern. Wie oben in der

26 Letzteres aus Gründen der `Sinnlichkeit`, dazu später mehr.

27 Ein `Graben`, der in der Postmoderne nach einer Auffassung explizit überbrückt wurde, vgl. Leslie A. Fiedler: »Überquert die Grenze, schließt den Graben! Über die Postmoderne« [1968/69], in: Wolfgang Welsch (Hg.): Wege aus der Moderne. Schlüsseltexte der Postmoderne-Diskussion, Berlin 1994, 57-74. Interessanterweise sorgt gerade diese Unterscheidung auch heutzutage noch für Aufregung, vgl. Benjamin Stein: »Fallen im Kopf«, Turmsegler.net, 23. Nov. 2007, URL: http: //turmsegler.net/20071123/fallen-im-kopf.

28 Schütte: »Erzählen für morgen«, 126.

29 Während diese Zielbestimmung sicherlich zutrifft, wendet sich Herbst doch an anderer Stelle dagegen, überhaupt ein gerichtetes Ziel des Widerstands zu haben, weil er dieses nicht genau fassen oder definieren kann, vgl. Herbst: »Flirren«, 19.

30 Vgl. bspw. $D d A, 153$ : „Vergnügen heißt allemal: nicht daran denken müssen, das Leiden vergessen, noch wo es gezeigt wird. Ohnmacht liegt ihm zu Grunde. Es ist in der Tat Flucht, aber nicht, wie es behauptet, Flucht vor der schlechten Realität, sondern vor dem letzten Gedanken an Widerstand, den jene noch übriggelassen hat.«

31 Vgl. KR, 8. Der Hinweis findet sich auch in Alban Nikolai Herbst: »Der Füchsin auf dem Grund. Verbeugung vor Marianne Fritz«, in: Volltext 6 (2007), 6-7. An Marianne Fritz hat er gerade diesen Widerstand geschätzt.

32 Herbst: »Flirren«, 33. 
Diskussion um Judith Leiß' Interpretation ausgeführt, handelt es sich dabei nicht um das Vorbringen sozialkritischer oder gesellschaftspolitischer Meinungen. Aber zunächst beinhaltet das Moment des Widerstands eine intendierte Änderung des Lesers in seinem gewohnten Leseprozess. Auch wenn Herbst eine ausgesprochene Funktion von Kunst beispielsweise in der Form einer Darstellung moralischer Maximen abweist, so formuliert er doch Aspekte, die Funktionalitäten und erwünschte Auswirkungen von Kunst benennen. Kunst soll der Zeit entsprechen und diese mitformen, sie soll nicht nur Spiegel der Zeit sein. Auch diese Forderungen sind voraussetzungsreich. Der Zeit zu entsprechen meint die Aufnahme oder den Bezug zu aktuellen Auffassungen von Identität und Realität sowie zu virulenten Themen und bedeutenden Denkfeldern oder Wissenschaften. ${ }^{33}$ Interessanterweise und im Grunde im Widerspruch zu seinen Auffassungen ist hier zumindest impliziert, dass die momentane `Zeit oder Epoche überhaupt einigermaßen einheitlich gesehen werden kann. Die Zeit mitzuformen setzt ein bestimmtes Wirklichkeitsbild voraus, das die Möglichkeit einschließt, durch Literatur Auswirkungen auf das Denken der Leser und damit auch auf ihre reale Alltagswelt zu haben.

Zwei Aufgaben weist Herbst der Kunst zu, eine explizite und eine implizite. Explizit benannt und als von besonderer Bedeutung herausgestellt (»zu allererst einmal«) ist der Blick auf Kunst als »Bearbeitungsform von Traumata, Ängsten und Fantasien [...], an die es [sic!] sich auf andere Weise bannend und/oder lösend nicht herankommen läß $\mathrm{t}$ ( $(K R, 51)$. Mit dieser Überlegung schließt er deutlich an das antike Konzept der Katharsis an, das in seiner Poetik unter dem Perversionsbegriff eine wichtige Rolle spielt. ${ }^{34}$ Außerdem ist sie mit seiner Überzeugung von der Beziehung von Kunst zum Unbewussten des Autors verbunden. Die Vorstellung eines autonomen Ichs, wie Herbst sie als grundlegend für die realistische Literatur erachtet, sieht er als nicht mehr zeitgemäß an. Sowohl die Annahme eines Unbewussten im Menschen als auch die Steuerung von Verhaltensweisen durch Vererbung und Sozialisation oder physiologische Vorgänge und Instinkte legen die Determiniertheit oder zumindest das Fehlen von Autonomie im Menschen nahe.

Nicht eindeutig genannt, aber zu erschließen ist die zweite Aufgabe von Kunst, nämlich der Umstand, dass Herbst entgegen dem ersten Anschein ein mimetisches Verständnis von Kunst hat. In seinen Formulierungen wird deutlich, dass er letztlich eine Form von Wirklichkeit abbilden will. Das ist auch der Grund, warum es ihm in den Überlegungen zum Kybernetischen Realismus überhaupt um einen Realismus geht. Die Begründung für seine Ablehnung des oben bezeichneten realistischen Erzählens ist das zugrunde liegende Wirklichkeitsverständnis. Der mimetische Charakter von Kunst bezieht sich für ihn nur bedingt auf eine alltägliche Realität, vielmehr

33 Herbst sieht die Naturwissenschaften wie Physik und Chemie als besonders wichtige Prägungen der Kultur des 20. Jahrhunderts; auch wenn er sich gegen ein rein naturwissenschaftlich-logisches Denken wendet, seien sie in der Literatur zu verarbeiten, oder wie er formuliert »mitzupoetisieren « $(K R, 107$, auch 101). Der realistischen Literatur wirft er vor, diese Auseinandersetzung zu scheuen, siehe Herbst: »Poetologische Thesen I«, 46 FN 37; vgl. einen ähnlichen Vorwurf aus der naturwissenschaftlichen >Richtung` bei C. P. Snow: The Two Cultures: and a Second Look. An Expanded Version of the Two Cultures and the Scientific Revolution [1959], Cambridge u. a. 1969, 16.

34 Siehe unten Abschnitt 7.2.4 ab Seite 336. 
zielt sie auf eine dahinter liegende Wahrheit. Durch Kunst soll der Mensch, sei es der Leser oder der Autor, mit dieser Wahrheit konfrontiert werden. Kunst soll damit also einen Erkenntniszuwachs im Menschen befördern oder als eine Art von Bewusstseinserweiterung fungieren.

\subsection{Grundlagen des Kybernetischen Realismus}

Herbst präsentiert seine Poetik, wie er sie in den Heidelberger Poetikvorlesungen 2007 vorgestellt hat, in seinem wie er selbst sagt »Größenwahn« als »Grundzüge einer nach-postmodernen Literaturästhetik« $(K R, 5)$. Damit stellt er nicht nur die aus den Erfahrungen seiner eigenen poetischen Arbeit gewonnenen Auffassungen als mehr oder weniger konsistente Autorpoetik dar, sondern vertritt auch den Anspruch auf eine Gültigkeit über sein Werk hinaus, sofern denn seine eben dargestellten Ansichten geteilt werden, die den Anspruch an Kunst überhaupt betreffen. Die Vorlesungen kategorisiert er aufgrund dieses Anspruchs als »normativen Auftritt« $(K R, 6)$. Früher allerdings hatte er sich davor verwahrt, seine »Poetologischen Thesen « als "normative[] Ausschlüsse[] $\ll^{35}$ zu verstehen. Seine Poetik der Intensität stehe neben anderen Ansätzen und wäre nur auf diese bezogen zu denken. Mit Bezug auf das Absterben des Buches und der kulturellen Leitfunktion von Literatur kommentiert er vorläufig abschließend und seine teils heftigen Anwürfe relativierend: "was sterben muß, stirbt eh. Da braucht keiner nachzutreten.« (ebd.) ${ }^{36}$

Der literaturgeschichtliche Bezug seiner Poetik, d.h. die Bücher oder Autoren, bei denen er die gleichen Grundhaltungen erkennt, oder aber die, von denen er sich absetzen will, kann unterschiedlich eingeordnet werden. In seinen Poetologischen Thesen (2003) stellt er seine favorisierte Literaturauffassung als Abgrenzung von den Polen `realistisches Dilemma und `experimentelles Dilemma dar. Ersteres wurde bereits angesprochen, Letzteres stellt er in (sprach-)experimenteller Literatur fest, die zu konsequent in der Verfolgung der eigenen Prämissen gewesen sei, ১theoretisch`, >abstrakt<, >kalt ‘ und dadurch hermetisch wurde, ${ }^{37}$ und letztlich die Leser verloren habe. Damit ist nicht nur gemeint, dass niemand mehr die Texte lese, sondern dass der Bezug zum und auf den Menschen verloren gehe. Beiden Dilemmata soll seiner Ansicht nach ausgewichen werden.

In den poetologischen Arbeiten vor den Vorlesungen, in denen noch nicht von einem Kybernetischen Realismus die Rede ist, bezeichnet Herbst die Literatur, die er im Sinn hat und die dort noch stärker als eine bereits vorhandene erscheint, mit verschiedenen Begriffen. Recht neutral spricht er von seiner `favorisierten` Literatur, von 'phantastischer Literatur oder im Anschluss an einen Essay von Matthieu Carrière über Kleist ${ }^{38}$ von der `intensiven` (oder auch `kriegerischen`) Literatur. Hier einzuordnen ist auch der Begriff `Dichtung`, der im emphatischen Sinn künstlerisch geformte

35 Herbst: »Poetologische Thesen III«, 52.

36 Vgl. ähnlich Barbara Bongartz / Alban Nikolai Herbst: »Inzest oder Die Entstehung der Welt. Der Anfang eines Romanes in Briefen«, in: Schreibheft 58 (2002), hg. v. Norbert Wehr, 3-163, hier: 23.

37 Vgl. Herbst: »Poetologische Thesen II«, 49f., 52, und Herbst: »Poetologische Thesen III «, 49.

38 Mathieu Carrière: für [sic!] eine Literatur des Krieges, Kleist, Basel / Frankfurt am Main 1981. 
Literatur bezeichnet. Auffällig ist - vor allem im Kontrast zum oft vorkommenden Begriff der `phantastischen Literatur $<$ - das Auftauchen des Begriffs $>$ Realismus $<$ in der Bezeichnung der Vorlesungen. Er macht dann auch deutlich, dass es ihm keineswegs um eine Definition oder Ableitung von phantastischer Literatur geht, sondern vielmehr um eine »Neufindung « $(K R, 44)$ des Realismusbegriffs. Auf diese Neufindung ebenso wie auf die anderen Begriffe wird weiter unten noch genauer eingegangen. Genau definiert er die favorisierte Literatur nicht, doch tauchen einige Autoren und Buchtitel immer wieder in seinen verstreuten Ausführungen auf. ${ }^{39} \mathrm{Zu}$ nennen sind als seine $>$ üblichen Verdächtigen ${ }^{40}$ : Wolf von Niebelschütz' Der blaue Kammerherr (1949) und Die Kinder der Finsternis (1959), José Lezama Limas La expresión americana (1957, Die amerikanische Ausdruckswelt, dt. 1992), Louis Aragons Blanche ou l'oubli (1967, Blanche oder das Vergessen, dt. 1972), Vladimir Nabokovs Ada or Ardor (1969, Ada oder Das Verlangen, dt. 1974), Thomas Pynchons Gravity's Rainbow (1973, Die Enden der Parabel, dt. 1981) und weitere Romane von Pynchon, Miodrag Bulatovićs Ljudi sa četiri prsta (1975, Die Daumenlosen, dt. 1975), Günter Steffens’ Die Annäherung an das Glück (1976), Gerd-Peter Eigners Brandig (1985), Kazuo Ishiguros The Unconsoled (1995, Die Ungetrösteten, dt. 1996) sowie >die Lateinamerikaner` wie Borges, García Márquez oder Julio Cortázar und sicherlich auch noch Marianne Fritz' Dessen Sprache du nicht verstehst $(1985)^{41}$.

Angesichts dieser etwas deutlicher gewordenen >real existierenden` favorisierten Literatur ist der Anspruch auf Allgemeingültigkeit genauer einzuordnen. Dabei kann es sich nur um eine angenommene Übereinstimmung in zentralen Grundannahmen, d. h. auf einem abstrahierenden Niveau handeln, die zudem nicht explizit ist, sondern die er in der von ihm betrachteten Literatur wiedererkennt. Er spricht jedoch auch als Kennzeichen genauer von der Aufspaltung der Erzähler, die typisch für seine Werke seien. Diese Beschreibungen sind jedoch so spezifisch, dass er wohl kaum annimmt (und auch nicht sagt), sie müssten auch unbedingt bei anderen Schriftstellern zu finden sein. Ebenso wie er in den Vorlesungen deshalb auch bemerkt, es könne nicht um Vorschriften oder Gebote gehen, da diese so ihre »Kraft» $(K R, 6)$ verlören, bemerkt er früher, Literatur müsse auf eine »normierte Ästhetik« verzichten, da diese dem Grundmoment zuwiderlaufen würde: »Es geht um Störung. « ${ }^{42}$

39 Vgl. neben den poetologischen Texten und gelegentlichen Weblog-Erwähnungen auch Alban Nikolai Herbst: »Kanon der Autoren - Drei Fragen«, in: Heinz Ludwig Arnold (Hg.): Literarische Kanonbildung (Text+ Kritik-Sonderband), in Zsarb. mit Hermann Korte, München 2002, 329, 334, 336, sowie URL-24, 4. Jan. 2012-26. Jan. 2012. Bei Letzterem handelt es sich jedoch eher um (literarische) Kindheits- und Jugendprägungen, die nur teilweise die hier gemeinte Literatur abdeckt.

40 In chronologischer Reihenfolge, da eine Gewichtung kaum auszumachen ist. Außerdem ist anzumerken, dass es sich hierbei nur um die am häufigsten Genannten handelt; die Auswahl ist also etwas subjektiv.

41 Fritz fällt aufgrund ihrer immer wieder beklagten Unzugänglichkeit etwas aus dieser Reihe heraus. Herbst erwähnt sie aber ebenfalls sehr häufig und in seiner schriftlichen »Verbeugung « nach ihrem Tod wird deutlich, wie viel von seiner Poetik er in der ihren wiedererkennt. Vgl. Herbst: »Der Füchsin auf dem Grund«.

42 Herbst: »Flirren«, 33. 
Im Folgenden sollen nun die zentralen Grundannahmen, die wichtigsten Begriffe bzw. Aspekte der herbstschen Poetik genauer erläutert werden. Dabei handelt es sich um den frühen Begriff des `Flirrens`, der Ähnlichkeiten mit den `Bedeutungshöfen` aus den Vorlesungen aufweist; um den Begriff einer Möglichkeitenpoetik, der vor allem das Wirklichkeitsverständnis betrifft; um die Frage nach der Intentionalität des Autors, die die Bedeutung seines Unbewussten an zentrale Stelle stellt; um den Perversionsbegriff, der sich auf den antiken Begriff der Katharsis bezieht; um die Wendung gegen Ironie und zum Pathos; schließlich um den Zusammenhang von Technik und Mimesis und damit die titelgebende `Neufindung` des Realismusbegriffs.

\subsubsection{Das Flirren und die Bedeutungshöfe}

Der Begriff des Flirrens wird zwar in den Vorlesungen nicht gebraucht, vereinigt in sich jedoch schon mehrere zentrale Aspekte der Poetik. Die Gedankensammlung "Flirren im Sprachraum " (2001/2004), in der dieser Begriff entwickelt wird, nimmt in lockererer Form viele der Themen und Thesen sowohl aus den »Poetologischen Thesen « als auch aus den Vorlesungen vorweg. Das »Flirren im Sprachraum« ist eine originale Bezeichnung für das Ungefähre, was Herbst durch seine Darlegungen zu Adornos Nicht-Identischem, zu seinem eigenen Widerstand gegen den Satz vom Ausgeschlossenen Dritten (auf die beide im nächsten Abschnitt einzugehen ist) sowie mit Überlegungen zu sogenannten `semantischen Höfen $>$ zu beschreiben versucht. Immer geht es um ein begrifflich gerade nicht fassbares Phänomen, um einen nicht bewusst steuerbaren Mehrwert, der über den Inhalt hinausgeht ${ }^{43}$ und sogar potenziell über die Intentionen des Autors. Auch in diesem Kontext kommt er auf das Unbewusste des Autors zu sprechen, auf die nötige Offenheit des Autors gegenüber seinem eigenen Projekt. Das »Flirren« sei »ein sich selbst ins Unbewußte absteigen, ja: hinabwehen Lassen ${ }^{44}$.

In den Vorlesungen bezeichnet der Begriff `Bedeutungshof $\prec$ oder $>$ semantischer Hof ${ }^{45}$ ein ähnliches Phänomen, das jedoch noch deutlicher auf den Text selbst und dabei auf die Wort- oder Satzebene bezieht. Er steht vor allem den moralischen und politischen Botschaften entgegen, die durch Literatur vermittelt werden wollen, oder gar den Vorgaben des Marktes. Dichtung im emphatischen Sinn hat diesen gegenüber das Ziel, solche semantischen Höfe zu >registrieren` und »in künstlerische Bewegung zu setzen « $(K R, 10)$. Dabei handelt es sich um einen poetischen Mehrwert, der sich im Umfang sowohl auf Wörter als auch auf Sätze und Absätze beziehen kann.

Semantische Höfe können Halos um einzelne Wörter sein, sie sind aber viel öfter, und dies vor allem in der erzählenden Prosa, Halos um Sätze und um Absätze, strahlen weit stärker aus deren Rhythmik als von ihren tatsächlichen, d. h. funktionalen Bedeutungen ab. $(K R, 12)$

Der semantische Hof gehört damit neben der festen Bedeutung und Funktion zum Wort. Zur Erläuterung greift er auf Walter Benjamins Unterscheidung zwischen dem

43 Was an den Begriff >Konnotation « erinnert, der aber nicht weit genug geht.

44 Herbst: »Flirren«, 22.

45 Vgl. KR, 10-13 und passim. Meines Wissens führt Herbst den Begriff erstmals in Herbst: »Schöne Literatur muß grausam sein!«, 178, ein, lässt ihn dort aber gänzlich unerläutert. 
Namens- und dem Begriffsanteil eines Wortes zurück. ${ }^{46} »$ Der Name ist das, was ein Wort i s $\mathrm{t}$; der Begriff das, was ein Wort bezeichnen soll.« $(K R, 12)$ Während sich die realistische Literatur nach Herbst mit dem Begriff, also der bloßen Bedeutung, zufrieden gibt, geht es ihm um das >Wesen « des Wortes. Das kann den »Klang «, »Form « 47 und Rhythmus sowie auch sämtliche Konnotationen der Wörter und des Textes umfassen. Eine weitere passende Unterscheidung ist die von Inhalt und der »Form seiner Übermittlung « ${ }^{48}$. Das Unbestimmte, das die semantischen Höfe kennzeichnet, ist für Herbst das Wesentliche an Dichtung, was eindeutig dahinter zurücksteht ist "präzise Umsetzung einer Absicht, also [...] Intentionalität.« $(K R, 10)$

\subsubsection{Möglichkeitenpoetikı und der Satz vom ausgeschlossenen Dritten}

Ein schwer zu fassendes, aber immer wieder an zentraler Stelle stehendes Thema kann unter dem sonst nicht verwendeten Begriff »Möglichkeitenpoetik« $(K R, 46)$ subsumiert werden. Schwer zu fassen ist es, weil Herbst weder seine Begriffe noch die Zusammenhänge genau definiert, was allerdings auch in ihrer Aussage selbst, im >Flirren`, begründet ist (und in der von Adorno geprägten Begriffsskepsis). Im Anschluss an die Raummetaphorik der 2. Vorlesung kommt er auf das Thema zu sprechen:

Die Raumlosigkeit des kybernetischen Raums führt über die Bestimmungslosigkeit [...] zwar einerseits ins Haltlose (ins Beliebige, würden Kritiker sagen), andererseits aber nimmt sie Potentialitäten auf, Möglichkeiten, die sich erst aus den geschilderten Dynamiken ergeben oder eben nicht ergeben. Beides hat strategisch erst einmal den gleichen Wert. Eine solche Möglichkeitenpoetik zieht dem Satz vom Ausgeschlossenen Dritten den Boden unter den Füßen ganz ebenso weg, wie ihn die Konzepte fester, autonomer Identität verloren haben. $(K R, 45 \mathrm{f}$.

Zwei Begriffe werden an dieser Stelle angesprochen, die zentral für dieses Konzept sind: der Begriff der `Möglichkeit`sowie der Satz vom ausgeschlossenen Dritten.

Die >Möglichkeiten « werden an anderer Stelle »faktische[n] Er/Kenntnisse[n] $(K R$, 103) entgegengesetzt. In der Literatur würden also nicht nur (reale oder historische) Fakten berücksichtigt oder, anders ausgedrückt, Referenzen auf die reale Welt, sondern nicht realisierte mögliche Situationen oder Welten dargestellt. Aus dem Kontext lässt sich erschließen, dass Herbst mit `möglich`weniger die tatsächliche Möglichkeit oder Wahrscheinlichkeit einer Realisation meint. Ein Anschluss an Mögliche-WeltenTheorien ist also wenig sinnvoll, da in diesen logische Widersprüche per definitionem ausgeschlossen sind. Wichtig dagegen ist in diesem Zusammenhang die Unterscheidung von möglichen und fiktiven Welten. ${ }^{49}$ Herbst geht es um eigenständige fiktive

46 Herbst bezieht sich hier auf Benjamins Aufsatz »Über Sprache überhaupt und über die Sprache des Menschen« (1916).

47 Vgl. Herbst: »Poetologische Thesen I«, 43.

48 Ebd., 41.

49 Siehe Zipfel: Fiktion, Fiktivität, Fiktionalität, 84. Dort auch Literaturhinweise auf die Diskussion dieser Konzepte. Vgl. auch Tobias Klauk/Tilmann Köppe: »Literatur und Möglichkeiten«, in: Scientia Poetica 14 (2010), 163-204, besonders 187-204. 
Welten, für die unwichtig ist, ob sie auf reale oder fiktive Ereignisse verweisen. Die Grundaussage ist die Nivellierung der Unterschiede zwischen imaginiertem und realem Geschehen. Dies macht er in einer Art von Definition im Weblog deutlich:

[Die MöglichkeitenPoetik.]

Ist möglicherweise das ontologische Fundament der artifiziellen Erzählungan-sich: in ihr erübrigt sich die Frage, ob etwas so oder wie es denn swirklich gewesen sei; sie weist sie als nicht nur unstatthaft, sondern vor allem als unangemessen ab und formuliert die Eigenständigkeit literarischer Welten. Eigenständigkeit bedeutet freilich nicht, es müsse eine Ezählung [sic!] nicht 'geerdet< werden; sehr wohl speist sie sich aus Erfahrungen. Diese aber werden in einen anderen Wirkzusammenhang übersetzt, der eine ganz eigene und eigenständige Imaginationswelt ist, zwar mit der >Realität $<$ verbunden, aber wie deren - scheinbar unmittelbare - Wahrnehmung selbst ihrerseits Interpretation von Welt, und zwar, im Roman, von sowohl sinnlicher w i e intellektueller Art..$^{50}$

Zudem will er auch sich widersprechende Möglichkeiten gleichwertig nebeneinander darstellen: »Diese Möglichkeiten werden jede für sich als `wahr « erzählt, auch dann, wenn sie einander nach dem Satz vom ausgeschlossenen Dritten widersprechen. ${ }^{51}$

Die gemeinsame Nennung von »Möglichkeiten« und »Potentialitäten« stellt auch wieder einen Zusammenhang her zu der letztlich auf Aristoteles zurückgehenden Vorstellung von Möglichkeiten und Potenzialen, ${ }^{52}$ die in Gegenständen vorhanden sind und entweder ausgeführt werden oder nicht. Interessanterweise bilden die nicht aktualisierten Möglichkeiten das »Feld des Virtuellen ${ }^{53}$, wie Elena Esposito hervorhebt. Herbst versichert jedoch, dass es mit der Möglichkeitenpoetik gar nicht so kompliziert sein muss:

Was die Möglichkeiten-Poetologie anbelangt, so ist sie doch imgrunde einfach: Es gibt mehrere Möglichkeiten, in der eine Geschichte sich fortsetzt. Thetis entscheidet sich nciht [sic!] für eine, sondern oft für zwei oder drei - auch wenn sie einander ausschließen. Man muß sich nur je auf sie einlassen. Dann liegen alle brav nebeneinander, und jede hat ihr Recht. Das ist, ich weiß, eine utopische Idee: daß es nämlich Freiheit $\mathrm{g}$ e $\mathrm{b}$ e. Entscheidet man sich nur für eine - die sozusagen notwendige - Möglichkeit, bleibt alles im alten Determinismus. ${ }^{54}$

Interessant ist dabei der Bezug der Möglichkeiten nicht auf die Realität - dass eine Möglichkeit auch wirklich wahrscheinlich und damit potenziell realisierbar wäre -, sondern auf den Fortgang der Geschichte. Es soll also nicht erzählt werden, wie etwas

50 URL-25, 28. Apr. 2006. In dieser Form wurde auch ein Wikipedia-Eintrag zum Lemma >Möglichkeitenpoetik« angelegt, der aber nach heftigen Diskussionen gelöscht wurde, vgl. Wikipedia: »Löschkandidaten: Möglichkeitenpoetik«, 20. Feb. 2008-3. März 2008, URL: http://de.wikipedia.org/wiki/ Wikipedia:L\%C3\%B6schkandidaten/20._Februar_2008\#M.C3.B6glichkeitenpoetik_.28erl..29.

51 URL-26, 22. Sep. 2010.

52 Vgl. explizit auch in Alban Nikolai Herbst: »Entelechie oder Hans Deters sagt, was ihn ankotzt. Über das Wohlverhalten in Text \& Betrieb, nämlich: Warum es keinen richtigen Streit mehr gibt und Weshalb die Leute, anstatt zu hassen, sich öffentlich lieber zu Tode lieben«, in: Sprache im technischen Zeitalter 35/141 (1997), 190-200, hier: 195.

53 Esposito: »Fiktion und Virtualität«, 269.

54 URL-27, 23. Okt. 2012. 
tatsächlich sich ereignen könnte, wie dies im Realismus mehr oder weniger der Fall ist, sondern die Möglichkeiten stellen unterschiedliche Potenziale der Fiktion dar. Damit wiederum soll in der Literatur ein Denkprinzip aufgezeigt werden, das in der logischen Erfassung der Welt nicht vorgesehen ist, ein Denken abseits des Satzes vom Ausgeschlossenen Dritten.

Wie bereits im Zusammenhang mit WB immer wieder angesprochen, ist der logische Satz vom Ausgeschlossenen Dritten (auch: tertium non datur) wichtig in Herbsts poetologischem Denken. Es ist Herbst ein Grundanliegen zu versuchen, dieses Axiom zu unterwandern. Es komme »in der Literatur darauf an, dem Satz vom ausgeschlossenen Dritten pari zu bieten. Das bewegt mich, seitdem ich angefangen habe zu schreiben. Vielleicht schreibe ich überhaupt nur deshalb «55, bemerkte er in einem Interview. Dichtung soll daher andere nicht binäre Möglichkeiten darstellen können, die sich logisch ausschließen müssten, aber in der Dichtung nebeneinander bestehen. Dabei belässt er es nicht nur bei der Vorstellung eines einzigen Widerspruchs und damit eines potenziellen Dritten, sondern fordert die Multiplikation, ein $>$ Viertes $<$, Fünftes etc. ${ }^{56}$

Der Satz vom ausgeschlossenen Dritten scheint sich in Herbsts poetologischen Äußerungen fast als Symbol für einen abstrakten Gegner verselbständigt zu haben, gegen den sich viele von seinen Forderungen richten. Die Definition oder eine Umschreibung des logischen Grundsatzes wird dabei nie ausgesprochen, daher ist nicht klar, ob eine Abgrenzung von den anderen `Gesetzen des Denkens`, dem Satz vom Widerspruch oder dem Prinzip der Zweiwertigkeit, besteht. Da Herbst ihn aber in verschiedenen Kontexten bringt, wird ein ungefähres Verständnis vermittelt. Eine wichtige Einordnung ergibt sich, wenn er über die Planung der Romanreihe spricht, die mit $V G$ begonnen hat. Anfangs wollte er sie "Die Konstruktion des Widersinns" nennen und merkt an, der >Widersinn « sei bereits eine Anspielung auf den >Satz gewesen und hätte »Adornos NichtIdentisches [sic!] im Gepäck» $(K R, 93)$ gehabt. So findet sich in Adornos Negative Dialektik (1966) auch der Hinweis auf den `Satz als Kern der Logik, die das identifizierende Denken ausmacht. ${ }^{57}$ Adorno kritisiert in seiner >Philosophie des Nichtidentischen`, die er vor allem im genannten Werk darlegt, das reduzierende Moment, das jedem Denken eigen sei. Im Grunde liegt hier dieselbe Thematik vor wie in Benjamins bereits genannter Unterscheidung von Namens- und Begriffsanteil eines Wortes. Begriff und Sache, also das bezeichnende Wort und das Bezeichnete, seien eben nicht identisch; vielmehr werde etwas von dem eigentlichen Wesen der Sache durch den Begriff nicht erfasst und ihr damit Gewalt angetan. Nach seiner Überlegung wird bei jeglichem Denken der Vorgang der Identifikation von Begriff und Sache vorgenommen und unterschiedliche Sachen

55 Bruno Piberhofer / Ferdinand Schmökel: „Die Welt als Vorstellung und Selbstreferenz. Ein Gespräch mit Alban Nikolai Herbst über seinen fantastischen Roman Thetis. Anderswelt«, in: Listen 15/53 (1999), 28-31, hier: 30.

56 Vgl. KR, 17, auch: Herbst: »Poetologische Thesen III«, 44, 49, Herbst: »Flirren«, 24.

57 Siehe Theodor W. Adorno: »Negative Dialektik« [1966], in: Ders.: Gesammelte Schriften, Bd. 6: Negative Dialektik. Jargon der Eigentlichkeit, hg. v. Rolf Tiedemann, Frankfurt am Main 1973, 7-412, hier: 17 . 
unter einen Begriff gefasst. Sie werden durch einen Begriff `identifiziert،. Das Wesen der Sachen sei aber komplexer als das begrifflich Erfasste. Dem Nichtidentischen, also der Differenz zwischen Begriff und Sache, könne die Philosophie sich lediglich annähern. Diese Auffassung bezeichnet Adorno auch als `Negative Dialektik«, die er folgendermaßen erklärt:

Es handelt sich um den Entwurf einer Philosophie, die nicht den Begriff der Identität von Sein und Denken voraussetzt und auch nicht in ihm terminiert, sondern die gerade das Gegenteil, also das Auseinanderweisen von Begriff und Sache, von Subjekt und Objekt, und ihre Unversöhntheit, artikulieren will. ${ }^{8}$

Herbst geht es also um die poetische Annäherung an das oder Darstellung vom begrifflich nicht Fassbaren, letztlich um eine tieferliegende Wahrheit. Wie bei den Begriffen des Flirrens und des Bedeutungshofs wird die Überzeugung ausgedrückt, mit Literatur etwas zum Ausdruck zu bringen, was das logische, das begriffliche Denken nicht kann. Da nach Adorno alles Denken identifizierendes, also begriffliches Denken ist, muss die Literatur auch über das bewusste Denken hinausgehen. Herbst zieht denn auch diese Schlussfolgerung:

Leider existiert zwischen Kunst und Leben dennoch ein Zusammenhang: Er beruht irgendwie auf jenem ominösen Dritten, das die formale Logik aus unseren Welterklärungsmodellen klugerweise ausgeschlossen hat. Nur eine bestimmte, meist elitäre Kunst bringt es mit krimineller Beharrlichkeit immer wieder ins Spiel und läßt nicht vergessen, daß in der Dichtung etwas sei, das sich weder auf die Sozialisation ihres Autors noch auf seine Gegenwart rückbinden lasse, ja es habe mit ihrem Urheber schlechterdings nichts zu tun. ${ }^{59}$

Um dieses `Etwas`, das über die Intentionen des Urhebers hinausgeht, soll es im nächsten Abschnitt gehen.

\subsubsection{Das Unbewusste in der literarischen Kommunikation}

Herbst vertritt die Auffassung, der kreative Anteil künstlerischer Prozesse (im Gegensatz zum handwerklichen Teil) entziehe sich dem Bewusstsein des Künstlers, er stamme aus dessen Unbewussten. Herbst geht gar soweit zu sagen, manchmal stimmten Aussagen des Textes gar nicht mit den Intentionen des Dichters überein (vgl. KR, 40). Grundlage für diese Annahmen ist die Überzeugung, dass die Vorstellung eines autonomen Ichs nicht mehr möglich sei. Die Gründe dafür sieht er wie bereits angesprochen in der Beeinflussung durch das Unbewusste, in Vererbung und Sozialisation oder auch physiologischen Prozessen im Gehirn. ${ }^{60}$

Das Leben werde zwar von den (modernen) Menschen gemeinhin als ein offener Verlauf erlebt. Dies erkläre sich jedoch durch die nicht zu überblickende Anzahl der lebensbestimmenden Prozesse. »[D]ie wirkenden Determinanten sind derart

58 Theodor W. Adorno: Vorlesung über Negative Dialektik. Fragmente zur Vorlesung 1965/66, hg.v. Rolf Tiedemann (Abteilung IV: Nachgelassene Schriften, hg. v. Theodor W. Adorno Archiv, Bd. 16), Frankfurt am Main 2003, 15f.

59 Herbst: Rede zum Phantastik-Preis Wetzlar, 3.

6o Hierzu verweist er öfters auf die moderne Hirnforschung; vgl. KR, 91, 11, 101. 
unüberschaubar, daß sich der Eindruck von Freiheit herstellt - die Empfindung von Freiheit.« $(K R, 100)$ Von Ursachen könne vielleicht auf die Folgen geschlossen werden, umgekehrt könnten jedoch nicht von den Folgen ausgehend die Ursachen hinreichend und notwendig bestimmt werden. Unüberschaubarkeit und damit Unwissen bedeute aber wiederum nicht, dass die prägenden Ursachen nicht existierten. Vielmehr geht Herbst von überindividuellen Sinnzusammenhängen aus, die sich über das Unbewusste ausdrücken.

Als Hinweise auf diese Zusammenhänge verweist Herbst auf Erlebnisse, die Künstler seiner Erfahrung nach immer wieder hätten. Er führt den

»immense[n] Eindruck von Fremdheit [an], dieses Das-habe-ich-nicht-gemacht!, [das] einen Künstler nicht selten überkommt, wird er mit dem Gelungenen eines eigenen Werks konfrontiert; es ist dann tatsächlich nicht mehr von ihm (geschaffen), sondern von etwas durch ihn, etwas, das durch ihn hindurch wirkte.« $(K R, 25)$

Auf dieses wirkende `Etwas kommt er immer wieder zu sprechen und kennzeichnet es durch verschiedene Formulierungen. Unbestimmt bleibe es immer, sei die Rede von der »Vorstellung, es gebe währende Muster, die sich durch die Individuen hindurch im Wortsinn realisieren « $(K R, 101)$, oder von einem »unpersönlichen Prinzip[] [...], das sich, wie ein Symbiont, unseren Körper ausgesucht hat - ein mächtiges Es, dessen ich mir aber sehr wohl bewußt bin $«^{61}$.

Die freudianische Formulierung vom `mächtigen Es` deutet an, dass Herbst sich mehr auf psychologisch-wissenschaftliche Vorstellungen vom unbewussten Ausdrücken überindividueller Themen bezieht als auf esoterisch wirkende möglicherweise metaphysische Konzepte übermenschlicher Kräfte. Gegen solche Interpretationen verwahrt er sich durch den expliziten Hinweis, »daß meine ganze Grundhaltung empirisch-positivistisch gesonnen ist und ich alles andere als ein spiritueller Mensch bin; ich spüre ein instinktives und geradezu körperliches Unbehagen gegen jederlei Esoterik. $(K R, 92)$ Wie im Abschnitt über den Kunstanspruch bereits angesprochen sollen die Ideen des Autors sich auf Ängste, Phantasien oder Traumata beziehen und diese durch die Kunst verarbeiten. Als entscheidendes Mittel, diese überhaupt hervorzuholen und zu kanalisieren, sieht Herbst die künstlerische Form an. Durch die Form werde wenn nicht garantiert, so doch ermöglicht, dass Kunst (bzw. Literatur als Kunst) entsteht. Gemeint sind eher strikte Formvorgaben, die zwar eher in der Lyrik $^{62}$ etabliert sind, sich aber auch beim Roman nutzen ließen. Die Form steht für ihn immer vor den Inhalten. „Kunst bestimmt sich ausschließlich durch Form; der Inhalt ist - für die Definition von Kunst - völlig einerlei.« $(K R, 40)$ Die gewählte Form zieht die Inhalte an; sie soll nicht dem Gegenstand angepasst werden, sondern diesen erst zu Kunst formen. Der Autor soll sich Formvorgaben schaffen, die ihm als

61 Herbst: »Schöne Literatur muß grausam sein!«, 184f.

62 Wohl daher wählt Herbst in seiner Lyrik noch wesentlich striktere Formvorgaben. In seinen Bamberger Elegien hat Herbst explizit mit Hexametern gearbeitet, vgl. als Beispiel URL-28, 2. März 2007, vgl. zur theoretischen Reflexion Alban Nikolai Herbst: »Verlorene Herkünfte«. Gastbeitrag in Benjamin Steins Weblog »Turmsegler.net«, 31. Mai 2007, URL: http://turmsegler.net/20070531/ verlorene-herkunfte. 
"Katalysatoren« oder als »Medium des Ausgrabens « $(K R, 24)$ dienen. ${ }^{63}$ Sie soll die produktive Nutzung des Unbewussten anregen:

[I]ndem wir die Form füllen wollen, treiben uns die Möglichkeiten - sowohl die je persönlichen des Handwerks wie die objektiv zuhandenen, überindividuellen [...] - bisweilen in Aussagenbereiche, die wir gar nicht wollen, ja die uns unter Umständen zumindest auf den ersten Blick ganz fremd und oft sogar unangenehm sind. $(K R, 38 \mathrm{f}$.)

Als Beispiele von Formvorgaben für sein eigenes (Prosa-)Werk gibt Herbst hier zum einen Zahlenreihen an, die als »Korsett" $(K R, 39)$ um die Konstruktion für den Zusammenhalt sorgen sollten, zum anderen Formen aus der Musikgeschichte, vor allem der europäischen Kunstmusik.

Deutlich wird hier, dass >Form ‘ für Herbst der entscheidende Faktor der Bestimmung von Literatur ist. Der selbst als unzulänglich erfasste, aber für ihn nächstliegende Versuch einer Erklärung von Kunst und ihrer Wirkung ist für ihn die Formulierung "Form und Formung " $(K R, 38)$. Die alte Frage, was Literatur zu Literatur macht, also nach der Literarizität oder Poetizität (oder allgemeiner noch Ästhetizität), beantwortet er zwar unbestimmt, aber emphatisch mit literarischer, also sprachlicher und struktureller Formung; die in dieser Frage oft auch vorgebrachte Fiktionalität ist dagegen kein Kriterium. ${ }^{64}$ Denn es schwingt der für ihn in diesem Jahrzehnt der poetologischen Aufsätze auch bedeutende juristische und private Diskurs um das Meere-Verbot und die Tagebuch-Rubrik des Weblogs mit. Die umstrittenen Fragen dieses Diskurses sind für ihn eindeutig durch die literarische Formung geklärt: [...] eine Verfremdung von Kunstwerken [...] [wird] in erster Linie eben nicht durch Verfremdung des Inhalts - der Handlung, der Personen - vorgenommen [...], sondern durch die sprachliche Gestaltung." $(K R, 40)$ Dass er also in Meere und auch in das Weblog eigene private Details einarbeitet, sieht er nicht als Problem an. Durch die künstlerische Formung seien sie zu Literatur geworden und stünden damit nicht mehr direkt in Kontakt zur Realität. Die 2003 erschienenen Aufsätze Poetologische Thesen sind direkt vom Prozess um Meere betroffen. Dort bezieht er seine poetologische Stellung, ohne den Bezug offenzulegen bzw. offenlegen zu können ${ }^{65}$ : Vermittels der Form der Gestaltung verwandeln sich selbst autobiografisch detaillierteste >Berichte in Dichtung. « ${ }^{66}$ Als weitere Beispiele für seine Form-These führt er Louis-Ferdinand

63 Das Ausgraben steht als Bild sowohl für Psychologen als auch Archäologen, mit deren Tätigkeit er die künstlerische Tätigkeit vergleicht. Gerade der Hinweis auf die Archäologen findet sich immer wieder, siehe Herbst: »Poetologische Thesen III«, 48, Herbst: »Das Weblog als Dichtung«, 27, KR, 15.

64 Für Überblicksdarstellungen der Debatte siehe Lutz Rühling: »Fiktionalität und Poetizität«, in: Heinz Ludwig Arnold / Heinrich Detering (Hg.): Grundzüge der Literaturwissenschaft, München 1996, 25-51, besonders 38-51, und Simone Winko: »Auf der Suche nach der Weltformel. Literarizität und Poetizität in der neueren literaturtheoretischen Diskussion «, in: Fotis Jannidis / Gerhard Lauer / Simone Winko (Hg.): Grenzen der Literatur. Zu Begriff und Phänomen des Literarischen, Berlin u. a. 2009, 374-396. Herbsts Ansichten sind in der Nähe von Roman Jakobsons Ansatz einzuordnen.

65 So zitiert er aus Meere, was ihm zu dieser Zeit gerichtlich verboten war, und schreibt daher ironisch anstatt einer `Quellenangabe〈: »Aber ich sage nicht, wo.« (Herbst: »Poetologische Thesen III«, 48)

66 Ebd., 49. 
Célines Werk an, das trotz >unmenschlicher « und `entsetzlicher ‘ Aussagen ein großes Kunstwerk sei, sowie, trotz anderweitiger moralischer Einwände, auch die Arbeiten von Louis Aragon, Gabriele D’Annunzio, Ezra Pound oder Ernst Jünger (vgl. KR, 11).

Die literarische Gestaltung durch eine vorgegebene Form sieht er also als Möglichkeit, über das Individuelle hinauszugehen. Da Herbst mit Formen jedoch nicht auf Individuen zurückgehende Formen meint, sondern etablierte, bereits vorhandene bezeichnet, haben sie den Vorrang über den zunächst individuellen Inhalt, den er ihnen einräumt. Das über das Individuelle Hinausgehende ist für ihn Bedingung für Kunst. »Das Individuelle bringt die Kunst aber um, die vielmehr einen prinzipiellen Sog ins Allgemeine hat.« $(K R, 26)$ Dies erklärt sich durch die Einbeziehung des Lesers in die Betrachtung. Literatur in Herbsts favorisiertem Sinne, also phantastische oder intensive Literatur, sieht er als gelungen an bzw. habe sie Erfolg, wenn das Unbewusste des Lesers angesprochen wird, wenn »die Sprache gewordenen Bilder mit den inneren Bildern der Leser übereinkommen« $(K R, 52)$. Oder - in einer anderen Formulierung - wenn aus seinen "phantastischen Räumen Türen in die Inneren Räume anderer « $(K R, 56)$ führen. Damit geht die Kunst über die individuellen Probleme oder Belange des Autors hinaus und gewinnt Bedeutung auch für andere Menschen. Obwohl die Metaphorik der inneren Bilder oder Räume eher phantastisch denn realistisch klingt, kann eine solche Sichtweise im Kontext der Ausführungen als ein Zeichen von Realismus, nicht von Wirklichkeitsfremde gedeutet werden. Durch den intendierten Anschluss an das unbewusste Verständnis des Lesers zeigt sich, dass die wirklichen Probleme und Themen der Menschen angesprochen werden sollen. Doch auch beim Leser selbst findet sich nach Herbst der Bezug zum Überindividuellen. Der Leser fordere »das große, ihn selbst überhöhende Gefühl; [...] [er wolle] in einen tragödischen, überindividuellen Kontext eingebunden ${ }^{67}{ }^{67}$ sein. Im Gegensatz zum Wunsch nach Regression, den er in der realistischen Literatur erkennt, sieht Herbst diesen Wunsch als berechtigt an. Zudem versuche der Leser in jedem Fall, dieses Gefühl zu befriedigen. Wenn die Dichtung es nicht auf die hier avisierte Weise leiste, würde diese Funktion von der Trivialliteratur übernommen, dort jedoch mit ökonomischer Zielrichtung.

In Bezug auf den Autor ergibt sich die Schlussfolgerung, dass die Frage der Urheberschaft unwichtig wird. Es geht nicht um die individuelle Person des Autors, sondern nur um die Wirkung des Gegenstands, also des Textes. In Übereinstimmung mit seiner Auffassung vom wirkenden `Etwas sieht Herbst den Autor oder Dichter als Archetyp, nicht als Person (ebenso wie den Leser). Er ist die »vorübergehende Realisierung eines Types und einer Haltung [...], die auf weitere und nächste Künstler nächster Generation übergeht « $(K R, 26)$. Der individuellen Wirkung der Autorpersönlichkeit spricht er dabei nur eine narzisstische Rolle zu (vgl. KR, 10), die er jedoch an anderer Stelle immer wieder verteidigt. ${ }^{68}$

67 Herbst: »Schöne Literatur muß grausam sein!«, 185.

$68 \mathrm{Im}$ Weblog kommt er immer wieder auf die Eitelkeit von Autoren im Allgemeinen und auch seine eigene zu sprechen, zu der er sich jedoch emphatisch bekennt. Vgl. bspw. URL-29, 23. Feb. 2012, URL-30, 25. Jan. 2011, und Sebastian Fasthuber: " Sie müssen verzeihen, aber darauf scheiße ich echt««. Interview mit Alban Nikolai Herbst, in: Volltext 5 (2003), 3-4, hier: 3. 
Auch auf andere Weise sieht er das Individuelle des Autors als wichtig für den Kybernetischen Realismus an. Seine Erlebnisse während der Arbeit am Werk sollen in das Schreiben mit einfließen und dort reflektiert werden, der Autor soll schließlich sogar zu einer Figur des Romans werden (vgl. $K R$, 91f.). Besonders signifikant ist dies bei längeren Projekten. Dort wird besonders deutlich, dass der Autor am Anfang noch nicht wissen kann, wie der Text später sein wird und was die Interaktion mit den Figuren und Handlungselementen wiederum für Auswirkungen auf den Text haben wird. Die Autoridentität befinde sich selbst in einem »Fließprozeß ${ }^{69}$ und ebenso müsse der Text `fließen . Wenn der Autor von vornherein alles festlege (unabhängig von seiner Entwicklung), mache er den Text zu einem industriellen Produkt und funktionalisiere die Literatur. Das steht jedoch den Absichten der Poetik entgegen und lässt sich auch nicht mit ihr vereinbaren: »Flirren läßt sich nicht funktionalisieren. « ${ }^{70}$

Die Auffassung vom Wirken eines Überindividuellen und der Bedeutung des Unbewussten für die kreativen Leistungen des Autors zeigen die unterschiedlichen Seiten von Herbsts Autorverständnis. Einerseits verliert der individuelle Autor an Bedeutung, andererseits betont er dessen besondere Rolle in einer Weise, die ein genieästhetisches Dichterverständnis zeigen. Deutlich wird dies in der Entgegensetzung von Künstler und "normale[n] Menschen " $(K R, 25)$, die sich durch die Art erkläre, mit der der Künstler auf das `Ausgraben $`$ zu bearbeitender Themen reagiere. Er setze sich mit ihnen auseinander, hielte die Wunden notfalls im Leiden offen und lasse sie nicht wieder zuschütten; er bearbeite sie so, dass andere Anschluss finden könnten. Der entsprechende `normale` Vorgang wäre der der Verdrängung und allenfalls einer mimetischen Beschreibung individueller Befindlichkeiten. Grundannahme ist dabei, dass der Dichter nicht ernstlich geistig erkrankt sei, sondern dass er als Spiegel eines Allgemeinen allgemein verdrängte Inhaltsmuster wieder hervorholt (auch gegen den Willen der Anderen) und diese zu Kunst verarbeitet (vgl. KR, 16f.). Ein Gegenbeispiel bringt Herbst allerdings selbst, wenn er auf den schizophrenen Künstler und Schriftsteller Adolf Wölfli verweist. ${ }^{71}$ Wie oben in den Analysen zu den Romanen herausgearbeitet wurde, spielen auch in Herbsts eigenem Werk die Nähe oder auch die Ununterscheidbarkeit von Wahnsinn (bzw. psychischer Belastung oder Krankheit) und Phantasie ein Rolle.

In allen poetologischen Äußerungen wird Herbsts Überzeugung vom deterministischen Menschenbild deutlich, das er auf verschiedenen Ebenen festmacht. Sind bisher auf der realen Ebene die am Produktionsprozess Beteiligten, nämlich Autor und Leser, in dieser Hinsicht dargestellt worden, so wendet er sich in der dritten Vorlesung auch der Figurenebene zu (siehe $K R$, 101ff.). Anhand der fiktiven Figuren stellt er die Ähnlichkeit seiner Überlegungen zur Determiniertheit realer Menschen mit dem antiken Schicksalsbegriff dar und liefert nebenbei eine Begründung für den programmatischen Rückgriff auf Mythologien. In der antiken Tragödie sei es das Schicksal, das die Entscheidungen des Menschen vorherbestimme, nach Herbsts Ausführungen sind es beim realen Menschen unbewusste Hirnprozesse, genetische

69 Herbst: »Flirren«, 21.

70 Ebd., 22.

71 Siehe ebd., 25. 
Veranlagungen und Sozialisation. In beiden Fällen sei es die Unüberschaubarkeit der Wirkungszusammenhänge, die dann ein ähnliches Gefühl von Determiniertheit hervorrufe, allerdings mit einer Erklärung auf unterschiedlichem Niveau, einer anderen Art von Unüberschaubarkeit.

Im Aufsatz »Schöne Literatur muß grausam sein!« bezieht er diese Vorstellung ohne den Schicksalsbegriff explizit zu nennen -, vor allem auf Figuren. Die antiken Tragödiencharaktere Elektra und Klytemnästra sind hier Beispiele für Mythologeme mit schicksalsgelenkten Figuren, die gleichzeitig als Grundlage für spätere inntensive Literatur dienen, die das Mythologem auf ihre neue Weise nutze oder veranschauliche. Dort hätten sie im modernen Leser eine Wirkung, »weil in jedem Leser selbst Elektra schlummert ${ }^{72}$. Dazu merkt er allerdings an, dass auch Klytemnästras in ihnen schlummerten. »Die Situation ist konkret und zugleich Urform «73. Er veranschaulicht auch diese Fälle nicht anhand von Beispielen, dennoch kann es als theoretische Überlegung dazu verstanden werden, was in den obigen Abschnitten zu seinen Romanen immer wieder angeklungen ist. Von Falbin, der wie von einer unbekannten Macht geführt am Bahnhof landet, über Wolpertinger-Figuren, die sich auf nordische mythologische Figuren beziehen oder aber andere kulturgeschichtliche Prinzipien repräsentieren, bis zu Achilles Borkenbrod in den Anderswelt-Romanen, der auf Homers Epen verweist.

\subsubsection{Perversionsbegriff}

Die Betonung des Unbewussten als eines wichtigen Elements der Kreativität des Künstlers verbindet sich mit dem Anspruch an Kunst, Traumata und Ängste zu verarbeiten, zum Perversionsbegriff, den Herbst im publizierten Briefwechsel mit Barbara Bongartz erstmals entwickelt. ${ }^{74}$ Der Begriff der $>$ Perversion $`$ oder der $>$ Perversionslust ‘ bezeichnet für ihn das Phänomen, dass aus der Darstellung und Rezeption von schrecklichen Ereignissen, von Verdrängtem, von Bedrohungen, Schäden und Leid Lust gewonnen wird. Er sieht dies als eine menschliche Eigenschaft. Von Perversion spricht er, weil diese Lust aus moralischen Gründen eigentlich nicht sein ssollter, aber dennoch vorhanden sei. Wie gesagt sieht er hier eine Verbindung von antiker kathartischer Kunstauffassung und Anstrengung um neue literarische Formen (vgl. $K R, 21,27)$. Dichtung bohre »vergiftete Speicher « $(K R, 53)$ an und verarbeite sie in der literarischen Form. Dadurch sollen Traumata gewissermaßen umgedreht werden, was die Wortbedeutung von `pervertere` (`umstürzen`, >völlig umwerfen`) aufnimmt. Herbst ist hier in der medizinisch-psychologischen Interpretationstradition des aristotelischen Katharsisbegriffs einzuordnen, die auf den Philologen Jacob Bernays zurückgeht. Bei Katharsis handele es sich weniger um eine Umwandlung der Leidenschaften in soziale Tugenden, wie Lessing dies gesehen hat, sondern um eine

72 Herbst: »Schöne Literatur muß grausam sein!«, 185.

73 Ebd., 184.

74 Vgl. Bongartz / Herbst: »Inzest oder Die Entstehung der Welt«, 24. Vgl. zum Begriff auch KR, 21. 
Intensivierung der Gefühle und dadurch bedingt eine Befreiung von ihnen. Dieses Verständnis wurde von Nietzsche und Freud aufgegriffen. ${ }^{75}$

Eingebettet ist die Begriffserläuterung in Anspielungen auf den Diskurs um Adornos Verdikt, »nach Auschwitz ein Gedicht zu schreiben, [sei] barbarisch « und der damit zusammenhängenden Erkenntnis, dass »es unmöglich ward, heute Gedichte zu schreiben ${ }^{76}$. Dieses Quasi-Verbot sieht Herbst nicht als ein ästhetisches, sondern als ein moralisches, weil trotz des Grauens »Kunstlust « $(K R, 27)$ hätte empfunden werden können. Zudem würde die Nicht-Befolgung heißen, Auschwitz sei nicht der Endzustand der Welt, sondern ein Grauen unter anderen gewesen. Mit Bezug auf spätere Völkerverbrechen wie den jugoslawischen Bürgerkrieg oder die Massaker in Ruanda, die einen deutlichen Einfluss auf das Anderswelt-Projekt in den 1990er Jahren ausgeübt haben, vertritt Herbst diese Position: explizit ohne die Verbrechen der Nationalsozialisten verharmlosen zu wollen, sieht er weitere historische Ereignisse als ähnliche Bestätigung dafür, dass Brutalität, Krieg und schlimmstes Morden dem Menschen eigen seien. ${ }^{77}$

Das Quasi-Verbot von Adorno sieht Herbst zusammen mit dem letzten Satz von

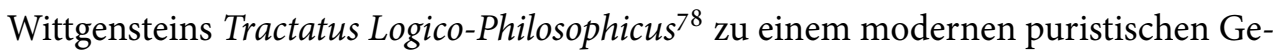
bot des Schweigens werden, das die ängstliche Moralität der deutschsprachigen realistischen Nachkriegsliteratur bewirkt und zu einer Tabuisierung der Ästhetisierung von Gewalt geführt habe. ${ }^{79}$ Dem setzt er die »Weiterentwicklung menschlichen Lebens [...], zu dem Kultur unabdingbar gehört ${ }^{80}$ entgegen und eine vitalistische Literatur, die offensiv mit den Schrecknissen der Menschheit umgehe. Aufgrund der Perversionslust, die es möglich mache, verdrängtes Schreckliches wieder hervorzubringen und zu verarbeiten, werde alles im Leben und in der Geschichte zu Material, alles Leid und alle Traumata. Es soll gerade nichts verdrängt, sondern alles offensiv aufgedeckt werden. »Kunst wird immer mit Leid geschrieben.« $(K R, 31)$ Das Extreme ist wichtig,

75 Vgl. Martin Vöhler / Dirck Linck (Hg.): Grenzen der Katharsis in den modernen Künsten. Transformationen des aristotelischen Modells seit Bernays, Nietzsche und Freud, Berlin 2009, VIIf.

76 Theodor W. Adorno: »Kulturkritik und Gesellschaft« [1951], in: Ders.: Gesammelte Schriften, Bd. 10/1: Kulturkritik und Gesellschaft I. Prismen. Ohne Leitbild, hg. v. Rolf Tiedemann, Frankfurt am Main 1977, 11-30, hier: 30. Für Variationen und Modifikationen des Satzes in Adornos eigenem Werk, die Reaktion in der deutschsprachigen Literatur sowie weiterführende Literaturhinweise siehe Petra Kiedaisch (Hg.): Lyrik nach Auschwitz? Adorno und die Dichter, Stuttgart 1995.

77 In Übereinstimmung mit dieser Haltung reagiert Herbst auch auf die Ereignisse des 11. Septembers 2001. In Inzest oder Die Entstehung der Welt fragt Bongartz per SMS: „WEITER SCHREIBEN?» Herbst antwortet emphatisch: „SELBSTVERSTÄNDLICH SCHREIBEN WIR WEITER!« (Bongartz / Herbst: »Inzest oder Die Entstehung der Welt«, 53) Vgl. zu dieser Reaktion Volker Mergenthaler: ") Weiter schreiben nach dem 11. September. Barbara Bongartz', Alban Nikolai Herbsts und Norbert Wehrs >Inzest oder Die Entstehung der Welt««, in: Ingo Irsigler / Christoph Jürgensen (Hg.): Nine Eleven. Ästhetische Verarbeitungen des 11. September 2001, Heidelberg 2008, 29-48, wo allerdings der mögliche Bezug auf Adornos Satz lediglich indirekt in einer Fußnote erwähnt wird (durch den Verweis auf Ruth Klügers weiter leben, ebd., 47).

78 Herbst nennt Wittgenstein selbst nicht, das wenn auch ungenaue Zitat ist jedoch eindeutig: »Worüber du nicht sprechen kannst, davon mußt du schweigen«, Herbst: »Poetologische Thesen III«, 40.

79 Vgl. auch Herbst: »Poetologische Thesen II«, $52 \mathrm{f}$.

8o Herbst: »Poetologische Thesen III«, 41. 
"Grenzsituationen ${ }^{81}$, ganz oben oder ganz unten wie in der Tragödie, sollen zum Gegenstand der Literatur werden. Das habe immer mit »Existenz im emphatischen Sinn $\mathrm{zu}$ tun, niemals mit einem Vierzigstundentag « $(K R, 31)$. Daran zeige sich auch, dass das Leid, das aus dem Leben genommen wird, nie einfach abbildend dargestellt wird, sondern transformiert und transzendiert, etwas einfach gesagt, zu Kunst gemacht werde. Herbst verwendet in diesem Kontext auch den Begriff der Katastrophe: »Eine Katastrophe ist alles, was zur Erhaltung des Lebens notwendige Strukturen auflöst, was sie ihres Illusions-, also Konventionscharakters überführt und damit untauglich macht. ${ }^{82}$ Katastrophen sind jedoch nicht nur nicht alltägliche Grenzsituationen wie Krieg, Gewalt und Terror, sondern auch jede Liebe, Sexuallust und der Orgasmus. Diesen sieht er als »kurzfristiges Zusammenbrechen jener Grenzen, die es einem ansonsten erlauben, seine Miete zu zahlen und definierten Tätigkeiten nachzugehen ${ }^{83}$. Dies ist als Hinweis für die Bedeutung von Sexualität in Herbsts Poetik zu verstehen.

Aus dieser Beschreibung ergeben sich auch die Begriffe »intensive Literatur « oder »kriegerische« bzw. "grausame« Literatur. Die Darstellung und der perverse Lustgewinn sind für ihn ein Verarbeitungsmodus, weil die Menschen sich selbst nur geschützt meinen, aber ahnen, es letzten Endes nicht zu sein (vgl. $K R, 32$ ). Er vergleicht dies mit archaischen Praktiken wie dem Bannen von Dämonen.

\subsubsection{Pathos vs. Ironie}

Die Ernsthaftigkeit dieses Anliegens gibt auch den Hintergrund für Herbsts entschiedene Ablehnung von Ironie. Dabei ist die Redefigur der Rhetorik von der poetischen Ironie zu unterscheiden, weswegen er auch von einer »ironische[n] Haltung “ ${ }^{84}$ (bzw. ihrer Ablehnung) spricht. Seine Zielrichtung ist dabei wieder deutlich, da sie mit seiner Abwehr gegen die realistische Erzähltradition zusammenhängt. Explizit nimmt er Schellings und Walter Benjamins Auffassung von Ironie aus seinem Angriff aus und damit wohl auch die gesamte damit verbundene >romantische Ironieく. Unter Ironie fasst er also verschiedene Formen der Relativierung. Als anschauliches Beispiel führt er die Erinnerung an seine Großmutter an, die - wenn es im Fernsehen allzu spannend wurde - zur Beruhigung meinte, es sei ja nur ein Film (vgl. KR, 30). Diese alltägliche Art der Distanzierung setzt Herbst mit sublimeren Formen gleich: mit der Veruneigentlichung durch Ironie in den Texten selbst ebenso wie durch den poststrukturalistischen Ansatz, alles sei Text. Angesichts des Regressionsvorwurfs ist das übereinstimmende Moment deutlich: die Distanzierung als Beruhigungs- oder Abwehrmechanismus einer Angst. In der deutschen Nachkriegsliteratur sei die Ironie zum »heiliggesprochenen Popanz ${ }^{85}$ geworden, in der Folge dann zum »Germanistenfetisch ${ }^{86}$. Ironie sei eine Tendenz der realistischen Literatur, die Vereinfachung

81 Herbst: „Schöne Literatur muß grausam sein!«, 180; vgl. auch insgesamt diesen Essay, in dem Herbst diese Position ausführlich darlegt.

82 Ebd., 178.

83 Ebd.

84 ebd., 185. Vgl. v. a. dort die Seiten 185 ff. für die folgende Argumentation.

85 Ebd., 186.

$86 K R, 30$, auch ebd. 
und Typisierung bei der bloßen Schilderung von Phänomenen 'versöhnlich auszugleichen $<{ }^{87}$ Für ihn stellt sie in diesem Kontext jedoch ein weiteres Zeichen von Regression dar, da letztlich weder Zweifel noch Ambivalenz vorhanden wäre. ${ }^{88}$

Für eine ironische Haltung setzt Herbst Autonomie voraus. Die spricht er dem Autor aber dahingehend ab, dass dieser mindestens im ersten Entwurf des Textes die literarischen Dynamiken keineswegs bewusst steuern kann, da er Medium eines überpersönlichen Unbewussten ist. ${ }^{89}$ Ironie würde das gerade vielleicht schmerzhaft wieder hervorgeholte Weggedrängte wegglätten, wieder eine Distanz dazu aufbauen, die es relativiert und verharmlost. Zudem argumentiert er dahingehend, dass der Gegenstand, das Objekt der Ironie immer kleiner sein müsste als das Subjekt, notfalls kleiner gemacht werden müsse, um an der Vorstellung eines intakten (autonomen) Subjekts festhalten zu können. Das Verhältnis von Subjekt zu Objekt sei zwar nicht klar definiert, aber immer ein hierarchisches. Da jedoch die in der intensiven Literatur beschworenen Grenzsituationen ihrerseits gerade das Subjekt >dekonstruierten ${ }^{90}$, sei ihre Betrachtung aus ironischer Perspektive nicht möglich. Politisch sei das ironische Zurechtstutzen des Objekts ein emanzipatives Verfahren, poetisch führe es aber zur völligen Uneigentlichkeit. Diese behindere wiederum eine Lusterfüllung, die für die Mechanismen der Perversionslust nötig sei. Daher setzt Herbst der Intensität keine Form von Relativierung entgegen, sondern fordert die Rückkehr zu Ernst und Pathos: »Dagegen muß man sich mit der Gewalt und Gewaltsamkeit des Lebens stemmen, vitalistisch, provokativ und entschieden." $(K R, 30)$

Im Gegensatz zu Herbsts Diagnose einer Zunahme oder gar Allgegenwart der Ironie in der Gegenwartsliteratur hat Albert Meier »seit ca. 1997 [...] ein[en] Widerstand gegen Ironie ${ }^{91}$ beobachtet. Meier zeigt beispielhaft anhand von Rainald Goetz und Michel Houellebecq eine Entwicklung zu einem Schreiben auf, das sich (zumindest bei diesen beiden Beispielen) der Krise von Subjekt und Erzählen bewusst ist, welche die Literatur der Postmoderne geprägt hat, und das dennoch einen »affirmativen Zugang der Literatur zur Welt « zu verfolgen sucht - aber ohne den »Absolutheitsanspruch der Ironie « ${ }^{92}$. Die Differenz in der Beobachtung erklärt sich vor allem in den betrachteten Texten, teils aber auch durch das zugrunde liegende Ironieverständnis. Wie Meier in etlichen Bezügen vor allem auf Schlegel nachweist, geht es ihm um

87 Vgl. Herbst: »Poetologische Thesen I«, 35.

88 Herbsts Ansichten treffen sich hier wieder mit Adornos: Viele Menschen geben dem, was sie sagen, den Charakter der Ironie, weil sie zu gar nichts fest stehen, mit keinem Urteil identifiziert - mit sich selber nicht identisch sind. So reden Kinder. Der Gestus der Überlegenheit als Ichschwäche.« (Theodor W. Adorno: „Graeculus (II). Notizen zu Philosophie und Gesellschaft 1943-1969«, in: Frankfurter Adorno Blätter 8 (2003), 9-41, hier: 15) Es ist jedoch nicht von einem direkten Einfluss oder gar Übernahme auszugehen, da diese Notiz aus dem Jahre 1960 erst spät publiziert wurde.

89 Dem möglichen Einwand, ein Erzähler könne unabhängig vom Autor eine ironische Haltung haben, steht entgegen, dass er gerade auch Erzählfiguren die Autonomie abspricht und aus diesem Grund die Erzählperspektive immer aufzuteilen sei.

90 Vgl. Herbst: »Schöne Literatur muß grausam sein!«, 186.

91 Albert Meier: »Irony Is Over. Der Verzicht auf Selbstreferenzialität in der neuesten Prosa «, in: Heinrich Detering (Hg.): Autorschaft. Positionen und Revisionen (Germanistische-SymposienBerichtsbände 24), Stuttgart 2002, 570-581, hier: 573.

92 Ebd., 574. 
Ironie im romantischen Verständnis als Selbstreflexion, das Herbst explizit nicht meint. Dennoch kommt es zur Übereinstimmung, wenn Meier für die >romantische Literatur (zu der er nicht nur Schlegel oder Tieck beispielhaft zählt, sondern auch Patrick Süskind und Paul Auster) konstatiert, sie verhalte "sich elementar >ironisch, indem sie auf keine Bedeutung fixiert werden mag und mit jedem Wort von sich wegverweist « ${ }^{93}$. Der Vergleich mit Goetz ist aufschlussreich. Wenn Meier aus Abfall für alle zitiert -

Lustigerweise weiß ich selber gar nicht richtig, was genau drin steht, in meinem eigenen Stück, was der Text in seiner Autonomie sagt, aber ich weiß natürlich ganz genau, was ich gemeint habe, wie ich es gemeint habe. ${ }^{94}$

- sieht er darin die Verantwortungsübernahme für den Sinn, für die Autorintention, obwohl Goetz der Diskurs um Sinnzuschreibungen und Intentionen bewusst sei und damit den Verzicht auf ironische Distanzierung oder Reflexion. Meier führt zudem Goetz' Referenz auf eine Wirklichkeit der Alltagswelt an, »[w]ie sie schlicht und einfach IST « ${ }^{95}$, mit »reale[n] Beschreibungen dessen [...], was da wirklich zu sehen ist ${ }^{96}$. Darin sieht er die Abkehr vom ängstlichen, stheorie-hörigen` Erzählen, das sowieso nichts bringe. Es soll hier nicht darum gehen, Rainald Goetz' Auffassung von Wirklichkeit genauer zu untersuchen, vielmehr ist Meiers Analyse aufschlussreich. Nach Herbsts Darstellungen ist schließlich fraglich, ob tatsächlich auf der »Höhe der philosophisch-poetologischen Reflexion der Gegenwart « ${ }^{97}$ geschrieben wird, wenn Meier davon ausgeht, dass dem »transzendental problematische[n] Subjekt [...] das empirische Individuum ${ }^{98}$ entgegengesetzt werde und er schließlich schlussfolgert: »Es kann daher von diesen - immer letzten - Dingen einfach, schnörkellos erzählt werden, weil es um echte Referenz auf faktische, physische Realität außerhalb der Texte geht.«99

Auch wenn Herbst wie Goetz sich gegen Ironie wendet, so wird doch der unterschiedliche Zugang deutlich: während Goetz sich auf einen offensichtlich scheinenden Zugang zur Alltagswirklichkeit beruft und sich ihm auch seine Intentionen beim Schreiben als offensichtlich vorhanden präsentieren, interessiert Herbst sich gerade für das, was über die Intentionen des Autors und über die Alltagswirklichkeit hinausgeht. Obwohl sich also einige Übereinstimmungen finden lassen, müssten Goetz' Ansichten Herbst folgend als nicht zeitgemäß oder gar als Rückschritt gewertet werden. Eine weitere Übereinstimmung findet sich jedoch trotz dieser unterschiedlichen Prämissen: Interessanterweise sind es auch für Houellebecq und Goetz die »Gegensätze von Lust und Schmerz, Leben und Tod« - bei Herbst die intensiven Momente

93 Meier: »Irony Is Over«, 573.

94 Rainald Goetz: Abfall für alle. Roman eines Jahres, Frankfurt am Main 1999, 1998 unter www.rainaldgoetz.de veröffentlicht, 744, zit. nach Meier: »Irony Is Over«, 571.

95 Goetz: Abfall für alle, 308.

96 Rainald Goetz: Rave. Erzählung, Frankfurt am Main 1998, 173.

97 Meier: »Irony Is Over«, 572.

98 Ebd., 580.

99 Ebd., 581. 
der Grenzsituationen -, die »eine substanzielle Wirklichkeitsreferenz zurückzugewinnen « ${ }^{100}$ ermöglichen; bei Goetz durch die »affirmative[] Kollektivität des Rave« und bei Houellebecq durch die »schmerzvoll-isolierende[] Körpererfahrung in der Kampfzone des Sex ${ }^{101}$.

\subsubsection{Mimesis und Technik}

Die beiden Begriffe `Technik und `Mimesis` sind weitere zentrale Aspekte des Kybernetischen Realismus. Die Technik wird zu einem solchen durch ihre zunehmende Bedeutung in der heutigen Zeit vor dem Hintergrund des Anspruchs einer zeitgemäßen Poetik. Dabei ist zum einen Technik generell als Gegensatz zur Natur gemeint. Zum anderen aber auch die mediale Technik, die spätestens seit WB eine zunehmende Rolle in Herbsts Werken spielt. Dabei handelt es sich in Anspielungen um Fernsehen und Kino, vor allem aber um Computertechnik und später das Internet und entsprechende fiktive zukünftige Formen. Beim Mimesisbegriff ist die Verbindung nicht gleichermaßen sofort ersichtlich. Aufgrund der Ablehnung realistischer Literatur schiene auf den ersten Blick auch die Ablehnung von Mimesis folgerichtig. Doch Herbst hält explizit an dem Begriff Mimesis fest (vgl. KR, 105 und 113). Wie »alle vorgängigen Ästhetiken « $(K R, 105)$, so die kühne Behauptung, ${ }^{102}$ verhalte sich der Kybernetische Realismus zur Wirklichkeit mimetisch. Begründet ist dies in dem Anspruch, eine eigentliche, die swahre Wirklichkeit vermitteln zu wollen, was eine Änderung des Wirklichkeitsbegriffs und damit der Referenz von Mimesis bedeutet. Die Wirklichkeit ist demnach nicht die Alltagswirklichkeit, das von den Menschen normalerweise Wahrgenommene oder Beobachtbare, wie dies für den von ihm angegriffenen Realismus der Fall ist. Es könne nicht mehr eine »feste Natur « $(K R, 113)$ nachgeahmt werden, sondern nur eine "prozessual verstandene[], [sich] in Bewegung befindliche[] Wirklichkeit« $(K R, 105)$. Die somit implizierte Annahme einer zugrunde liegenden Wahrheit, die über die realen Phänomene hinausgeht und die es zu erkennen gilt, ist eine Interpretation der die Welt bestimmenden Prinzipien, die der >Weltanschauung ২ des modernen (westlichen) Menschen entspricht. Den über das Subjektive hinausgehenden Wahrheitswert bekommt diese Interpretation für Herbst also durch die Annahme, dass nicht die pragmatischen oder teils naiven Annahmen der Alltagswahrnehmung die eigentliche Welt ausmachen, sondern die Einbeziehung komplexer Überlegungen aus Philosophie, den Sozialwissenschaften und vor allem den Naturwissenschaften.

Es soll also nicht dargestellt werden, wie der Mensch die Welt unreflektiert im Alltag wahrnimmt, sondern wie reflektiert angenommen werden kann, dass sie auf ihn wirkt. Dieses bereits mehrfach angesprochene Verständnis von Wirklichkeit sieht

100 Ebd.

101 Ebd., 580.

102 So im Grunde aber auch Christine Brooke-Rose: „For ultimately all fiction is realistic, whether it mimes a mythic idea of heroic deeds or a progressive idea of society, or inner psychology or, as now, the non-interpretability of the world, which is our reality as its interpretability once was (and may return). A fantastic realism. "(Christine Brooke-Rose: A Rhetoric of the Unreal. Studies in Narrative and Structure, especially of the Fantastic, Cambridge u. a. 1981, 388). 
Herbst denn auch als das zentrale Merkmal des `Kybernetischen Realismus`. In einer Art >Definition` erklärt er jedoch weniger den Begriff >Kybernetischer Realismus oder auch nur `Realismus` als seine wiederholt angebrachte Wirklichkeitsvorstellung:

Damit ist, grob umrissen, eine Auffassung gemeint, die sich von Schopenhauers auf Kant fußendem Satz herleitet, Wirklichkeit sei das, was wirke. $(K R, 21)^{103}$

Für diese Art von Wahrheitsfindung bzw. eher Wahrheitsannäherung (da es die eine Wahrheit nicht gibt bzw. sie nicht eindeutig bestimmt werden kann) sieht Herbst die Kunst zuständig. Den Wahrheitsbegriff stellt er dabei nicht als einfach bestimmbar dar; denn »Wahrheitsfindung wie Wahrheitserschaffung ersteht im Wechselspiel $(K R, 5) .{ }^{104}$

Möglicherweise schließt er hier wieder einmal an Adorno an, für den

»[n]icht Ähnlichkeit mit den Produkten der Natur, sondern mit der diese hervorbringenden Kraft der Natur [...] Ziel der Kunst [ist]. Nicht die >natura naturata<, sondern die >natura naturans` hat Adorno vor Augen, wenn er die Ähnlichkeit zwischen Natur, Künstler und Kunst betont. «105

Auch Adorno sieht ein >Anderes‘, einen begrifflich nicht fassbaren Wahrheitsgehalt in der Realität, der im Kunstwerk dargestellt wird. Insofern sieht er sogar eine Umkehrung der »Nachahmungslehre«; das Kunstwerk ahmt insofern nicht nach, sondern zeigt die »Möglichkeit des Möglichen «. ${ }^{106}$

Es muss immer mitbedacht werden, dass Herbst sich durch eine solche Konzeption von einem Realismus in der oben beschriebenen Form absetzt und damit vom herkömmlichen Verständnis von Mimesis als Nachahmung der beobachtbaren Natur. Doch »[j]ede historische Ausformung von Mimesis hat ihre eigene Konstellation, selbst wenn jahrhundertelang dieselbe Autorität, nämlich Aristoteles, angerufen wird « ${ }^{107}$ und Herbst ist mit seiner Umdeutung nicht allein. Häufig wird eine solche mit postmoderner, metafiktionaler Literatur in Verbindung gebracht. Die auf die Konstruktion angewiesene Wirklichkeitserfahrung des Menschen wird in der selbstbezüglichen Erzählweise der Metafiktion reflektiert und wird »paradoxerweise zu einer neuen Mimesis«:

Auch das postmoderne Erzählwerk ahmt Welt und ihre Erfahrung nach. Der Unterschied zur traditionellen Mimesis besteht bei genauerem Hinsehen lediglich darin, daß die nachgeahmte Welt eine anders aufgefaßte geworden ist, eine Welt der Fiktionalität und Diskontinuität $[\ldots] \cdot{ }^{108}$

103 Siehe dazu ausführlichere Erläuterungen in der Einleitung ab Seite 25.

104 In »Flirren«, 29, spricht Herbst von Literatur als »Trägerin von Wahrheitsfunktionen (oder sagen wir: Wahrheitsentwürfen)«.

105 Gunter Gebauer / Christoph Wulf: Mimesis. Kultur - Kunst - Gesellschaft, Reinbek 1992, 398.

106 Vgl. Adorno: Ästhetische Theorie, $199 \mathrm{f}$.

107 Gebauer/Wulf: Mimesis, 423.

108 Werner Wolf: „Geschichtsfiktion im Kontext dekonstruktivistischer Tendenzen in neuerer Historik und literarischer Postmoderne. Tom Stoppards Travesties", in: Poetica 18 (1986), 305-357, hier: 334. Die Hinweise auf Wolf und Brooke-Rose finden sich bei Herbert G. Klein: Konstruierte Wirklichkeiten. Kybernetische Bewußtseinsformen im anglo-amerikanischen Roman des 20. Jahrhunderts, 
Herbst betont besonders die zeitspezifische Weltwahrnehmung und damit die immer stärker werdende Prägung durch die mediale und technische Vermittlung. Es geht ihm in den Vorlesungen also weniger um metafiktionale Schreibweisen (zumindest thematisiert er solche im Mimesis-Zusammenhang nicht) als um den Zusammenhang mit Technik. Eine Umkehrung der Referenz von Mimesis stellt er am Beispiel des Eingangssatzes von William Gibsons Neuromancer (1984) fest.

Der Himmel über dem Hafen hatte die Farbe eines Fernsehers, der auf einen toten Kanal eingestellt ist. ${ }^{109}$

Nicht mehr die Natur sei das Original, das dargestellt wird, vielmehr werde die Natur mit der Technik verglichen, die zum neuen Original wird. Mit Bezug auf Marx’ Begriff der Verdinglichung konstatiert Herbst eine ähnliche Umkehrung der »seelischen Verhältnisse« auch schon für die moderne urbane Welt:

Gemessen am Naturzusammenhang ist städtische Kultur ja ohnedies phantastisch, weil sie Unbelebtes bis ins strukturelle Detail belebt und schließlich so sehr über das natürlich Organische stellt, daß dieses - zum Beispiel ein Angestellter - fast auf die Stufe von Gegenständen herabsinkt. $(K R, 65)$

Die Wirklichkeit, die der Mensch erlebe, sei keine »feste Natur" $(K R, 113)$ mehr, die dokumentiert werden könnte, er nehme die Welt vielmehr medial vermittelt, technisch geprägt und in ständiger Bewegung wahr. Gerade die naturwissenschaftlichen Entwicklungen des 20. Jahrhunderts mit Entdeckungen, die das Erleben von Zeit und Raum infrage stellen, prägen dieses Wirklichkeitsverständnis. Diese Zusammenhänge soll der Kybernetische Realismus berücksichtigen und darstellen, um gerade nicht so »unrealistisch « wie der attackierte Realismus zu sein. ${ }^{110}$

Das deutliche Bekenntnis zum wenn auch modifizierten Mimesisbegriff hat sich in Herbsts poetologischen Überlegungen erst entwickelt. In der »GrimmelshausenPreisrede« von 1995 behauptet er noch, dass »Kunst nichts dokumentiere und nichts spiegle, ja nicht einmal Wirklichkeit interpretiere ${ }^{111}$. Doch handelt es sich hier nicht um eine grundsätzlich andere Position, sondern nur um eine Frage der Formulierung. Auch hier schon geht es um den Unterschied zwischen Authentizität (der >realistischen 'Wiedergabe äußerer Umstände und Fakten) und tieferer Wahrheit, darum, einem Gegenstand "gerecht « ${ }^{112}$ zu werden. Auch im Aufsatz »Flirren im Sprachraum « lassen die Formulierungen die gleiche Position erkennen. Die >fantastische Dichtung،

Heidelberg 1998, 14. Anzumerken ist zudem, dass es Herbst jedoch nach wie vor um einen Wirklichkeitsbezug geht, der auch in dieser metafiktionalen Deutung von Mimesis vorhanden ist. Es gibt jedoch andere Umdeutungen, die von einer »Mimesis der Poiesis«, also der Nachahmung des literarischen schöpferischen Prozesses oder einer »Mimesis des Erzählens« reden, siehe Jürgen Landwehr: »Von der Repräsentation zur Selbstbezüglichkeit und die Rückkehr des/zum Imaginären. Konzepte von Literatur und literarischem (Struktur-)Wandel und ein `verkehrtes« Mimesis-Modell «, in: Michael Titzmann (Hg.): Modelle des literarischen Strukturwandels, Tübingen 1991, 275-295, hier: 289, und Nünning: »Mimesis des Erzählens«.

109 Zit. nach $K R, 49$.

$110 \mathrm{Vgl} . K R, 114$.

111 Herbst: Grimmelshausen-Preisrede, 6.

112 Ebd., 5. 
nennt er hier die "tatsächlich realistische ${ }^{113}$. Wie ungewiss der Zugriff oder die Existenz einer tieferen Wahrheit ist, zeigt sich in seiner Klarstellung, es werde keine vom Autor als richtig oder falsch empfundene Wirklichkeit dargestellt, da sie immer von der subjektiven Wahrnehmungsweise des Autors abhänge. Der Hinweis auf die bleibende künstlerische Bedeutung von Mimesis bei »Verzicht auf Intention « ${ }^{114}$ deutet jedoch schon auf die spätere Verwendung des Mimesisbegriffs hin.

Die Überlegungen zur Mimesis bewirken auch eine Verständnisänderung bezüglich des Realismusbegriffs. Herbst versteht sie als dessen "Neufindung " $(K R, 44)$. Schon in Vorüberlegungen im Weblog spricht er von einem »a n d e r e [ $n$ ] Realismus « ${ }^{115}$. Wie auch schon beim Mimesisbegriff ist Herbst nicht der erste, der den Realismusbegriff anders begreift und neu belegt: "Der nahezu universellen Verwendbarkeit des Realismusbegriffs entsprechend werden in Autorpoetiken sowie in der Literaturwissenschaft und Literaturkritik bis heute immer wieder `neue Realismen $>$ diagnostiziert $[\ldots] \cdot \ll^{116}$

Der poetische oder literarische Realismus des 19. Jahrhunderts kann nun nicht als ein >neuer Realismus bezeichnet werden, ähnelt aber Herbsts Auffassung insofern, als auch er die Wirklichkeit nicht naturalistisch genau nachahmen oder abbilden, sondern gerade eine idealisierte, aber wahrscheinliche Wahrheit präsentieren wollte. Dies kann sogar dazu führen, mit Realismus »keine Mimesis, also Nachahmung von Wirklichkeit, sondern Poïesis, das künstlerische Schaffen von Wirklichkeit ${ }^{117} \mathrm{zu}$ meinen. Die Prämissen sind jedoch von Herbsts Konzept zu unterscheiden. Zum einen bleibt im literarischen Realismus der Bezugspunkt die Alltagswirklichkeit und ihre >wahrscheinliche Darstellung, zum anderen ist das >Wahre oder >Wesentliche das darüber hinaus zum Ausdruck gebracht werden soll, anders akzentuiert: es handelt sich dabei zumeist um > Verklärung und Aussparung des Unliebsamen. Vor allem das Schöne und moralisch Hochstehende - und damit die Wirklichkeit, wie sie sein soll soll dargestellt werden, das Hässliche dagegen ausgeklammert werden. ${ }^{118}$

Der europäische magische Realismus besonders der 1920er Jahre, wie ihn Michael Scheffel beschreibt, ${ }^{119}$ hat gänzlich andere Voraussetzungen als Herbsts Poetik. Auch er bezieht sich auf die »alltägliche Erfahrungswirklichkeit « ${ }^{120}$ und stellt stabile und

113 Herbst: »Flirren«, 25.

114 Ebd.

115 URL-31, 1. Juni 2005.

116 Helmut Weidhase / Kai Kauffmann: »Realismus«, in: Dieter Burdorf / Christoph Fasbender / Burkhard Moennighoff (Hg.): Metzler Lexikon Literatur. Begriffe und Definitionen, 3., völlig neu bearbeitete Auflage, Stuttgart / Weimar 2007, 628-630, hier: 630.

117 Sabina Becker: Bürgerlicher Realismus. Literatur und Kultur im bürgerlichen Zeitalter 1848-1900, Tübingen [u.a.] 2003, 9.

118 Vgl. Lars Korten: Poietischer Realismus. Zur Novelle der Jahre 1848-1888. Stifter, Keller, Meyer, Storm, Tübingen 2009, 42, 48, 69, und Claudia Stockinger: Das 19. Jahrhundert. Zeitalter des Realismus, Berlin 2010, besonders 8, 10, 12f., 208.

119 Vgl. Michael Scheffel: Magischer Realismus. Die Geschichte eines Begriffes und ein Versuch seiner Bestimmung, Tübingen 1990, besonders 110-113.

120 Ebd., 111. 
homogene Welten dar. Er unterscheidet sich dadurch deutlich von der Phantastik mit ihren kollidierenden Realitätssystemen. Der direkte Bezug zur Phantastik ist aber ein wichtiges Kennzeichen der herbstschen Poetik. Damit hängt für Herbst auch der Bezug zum magischen Realismus lateinamerikanischer Ausprägung zusammen: der Kybernetische Realismus beziehe sich auf die »Phantastische Literatur [...] und, damit zusammenhängend, auf den Magischen Realismus« $(K R, 45) \cdot{ }^{121} \mathrm{Er}$ spricht auch vom »kybernetisierte[n] Borges « (ebd.). Im Unterschied zu diesem magischen Realismus betont er aber die Einbeziehung der Entwicklungen, die die moderne westliche Welt bestimmen, die der Naturwissenschaften des 20. Jahrhunderts und der Technik. Zudem sieht er seine Spielart von Realismus als urban an, im Gegensatz zum eher ländlichen lateinamerikanischen magischen Realismus. ${ }^{122}$

\subsection{Der Kybernetikbegriff}

Die Verwendung des Begriffs >kybernetisch` im Titel der Poetikvorlesungen und damit auch als allgemeine Bezeichnung seiner Poetik ist eine »ungewöhnliche[] Rubrizierung « ${ }^{123}$. Dieses im Deutschen keineswegs mehr alltäglich gebräuchliche oder allgemeinverständliche Wort fällt auf und lässt durch seine prominente Stellung im Titel der Vorlesungen und in der Bezeichnung der Poetik eine längere Auseinandersetzung mit der Auswahl und Verwendung des Begriffs vermuten. Herbst begnügt sich jedoch mit wenigen Andeutungen, die bei genauer Betrachtung Zweifel an der

121 Vgl. auch Herbst: »Poetologische Thesen III«, 41, 43. - Die Ineinssetzung von Phantastik und magischem Realismus ist jedoch kritisch zu sehen. Zwar gibt es keine eindeutig etablierte Definition vom Begriff `magischer Realismus`, doch ist Uwe Dursts Argumentation als fundiert anzusehen, die zu folgender Definition führt:

Das Magisch-Realistische ist als eine Struktur zu definieren, in der ein realitätsssystemisch nicht ambivalentisiertes wunderbares Ereignis ohne intratextuelle Klassifikation seiner Realitätsinkompatibilität in einer realistischen Realität auftritt. Mit einer solchen Bestimmung wird [...] das Magisch-Realistische vom Phantastischen abgesetzt: die Erzählinstanz garantiert die erzählte Welt. (Uwe Durst: Das begrenzte Wunderbare. Zur Theorie wunderbarer Episoden in realistischen Erzähltexten und in Texten des $>$ Magischen Realismus $\triangleleft$, Berlin 2008, 248f.)

In Herbsts Welten wird der Auftritt des Wunderbaren jedoch zum einen sehr ambivalent bewertet, zum anderen wird die Welt nicht durch eine Erzählinstanz garantiert. Diese Feststellung soll jedoch keineswegs die Affinität des herbstschen Schreibens zur lateinamerikanischen Literatur des magischen Realismus infragestellen, lediglich seine Prämissen als anders herausstellen.

122 Vgl. KR, 67, sowie URL-32, 30. Mai 2006.

123 Jürgensen: »Unwirkliche Städte, unwirkliches Ich«, 105. Es findet sich keine ausführlichere Auseinandersetzung mit diesem Begriff in der Sekundärliteratur zu Herbst. Jürgensen selbst sowie Stefan Scherer im KLG-Artikel gehen in kurzen Bemerkungen in Bezug auf den Untertitel von $B A$ auf den Begriff ein, versuchen sich aber gar nicht erst in einer weitergehenden Erklärung. Schütte geht nicht über das Zitat hinaus. Ausschließlich Giacomuzzi geht auf die Herkunft des Wortes, den Bezug zur Wissenschaft und damit verbundene Ideen kurz ein. Sie stellt die Verbindung zur Analogisierung von Mensch und Maschine her und leitet daraus Herbsts Aufhebung der Unterscheidung »Zwischen künstlich und natürlich arrangierter Welt« ab. Vgl. Giacomuzzi: »Die ১Dschungel.Anderswelt` und A. N. Herbsts >Poetologie des literarischen Bloggens««, 141. Zu dieser Verbindung und meinen Einwänden im Folgenden ausführlich mehr. 
Stimmigkeit der Begriffsverwendung hervorrufen. Bevor auf die Kritik am Begriff sowie Herbsts mögliche Zielrichtung eingegangen wird, soll erst einmal geklärt werden, in welcher Weise Herbst den Kybernetikbegriff verwendet.

Nach dem bereits thematisierten Vorkommen des Begriffs im Untertitel von $B A$ bleibt der Kybernetikbegriff präsent in Herbsts poetologischen Texten. Im Weblog wendet er den Begriff erstmals für die Bezeichnung der Poetik selbst an. 2004 schreibt er noch von »Kybernetische[r] Poetik «124, und 2005 ist vom »a n d e r e [ n ] Realismus ${ }^{125}$ die Rede, in dessen Erläuterung jedoch mehrfach etwas als »kybernetisch « bezeichnet wird. 2006 findet er dann zum vollständigen Begriff »Kybernetischer Realismus «, ${ }^{126}$ den er in der Folge entwickelt und in den Vorlesungen dann zusammenfasst. Dort setzt sich Herbst an drei Stellen mit der Begriffsverwendung auseinander:

Der von mir avisierte Kybernetische Realismus wird das ${ }^{127}$ bewußt tun, deshalb ist das Wort `kybernetisch ‘ am Platz: Kybernetik ist Steuerungslehre. $(K R, 58)$

[...] zumindest ist dies das Ziel ${ }^{128}$, auf das er bewußt zusteuert: aus der Bewußtheit ergibt sich der Steuer-, eigentlich Steuermannsbegriff und bezieht sich dabei als Poetik unter anderem auf einen Satz Ernst Haeckels, der die Evolution erstmals begrifflich als einen ökologischen Prozeß aufgefaßt hat; poetisch entscheidend ist dabei der Satz: Keine Bewegung in dem einen Bereich ohne Spiegelung in anderen (Bereichen). (KR, 81)

Dazu halten in nahezu derselben Epoche [der (literarischen) Moderne] die ökologischen Konzepte Ernst Haeckels in die moderne Wissenschaft Einzug: Konzepte vernetzter Systeme. So alt ist der moderne Begriff der Kybernetik, der seinerseits letztlich einer aus der Antike ist. $(K R, 102)$

Die Verwendung des Begriffs `Kybernetik ist hier auf zwei Aspekte beschränkt. Auf die kurze >Definition` als Steuerungslehre (mit dem Hinweis auf die etymologische Herkunft) sowie auf den Bezug zu vernetzten Systemen. Was nicht erfolgt, ist ein Hinweis auf die Wissenschaft, die in Deutschland zwischen 1950 und 1975 ihre Blütezeit hatte ${ }^{129}$ (höchstens aus dem dritten Zitat ließe sich ein solcher konstruieren), oder auf einen ihrer wesentlichen Vertreter (bspw. Norbert Wiener). Für Herbst ist ein solches Vorgehen unüblich; gerade in den Vorlesungen bezieht er sich viel auf poetische und auch theoretische Vorbilder oder Einflüsse. Sollte hier ein Bezug auf die Wissenschaft gemeint sein, wäre angesichts der begrifflichen Prominenz innerhalb der Poetik anzunehmen, dass er ihn auch explizit macht. Es finden sich jedoch keine Hinweise darauf.

Ein weiterer in den Vorlesungen vorkommender Begriff, der sich auf die Kybernetik beziehen lässt und kontextuell auch im Text darauf bezogen wird, ist der Begriff `Regel-

124 URL-33, 23. Nov. 2004.

125 URL-31, 1. Juni 2005.

126 URL-32, 30. Mai 2006, sowie URL-34, 1. Juni 2006.

127 Hier geht es um das bereits erwähnte `Ausgraben`verdrängter psychischer Belange.

128 Das Ziel soll sein, die "postmodernen Ästhetiken ab[zulösen], indem er ihre poetischen Ergebnisse bündelt und mit (über)lebensfähigen Theoremen der Moderne vereinigt«.

129 Vgl. Michael Hagner / Erich Hörl (Hg.): Die Transformation des Humanen. Beiträge zur Kulturgeschichte der Kybernetik, Frankfurt am Main 2008, 7. 
kreis`. Herbst bringt ihn in der dritten Vorlesung ins Spiel. Er sei als eine Grundstruktur des Kybernetischen Realismus anzusehen. Interessanterweise ist nachzuvollziehen, wie Herbst auf diesen Begriff gestoßen ist, da er ihn mit einer anscheinend zur Erklärung bestimmten Fußnote versieht (KR, $81 \mathrm{FN} 2$ ). Diese besteht aus einer URL, die auf einen Abschnitt zu Regelkreisen im Buch Dynamische Lebensplanung (2004) von Bruno Zinkanell bei Google Books führt. In der URL ${ }^{130}$ sind die Suchbegriffe »Kybernetik« und »Steuerungslehre« aufgeführt sowie als Quelle »web« angegeben. Herbst hat also über die Suchmaschine Google lediglich nach den Begriffen » Kybernetik« und "Steuerungslehre" gesucht, damit weder nach diesem speziellen Buch (das thematisch offensichtlich auch nicht in den Kontext passt) noch nach dem Begriff >Regelkreis selbst. Dieser scheint also durch eine mehr oder weniger zufällige Entdeckung ins Blickfeld geraten zu sein und wurde verwendet, weil er in den zu beschreibenden Kontext zu passen schien und die Verbindung zum Kybernetikbegriff stützen würde. Wichtiger als dieser kleine Hinweis ist aber, dass sich im Text zeigt, dass er nicht wirklich passt. Herbst ändert ihn auch sofort nach Einführung ab zur »Regelspirale[] « $(K R, 81)$ und widmet sich der Bedeutung von kreis- bzw. spiralförmigen Bewegungen in literarischen Werken oder literaturgeschichtlichen Entwicklungen. Diese seien als Kennzeichen des Kybernetischen Realismus zu begreifen; es handelt sich jedoch nicht um Regelkreise, ein möglicher Regler wird gerade nicht thematisiert, ist nicht ersichtlich und scheint für das zu beschreibende Phänomen damit irrelevant zu sein.

Der Begriff `Kybernetik « wird von Herbst also nicht auf die gleichnamige Wissenschaft bezogen, selbst das Bemühen, zugehörige Begriffe zu verwenden, scheitert. Der Blick auf andere poetologische Texte und vor allem das Weblog bestätigt diese Annahme. In dem Vortrag "Das Weblog als Dichtung «, der im Jahr der Vorlesungen publiziert wurde, wird Kybernetik begrifflich gleichgesetzt mit `Internet « und >Computer«. »[K]ybernetische[] Terminologie« entspricht hier der Umschreibung »in netztechnischer Hinsicht « und wird mit den »Grundbegriffe[n] des Programmierens $«^{131}$ zusammengebracht. Das Internet wird als »kybernetische[s] Netz[] «132 umschrieben, Leser "kybernetisieren ${ }^{133}$ sich im Netz, eine Onlinepublikation ist eine »kybernetische «134. Diese Begriffsverwendung deckt sich damit wohl mit der vom Ursprung weitgehend losgelösten Verwendungsweise des Präfixes `Cyber- $<$ in englischen Begriffen. In diesen Vortrag baut Herbst auch ein poetisches Gedankenspiel über die >Kybernetisierung〈Stuttgarts (des Veranstaltungsorts) ein, das sich "als und im Cyberraum « ${ }^{135}$ neu formt. An dieser Stelle passt die Gleichsetzung mit Internet nicht mehr ganz, vielmehr überträgt er den semantisch ebenfalls nicht ganz stimmigen Begriff der `cyberreality ins Deutsche, der passender durch den Begriff der

\footnotetext{
130 http://books.google.de/books?id=4Swrieu2944C\&pg=PA133\&1pg=PA133\&dq=kybernetik+ steuerungslehre \&source $=$ web \&ots $=1 \mathrm{EC} 8 \mathrm{VacXR} \& \operatorname{sig}=1 \mathrm{oVIvvfDtSupCFc1}-86 \mathrm{xwdyqgoE} \mathrm{v}=$ onepage \&q=kybernetik\%20steuerungslehre\&f=false

131 Herbst: "Das Weblog als Dichtung «, gf.

132 Ebd., 13.

133 Ebd., 19.

134 Ebd., 28.

135 Ebd., 21.
} 
>virtuellen Realität` gefasst wird. Ähnliche Stellen lassen sich auch gehäuft im Weblog finden. Um nur zwei zu nennen: in Bezug auf die US-amerikanische Fernsehserie Alias schreibt Herbst von Waffen und Firmen im »Bereich[] der Kybernetik « ${ }^{136}$, was sich auf solche bezieht, die mit Computer und Internet zu tun haben; oder in Bezug auf Online-Datenspeicherung spricht er vom »Zeitalter der Kybernetik « ${ }^{137}$.

Herbsts Verwendung des Begriffs `Kybernetikı ist also nicht einheitlich; es können aber drei Aspekte ausgemacht werden, die er mit ihm verbindet. Erstens kommt er mehrfach über die etymologische Erklärung auf die Bedeutung als Steuerungslehre, die jedes Mal in Kombination mit dem Aspekt der Bewusstheit einer Handlung verwendet bzw. erläutert wird. Zweitens verbindet er die Kybernetik mit vernetzten Systemen, was jeweils mit dem Hinweis auf Haeckels Ökologiebegriff erfolgt. Diese Assoziation verweist am ehesten auf die Wissenschaft Kybernetik. Drittens verwendet er den Begriff großteils synonym zu `Internet` bzw. `Computer «. In den Vorlesungen scheint die Kybernetik - trotzdem sie den Titel prägt - nicht von zentraler Bedeutung zu sein, sondern wirkt vielmehr wie nachträglich eingefügt. Sie wird wenig thematisiert und erläutert. Neben der zufälligen und nicht schlüssigen Verwendung des Begriffs $>$ Regelkreis`, scheint Herbst auch die etymologische Verbindung zum `Steuermann und damit die nicht ganz falsche, aber doch vereinfachende Übersetzung als ,Steuerungslehre erst nachträglich klar geworden zu sein. Darauf weist er in einer weiteren Fußnote hin. ${ }^{138}$

Gerade angesichts dieser theoretisch wenig fundierten oder schlüssig erklärten Verwendung halte ich den von Herbst verwendeten Kybernetikbegriff für unstimmig. Im Deutschen ist beim Wort Kybernetik der erste Gedanke keineswegs der an Internet oder Computer, wie das vielleicht im Englischen durch den Gebrauch der Vorsilbe $\curlywedge$ Cyber- $\iota$ möglicherweise der Fall ist (dabei sei noch einmal zurückgestellt, dass dies die Begriffsverwendung auch nicht stimmiger machen würde). Vielmehr verweist der deutsche Begriff \Kybernetik « eher auf die Wissenschaft und damit verbundene Denkweisen und Themen. Doch auch wenn dieser Bezug eindeutig wäre, so ist doch die Wissenschaft selbst in Definition und Umfang schwer zu fassen. Selbst in ihrer Blütezeit findet sich der bezeichnende Buchtitel Keiner weiß, was Kybernetik ist (1968) für eine »verständliche Einführung «. ${ }^{139}$ Weder hat Norbert Wiener eine umfassende

136 URL-35, 17. Mai 2009.

137 URL-36, 16. Mai 2008.

138 Siehe $K R, 102$ FN 13, mit Verweis auf URL-37, 26. Dez. 2007. Die dort aufgestellte Behauptung, der Begriff sei schon in der Antike verwendet worden, ist allerdings nicht richtig: >Kybernetik wurde als Begriff erst von Norbert Wiener gebildet. Es handelt sich bei seiner Wortschöpfung aber nicht um einen direkten Verweis auf die Antike, sondern um einen etymologisch komplexeren Bezug auf den ersten wichtigen Artikel über Rückkopplungsmechanismen; siehe Norbert Wiener: Kybernetik. Regelung und Nachrichtenübertragung im Lebewesen und in der Maschine [1948], übers. von E. H. Serr, unter Mitarb. v. E. Henze, Düsseldorf u. a. 1992, 39. Vgl. auch Lars Bluma: Norbert Wiener und die Entstehung der Kybernetik im Zweiten Weltkrieg. Eine historische Fallstudie zur Verbindung von Wissenschaft, Technik und Gesellschaft, Münster 2005, $27 \mathrm{f}$.

139 Rolf Lohberg / Theo Lutz: Keiner weiß was Kybernetik ist. Eine verständliche Einführung in eine moderne Wissenschaft, Stuttgart 1968. 
Definition formuliert, als er 1948 den Begriff formte und einführte, noch waren sich die bundesdeutschen Kybernetiker jemals einig, was Kybernetik sei. ${ }^{140}$ Und auch

»heutzutage weckt die Kybernetik die verschiedensten Assoziationen von menschlichen Maschinen und maschinell ergänzten Menschen, von redenden und sich selbst steuernden Autos und technisch substituierten Menschen im Fernsehen, von Diskussionen über die Existenz eines freien Willens in den Feuilletons, von der Befreiung des Menschen von jeglicher Routinearbeit und dem Verlust der menschlichen Kontrolle über das Leben. « $^{141}$

Die hier lediglich anklingenden Themen der Kybernetik als Wissenschaft erzeugen auf den ersten Blick den Eindruck, in Vielem mit den Themen in Herbsts Werken übereinzustimmen. Letztlich zeigt sich jedoch, dass weder die Denkweise noch (und vor allem) die Bewertung übereinstimmt. Sowohl die prominente Position des Begriffs in der Bezeichnung der Poetik als auch die `verlockende` Nähe der Themen zwischen Kybernetik und herbstscher Poetik erfordern aber eine nähere Beschäftigung mit ihr als bisher in der Sekundärliteratur (und auch Herbsts eigenen Texten) geschehen. Dabei ist anzumerken, dass Herbst als ein literarischer Autor keineswegs zu wissenschaftlicher Exaktheit verpflichtet ist. Darum ist das Ziel der folgenden Ausführungen weniger, die Begriffsverwendung zu `widerlegen`, als in Kontrast zu den mit der Kybernetik verbundenen Aspekten die Grundlagen der herbstschen Poetik zu akzentuieren.

\subsubsection{Was ist Kybernetik?}

Die Kybernetik war eine interdisziplinäre Wissenschaft, die aus den sogenannten Macy-Konferenzen (1946-1953) hervorging. Der Mathematiker Norbert Wiener prägte den Begriff in seinem Werk Cybernetics or Control and Communication in the Animal and the Machine von 1948. Dieser bezeichnete nach Wiener »das gesamte Gebiet der Regelung und Nachrichtentheorie, ob in der Maschine oder im Tier «142. Für die Kybernetik kennzeichnend war die mathematische Beschreibung und Darstellung von Systemen und die Untersuchung von Regelungs- und Rückkopplungsprozessen. Da alle Vorgänge als Systeme bzw. im Kontext eines übergeordneten Systems verstanden wurden sowie aufgrund ihrer Interdisziplinarität wurde sie als »Universalwissenschaft « mit grenzenloser Einsetzbarkeit aufgefasst. ${ }^{143}$ Im Kontext der Diskussion von Herbsts Verwendung des Begriffs sind vier eng miteinander verknüpfte Aspekte entscheidend, die gleichzeitig auch zentrale Themen der Wissenschaft waren: die Analogisierung von Gehirn und Maschine (und damit von Mensch und Maschine),

140 Vgl. Philipp Aumann: Mode und Methode. Die Kybernetik in der Bundesrepublik Deutschland, Göttingen 2009, 60 und 11. Zum von vornherein vergeblichen Versuch einer Definition siehe dort v. a. S. $49-59$.

141 Ebd., 11.

142 Wiener: Kybernetik, 39.

143 Vgl. Aumann: Mode und Methode, 12, 54-58, sowie Michael Hagner: „Vom Aufstieg und Fall der Kybernetik als Universalwissenschaft«, in: Michael Hagner / Erich Hörl (Hg.): Die Transformation des Humanen. Beiträge zur Kulturgeschichte der Kybernetik, Frankfurt am Main 2008, 38-71. 
die Betrachtung der Dichotomie Natur vs. Geist, die neue Betrachtungsweise von Kausalität sowie das Verhältnis der Kybernetik zum Computer.

Bereits im Titel der wienerschen Gründungsschrift zeigt sich prominent die Verbindung von Tier und Maschine. Etwas allgemeiner gefasst grenzt Wiener die Kybernetik denn auch auf die »Feststellung der funktionalen Gleichartigkeit von Nachrichtenund Regelungsprozessen in Organismen und Maschinen ${ }^{144}$ ein. Organische Systeme sollten demnach analysiert werden wie Computer, wohingegen diese bzw. technische Systeme im Allgemeinen nach deren Vorbild konstruiert werden sollten. Diese Gleichsetzung zeigte sich sehr deutlich in Wieners Formulierungen, wenn er von den "lebenden Maschinen [spricht], die wir Tiere nennen " ${ }^{145}$ oder von einer "große[n] Rechenmaschine, entweder in Form eines mechanischen oder elektrischen Gerätes oder in der Form des Gehirnes selbst « ${ }^{146}$. Die Analogisierung wurde durch eine neuartige Wendung in der Betrachtungsweise ermöglicht, durch die »Verwissenschaftlichung von Information unter Abstraktion von deren materiellen Trägern ${ }^{147}$. Nicht die Materialität wurde betrachtet, sondern die Funktion. Erst durch diesen Abstraktionsgrad war eine Gleichsetzung möglich. Eine weitere Voraussetzung für die Analogie war die Ansicht, alle menschlichen Denkvorgänge rational und vollständig analysieren zu können. Die Analyse und Erklärbarkeit ist die Voraussetzung für die technische Nachbildung. Diese Annahme bestimmte das mechanistische Menschenbild der Kybernetik. Die Forschung an kybernetischen Maschinen beinhaltet immer die Frage, ob das menschliche Gehirn nur durch die » Menge an neuronalen Schaltungen « ${ }^{148}$ leistungsfähiger sei als alle anderen Systeme, oder, andersherum betrachtet, ob ein Rechner mit ausreichender Rechengeschwindigkeit und Speicherkapazität die Leistung des Gehirns erreichen würde. Bei dieser Anschauung handelte es sich um den Versuch einer rational-szientistischen Erklärung der bislang nur grob verstandenen Gehirntätigkeit. ${ }^{149}$ Die Wirkung war, dass das cartesianische Denken erschüttert wurde, die Kybernetik gar als »vierte Kränkung der Menschheit nach Kopernikus, Darwin und Freud ${ }^{150}$ angesehen wurde, da das Denken nicht mehr ausschließlich dem Menschen vorbehalten schien. Doch stieß sie auch an ihre Grenzen, da festgestellt wurde, dass die Funktionsweise der Nervenbahnen keineswegs mit elektrischen Schaltungen identisch waren, geschweige denn alle psychischen Funktionen des menschlichen Geistes erklärt werden konnten.

Das kybernetische Vorhaben, die Schrift des Denkens zu lesen und das Denken als Schrift zu entziffern, also zuallererst das Denken auf seine wesentli-

144 Aumann: Mode und Methode, 11.

145 Wiener: Kybernetik, 20.

146 Ebd., 192.

147 Aumann: Mode und Methode, 58.

148 Ebd., 45.

149 Vgl. Bluma: Norbert Wiener und die Entstehung der Kybernetik im Zweiten Weltkrieg, 152.

150 Hagner / Hörl (Hg.): Die Transformation des Humanen, 10. Vgl. auch Erich Hörl: »Das kybernetische Bild des Denkens«, in: Michael Hagner / Erich Hörl (Hg.): Die Transformation des Humanen. Beiträge zur Kulturgeschichte der Kybernetik, Frankfurt am Main 2008, 163-195, besonders 18of. und 170, sowie David Porush: »Technology and Postmodernism. Cybernetic Fiction «, in: SubStance 9/2 (1980), 92-100, hier: 92. 
chen logisch-mathematischen Codes zu bringen und dabei noch das LogischMathematische selbst vom Ideenhimmel auf den Boden der physiologischen bzw. physiko-technischen Tatsachen seiner Schaltbarkeit herabzuholen, dieses Vorhaben bildete den Horizont und zugleich die Grenze der Zeit. ${ }^{151}$

Aus den beiden genannten Grundtypen der Analogiebildung, der Abstraktion von der Materialität und der Annahme der Mechanisierbarkeit und Mathematisierbarkeit des Denkens, wurden Schlussfolgerungen über die Körperlichkeit, die Materialität, gezogen. Allerdings ergibt dies einen logischen Zirkel und dementsprechend kein eindeutiges Ergebnis, sondern vielmehr zwei sich gegenüberstehende Schlüsse. Die Abstraktion von der Materialität führt zum Schluss, mentale Prozesse seien unabhängig von ihren physiologischen Grundlagen, die daher auch durch eine Maschine oder einen Datenträger ersetzt werden könnten. ${ }^{152}$ Die Gleichsetzung elektrischer Schaltkreise mit neuronalen Aktivitäten zusammen mit der Annahme, diese seien für alle Vorgänge im menschlichen Gehirn zuständig, ergab, »daß Logik in Materie verkörpert und ausgedrückt ist, in natürlichen wie in künstlichen Systemen «153. Von hier aus ist der Weg nicht mehr weit zur Vorstellung von Androiden, also menschenähnlichen Robotern, oder eben Holomorfen wie in der Anderswelt, die als technisch gebildete Wesen mit menschlichem Denkvermögen beschrieben werden.

Die Analogisierung von Gehirn und Maschine und vor allem die Überzeugung von ihrer Gültigkeit weist darüber hinaus auf den Anspruch der Kybernetik, die Trennung der zwei $>$ Kulturen ${ }^{154}$ - der Geistes- und der Naturwissenschaften - zu überwinden bzw. eine Brücke zwischen Natur und Geist zu bilden, oder gar »den psycho-physischen Dualismus oder das Leib-Seele-Problem aufzuheben «155. Aus der Sicht der Kybernetiker ist dies zunächst als gelungen zu betrachten: »Wo das Denken zum subjektlosen neuronalen Prozeß wird, kann keine Rede mehr von einer Subjekt-Objekt-Relation als ontologischer Leitbeziehung und dem entsprechenden Weltendualismus sein. « ${ }^{156}$ Es stellt sich allerdings die Frage, ob es sich tatsächlich um eine Brücke oder Aufhebung handelt oder vielmehr um eine Negierung des Bereichs des Geistes. ${ }^{157}$ Denn das kybernetische Denken mit dem Anspruch auf

151 Hörl: »Das kybernetische Bild des Denkens«, 167. Auch wenn die Gleichsetzung von Gehirn und Computer später durch die Kognitionswissenschaft überwunden wurde, wird dieses >Computermodell in einer neuen Forschungsdisziplin, der `computational psychiatry $\prec$, wieder virulent. Sein Status bzw. seine Funktion ist allerdings noch umstritten. Vgl. dazu Manuela Lenzen: „Geschaltet. Computer und Geist«, in: Frankfurter Allgemeine Zeitung 18.4.2012.

152 Vgl. Klein: Konstruierte Wirklichkeiten, 79 und 81.

153 Jean-Pierre Dupuy: The Mechanization of the Mind. On the Origin of Cognitive Science, Princeton / Oxford 2000, 12, zit. nach Hörl: »Das kybernetische Bild des Denkens«, 171.

154 Der Begriff geht auf auf einen 1959 gehaltenen Vortrag von C. P. Snow zurück, der eine Debatte ausgelöst hat, vgl. Snow: The Two Cultures: and a Second Look, und Klein: Konstruierte Wirklichkeiten, 7 .

155 Aumann: Mode und Methode, 56.

156 Hörl: »Das kybernetische Bild des Denkens«, 175.

157 Angesichts der Prominenz der Dichotomie Natur vs. Geist in Herbsts Werk ist anzumerken, dass die Begriffe bei den Kybernetikern etwas anders besetzt sind: die Natur umfasst hier die Naturwissenschaft und die Technik, wohingegen Geist und Psyche eher für das bislang Unerklärliche stehen. 
vollständige rationale Erfassung der Wirklichkeit war ein mathematisierendes Denken, das dadurch aber auch vereinfachend wirkte:

Kybernetik war die Bestrebung, die Diversifizierung des Wissens durch eine einheitliche Betrachtungsweise aufzuhalten und damit intellektuelle Sicherheit zu schaffen. Infomationstheoretisch verstanden war Kybernetik der Versuch, die Komplexität des Wissens durch Vereinheitlichung zu reduzieren und somit ebenfalls Sicherheit zu schaffen. ${ }^{158}$

Eine wichtige Erweiterung der traditionellen wissenschaftlichen Denkstrukturen war das Denken in Systemen und dabei besonders die Annahme, dass dort Kausalitäten nicht linear, sondern in Kreisbahnen oder interlinear wirkten. ${ }^{159}$ Doch auch durch solches immer komplexer werdendes Denken wie hier die Erweiterung gegenüber dem klassischen Kausalbegriff blieb sie im rational-logischen Denksystem gefangen.

Schließlich ist als eine prominente Facette der Kybernetik ihre enge Verknüpfung mit dem Computer zu nennen. Da kybernetische Maschinen im Gegensatz zu mechanischen Maschinen als Rechenmaschinen beschrieben wurden, waren Computer immer von zentraler Bedeutung. Die Kybernetik galt als wissenschaftliche Grundlage für die technische Entwicklung des Computers und stand als Begriff für die positiven wie (möglichen) negativen Auswirkungen der Technisierung und Computerisierung der Gesellschaft. ${ }^{160}$ In der häufigen Verwendung des Präfixes `Cyber- $<$ in computerund internetbezogenen Begriffen im Englischen, von denen einige in ihrer englischen Form auch in den deutschen alltäglichen Sprachgebrauch übergegangen sind, zeigt sich auch heute noch diese Verknüpfung. Doch auch wenn der Begriff `Kybernetik häufig damit verbunden wurde, war es doch nur ein »klingender Titel « ${ }^{161}$, keine stimmige Gleichsetzung: Kybernetik ist nicht dasselbe wie Informatik oder Computer Science, sie ist auch nicht identisch mit Künstlicher Intelligenz (KI). Diese beruhten (und beruhen) zwar auf Erkenntnissen der Kybernetik, sind jedoch eine spezifische Anwendung und spezialisierte Fortentwicklung. ${ }^{162}$ Vor allem teilen sie mit ihr nicht alle grundlegenden Annahmen.

\subsubsection{Parellelen zwischen Kybernetik und Herbsts Romanen und Poetik}

Bei dieser kurzen Vorstellung wichtiger Themen der Kybernetik fallen viele Bezüge zu Themen in Herbsts Werk und Poetik auf. Die zentrale Analogie von Gehirn und Maschine und damit verbundene Themen wie Automaten und Roboter im Verhältnis zum Menschen ist bei Herbst seit WB zu finden. Dort waren in einer Lesart die Bewohner und Gäste des Hotels entweder programmierte Gestalten oder aber durch die Computerprogramme von Daniello in ihrem Denken und Handeln beeinflusst. In den $A W$-Romanen wird es ein zentrales Thema durch die Holomorfen und ihre >menschliche` Identitätskrise. Die Dichotomie Natur vs. Geist wurde in Bezug auf WB

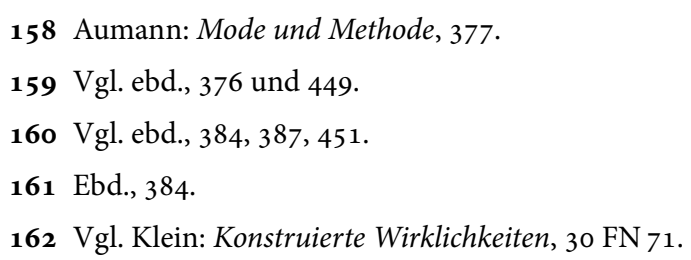


ausführlich behandelt und ist auch in den $A W$-Romanen zu finden. Ebenso spielt eine veränderte Auffassung von Kausalität (als Wirkungsgefüge) auch in Herbsts Poetik eine Rolle. Mit seinen Erzählkonstruktionen, die mal als Rhizom mal als unendliche Schleife beschrieben werden können, bezieht er sich auf systemisches Kausalitätsdenken. Auch im Begriff der `Möglichkeitenpoetikı, die die >Wahrheit ‘ und Existenz verschiedener nebeneinander bestehender Situationen annimmt und darstellt, finden sich Anklänge an moderne naturwissenschaftliche Theorien oder Fragestellungen wie das Gedankenexperiment von Schrödingers Katze, das wiederum in Bezug zu kybernetischen Überlegungen steht. ${ }^{163}$ Schließlich ist Herbsts Beschäftigung mit dem Computer offensichtlich - wie auch in der Analyse seiner eigenen Belegung des Kybernetikbegriffs deutlich geworden ist: von ersten Überlegungen in den Dschungelblättern Mitte der 1980er Jahre, über den »Biocomputer« in WB und der Omnipräsenz von Computertechnik in der Anderswelt bis zu Herbsts >realem` Experiment mit dem literarischen Weblog. Es gibt also offensichtlich viele thematische Übereinstimmungen zwischen Kybernetik und Herbsts Werk. Abgesehen davon, dass die Kybernetik in keinem Fall alle Themen in seinem Werk abdeckt oder auch nur betrifft, sind es vor allem nicht die entscheidenden. Vielmehr stehen die Ansichten der Kybernetik sogar denen von Herbst in seinen poetologischen Texten explizit postulierten und mehr oder weniger implizit in seinen Romanen vertretenen Positionen entgegen.

Der Vergleich des Gehirns mit einer Maschine und umgekehrt durch die Kybernetiker ist eine tatsächliche Analogisierung - sie haben nicht nur Ähnlichkeiten festgestellt, sondern eine funktionale Gleichheit angenommen. Wie oben dargestellt implizierte das die Annahme, alle Vorgänge im Hirn und damit im Denken des Menschen logisch-rational fassen zu können. Diese Auffassung steht jedoch Herbsts Grundanliegen entgegen. Zwar spricht er immer wieder seine Beschäftigung mit der Hirnforschung an und daraus folgend die Annahme, Menschen seien durch physiologische Vorgänge determiniert. An zentraler Stelle seiner Poetik steht aber dennoch die Annahme der poetischen Kraft des Unbewussten des Autors. Dass damit keineswegs ein maschinell-logisches Funktionieren gemeint ist, zeigt sich im Zusammenhang mit den im Ungefähren bleibenden Bedeutungshöfen und seiner unumwundenen Bekämpfung des Satzes vom ausgeschlossenen Dritten. ${ }^{164}$ Bei allen naturwissenschaftlichen Bedenken und rationalen Überlegungen bleibt sein Augenmerk doch gerade auf dem Irrationalen, dem logisch gerade nicht Bestimmbaren. Auch die zentrale Stellung der Dichotomie Natur vs. Geist ähnelt der bei den Kybernetikern, hat jedoch eine gänzlich andere Ausrichtung. Wie schon angemerkt bedeutet Natur bei ihm

163 Vgl. ebd., 206-216, 237.

164 Neben dem logozentristischen, mechanistischen Weltbild der meisten Kybernetiker findet sich noch eine für Herbsts Ansichten interessante Abspaltung: der Philosoph Gotthard Günther sah in der Kybernetik die »Wende in eine transklassische metaphysische Zukunft des Menschen«. Als >transklassisches« Denken bezeichnete er solches abseits des platonisch-aristotelischen Denkens und der klassischen Logik-Kalküle. Es war für ihn in der Kybernetik angelegt; interessanterweise machte er Vorboten dafür in US-amerikanischer Science-Fiction-Literatur und im »von einer nichtaristotelischen Intuition und Inspiration« getragenen »Dichten« aus. Dieser Denkansatz wurde jedoch keineswegs vom »Mainstream der >Wald- und Wiesen-Kybernetiker « geteilt und stellt damit einen nicht generell der Kybernetik zugehörigen Sonderfall dar. Vgl. dazu Hörl: »Das kybernetische Bild des Denkens«, 182-195, Zitate auf S. 182, 187, 193. 
gerade das Irrationale, ja sogar das Animalische und Körperliche, das durch den logischen Geist nicht bezwungen werden kann. Die Kybernetiker sahen den Geist als das Irrationale, das durch die (natürliche) Technik und Logik erklärt werden sollte. Der Graben zwischen den beiden Sphären sollte aufgehoben werden, jedoch im Grunde durch die Negierung des Geistes. Herbst zieht dagegen die Natur (in seinem Sinne) vor; die Präferenz in den Romanen ist eindeutig. Am Anschaulichsten ist dies wohl in $W B$ dargestellt durch die figürliche Verknüpfung mit Lipom und Murnau. Zwar hat die poetische Kraft Lipoms auch ihre Kehrseite, doch ist Murnau die eher lächerliche Figur, die trotz ihrer Modernität ums Überleben bangen muss. Deters gelingt es zu vermitteln, sodass beide Parteien zusammen eine Chance haben. Die Elbenposition wendet sich gegen die Übermacht der modernen Technisierung - und damit im Grunde gegen die Position der Kybernetik.

Einen breiten Raum in den Vorlesungen nimmt in Bezug auf die Zeitgemäßheit die Bedeutung der Neuen Medien und vor allem des Internets ein. In der 2. Vorlesung entwirft Herbst sein Verständnis des Internets (oder Cyberspace) als eines poetischen, phantastischen Raums. Er begründet die Zuordnung als »[Raum] von Zeitgenossenschaft« mit der Annahme, das Internet werde »innerhalb weniger Jahrzehnte die weltweit vorherrschende Kommunikationsplattform und also kulturbestimmend " $(K R, 44) .{ }^{165}$ In der 3 . Vorlesung beschäftigt er sich dann diesbezüglich vor allem mit den Auswirkungen des Internets auf das Buch als Medium. Dabei ist er hin- und hergerissen. Auf der einen Seite ist das Internet die wesentliche Möglichkeit, durch die technisch mögliche Grenzenlosigkeit und immerwährende Veränderbarkeit die unendliche Fülle der Realität und damit die Unabschließbarkeit ihrer Erzählung zu versuchen. Auf der anderen Seite ist ein »entscheidender, lebenabgewandter [sic!], also unvitaler und letztlich pessimistischer Nachteil der neuen Medien [...] genau diese Körper- und Materiallosigkeit« $(K R, 94)$. Diese lässt ihn am eigentlich von ihm eingestanden nicht mehr zeitgemäßen Buch festhalten und an dem Versuch, »zeitgenössische ästhetische Erfordernisse mit den alten Techniken zu vermitteln« $(K R, 94)$. Er begründet dies mit ideologischen Einwänden, die sich gegen die angenommene Körperfeindlichkeit des Monotheismus richten. ${ }^{166}$ Gemeint ist die Verbindung zur philosophischen Traditionslinie, die in WB bereits hinter der Murnau-Position steht. In den Vorlesungen deutet er kurz eine abendländische Tradition seit Aristoteles an, die er als lebensfeindliche Bewegung ins Körperlose beschreibt und die (später) stark mit dem Monotheismus verbunden ist. Darin würde der Geist präferiert, der Körper sei dagegen nie als Träger von Lust, sondern immer nur als Träger von Leiden und Krankheit betrachtet worden. Das Wort hätte als »entkörperter Fetisch «, als Geist, den höchsten Stellenwert, das Buch wäre dagegen »als Ding sein Leib« (KR, 96). Kennzeichnend sei in dieser Denkrichtung zudem die Konzentration immer auf ein Wesentliches (beispielsweise, aber nicht nur, Gott), alles andere sei akzidentiell (vgl. KR, 95). Das ist als eine Zentralperspektive angenommen, die einen Hauptstrang

165 Dabei erstaunt die verhaltene Prognose; dies ist bereits eingetreten.

166 Vgl. KR, 94-98. Diese Argumentation führt Herbst immer wieder an (vgl. Piberhofer / Schmökel: "Die Welt als Vorstellung und Selbstreferenz«, 3of., Herbst: »Flirren«, 24, Herbst: Die anthropologische Kehre, 1 FN 2). 
in den Mittelpunkt der Betrachtung stellt. ${ }^{167}$ Herbst sieht sein Beharren auf dem Buch in diesem Kontext als ein »heidnisches« $(K R, 94)$ an; ${ }^{168}$ die Verkörperung des Natürlichen und des Sinnlichen.

Zudem drückt Herbst seine Sorge gegenüber der persönlichen Erfahrung der direkten, unkörperlichen Wirkung des Wortes in Chats aus (vgl. KR, 99). Seine Befürchtung ist die Aussetzung des Körpers als Mittler, die direkte Wirkung auf das Gehirn (also den Geist). Er steht damit der »Vergeistigung des Körperlichen « entgegen; dabei versteht er das Körperliche bzw. den Körper als ein wichtiges Mittel, die Wirklichkeit in ihrer Gänze zu erfassen, »wozu eben auch sinnliche Komponenten« $(K R, 99)$ gehören. Das Körperliche meint hier jegliche sinnliche Erfahrung, explizit betont wird aber die sexuelle. Andererseits tritt Herbst vehement dafür ein, den >raumlosen Raum des Internets und speziell von Chats als einen wirklichen zu begreifen. Immer unter der Prämisse, Wirklichkeit sei das, was wirke, führt er das einfache Beispiel einer in einem Chat entstehenden Liebesbeziehung an, um zu zeigen, dass reale Wirkungen in einer virtuellen Umgebung entstehen können; »das eigentlich Abstrakte, material gar nicht Existente geht bis in die Herzen « $(K R, 22) .{ }^{169}$

Herbst beobachtet auch auf den Menschen in der Arbeitswelt bezogen einen konkreten Bedeutungsverlust des Körpers. In Fortführung der modernen Kritik an der Verdinglichung des Arbeiters und der Ersetzung durch Maschinen konstatiert er die zunehmende Bedeutungslosigkeit des Körpers in »)realen Arbeitsprozessen « ${ }^{170}$ aufgrund des umfassenden Einsatzes von Computern und ihren Auswirkungen auf die menschlichen Bediener. Eine gleiche Entwicklung sieht er in Bezug auf Soldaten, wie er am Beispiel des hochtechnisierten (Zweiten) Golfkriegs erläutert. ${ }^{171}$

Die Gegenüberstellung von Geist/Gehirn und Körper und ihre Darstellung als durch das Internet (bzw. den Computer und Neue Medien) hervorgerufene, aktuelle Problematik in Bezug auf die Identität wie die Wirklichkeitserfahrung des Menschen steht in direkter Beziehung zu Ungefuggers Zielen in der Anderswelt und kann in Bezug gesetzt werden zur Abstraktion der Kybernetiker von Materialität und ihren entsprechenden Visionen von denkenden Maschinen. Es kann davon ausgegangen werden, dass die »anthropologischen Fragen, die mit der Kybernetik aufgeworfen wurden, nach wie vor unerledigt sind $\aleph^{172}$, und Herbst sieht es als Aufgabe einer zeitgemäßen Poetik an, sich mit diesen auseinanderzusetzen. Hier wird jedoch besonders deutlich, wie sehr Herbst der Kybernetik entgegensteht.

167 Im politischen Kontext sieht er den Monotheismus als Struktur der Dikatur, vgl. Piberhofer / Schmökel: »Die Welt als Vorstellung und Selbstreferenz«, 31.

168 Kurz angedeutet sei die Widersprüchlichkeit der Argumentation: Herbsts Beharren auf dem Buch als Körper oder Material versteht er als heidnisch, während er hinter dem Buch als konzentriertem, abgeschlossenen Ganzen den reinzigen Gott $\triangleleft$ sieht und dementsprechend die Neuen Medien als sunendlichen offenen Medien wiederum mit dem Polytheismus und neuheidnischen Bewegungen verbindet $(K R, 96)$.

169 Herbst stellt Chats zudem oft als erotische Erlebnisse dar, die wiederum körperlich sind. Vgl. Piberhofer / Schmökel: »Die Welt als Vorstellung und Selbstreferenz«, 31.

170 Herbst: »Flirren«, 22.

171 Vgl. ebd., 23.

172 Hagner / Hörl (Hg.): Die Transformation des Humanen, 7. 
In diesem Kontext ist nun auf den zurückgestellten Einwand zurückzukommen, auch die Gleichsetzung von Kybernetik mit Internet würde die Verwendung des Begriffs nicht sinnfälliger machen. Wie gerade deutlich wurde, erachtet Herbst das Internet als prägend für die Zeit, wodurch es Auswirkungen auf eine zeitgemäße Poetik hat. Neben dem ausführlich behandelten Umstand, dass der missliche Anklang an die Wissenschaft in jedem Fall vorhanden ist, muss konstatiert werden, dass das Internet (bzw. Computer) - so prägend das Thema angesichts des Weblogprojekts Die Dschungel und der Thematik der $A W$-Reihe ist - keineswegs als der zentrale Aspekt der herbstschen Poetik angesehen werden kann. Der Themenkomplex des "Ausgrabens" von unbewussten Gefühlen oder gar Traumata kann als umfassender angesehen werden. Dieses Prinzip gilt für Herbst unabhängig vom Medium und auffällig ist, dass gerade die Bezeichnung - das »Ausgraben « - aus dem Roman Meere stammt. ${ }^{173}$ Dieser Text kann hier exemplarisch angeführt werden für Teile von Herbsts Werk, in denen viele seiner zentralen Themen zu finden sind und die er - gerade in diesem Fall - sicherlich als zu seiner Poetik zugehörig versteht, wo das Internet und Computer aber eine wenn überhaupt untergeordnete Rolle spielt.

Eine ähnliche Argumentation gilt auch für die Beschäftigung mit denkenden Maschinen (den Holomorfen) oder der cyborgartigen Veränderung des Menschen, worunter Herbst Piercings und andere `Körpermutilationen $`$ versteht ${ }^{174}$ : diese Themen kehren zwar immer wieder, bilden jedoch nicht den Kern der Poetik. In Bezug auf diese Zusammenhänge muss der Begriff der Kybernetik im Grunde als veraltet angesehen werden. Zwar entstammt die Thematik dem Denken der Kybernetik und im Wort Cyborg ist der Bezug zumindest rudimentär noch enthalten; was die denkenden Maschinen angeht, die Roboter und Holomorfen, wären Begriffe wie Biotechnologie, Bionik oder Künstliche Intelligenz (KI) inzwischen weitaus passender. Doch letztlich sind dies bei Herbst nur Themen und keine poetologischen Grundlagen.

173 Zitiert wird die Stelle in $K R, 15$, mit verstecktem « Nachweis auch in Herbst: »Poetologische Thesen III«, 48. Die Originalstelle findet sich in Alban Nikolai Herbst: Meere, Letzte, vervollständigte Ausgabe 2007, Frankfurt am Main 2008, 103.

174 Der Begriff Cyborg stammt aus der Raumfahrt. Die NASA beauftragte zwei Wissenschaftler, über die Anpassung von Astronauten an den Weltraum nachzudenken. Diese (Manfred Clynes und Nathan Kline) schufen 1960 in einem Aufsatz aus den Wörtern `cybernetic organism ‘ den Begriff Cyborg. In der Populärkultur, v. a. der Science-Fiction, wurde der Begriff vielfach aufgegriffen. Cyborgs sind jedoch keine Roboter, was vielfach verwechselt wird, sondern technisch modifizierte Organismen. Aufgrund von Entwicklungen in der Medizin, die Technikimplantate in Menschen ermöglichten, erhielt die Diskussion um Cyborgs immer wieder Nahrung. Künstliche Gliedmaße, Cochlea-Implantate, Hörgeräte oder die an dieser Stelle auch oft erwähnten omnipräsenten Mobiltelefone stellen noch nicht unbedingt die Grenzen des Menschseins infrage; wäre es jedoch möglich, eines Tages alle Teile außer dem Gehirn zu ersetzen, wäre die Frage berechtigt, ob noch von einem Menschen gesprochen werden kann (vgl. James Hughes: Citizen Cyborg. Why Democratic Societies Must Respond to the Redesigned Human of the Future, Cambridge, Mass. 2004, 100f.). Dies erinnert zum einen an die oben erwähnte Schiffsüberlegung von Thomas Hobbes' zur Identitätsfrage, zum anderen an die Überlegung, was einen Menschen ausmacht, die in der $A W$-Reihe anhand der Holomorfen behandelt wird. In den Vorlesungen spielen diese Themen allerdings keine Rolle; poetologisch werden sie v. a. in Herbst: Die anthropologische Kehre betrachtet. Vgl. zu Cyborgs im Allgemeinen und speziell zum Verhältnis von Cyborgs und Prothesen Westermann: Anthropomorphe Maschinen, 153-219, 225-276. 
Interessanterweise ist Herbst mit der problematischen Kombination des Kybernetikbegriffs mit Literatur nicht allein. David Porush hat in den 1980er Jahren zwei Aufsätze und ein Buch zu verschiedenen englischsprachigen Autoren verfasst, die er unter dem Begriff »cybernetic fiction « subsumiert. ${ }^{175}$ Herbert G. Klein griff 1998 diesen Ansatz in Bezug auf eine ähnliche Korpuswahl auf und modifizierte ihn. ${ }^{176}$ Porush bleibt in seiner $>$ Definition $\prec$ recht vage:

Postmodernist fiction (which does not exclude science fiction by any means) returns to the theme [of the Mechanized Man] by rendering it in texts which themselves imitate machines, purport to be machines or sgenerated by machines, or are structured like highly polished and integrated mechanical devices. I call this sub-genre of postmodernist fiction $>$ cybernetic fiction $\triangleleft{ }^{177}$

Obwohl er ihn kurz zu erklären versucht, hat auch er lediglich einen vagen Kybernetikbegriff, letztlich geht es ihm um eine ungefähre Verbindung zu Computern, Robotern und der Analogie zwischen Mensch und Maschine. Auch sein Maschinenbegriff ist nicht genau gefasst und führt zu Widersprüchen in der Argumentation. Klein verwendet den Begriff nicht ganz so plakativ, sondern spricht eher von kybernetischen Bewusstseinsformen und bietet ein umfassendes Hintergrundkapitel über die philosophischen Grundlagen des kybernetischen Denkens. Interessant sind diese Ansätze vor allem deswegen, weil die Einstellung, die in den untersuchten Texten erkannt wird, wie bei Herbst den kybernetischen Zielen gerade entgegensteht. Porush stellt fest, »[that] the cybernetic position directly threatens literature ${ }^{178}$ und dass daher in der Literatur eine Gegenposition aufgebaut wird: »[C]ybernetic fiction [...] effectively resist[s] the cybernetic paradigm from within [...]. [It] offers an equally taunting counternarrative. ${ }^{179}$ Neben der $»$ counternarrative ${ }^{180}$ und dem »countergenre ${ }^{181}$ soll es sogar als Art von `Impfung< dienen: »Cybernetic fiction, by anticipating the effacement of the discontinuity between man and machine, inoculates against the postmodern disease of technological determinism. ${ }^{182}$ Klein erkennt ebenfalls eine Gegenbewegung gegen »kybernetische[] Grundannahmen ${ }^{183}$ und schlägt daher den Begriff »trans-kybernetische Literatur « vor. Ich halte es jedoch wie bei Herbst nicht für sinnvoll oder auch nur für einleuchtend, Literatur, die sich in Bezug auf einige

175 Vgl. David Porush:»Technology and Postmodernism. Cybernetic Fiction«, in: SubStance 9/2 (1980), 92-100; David Porush: The Soft Machine. Cybernetic Fiction, New York / London 1985; David Porush: »Cybernetic Fiction and Postmodern Science«, in: New Literary History 20/2 (1989), 373-396. Bei The Soft Machine handelt es sich lediglich um die genauere Ausführung seiner Thesen aus dem älteren Aufsatz. Die untersuchten Autoren - bspw. John Barth, Donald Bartelme und besonders Thomas Pynchon - sind durchaus mit Herbst in Verbindung zu bringen. Dies gilt aber auch schon durch die metafiktionale und ’postmoderne Schreibweise.

176 Vgl. Klein: Konstruierte Wirklichkeiten.

177 Porush: »Technology and Postmodernism«, 93.

178 Porush: »Cybernetic Fiction and Postmodern Science«, 381.

179 Ebd., 374.

180 Noch einmal ebd., 393.

181 Ebd., 381.

182 Porush: »Technology and Postmodernism«, 100.

183 Klein: Konstruierte Wirklichkeiten, 194. 
- wenn auch zentrale Themen oder Aspekte - als eine »counternarrative« gegen die Kybernetik oder gar als >Impfstoff‘ gegen deren Gefahren interpretieren lässt, gerade als eine kybernetische zu bezeichnen. Auch die Abänderung in »trans-kybernetisch « ist dabei nicht hilfreich. ${ }^{184}$

\subsubsection{Worum es Herbst eigentlich geht: ‘Ökologie`, ‘Analogie` und ‘Seele`}

Sieht man nun aber den Begriff >kybernetisch` und den Bezug zur Kybernetik als nicht stimmig an, bleibt neben der Frage, warum Herbst ihn denn überhaupt benutzt (deren Beantwortung rein spekulativ wäre), die ungleich wichtigere, worauf es ihm in diesem Kontext eigentlich ankommt. Diese Zusammenhänge stellt er vor allem in der 3. Vorlesung dar, die als einzelne auch noch einmal den Gesamttitel trägt.

Zunächst fällt bei den eingangs erwähnten Zitaten zum Kybernetikbegriff in den Vorlesungen die mehrfache Kombination mit Ernst Haeckels Ökologiebegriff auf: ${ }^{185}$ "[P] oetisch entscheidend ist dabei der Satz: Keine Bewegung in dem einen Bereich ohne Spiegelung in anderen (Bereichen). « $(K R, 81)^{186}$ In seinen kontextuellen Erläuterungen wird deutlich, dass es ihm hier auf Wirkungsgefüge ankommt. Kausale Zusammenhänge seien nicht mehr genau bestimmbar, überall gelte das Prinzip der Nicht-Linearität, auch des Nicht-Hierarchischen. Die poetologische Konsequenz formuliert Herbst so:

Kybernetischer Realismus erzählt ökologisch, nicht ökonomisch ${ }^{187}$; es handelt sich um eine Poetologie der Spiegelungen und Wechselwirkung. Das bedeutet, daß in jederlei denkbare Richtung erzählt wird, auch in der Vertikalen und nicht nur horizontal, also nicht-linear. $(K R, 81)^{188}$

Die Anwendung ist am sichtbarsten in der nicht linearen Erzählweise, betrifft aber auch das multiperspektivische Erzählen. Herbsts Erläuterung der Wechselwirkungen und sogenannten >Regelkreise` führt Herbst aber schnell auf das Thema der Identität, das Auswirkungen auf verschiedenste Bereiche seiner Poetik hat. Erstmals formuliert er rundheraus seine Ablehnung von Identität; er setzt ihr die Ähnlichkeit entgegen und verbindet mit ihr die Analogie: "Aufgrund von Ähnlichkeiten erlauben sich sogar Schlüsse, die etwas von Wahrheit haben: Analogien.« $(K R, 85)$ Diese Überlegungen

184 Während Porushs Ansatz insgesamt nicht stimmig ist, >das Kybernetische` an der Literatur nicht wirklich bestimmt und zudem vielfach auf Merkmale verwiesen wird, die die (ebenfalls, aber nicht ganz so problematischen) Begriffe >postmoderne und/oder `metafiktionale nen, argumentiert Klein genauer. Ich halte bei ihm lediglich die Einordnung in das begriffliche Schema für nicht geglückt.

185 Der Bezug auf Haeckel gilt ausschließlich dem Ökologiebegriff. Herbst distanziert sich in einer Fußnote explizit von dessen politischen Implikationen; vgl. KR, $81 \mathrm{FN} 1$.

186 Das Haeckel-Zitat ist nicht bibliographisch nachgewiesen.

187 Neben dem Wortspiel ist dies ein Hinweis auf die Marktabgewandtheit des Kybernetischen Realismus sowie auf die `barocke Fülle` (vgl. KR, 93).

188 Nebenbei sei hier angemerkt, dass die Aspekte der Wechselwirkung und des Beziehungsgefüges in Systemen, die mit der Kybernetik verbunden werden können, auch in Haeckels Ökologiebegriff enthalten sind, weswegen Herbst ihn auch erwähnt. Stellt man sich daraufhin vor, er hätte seine Poetik `ökologischen Realismus` genannt, so ist die Erläuterungsbedürftigkeit und Problematik dieses Begriffs aufgrund seiner Konnotationen augenfälliger; prinzipiell gilt dies aber auch für den gewählten Begriff. 
sind zentral für Herbsts Einstellung zur Identitätsthematik. Zur Veranschaulichung bringt er wiederholt ${ }^{189}$ ein Beispiel aus Geschichte und Eigensinn (1981) von Oskar Negt und Alexander Kluge. Eine Karte von der Ausdehnung des Eisschildes im Europa der Eiszeit wird einer Abbildung des menschlichen Gehirns gegenübergestellt. Gedreht ähnelt die Kontur des Eisschildes der des Gehirns, das sich wiederum gerade in der Eiszeit sprunghaft entwickelt hat. Wie Herbst konstatiert, gibt es »keine deduktive, monokausal notwendige und monokausal hinreichende Schließkette von der Eiszeit zum Gehirn, aber es gibt eine unmittelbare Evidenz« $(K R, 86)$. Es geht ihm also gerade nicht um die Identität zweier Sachverhalte, diese wird hier sogar durch die negativ konnotierte Kennzeichnung als "geschlossen « $(K R, 85)$ abgelehnt. Die »unmittelbare Evidenz«, der »Eindruck eines je schon Bekannten, ja oft Vertrauten«, also subjektive Verbindungen ohne objektive Beweiskraft, stellen für ihn Kennzeichen von Dichtung dar: die Evidenz wird »in Form von Inspiration empfunden. Dabei wird der Identität - der Verführung, etwas als identisch auszugeben - sogar bewußt widerstanden und an ihre Stelle die Täuschung gesetzt« $(K R, 86)$. Vorherrschend ist jedoch nicht die Vorstellung einer Täuschung im Sinne der Vorspiegelung falscher Tatsachen, sondern gerade der Versuch der Darstellung einer hintergründigen Wahrheit. An die Stelle der Identität wird also der Begriff >Analogie ‘ gesetzt.

Dieses Prinzip der Analogie aufgrund von Ähnlichkeiten ist kennzeichnend für bestimmte zentrale Aspekte des herbstschen Werks:

- für Personen: Figuren werden einerseits als vollwertige Personen erzählt, die im Leser Mitfreude und Mitleid auslösen können; andererseits wird mit ihrer Determiniertheit und auch Oberflächlichkeit bewusst umgegangen (vgl. $K R$, 86)

- für Mythen: verschiedene Mythen werden ineinander geblendet oder ein Mythos in verschiedener, durchaus widersprüchlicher Gestalt erzählt; in beiden Fällen wird mit Ähnlichkeiten, nicht mit Identität gearbeitet (vgl. KR, 86f.)

- für Wirklichkeit und Fiktion: erzählt werden mögliche andere Welten und dabei werden »reale und imaginierte Fakten « $(K R, 117)$ gemischt; ebenso sind Autor-Figur im Text und realer Autor ähnlich, aber nicht identisch

Es wird der Anschein erweckt (teils eine bewusste »Täuschung «, KR, 86) einer direkten kausalen Verbindung oder von Identität, doch handelt es sich um Ähnlichkeiten, die einen poetologischen Spielraum haben, quasi eine "Leerstelle[] $(K R, 88)$, die vom Leser zu erkunden oder zu füllen ist. Es handelt sich um ein Sowohl-als-auch, nicht um ein logisch binäres Entweder-oder. In der fiktiven Welt wird die Annahme veranschaulicht, dass zwei Einordnungen oder Zuschreibungen zugleich gültig sein können.

Hinter beiden Aspekten - der Nicht-Linearität bzw. >Poetologie der Wechselwirkung` und der Favorisierung der Ähnlichkeit gegenüber der Identität - lässt sich letztlich wieder die zentrale Absicht ausmachen, die zeitgenössische Wirklichkeit zeitgemäß abzubilden, eben einen `neuen` Realismus zu schaffen. Beide Aspekte ma-

189 Siehe KR, 41f. und 85f.; vgl. auch schon Herbst: Rede zum Phantastik-Preis Wetzlar, 5. 
chen die Verwandlung zu einer "Grundbewegung « seiner Poetik, ${ }^{190}$ zusammen mit der »sinnliche[n] Repräsentanz der Nähe (der Ähnlichkeit) ineinander verwandelter Gestalten« $(K R, 86)$. Als Beispiel für die Verwandlung führt er literarische Figuren an, was auch als naheliegendes anschauliches Beispiel für den Zeit- und Wirklichkeitsbezug fungiert: »Erzählerisch" reflektiert werden sollten »die Spaltungen bzw. Verwandlungen, denen die erzählten Personen im Laufe der Romanhandlung ebenso ausgesetzt sind wie Realpersonen in den Bezügen ihrer jeweiligen Sozialsysteme ( $K R$, 87). Wie im Laufe dieser Arbeit mehrfach anhand der Romane überlegt, möchte er die identitätsbezogenen Erfahrungen des Menschen in heutigen Sozialgefügen durch die erweiterten Darstellungsmöglichkeiten literarischer Figuren "sinnlich " veranschaulichen. Neben dieser psychischen Erfahrung sind es moderne naturwissenschaftliche Theorien, die er verstärkt in der Literatur verarbeitet sehen möchte, und die beispielsweise durch das veränderte Verständnis von Raum und Zeit als nicht mehr absolute, statische Größen oder von nicht mehr genau bestimmbaren Zuständen wie im bereits genannten Beispiel von Schrödingers Katze der Grundbewegung der Verwandlung folgen. ${ }^{191}$

Als letzter Punkt ist noch einmal die Beschäftigung mit Technikthemen und speziell mit dem Internet aufzugreifen. Zwar kann dies wie oben nachgewiesen nicht unbedingt als notwendige Bedingung für Herbsts Poetik gesehen werden, doch ist die zentrale Bedeutung angesichts seines Kybernetikverständnisses offensichtlich. Er hält die Beschäftigung mit Technik und vor allem ihre Thematisierung in der Literatur für sehr wichtig, da er sie als kennzeichnend für die zeitgenössische Kultur erachtet. Zudem hält er die Technisierung für eine Entwicklung, die nicht mehr rückgängig gemacht werden kann und damit nicht einfach zu vernachlässigen sei. Dass es ihm jedoch gerade nicht darum geht, sie unhinterfragt zu begrüßen und als unhintergehbaren Umstand zu akzeptieren, zeigt sich am Schluss der Vorlesungen. Wieder einmal bringt er - nicht zufällig - >höchst unscharfe Begriffe ins Spiel: das Menschliche und die Seele. Zunächst sieht er in der zeitgemäßen »Affirmation « der technischen Entwicklungen, die er bei verschiedenen Kulturschaffenden (David Cronenberg, J. G. Ballard, Donna Haraway) beobachtet, einen Verlust dessen, »was wir unter dem höchst unscharfen Begriff `menschlich`verstehen « $(K R, 121)$, und damit einhergehend eine Entwicklung hin zur »Kälte« $(K R, 121 / 123)$ der Technik. Herbst will jedoch nicht affirmieren, sondern sich durchaus im Sinne des bereits behandelten Widerstands dagegenstemmen:

Dagegen ist es die Zielrichtung eines Kybernetischen Realismus, soviel wie nur möglich dieses Menschlichen - von dem, was für uns bislang die Seele der Dichtung ausgemacht hat - in die neuen technischen Welten, die ganz zweifelsfrei kommen werden, hinüberzuretten. $(K R, 121)$

Und der letzte Absatz der Poetik:

Für das, was dieser Begriff [Seele] immer gemeint hat, ist in den künstlichen Welten der Technologie, von denen wir existentiell abhängen, künstlerisch ein

190 Dies ist auch die zentrale These bei Reber, die den Begriff der Metamorphose in den Mittelpunkt ihrer Analysen stellt, vgl. Reber: Formenverschleifung.

191 Vgl. zu den Veränderungen von Raum und Zeit bei Herbst ebd., 369-388. 
Raum zu schaffen. [...] Kybernetischer Realismus heißt, es genau hiermit ästhetisch aufzunehmen, und zwar nicht, wie man meinen könnte, in der technischen Kälte, sondern indem wir ihr tun, was sie uns tun will: sie vereinnahmen - so daß wir ihr ein Organisches geben können, für das unser Körper einsteht - wie der auch der Tiere und Pflanzen. Und unsere Seele. $(K R, 122 \mathrm{f}$.

An dieser Stelle vereint Herbst seine zentrale Themen. Die Technik darf nicht ignoriert werden, da sie nun einmal vorhanden ist und zur Kultur der Zeit gehört (und auch einige Möglichkeiten erschafft). Die Technisierung bedeutet jedoch auch - über den notwendigen Zwischenschritt einer kompletten Rationalisierung, dem Anspruch, alles rational erfassen und erklären zu können - ein Erkalten der menschlichen Lebenswelt. Zugrunde liegt die Annahme, dass Gefühle im Allgemeinen und viele Gedanken des Menschen zu komplex bzw. anders geartet sind, um in eine binäre Struktur übersetzt werden können. Daher will Herbst der Kälte der technischen Umgebung zum einen die gerade nicht nach logischen Prinzipien erfassbare poetische Schaffenskraft entgegensetzen, zum anderen die Körperlichkeit des Menschen, die ebenfalls dem Rationalen entgegensteht. Der Körper und alles damit Verbundene (bspw. die Sexualität) sieht er nach anderen Prinzipien funktionieren. Körper und Seele des Menschen bilden ein »Organisches«, das der Technik entgegengesetzt wird. Damit wird impliziert, dass sie auch ein (organisches) Ganzes bilden, was der vielfach beschworenen Fragmentarisierung entgegensteht. Herbst hält an etwas scheinbar Überkommenem fest und will es gegen die neuen Entwicklungen verteidigen. Schon vorher findet sich diese Stoßrichtung in der Kennzeichnung seiner Poetik als einer solchen, »die sich dem Menschen zuwenden will« $(K R, 75)$. Dabei kommt er zu der tautologischen Schlussfolgerung, sie müsse dafür den Blick zurück aufs Humanitäre richten. Da sich hinter den umfassenden Einfluss von Computer und Technik nicht zurückgehen lasse, müsse die Bewahrung des Menschlichen in der technischen Welt versucht werden. Wieder formuliert er einen unauflösbaren, aber bewussten Widerspruch in Anlehnung an Adorno: »i $\mathrm{n}$ der Verdinglichung [sei] g e g e $\mathrm{n} «(K R, 76)$ sie zu arbeiten.

Bezeichnenderweise finden sich in dieser finalen Zielsetzung der Vorlesungen deutliche Bezüge zu Herbsts früheren Werken. Die Rede von der (technischen) Kälte schließt an den Kälte-Diskurs in $V G$ an, wo von Technik (geschweige denn Internet) noch gar nicht die Rede war. In Ansätzen bzw. auf abstrakter Vergleichsebene ist jedoch dort der hier wieder auftauchende Gegensatz zwischen natürlichen menschlichen Bedürfnissen und moderner Welt enthalten und sogar schon das > Gegenmittel : auch Falbin versucht, der `Kontaktarmut das Körperliche entgegenzusetzen.

Wichtiger noch ist der Bezug zu dem Konflikt der Geister aus WB. Ohne dass Herbst in den Vorlesungen auf diesen Bezug eingeht, ist seine Diagnose von der >unmenschlichen` technischen Kälte und die abhelfende Forderung, Seele in die Technik zu bringen, eine Umformulierung des Streits zwischen Lipom und Murnau und der `Lösung ‘, die Deters vorbringt. Dieser meint in der Thing-Rede, es mache »keinen Sinn, die Bäume zu besingen, wenn es keine mehr gibt, und ebenso wenig, die Technik nicht zu besingen, wenn sie überall ist « $(W B, 828)$. Er empfiehlt den Geistern, in die Automaten, die Maschinen und die Städte einzudringen, nur so habe 
die Natur eine Chance. Interessanterweise hat Leslie A. Fiedler ziemlich genau dies schon einmal 1968/69 als eine Anforderung an eine zeitgemäße Poetik formuliert:

Sie [unsere neuesten Poeten] sind überzeugt davon, daß Wunder und Phantasie, die den Geist vom Körper, den Körper vom Geist befreien, einheimisch werden müssen in einer Maschinenwelt, verändert vielleicht oder sogar transformiert, aber auf keinen Fall zerstört oder verdrängt werden dürfen. ${ }^{192}$

Eine Trennung von Körper und Geist befürwortet Herbst zwar wohl nicht, die Hoffnung aber, "gleichermaßen zu Hause in der Welt der Technologie und im Reich des Wunders ${ }^{193} \mathrm{zu}$ sein, ist eine Formulierung, die ebenso wie Deters' eine zentrale Anforderung von Herbst an die Poetik zusammenfasst.

192 Fiedler: »Überquert die Grenze, schließt den Graben!«, 72.

193 Ebd., 73. 
Teil V

Das Weblog 



\section{Das Weblog Die Dschungel. Anderswelt}

\subsection{Einleitung}

\subsubsection{Herbsts Internetpräsenz}

In den vorhergehenden Kapiteln ist bereits deutlich geworden, dass Computer und virtuelle Welten in den Romanen von Herbst eine wichtige Rolle spielen. Beruflich wandte er selbst sich dem Internet erst relativ spät zu. Nach der kurzen Mitarbeit an Thomas Hettches Projekt »Null« $(1999)^{1}$ hat sich Herbst im September 2003 eine eigene Website eingerichtet, die unter zwei URLs zu finden ist: http://www. albannikolaiherbst.de und http://www.die-dschungel.de.

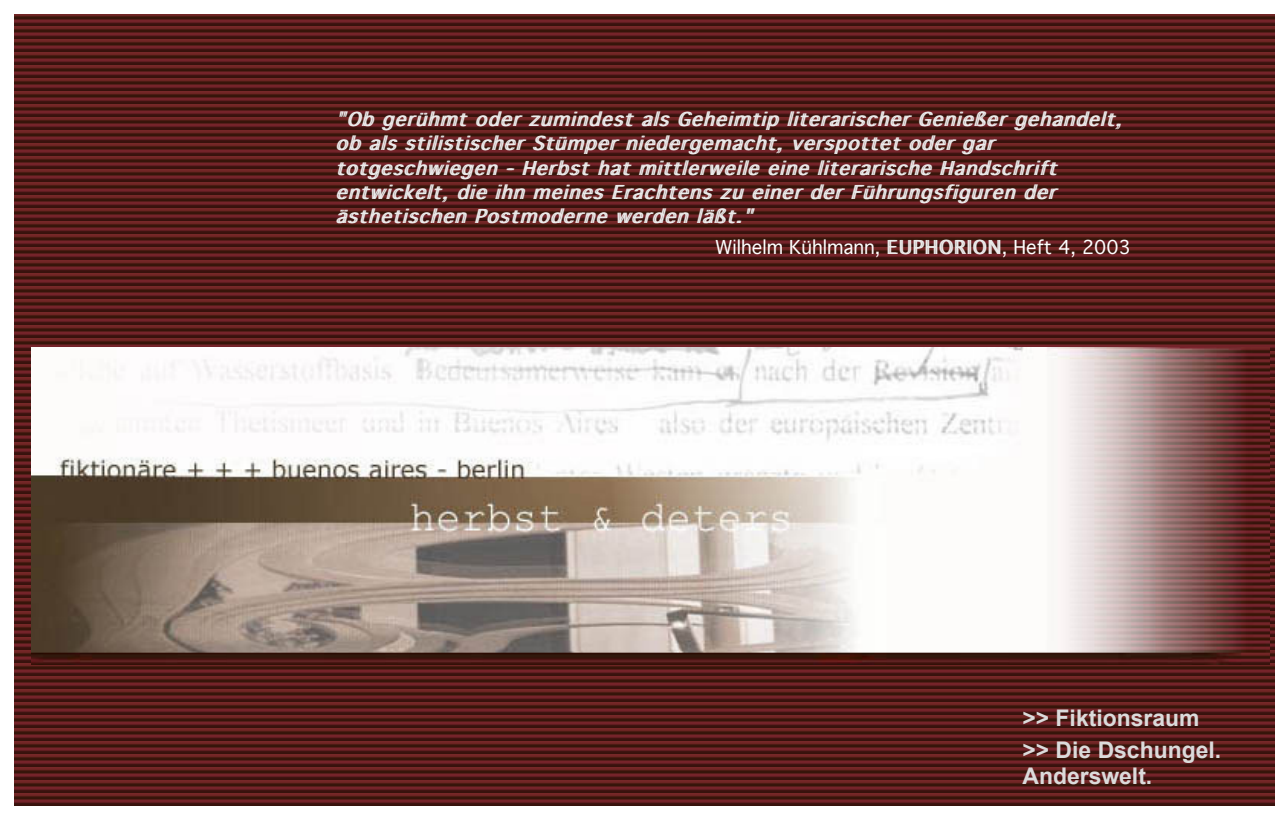

Abbildung 1: Startseite der Website

Auf der Eingangsseite sind inzwischen zwei Navigationsmöglichkeiten gegeben (siehe unten rechts auf Abbildung 1), ein Link in einen »Fiktionsraum «, der zur eigentlichen Website führt, und einen externen Link zu seinem Weblog, das auf der Plattform eines professionellen Webloganbieters gehostet wird. Die Website hat sich seit ihrer

1 Das ursprünglich auf den Webseiten des Dumont-Verlags geführte Projekt ist wie so viele der ersten Erprobungen von Netzliteratur nicht mehr abrufbar. Es wurde 2000 als Anthologie in Buchform veröffentlicht. 
Einrichtung in Layout und Struktur nicht gravierend verändert, ${ }^{2}$ da das Weblog das Hauptprojekt und damit auch die Hauptpräsenz für Herbst im Netz ist.

Luigi Ghezzi führte bereits 2002 drei Funktionen für Schriftsteller-Homepages auf. Diese Auflistung ist zwar recht abstrakt gefasst, kann gerade daher aber wohl immer noch Geltung beanspruchen:

1. ein Schaufenster, das die Promotionsdienstleistung der literarischen Werke anbieten kann, 2. einen Behälter für Rezensionen, Artikel, Aufsätze, 3. einen Ort der Kommunikation zwischen Autor und Leser, der noch viele interaktive Experimentiermöglichkeiten bietet. ${ }^{3}$

Für die ersten beiden Funktionen hat Herbst die statische Website ${ }^{4}$ vorgesehen, für die dritte das Weblog. Die Website stellt Herbsts Werk eher nüchtern dar. Die Bücher werden aufgeführt, kleinere Texte und Hörstücke als Dateien zum Download zur Verfügung gestellt. In gleicher Weise stehen auch Pressetexte, Sekundärliteratur zu seinem Werk in Form von Aufsätzen sowie Bilder zum Download bereit. Durch den Begriff »Fiktionsraum « und durch die Firmierung des Auftritts unter den Namen "herbst \& deters - fiktionäre. buenos aires - berlin« mit der Abbildung des bereits aus $B A$ bekannten Schilds wird die Fortsetzung der Romanpoetik gleich auf der Startseite deutlich gemacht. Scherer bemerkt dazu:

Auch in der Netzpräsentation kehrt die bekannte Verunklärung der Autorschaft wieder: Der empirische Autor Herbst und seine Figur Deters treten dort gemeinsam, ohne Markierung einer Differenz als `Fiktionäre ‘ auf. Von der Startseite aus gelangt man in einen >Fiktionsraum<, in dem man zahlreiche literaturkritische und literarische Texte findet, daneben Kurzbiographien von Herbst, Deters, Ribbentrop und Dietrich Daniello, und zwar so ungeschieden wie in den Romanen selbst, sodass auch hier der Besucher nicht entscheiden kann, was wahr und was erfunden ist ganz entsprechend einem Begriff von Wirklichkeit, der das Erfundene einschließt. ${ }^{5}$

Den Anschluss an die Poetik hat Herbst dann allerdings vor allem in das Weblog rausgelagert`, der »Fiktionsraum« dient der relativ objektiven Information der Öffentlichkeit. Die schon anfangs "zweifelhafte[] Hoffnung « des Autors, »das Netz könne seinen Buchumsatz steigern " $\left(K T L B^{6}, 6\right)$ hat sich als Trugschluss herausgestellt, war aber zu Beginn eins der Ziele der Unternehmung:

2 Vgl. http://web.archive.org/web/20031230153540/http://www.albannikolaiherbst.de.

3 Luigi Ghezzi: »Homepages von Schriftstellern. Zur Konstruktion einer literarischen Identität im Netz«, in: Erhard Schütz / Thomas Wegmann (Hg.): literatur.com. Tendenzen im Literaturmarketing, Berlin 2002, 24-41, hier: 40.

4 Unter der Bezeichnung >statische Websites` werden solche gefasst, die nur unregelmäßig aktualisiert werden und dementsprechend eine kontinuierlich präsente Oberfläche zeigen. Diesen stehen `dynamische Websites` gegenüber, die häufig aktualisiert werden und meist durch ein Content Management System mit einer Datenbank gepflegt und generiert werden, wie beispielsweise Weblogs.

5 Scherer: »Alban Nikolai Herbst $[K L G] \ll$. Die Seite mit den Biographien ist unter http://www.diedschungel.de/ANH/main.html?bio.html mainFrame zu finden. Vgl. dazu auch Jürgensen: »Ins Netz gegangen «, 417 .

62011 hat Herbst eine Auswahl seiner Reflexionen über das literarische Weblog als Buch herausgebracht. Dieses ist als »Erste Lieferung « annonciert: Kleine Theorie des Literarischen Bloggens. Die Dschungel. Anderswelt, Bern 2011. 
Die Homepage dient dem Sekundären, Vertrieb usw., das Literarische Weblog der entstandenen und entstehenden Ästhetik. Insgesamt ist aber die Entlohnung von Netzarbeit ein großes Problem. ${ }^{7}$

Dass die Homepage zu einem Nebenprojekt geworden ist, zeigt sich auch daran, dass beispielsweise die Termine seit 2007 nicht mehr aktualisiert wurden und nun in der Seitenleiste des Weblogs untergebracht sind.

\subsubsection{Das Weblog}

Das Weblog - um das es im nun folgenden Kapitel vor allem gehen wird - führt Herbst seit Juni 2004 unter dem Titel Die Dschungel. Anderswelt ${ }^{8}$. Einen visuellen Eindruck verschafft Abbildung 2 auf der folgenden Seite. Bereits im Jahr 2003 hatte es erste Anfänge auf einer anderen Plattform gegeben, die jedoch noch nicht den späteren ambitionierten und professionellen Rahmen hatten, sondern eher vom vorsichtigen Herantasten an etwas Neues zeugten. ${ }^{9}$

Im Gegensatz zu statischen, selten aktualisierten Websites oder >Homepages` sind Weblogs ein anderes Medienformat, das Ende der 1990er Jahre entstanden ist und es in der Folge zu großer Beliebtheit gebracht hat.

Es handelt sich bei ihnen um regelmäßig aktualisierte Webseiten, die bestimmte Inhalte (zumeist Texte beliebiger Länge, aber auch Bilder oder andere multimediale Inhalte) in umgekehrt chronologischer Reihenfolge darstellen. Die Beiträge sind einzeln über URLs adressierbar und bieten in der Regel die Möglichkeit, Kommentare zu hinterlassen. ${ }^{10}$

Weblogs stellten ursprünglich regelmäßig aktualisierte Websites dar, auf denen die Entdeckungen der frühen `Surfer ‘ protokolliert und als Links zur Verfügung gestellt wurden. Es waren damit `Logbücher des Internets, des >Webs`. Es hat sich inzwischen eine überaus große Vielfalt von Formen herausgebildet, die private Tagebuchblogs ebenso umfassen wie Firmenblogs zur Werbung oder auch zur Arbeitsorganisation. ${ }^{11}$

7 Frédéric Valin: »Interview mit Alban Nikolai Herbst«, 19. März 2008, URL: http://www.spreeblick. com/2008/03/19/interview-mit-alban-nikolai-herbst.

8 Alban Nikolai Herbst / Alexander von Ribbentrop: „Die Dschungel. Anderswelt. Die Dschungelblätter«. Weblog, seit 2004, URL: http://albannikolaiherbst.twoday.net.

9 Vgl. Alban Nikolai Herbst: »Weblogbuch«, 2003/2004, URL: http://tools.freecity.de/blog/show. phtml?id=albannikolaiherbst.

10 Jan Schmidt: Weblogs. Eine kommunikationssoziologische Studie, Konstanz 2006, 13.

11 Vgl. zum Begriff und zur Geschichte des Weblogs und als allgemeine Einführung ebd., 13-21, und Robert Folger: "New kids on the blog? Subjektkonstitution im Internet«, in: Jörg Dünne / Christian Moser (Hg.): Automedialität. Subjektkonstitution in Schrift, Bild und neuen Medien, Paderborn 2008, 283-304, hier: 284ff. 


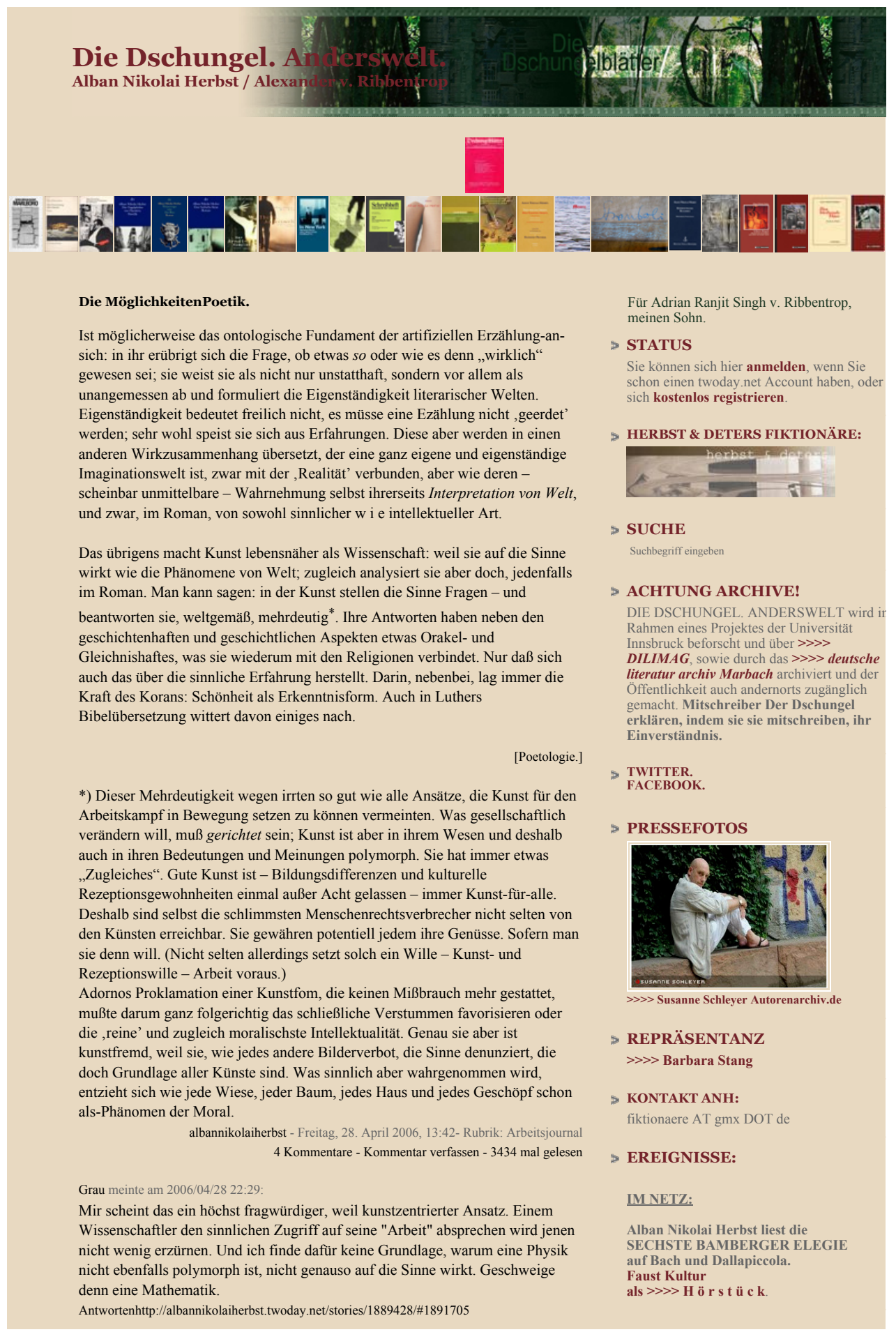

Abbildung 2: Das Weblog mit Header (oben), Seitenleiste (rechts) und Spalte für Einträge und Kommentare (links), Stand: Februar 2013 
Herbst bezieht sich in seinen Reflexionen und auch im Hauptteil seines Schreibens auf Blogs, die primär als Tagebuch fungieren. Den Begriff >Weblog〈erklärt er folgendermaßen:

Es handelt sich um eine Art im Internet öffentlich geführtes Tagebuch meist privaten, weniger häufig themengebundenen Inhalts. ${ }^{12}$

Auf die Frage, was sein Blog von herkömmlichen unterscheidet und was das Literarische an seinem Weblogverständnis ausmacht, werde ich später eingehen.

Als erstes oder zumindest bekanntestes deutschsprachiges literarisches Weblog wird oft auf Rainald Goetz' Abfall für alle verwiesen. Goetz führte 1998 auf der Domain www.rainaldgoetz.de ein Internettagebuch. 1999 wurden die dort zuerst publizierten Texte dann als Buch veröffentlicht. ${ }^{13}$ Zwar steht noch auf dem Buchrücken der broschierten Erstausgabe nicht wie üblich Autorname und Buchtitel, sondern die alte URL, doch ist das Projekt schon seit der Buchveröffentlichung nicht mehr im Internet zugänglich. Wenn der Leser das Tagebuch 1998 nicht unmittelbar mitverfolgt hat, bekommt er anhand des Buches keinerlei Eindruck von der ursprünglichen Publikationsform; er ist auf >zeitgenössische` Artikel und Aufsätze angewiesen, die diese thematisieren und schildern.

Roberto Simanowski hat eine eingängige Unterscheidung eingeführt, zwischen »Literatur im Netz« und eigentlicher »Netzliteratur ${ }^{14}$. Bei ersterer handelt es sich um Literatur, die ohne Verlust auch als Buch veröffentlicht werden kann und mit der »keine signifikant neuen Autorschaftskonzepte verbunden ${ }^{15}$ sind. Mit `Netzliteratur wird solche Literatur bezeichnet, die an das Medium Internet gebunden ist und »sich der spezifischen Eigenschaften des Internet [sic!] - also der Konnektivität - in ästhetischer Absicht bedient ${ }^{16}{ }^{6}$. Goetz’ Abfall für alle ist damit - zumindest ursprünglich - der `Literatur im Netz« zuzuschlagen. Damit handelt es sich im Grunde nicht um ein Weblog im eigentlichen Sinn, es könnte als Internettagebuch oder als Proto-Blog bezeichnet werden. Was es von einem herkömmlichen Tagebuch unterscheidet, ist die ursprünglich vorhandene Nähe zum Leser, der den Entstehungsprozess kontinuierlich verfolgen konnte. Es war eine »Gegenwartsnähe, die dem Leser den Eindruck suggeriert, dem Autor während des Schreibens gewissermaßen direkt über die Schulter schauen bzw. das Werk beim Entstehen beobachten zu können ${ }^{17}$. So auch Herbsts Einschätzung dieses Weblogs, »das eigentlich gar keines war: eine »Transformation in den Netzcharacter [sic!] fand [...] nicht statt; was er allein bedienen ließ, war die unmittelbare Aktualität« (vgl. KTLB, 94).

12 Herbst: »Das Weblog als Dichtung «, 14.

13 Vgl. Rainald Goetz: Abfall für alle. Roman eines Jahres, Frankfurt am Main 1999, 1998 unter www.rainaldgoetz.de veröffentlicht.

14 Roberto Simanowski: Interfictions. Vom Schreiben im Netz, Frankfurt am Main 2002, 17. Auch Roberto Simanowski: »Autorschaften in digitalen Medien. Eine Einleitung «, in: Text + Kritik 152 (2001): Digitale Literatur, 3-21, hier: 6.

15 Jürgensen: »Ins Netz gegangen«, 407.

16 Simanowski: Interfictions, 17.

17 Jürgensen: »Ins Netz gegangen «, 410. 
Wichtig ist diese Einordnung von Abfall für alle, weil an diesem sehr bekannten Beispiel der Gegensatz zu Herbsts Weblog aufgemacht werden kann. Ursprünglich hat auch Herbst überlegt,

"wesentliche Teile seines Literarischen Weblogs als Buch zu publizieren. Ein Collagenwerk also nach der Art des benjaminischen [sic!] Passagenwerkes, eine Art Teppich aus Literarischem Tagebuch, Arbeitsjournal, Aphorismen, Entwürfen, Diskussionen und Fotografien. Beiliegen soll diesem Buch zudem eine CD-Rom mit dem gesamten Weblog als Schnittstelle zwischen Netz und Buch. ${ }^{18}$

Inzwischen ist jedoch schon durch die schiere Menge der Einträge und Diskussionen klar, dass eine Veröffentlichung nicht möglich ist, ohne den Charakter des Gesamtwerks und vor allem seiner Rezeption zu beschneiden und zu verändern. Dies zeigt sich auch schon anhand von KTLB, das Auszüge aus der gleichnamigen Rubrik sammelt. Es fehlen hier jedoch komplett die zugehörigen Kommentarbäume, weitere Angaben wie das Datum wurden weggelassen und zudem ist die Anordnung anders (nicht chronologisch bzw. umgekehrt chronologisch) gewählt. Die Texte wirken so wie aus dem Kontext gerissen bzw. bewusst in einen anderen Kontext und in eine andere (An-)Ordnung gesetzt.

Drei Aspekte sind es vor allem, die Herbsts Weblog zu `Netzliteratur machen und es damit von Buchpublikationen deutlich unterscheiden: das bewusste intensive Nutzen der Kommentarfunktion und damit die Leserinteraktion, die Verlinkung innerhalb der Seite und nach extern auf fremde Websites, sowie die kontinuierliche Fortschreibung, d. h. keine Begrenzung des Projektes im Vorhinein. ${ }^{19}$ Herbst stellt in dieser Hinsicht das Blog immer wieder in Kontrast zum Buch: das Blog sei »weiterschreibendes Geschehen«, es »entsteh[e]«, das Buch sei im Gegensatz dazu »immer schon fertig $\aleph^{20}$. Oder normativer: »Für das Komplette und Fertige sind die Bücher zuständig (etwas, das ich an Büchern nicht mag), für den Prozeß, also das Prozessuale, ist es Die Dschungel.« (KTLB, 107f.) Diese Überlegungen stehen auch im Kontext seiner Poetik der Zeitgemäßheit, die er in seinen Poetikvorlesungen reflektiert. ${ }^{21}$ Dort macht er klar, dass er gefühlsmäßig am Medium Buch hängt, aber sieht, dass

18 Lothar Glauch: »Die Muse küsst binär«, 30. Apr. 2005, URL: http://www.heise.de/tp/r4/artikel/19/ 19939/1.html. Vgl. auch die eigens eingerichtete Rubrik zum Thema im Blog: URL-38.

19 Dass Thomas Ernst in seinem kurzen Versuch einer Typologie des literarischen Weblogs Die Dschungel ausgerechnet in die Kategorie »Litblogs, die das Medienformat Weblog zur Archivierung und Distribution literarischer Texte nutzen, die auch jenseits des Mediums Weblog funktionieren würden « einordnet, zeugt gerade auch noch in Gegenüberstellung zu Rainald Goetz von einer Verkennung des Charakters dieses Weblogs. Dementsprechend sind auch die anderen Typeneinteilungen wenig hilfreich. Vgl. Ernst: »Weblogs«, 294-298, hier: 294. Auch Florian Hartling meint, dass Herbsts Blog nur »beinahe wie Netzliteratur« wirke, da die Texte »durchweg im klassischen Printmedium reproduzierbar wären " (Hartling: Der digitale Autor, 229). Er gesteht aber ein, dass "seine Poetologie $[\ldots]$ strukturell und selbstreflexiv die Merkmale des Netzes" nutze und dass Herbst »eindeutig [...] als Vertreter einer digitalen Literatur angesehen« werde. Seine Einschätzung bezüglich der Einordnung vernachlässigt wie auch Ernst die schiere Dimension und strukturelle Unbegrenztheit

20 Herbst: »Das Weblog als Dichtung«, 9.

21 Siehe Abschnitt 7.3.2 auf Seite 354. 
das Internet Möglichkeiten bietet, die seinen poetischen Vorstellungen beispielsweise von der ungebundenen `Fülle ‘ des Erzählens entgegenkommen. Zwar ist diese `Fülle a auch in den umfangreichen Romanen zu finden, doch übersteigt die Menge der im Weblog entstandenen Texte diese bei weitem. Es besteht aber auch abseits von quantifizierenden Vergleichen ein grundlegender Unterschied:

Während der in einem Buch blätternde Leser sich immer im Besitz des ganzen Textes weiß, fehlt dem linkverfolgenden Leser das Bewusstsein von der Endlichkeit des Textangebots. ${ }^{22}$

Zusätzlich gilt auch, dass der Leser aufgrund der umgekehrt chronologischen Anordnung normalerweise nicht mit dem >Anfang` des Weblogs anfängt, sondern mit den neuesten Einträgen und sich von dort ggf. über verschiedene Navigationsmöglichkeiten andere Teile erschließt. Auf diese Navigationsmöglichkeiten und Elemente des Weblogs soll nun genauer eingegangen werden.

\subsubsection{Aufbau des Weblogs}

Das Weblog wird auf der Plattform des Webloganbieters twoday.net gehostet. ${ }^{23}$ Das Angebot wird Herbst kostenlos als Sponsoring von diesen zur Verfügung gestellt, ${ }^{24}$ sonst wäre es für ihn aufgrund der Größe des Projekts nicht zu finanzieren. Das Layout ist individuell angepasst, dennoch ist v. a. durch das Nutzen eines professionellen Anbieters der typische Aufbau eines Weblogs und das spätestens seit Einsetzen des >Hypes` ums Blogging übliche technische Niveau (mit Content Management System, Abonnement via RSS-Feed, Kommentarfunktion etc.) gegeben. ${ }^{25}$ Drei Elemente aus Abbildung 2 werden im Folgenden genauer beschrieben:

- Header

- Seitenleiste

- Spalte für Einträge bzw. einen Eintrag und Kommentare darunter

\section{Header}

Der Titel des Weblogs bietet durch den Untertitel bzw. Titelzusatz »Anderswelt« Anschluss an Herbsts Romantrilogie. Dies ist jedoch nicht inhaltlich-thematisch zu sehen, sondern kann als ein Hinweis darauf gedeutet werden, dass er hier direkt an die Poetik seiner Romane anschließt, was die Vermischung von Fiktion und Schilderung von Fakten der aktualen Welt bedeutet.

Der eigentliche Titel Die Dschungel wiederum schließt an ein früheres Projekt von $\mathrm{ihm}$ an, die Zeitschrift Dschungelblätter, die er von 1985 bis 1989 herausgegeben hat (und die im Bild mit einem Dschungel neben dem Titel auch genannt werden). Die

22 Glauch: Die Muse küsst binär.

23 Für weitere Informationen zu diesem Anbieter vgl. Schmidt: Weblogs, 149-170, besonders $149 f$.

24 Vgl. URL-39, 8. Aug. 2006, sowie Herbst: »Das Weblog als Dichtung«, 10.

25 Für eine Auflistung und Erläuterung der üblichen Blog-Elemente ist der Wikipedia-Eintrag sehr hilfreich, vgl. Wikipedia: »Blog«, 17. März 2015, URL: http://de.wikipedia.org/wiki/Blog. 


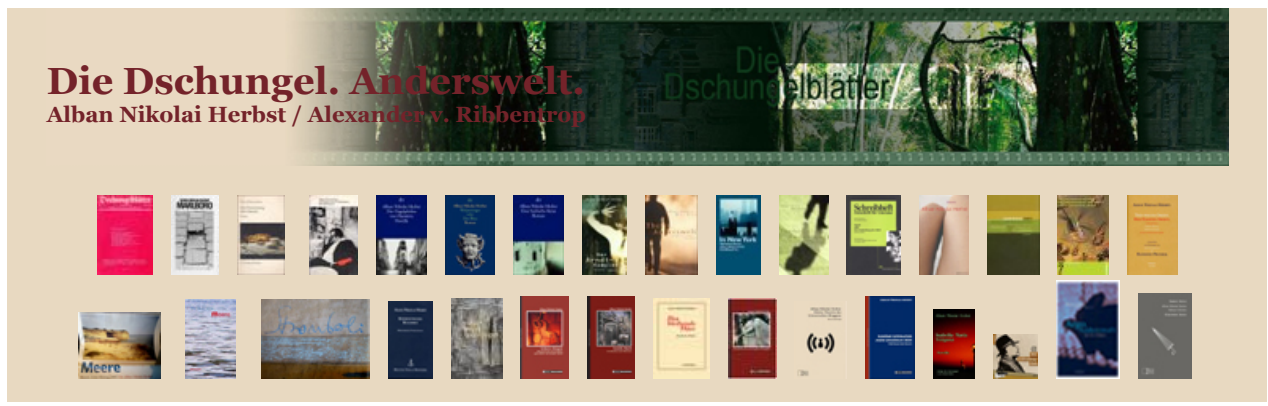

Abbildung 3: Header des Weblogs, Stand: März 2015

Zeitschrift bezog sich in ihrem Titel auf Rudyard Kipling, der in diesen immer wieder zitiert wurde. Dieser verwendete »)jungle $<$ weiblich, sie wird ihm zur poetischen Mutter - oder zur, um das zugleich zeitgenössisch wie metaphorisch-plausibel auszudrücken [...] Matrix « ${ }^{26}$. Dieser literarische Bezug begleitet Herbst sogar schon länger, da er bereits in den 1970er Jahren seine Texte fotokopiert in einem Fantasieverlag mit dem Namen »Die Dschungel « veröffentlichte. ${ }^{27}$

Direkt unter dem Titel findet sich die Nennung des bzw. der Autorennamen (wie auch schon in der URL). Zum einen wird das Projekt dadurch, ebenso wie auch durch die Fotos in der Seitenleiste, deutlich zu einem individuellen Autorprojekt. Trotz der Mitarbeit weiterer Autoren und der Mitwirkung der Leser in den Diskussionen, bleibt das Projekt klar auf Herbst zugeschnitten. Seit März 2007 führt Herbst hier an prominenter Stelle auch wieder seinen Geburtsnamen Alexander von Ribbentrop, der zumindest in der Öffentlichkeit lange nicht bekannt war.

Darunter finden sich kleine Abbildungen (Thumbnails) der Cover der bisher erschienenen Bücher von Herbst. Diese verweisen wie der Titel auf den Anschluss an das Gesamtwerk des Autors und veranschaulichen die vollbrachte Leistung auch quantitativ, was Herbst immer wieder wichtig ist zu betonen.

\section{Seitenleiste}

Ungewöhnlich für ein Weblog, jedoch die Gleichbehandlung mit den Printpublikationen betonend, ist die Widmung an den Sohn: „Für Adrian Ranjit Singh v. Ribbentrop, meinen Sohn.« Diese hat Herbst fast von Anfang an aufgeführt, weswegen die oben genannte `Offenlegung` der eigenen bürgerlichen Identität auch schon vorweggenommen war. Allerdings war sie im Literaturbetrieb auch spätestens seit 1999 bekannt. Die Widmung erfolgt explizit in einem sehr frühen Eintrag:

26 URL-40, 26. Juni 2004.

27 Vgl. URL-40, 26. Juni 2004. 
Ich widme dieses Weblog meinem Sohn, der es eines Tages lesen wird: in dieser oder einer anderen, dann zeitgemäßen Form, von der ich momentan noch nichts weiß und vielleicht niemals etwas wissen werde: für Adrian. ${ }^{28}$

Auf die identitätsstärkende Funktion des Weblogs, die auch den Sohn betrifft, weswegen eine Widmung sinnfällig ist, ist später zurückzukommen. Auch wenn viele Einträge bestimmt nicht für ein noch so junges Kind (geb. 2000) gedacht sind (beispielsweise sexuell explizite Darstellungen), spricht Herbst ihn auch immer wieder direkt an (wobei er immer die Zukunft als Lektürezeitpunkt ansieht und im obigen Zitat gleich eine mögliche Medienentwicklung mitanspricht):

Mein Sohn, wenn Du das eines Tages liest - denn für Dich, eigentlich $n \mathrm{u} \mathrm{r}$ für Dich, entsteht dieses Tagebuch; alle anderen lesen nur $\mathrm{m}$ i t -: [...]. ${ }^{29}$

Stringent hält er diese Absicht jedoch nicht durch, da er auch immer wieder die "Leserin « anspricht, die wie ein generisches Femininum gebraucht wird. ${ }^{30}$

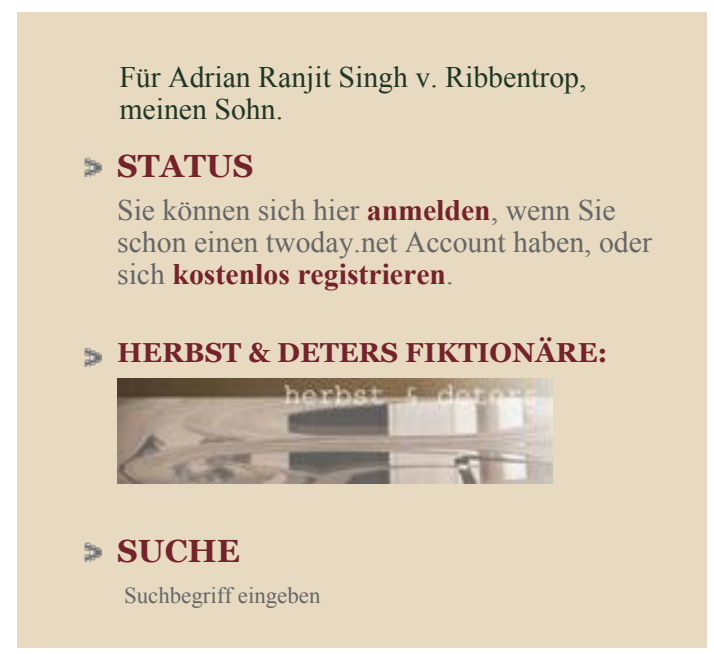

Abbildung 4: Ausschnitt der Seitenleiste mit Widmung, Anmeldung, Suchfeld und Link zur Homepage

Weitere Elemente der Seitenleiste sind generische Elemente eines Weblogsystems, die von Herbst für Ankündigungen angepasst wurden, die längerfristig gelten.

- Anmeldung für Kommentare

- Suchfeld

- Links auf die eigene Website www.albannikolaiherbst.de, Twitter, Facebook, seine `Repräsentanz` durch die Literaturagentin Barbara Stang, E-Mail-Kontakt

28 URL-41, 6. Juli 2004. Die Durchstreichungen stammen von Herbst, der eine Zeitlang alle auf sich verweisenden Pronomina durchgestrichen hat, um den subjektzentrierten Charakter der Aufzeichnungen zu hinterfragen; kurze Zeit später hat er dies aber wieder aufgegeben.

29 URL-42, 15. Juni 2006.

30 Vgl. dazu auch $W V$, ii, wo er von »der schwimmbereiten Leserin« spricht mit dem Zusatz in Klammern »Männer lesen Bücher nur selten«. 
- Pressefotos

- Archivierungshinweis (seit 2007) 31 $^{31}$

- Ereignisse (eigene Lesungen und Auftritte)

- Ankündigungen neu erschienener Bücher

- »Die Kapitel« - Kategorien als Navigationslinks

- »Neues« - neueste Einträge und Kommentare aufgeführt als Liste

- Literaturlinks

- "Archiv« - die bisherigen Monate seit Juni 2004 als Navigationslinks

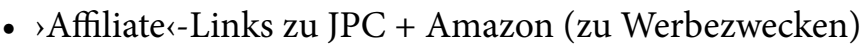

- Statistik und Impressum

\section{Einträge}

Die Einträge selbst enthalten ebenfalls die Elemente eines üblichen Weblogeintrags:

- der Titel des Eintrags, den Herbst im Arbeitsjournal als oft eher kryptische Bezeichnung wichtiger Ereignisse des Tages nutzt

- der Eintrag selbst, der außer Text noch Bilder enthalten kann, aber ansonsten keinen weiteren Spielraum für individuelle Layoutänderungen zulässt

- Autor (neben Herbst schreiben weitere Autoren; die aktivsten werden weiter unten vorgestellt)

- Datum und Uhrzeit

- Rubrik/Kategorie/Kapitel (für die Navigation der Seitenleiste)

- Kommentare

- genaue Anzahl der Aufrufe des Eintrags

Jeder Eintrag und jeder Kommentar haben also ein Datum und eine Uhrzeit, womit der Ablauf der Postings genau nachvollzogen werden kann, sowie einen permanenten Link, d. h. eine URL, die genau auf den spezifischen Eintrag verweist. Die Kommentare können sowohl unangemeldet als auch angemeldet erfolgen, was Herbst immer als anonym vs. nicht anonym bezeichnet, obwohl auch die Anmeldung keinen Klarnamen oder gar Nachweis erfordert. Zur Bedeutung dieser Unterscheidung für Herbst später mehr.

Es gibt verschiedenste Arten von Einträgen, wobei das Arbeitsjournal (bzw. anfangs das Tagebuch) wohl die regelmäßigste und häufigste Art ist. Das Arbeitsjournal dient der täglich mehrfach aktualisierten Aufzeichnung der Geschehnisse und Überlegungen des Tages, was die Protokollierung der literarischen Arbeit umfasst. Außerdem gibt es verschiedene >Reihen`, die Aphorismen, poetologische Überlegungen, Operund Literaturkritiken und anderes umfassen. Herbst stellt auch immer wieder >Arbeitsproben $\triangleleft$ d. h. frühe Fassungen von Texten, Erzählungen und Gedichten, ein, die teils ausführliche Diskussionen mit den Lesern nach sich ziehen. Ein regelmäßiger

31 Seit 2007 wird das Weblog durch das Deutsche Literaturarchiv Marbach (http://literatur-im-netz. dla-marbach.de/zdb2475905-3.html) sowie durch das Projekt DILIMAG am Innsbrucker Zeitungsarchiv (IZA) (http://webapp.uibk.ac.at/dilimag/magazineDetail.jsf?id=79) archiviert. 
Eintrag sind auch die »DTs«: Diese Abkürzung bedeutet »Den Tag strukturieren« und ist eine Auflistung des Tagesablaufs, die Herbst phasenweise ins Blog einstellt. ${ }^{32}$

Es gibt verschiedene Wege, die Einträge zu erreichen. Auf der Hauptseite, dem Zeitstrahl jedes Weblogs, sind die Einträge in chronologischer Reihenfolge aufgeführt, wobei jedoch die Einträge des Arbeitsjournals normalerweise nicht aufgeführt werden. Diese können wie andere auch über die Rubriken oder die Auflistung "Neues« in der Seitenleiste aufgerufen werden. Ein wichtiger anderer Zugangsweg erfolgt nicht über den Browser, sondern über ein externes Programm, einen Feedreader. Über das Abonnement des auf der Seite zur Verfügung gestellten RSS- bzw. Newsfeeds können die Einträge in der Reihenfolge des Einstellens automatisch abgerufen werden.

Vor allem die Einträge des Arbeitsjournals enthalten meist Vermerke über den Ort (wenn Herbst auf Reise ist) sowie welche Musik er gerade hört. Zumindest ersteres ist typisch für Herbst schon in den Romanen, in denen meist auf der letzten Seite die Entstehungsorte und -zeiten vermerkt sind. ${ }^{33}$

\subsection{Literarizität und Kunstanspruch}

Der Aspekt der Literarizität bzw. der Kunstanspruch des gesamten Projektes ist von entscheidender Bedeutung für das Weblog Die Dschungel. Herbst versteht es explizit als ein literarisches und setzt es damit immer wieder von anderen Weblogs, vor allem den von ihm so genannten »Plauderblogs" (KTLB, 83 und 96), ab.

Eine etablierte Definition des Terminus `literarisches Weblog`gibt es bisher nicht. Thomas Ernst schlägt diesbezüglich drei »mögliche Bestimmungsmerkmal[e]« vor:

[F]ormal - die textlichen Blogbeiträge verfügen über eine hohe literarische Qualität; inhaltlich - das Blog setzt sich mit literarischen Texten oder dem Literaturbetrieb selbstreflexiv auseinander oder bildet literarische Texte wie z. B. Gedichte ab; oder über die Autorschaft - der Blogautor ist ein bekannter Literat oder ein sich als Netzliterat inszenierender Blogger. ${ }^{34}$

Herbsts Blog erfüllt alle drei Kriterien. Es sind vor allem seine Textauszüge, die sich unter das formale Kriterium der literarischen Qualität einordnen lassen (ohne auf Wertungsaspekte einzugehen). Zudem beansprucht er selbst auch eine literarische sprachliche Formung aller (eigenen) Beiträge. Der sinhaltliche` Aspekt ist dadurch erfüllt, dass Herbst sich als »Märtyrer, der sich für Kunst (auf-)opfert « ${ }^{35}$, und manischer Arbeiter gibt und dementsprechend fast rund um die Uhr und rund ums Jahr für die Arbeit an der Literatur lebt. Entsprechend dreht sich auch ein Großteil der Reflexionen um Literatur und auch den Literaturbetrieb. Damit korrespondierend -

32 Zugleich sind sie auch eine Rubrik: URL-43, vgl. KTLB, $129 \mathrm{FN} 20$, sowie 32, und mit einer Erklärung für die »später eingestiegen[en] « Leser des Blogs URL-44, 7. Dez. 2007.

$33 V G$, 342: "Juli 1981 - Februar 1983«; WB, 1017: »Frankfurt am Main / Mannheim / Olevano Romano / Frankfurt am Main; 1984 - 1992«; TA, 895: »November 1993 - Juni 1998«; BA, 272: Juli 1998 - Juni 2001«; Argo, 872: »Berlin, Herbst 2001 - Frühjahr 2013«.

34 Ernst: »Weblogs«, 294.

35 Jürgensen: »Ins Netz gegangen«, 420. Vgl. auch KTLB, 69 f. 
wenn nicht zusammenfallend - ist auch das `Bestimmungsmerkmal eines (bekannten) Literaten als Blogautor erfüllt, ein Aspekt, der weiter unten unter dem Stichwort der institutionellen Zuschreibung diskutiert wird.

In Herbsts eigenen Reflexionen sind diese Kriterien auch vorhanden, wie gleich zu sehen sein wird. Er gesteht zu, dass es auch andere Formen literarischer Weblogs als seine gebe - solche, deren Literaturbezogenheit darin bestünde, literarische Texte zu präsentieren und Literatur dadurch zu vermitteln. ${ }^{36}$ Eine solche Auffassung vertritt er jedoch explizit nicht. Er geht darüber hinaus, indem er das gesamte Weblog als literarisch sieht.

In der Rubrik Kleine Theorie des literarischen Bloggens, die die Grundlage für die 2011 auch als Buch erschienene >erste Lieferung ‘ bildet, reflektiert er die poetologischen Implikationen und vor allem seine Intentionen bezüglich seines Experimentierens mit der nicht nur für ihn neuen Publikationsform. In den teils aphoristischen Texten spricht er vom literarischen Weblog, als sei es eine präzise abzugrenzende neue Gattung, auch wenn er im Grunde nur von seinem eigenen Weblog spricht und auch nur sprechen kann. Tatsächlich präsentiert er keine `systematische`, voll ausformulierte Definition des Terminus `literarisches Weblog‘, obwohl er doch mehrfach auf Definitionen verweist. Einige oben bereits angesprochene Aspekte aufnehmend, beschreibt Herbst in einem Kommentar an den Autor Ken Yamamoto sein Blog als ein

»Netzprojekt, $[\ldots]$ das $[\ldots]$ zum Beispiel ausprobieren will, wie sich Romane in den Zeiten ihres Entstehens nahezu in Echtzeit miterzählen. Das zugleich immer auch reflektiert, was es tut.« $(K T L B, 87)$

Auch wenn es ein Teilaspekt des Projekts war und ist, eine Plattform zu Präsentation seiner Texte zu schaffen, und er auch immer wieder ganze Erzählungen und sogar Romane im Blog veröffentlicht, ist dies nicht der entscheidende Faktor. Wie oben erwähnt ist für die Bereitstellung abgeschlossener Texte und ınicht literarischer Informationen eher die Homepage vorgesehen. Vielmehr ist es das Erzählen der Entstehung von Kunstwerken, die Reflexion dieses Vorgangs sowie - und das ist sowohl das Entscheidende als auch in Übereinstimmung mit seiner (sonstigen) Poetologie stehende - die literarische Formung der Beiträge und die Form des Ganzen. Ihm ist es wichtig zu betonen, »daß es selbst literarisch ist; seine Form ist Literatur. Das ist etwas anderes, als wenn Literatur allein die in ihm veröffentlichten Beiträge sind « $(K T L B, 88)$.

Auch in den Poetikvorlesungen proklamiert er die Formung als das entscheidende Kriterium für Literatur. Kurz vor dem Start des Weblogs schreibt er in Bezug auf das Verhältnis von Schilderungen des eigenen realen Lebens und Literatur: „Vermittels der Form der Gestaltung verwandeln sich selbst autobiografisch detaillierteste `Berichte in Dichtung. «77 In diesem Aufsatz war die Bemerkung ziemlich eindeutig auf Meere bezogen, das zu dieser Zeit wegen des Prozesses jedoch nur in Andeutungen benannt

36 Vgl. beispielhaft für dieses Verständnis mit der Bezeichnung »Literatur-Blogs« und auch »Literarische-Weblogs« Regula Freuler: »Bücherwürmer online«, in: Neue Zürcher Zeitung, 29. Apr. 2007.

37 Herbst: »Poetologische Thesen III«, 49. 
werden durfte. In Meere ist literarische Formung offensichtlich: die Geschichte ist bewusst komponiert, es wird leitmotivisch erzählt, eine teils sehr poetische, metaphernreiche Sprache ist gewählt. Wenn der Leser als im Normalfall Außenstehender die persönlichen Umstände des Autors und seiner Beziehung nicht genauer, d. h. bis in intimste Details kannte, war ein eindeutiger Bezug zumindest der Liebesgeschichte auf die Biographie des Autors nicht zwangsläufig gegeben. ${ }^{38}$ Dass eine Parallelisierung der Hauptfigur Fichte mit dem Autor Herbst in Bezug auf die Verwandtschaft mit einer Nazi-Größe und der damit verbundenen Erzählelemente naheliegt, war auch zu dieser Zeit schon gegeben, da Herbsts bürgerlicher Name bereits bekannt war. Jedoch widerspricht die Möglichkeit einer solchen Parallelisierung nicht der Literarizität der Darstellung.

Im Weblog ist die von Herbst immer wieder behauptete `Formung ‘ jedoch weniger offensichtlich oder gar `nachzuweisen`. Insgesamt sind die Einträge sehr heterogen. Auf der einen Seite sind es reindeutig literarische Texte, Gedichtentwürfe, Arbeitsversionen von Erzählungen, fertige und teils vorher bereits in Druckform veröffentlichte Erzählungen und Romane ${ }^{39}$, oder auch immer wieder das Einstellen von Abschnitten des damals entstehenden Romans Argo. Anderswelt..$^{40}$ Auf der anderen Seite stehen die Einträge des Arbeitsjournals oder Tagebuchs, die meist, wenn auch nicht immer, wie schnell hingeschrieben wirken, ohne groß über das handwerkliche Können des geübten Schriftstellers hinauszugehen.

\subsubsection{Literarizität und Fiktionalität}

Neben dem Erzählen des Entstehungsprozesses von Kunstwerken gibt es einen weiteren Aspekt, der über die oben von Thomas Ernst genannten Bestimmungsmerkmale für literarische Weblogs hinausgeht. Dieser betrifft nicht die literarische Qualität einzelner Texte, sondern geht über die Textgrenzen hinaus. Denn Herbst

»unterläuft die Grenzziehung zwischen Text und Paratext insofern, als je nach Click jede Seite zum Haupttext werden kann und überdies viele Textbausteine auf mehreren >Unterseiten auftauchen, in je anderem Zusammenhang, und die einzelnen Seiten vielfach verlinkt sind. Grundsätzlich aufgehoben ist damit die Unterscheidung zwischen fiktionalen und non-fiktionalen Texten, und so erscheint das Weblog insgesamt als weitverzweigter, permanenter Roman in progress, der [...] (zumindest potentiell) bis zum Tod des Autors weiter Triebe schlagen könnte. « ${ }^{41}$

Die Texte werden also nicht einzeln als autonome Textteile betrachtet, sondern die Struktur des Ganzen wird zum Kriterium der Literaturhaftigkeit.

38 Dies ist auch ein Einwand, der im Kontext von Verbotsprozessen öfter erhoben wird. Ein Prozess lenke viel mehr Aufmerksamkeit auf die `Geschädigten`, sofern sie nicht einer breiteren Öffentlichkeit vorher schon bekannt wären, als wenn sie nicht prozessiert hätten. Im Fall von Maxim Biller und Esra liegt der Fall etwas anders, da eindeutige Verweise auf eine Person des öffentlichen Lebens die Zuordnung auch für Außenstehende einfach machten.

39 Beispielsweise der gesamte Manhattan-Roman In New York: »(Internet-)Ausgabe Zweiter Hand 2009«, URL-45.

40 Vgl. URL-46.

41 Jürgensen: »Ins Netz gegangen«, 418f. 
Wesentlich bestimmt wird diese Struktur durch das Spiel mit der Identität der verschiedenen Autoren und auch Kommentatoren. Die künstlerische Organisation des Zusammenspiels dieser Identitäten ist als ein Kriterium für die Einordnung als Literatur zu sehen. Für den Leser ist nicht immer zu erkennen, ob sich hinter einem Namen nicht eine Rolle eines sonst anders agierenden Mitautors verbirgt. Auch bezüglich der geschilderten Ereignisse ist - wie noch zu sehen sein wird - die Entscheidung zwischen fiktionaler und faktualer Lesart nicht immer eindeutig möglich. Herbst ist wie auch schon in der Zeitschrift Dschungelblätter nicht nur schreibender Autor, sondern hat auch die formende Autorfunktion eines Herausgebers, der die Reaktionen und Kommentare der Koautoren anstößt und wieder auf sie reagiert.

In einem Herausgeber-Weblog (synonym zu $>$ Herausgeber-Zeitschriftı) wie Der [sic!] Dschungel wird der Herausgeber zu einem ein Material organisierenden Autor, das ihm andere zuspielen, so, wie der Dichter das Material organisiert, das ihm die Wirklichkeit zuspielt. Damit ist der auktoriale Erzähler zwar wieder hergestellt, allerdings geerdet über die Kommentare anderer. Seine Auktorialität ist ans Material verpflichtet, wie er selbst an seine Wirklichkeit. $(K T L B, 114)$

Das Spiel mit verschiedenen Identitäten wird dabei sehr systematisch betrieben und auch reflektiert, sodass sich das Blog in dieser Hinsicht von anderen snormalen Weblogs abhebt und eher komplexen Erzählsituationen ähnelt.

Wenn Herbst das Weblog abseits des >Form«-Arguments als Literatur einordnet, scheint er Fiktion und Literatur in eins zu setzen. Für die »Alltagsintuition ${ }^{42}$ ist Fiktionalität auch eng mit der Klassifikation als Literatur verbunden, ebenso wie für viele ältere literaturtheoretische Arbeiten. Für die neuere Fiktionalitätstheorie ist sie jedoch »in keiner Weise eine Bestimmungsgröße von Literatur « ${ }^{43}$. Eigentlich versucht auch Herbst, eine solche Trennung zu etablieren, wenn er die Trennschärfe von Fiktion und Realität schon in der alltäglichen Wahrnehmung konstatiert. Er nimmt jedoch an, dass die 'gute Formulierung « und kontinuierliche Schilderung der eigenen Erlebnisse und Befindlichkeiten für eine Literarisierung sorgt, indem der Autor (bzw. eher der Autor in der angenommenen Identität als Ich-Erzähler) für den Leser zu einer (literarischen) Figur wird: »Für irgend einen Leser wird man zur Figur: das ist festzuhalten.« $(K T L B, 34)$ Genau dies geschieht auch: der Leser macht sich aufgrund der präsentierten, natürlich ausgesuchten angenommenen Fakten und auch Eigencharakterisierungen ein Bild sowohl vom Menschen Herbst als auch vom Autor Herbst ${ }^{44}$ oder auch von den Mit-Autoren. Ganz abgesehen von bewussten oder unbewussten Stilisierungen einer jeden Selbstdarstellung ist es im Fall von Die Dschungel

42 Winko: »Auf der Suche nach der Weltformel«, 375.

43 Zipfel: Fiktion, Fiktivität, Fiktionalität, besonders 313-322, hier: 322. Zipfel vertritt in Anlehnung an Lamarque/Olsen, deren Literaturdefinition als `soziale Praxis`ohne den Begriff der Fiktion auskommt, die Annahme, dass Fiktion und Literatur »unterschiedliche Phänomenbereiche« (ebd., 313 f.) bezeichnen. Fiktion sei ein systematisch bestimmter und bestimmbarer Begriff, Literatur dagegen historisch bestimmt und epochal variabel. Die Trennung von Literarizitäts- und Fiktionalitätsdebatte vermerkt auch Winko: »Auf der Suche nach der Weltformel«, 375; vgl. auch Rühling: "Fiktionalität und Poetizität«, 25.

44 \Mensch` im Sinne von individueller Person und `Autor` im Sinne einer mehr oder weniger inszenierten Autor-Figur. 
noch deutlicher, dass eine Unterscheidung von Realität und Fiktionalisierung nicht möglich ist, sich Herbst also als Figur inszeniert. Während eine solche Wahrnehmung als Figur, das Miterleben und -verfolgen eines fremden Lebens, sicherlich auch in den »Plauderblogs« möglich sind ${ }^{45}$ ist es hier doch beabsichtigt und reflektiert. Ebenso wie er den an ihn gerichteten Vorwurf des "Netzexhibitionismus" $(K T L B, 9)$ lediglich als zum Experiment zugehörig betrachtet, sieht er auch den "vermeintliche[n] Voyeurismus« der Leser nicht als den entscheidenden Grund für das Verfolgen des Blogs: nicht dieser halte die Leser, »sondern der Austausch mit einem anderen Leben: daß ein anderes Leben Teil des eigenen wird und es dadurch erweitert $(K T L B, 54)$.

Was die Verbindung von Stilisierung und Inszenierung mit der Bezeichnung >literarische Figur und von da zur `Literaturhaftigkeit`angeht, handelt es sich um ein unpräzises Vermengen nahe beieinanderliegender Begriffe. In Erweiterung der Überlegung, dass der Autor zu einer literarischen Figur werde, führt Herbst in seinem programmatischen Aufsatz »Das Weblog als Dichtung « fort, dass auch »die meisten Leser ihrerseits dazu tendieren, literarische Figuren zu werden ${ }^{46}$, wobei in diesem Kontext die kommentierenden Leser gemeint sind. Die Begründung wird etwas später nachgeliefert, wenn er schreibt, sie träten »als Avatare ihrer selbst auf; auch sie sind letztlich Literatur. ${ }^{47}$ Die Einnahme von Rollen und die dadurch mögliche Selbststilisierung und -inszenierung werden von ihm mit literarischen Figuren gleichgesetzt. Dabei bringt er verschiedene begriffliche Bereiche, nämlich Psychologie, Psychoanalyse und Literaturtheorie, zusammen. Die verschiedenen Rollen, die in Weblogs, Chats oder Foren eingenommen werden, sieht Herbst auch in Verbindung mit dem psychoanalytischen Begriff des Ich-Ideals. ${ }^{48}$ In Anlehnung daran treten die Leser dann »als ideale Figuren aus ihrer persönlichen Realität in die Netz-Erzählung ein« und machen sich, »[a]nalytisch gesprochen«, wie der »bloggende Dichter « zu einer »Projektionsfläche ${ }^{49}$. Die Schlussfolgerung der >Literaturhaftigkeit $<$ erfolgt dann allerdings durch die sprunghafte Gleichsetzung von psychologischer Rolle (der Person in der wörtlichen Bedeutung von lat. persona - Maske) und literarischer Figur.

Ohne Weiteres ist eine solche Gleichsetzung aus literaturwissenschaftlicher Sicht nicht berechtigt. Fotis Jannidis hat in seiner Studie Figur und Person »die prinzipielle Differenz der Figur zur Person " genau nachgezeichnet, die er "vor allem in der begrenzten Informationsmenge der Figur und ihrer Abhängigkeit von den [vorher eingehend geschilderten] Momenten der narrativen Kommunikation ${ }^{50}$ sieht. Es besteht also ein kategorialer Unterschied, doch deuten gerade die Unterschiede, die Jannidis benennt, auf das hin, was Herbst meint. Die Gemeinsamkeit, die Herbst bezeichnet, ist die Art ihrer Wahrnehmung. Der Leser erhält über den Autor (ebenso wie über die Mit-Autoren oder kommentierende andere Leser) Informationen in einer Art und (mangelnden) Fülle wie über literarische Figuren. Die Unterschiede in der Position

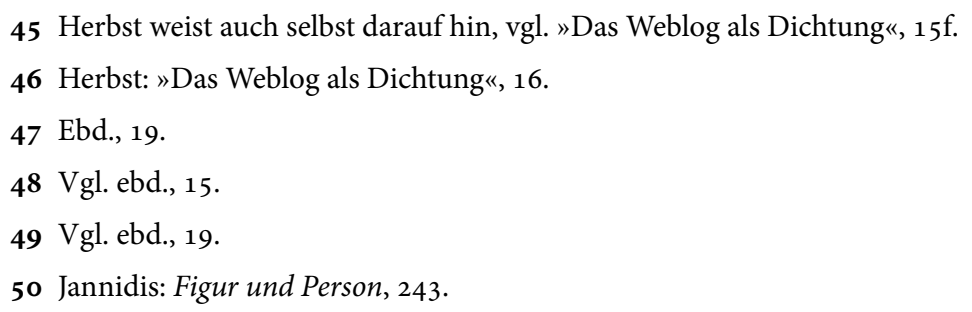


in der narrativen Kommunikation sind dabei jedoch nicht klar ersichtlich. Es kann also der Eindruck erweckt werden, dass es sich hier um literarische Figuren handelt. In einem Kommentar hat Herbst die Bildlichkeit dieser Ansicht etwas detaillierter beschrieben, sodass das sals ob< deutlicher wird:

Dazu bedarf es der Betrachtung der Person (auch des Autors, auch der Kommentatoren) als einer F i g u r : also als wären sie alle literarische Fiktion und die Geschehen eine Geschichte. ${ }^{51}$

Betont wird hier die Betrachtung und auch der Konjunktiv, während er sonst wesentlich bildlicher davon spricht, dass bspw. Leser zu Figuren tatsächlich werden. An anderer Stelle bringt er noch einmal alle genannten Begriffe zusammen, wenn er das entgegengesetzte Phänomen beschreibt, nämlich die Person-Werdung literarischer Figuren:

\begin{abstract}
Es war Karl May vergönnt, Gestalten zu erschaffen, die ganz unabhängig davon, ob man je die Bücher gelesen, der Welt sich ein für alle Male eingeschrieben haben. Jeder, wirklich jeder Mensch unsres Kulturraums, welchen Geschlechts auch und wie immer gebildet oder ungebildet er sei oder sie, trägt sie als Ideen in sich und hat, wenn wir von ihnen sprechen, sofort ein Gesicht. [Solche Figuren], die man Personen nennen muß, versteht man Wirklichkeit als das, was wirkt. Es sind literarischste, um [...] Freud zu travestieren, IchPerson-Ideale. ${ }^{52}$
\end{abstract}

\title{
8.2.2 Institutionelle` Zuschreibung von Literarizität
}

Das Interesse am Blog entsteht vermutlich auch, weil Herbst als mehr oder weniger bekannter und arrivierter Schriftsteller Einblicke in seine Arbeitsweise gibt. Mit dem etwas merkwürdigen Begriff der `Produktivitätstheorie bezeichnet Herbst, dass das Erzählen der eigenen privaten Umstände des Autors die »Bedingungen der künstlerischen Produktivität [kommentiert] « $(K T L B, 39)$. Der Leser kann so miterleben, welche Auswirkungen beispielsweise die reale Begegnung mit einer Frau auf die Figurengestaltung in einem Roman hat. Im Gegensatz zum Buch, bei dem der Schaffensprozess nicht gezeigt wird, »quasi stillgesetz « $(K T L B, 37)$ ist, wird er in Die Dschungel kontinuierlich thematisiert. Auch in einer relativ frühen externen Beschreibung des Projekts wird auf diesen Aspekt hingewiesen: »Herbsts Weblog etwa ermöglicht dem Leser, einem [sic!] zeitgenössischen Autoren [sic!] beim Denken zu beobachten [...]...153

Diese Annahme verweist schon darauf, dass es sich vornehmlich um ein >literarisches $<$ Weblog handelt, weil es als solches intendiert ist und deklariert wird. Neben dem expliziten Hinweis auf die sprachliche Formung kann diese institutionelle Les$\operatorname{art}^{54}$ - obwohl nicht explizit benannt und vielleicht sogar nicht bewusst vorgebracht

51 URL-47, 14. Juli 2005.

52 URL-48, 7. Jan. 2012.

53 Glauch: Die Muse küsst binär.

54 Nach der >Institutionentheorie ist ein literarisches Werk »Teil einer sozialen Praxis [...]: Ein Gegenstand ist ein literarisches Werk, wenn er mit der Absicht hervorgebracht wurde, gemäß den Regeln der `Institution Literatur r rezipiert zu werden.« (Jürn Gottschalk / Tilmann Köppe: "Was ist Literatur? Eine Einleitung «, in: dies. (Hg.): Was ist Literatur? Basistexte Literaturtheorie, Paderborn 2006, 7-21, hier: 15) Vorgeschlagen und ausführlicher begründet wird dieser Ansatz 
- als prominenteste in Herbsts Überlegungen identifiziert werden. Exemplarisch ist dabei die Wendung, dass die offenen privaten Schilderungen allein schon durch die Veröffentlichung einen künstlerischen Charakter haben:

Indem Privatestes publiziert und dadurch ästhetisiert wird, schlägt es sich der Kunst zu, zumal dann, wenn es in künstlerischem Zusammenhang steht. $(K T L B, 79)$

Dabei ist vor allem auch auf den Zusatz zu achten, dass der >künstlerische Zusammenhang in besonderer Weise zu einer Literarisierung beiträgt. Ähnlich auch die Formulierung, wenn er sich überlegt, das Weblogprojekt eines Tages ganz plötzlich beenden zu können, alles auf CD-ROM zu speichern und als vollendetes Werk zu begreifen:

[...] weil ein paar Jahre Schriftstellerleben alleine dadurch Literatur geworden sind, indem ich die Aufzeichnungen über sie aus dem Leben nehme und sie nun als, schriftlich gesehen, abgeschlossenes Werk im Fundus stehen. ${ }^{55}$

Auffällig ist hier zum einen, dass er betont, dass es sich um ein "Schriftstellerleben " handelt, zum anderen, dass es durch einen Abschluss in Form einer Speicherung (was im Grunde der Formgebung als Buch korrespondiert) zur Literatur wird. Letzteres steht dabei sehr in Spannung zu den Äußerungen seiner ausformulierten Poetologie, in der es ihm selbst in den an sich abgeschlossenen Büchern um die Unabschließbarkeit geht, und auch zu anderen Äußerungen, die der kontinuierlichen Veröffentlichung im Internet keinen geringeren oder in Bezug auf /Literaturhaftigkeit k keinen grundlegend anderen Wert als der Printpublikation beimessen. Die Bedingung, dass es sich bei einem literarischen Weblog zwangsläufig um das eines Schriftstellers (was auch immer einen solchen auszeichnet) handeln muss, führt er nie explizit auf, jedoch kommen entsprechende Anspielungen in solchen verstreuten Äußerungen immer wieder vor. Eine Art Begründung findet sich in der Annahme oder >Prophezeiung، über eine mögliche spätere Bewertung des Projekts im Zusammenhang mit seinem Gesamtwerk:

Bleiben diese [seine Romane] [...], dann wird Die Dschungel Bedeutung bekommen; werden sie vergessen, besteht die Gefahr, daß man sich lediglich lächerlich macht oder für peinlich empfunden wird, je nach Perspektive.

$(K T L B, 35)$

Angesichts der Rezeption der Tagebücher beispielsweise Thomas Manns und der privaten oder sogar intimen Einträge, die jedoch im Kontext von dessen schriftstellerischer Bedeutung gelesen werden, stellt sich diese Perspektive durchaus. In Bezug auf das neue Medium ist es für Herbst die Alternative zwischen »Narr sein oder Prophet» (ebd., 36).

von Stein Haugom Olsen: »Wie man ein literarisches Werk definiert « [1976], in: Jürn Gottschalk / Tilmann Köppe (Hg.): Was ist Literatur? Basistexte Literaturtheorie, Paderborn 2006, 72-89, v. a. 81-89.

55 URL-49, 17. Juni 2006. 
In den Kontext einer institutionellen Auffassung von Literatur gehört auch Herbsts ganz pragmatische Einordnung des eigenen Weblogs als eine Art `Werkzeug` für den Schriftsteller. Er bezeichnet es als »Handwerksarchiv« $(K T L B, 64)$, als eine Fundgrube oder Notizensammlung für literarische Texte: »alles, eben auch das Persönliche, wird als Material für weitere Dichtung betrachtet. Das - und $\mathrm{n} \mathrm{u} \mathrm{r}$ das - ist hier Programm.« $(K T L B, 81)$ Den Vorteil der ins Weblog eingebetteten Notizen gegenüber »konventionellen, überkommenen `Notaten für später« « sieht er »in der Einbettung in die seinerzeit tatsächlich wirkenden Umstände« $(K T L B, 63)$. Dies korrespondiert wieder mit der Auffassung, die Entstehung des Kunstwerks gehöre zum Kunstwerk selbst. Selbst wenn er entsprechendes Material erst später einbaut, ist das Weblog so für ihn ein über die Umfänge eines herkömmlichen Tagebuchs oder Arbeitsjournals hinausgehendes Archiv. Schließlich erkennt er neben dieser auf zukünftige Texte ausgerichteten Einordnung auch den alltäglichen Nutzen, wenn er neben der bereits erwähnten Strukturierung des Alltagsgeschäfts auch das tägliche Üben im Schreiben hervorhebt, ein »Training der geistig-schöpferischen Tätigkeit«, das das Weblog zu einem »Exerzierplatz der Ideen« $(K T L B, 40)$ werden lässt.

\subsection{Das Fiktive im Realen: Arbeitsjournal und Autofiktion}

\subsubsection{Das Private im Weblog}

Die Rubriken Tagebuch und Arbeitsjournal ${ }^{56}$ machen den weitaus größten Anteil am Weblog aus. Dort schreibt Herbst im Normalfall mehrfach täglich von seinen Tages- und damit Arbeitsabläufen. Die genaue Schilderung auch privater Dinge hat er dabei zu einer »entscheidenden Kategorie des Literarischen Weblogs" (KTLB, 125) erklärt und damit einen programmatischen Stellenwert gegeben. Auf radikale Weise hat Herbst mindestens anfangs ${ }^{57}$ alles öffentlich gemacht - private Erlebnisse, seine prekäre ökonomische Situation, Korrespondenzauszüge, Arbeitsskizzen und poetologische Überlegungen. Die Offenheit, die ihn nicht nur in privaten, sondern auch in künstlerischen Belangen angreifbar macht, macht das Weblog zu einem Experiment bezüglich des Zusammenhangs und der Grenze zwischen Privatem und Kunst. Das Interesse bzw. die Obsession, mit der er sich diesem Thema widmet, erklärt sich zum einen durch die von Anfang an bestehende Verarbeitung privater Erlebnisse und Probleme in seinen Büchern, auf die im Folgenden noch einmal zurückzukommen ist, zum anderen durch den Prozess um seinen Roman Meere..$^{8}$ Der Beginn des Weblogs fiel zusammen mit dem Prozess (2003/2004), in dem genau diese Aspekte debattiert wurden. Das 2003 erschienene Buch wurde wegen der Verletzung

56 URL-50 sowie URL-51.

57 Genauer gesagt wollte er das Private ganz am Anfang aussparen, hat sich dann nach kurzer Zeit aber gerade für die radikale Variante entschieden. Um die eigene >Verletzbarkeit $\measuredangle$ zu mindern, waren beim Tagebuch allerdings keine Kommentare zugelassen. Vgl. KTLB, 40 und 49.

$58 »[D]$ ie Gründung Der Dschungel [ist] eine Reaktion auf das Buchverbot gewesen [...], namentlich der gesamte, immer wieder in ihr bearbeitete Komplex des Verhältnisses von Allgemeinem und Privatem, Privatem und Literarisiertem.« (URL-52, 22. Okt. 2011). Vgl. auch schon URL-41, 6. Juli 2004 . 
von Persönlichkeitsrechten verboten. ${ }^{59}$ Herbsts damalige Lebensgefährtin sah ihre gemeinsame Beziehung ungefragt in intimsten Details beschrieben, während er von literarischer Formung ausging und deshalb mit künstlerischer Freiheit argumentierte. Im Prozess ging es daher immer wieder um die Grenze zwischen der Darstellung wiedererkennbarer Fakten und den damit verbundenen Persönlichkeitsrechten und der literarischen Formung, die über das Private hinausgehende Aspekte schafft. ${ }^{60}$

Zwei wesentliche Argumente lassen sich für die Einbeziehung des Privaten in das Literarische Weblog in Herbsts Überlegungen ausmachen. Auf der einen Seite ist dies die Annahme, die Entstehungsgeschichte und die Befindlichkeiten des Autors während des Schreibens als zum Werk gehörig zu sehen. Diese vertrat Herbst zur gleichen Zeit in den Vorlesungen auch für seine Romanpoetik. Dabei beruft er sich auf ähnliche Auffassungen v. a. in der Musik des 20. Jahrhunderts.

Wie Anfang des letzten Jahrhunderts die Künste, vornehmlich Musik, dazu tendierten, ihre Entstehungsgeschichte als Teil der Komposition-selbst [sic!] zu begreifen, so ist der derzeit attestierte Hang von Literatur zum Privaten dessen Weiterentwicklung. Die psychischen Bedingungen zur Entstehung eines Werkes werden zu seinem Material, einem Material. (KTLB, 7 , vgl. auch 108) $)^{61}$

59 Vgl. dazu Schnell: „Über die Wahrnehmung eines literarischen Kunstwerks«, und Karl-Heinz Ladeur/ Tobias Gostomzyk: »Ein Roman ist ein Roman ist ein Roman? Zu den gerichtlichen Auseinandersetzungen um die autobiografischen Werke von Maxim Biller, Alban Nikolai Herbst und Birgit Kempker und der Notwendigkeit einer Rekonstruktion der Kunstfreiheit«, in: Zeitschrift für Urheber- und Medienrecht 48/6 (2004), 426-435, besonders 429f. Kreknin hat weitere Quellen aus der Presse aufgeführt, vgl. Kreknin: Poetiken des Selbst, 377, FN 89.

6o Nach einer Einigung konnte Herbst das Buch mit wenigen Änderungen 2007 in der Literaturzeitschrift Volltext sowie 2008 als Buch im dielmann-Verlag wieder publizieren. Ralf Schnell warf daraufhin die Frage nach der »ästhetische[n] Wirkung der vorgenommenen Eingriffe auf« (Schnell: "Über die Wahrnehmung eines literarischen Kunstwerks«, 204), die erst durch einen Vergleich benannt werden könne. Im Kontext der hier genannten Diskussion stellt sich die Frage, welche Art von Änderungen eine Publikation wieder ermöglichten. Der mare-Verlag hat 2009 alle drei Versionen zusammen in einer limitierten Auflage in einem Schuber herausgebracht. Die neue Buch-Fassung aus dem dielmann-Verlag, ein Exemplar der Volltext-Ausgabe von 2007 sowie die originale Version von 2003, deren inkriminierte Stellen Herbst eigens von Hand überklebt hat. Die Änderungen, die ich durch einen Vergleich der überklebten Fassung mit einem bereits ausgelieferten Exemplar der Originalfassung überprüfen konnte, beziehen sich ausschließlich auf die weibliche Hauptfigur Irene, deren Vorbild vermutlich die Klägerin war, und sind marginal. Herbst hat sie auch selbst als ästhetisch nicht relevant bezeichnet. Die Herkunft der Figur Irene (bzw. die ihres Vaters) wurde nach Persien verlegt, weswegen die neue Fassung auch als >persische $<$ bezeichnet ist. Entsprechend hat die Figur einen anderen Nachnamen und alle Herkunftsanspielungen bis hinein in Details (bspw. nebenbei erwähnte Gewürze) sind auf Persien ausgerichtet. Ebenso wurden familiäre Details, ihre musikalischen Vorlieben sowie Beschreibungen ihres Aussehens leicht, meist nur durch Ersetzung einzelner Wörter, verändert. Herbst hat diese Umarbeitung zudem genutzt, einige fremdsprachige Sätze (in Farsi) einzuarbeiten, die die familiäre Herkunft noch betonen. Die wahrscheinlich für die Wiederzulassung ausschlaggebende Änderung betrifft die Widmung, die den vermutlichen Klarnamen der Klägerin enthielt. In der überklebten Fassung ist sie ersetzt durch den auf Thetis anspielenden Satz »Für Niamh, die übers Meer davonritt ...«. In der Volltext-Fassung wie in der neuen Buchfassung ist die Widmung entfallen.

61 Pointiert formuliert diese Ansicht der Protagonist Éduard in André Gides Les Faux-Monnayeurs (Die Falschmünzer) von 1925: „Dieses Heft bietet Aufschluß über die Entstehung eines Romans, ja über den Roman im allgemeinen. Denken Sie nur, wie erhellend es wäre, hätten Dickens oder Balzac solch ein Heft verfaßt [...]! Wir könnten [die] Entstehung mitverfolgen, das allmähliche 
Stärker in Bezug auf die Romane, aber auch auf das Weblog als eigenständiges 'Werk ‘ ist dies im Kontext des selbstreflexiven und metafiktionalen Schreibens zu sehen. Es geht Herbst auch um die Darstellung der Entstehung von Literatur, der künstlerischen Produktion.

Auf der anderen Seite hängt die Begründung auch mit der Ernsthaftigkeit zusammen, mit der Herbst mit dem Weblog experimentiert bzw. es als neue literarische Form ausprobiert. Er möchte die allgemein im Internet sich etablierenden Abläufe und Kommunikationsstrukturen anwenden, aber auch literarisch ver- und bearbeiten; dazu gehört auch das weit verbreitete Erzählen privater Vorgänge. Dies korreliert mit dem beschriebenen Anspruch eines >neuen ২ Verständnisses von Mimesis: eine von ihm wahrgenommene allgemeine Öffnung zum Privaten soll abgebildet und in die Kunst übertragen werden.

Das Literarische Weblog spiegelt das Netz; in ihm wiederholt sich - bzw. Literatur führte es vor -, was im Netz allgemein geworden ist. Das Literarische Weblog verstanden als ein Publikationsforum, das nicht nur Texte publiziert, sondern sie den Netzdynamiken aussetzt, das also nicht nur Ausweichorgan, nämlich ein publizitäres Übergangsobjekt ist - wird zum poetischen und poetologischen Minimundus des Internets, weil es dessen Vorgänge ästhetisiert. Dazu gehört selbstverständlich auch die erzählte Privatheit; dazu gehören aber ebenso das Abstrakte der Theorie wie die Narration sinnlicher Geschichten, sowie eine Zeitmitschrift, die sich aus den unmittelbar zeitnah reflektierten Vorgängen selbst ergibt, indem man sie reflektiert. Das Literarische Weblog hat mit der Geistes-Geschichtsschreibung des kybernetischen Zeitalters begonnen. (KTLB, $76 f.)^{62}$

Diese zwei Begründungen für die Einbeziehung des Privaten in das Weblog sind zugleich auch wichtige Gründe, warum Herbst überhaupt angefangen hat, ein Weblog zu führen. An dieser Stelle sei daher auch ein weiterer Grund erwähnt, der jedoch mit der Schilderung von Privatem wenig zu tun hat. Anfangs hatte er gehofft, im Internet eine »literarische Präsenz « ${ }^{63}$ zu schaffen, die - gerade angesichts des Prozesses, durch den ein Buch verboten und die Aussicht, weitere zu veröffentlichen, nicht gerade verbessert wurde - seine Bücher bewerben und überhaupt die Aufmerksamkeit auf sich und seine Bücher lenken sollte. Später hat er jedoch das Erreichen zumindest von neuen Verdienstmöglichkeiten verneint, jedoch oft über das Weblog (bzw. die Website) als neue Publikationsform für seine Bücher und Texte reflektiert. ${ }^{64}$

Heranreifen des Werks! Das wäre doch faszinierend... interessanter als das Werk selbst...« (André Gide: »Die Falschmünzer « [1925], in: Ders.: Gesammelte Werke, Bd. 9: Die Falschmünzer. Tagebuch der Falschmünzer, hg. v. Raimund Theis, übers. von Christine Stemmermann, Stuttgart 1993, 23365, hier: 187)

62 Vgl. auch Herbst: »Das Weblog als Dichtung «, 16: »Aus dem Internet gärt [...] ein kräftig durchwalkter Teig aus Wirklichem und Erdachtem. Damit ist es d e r Spiegel der gegenwärtigen auch und gerade politischen Realität in der industriell medialisierten westlichen Welt. Das macht die Netz-Publikation für Literaten reizvoll: hier ist das Ästhetische - als Abbildung - tatsächlich mit dem Realen zwar nicht identisch, aber analog."

63 Valin: Interview mit Alban Nikolai Herbst.

64 Vgl. schließlich die Veröffentlichung von E-Books über Amazon.de: URL-53, 29. Dez. 2012. 
Gerade in der Radikalität der offenen privaten Darstellung sieht er den künstlerischen Wert gegeben. Die Radikalität von Kunst ist dabei für ihn gesetzt.

Insofern alle Kunst radikal ist, muß ein Weblog, das mit einer künstlerischen Zielsetzung antritt, die Eigenheiten des Weblogs radikalisieren. Als eine dieser Eigenheiten stellte sich zunehmend das veröffentlichte Private heraus. (KTLB, 38)

Noch einmal wird hier der Anspruch deutlich gemacht, das für die aktuelle zeitliche Befindlichkeit wichtige Internet wiederzugeben. Der weitere Anspruch, dass es sich um Kunst (bzw. Literatur) handelt, basiert in diesem Zusammenhang vor allem auf einem institutionellen Kunstbegriff. ${ }^{65}$

Das offene Tagebuch ist ein »aktionistisches Experiment, mit dem Herbst die Verschiebung von Privatem in den öffentlichen Raum bis zur eigenen Schmerzgrenze und der anderer treibt ${ }^{66}$. Die sanderen $\triangleleft$ sind dabei nicht nur die Frauen in seinem Leben, mit denen er eine Beziehung hat oder hatte, sondern auch Personen beispielsweise aus dem Literaturbetrieb, deren Mails oder Briefe er teils anonymisiert ins Netz stellt (vgl. bspw. $K T L B, 68 f$.). Zumindest die privaten Einsprüche haben dazu geführt, dass er 2006 das Tagebuch aus Rücksicht auf eine wiederaufgenommene Beziehung aufgegeben hat. ${ }^{67}$ Als die Beziehung jedoch wieder scheitert, bricht er das "zweieinhalbjährige Schweigen [s]eines Tagebuches « ${ }^{68}$. Er spricht über seine sexuelle Situation, weil er sie für keinen Einzelfall hält sowie zur eigenen Erleichterung. Dennoch bricht er das Schweigen nicht wirklich, da er auch danach wenig über die betreffende Frau erzählt. Hatte er sie während der Zeit der Beziehung als `die Geliebte` pseudonymisiert, so erfolgen die gelegentlichen Erwähnungen seitdem in verschiedenen Schriftsystemen. Die häufigsten Namen, die Herbst verwendet, sind Lakshmi - der Name der hinduistischen Göttin der Schönheit, den er in Devanagari setzt, dem Schriftsystem bspw. von Sanskrit und Hindi - und Astarte, der Name der semitischen Liebesgöttin, den er in hebräischen Buchstaben wiedergibt.

Herbst beabsichtigte, in der Folge ein Arbeitsjournal zu führen, das zwar tagebuchmäßig angelegt, aber rein auf die Arbeit bezogen sein sollte. ${ }^{69}$ Die Rubrik Tagebuch selbst hat er dann für andere Mitschreiber geöffnet und als `chorisches` (da mehrstimmiges) Tagebuch in seine Programmatik eingebaut. ${ }^{70}$ Die mit der Aufteilung auf mehrere Personen einhergehende zunehmende Fülle kommt dabei seinen poetologischen Absichten ebenso entgegen, wie die Dezentralisierung der Perspektive. Wie in seinen Büchern auch aus unterschiedlichen Perspektiven und mit unterschiedlichen Stimmen erzählt wird, so sollte auch im Weblog nicht die Sicht des einzelnen Autors Herbst vorherrschen. Die wohl durch Regelmäßigkeit wie auch Länge der Beiträge prominentesten Beiträger waren oder sind dabei ein Paul Reichenbach und

65 Vgl. Abschnitt 8.2.2 auf Seite 380.

66 Giacomuzzi: »Die >Dschungel.Anderswelt und A. N. Herbsts >Poetologie des literarischen Bloggens « 142 .

67 Vgl. URL-54, 3. Juli 2006.

68 URL-55, 6. Aug. 2008.

69 Vgl. URL-56, 3. Juli 2006; URL-57, 25. Aug. 2006.

70 Vgl. URL-58, 15. Aug. 2006, sowie vorher als Überlegung bereits URL-59, 5. Aug. 2006. 
ein Bruno Lampe, die beide weitgehend anonyme Schilderungen bieten (anonym in dem Sinne, dass keine näheren Angaben zur Person erfolgen, diese aber auch nicht Thema sind), aber durch Stil und inhaltliche Ausrichtung eine betonte Bildung und Schriftlichkeit vertreten. ${ }^{71}$ Während der Schriftsteller Thomas Findei $\beta^{72}$ nahezu unter seinem Klarnamen (als >findeiss $`$ ) schreibt, sind als (zumindest von außen) nicht weiter zu identifizierende wichtige Mitautoren zu nennen (wobei es bei einer subjektiven Auswahl bleiben muss): montgelas, der sogar unter den Biographien auf Herbsts Website $^{73}$ aufgeführt ist, diadorim ${ }^{74}$ und Cellini. Letztere ist eine etwa 50-jährige Frau, die in relativ konventionell erzählenden, aber sehr eingängigen und atmosphärischen Beiträgen sowohl Erlebnisse ihres beruflichen Alltags als Sekretärin eines Hamburger Unternehmens als auch private Familienbeziehungen und eigene BDSM-Erlebnisse geschildert hat. Aufgrund privater Umbrüche hat sie sich aber aus dem Tagebuch zurückgezogen. ${ }^{75}$ Von Anfang an gehörte jedoch explizit zum Konzept des >chorischen Tagebuchs, dass der Leser nicht weiß, ob es sich bei den Tagebuchschreibern um jeweils eine `reale` Person handelt oder ob Herbst oder andere >reale` Autoren weitere Beiträge unter Pseudonym einstellen. Somit kann auch die gerade genannte Beschreibung von Cellini falsch sein (wenn beispielsweise sie auch aufgrund ihres Schreibstils und auch allein angesichts des Umfangs ihrer Beiträge kaum von Herbst serschrieben`sein kann). Diese von Herbst mit den Begriffen >literarische Figuren oder auch `Avatare verbundene Möglichkeit gilt auch für die Kommentatoren und soll weiter unten noch näher betrachtet werden. ${ }^{76}$

Herbsts eigenes Arbeitsjournal hat im Laufe der Jahre, vermutlich im Zuge einer weiteren Trennung von seiner Lebensgefährtin, weitestgehend die Funktion und den Charakter des früheren Tagebuchs angenommen. Darin schildert er neben seiner alltäglichen schriftstellerischen Arbeit auch seine persönlichen Erlebnisse, wobei die beteiligten Personen (wie jedoch vorher auch) meist anonymisiert sind. Nach vielen wechselnden Beiträgern zum >chorischen Tagebuch haben die Einträge von anderen Mitschreibern etwa seit 2010 vor allem in ihrer Vielfalt stark abgenommen. So hat

71 Giacomuzzi vermutet hinter Reichenbach Herbst selbst, ohne jedoch ausführlichere oder stichhaltige Argumente zu nennen (vgl. Giacomuzzi: »Die >Dschungel.Anderswelt $<$ und A. N. Herbsts 〉Poetologie des literarischen Bloggens« «, 143); >Bruno Lampe ist durch die Verlinkung leicht als eins der Pseudonyme des Übersetzers Helmut Schulze zu erkennen, der auch seit 2004 das eigene (Lyrik-)Blog (»parallalie«. Weblog, seit Juli 2004, URL: http://parallalie.twoday.net) betreibt, vgl. LITBLOGS.NET: »Helmut Schulze«, Literarische Weblogs in deutscher Sprache, 29. März 2008, URL: http://www.litblogs.net/helmut-schulze, und Markus A. Hediger / Benjamin Stein / Hartmut Abendschein (Hg.): Literarische Weblogs. spa_tien. Zeitschrift für Literatur. Sonderausgabe (2007), 128.

72 Vgl. Thomas Findeiß: »realfiction«, URL: http://www.realfiction.de.

73 Vgl. Alban Nikolai Herbst: »Die Dschungel: biografie +++ curriculum vitae«, URL: http://www.diedschungel.de/ANH/main.html?bio.html mainFrame.

74 diadorim hat sich inzwischen als die Schriftstellerin Sabine Scho zu erkennen gegeben, siehe URL-60, 23. Sep. 2014.

75 Das Tagebuch hat sie von 2007 bis 2009 geführt, vgl. URL-61, 12. Nov. 2007, und URL-62, 15. Juli 2009.

76 Siehe Abschnitt 8.4 auf Seite 396. 
sich im Juni 2010 auch Paul Reichenbach $>$ abgemeldet ${ }^{77}$. Herbst konstatiert denn auch das $>$ Auf-der-Strecke-Bleiben $<$ des $>$ chorischen Tagebuchs. $^{78}$

\subsubsection{Autofiktionales Schreiben im Weblog}

Auf die Rubriken »Arbeitsjournal« bzw. »Tagebuch« bezogen, die den Hauptteil der Dschungel-Texte ausmachen, bezeichnet wohl kein Begriff Herbsts Schreiben im Weblog besser als der der Autofiktion - zumindest wenn man ihn zunächst wörtlich nimmt. Herbst betreibt explizit `Selbst-Fiktionalisierung ‘. Deutlich hat er seine Absicht mitgeteilt, beim Erzählen seiner alltäglichen Erlebnisse nicht immer das zu schildern, was er tatsächlich erlebt hat; vielmehr beschreibt er Erlebnisse anders als sie stattgefunden haben oder schreibt sogar von Ereignissen, die gar nicht stattgefunden haben. Er fiktionalisiert.

Einerseits geht er von der Lesererwartung aus, im Weblog authentische Aufzeichnungen zu finden: »[D] as Literarische Weblog [hat] stets die Annahme auf seiner Seite, es sei ebenfalls authentisch und erzähle demzufolge von Ereignissen, die sich tatsächlich abgespielt haben. " $(K T L B, 43)$ Begründet sieht er diese Erwartung darin, dass die meisten >normalen $\triangleleft$, $d$. h. nicht literarischen, persönlichen Weblogs, intimen oder dokumentarischen Charakters sind, die Erwartung der Authentizität also eine Genre-Erwartung ist. Er spricht dort auch vom »authentische[n] Eindruck « der Schilderungen, der allerdings Teil eines »Täuschungsmanövers« sei. Andererseits gilt die Täuschung wohl nur den Erwartungen des Lesers oder einem oberflächlichen oder neuen Leser. Denn immer wieder macht er explizit, nicht immer Tatsachen zu beschreiben: „Man darf nur nicht meinen, daß alles, was ich über mich schreibe, ungebrochen wahr ist." $(K T L B, 101)$ Zudem warnt er davor, selbst der jeweilige Schreiber könne fiktiv sein, also das Pseudonym bzw. der Avatar eines realen Schreibers. Kein Leser könne und solle sich sicher sein, »ob unter den Schreibern nicht auch literarische Figuren sind, also von uns, den Tagebuchschreibern, hinzugestaltete Fiktionen." $(K T L B, 68)$ In nur geringfügig anderer Formulierung und zudem mit Hinweis auf ähnliche Experimente in herkömmlichen Chats weist er darauf bereits in einem der ersten Einträge hin: »Niemand kann sich sicher sein, ob nicht ein Blog Scharade ist, worin der Dichter neue Figuren probiert. In manchen Chats ist ein solches Experimentieren längst nicht mehr ungewöhnlich.« $(K T L B, 12)^{79}$

\section{Wie ist >Autofiktion $<$ definiert?}

In der literaturwissenschaftlichen Terminologie gibt es eine mittlerweile etablierte Verwendungsweise des Begriffs `Autofiktion<, obwohl dieser noch recht jung ist. Mit dieser Verwendungsweise ist Herbsts Verfahren der Autofiktion (das er wohlgemerkt selbst nicht so nennt) abzugleichen. Der Begriff geht auf den französischen Literaturwissenschaftler und Autor Serge Doubrovsky zurück, der ihn erstmals im Vorwort

77 Vgl. URL-63, 16. Juni 2010.

78 Vgl. URL-64, 26. Aug. 2012. Dort auch der Hinweis, dass er selbst nicht wisse, was aus Paul Reichenbach geworden sei.

79 Auch: URL-65, 28. Juni 2004. 
seines Romans bzw. seiner Autobiographie Fils (1977) in Kontrastierung zum Gattungsbegriff der Autobiographie verwendet. ${ }^{80}$ Frank Zipfel zeichnet die sich seitdem vor allem im französischen Sprachraum häufende Verwendung systematisch nach und macht drei Kategorien aus: ${ }^{81}$ Autofiktion als

- besondere Art autobiographischen Schreibens,

- als besondere Art des fiktionalen Erzählens,

- als Kombination von autobiographischem Pakt und Fiktionspakt.

Die Texte der ersten Kategorie befolgen den rautobiographischen Pakt . Dieser Begriff bezeichnet die angenommene Übereinkunft zwischen dem Verfasser einer Autobiographie und seinem Leser, von einer referenziellen, also $>$ wahrhaftigen $<$ Darstellung des Lebens auszugehen. Damit einher geht die Annahme der Identität von Autor, Erzähler und Protagonist. ${ }^{82}$ Verwendet werden jedoch Erzähltechniken, die eher in fiktionalem Erzählen zu finden sind. Doubrovskys eigene psychoanalytisch-assoziative Darstellung ist hier einzuordnen.

Die zweite Kategorie bezeichnet in Anschluss an Genette fiktionale Texte, in denen eine Figur vorkommt, die den Namen des Autors trägt und möglicherweise Ähnlichkeiten mit diesem aufweist. In diese Kategorie fallen einige bekannte Texte von Borges sowie wie bereits erwähnt auch welche von Herbst. Zipfel gibt jedoch zu bedenken, dass eine solche Erzählkonstruktion mit einer Einordnung als mehr oder weniger phantastische Literatur einhergeht und daher nicht von einer Annahme von Tatsachenbehauptungen auszugehen ist. Vielmehr sei eine poetologische Funktion anzunehmen. ${ }^{83}$

Unter der dritten Kategorie werden in Anschluss an die französische Schriftstellerin Marie Darrieussecq Texte eingeordnet, die dem Leser sowohl den autobiographischen Pakt als auch den Fiktionspakt anbieten. Unter Letzterem ist der Hinweis auf die Fiktionalität des Textes bzw. eigentlich die hypothetische Übereinkunft zwischen

8o Vgl. Frank Zipfel: »Autofiktion. Zwischen den Grenzen von Faktualität, Fiktionalität und Literarität?«, in: Fotis Jannidis / Gerhard Lauer / Simone Winko (Hg.): Grenzen der Literatur. Zu Begriff und Phänomen des Literarischen, Berlin u. a. 2009, 285-314, hier: 285. Auch Frank Zipfel: "Autofiktion«, in: Dieter Lamping (Hg.): Handbuch der literarischen Gattungen, In Zusammenarbeit mit Sandra Poppe, Sascha Seiler und Frank Zipfel, Stuttgart 2009, 31-36, hier: 31; Claudia Gronemann: ") Autofiction $<$ und das Ich in der Signifikantenkette. Zur literarischen Konstitution des autobiographischen Subjekts bei Serge Doubrovsky«, in: Poetica 31 (1999), 237-262, 239f.; und Martina Wagner-Egelhaaf: »Autofiktion. Theorie und Praxis des autobiographischen Schreibens«, in: Johannes Berning / Nicola Kessler / Helmut H. Koch (Hg.): Schreiben im Kontext von Schule, Universität, Beruf und Lebensalltag, Berlin 2006, 80-101, 97f. Vgl. auch Peter Gasser: »Autobiographie und Autofiktion. Einige begriffskritische Bemerkungen«, in: Elio Pellin / Ulrich Weber (Hg.): '... all diese fingierten, notierten, in meinem Kopf ungefähr wieder zusammengesetzten Ichs $\triangleleft$. Autobiographie und Autofiktion, Göttingen 2012, 13-27.

81 Vgl. Zipfel: »Autofiktion [Handbuch] «, 32ff. Ähnlich auch Zipfel: »Autofiktion [Grenzen der Literatur]«.

82 Der Begriff geht auf Philippe Lejeune zurück, vgl. Philippe Lejeune: Der autobiographische Pakt [1975], übers. von Wolfram Bayer / Dieter Hornig, Frankfurt am Main 1994, 13-51, besonders $27 f$., und Martina Wagner-Egelhaaf: Autobiographie, 2., aktualisierte und erw. Aufl., Stuttgart 2005 , $68-72$.

83 Vgl. Zipfel: »Autofiktion $[$ Handbuch] «, 33 . 
Leser und Autor zu verstehen, von einer ausgedachten Geschichte auszugehen. ${ }^{84}$ Dem Leser ist es demnach nicht möglich, sich eindeutig für eine Interpretationsmöglichkeit zu entscheiden. Nach Darrieussecq würden phantastische Elemente die Lesart eindeutig zugunsten des Fiktionalen auflösen und dadurch die Einordnung als Autofiktion verhindern. Dagegen einzuwenden ist, dass phantastische Elemente zwar ausschließen können, dass es sich insgesamt um einen rein autobiographischen Text handelt, nicht aber, ob nicht vielleicht wesentliche Teile davon autobiographisch sind und bloß die Darstellung phantastisch ist. Ihrer Ansicht unterliegt die Annahme einer kompletten Trennung von Realismus und Phantastik. Genau diese Trennung will Herbst jedoch (wie in seiner Poetik dargelegt) nicht mitgehen. Wie oben aufgeführt, geht er von der Authentizitätserwartung des Lesers aus, wenn sie sein Tagebuch lesen, eine Erwartung, die er durch viele Details und realistische Schilderungen unterstützt. Dies entspricht gewissermaßen dem autobiographischen Pakt. Gleichzeitig gibt er den Lesern jedoch immer wieder unmissverständlich zu verstehen, dass den realistischen Schilderungen Fiktionen zumindest beigemischt sind. Für den Leser ist es so nicht möglich zu entscheiden, ob bzw. wann es sich um autobiographisches Erzählen oder um fiktionales handelt. Herbsts autofiktionales Schreiben ist damit dem dritten Typus dieser Einteilung zuzuordnen. ${ }^{85}$

\section{Wozu autofiktionales Schreiben?}

Zwei Begründungen für das (auto-)fiktionale Schreiben im Weblog lassen sich in Herbsts poetologischen Überlegungen ausmachen. Zum einen ist dies das Spiel mit den Grenzen von Realität und Fiktion, das schon seine Romane und Erzählungen prägt, und seine Poetik bestimmt. Damit hängt auch das bereits angesprochene Aufnehmen entsprechender Tendenzen in bereits bestehenden Weblogs zusammen. ${ }^{86}$ Zum anderen geht es Herbst um die Darstellung einer tieferliegenden Wahrheit, die durch bloßes >Aufschreiben « der Ereignisse nicht erreicht wird.

Der programmatische Ansatz basiert auf seiner spezifischen Definition von Wirklichkeit. Es geht ihm weniger um eine genaue Darstellung der realen Geschehnisse als um eine wahrhaftige Schilderung. Dies ist durchaus mit dem Verhältnis von historischer (wissenschaftlicher) Geschichtsschreibung und dem Anspruch mancher historischer Romane zu vergleichen. Herbst gibt immer wieder zu bedenken, dass wir sowohl die historischen Ereignisse, die wir noch nicht miterleben konnten, weil sie schon lange her sind, als auch aktuelle Ereignisse, die wir nicht selbst erlebt haben, einfach glauben müssen. Dafür würden wir uns auf die Glaubwürdigkeit der Leute oder

84 Wohl am bekanntesten sind Ecos Ausführungen dazu, vgl. Umberto Eco: Im Wald der Fiktionen. Sechs Streifzüge durch die Literatur [1994], München 1996, 103ff. Weitere Verweise finden sich bei Zipfel: Fiktion, Fiktivität, Fiktionalität, 283f. Lejeune spricht hingegen vom »Romanpakt» (Lejeune: Der autobiographische Pakt, 29); Erläuterungen zum hier nicht maßgeblichen Unterschied zwischen den Begriffen finden sich bei Zipfel: Fiktion, Fiktivität, Fiktionalität, 284.

$85 \mathrm{Zu}$ Kreknins Argumentation, Zipfels Konzept sei für Herbst nicht ausreichend, vgl. Kreknin: Poetiken des Selbst, $396 \mathrm{ff}$.

86 Bezüglich des Zusammenhangs mit seiner Literaturauffassung und mit seinem Spiel mit den Erwartungen des Lesers bzw. der Kommunikation mit dem Leser vgl. die Abschnitte 8.2 »Literarizität und Kunstanspruch« und 8.4 »Versteckte Identitäten: Anonymität und das Pseudonym«. 
Institutionen verlassen, die uns die Informationen gegeben haben (bspw. Historiker). Dorrit Cohn weist bezüglich des Vergleichs von Geschichtsschreibung und historischen Romanen auf die Ansicht Tolstojs hin, »that the novelist can succeed in doing what the historian inevitably fails to achieve: to narrate the past truthfully ${ }^{87}$. Die gleiche Ansicht vertritt auch Herbst, auch wenn es ihm weniger um die Geschichtsdarstellung als um die Darstellung der eigenen Erlebnisse geht. Es geht ihm wie immer um die Darstellung einer tieferliegenden Wahrheit. Den Vorgang der fiktionalisierenden Darstellung realer Ereignisse mit dieser Prämisse nennt er dabei in Bezug auf Aragons autobiographische Erzählung Le mentir-vrai (1964) "wahrlügen ${ }^{88}{ }^{88}$ Indem 'gelogen ` wird, d. h. Ereignisse erzählt werden, die niemals stattgefunden haben, die aber die Motive oder Intentionen des Autors besser veranschaulichen und vor allem konsistent zum Rest der `Erzählung`sein müssen, soll ein Mehrwert erzeugt werden, der über die realistische Schilderung hinausgeht. ${ }^{89}$

In der Gattungsdiskussion der Autobiographie findet sich diesbezüglich die Kategorie der autobiographischen Wahrheit. Es ist anzunehmen, dass die Leser einer Autobiographie etwas aus dem Leben des Autors erfahren möchten. Dabei ist jedoch nicht leicht zu beurteilen, ob es sich bei dem Berichteten auch um die Wahrheit handelt. Die fehlende Erinnerung oder auch die bewusste Aussparung können dafür sorgen, dass der Leser nicht die volle Wahrheit erfährt. Während das Gedächtnis im Falle eines regelmäßig oder bei Herbst im Normalfall sogar täglich aktualisierten Blogs nicht der Grund für mangelnde Wahrheit ist, ist im Gegensatz zu einer herkömmlichen Autobiographie nicht der Anspruch der Wahrhaftigkeit gegeben, d. h. der Darstellung nach bestem Wissen und Gewissen. Mit Goethes Autobiographie Dichtung und Wahrheit (1811/1812/1814/1833) steht die Problematisierung der autobiographischen Wahrheit sogar bereits im Mittelpunkt eines frühen zentralen Werks dieser Gattung. Goethe ging es nicht so sehr um die Schilderung der Fakten seines Lebens als um eine höhere Wahrheit.

Es sind lauter Resultate meines Lebens, und die erzählten einzelnen Facta dienen bloß, um eine allgemeine Beobachtung, eine höhere Wahrheit, zu bestätigen..$^{90}$

Er schildert sein Leben im Grunde wie einen Bildungsroman, zeigt retrospektiv seine Entwicklung zum Künstler auf, jedoch unter der Annahme, diese wäre von

87 Dorrit Cohn: The Distinction of Fiction, Baltimore, Md 1999, 151.

88 Vgl. u. a. KTLB, 43; Faure: ")Jetzt hab ich Metall im Mund ««, 13; Alban Nikolai Herbst: „Schreiben heute? Dichten heute. Kein Abgesang, sondern Plädoyer«, in: Kunst und Kultur 8 (1999), URL: http://www.sandammeer.at/spiritus/schreibendichten.htm.

89 Vgl. auch Carola Hilmes: Das inventarische und das inventorische Ich. Grenzfälle des Autobiographischen, Heidelberg 2000, 388:

Der Tendenz einer Aktualisierung der eigenen Lebensgeschichte in der Form des literarisch gestalteten Tagebuchs steht die Tendenz einer Distanzierung und Fiktionalisierung gegenüber, die ebenfalls im Dienste der Aufrichtigkeit erfolgt. Die historische Wahrheit tritt dabei zurück gegenüber einer ästhetischen Wahrheit, das inventarische verwandelt sich in ein inventorisches Ich.

90 Goethe in einem Gespräch mit Eckermann am 30.3.1831, zit. nach Wagner-Egelhaaf: Autobiographie, $2 \mathrm{f}$. 
Anfang an in ihm angelegt gewesen. So bekommt die Darstellung einen »rückwirkend festgestellten Resultatcharakter ${ }^{91}$. In den Anmerkungen der $»$ Hamburger Ausgabe« erklärt Erich Trunz entsprechend die titelgebenden Begriffe folgendermaßen:

Goethe schildert in der Autobiographie das Leben als Zusammenhang; vom Ganzen her erhält das einzelne seine Bedeutung; Schau des Ganzen aber ist Deutung. Diese Deutung - aus der Sicht des Alters - nannte er Dichtung. Die Tatsächlichkeit der Einzelheiten nannte er Wahrheit. Der Titel Wahrheit und Dichtung bedeutet also: die Tatsachen und ihr Zusammenhang; oder: die Richtigkeit der Einzelheiten und die verbindende Schau und künstlerische Form..$^{92}$

Das Konzept der >verbindenden Schau der Autobiographie findet sich auch in den Überlegungen von Herbst zum autofiktionalen Schreiben. Dort ist es aber nicht in der Rückschau enthalten, vielmehr soll das verbindende Element bereits im Vorhinein etabliert werden; dies macht es zu einem Element des autofiktionalen Schreibens. Herbst bezeichnet es durch die Formulierung `Das Leben als Roman begreifen`.

\subsubsection{Das Leben als Roman begreifen}

In Ausweitung auf alle >öffentlichen Tagebuchschreiber behauptet Herbst, diese gingen mit sich um, »als wären sie Protagonisten einer Erzählung« (KTLB, 41), was ihnen im Rückschluss den Status einer (literarischen) Figur gebe. Zugespitzt formuliert er: "Der öffentliche Tagebuchschreiber [...] begreift das Leben ganz offen als Roman." (ebd.) Von der einen Formulierung zur anderen ist ein wichtiger Sprung zu beobachten. Nicht nur im Tagebuch wird der Schreiber zur Figur, sondern durch das Erzählen des eigenen Lebens (oder von Teilen davon), durch die narrative Formung, wird das gesamte Leben als Erzählung oder Roman begriffen. Hier wird die zentrale Bedeutung des Erzählens für Herbst sehr deutlich herausgestellt. Das strenge Reglement im Alltag (bzw. an fast jedem Tag, da Herbst auch an Wochenenden und überwiegend sogar an Feiertagen arbeitet), das er durch das Führen des Arbeitsjournals, der DTs und möglicherweise durch die vermeintliche öffentliche Kontrolle schafft, ermöglicht ihm nicht nur ein kontinuierliches Arbeiten auch gegen innere Widerstände hinweg. Vielmehr ist es ein Hilfsmittel, ein stabiles Selbstbild überhaupt erst erzählend zu schaffen. Er spricht von »kindlich-magische[m] Denken[]«, wenn er die zugrunde liegende Denkweise beschreibt: »Ich schreibe den Protagonisten des Weblogs um, nämlich mich, und beziehe daraus die Zuversicht, ich würde mich auch im Leben ändern.« $(K T L B, 42)^{93}$

Diese Funktion der Auffassung, das Leben als Roman zu begreifen, beschreibt Herbst im Anschluss an seine Überlegungen zur kathartischen Rolle von Kunst im

91 Ebd., 3.

92 Erich Trunz: »Anmerkungen [zu Dichtung und Wahrheit Buch 1-13] «, in: Johann Wolfgang von Goethe: Werke. Hamburger Ausgabe in 14 Bänden, Bd. 9: Autobiographische Schriften I, hrsg. und komm. von Erich Trunz, München 1998, 640-840, hier: 640.

93 Diese Denkweise erinnert an die Vorgänge in $V G$, wo durch das Umschreiben einer erfundenen Figur, die Namensänderung und den Ortswechsel auch das eigene Leben des >Autor $<$-Erzählers umgeschrieben werden soll. 
Rahmen seiner Poetik. ${ }^{94}$ Ein Merkmal von Kunst ist für ihn demnach, problematische Erfahrungen zu verarbeiten und sogar $>$ Lust $\prec$ aus ihnen zu gewinnen. Analog zum (klassischen) Roman oder zu mythischen Erzählungen, in denen der Held oder Protagonist Erlebnisse nach einem mehr oder weniger sinnvollen Plan erlebt, soll dies auch durch die Erzählung des eigenen Lebens geschehen. Im Gegensatz zum Roman, wo es für den Autor normalerweise gleichsam gottgleich möglich ist, die Geschicke einer Figur zu bestimmen, ${ }^{95}$ ist dies im Leben nicht im Vorhinein möglich. Erst im Nachhinein ist es möglich, einen Sinn zu erkennen bzw. hineinzuinterpretieren oder zu konstruieren. Das Erzählen des eigenen Lebens soll sich nun den Mechanismen einer literarischen Erzählung annähern und die Bedeutung konstituieren: »Man legt um das eigene Leben einen Rahmen, als ob es einen Sinn, ja sogar eine Logik hätte." $(K T L B, 79)$ Das Erzählen unter dieser Prämisse hat also einen identitätsstiftenden Charakter. Letztlich ist es also weniger magisches als psychologisches Denken, da es als Schaffung einer buchstäblich narrativen Identität gesehen werden kann.

Als ein relativ früher und aufschlussreicher Vorstoß in Richtung Verbindung bzw. Vergleich von Narrativität und Identität ist der Aufsatz »Unity Identity Text Self « von Norman N. Holland aus dem Jahr 1975 zu sehen. Er erläutert die vier Begriffe des Titels und formt sie zu einer Art Gleichung:

$>$ Unity is to text as identity is to self.^ Or you could say, >Identity is the unity I find in a self if I look at it as though it were a text. ${ }^{96}$

$\mathrm{Da}$ `Text ^ für ihn einfach das ist, was ein Autor geschrieben hat, und `Roman` bei Herbst für literarische Texte steht, ist die Ähnlichkeit der Auffassungen deutlich. Bei Hollands Annahme sind jedoch zwei Voraussetzungen auszumachen. Zum einen erläutert er seine Auffassung von Identität als die einer sprimären Identitätı, die in der Kindheit gebildet wird und prinzipiell unveränderlich, wenn auch fähig zu unzähligen Variationen ist. Zum anderen geht er analog dazu von einer eindeutig bestimmbaren Aussage eines Textes aus (auch wenn er hier die Rolle der Identität des individuellen Lesers ausführlich würdigt). Interessant sind diese Voraussetzungen, weil sie im Grunde auch für Herbst gelten, auch wenn sie seinen poetologischen und anthropologischen Ansichten wohl direkt widersprechen. Eigentlich geht er weder von einer unveränderlichen oder einheitlichen Identität beim Menschen noch von eindeutigen Aussagen in Texten aus. Dennoch steht der Roman in diesem Zusammenhang im Sinne des klassischen Romans für eine strukturierte Komposition und eine intendierte Sinn-Aussage. Und die Funktion des Konzepts ist entsprechend die Konstruktion einer einheitlichen Identität, die von allein nicht vorhanden ist und nur durch das >als ob < dieser Form der Betrachtung erreicht werden kann.

Dieser Aspekt der Wahrnehmung einer einheitlichen Identität ist ursprünglich die Grundfunktion der Autobiographie, die wie oben dargestellt eine Rückschau auf das

94 Vgl. oben Abschnitt 7.2.4 auf Seite 336.

95 Es ist jedoch anzumerken, dass Herbst für die Romane seiner poetischen Vorstellung nicht davon ausgeht. Entsprechend der nicht planbaren (postmodernen) Wirklichkeit sei auch nicht von einem von Anfang an feststehendem Ziel eines Romans auszugehen, vgl. KR, 104.

96 Norman N. Holland: »Unity Identity Text Self«, in: Publications of the Modern Language Society 90/5 (1975), 813-822, hier: 815. 
gesamte Leben in narrativer und meist zielgerichteter Form, quasi als Bildungsroman, gibt. Herbst zitiert auch einmal aus einem seiner liebsten Romane, Aragons Blanche, aus dem er die Formulierung >das Leben als Roman begreifen` vermutlich übernommen hat. Dort wird sie in Zusammenhang mit der autobiographischen Rückschau und angesichts des >Fiktionsrangs der eigenen Geschichte verwendet:

Wenn das innere Auge unser Leben zu projizieren sucht, so ist das ähnlich wie mit den Träumen, an die wir uns zu erinnern glauben und die wir dann doch nicht genau wiederzugeben vermögen. Ein noch verschwimmendes Bild, man möchte sehen, was dahinter ist, oder davor, doch das gelingt einem nicht. [...] Ich lese mein Leben noch einmal wie einen Roman, der mir gefallen hätte oder auch nicht, kurz, der seinerzeit einen gewissen Eindruck auf mich gemacht hätte. ${ }^{97}$

Ein weiterer lebenspraktischer Aspekt dieser Auffassung ist ein konstruktiver oder tröstlicher Umgang mit Rückschlägen oder Scheitern. Wenn solche schon geschähen, dann komme »mindestens eine >schöne Erzählung« « (ebd.) heraus. Auch hier (im Leben) wie für Kunst geht Herbst davon aus, dass die `Form` bzw. die `Formung ‘ Halt gibt und Schwierigkeiten beherrschbar macht. Das Verhältnis zu Katastrophen des eigenen Lebens ist damit aber zwiespältig und in der Radikalität der Auffassung gefährlich. Einerseits sind sie persönlich verletzend, andererseits sind sie für die $>$ Erzählung`sogar wichtig. Wie Herbst für seine Poetik feststellt, dass die Schilderung von Grenzsituationen ergiebiger ist als Alltagsbeschreibungen, ${ }^{98}$ sieht er auch persönliche 'Katastrophen` oder auch Probleme im Rahmen der `Erzählung` als Möglichkeit, »aus dem Leben die Banalität herauszustreichen " $(K T L B, 118)$, die durch viele >Alltagsprozeduren « entstehe. Umso erstaunlicher ist es, dass ein Großteil seines Arbeitsjournals gerade aus Schilderungen der alltäglichen Abläufe oder von Details bezüglich des Ortes oder der Musik, die er gerade hört, besteht, die gerade aufgrund ihrer `Banalität Spott auf sich gezogen haben. ${ }^{99}$

Neben dieser Funktion der beschriebenen Auffassung als Hilfsmittel, um mit persönlichen Fehlschlägen umzugehen, findet sich sogar ein ethischer Anspruch: das Projekt sei ein Experiment als Erprobung der Frage nach dem ^richtigen $<$ Leben (vgl. $K T L B, 119)$. Dies sind jedoch Interpretationen und Überhöhungen des Projektes, die weniger mit der Auffassung von Roman- oder Literaturhaftigkeit zu tun haben, als mit der Radikalität der Offenlegung fast aller Tätigkeiten. Der Anschluss an den Vergleich mit einem Roman findet sich eher noch in seinen Überlegungen zum Autor als Figur in den Poetikvorlesungen. Für eine adäquate zeitgenössische Literatur hält Herbst es dort für notwendig, das Autoren-Ich in die Erzählung hineinzunehmen, den Autor zu einer Figur zu machen. In seinen eigenen Werken führt er denn auch mehrfach eine Figur namens Herbst ein (Eine Sizilische Reise, Buenos Aires). Wie bereits oben erwähnt, ist damit jedoch keine reale Referenz auf den Autor vorhanden (mit Tatsachenbe-

97 Zit. nach Herbst: »Poetologische Thesen III«, 45 f.

98 Vgl. $K R$, 31, sowie Herbst: »Schöne Literatur muß grausam sein!«, 178-180.

99 Vgl. Andreas Rosenfelder: »Ein Labyrinth, das keine Sackgassen kennt. Nachrichten aus der aufregenden Grauzone zwischen Literatur und Nicht-Literatur: Wie sind die Texte in Weblogs beschaffen?«, in: Literaturen 11 (2006), 52-58. Die Reaktion folgte prompt: URL-66, 27. Okt. 2006. 
hauptung), sondern der Autor als abstrakte Ebene des Kommunikationsgefüges wird in der Erzählung als Figur visualisiert.

\subsubsection{Autobiographisches Schreiben im Weblog}

Neben den autofiktionalen Schilderungen seines Arbeitsalltages, gibt es in Herbsts Blog auch Elemente, die stärker dem autobiographischen Schreiben zuzuordnen sind. Wenn die Erzählung auch in den alltäglichen Texten zur narrativen Identitätskonstruktion genutzt wird, wird dies in anderen Passagen noch deutlicher.

Die Autobiographie definiert Carola Hilmes in Anlehnung an Lejeune folgendermaßen:

Rückblickende Prosaerzählung in der ersten Person, die das eigene Leben zum Gegenstand hat, vornehmlich die innere Entwicklung des Individuums, dieses von einem erreichten Punkt aus konsequent auf diesen Punkt hinführend, wobei die historische Richtigkeit der Fakten weitgehend gewahrt und gegenüber dem Leser auch versichert wird. ${ }^{100}$

Die kontinuierliche Fortschreibung der Selberlebensbeschreibung im Weblog steht dem ordnenden Rückblick diametral entgegen. Zwar ist darstellendes Schreiben bis auf Extremfälle immer retrospektiv, doch kann die fast unmittelbare, lediglich durch einige Stunden verzögerte Wiedergabe nicht als rückblickend in einem ordnenden Sinn bezeichnet werden. Auch wird wohl kaum ein abgeschlossenes Bild der Entwicklungsgeschichte einer Persönlichkeit gezeigt. Damit sind die Kriterien für die Gattung Autobiographie verfehlt, wie sie auch Wagner-Egelhaaf in Anlehnung an Lejeune skizziert. ${ }^{101}$ So orientiert sich Herbst mit seinem ähnliche Ziele verfolgenden Konzept des `Lebens als Roman begreifen` an der Auffassung fiktionaler Literatur. $\mathrm{Da}$ er sein Leben nicht retrospektiv, sondern begleitend schildert, kann (und will) er kein abgeschlossenes Persönlichkeitsbild darstellen. Um jedoch dennoch eine sinnhafte Darstellung zu erreichen, versucht er es durch erzählerische Mittel wie eine zielgerichtete Erzählung wirken zu lassen.

Als autobiographisch im eigentlichen Sinn können immer wieder eingestreute Texte gesehen werden, in denen Herbst tatsächlich aus größerer Distanz zurückblickend über sein Leben berichtet. Diese werden auch durch fremde Kommentare angeregt und auch bei den Kommentaren eingeordnet. Um die Jahreswende 2011/12 sind sie gehäuft zu finden. Zum einen sind dies Texte im Arbeitsjournal, die anlässlich eines Tagungsbesuchs im Dezember 2011 in Braunschweig entstanden sind, wo Herbst große Teile seiner Kindheit verbrachte. Zum anderen sind dies vielleicht gerade durch diese Erinnerungen angeregte Texte zu literarischen Prägungen, die er im Januar 2012 während der Arbeit an einem Kinderbuch ${ }^{102}$ anstelle des Arbeitsjournals verfasst hat. In seinen Erinnerungen an Braunschweig ${ }^{103}$ verbindet er die Erzählung seiner sexuellen Entwicklung mit Andeutungen der Familienverhältnisse (zum Bruder, zur Mutter,

100 Hilmes: Das inventarische und das inventorische Ich, 386.

101 Vgl. Wagner-Egelhaaf: Autobiographie, $5 \mathrm{f}$.

102 Der sogenannte >Jungenroman II‘, der bislang noch nicht veröffentlicht wurde; vgl. dazu Abschnitt 8.4.2 auf Seite 403 .

103 Vgl. URL-67, 10. Dez. 2011; URL-68, 11. Dez. 2011. 
zum Vater) und mit der Schilderung von Eindrücken und dem Verweis auf deren Auswirkungen auf seine Bücher. So verweist er auf die Bedeutung Braunschweigs für die sinnliche Prägung seines Mittelalterbildes sowie auf Erfahrungen mit Blutegeln, was beides Einzug in $W B$ gehalten hat. Neben einer atmosphärischen, wenn auch nur skizzenhaften Schilderung einer Jugend der 1960er Jahre wird die Konzentration auf den Bezug zum eigenen literarischen Schaffen deutlich. Während ein sicherlich zentrales Ereignis wie der >Herauswurf durch die Mutter und die Wahl, in ein Erziehungsheim oder zum Vater zu gehen, nur nebenbei erwähnt werden, werden die literarischen Prägungen ausführlicher und anschaulicher erzählt. Auch die Hervorhebung des Sexuellen und die detaillierte Schilderung seiner pubertären Entwicklung ist als Bezug darauf zu sehen, dass dieses Motiv auch in seinen Texten eine wichtige Rolle spielt. Der Hinweis auf Prägungen, die einen literarischen Niederschlag gefunden haben, hat hier wie oft in ähnlichen Passagen im Weblog (v. a. in den Kommentaren) die Funktion einer ergänzenden Erläuterung und auch Einordnung der eigenen literarischen Texte. Noch deutlicher wird die Fokussierung auf das eigene literarische Selbstverständnis in der Schilderung seiner Prägungen, wobei er als solche nur die auffasst, die ihn sgeprägt ( (im Gegensatz zu `beeinflusst`) haben, bevor oder als er mit dem Schreiben begann. ${ }^{104}$ Von Dostoevskij über Karl May, Tarzan- und Weltraumromane bis zu Thomas Mann, Joyce und Aragon beschreibt er weniger oder nur andeutungsweise die Bücher selbst als die Auswirkungen, die sie auf ihn gehabt haben. Eingeflochten sind bewusst im ungefähr Chronologischen bleibende Schilderungen der Stationen seiner Jugend. Wieder wird also das Persönliche in Bezug auf die literarische Entwicklung gesehen und dargestellt.

\subsubsection{Grenzen des Spiels zwischen Realität und Fiktion}

Wie die Figuren (Laupeyßer und Deters) in den Büchern stößt Herbst auch im Blog an die Grenzen des Spiels mit Realität und Fiktion. Besonders prägnant war es in $V G$ die "nicht wegzudisputieren[de] « $(V G, 194)$ oder »hautnahe Realität $(V G, 11)$ von Agnes, die durch die Bedürfnisse ihres kleinen Kindes bedingt war. Nicht nur sind es die körperlichen (aber auch emotionalen) Bedürfnisse eines Kindes, sondern auch seine Hilfsbedürftigkeit und noch vorhandene Reflexionslosigkeit, die philosophische Gedankenspiele mit der Realität verbieten. Auch im Blog ist es im Zusammenhang mit einem Kind, diesmal Herbst eigenem (und realen), dass die Grenzen des Spiels aufgezeigt werden. Zudem ist zu bemerken, dass erst ex negativo, d. h. wenn die Grenzen offensichtlich sind bzw. gezogen werden, es tatsächlich als Spiel kenntlich wird.

Der `Vorfall war wie folgt: Nach einer kleinen Bemerkung von Herbst über den eigenen Umgang mit seinem Sohn kam es zu einer Diskussion in den Kommentaren über Erziehung (bezüglich des Erlernens eines Musikinstruments), ${ }^{105}$ die in dem Vorwurf an Herbst gipfelten, »daß [s] ein Sadismus auch an [s]einem Kind ausgetragen werde « $(K T L B, 111)$, wobei wohl auch von Kindesmissbrauch die Rede war. Herbst befürchtete angesichts des schwerwiegenden Vorwurfs und gerade seiner eher

104 Vgl. URL-24, 4. Jan. 2012-26. Jan. 2012.

105 Vgl. URL-69, 16. Mai 2009-18. Mai 2009. 
komplizierten Familienkonstellation Konsequenzen für seinen Sohn und reagierte umgehend, indem er androhte, die Polizei einzuschalten. Nach einer angeblich schon vor dieser Androhung erfolgten Entschuldigung des Kommentators löschte er jedoch die betreffenden Kommentare. Angesichts der Brisanz weniger der Ausgangssituation als der verwendeten Begrifflichkeit in der aufgeschaukelten Diskussion sind ihm dabei die Grenzen der programmatischen Darstellung des Privaten im Weblog klargeworden. Den Vorfall thematisiert er im Rahmen seiner Reflexionen über die Gattung Literarisches Weblog: »Hier sind die Grenzen der Offenheit eines Literarischen Weblogs deutlich gezogen; auf diesem Weg läßt sich Offenheit de facto zerstören. « ${ }^{106}$ Auch wenn es ihm vor allem um seinen Sohn bzw. um die Konsequenzen für ihr Verhältnis ging, drohte wie auch im Fall von Meere zumindest die Möglichkeit einer juristischen Beschränkung der ästhetischen Anliegen. Wäre es tatsächlich zu einer Anzeige und Untersuchung gekommen, hätte das Weblog zumindest vorübergehend aufgegeben werden müssen.

Trotz dieser an diesem Vorfall offensichtlich gewordenen Gefahr juristischer (und auch verbundener emotionaler) Konsequenzen folgt er seiner Linie radikaler Offenheit. So schildert er beispielsweise die

»Fantasie eines Gesamtmordes, [...] die Frau [d. i. seine ehemalige Lebensgefährtin und Mutter seines Sohnes] kehrt dann heim aus Paris und findet uns alle tot: die Zwillingskindlein, Dich [d. i. der Sohn], mich. Das war ein kurzer Aufschuß in meinem Kopf, dem das Herz dann gleich den Dämpfer versetzte: du 1 i e b s t die Kinder, Herbst ... «107

Angesichts der eben beschriebenen, aus dem Ruder gelaufenen Diskussion ist es verwunderlich, dass an dieser Stelle keine Leserreaktionen kamen. ${ }^{108}$

\subsection{Versteckte Identitäten: Anonymität und das Pseudonym}

Das Spiel mit verschiedenen Rollen, an dem Herbst und seine Mit-Autoren und auch kommentierende Leser teilnehmen, ist ein Experiment mit den Möglichkeiten des immer noch neuen Mediums Internet. (Reale) Personen können durch die mediale Vermittlung und Distanz leichter als im realen Leben verschiedene Nicknames bzw. Pseudonyme und damit Rollen einnehmen, weshalb die Zuordnung von Äußerungen zu bestimmten Personen erschwert ist oder unmöglich gemacht wird. Dieses Experiment greift die vielfach im alltäglichen Umgang mit dem Internet in Foren, Chats, sozialen Netzwerken oder Online-Spielen gebräuchliche Praxis auf. Neben dem explizit erwünschten Spiel-Charakter, ${ }^{109}$ der sowohl im Ausprobieren von Rollen auf

106 URL-70, 17. Mai 2009.

107 URL-71, 28. Apr. 2009.

108 Kreknin geht kritisch auf die detaillierte Einschreibung des Sohns ein. Als Minderjähriger könne dieser seine Rolle nicht aktiv bestimmen und werde so >entmündigt`. Kreknin betont die existenzielle Dimension dieser Vermischung von Kunst und Alltagswirklichkeit und wertet dies als »autoritäre Praxis«, die zudem im Widerspruch zur theoretisch avisierten Dehierarchisierung von Identität und Autorschaft stehe. Vgl. Kreknin: Poetiken des Selbst, 413f., 417f., 427. Zu Herbsts Reaktion auf diesen Vorwurf nach Lektüre der Arbeit vgl. URL-72, 2. März 2014.

109 Vgl. URL-6, 8. Mai 2009. 
Produzentenseite als auch im Nachvollziehen und detektivischer Suche aufseiten des Rezipienten bestehen kann und vor allem in der systematischen Anwendung über das alltägliche Phänomen hinausgeht, hat dies Experiment auch mit den ebenfalls alltäglich im Internet zu findenden Schattenseiten zu kämpfen: unkonstruktiven oder auch destruktiven, störenden und sogar beleidigenden Kommentaren von sogenannten $>$ Trolls ${ }^{110}$.

Schon die bereits angesprochenen Bezeichnungen von Herbst für diese Rollen, die für ihn aus Autor und Lesern literarische Figuren machen oder die er mit dem im Internet gebräuchlichen Begriff >Avatar ${ }^{111}$ bezeichnet, enthalten implizit die Frage nach ihrer Identität und gewissermaßen auch ihrem ontologischen Status. Dabei werfen gerade auch die negativen Beispiele Fragen auf. Herbst geht diesem Komplex in Überlegungen zum rechtlichen und zum emotionalen Status der Avatare nach. Wie bereits oben am Beispiel des Missbrauchsvorwurfs angesprochen, könnte bei schweren strafrechtlichen Verstößen durch technische Recherchen möglicherweise ein Bezug zur zugehörigen »realen juristischen Person « $(K T L B, 92)$ hergestellt werden. Herbst ordnet dem jedoch in Bezug auf ein literarisches Weblog eine untergeordnete Rolle zu. Häufiger stelle sich die Frage, ob Avatare in heftigen Kommentardiskussionen beleidigt werden können. Herbst stellt dazu fest:

Tatsächlich kann der Urheber eines unter Pseudonym eingestellten Beitrages und Kommentars von einem Gegenanwurf gekränkt werden; wir empfinden das unmittelbar, und es schmerzt uns. Die Emotionen, in denen sich die Realperson aus den Spaltungen eigentlich wieder zusammensetzt, springen einen nicht selten aus den folgenden Kommentaren dann an. $(K T L B, 93)$

Das verwundert nur, wenn angenommen wird, dass durch eine eingenommene Rolle auch eine gewisse Distanz zur eigenen >realen< Identität eingenommen wird, nicht aber, wenn von der dahinter stehenden Realperson ausgegangen wird. Interessant ist die Schlussfolgerung, dass sich durch die Emotionen die Spaltungen wieder zu einer Person zusammensetzen bzw. hinter ihnen eben eine einheitliche Person steht. Vermutlich im Gegensatz zu den >Trolls $\triangleleft$ besteht daher für Herbst eine Voraussetzung

110 Vgl. dazu den Wikipedia-Eintrag zum Begriff »Troll«, Wikipedia: »Troll (Netzkultur)«, 17. März 2015, URL: http://de.wikipedia.org/wiki/Troll_(Netzkultur).

111 Für eine eingängige Erläuterung vgl. Tim Jordan: Cyberpower. The Culture and Politics of Cyberspace and the Internet, London 1999, 59:

\footnotetext{
An avatar is a stable identity that someone using Barlovian cyberspace [d. i. der virtuelle Raum, der durch Computernetzwerke geschaffen wird, im Gegensatz zum fiktionalen Cyberspace nach William Gibson] has created. The existence of an avatar means someone has used some of cyberspace's resources in ways that result in other avatars recognising a stable online personality. Someone's avatar may be constructed from the style of their online writing, from the repeated use of a name or self-description, or from any of a number of other virtual possibilities. More than one avatar can be created and the relationship between these identities and someone's offline life is complicated.
}

Vgl. auch Malsch:»Vom Wiedereintritt des Autors in seine Geschichte«, 57 FN 8: »Avatare oder rassistent agents s sind ein in den Forschungspublikationen der Verteilten Künstlichen Intelligenz viel diskutiertes Konzept.« Vgl. zudem BA, 24 sowie 33, wo der Avatarbegriff auch auf Laupeyßer und Falbin aus $V G$ ausgedehnt wird. 
für das Spiel darin, dass eine gewisse Form von Identität zwischen der Realperson/dem Autor und dem Avatar besteht. Dieser soll

»nicht als Hecke verwendet werden, hinter die man sich duckt, um aus dem Hinterhalt Schlammbatzen zu werfen. Sondern man muß die Avatare fühlen, muß sie sein und ein Gefühl für ihre Persönlichkeit, auch für ihre Geschichte bekommen, die man darum kennen muß.«(KTLB, 109)

Der Anspruch ist also ähnlich dem der Schaffung eine kohärenten literarischen Figur. In den verwendeten Begriffen deuten sich diese Zusammenhänge dadurch an, dass aus einer realen Person eine Figur bzw. ein Avatar wird, die erst »Person[]«, d. h. stimmig und gewissermaßen vollständig wird, indem ihre Konstruktion ernstgenommen wird. Diese Ernsthaftigkeit betont er auch, indem er von der Entwicklung eines »Character[s]« [sic!] $(K T L B, 41)$ spricht. Die eingeforderte Identität ergibt auch die Annahme, dass eine Übereinstimmung des geschaffenen Charakters mit zumindest Fragmenten des eigenen Selbst besteht.

Folgerichtig ist es eine psychologische Interpretation dieses Phänomens, die Herbst durch Rückgriff auf ursprünglich freudsche Begriffe nahelegt. Er spricht in Bezug auf die Einnahme verschiedener Identitäten im Internet daher vom »Tanz der Ich-Ideale«:

Es kommunizieren in Chats nämlich die Selbst-Projektionen oder doch idealisierte Abspaltungen des schreibenden Ichs. [...] Man muss sich letztlich nicht festlegen, sondern kann verschliffen agieren - zumal aus dem Hintergrund und deshalb unangreifbar. Das hat sich auf die Weblogs übertragen, wobei sich die ausgestellte Ich-Abspaltung durchaus schon etwas mehr in Richtung auf ein geformtes Ich-Ideal $\mathrm{f} \mathrm{e} \mathrm{s} \mathrm{t}$ i g t. ${ }^{112}$

Der Begriff des Ich-Ideals ist - wie aus dieser Verwendungsweise ersichtlich - jedoch nicht mit dem freudschen Über-Ich (das Freud synonym mit Ich-Ideal verwendet) gleichzusetzen. Vielmehr ist es ganz wörtlich ein ideales Ich, das als mehr oder weniger bewusste Projektion zu sehen ist. Die oftmals im Internet und auch in Herbsts Weblog mögliche Anonymität ermöglicht das Ausprobieren von Verhaltensweisen, die sich diesem Ich-Ideal annähern. Die Kehrseite solcher >idealer` oder ১idealisierender Verhaltensweisen nimmt Herbst angesichts der negativen Erfahrungen auch mit auf, indem er davon ausgeht, dass nicht nur idealisierte Abspaltungen des Ich existieren und durch eine niedrige Hemmschwelle ausprobiert werden können, sondern auch der »dunkle[] Contrepart« $(K T L B, 93)$ des Ich-Ideals. Dieser besteht in den durch die Anonymität nicht mehr sozial kontrollierbaren `Ausfällen`, die zu Beleidigungen und eben dem >Trollen führen.

Herbst betont jedoch vor allem eine positive Sichtweise auf die Möglichkeiten des Internets für das Ausleben verschiedener Rollen. Er sieht dabei Parallelen zu Rollenspielen, die als anschaulicheres Beispiel dienen. So könne beispielsweise eine Frau, die im realen Leben eine medizinisch-technische Assistentin sei, sich möglicherweise viel besser durch ihre Rolle als mittelalterliches Burgfräulein ausdrücken. »Der literarische Spiegel kann hiervon im Netz der Avatar sein." $(K T L B, 109)$ Die sentfremdete Arbeit würde vielleicht gar nicht die Möglichkeit zu einer persönlichen Reifung zulassen. An 
dieses marxistische Vokabular schließt er auch an, wenn er die Möglichkeiten sowohl von Literatur als auch von der Kommunikation im Netz, die er als ähnlich ansieht, als positive Chance begreift:

Vielmehr ist die Fragmentierung des Ichs zu ergreifen, wie die marxistische Forderung umzusetzen, endlich über die Produktionsmittel selbst zu verfügen. Ich w ill mich als Fragmentierten: bin Herbst und Ribbentrop und Daniello und Deters und Kerbmann und Bertrecht und Borkenbrod und sogar Niamh of the Golden Hair. Ich bin es aber je in verschiedener Hinsicht. $(K T L B, 110)$

\subsubsection{Anonymität}

Dass die Beibehaltung der Anonymität Herbst trotz der Probleme mit beleidigenden Kommentaren wichtig ist, wird immer wieder deutlich. Eigentlich könnte er die Kommentarfunktion ganz abstellen, unliebsame Kommentare einfach löschen oder aber auch eine Anmeldung unter Klarnamen verlangen. ${ }^{113}$ Wie oben bereits erwähnt geht es ihm aber um die 'Spiegelung` der Verfahrensweisen des Internets und um deren Ästhetisierung.

Die anonyme Kommentarfunktion ist in Der Dschungel in der Tat wichtig, weil es ein Spiel erlaubt [...]; die Möglichkeit, unter verschiedenen Identitäten zu kommentieren, ist sogar ein Herzstück Der Dschungel. Sie ist nämlich ein Herzstück sowohl des Internets als solchem wie des Weblogs im besonderen. ${ }^{114}$

Die Offenheit und der freizügige Umgang mit intimen Belangen, die er gerade in Chats erlebt, sieht er dabei als einen wichtigen Aspekt des neuen Mediums. Die Offenheit entstehe durch »eine gefühlte enorme Nähe [verbunden] mit hoher Anonymität ${ }^{115}$. Die freie Wahl zwischen Preisgeben und Verbergen ermöglichen für ihn »die distanzierteste Form höchster Intimitä « ${ }^{116}$. Dabei passt dieser Aspekt zu seiner Auseinandersetzung mit dem Zusammenhang zwischen Privatem und Allgemeinen bzw. Öffentlichen.

Ein weiterer Grund für die Beibehaltung der Anonymität bei den Lesern ist ihre Voraussetzung beim oben beschriebenen Spiel mit verschiedenen Identitäten bei ihm selbst und seinen Koautoren. Die gewollte Ungewissheit der Zuordnung erstreckt sich so auch auf die Kommentatoren, hinter denen teilweise auch Herbst selbst steht. Die Verwirrung des Lesers entsteht erst durch die Fülle der beteiligten Personen und Beiträge, die durch eine Begrenzung des Zugangs gemindert würde.

Von einigen Koautoren und Lesern wurde ihm mehrfach geraten, die Anmeldung (ohne Gastzugang) zwingend erforderlich zu machen und >trollige zu löschen. Bezüglich des Löschens ist Herbst auch mehrfach darauf eingegangen und verfolgt demnach keine ganz stringente Linie. Er verteidigt jedoch eben aus Gründen der Stringenz und seiner Neigung, Angriffe eher als Bestärkung zu sehen,

113 Die Überprüfung des realen bürgerlichen Namens wäre wohl kaum möglich, Herbst lässt jedoch sogar das Kommentieren ohne Anmeldung, d. h. unter wechselnden Namen zu.

114 URL-73, 17. Mai 2009.

115 Herbst: »Das Weblog als Dichtung«, 15.

116 Ebd., 25. 
die Beibehaltung der meisten Kommentare. Für Angriffe auf seine eigene Person, denen er bewusst nicht ausweichen will, hat er zeitweise eine eigene Kategorie, den ANTI-HERBST, eingerichtet.

Entgegen seiner Verteidigung der Anonymität wirft er jedoch `Angreifern $\triangleleft$ des Öfteren vor, nicht unter Klarnamen zu agieren. Gemeint ist damit wie gesagt noch nicht einmal der bürgerliche Name, sondern die Anmeldung ohne auswechselbaren Gastzugang. Dies scheint seinem Spiel mit unterschiedlichen Rollen und Identitäten und der positiven Einstellung gegenüber den Möglichkeiten der Anonymität zunächst zu widersprechen. Hier greift jedoch seine Forderung, die Avatare sollten keine »Hecke« $(K T L B, 109)$ sein, hinter der der Autor oder Kommentator sich verstecke, um aus dem Hinterhalt anzugreifen. Vielmehr nimmt er eine nötige (Teil-)Identität zwischen Autor und Avatar an. Zum einen ist hier sein Wille zur offenen Konfrontation ersichtlich, seine postulierte Abneigung gegen das Aus- und Zurückweichen bei Streitigkeiten. Zum anderen die ambivalente Haltung gegenüber der Verbindung von Namen und Identität. In der Konfrontation sucht er eine eindeutige Zuordnung, die er sonst - im Spiel - nicht für wichtig erachtet. Die Zuordnung kann dabei über ein Pseudonym erfolgen, sollte - da es beim Vorwurf bleibt, ist es wohl nicht zu ermitteln - jedoch eine Persönlichkeit erkennen lassen.

\subsubsection{Pseudonym}

Auffällig ist in diesem Kontext - vor allem wenn nicht wie meistens im Internet von Avataren oder Nicknames geredet wird, sondern traditionell von Pseudonymen -, dass Herbst selbst sich eines Pseudonyms bedient. Als in entsprechenden Kommentardiskussionen dies als Vorwurf aufkommt, erklärt er seine Einstellung zum Pseudonym. >Alban Nikolai Herbst`sei für ihn sein »regulärer, im Paß eingetragener Name « ${ }^{117}$, unter dem er studiert, private und berufliche Verträge unterschrieben habe und sogar Strafmandate bekomme. Wichtig für ihn ist hier die Unterscheidung zwischen einem »Künstlernamen «, unter dem er offiziell und vor allem persönlich zu erreichen sei, und einem quasi-anonymen Pseudonym in Form eines >Nicknames .

Auch wenn die Funktion des Pseudonyms oder Künstlernamens in diesem Kontext tatsächlich nicht die des Versteckens oder des Schutzes durch Anonymität hat, so war dies doch zum einen ursprünglich für ihn der Fall, zum anderen hat die Debatte um Pseudonyme und das Experimentieren mit Anonymität und Verstecken im Blog allgemein entscheidende Auswirkungen auf seinen eigenen Umgang mit dem Pseudonym. Zunächst sollen jedoch die Gründe für den Namenswechsel und die Geschichte des Namens skizziert werden.

Wie bereits erwähnt ist Herbsts eigentlicher Name Alexander Michael von Ribbentrop. Er stammt aus dem alten Adelsgeschlecht der von Ribbentrops. Der wohl bekannteste Namensträger und Verwandte ist der aus einer entfernten Linie stammende ${ }^{118}$ Joachim von Ribbentrop, der Hitlers Außenminister war und den Hitler-Stalin-Pakt aushandelte. Dieser wurde in den Nürnberger Prozessen schuldig gesprochen und 1946 durch Erhängen hingerichtet. Nachdem Herbst in der Kindheit und auch bei

117 URL-74, 27. Okt. 2005.

118 Vgl. URL-75, 10. Feb. 2005. 
seinen ersten Schritten im Literaturbetrieb immer wieder feindlich damit konfrontiert wurde, kam anlässlich seines ersten geschriebenen Romans »Die Erschießung des Ministers ${ }^{119}$ vom befreundeten Philosophiehistoriker Arno Münster ${ }^{120}$ der Vorschlag, sich ein Pseudonym zuzulegen. Die Wahl des neuen Namens übernahmen dann Freunde ${ }^{121}$ und setzten ihn aus verschiedenen für Herbst wichtigen Bezügen zusammen: auf den Musiker Alban Berg, auf die literarische Figur Nikolai Stavrogin aus Dostoevskijs Roman Böse Geister (bzw. Die Dämonen) sowie auf den sogenannten Deutschen Herbst Ende der 1970er Jahre mit den Attentaten der RAF. ${ }^{122}$ Herbst ging unter neuem Namen nach Frankfurt am Main und begann dort sein Studium. Schon sein erstes publiziertes Buch Marlboro erschien 1981 unter dem Pseudonym. Obwohl die Zusammenhänge einigen im Literaturbetrieb bekannt waren, war dieser Umstand in Rezensionen kein Thema. Erstmals öffentlich schriftlich aufgeführt wurde der Originalname schließlich erst 1999, als Herbst ins Kritische Lexikon zur deutschsprachigen Gegenwartsliteratur $(K L G)$ aufgenommen wurde. Im Klappentext seiner Bücher hat Herbst beide Namen erstmals 2003 in der Erstausgabe von Meere vermerkt, worin die Problematik thematisiert und literarisch verarbeitet wird. ${ }^{123}$

Schon in den anderen Romanen, v. a. aber in $V G$, ist die Auseinandersetzung mit einem Identitätswechsel und vor allem einem (falschen) Pass immer wieder zu finden, wie oben detailliert herausgestellt wurde. In $V G$ finden sich wie erwähnt auch einige Hinweise auf Probleme nicht nur allgemein mit der deutschen Vergangenheit, sondern auch mit einem belasteten Namen. In Meere ist dies neben der Liebesgeschichte und der Künstlerthematik eines der wichtigsten Motive. Der Künstler Julian von Kalkreuth nennt sich hier mit neuem Namen Fichte. Sein Großvater Wernher von Kalkreuth war als Arzt in die nationalsozialistischen Verbrechen verwickelt. Fichte erzählt von Erlebnissen in der Schule, die das unschuldige (da nach dem Krieg geborene und daher unbeteiligte) Kind zu erleiden hatte:

>Du wirst auch einmal aufgehängt wie dein Großvater, Kalkreuth.

Fichte war acht oder neun gewesen, als dieser Satz fiel. Eher neun. ${ }^{124}$

Herbst erzählt von solchen Erfahrungen mit Verweis auf die Verarbeitung in Meere auch in seinem Blog. Parallel zur genannten Stelle schreibt er dort:

Der Bezug wurde bereits im Kindergarten hergestellt, später in der Schule und dort auch gegen mich verwandt, auch von Lehrern; da war ich vielleicht acht oder neun. ${ }^{125}$

119 Erst 1986 als Die blutige Trauer des Buchhalters Michael Dolfinger erschienen.

120 Vgl. URL-76, 23. Feb. 2011; URL-77, 18. Jan. 2012; Fasthuber: "Sie müssen verzeihen, aber darauf scheiße ich echt «

121 Vgl. URL-76, 23. Feb. 2011.

122 Vgl. Munzinger Online: Herbst, Alban Nikolai, sowie Scherer: »Alban Nikolai Herbst [KLG]«. Zur Bedeutung von Dostoevskijs Roman für Herbst vgl. URL-78, 4. Jan. 2012; dort wird auch schon die RAF erwähnt, Näheres dazu vgl. URL-79, 9. Feb. 2012.

123 Neben den offensichtlichen Bezügen weist Herbst auch im Blog explizit darauf hin, vgl. URL-76, 23. Feb. 2011.

124 Herbst: Meere (2008), 31, ähnlich auch 35.

125 URL-76, 23. Feb. 2011. 
Vor allem thematisiert er in Meere jedoch die Wandlung von Kalkreuth zu Fichte, die Möglichkeiten und Auswirkungen sowie die Schwierigkeiten, die weniger in dem äußeren Umgang mit der Namensänderung, als im subjektiv gefühlten Wechsel bestehen. Wieder aufgegriffen werden Formulierungen aus $V G$ (dort bspw. 8, 237, 289) wie »sich selbst erfinden ${ }^{126}$ und dass $» K a l k r e u t h$ Fichte erfunden hatte ${ }^{127}$. Der neue Name bringt für ihn eine vollständige Identitätsumstellung mit sich, da er eine neue Sicherheit gewinnt und einen neuen Charakter annimmt. Zwar mögen ihn »die anderen « immer noch nicht, schaffen es aber nicht mehr, »ihn kleinzumachen ${ }^{128}$. Er versteht Fichte dabei als eigentlich fertiges »Konzept ${ }^{129}$, als sein "größtes Kunstwerk «, das »unhinterfragbar ${ }^{130}{ }^{13}$ geworden ist.

Im Blog beschreibt er (vermengt mit Verweisen auf Meere und daher auf beide, Herbst selbst und Fichte bezogen) die eigentliche Problematik:

Aber wie kriege ich in den Kopf und ins Herz, nicht mehr der zu sein, der ich war, ohne das aber gleichzeitig aufgab, es zu sein. ${ }^{131}$

Fichte hat diesen Prozess bereits vollzogen. Dennoch besteht für ihn die Schwierigkeit, dass weiterhin Kalkreuth in ihm existiert.

Ich merkte Kalkreuth bald kaum noch, obwohl er wie ein Virus bloß eingekapselt war, so daß sich periodisch neue Virenflut in mich ausschütten konnte, jedes Virion eine alte Angst. ${ }^{132}$

Es wird eine Entwicklung in Fichte angestoßen, die wieder auf seine Ursprünge zurückgeht. Er merkt, dass er Kalkreuth in sich nicht unterdrücken kann, dass dieser »ins Leben zurück [muss], um ein paar Dinge zu ordnen, die für Fichte tabu sind «133. Er merkt, dass er sich "nicht länger in Fichte verstecken ${ }^{134}$ kann. Fichte kann er nicht aufgeben, Kalkreuth nicht verleugnen; beide bestehen nebeneinander. In keinem seiner Werke unterscheidet Herbst so deutlich wie hier zwischen einem Ich und einer konstruierten Identität. Wie in WB bei Deters wird mitten im Satz von sich $\mathrm{zu}$ >er oder zu Fichte` gewechselt, wobei teils keine Bedeutungsunterscheidung zu erkennen ist, teils tatsächlich zwischen dem `Original-Ich $\prec$ und dem konstruierten Ich Fichte differenziert wird.

Was Herbst in Meere anhand der Figur Kalkreuth/Fichte als Sehnsucht beschrieben hat, findet sich als Entwicklung bei ihm selbst erst einige Jahre später im Weblog. Im März 2007 entscheidet er, auf neuen Visitenkarten beide Namen, den Künstlernamen wie den bürgerlichen Namen, zu verwenden und fortan auch auf neuen Büchern und

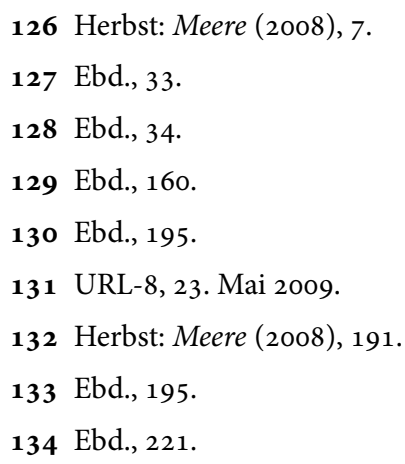


auf Neuausgaben gleichberechtigt nebeneinander zu verwenden. Diese Entscheidung sieht er als »ein Ergebnis von MEERE« und hebt ihre Bedeutung besonders hervor: »Keine weitere Frage mehr - meinen Namen (meine Identität) habe ich mir zurückgeholt. «135 Besonders zu beachten ist hier die Gleichsetzung von Name und Identität. Der neue Name war zwar auch wesentlich ein Mittel, um Vorwürfen, Anfeindungen oder einfach Nachteilen wegen des belasteten Familiennamens zu entgehen, zugleich aber auch die Inanspruchnahme einer geänderten Identität über den geänderten Namen hinaus, eine andere Einstellung oder gar einen modifizierten Charakter betreffend. Im Gegensatz zu den neu publizierten Büchern setzte er diese Entscheidung im Weblog unmittelbar um. Seitdem stehen wie oben bereits aufgeführt im Header unter dem Titel beide Namen durch einen Schrägstrich getrennt. ${ }^{136}$

Die in Meere abgebildete Auseinandersetzung mit diesen Zusammenhängen führt Herbst auf die Geburt seines Sohnes zurück. ${ }^{137}$ Die Erfahrung eines eigenen Kindes, dessen vollständiger Name (d. h. auch der Name von Ribbentrop) in der Widmung bereits fast von Anfang an aufgeführt ist, habe bei ihm ein `Familiengefühl ausgelöst, das den Namen wieder wichtig gemacht habe. Seine Argumentation ist dabei, dass er nicht wolle, dass auch sein Sohn darunter leiden oder sich wegducken solle. Die Verbrechen, die mit dem Namen verbunden sind, könne er zwar nicht wieder gutmachen, aber er könne ihnen etwas Gutes, nämlich sein Werk entgegensetzen, den Namen sozusagen wieder anders bzw. positiv belegen. ${ }^{138}$

Ganz vertraut Herbst der Wirkung dieser Einstellungsänderung allerdings nicht. 2011 und 2012 hat er jeweils ein Kinderbuch geschrieben, einen `Jungenroman - wie er es als Deckname nennt - und ein Folgebuch, die er unter einem neuen Pseudonym veröffentlicht hat. Im Blog hat er dazu zunächst nur Andeutungen gemacht, auch den Verlag nicht genannt. Er begründete dies damit, den Büchern angesichts seines umstrittenen Rufes in der Branche eine Chance geben zu wollen. ${ }^{139}$ Später hat er das Pseudonym dennoch publik gemacht, nachdem die Publikation der Folgeromane gescheitert ist. ${ }^{140}$ Der erste Roman ist unter dem aus Wolpertinger entlehnten Pseudonym `Ornit Karlsson` erschienen. ${ }^{141}$

135 URL-80, 23. März 2007.

136 Dass dies zwischen Februar und April 2007 geändert wurde, d. h. also etwa seit der Entscheidung im März 2007 so besteht, ist über die »Wayback Machine« (http://wayback.archive.org/web/*/http: //albannikolaiherbst.twoday.net) nachzuvollziehen. Auf der eigentlichen $>$ Homepage $<$ albannikolaiherbst.de gibt es unter der Rubrik »Biografie« eine biographische Auflistung verschiedener fiktiver und realer Namen. Dort werden Alban Nikolai Herbst und Alexander von Ribbentrop aufgeführt, der Intention dieser Seite entsprechend jedoch nicht als identisch dargestellt. Vgl. Alban Nikolai Herbst: »Die Dschungel: biografie +++ curriculum vitae«, URL: http://www.diedschungel.de/ANH/main.html?bio.html mainFrame.

137 Vgl. Fasthuber: »Sie müssen verzeihen, aber darauf scheiße ich echt «".

138 Siehe URL-81, 13. März 2007. Vgl. auch URL-82, 15. Juni 2006.

139 Vgl. URL-83, 16. Nov. 2011.

140 Vgl. URL-84, 12. März 2013.

141 Ortnit Karlsson [d. i. Alban Nikolai Herbst]: Das Katastrophen-Quartett. Frau Schneider aus Thor, Köln 2012. 


\subsection{Identitätskonstruktion und Inszenierung als Teil der eigenen Kunst}

Die eben geschilderten Entwicklungen, die Herbst literarisch stark bearbeitet in Meere und später dann im Weblog als eigene schildert, setzen interessanterweise die Vorstellung einer mehr oder weniger einheitlichen Identität voraus, die sich entwickeln oder auch neu geschaffen werden kann. Ihren prägnantesten Ausdruck findet diese Vorstellung in der Formulierung vom >fertigen Konzept $\iota$, die in Meere verwendet wird. Herbst bestätigt sie später als seine eigene in Schilderungen seiner Jugend im Weblog und der Überlegung, wie lange ein Mensch >geprägt` werden könne, im Gegensatz zu einer weiterhin möglichen späteren Beeinflussung:

Ich schreibe unterdessen das Jahr 1976, fast schon 1977 und bin einundzwanzig Jahre alt. Läßt es sich da noch von „Prägungen“ sprechen? Sind wir nicht schon abgeschlossen, wie [...] ich es, eigentlich, glaube? ${ }^{142}$

Die Einheitlichkeit bezieht sich somit nicht auf eine diachrone Betrachtung, da gerade eine zeitliche Entwicklung mit signifikanten Umbrüchen geschildert wird. Es handelt sich vielmehr um die Konstruktion eines kohärenten Selbstbildes, das auch nach außen kommuniziert und inszeniert wird.

Die Inszenierung dieses Selbstbildes erfolgt in Interviews und Essays, also in »Elemente[n] des auktorialen Epitextes [seines Werkes] mit einem öffentlichen Resonanzradius ${ }^{143}$, sowie seit knapp einem Jahrzehnt vor allem im Weblog. Angesichts der Fokussierung dieser Arbeit auf das Prosawerk und Weblog konzentriere ich mich auf die textliche Inszenierung und die den bisher untersuchten Motiven korrespondierenden Aspekte. Herbsts diesbezügliche Inszenierung bei Lesungen oder in anderer, bspw. persönlicher Kommunikation im Literaturbetrieb kann nur vermittelt durch Herbsts Schilderungen im Weblog berücksichtigt werden. ${ }^{144}$

In der neueren literaturwissenschaftlichen Forschung zu Inszenierungspraktiken werden diese als »jene textuellen, paratextuellen und habituellen Techniken und Aktivitäten von SchriftstellerInnen [definiert], in oder mit denen sie öffentlichkeitsbezogen für ihre eigene Person, für ihre Tätigkeit und/oder für ihre Produkte Aufmerksamkeit erzeugen ${ }^{145}$. Es geht um die »absichtsvolle Bezogenheit auf öffentliche Reso-

142 URL-7, 24. Jan. 2012.

143 Christoph Jürgensen / Gerhard Kaiser: „Schriftstellerische Inszenierungspraktiken. Heuristische Typologie und Genese«, in: dies. (Hg.): Schriftstellerische Inszenierungspraktiken. Typologie und Geschichte, Heidelberg 2011, 9-30, hier: 12.

144 Auch weitere Untersuchungen wären denkbar, wie die Darstellung auf Fotos sowohl im Blog als auch bspw. auf dem Schutzumschlag der ersten Meere-Ausgabe (vgl. Herbst: Meere (2003)). Dort ist ein Porträtfoto gewählt, das durch den unbewegten und ernsten Gesichtsausdruck, den durchdringenden, ’harten` Blick den Männlichkeitsdiskurs widerspiegelt, auf den noch zurückzukommen ist. Zur Untersuchung von Porträtfotografien von Gegenwartsautoren vgl. Katrin Blumenkamp: »Typologien des >Als obく. Praktiken der Autorinszenierung um die Jahrtausendwende«, in: Christoph Jürgensen / Gerhard Kaiser (Hg.): Schriftstellerische Inszenierungspraktiken. Typologie und Geschichte, Heidelberg 2011, 363-381. Kreknin geht im Kontext der Autofiktionsfrage mehrfach auf die »beglaubigende« Funktion von Fotografien in Herbsts Weblog ein, vgl. Kreknin: Poetiken des Selbst, 394, 400, 403, 407, 413, 422.

145 Jürgensen / Kaiser: "Schriftstellerische Inszenierungspraktiken«, 10. 
nanzräume, [...] die Markierung und das Sichtbar-Machen einer sich abgrenzenden, wiedererkennbaren Position innerhalb des literarischen Feldes ${ }^{146}$.

Nach Stephan Porombka stellt sich zumindest bei jüngeren oder den `medienkompetenten Autoren nicht mehr die Frage nach dem ^Ob< einer Inszenierung, sondern nur noch nach dem $>$ Wie ${ }^{1}{ }^{147}$ Dabei unterscheidet er drei verschiedene Formen von Inszenierung:

1. [die] Inszenierung von Authentizität, 2. [die] Inszenierung von Inszenierung und 3. [die] Inszenierung von Thematisierung der eigenen Inszenierung ${ }^{148}$

Herbst ist hier als eine komplexe Mischung vor allem der ersten und dritten Form einzuordnen. Einerseits inszeniert er Authentizität. Diese bezieht sich jedoch nicht auf eine Authentizität durch Darstellung von Tatsachen. Die vermutete Lesererwartung gegenüber dem Weblog negiert er explizit. Doch dem Konzept des >Wahrlügens، entsprechend, will er wie oben dargestellt eine ästhetische Wahrheit vermitteln, eine eigentliche, sauthentische Wahrheit. Andererseits stellt er die Fiktionalisierung explizit heraus und reflektiert über die bewusste Inszenierung: er sthematisiert die eigene Inszenierung`. Dies bezieht er sogar auf jeden Autor und unterstreicht Porombkas Aussage:

Wer als Autor den Öffentlichen Raum betritt, ist in jedem Fall Figur. Das gilt auch für Lesungen vor Publikum. Der Autor [...] ist: Rolle. Ob er das wahrhaben will oder nicht. Wer von Authentizität ausgeht, auch der Dichter selbst, ist auf dem Holzweg. $(K L T B, 101)$

Porombka stellt fest, dass »[i]n den letzten Jahren« Autoren und Texte vor allem "aus der Perspektive des Marketing und der Aufmerksamkeitsökonomie ${ }^{149}$ betrachtet wurden und auch seine Einteilung deckt vor allem diese Aspekte ab. Bei Herbst ist dahingegen eine sehr enge Verbindung von Inszenierung und Werk bzw. poetologischen Positionen zu konstatieren. Es geht im Weblog auch um Aufmerksamkeit, um "Sichtbar-Machen ${ }^{150}$ und auch um Marketing. Die Inszenierung ist aber nicht nur nach außen gerichtet, sondern korrespondiert mit Motiven des Werks und dient wie oben dargestellt einer narrativen Konstruktion von Identität. Neben der Selbstdarstellung als Autor in Ausrichtung auf die »öffentliche[n] Resonanzräume « ${ }^{151}$ bedeutet die Inszenierung die Präsentation eines Selbstbildes als Autor. Herbst benutzt den Begriff `Inszenierung` auch selbst und weist berechtigterweise darauf hin, dass es sich dabei nicht um die Inszenierung von etwas handelt,

146 Ebd.

147 Vgl. Stephan Porombka: Clip-Art, literarisch. Erkundungen eines neuen Formats (nebst einiger Gedanken zur sogenannten rangewandten Literaturwissenschaft`)«, in: Christine Künzel / Jörg Schönert (Hg.): Autorinszenierungen. Autorschaft und literarisches Werk im Kontext der Medien, Würzburg 2007, 223-243, hier: 226.

148 Blumenkamp: »Typologien des `Als ob ««, 364. Blumenkamp modifiziert Porombkas Unterscheidung leicht, die dadurch eingängiger wird. Für die Originalformulierung vgl. Porombka: „Clip-Art, literarisch $\lll, 228$.

149 Ebd., 225.

150 Jürgensen / Kaiser: »Schriftstellerische Inszenierungspraktiken«, 10.

151 Ebd. 
»das es nicht gibt - also täuschen -, sondern genau das, w a s es gibt, als ein künstlerisches Material begreifen, über das ich verfügen kann und muß«152.

Damit geht es ihm also nicht um die Inszenierung als Vortäuschung, sondern um das Selbstverständnis als Teil der eigenen Kunst. ${ }^{153}$ Diese Einstellung findet sich auch in Meere formuliert, wenn die Figur Fichte von diesem selbst als »wahrscheinlich [s]ein größtes Kunstwerk, [s] ein lebendigstes jedenfalls « ${ }^{154}$ bezeichnet wird. Inszenierung dient demnach nicht nur der Selbstdarstellung, vielmehr ist die Thematisierung von Inszenierung ebenso wie Fragen nach der Authentizität Teil des poetischen Verfahrens. Ob es sich wirklich psychologisch betrachtet um das Selbstbild von Herbst handelt, kann von außen nicht beurteilt werden und ist hier irrelevant. Herbst bringt jedoch zum Ausdruck, dass er die im Folgenden skizzierte Identität nach umfangreicher innerlicher Reflexion annimmt und sich nicht nur äußerlich auf diese Weise inszeniert.

Das Selbstbild bezieht sich vor allem auf zwei Aspekte: auf Status und Produktivität als Schriftsteller sowie auf die persönliche Männlichkeit, die weniger eine Schilderung von Potenz betrifft als auf die Betonung des Sinnlichen und Körperlichen zielt, das Ausleben körperlichen Genusses teils auch entgegen die vorherrschende Moral $\left(\right.$ BDSM $^{155}$, Polyamorie $\left.{ }^{156}\right)$.

\subsubsection{Status und Produktivität als Schriftsteller}

Jürgensen weist darauf hin, dass Herbst als Publikationsform im Netz bezeichnenderweise das literarische Weblog oder »ein digitales Tagebuch « gewählt hat, »und damit ausgerechnet jene Gattung [...], die sich vorrangig der Ich-Darstellung widmet ${ }^{157}$. Herbst bedient sich des Blogs aber nur teils in der Art von Identitätskonstruktion, wie sie als typisch für `normale « Weblogs empirisch untersucht und beschrieben wurde. ${ }^{158}$ Als Beispiele sind hier der Verzicht auf eine "Positivselektion von Eigenschaften «, die präsentiert werden, um »kompetent und sympathisch wahrgenommen zu werden « ${ }^{159}$, und auch der Verzicht auf das Ziel, "Aspekte des eigenen Selbst authentisch darzustellen ${ }^{160} \mathrm{zu}$ nennen. Der Begriff des Authentischen wird von Herbst wie gesagt anders interpretiert. Dies ist dadurch begründet, dass er bereits vorher ein relativ stabiles Identitätsbild als Autor vertreten hat und auch viel von seiner recht weit

152 URL-85, 10. Aug. 2005.

$153 \mathrm{Vgl}$. dazu auch Sandra Heinen: Literarische Inszenierung von Autorschaft. Geschlechtsspezifische Autorschaftsmodelle in der englischen Romantik, Trier 2006, 29.

154 Herbst: Meere (2008), 195.

155 Vgl. beispielhaft URL-86, 10. Dez. 2007, und dort vor allem die Diskussion in den Kommentaren, URL-87, 15. Dez. 2006, sowie Herbst: Die anthropologische Kehre, 5.

156 Vgl. URL-88, 13. Dez. 2011.

157 Jürgensen: »Ins Netz gegangen«, 407.

158 Vgl. Schmidt: Weblogs, 70-83, und Sabina Misoch: Identitäten im Internet. Selbstdarstellung auf privaten Homepages, Konstanz 2004, 133-136, 166-183.

159 Schmidt: Weblogs, 71.

160 Ebd., vgl. auch Misoch: Identitäten im Internet, $173 \mathrm{ff}$. 
ausformulierten Poetik mit in die Arbeit am Weblog eingebracht hat, die mit den Mechanismen und Möglichkeiten des Mediums in Zusammenhang steht.

In der bereits erwähnten Reihe von Blogeinträgen unter der Bezeichnung »Prägungen ${ }^{161}$, in der Herbst literarische Vorbilder und Einflüsse benennt, sind die Aspekte Schriftstelleridentität und Männlichkeitsdiskurs sehr deutlich miteinander verflochten. Er schildert nicht nur seine Lesebiographie, sondern auch seine innere Entwicklung in der Jugend. Die äußerlich wichtigen Stationen werden nur angedeutet, der Fokus liegt auf der Entwicklung seiner inneren Gefühlslage und Haltung und seiner sexuellen Entwicklung. Diese wird nicht nur eng verflochten mit den literarischen Prägungen geschildert, sondern wird durch diese teils auch ausgelöst. Herbst spricht sehr offen auch problematische und schmerzvolle Erfahrungen in seiner Familie und Umgebung an. Er beschreibt sich selbst zunächst als sehr schüchtern und in seinem Verhalten gehemmt: »als [er] selbst noch furchtsam war und geduckt«, liest er »als Verklemmter den stilistisch wahrscheinlich bedeutendsten Verklemmten, den es jemals gab ${ }^{162}$ und findet so in Kafka durch dessen Briefe eine Art Verbündeten. Mit Sherlock Holmes »kultivierte [er] eine gewisse Arroganz $\aleph^{163}$, eignet sich die »holmes'sche Attitüde der Unberührbarkeit « ${ }^{164}$ an. Trotz einer recht sprunghaften Chronologie wird seine Entwicklung zwischen den ausführlichen literarischen Würdigungen deutlich. Von Anfang an wird die Ausrichtung auf Literatur und ihre besondere Bedeutung herausgestellt.

Noch vor der Entscheidung, einen anderen Namen anzunehmen und auch die Stadt zu wechseln, fängt er an, durch seine Lektüren und seine ersten schriftstellerischen Schritte ein Selbstbewusstsein zu entwickeln, mit dem er Gruppen und - wie er betont - vor allem Frauen gegenübertreten kann. Dies kann einerseits als eine normale Entwicklung gesehen werden, die dadurch entsteht, dass beispielsweise sein Großvater ihn zum Kampfsport schickt, um ständigen Attacken in der Schule besser begegnen zu können; ${ }^{165}$ andererseits deuten die Formulierungen, die er in dem Zusammenhang gebraucht, an, dass er diesen Entwicklungsschritt als willentliche Formung einer Figur versteht, als Entscheidung, ein >Konzept $\triangleleft$ zu erschaffen. Bei der Schilderung seines Zivildienstes 1976 bemerkt er dann:

[D]er da entstand, war noch gar nicht. Der brauchte noch fünf Jahre $[\ldots]{ }^{166}$

Damit ist die Schaffung eines Anderen, der seltsam distanziert bezeichnet wird, beziffert, die 1981 >stattgefunden h hat und damit im Jahr des Namenswechsels. Durch die Angabe überhaupt eines Zeitpunktes wird zudem der Umbruchcharakter (im Gegensatz zu der eigentlich vorhergehenden Entwicklung) betont. Es entsteht also eine Art >Kunstfigur ‘. Diese ist allerdings nicht nur als Rolle zu sehen, sondern wird von Herbst internalisiert. In einer vorwegnehmenden Schilderung formuliert er:

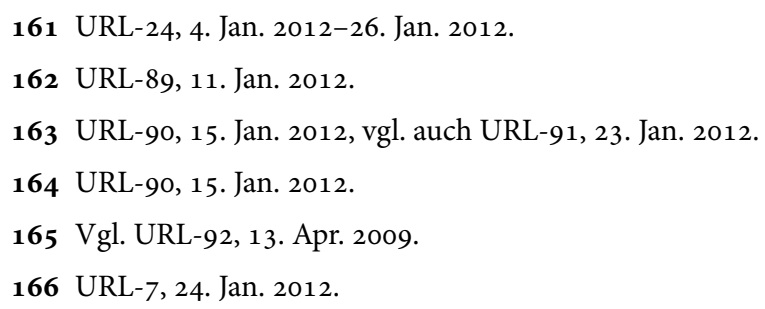


Da bin ich aber schon ich. Noch werde ich's. ${ }^{167}$

Das "noch" ist auf den Zeitpunkt bezogen, den er gerade schildert. Mehrere Ichs werden nebeneinander gestellt: Aus der Perspektive der heutigen Zeit schreibt er, dass er damals erst er selbst wurde und setzt damit die heutige, entwickelte oder angenommene Identität als die eigentliche fest. Die Kohärenz, die in den »Prägungen « bezüglich der Entwicklung bzw. der Entstehung der Autor-Figur Herbst vermittelt wird, findet sich darin, dass alles so erzählt wird, als sei es immer schon darauf hinausgelaufen, dass er Schriftsteller wurde.

In Meere finden sich neben autobiographischen Episoden, die fast identisch im Blog geschildert werden, auch viele Formulierungen, die mit den Schilderungen in den »Prägungen« korrespondieren. So wird die Kunstfigur Fichte ähnlich distanzierend wie eben dargestellt als »Konzept« beschrieben, das »rundum fertig « ${ }^{168}$ ist. Auch die antrainierte Härte, die Arroganz und Zurschaustellung des Selbstbewusstseins, die in den »Prägungen« beschrieben wird, wird in Meere prägnant formuliert:

Die Sache war einfach: Die anderen mochten Kalkreuth nicht, der mochte nicht die anderen. Das hat sich, seit Fichte da ist, geändert. Sie mögen zwar auch den nicht, aber sie schaffen es nicht, ihn kleinzumachen. ${ }^{169}$

Was hier von der Referenz her sehr abstrakt und verallgemeinernd bezeichnet wird, stellt Herbst auch als sein Verhältnis zum Literaturbetrieb dar. Er gibt sich als extrem produktiver Autor, der quer zu diesem steht, aber seine ästhetische Position kompromisslos und ohne Rücksicht auch auf eigene Verluste vertritt. ${ }^{170}$ Unabhängig vom Kontext ist dabei das Vertreten der eigenen Position wichtig: »seit ich meine Position definiert habe und bereit bin, sie durchzukämpfen «171 . Auf diese Weise präsentiert er sich auch in Interviews, beispielsweise mit einer Formulierung, die Bezug nimmt auf seine Entwicklung: »etzt habe ich Metall im Mund und kann kräftiger beißen «. ${ }^{172}$ Das Verhältnis Herbsts zum Literaturbetrieb umfassend zu untersuchen, würde den Rahmen dieser Arbeit sprengen; zudem ist eine objektive Perspektive an dieser Stelle irrelevant, da es um Herbsts eigene Inszenierung geht. Dass die immer wieder vorgebrachte angebliche Ausgrenzung im Literaturbetrieb aber auch als eine Art Auszeichnung vorgebracht werden kann, zeigt nicht nur Herbst selbst, sondern auch Ralf Schnell, der den horen-Band zu Herbsts Werk gerade mit einer solchen Charakterisierung einleitet:

Treffender als in diesen wenigen Zeilen lässt sich die Position des Schriftstellers Alban Nikolai Herbst im literarischen Leben Deutschlands kaum umschreiben:

167 URL-10, 4. Feb. 2012.

168 Herbst: Meere (2008), 160.

169 Ebd., 34.

170 Vgl. dazu auch Jürgensen: »Ins Netz gegangen «, 419-422, hier: 419: Herbst verbinde »das traditionsreiche Konzept des Autors als Märtyrer mit dem Konzept des nonkonformistischen Außenseiters«.

171 URL-93, 13. Apr. 2009.

172 Faure: ») Jetzt hab ich Metall im Mund««, 15. 
'Gewisse Kreise` des Literaturbetriebs haben ihn stigmatisiert; als `rufschädigend ‘ gilt, mit ihm - und sei es nur virtuell - in Kontakt zu stehen [...]. ${ }^{173}$

Es wird jedoch im Blog auch deutlich, dass Herbst nicht nur Ablehnung entgegenschlägt, er vielmehr viele Freundschaften und Verbindungen auch im Literaturbetrieb pflegt, beispielsweise in den genauen Protokollen seiner Buchmessenbesuche. ${ }^{174}$ Auch wenn also ästhetische wie persönliche Differenzen zu bestimmten Beteiligten im Literaturbetrieb angenommen werden müssen, so ist Herbst seit langem eindeutig aktives Mitglied in diesem und seine wie auch immer grundierte Außenseiterrolle ein Aspekt, den er zu einem Teil seiner Inszenierung gemacht hat. Die Ambivalenz des Verhältnisses zu »den Anderen« findet sich auch wieder in Meere als Eigenbeschreibung von Fichte:

Aber sie wünschte sich noch dazuzugehören. Er wünschte das seit langem nicht mehr. Und auch das ist nicht wahr. Anerkennung. Der Kunstbetrieb. Die Häme. Fichtes Wutanfälle. Und immer entsetzlich produktiv. ${ }^{175}$

Diese Produktivität wird ganz objektiv deutlich, zum einen durch die Anzahl der Bücher und Hörspiele, die Herbst publiziert und produziert, zum anderen durch die Menge an Text, die er jeden Tag im Weblog schreibt. Im Anschluss an den Ablehnungsdiskurs im Literaturbetrieb meint er, er ziehe »die ganze riesige Kraft aus der Ablehnung direkt heraus « ${ }^{176}$. Die konstante Produktion ist ihm wichtig zu betonen. So rechtfertigt er sich gegenüber Anwürfen in Kommentaren oft durch das Aufzählen der Quantität seiner Werke. Auch am 50. Geburtstag (7. Februar 2005) beginnt ein Lebensrückblick mit der Versicherung der Produktivität:

Fünfzehn Bücher geschrieben und veröffentlicht. Eines davon ist derzeit verbo-

ten.

Siebzehn Hörstücke geschrieben, teils inszeniert und ausstrahlen lassen.

Drei Theaterstücke geschrieben und veröffentlicht. Eines ist uraufgeführt.

Fünf Arbeiten für Sprache \& Musik (Libretti). Alle wurden uraufgeführt, bzw. ur-ausgestrahlt.

Ungefähr zwanzig verstreut veröffentlichte Erzählungen.

Ungefähr zehn verstreut veröffentlichte Lang-Essays poetologischen Inhalts.

Zwei Essays anti-militärischen Inhalts.

Nicht zählbarer literarischer Kleinkram.

Eine Literaturzeitschrift herausgegeben.

Ein Literarisches Weblog intensiv geführt. Es weiterführend. ${ }^{177}$

Die Literatur bzw. Kunst und ihre Produktion sind damit das wesentliche Element der Identitätskonstruktion. Die Haltung und Form, die Herbst wie erwähnt beispielsweise mit den »DTs« erzwingt, ergeben das kohärente und stabile Schriftsteller-Ich, das er

173 Ralf Schnell: »Dschungel-Passagen - Zu diesem Band«, in: die horen 53/231 (2008): Panoramen der Anderswelt. Expeditionen ins Werk von Alban Nikolai Herbst, 5-8, hier: 5.

174 Vgl. URL-94.

175 Herbst: Meere (2008), 131.

176 URL-95, 25. Jan. 2012.

177 URL-96, 7. Feb. 2005. 
dem Leser präsentiert. ${ }^{178}$ Es ist »[s]eine Erfahrung, allein durch [s] eine künstlerische Arbeit ein Ich geworden zu sein, und zwar ein begründbares «179. Das Zentrum seines Lebens bleibt »identisch [...], weil nicht Menschen darin stehen, sondern die mich immer begleitende, mich durchziehende Kunst ${ }^{180}$. Auch den bereits erwähnten Vorwurf des `Netzexhibitionismus` sieht er als Teil seiner Identitätskonstruktion als Schriftsteller:»Es ist der möglicherweise vergebliche Versuch des Künstlers, sich seiner selbst zu vergewissern, was ins Befremden umschlägt. So viel Zweifel will h i n t e r den Screen.« $(K T L B, 9)$

\subsubsection{Männlichkeit und Sexualität}

Der zweite der oben genannten Aspekte, die Betonung persönlicher Männlichkeit und - weiter gefasst - die offensive Thematisierung sexueller Themen, nimmt die Körperdiskurse der Romane wieder auf. So wie in WB Murnaus Position und in den $A W$-Romanen der ungefuggerschen Position der Körperlosigkeit die Betonung des Körperlichen und der Sexualität entgegengesetzt wird, so vertritt Herbst auch im Blog eine entsprechende Haltung bzw. reflektiert diese Themen. Das Interesse entspricht auch seiner intendierten Reflexion des Mediums Internet. Dieses sieht er zwischen zwei Polen: auf der einen Seite ist es ein "sexualisierte[s] Medium « $(K T L B, 61)$ wie kein anderes, auf der anderen Seite steht die "Auflösung des organischen Körpers im Netz« $(K T L B, 90)$. Dieser setzt er das »Primat des Sexuellen« entgegen, ihr soll begegnet werden, indem »man sich radikal zu ihm [dem Körper] zurückbeugt« (ebd.).

Entsprechend diskutiert er seine eigene Neigung zu BDSM, das sich als Thema explizit in $V G$ und Meere findet sowie als `Geschlechterkampf`-Thematik auch durch die anderen Romane zieht, stellt sich als bekennenden Macho vor und lässt »insgesamt Tabu-Themen eine große Rolle [...] spielen ${ }^{181}$. Beziehungen zu Frauen schildert er teils explizit, wobei er die Namen ähnlich wie bei der früheren Lebensgefährtin pseudonymisiert. Wichtig anzumerken ist, dass es dabei irrelevant ist, ob die präsentierten >Fakten « wirklich stimmen oder nicht. Als er vom Flirten mit einer jungen Frau berichtet, von der er später zugibt, sie sei erfunden, bemerkt er, dass eine solche Begegnung "nach so viel autobiografischer Vorarbeit glaubhaft geworden " (KTLB, 44) sei. Gemeint ist damit, dass ein solches geschildertes Verhalten in das Bild passt, das sich der Leser von ihm gemacht hat bzw. das er dem Leser präsentiert hat. Die Ausschmückung zeigt sich beispielsweise auch, wenn er sich mit einer Frau trifft, die er »Löwin« benennt. Diese Treffen schildert er als Reisen in die »Serengeti«, nennt afrikanische Ortsnamen, erzählt von der Fahrt und stellt Bilder ein. Doch auch diese detailliert ausgeschmückten Reiseerzählungen stellen sich als Fiktion heraus: „Seren-

178 Kreknin spricht in diesem Zusammenhang von der »hohe[n] Konsistenz [...] [einer] Autor-SubjektFigur [...], die keinen Zweifel an der Einheitlichkeit ihrer jeweiligen Ausprägung aufkommen lässt « (Kreknin: Poetiken des Selbst, 400). In den zusammenführenden Schlussthesen seiner Arbeit nimmt diese Beobachtung eine zentrale Stelle ein, da er eine $>$ Aporie $<$ zwischen dieser $>$ Praxis $<$ und Herbsts theoretischen Positionen konstatiert, vgl. ebd., 400, 417 f., 428.

179 URL-2, 15. Juni 2005.

180 URL-3, 14. Juni 2005.

181 Valin: Interview mit Alban Nikolai Herbst. 
geti ist, wiewohl tatsächlich andernorts, eine innere ${ }^{182}$. Hier ist der fiktionalisierende Umgang mit (vermutlich) realen Gegebenheiten besonders offensichtlich.

Was in den genannten Beispielen von Fiktionalisierung im Kleinen vorgeführt wird, erhält im Großen wieder eine Bedeutung durch das Motiv, das Leben als Roman zu begreifen. Durch das tägliche, reflektierte Erzählen seiner Tätigkeiten, Gedanken und Erlebnisse werden Themen und Überlegungen hervorgehoben, es wird ein Zusammenhang hergestellt, »um das eigene Leben ein Rahmen « $(K T L B, 79)$ gelegt. Durch die unbedingte Inszenierung als Schriftsteller, der für seine künstlerische Position lebt und kämpft, wird eine Identität konstruiert, die als Teil des Werks zu sehen ist. So wird eine Autoridentität vorgeführt, die sich durch erzählerische Kohärenz und relative Stabilität auszeichnet. 



\section{Fazit und Ausblick}

Ziel dieser Arbeit war es, die Konstruktion und Auflösung von Identität und Realität in Herbsts Werk darzustellen und die behandelten Themen dem engagierten Leser, den Herbst vor Augen hat, aufzubereiten. Nun sollen abschließend einige Themen und Motive der vorherigen Kapitel übergreifend betrachtet werden. Auf sehr abstrahierende Weise hat dies Stefan Scherer bereits getan:

Löste die >Verwirrung des Gemüts $<$ zuerst die Einheit der Person auf, der $>$ Wolpertinger sodann die Einheit der Zeit, so entgrenzt sich in >Anderswelt $<$ [...] die Einheit des Orts. ${ }^{1}$

Patorski/Moosbach übernimmt diese Einteilung einerseits, ${ }^{2}$ unternimmt andererseits noch einen Einteilungsversuch mit anderer Perspektive:

In Die Verwirrung des Gemüts wurde noch die Möglichkeit eines anderen Ichs verhandelt, und im Wolpertinger waren dies bereits die Möglichkeiten eines in der Zeit vervielfältigten Ichs. In Thetis [...] war es die Möglichkeit einer anderen Welt, in Buenos Aires und Argo sind es konsequenterweise [...] die Welten, die sich immer weiter multiplizieren. ${ }^{3}$

Haben diese beiden Betrachtungsweisen ihre Berechtigung, so sind sie doch sehr formalisierend und verkürzend. Im Folgenden wird daher zuerst eine ausführlichere Zusammenführung mit Blick auf die beiden Themenkomplexe Identität und Realität sowie die Poetik und das Weblog gegeben. Dann folgt die kurze Darlegung einer werkübergreifenden Denkweise. Schließlich werden noch Aspekte genannt, die über den Rahmen dieser Arbeit hinausgehen und in der Forschung weiter verfolgt werden könnten.

Identität In Die Verwirrung des Gemüts beziehen sich die Fragen der Identität vornehmlich auf entsprechende sozialpsychologische Fragestellungen. Die `Gemütsverwirrung ist eine Identitätskrise, die Fragmentierung eines Bewusstseins, die metafiktional überhöht wird und erzähltechnisch durch die Aufspaltung einer Person in verschiedene Figuren veranschaulicht wird. In verschiedensten poetischen Motiven wird das Problem einer Figur dargestellt, mit der durch sererbte` und familiäre Faktoren zugeschriebenen Identität zurechtzukommen. Der Figur wird die Fähigkeit des Menschens zu Grausamkeit, die sich vor allem auch in der Schuld der Elterngeneration in der Zeit des Nationalsozialismus zeigt, zur Belastung. Sie will die zugeschriebene Identität, die sie einerseits belastet und ihr andererseits nicht einmal bspw. durch

1 Scherer: »Alban Nikolai Herbst $[K L G]$ «.

2 Vgl. Patorski / Moosbach: »Die Anderswelt als Rhizom«, 20.

3 Ebd., 12. 
vorgeformte Strukturen und Werte Sicherheit gibt, ablegen, indem sie sich durch einen Pass und einen anderen Namen eine neue Identität erschafft und ihr Leben in einer anderen Stadt neu beginnt.

Durch das Aufspalten der Figur des `Autor<-Erzählers in mehrere Figuren wird die Fragmentierung von Identität veranschaulicht und die klassische Vorstellung einer einheitlichen, stabilen Identität verworfen. Andererseits wird anhand des >Autor<-Erzählers auch gezeigt, dass Identität im großen Maß konstruiert wird: er lehnt die Eingaben von außen, die ihm eine Außenperspektive geben könnten, fast vollständig ab und bildet unabhängig davon eine neue Identität. Diese ist zwar durch äußerliche Faktoren (Pass, Name) gekennzeichnet, doch basiert sie auf seinen inneren Vorstellungen, der Innenperspektive. Diese Identität ist zwar keine gesicherte, stabile, setzt aber der Unmöglichkeit einer tatsächlich einheitlichen Identität die prozessuale Identitätskonstruktion entgegen.

Wolpertinger schließt durch die Deters-Figur an den Vorgängerroman an, auch wenn das Setting ein anderes ist. Schon in $V G$ wird angedeutet, dass die bloße Flucht und der Namenswechsel es nicht vermögen, die Identitätsprobleme zu lösen. In WB wird die Namensthematik zwar beibehalten, von der sozialpsychologischen Komponente jedoch weitgehend abstrahiert. Mythologisch geprägte Figuren und phantastische Welten kommen ins Spiel. Diese Figuren sind vor allem durch ihren Namen mit den mythologischen Vorbildern verknüpft. Der Name schafft die Verbindung zwischen verschiedensten Mythen, die wiederum die jeweilige Figurenidentität bestimmen. So geht es vor allem um numerische Identität, um Figurenidentifizierung, um die Frage, ob Figuren verschiedener Ebenen dieselbe Figur bzw. Person seien, was auch - in Verbindung mit den metanarrativen Diskursen - als Spiel mit dem Leser zu sehen ist. Der Aspekt der Determiniertheit, der in VG auf die Alltagswirklichkeit rekurrierte, wird hier präsentiert durch die Prägung der Figuren durch veranschaulichte Prinzipien, durch mythische und intertextuelle Vorbilder. Die Namensproblematik leitet über auf philosophische Fragen nach dem Verhältnis von Name bzw. Begriff und Wesen einer Sache. Im Anschluss an Walter Benjamin und Adorno wird davon ausgegangen, dass Begriff und Sache nicht identisch sind, dass das eigentliche Wesen, was die Sache ausmacht, über den Begriff hinausgeht.

Jedes Ding ist nämlich in Wahrheit mehrere Dinge auf einmal. Aber wir betrachten und schneiden die Dinge zurecht nach jeweils nur einer Funktionsweise. $(W B, 718)$

Diese Form des Denkens, die sich gegen differenzierende (binäre) logische Begriffsbildung wendet und für nicht vollständig zu bestimmende Mehrdeutigkeit eintritt, wird mit mythischem Denken in Verbindung gebracht und mit der sogenannten MythosPosition. Diese wird durch die Figur des Elberich Lipom als Gegenposition der in der Moderne an oberste Stelle gesetzten Vernunft personifiziert. Teils im Gegensatz zu bekannten Mythostheorien steht sie für einen ursprünglichen Naturzustand, für sinnliches Erleben und körperliches Fühlen im Gegensatz zu logischem Denken; dies drückt sich auch in der Propagierung von ausschweifender Sexualität, Trieb und Lust aus. So wird ein Prinzip figürlich veranschaulicht, das als Motiv bereits in VG eingeführt wurde und für das herbstsche Werk eine wichtige Rolle spielt. 
In den Anderswelt-Romanen kann insgesamt eine Rückkehr zu psychologischen bzw. sozialpsychologischen Identitätsaspekten konstatiert werden. Diesmal geht es jedoch nicht, wie in beiden Vorgängerromanen, um aufgespaltene Identitäten. Hier werden der Science-Fiction-Situierung gemäß die menschlichen Identitätsfragen auf Holomorfe übertragen und veranschaulicht. Aspekte von Identität zeigen sich im engeren Sinn in den $A W$-Romanen in der Abgrenzung der Holomorfen von den Menschen, in der Identitätskrise von Herrn Drehmann, dem Versuch der Rebellen, eine autonome Holomorfenkultur zu entwickeln und den Spannungen, die sich durch Ähnlichkeiten mit den Menschen ergeben. Es steht die Frage im Mittelpunkt, was einen Menschen und was einen Holomorfen ausmacht. Individualität und Identität, also die Frage, wie sich ein Mensch von den anderen als Individuum abgrenzt, zeigt sich bei der Identität der Klone, veranschaulicht an Dolly als einer der 15 Klontöchter von Dr. Spinnen. Die menschliche Identität in der Anderswelt zeigt sich im Spannungsverhältnis von individueller Selbstbestimmung über Körper und Geist auf der einen und Kollektivierung, Entkörperlichung und Entsexualisierung auf der anderen Seite. Wie auch schon in WB ist Sexualität für Herbst eine wichtige Determinante der Identität. Der Regulierung der individuellen sexuellen Bedürfnisse über Entkörperlichung und Hygienisierung im Westen und im Zentrum steht die freie Entfaltung der Sexualität (und anderer `natürlicher` Triebe wie Gewalt, Liebe und Hass) verschiedener Personen entgegen, die vorwiegend aus dem mythisch geprägten Osten der Anderswelt stammen. Hier stechen v. a. die wiederkehrenden Themen von Dominanz, Männlichkeit und Macht sowie der `Geschlechterkampf ‘ hervor. Die Identität der Menschen ist außerdem geprägt durch Unreinheit, Unbeherrschtheit und Triebhaftigkeit.

Wirklichkeit und Realität In $V G$ liegt eine starke Orientierung an der realen zeitgenössischen Welt vor. Es passieren jedoch unwahrscheinliche und unmögliche Dinge, die durch eine schematische Beschreibung der Erzählkonstruktion veranschaulicht, aber in ihrer Verwirrtheit nur bedingt vorstellbar werden. In verschiedenen Passagen werden die Begriffe $>$ Realität $\triangleleft$ und $>$ Wirklichkeit unterschieden und so ein bestimmter Wirklichkeitsbegriff etabliert: Wirklichkeit ist das, was wirkt. Somit können auch Fiktionen zu Wirklichkeit werden, insofern sie eine Wirkung auf reale Menschen haben. Auf diese Weise wird die Konstruiertheit der einzelnen individuellen Wirklichkeiten aufgezeigt. Zudem wird auch eine Lesart zumindest als möglich angedeutet, dass es sich um schizophrene Wahnbilder handeln könnte.

Die Thematik einer solchen Lesart ist auch in WB zu finden, allerdings auch bzw. vor allem hier nur als eine unter vielen. Zwar gibt es hier auf Teilen der vielen unterschiedlichen Ebenen und Lesarten auch Bezüge auf die reale Welt, vornehmlich tritt jedoch durch die Elbenwelt ein phantastischer Bezug hinzu. Der poetisch-spielerische Konstruktionscharakter tritt in den Vordergrund, durch die endlosen Ebenenschleifen kann keine Ebene mehr als sicherer Referenzpunkt ausgemacht werden, sämtliche Versuche der Realitätsbestimmung werden sabotiert. Eine der möglichen Lesarten ist die Virtualität fast sämtlicher Ereignisse, ihre Programmierung durch einen Biocomputer im Keller des Hotels Wolpertinger. 
Das mit dem Identitätsdiskurs verbundene nicht binäre Denken findet sich auch im Diskurs um Realität und Wirklichkeit. Zwar wird die Unterscheidung zwischen Realität und Fiktion nicht geleugnet, insofern eine meist als relativ hart dargestellte Realität zugegeben wird, die das Subjekt meist körperlich zu Handlungen zwingt (die aus $V G$ übernommene sogenannte Agnes-Realität), doch wird dafür plädiert, diese Unterscheidung nicht vorzunehmen. Verschiedene Formen der Veränderung von Realität durch Fiktion werden dargestellt, von der Neuerfindung der eigenen Vergangenheit durch Deters, über die träumende oder literarische Imagination ganzer Handlungen und Welten bis zu computergestützter virtueller Realität. Der Wirklichkeitsbegriff hat damit auch Auswirkungen auf die Frage nach den Referenzen der Fiktion. In Bezug auf das Verhältnis von Elben und Menschen findet Alda zu einer Formulierung, die darauf verweist:

Wir müssen uns mit realen Geschöpfen auffüllen wie Sie sich mit fiktiven. Darum stehlen wir euch die Kinder, und ihr stehlt uns die Inspiration. (WB, 730)

Auf fiktionstheoretische Überlegungen übertragen ist das ein metaphorisches Bild für das principle of minimal departure, das davon ausgeht, dass fiktive Welten an sich nicht vollständig beschrieben werden und deshalb mit dem Alltagswissen der Leser aufgefüllt werden; die fiktive Welt weicht von der realen Welt nur soweit ab, als es explizit dargestellt ist. Auf der anderen Seite geben die explizit erfundenen, phantastischen Figuren und Motive einer Erzählung besondere Inspiration. Auch auf den Autor Herbst trifft dies zu, insofern er sich die Inspiration sowohl vom Fiktiven als auch vom Realen holt - durch die vielfältigen Versatzstücke aus Mythologie, Intertexten, eigenen Erlebnissen und historischen Ereignissen, die er zur Geschichte zusammenfügt. Wird die Unterscheidung zwischen Realität und Fiktion nivelliert, so wird auch die Unterscheidung unwichtig, ob die fiktiven Figuren und Schilderungen auf die reale Welt verweisen oder ihrerseits wieder auf Fiktion.

Der Unterschied zu den anderen Romanen kann bezüglich TA darin ausgemacht werden, dass es sich eindeutiger um zwei voneinander geschiedene Welten handelt, wodurch eine räumliche Komponente ins Spiel kommt. Doch während in $W B$ alle vermeintlichen Sicherheiten zerschlagen werden, kann sich der Leser in $T A$ wieder etwas besser orientieren, da der Weltenaufbau einfacher strukturiert ist. Die beschriebenen Welten werden wieder etwas näher an die reale Welt angebunden; das reine Spiel mit metafiktionalen Konstruktionen, mit Verweisen und Verwirrung tritt zurück. Die realen menschlichen Fragen nach Identität und Wirklichkeitswahrnehmung werden in einer ähnlichen und doch andersgearteten Welt gespiegelt und gerade durch die Andersartigkeit verdeutlicht. Zudem wird die Unsicherheit der Weltwahrnehmung im technischen Szenario gezeigt. Die Illusionshaftigkeit der simulierten Umwelt in der zukünftigen Anderswelt zeigt, dass der Mensch die Unterscheidung zwischen realen und nicht realen Dingen nicht unbedingt wahrnimmt. So wird die Gültigkeit der Wirklichkeitsdefinition als das, was wirkt, anschaulich.

In $B A$ wird der Weltenaufbau wieder komplexer. Die Gültigkeit einer zentralen Perspektive wird zerstört, indem die Beobachtungsperspektiven über die multiplizierten 
Welten hinweg in einer absurden Schleife enden. Als Gedankenexperiment steht hier die Frage, ob jeder Gedanke eine eigene Welt bildet.

Poetik Herbsts Poetik des Kybernetischen Realismus schließt an die beiden Themenkomplexe insofern an, als er dort sein Menschen- und Wirklichkeitsbild explizit von dem eines realistischen Schreibens abgrenzt, das er in der deutschsprachigen Gegenwartsliteratur als Mainstream erkennt. An dieser Form des Realismus kritisiert er die Annahme eines autonomen Ichs und das Festhalten an einer solchen Vorstellung, was er als Regression ablehnt.

Unter der Bezeichnung des Kybernetischen Realismus fasst er seine Autorpoetik. Zentral ist für ihn, dass moderne Technik im Sinne vor allem der neuen Medien nicht ignoriert werden dürfe, da sie zur Kultur der Zeit gehöre. Die Technisierung bedeute jedoch auch - über den Zwischenschritt einer vollständigen Rationalisierung, also dem Anspruch, alles rational erfassen und erklären zu können - ein Erkalten der menschlichen Lebenswelt. Zugrunde liegt die Annahme, dass Gefühle im Allgemeinen und viele Gedanken des Menschen zu komplex bzw. anders geartet sind, um in eine binäre Struktur übersetzt werden zu können. Daher will Herbst der Kälte der technischen Umgebung zum einen die gerade nicht nach logischen Prinzipien erfassbare poetische Schaffenskraft entgegensetzen, zum anderen die Körperlichkeit des Menschen, die ebenfalls dem Rationalen entgegensteht. Der Körper und alles damit Verbundene (bspw. die Sexualität) sieht er nach anderen Prinzipien funktionieren. Körper und Seele des Menschen bilden ein »Organisches«, das der Technik entgegengesetzt wird. Damit wird impliziert, dass sie auch ein (organisches) Ganzes bilden. Herbst hält an etwas scheinbar Überkommenem fest und will es gegen die neuen Entwicklungen verteidigen. Er kennzeichnet seine Poetik als eine solche, »die sich dem Menschen zuwenden will« $(K R, 75)$. Dabei kommt er zu der tautologischen Schlussfolgerung, sie müsse dafür den Blick zurück aufs Humanitäre richten. Da sich hinter den umfassenden Einfluss von Computer und Technik nicht zurückgehen lasse, müsse die Bewahrung des Menschlichen in der technischen Welt versucht werden.

Weblog Diesen Anspruch an Technik und Kultur versucht Herbst in seinem Weblog umzusetzen. Er versteht es explizit als >literarisches Weblog〈, das ermöglicht mitzuerleben, wie sich »Romane in den Zeiten ihres Entstehens nahezu in Echtzeit miterzählen« $(K T L B, 87)$ lassen. Die Literarizität entsteht für ihn durch das Erzählen der Entstehung von Kunstwerken, die Reflexion dieses Vorgangs und die literarische Formung der Beiträge sowie die Form des gesamten Blogs: »seine Form ist Literatur « $(K T L B, 88)$. Ein weiterer wichtiger Aspekt für die Einordnung als Literatur ist die künstlerische Organisation des Zusammenspiels der unterschiedlichen angenommenen Identitäten von Herbst selbst und auch den Mit-Autoren bzw. Kommentatoren. Außerdem wichtig ist hier die >institutionelle Z Zuschreibung: Herbst versteht das Weblog als eins seiner Instrumente als Schriftsteller, sodass es zum Teil seines Werks und damit zu Literatur wird. Schließlich ist das Konzept des `Lebens als Roman` zu nennen. Zum einen ist darunter zu verstehen, dass die Leser den Autor in seinen alltäglichen Schilderungen als eine Romanfigur erleben; zum anderen begreift er selbst es so. Durch diese Art der Autofiktionalisierung soll das Leben so gelebt werden 
wie ein zielgerichteter, sinnerfüllter Roman, trotz der Annahme, dass es gar keinen Sinn gebe. Dies erfolgt durch das tägliche, reflektierte Erzählen seiner Tätigkeiten, Gedanken und Erlebnisse; so werden Themen und Überlegungen hervorgehoben, es wird ein Zusammenhang hergestellt, »um das eigene Leben ein Rahmen« $(K T L B, 79)$ gelegt. Zudem wird durch die unbedingte Inszenierung als Schriftsteller, der für seine künstlerische Position lebt und kämpft, eine narrative Identität konstruiert, die als Teil des Werks zu sehen ist. So wird eine Autoridentität vorgeführt, die sich durch erzählerische Kohärenz und relative Stabilität auszeichnet.

Eine zusammenfassende Aussage für die Romane zu formulieren, würde ihnen nicht gerecht werden. Herbst deutet ein übergreifendes Thema jedoch interessanterweise gerade in seiner Absage an ein solches an:
Was aber das reine Große Thema anbelangt [...]: Es gibt keines. Aber de facto nicht. Weil Welt nicht monotheistisch aufgebaut ist, also nicht die Welt unserer wirklichen Erfahrung, wohl allerdings die Welt unserer interpretierenden Vor- stellung. Leben hat keinen Sinn; es rist‘ nur und begibt sich und hört plötzlich auf, unplanbar. Einen Sinn hineinzutun, ist unser Gerüst, das wir bauen, um einen Sinn zu unterschieben. Und immer wieder kracht das Gerüst ein. [...] Es hat nämlich auch keinen Sinn, keinen Sinn unterschieben zu wollen. Wir müs- sen, glaube ich, beides tun: erkennen, daß es keinen gibt, und gerade deshalb einen konstruieren, und feststellen, daß die Konstruktion nicht genügt; dann aber erst recht konstruieren. ${ }^{4}$

Insgesamt propagiert Herbst in seinen Romanen immer wieder ein ınicht monotheistisches« Denken (und versucht, es praktisch umzusetzen), das sich gegen die Eindeutigkeit, das binäre Denken in den Kategorien wahr oder falsch richtet und für die Mehrdeutigkeit, die phantastische Erweiterung der Welt eintritt. Mehrfach wird dafür die Formulierung gebraucht vom Anschreiben gegen den Satz des ausgeschlossenen Dritten.

In $V G$ sind es die Aufspaltungen des `Autor -Erzählers, die zugleich identisch mit ihm sind und doch verschieden. In WB kämpfen die Sìdhe (die Elben) und Lipom und damit die eigentlich präferierte Mythos-Position gegen den Satz vom ausgeschlossenen Dritten an (vgl. WB, 665). Immer wieder wird versucht darzustellen, dass die verschiedenen Mythen identisch sind und gleichzeitig nicht; dass Deters und Deters II und der $>$ Dritte $<$ identisch sind, gleichzeitig aber verschiedene Personen; dass Anna und Alda (und Berta) auf gleiche Weise miteinander verbunden sind; dass die Elben gleichzeitig als solche existieren, imaginiert sind und computertechnisch programmiert. In den $A W$-Romanen sind es die verschiedenen Welten, die zusammen gedacht werden, die gleichzeitig existieren und die nicht mehr hierarchisch unterschieden werden können.

Die Werke von Herbst, vor allem aber $W B$, können damit als ein Plädoyer für Phantasie und Vorstellungskraft jenseits einengender Logik gesehen werden. Sie treten ein für logische Mehrdeutigkeit, die die Vorstellungskraft des modernen Menschen sehr strapaziert, und stellen gleichzeitig den Versuch dar, dieses Denken literarisch 
in die Praxis umzusetzen. Noch einmal kann ein Vergleich mit Wielands Oberon in Anspruch genommen werden:

Aus seinem Feenmärchen wird so ein Kapitel über die Einbildungskraft und das schöpferische Vermögen des menschlichen Kopfes.

Die Geister schaffende Phantasie beschreibt Wieland in seinen theoretischen Schriften als den Ursprung der Poesie. [Er] verteidigt [...] die Geisterwelt als Quelle oder besser noch als Symptom schöpferischer Begabung. ${ }^{5}$

Dieses Denken, das Realität und Fiktion als gleichberechtigt nebeneinander sieht und die Ähnlichkeit der Identität gegenüberstellt, schließt nicht nur - wie oben genauer ausgeführt - an Adorno an, sondern findet sich schon im Denken der frühen Neuzeit. Dessen Episteme »beruhte auf dem Privileg der Ähnlichkeit und der Analogie, wertete also die Suche nach Entsprechungen auf: Es ging darum, anzunähern statt zu unterscheiden $\aleph^{6}$. Statt einer einzelnen, herausgehobenen Perspektive standen mehrere zugleich nebeneinander. Die Imagination trennte nicht, sondern vermittelte wirkliche und fiktive Welt und ermöglichte »den Übergang der einen zu der anderen « ${ }^{7}$. Elena Esposito verbindet dies interessanterweise mit dem Begriff >Virtualität « »im eigentlichen Sinne«, denn deren Absicht sei es, »eine alternative Realitätsdimension zu schaffen: keine falschen realen Objekte, sondern wahre virtuelle Objekte, für welche die Frage der realen Realität ganz und gar gleichgültig ist « ${ }^{8}$. Dies deckt sich mit der Definition von Virtualität durch Charles Peirce:

Ein virtuelles $\mathrm{X}$ (wobei $\mathrm{X}$ ein allgemeiner Begriff ist) ist etwas, das zwar kein $\mathrm{X}$ ist, aber die Wirksamkeit (virtus) eines $\mathrm{X}$ hat. Das ist die richtige Bedeutung des Wortes, es wurde jedoch weitgehend mit >potentiell verwechselt, was beinahe sein Gegenteil ist. Denn das potentielle X hat die Natur eines X, hat aber keinerlei tatsächliche Wirksamkeit. ${ }^{9}$

Dies ist ein interessanter begriffsgeschichtlicher Ansatz, der sich lohnt, weiter verfolgt zu werden. Damit weist er auf die Aspekte hin, die in dieser Arbeit nicht einbezogen werden konnten. Dazu gehört die Frage, wie sich das Denken, das der Möglichkeitenpoetik von Herbst zugrunde liegt, zu früheren vor-modernen Denkformen verhält. Hier gilt es aber, den Anspruch auf Zeitgemäßheit in Herbsts Poetik zu betonen. Er propagiert keineswegs eine Kehrtwende zu einem früheren Denken. Dafür sind in seinen Büchern zu viele moderne Bezüge und Elemente enthalten. Doch will er dieses `annähernde`, nicht binäre Denken gerade mit der Technik, die die moderne Zeit bestimmt, verbinden. Wie in WB die Elben mit Deters' Hilfe beschließen, in die

5 Hannelore Schlaffer: »Poesie und Prosa. Wielands Verserzählungen«, in: Walter Erhart / Lothar van Laak (Hg.): Wissen - Erzählen - Tradition. Wielands Spätwerk, Berlin / New York 2010, 153-167, hier: 158 .

6 Esposito: »Fiktion und Virtualität«, 276, mit Bezug auf Michel Foucault: Die Ordnung der Dinge. Eine Archäologie der Humanwissenschaften [1966], übers. von Ulrich Köppen, Frankfurt am Main 1974, Kap. II.

7 Esposito: »Fiktion und Virtualität«, 279.

8 Ebd., 270.

9 Charles Sanders Peirce: Schriften I. Zur Entstehung des Pragmatismus, hrsg. und mit einer Einl. vers. von Karl-Otto Apel, Frankfurt am Main 1967, 228. 
technischen Welten aufzubrechen, will Herbst das, "was für uns bislang die Seele der Dichtung ausgemacht hat [...] in die neuen technischen Welten [...] hinüber[]retten« $(K R, 121)$. Eine solche Untersuchung ginge über die Beschränkung auf Herbsts selbstgewählte Wissenskontexte hinaus. Auf diese Weise könnten weitere Vergleiche $\mathrm{zu}$ literarischen Denktraditionen gezogen werden. Im Kontext einer Einordnung in die Literaturgeschichte wäre auch der weite Begriff der Postmoderne ins Spiel zu bringen. Während Kühlmann diesen mit kurzem Hinweis auf die Begriffsproblematik plakativ auf Herbst bezieht, ${ }^{10}$ der diese Einordnung wiederum auf seiner Website und in Klappentexten verwendet, versteht Herbst selbst seine Ästhetik als eine »nachpostmoderne $(K R, 5)$. Bei diesen Differenzen könnte eine Untersuchung ansetzen, die über die Überlegungen von Jürgensen ${ }^{11}$ hinausgehen.

Neben einer möglichen Vertiefung der Überlegungen dieser Arbeit an vielen Punkten fallen mehrere Aspekte auf, die hier ausgeklammert wurden. Fast vollständig entfallen ist die politische Dimension der Bücher, deren Vorhandensein genauer diskutiert werden könnte. In WB findet sich beispielsweise ein Nebenstrang mit Bertrecht und seinen Freunden, die als Terroristen durch etliche Details auf die RAF verweisen, die nach eigenem Bekunden eine wichtige, auch sprachlich-literarische Prägung von Herbst darstellt. ${ }^{12}$ Fortgeführt wird die Terrorismusthematik auch in den $A W$-Romanen mit der Gruppe der Myrmidonen.

Interessant wären auch weitere interdisziplinäre Untersuchungen. Ebenso wie Thomas Malsch eine soziologische Perspektive eingebracht hat, könnte dies beispielsweise durch die Musikwissenschaft und die Physik geschehen. Was in der vorliegenden Arbeit nur angerissen werden konnte, ist die Rolle, die musikalische Strukturen bei Herbst für die Formung seiner Texte spielen. Bei $W B$ ist der Bezug auf Beethovens 6. Sinfonie, bei $T A$ der auf Sibelius' 4. Sinfonie angesprochen worden. Im Weblog sind sowohl private Reflexionen über vor allem Neue Musik zu finden als auch Opernkritiken, die regelmäßig beispielsweise in der Frankfurter Allgemeinen Sonntagszeitung veröffentlicht werden. Eine musikwissenschaftlich grundierte Untersuchung der Strukturen könnte daher interessant sein. In eine ähnliche Richtung könnte ein Abgleich der naturwissenschaftlichen Anspielungen in $W B$ und den $A W$-Romanen gehen. Wie dargestellt handelt es sich hier keineswegs um die Abbildung von Theorien der wirklichen Physik. Herbst betont aber immer wieder sein Interesse an solchen. In diesem Zusammenhang wäre ein Vergleich der komplexen modernen Physik mit den Zeit- und Raummodellen, die Herbst in seinen Romanen entwirft, interessant.

10 Vgl. Kühlmann: »Postmoderne Phantasien«, 499.

11 Vgl. Jürgensen: »Ich sind auch andere«.

12 Vgl. URL-79, 9. Feb. 2012, sowie der Bezug seines Künstlernamens zum `Deutschen Herbst 1977. 
Diese Arbeit hat gezeigt, dass sich die Werke von Herbst nicht einfach konsumieren lassen. Vielmehr fordern die komplexen Strukturen, versteckten Hinweise und impliziten kulturphilosophischen Grundlagen den Leser zu einer intensiven Auseinandersetzung und eigenem Nach- und Mitdenken auf. Herbst selbst findet in Thetis eine prägnante Formulierung, die diesen Anspruch auf den Punkt bringt:

Ich aber will, daß Raum fürs Ungeheure bleibe.

Der ist auch im Kopf zu schaffen. Nur zu beobachten reicht nicht. $(T A, 9)$ 



\section{Literaturverzeichnis}

Alle URLs wurden im Mai 2015 auf ihre Zugänglichkeit überprüft, daher wurde kein Abrufdatum angegeben. Soweit vorhanden wurde das Datum der Veröffentlichung bzw. der letzten Aktualisierung angegeben.

\section{Siglenverzeichnis}

AW Die Anderswelt-Romane: Thetis und Buenos Aires

BA Alban Nikolai Herbst: Buenos Aires. Anderswelt. Kybernetischer Roman, Berlin 2001.

DdA Max Horkheimer / Theodor W. Adorno: Dialektik der Aufklärung. Philosophische Fragmente [1944/1969], Frankfurt am Main 1988.

KR Alban Nikolai Herbst: Kybernetischer Realismus. Heidelberger Vorlesungen, Heidelberg 2008.

KTLB Alban Nikolai Herbst: Kleine Theorie des Literarischen Bloggens. Die Dschungel. Anderswelt, Bern 2011.

TA Alban Nikolai Herbst: Thetis. Anderswelt. Fantastischer Roman, Reinbek 1998.

VG Alban Nikolai Herbst: Die Verwirrung des Gemüts. Roman, München 1983.

WB Alban Nikolai Herbst: Wolpertinger oder Das Blau [1993]. Roman, Taschenbuchausgabe, München 2000.

WV Alban Nikolai Herbst: Wurm Vorsatz, Beilage zu Buenos Aires. Anderswelt, 2001.

\section{Quellenverzeichnis Alban Nikolai Herbst}

\section{Romane, Websites, weitere selbstständige Veröffentlichungen (chronologisch)}

Herbst, Alban Nikolai: Marlboro. Prosastücke, Hannover 1981.

Herbst, Alban Nikolai: Die Verwirrung des Gemüts. Roman, München 1983.

Herbst, Alban Nikolai (Hg.). Dschungelblätter (1985-1989). 
Herbst, Alban Nikolai: Die blutige Trauer des Buchhalters Michael Dolfinger. Lamento/Roman, Göttingen 1986.

Herbst, Alban Nikolai: Joachim Zilts Verirrungen, St. Gallen 1986.

Herbst, Alban Nikolai: Die Orgelpfeifen von Flandern. Novelle, Frankfurt am Main 1993.

Herbst, Alban Nikolai: Wolpertinger oder Das Blau [1993]. Roman, Taschenbuchausgabe, München 2000.

Herbst, Alban Nikolai: Wolpertinger oder Das Blau. Roman, Originalausgabe, Frankfurt am Main 1993.

Herbst, Alban Nikolai: Eine Sizilische Reise. Fantastischer Bericht [1995]. Roman, München 2002.

Herbst, Alban Nikolai: Der Arndt-Komplex. Novellen, Reinbek 1997.

Herbst, Alban Nikolai: Thetis. Anderswelt. Fantastischer Roman, Reinbek 1998.

Herbst, Alban Nikolai: In New York. Manhattan Roman, Frankfurt am Main 2000.

Herbst, Alban Nikolai: Buenos Aires. Anderswelt. Kybernetischer Roman, Berlin 2001.

Herbst, Alban Nikolai: Wurm Vorsatz, Beilage zu Buenos Aires. Anderswelt, 2001.

Herbst, Alban Nikolai: Herbst \& Deters - Fiktionäre, http://www.albannikolaiherbst.de und http://www.die-dschungel.de, seit Sept. 2003.

Herbst, Alban Nikolai: Meere. Roman, hg. v. Denis Scheck, Hamburg 2003, verbotene Originalversion.

Herbst, Alban Nikolai: »Weblogbuch«, 2003/2004, URL: http://tools.freecity.de/blog/ show.phtml?id=albannikolaiherbst.

Herbst, Alban Nikolai / Alexander von Ribbentrop: „Die Dschungel. Anderswelt. Die Dschungelblätter«. Weblog, seit 2004, URL: http://albannikolaiherbst.twoday.net.

Herbst, Alban Nikolai: Die Niedertracht der Musik. 13 Erzählungen, Köln 2005.

Herbst, Alban Nikolai: Dem Nahsten Orient / Très Proche Orient. Liebesgedichte, übers. von Raymond Prunier, Frankfurt am Main 2007.

Herbst, Alban Nikolai: »Meere. Roman«. Letzte Fassung, 2007. Auch `Persische Fassung`genannt, in: Volltext April/Mai 2007, 13-39.

Herbst, Alban Nikolai: Der Engel Ordnungen, Frankfurt am Main 2008.

Herbst, Alban Nikolai: Kybernetischer Realismus. Heidelberger Vorlesungen, Heidelberg 2008.

Herbst, Alban Nikolai: Meere, Letzte, vervollständigte Ausgabe 2007, Frankfurt am Main 2008. 
Herbst, Alban Nikolai: Meere. Ein Roman - drei Fassungen, Hamburg 2009.

Herbst, Alban Nikolai: Azreds Buch. Geschichten und Fiktionen, Berlin 2010.

Herbst, Alban Nikolai: Selzers Singen. Phantastische Geschichten und solche von fremder Moral, Berlin 2010.

Herbst, Alban Nikolai: Das bleibende Thier. Bamberger Elegien, Berlin 2011.

Herbst, Alban Nikolai: Die Fenster von Sainte Chapelle. Eine Reiseerzählung, Berlin 2011.

Herbst, Alban Nikolai: Kleine Theorie des Literarischen Bloggens. Die Dschungel. Anderswelt, Bern 2011.

Karlsson, Ortnit [d. i. Alban Nikolai Herbst]: Das Katastrophen-Quartett. Frau Schneider aus Thor, Köln 2012.

Herbst, Alban Nikolai: Argo. Anderswelt. Epischer Roman, Berlin 2013.

\section{Unselbstständige Veröffentlichungen (chronologisch)}

Herbst, Alban Nikolai: »Grimmelshausen-Preisrede zum 15. November 1995«, 1995, URL: http://www.die-dschungel.de/ANH/txt/pdf/grimmelshausen_rede.pdf.

Herbst, Alban Nikolai: »Schreibauskunft. Zum Roman `Anderswelt«", in: Neue Deutsche Literatur 44/5 (1996), 83-87.

Herbst, Alban Nikolai: „Entelechie oder Hans Deters sagt, was ihn ankotzt. Über das Wohlverhalten in Text \& Betrieb, nämlich: Warum es keinen richtigen Streit mehr gibt und Weshalb die Leute, anstatt zu hassen, sich öffentlich lieber zu Tode lieben", in: Sprache im technischen Zeitalter 35/141 (1997), 190-200.

Herbst, Alban Nikolai: »Rede aus Anlaß der Verleihung des Phantastik-Preises der Stadt Wetzlar zum 16. September 1999 gehalten von einem Feinde«, 1999, URL: http://www.die-dschungel.de/ANH/txt/pdf/phantastik_rede.pdf.

Herbst, Alban Nikolai: „Schreiben heute? Dichten heute. Kein Abgesang, sondern Plädoyer «, in: Kunst und Kultur 8 (1999), URL: http://www. sandammeer.at/ spiritus/schreibendichten.htm.

Bongartz, Barbara / Alban Nikolai Herbst: »Inzest oder Die Entstehung der Welt. Der Anfang eines Romanes in Briefen «, in: Schreibheft 58 (2002), hg. v. Norbert Wehr, $3-163$.

Herbst, Alban Nikolai: »Größenfantasien (Tel Aviv)«, 2002, URL: http://www.diedschungel.de/ANH/txt/pdf/groessenfantasien.pdf.

Herbst, Alban Nikolai: „Kanon der Autoren - Drei Fragen«, in: Heinz Ludwig Arnold (Hg.): Literarische Kanonbildung (Text+ Kritik-Sonderband), in Zsarb. mit Hermann Korte, München 2002, 329, 334, 336. 
Herbst, Alban Nikolai: »Schöne Literatur muß grausam sein! Antimilitaristische Spekulationen zum Thema Krieg \& Katharsis«. Rede vor der Deutschen Literaturkonferenz am 23. März 2002 in Leipzig, in: Neue Deutsche Literatur 50/4 (2002), $176-187$.

Herbst, Alban Nikolai: »Poetologische Thesen I. Das realistische Dilemma oder Die >Menschlichkeit«, in: L. Der Literaturbote 18/69 (2003), 34-51.

Herbst, Alban Nikolai: »Poetologische Thesen II. Das experimentelle Dilemma«, in: L. Der Literaturbote 18/70 (2003), 46-55.

Herbst, Alban Nikolai: »Poetologische Thesen III. Intensität oder Die Ambivalenzen«, in: L. Der Literaturbote 18/72 (2003), 40-52.

Herbst, Alban Nikolai: »Das Flirren im Sprachraum«, in: Zettelkasten 23 (2004), 1135 .

Herbst, Alban Nikolai: »Fantastische Räume. Vortrag zum Fantastik-Symposion Linz Mai 2004", 2004, URL: http://www.die-dschungel.de/ANH/txt/pdf/fantastische_ raeume_2004_1.pdf.

Herbst, Alban Nikolai: »Die anthropologische Kehre. 42 Partikel«. Vortrag im Rahmen der Tagung >Medienkonzepte und Medieninnovation 1950-2000<, Universität Siegen, 16. Dezember 2005, URL: http://www.die-dschungel.de/ANH/txt/pdf/ anthropolog_kehre.pdf.

Herbst, Alban Nikolai: » Dieser mächtige Raum...く. Zu einer Poetik des Fantastischen«, in: die horen 50/217 (2005), 13-15, 18-24.

Herbst, Alban Nikolai: „Das Weblog als Dichtung. Einige Thesen zu einer möglichen Poetologie des Weblogs«, in: Markus A. Hediger / Benjamin Stein / Hartmut Abendschein (Hg.): Literarische Weblogs, Bern 2007, 9-30.

Herbst, Alban Nikolai: »Der Füchsin auf dem Grund. Verbeugung vor Marianne Fritz«, in: Volltext 6 (2007), 6-7.

Herbst, Alban Nikolai:»Verlorene Herkünfte«. Gastbeitrag in Benjamin Steins Weblog »Turmsegler.net «, 31. Mai 2007, URL: http://turmsegler.net/20070531/verloreneherkunfte.

\section{Interviews}

Fasthuber, Sebastian: »Sie müssen verzeihen, aber darauf scheiße ich echt «". Interview mit Alban Nikolai Herbst, in: Volltext 5 (2003), 3-4.

Faure, Ulrich: ») Jetzt hab ich Metall im Mund und kann um so kräftiger beißen «". Interview mit Alban Nikolai Herbst, in: Börsenblatt für den Deutschen Buchhandel 19 (7. März 1995), 12-15. 
Piberhofer, Bruno / Ferdinand Schmökel: »Die Welt als Vorstellung und Selbstreferenz. Ein Gespräch mit Alban Nikolai Herbst über seinen fantastischen Roman Thetis. Anderswelt«, in: Listen 15/53 (1999), 28-31.

Valin, Frédéric: »Interview mit Alban Nikolai Herbst«, 19. März 2008, URL: http: //www.spreeblick.com/2008/03/19/interview-mit-alban-nikolai-herbst.

\section{Weitere Literatur}

Adorno, Theodor W.: »Kulturkritik und Gesellschaft« [1951], in: Ders.: Gesammelte Schriften, Bd. 10/1: Kulturkritik und Gesellschaft I. Prismen. Ohne Leitbild, hg.v. Rolf Tiedemann, Frankfurt am Main 1977, 11-30.

Adorno, Theodor W.: Vorlesung über Negative Dialektik. Fragmente zur Vorlesung 1965/66, hg. v. Rolf Tiedemann (Abteilung IV: Nachgelassene Schriften, hg. v. Theodor W. Adorno Archiv, Bd. 16), Frankfurt am Main 2003.

Adorno, Theodor W.: »Negative Dialektik« [1966], in: Ders.: Gesammelte Schriften, Bd. 6: Negative Dialektik. Jargon der Eigentlichkeit, hg. v. Rolf Tiedemann, Frankfurt am Main 1973, 7-412.

Adorno, Theodor W.: Ästhetische Theorie [1970], hg. v. Gretel Adorno / Rolf Tiedemann, Frankfurt am Main 1990.

Adorno, Theodor W.: »Graeculus (II). Notizen zu Philosophie und Gesellschaft 1943-1969«, in: Frankfurter Adorno Blätter 8 (2003), 9-41.

Albath, Maike: »Der götterhaften Giftbrühe entstiegen«, in: Der Tagesspiegel, 31. Okt. 1998.

[Anonym]: »Penis im Hirn«, in: Der Spiegel, 28. Apr. 1980, 256-257.

Apel, Friedmar: »Täglich sieben trockene Martinis«, in: Frankfurter Allgemeine Zeitung, 6. Okt. 1998.

Apollodor: Die griechische Sagenwelt. Apollodors Mythologische Bibliothek, übers. von Christian Gottlob Moser / Dorothea Vollbach (Sammlung Dieterich 354), Köln 1997 .

Assmann, Aleida / Jan Assmann: »Mythos«, in: Hubert Cancik u. a. (Hg.): Handbuch religionswissenschaftlicher Grundbegriffe, Bd. 4, Stuttgart u. a. 1998, 179-200.

Aumann, Philipp: Mode und Methode. Die Kybernetik in der Bundesrepublik Deutschland, Göttingen 2009.

Ayren, Armin: »Die Verwirrung der Grammatik«, in: Frankfurter Allgemeine Zeitung, 5. Okt. 1983.

Bal, Mieke: »Notes on Narrative Embedding«, in: Poetics Today 2/2 (1981), 41-59. 
Becker, Sabina: Bürgerlicher Realismus. Literatur und Kultur im bürgerlichen Zeitalter 1848-1900, Tübingen [u.a.] 2003.

Benjamin, Walter: Ursprung des deutschen Trauerspiels [1925], in: Ders.: Gesammelte Schriften, Bd. 1/1, hg. v. Rolf Tiedemann / Hermann Schweppenhäuser, Frankfurt am Main 1974, 203-430.

Bluma, Lars: Norbert Wiener und die Entstehung der Kybernetik im Zweiten Weltkrieg. Eine historische Fallstudie zur Verbindung von Wissenschaft, Technik und Gesellschaft, Münster 2005.

Blume, Peter: Fiktion und Weltwissen. Der Beitrag nichtfiktionaler Konzepte zur Sinnkonstitution fiktionaler Erzählliteratur, Berlin 2004.

Blumenberg, Hans: »Wirklichkeitsbegriff und Möglichkeit des Romans« [1963/1969], in: Hans Robert Jauß (Hg.): Nachahmung und Illusion, München 1969, 9-27.

Blumenberg, Hans: »Wirklichkeitsbegriff und Wirkungspotential des Mythos«, in: Manfred Fuhrmann (Hg.): Terror und Spiel. Probleme der Mythenrezeption, München 1971, 11-66.

Blumenberg, Hans: Arbeit am Mythos, Frankfurt am Main 1979.

Blumenkamp, Katrin: »Typologien des `Als ob‘. Praktiken der Autorinszenierung um die Jahrtausendwende «, in: Christoph Jürgensen / Gerhard Kaiser (Hg.): Schriftstellerische Inszenierungspraktiken. Typologie und Geschichte, Heidelberg 2011, 363381 .

Bolle, Kees W.: »Hieros Gamos«, in: Mircea Eliade u. a. (Hg.): The Encyclopedia of Religion, Bd. 6: God-Ichi, New York / London 1987, 317-321.

Borrmann, Norbert: Vampirismus oder die Sehnsucht nach Unsterblichkeit, Kreuzlingen / München 1999.

Botheroyd, Sylvia / Paul F. Botheroyd: Lexikon der keltischen Mythologie, München 1995.

Breton, André: Nadja [1928/1963], übers. von Bernd Schwibs, mit einem Nachw. von Karl Heinz Bohrer, Frankfurt am Main 2002.

Brittnacher, Hans Richard: »Der verspielte Untergang. Apokalypsen bei Alban Nikolai Herbst«, in: die horen 53/231 (2008): Panoramen der Anderswelt. Expeditionen ins Werk von Alban Nikolai Herbst, 29-42.

Brooke-Rose, Christine: A Rhetoric of the Unreal. Studies in Narrative and Structure, especially of the Fantastic, Cambridge u. a. 1981.

Bunia, Remigius: Faltungen. Fiktion, Erzählen, Medien, Berlin 2007. 
Burdorf, Dieter / Christoph Fasbender / Burkhard Moennighoff (Hg.): Metzler Lexikon Literatur. Begriffe und Definitionen, 3., völlig neu bearbeitete Auflage, Stuttgart / Weimar 2007.

Bürger, Peter: Das Verschwinden des Subjekts. Eine Geschichte der Subjektivität von Montaigne bis Barthes, Frankfurt am Main 1998.

Carrière, Mathieu: für [sic!] eine Literatur des Krieges, Kleist, Basel / Frankfurt am Main 1981.

Cohn, Dorrit: The Distinction of Fiction, Baltimore, Md 1999.

Dath, Dietmar: »Flaschendrehen und andere Spiele«, in: Frankfurter Allgemeine Zeitung, 9. Okt. 2001.

Dean, Martin R.: »Warum die Kaffeemaschine wirklicher als die Krähe ist«, in: Basler Zeitung, 9. Mai 1997.

Döbler, Katharina: »Delirium und Moralium«, in: Neue Zürcher Zeitung, 6. Okt. 1998.

Döbler, Katharina: »Mitten hinein ins Wollknäuel«, in: Die Zeit, 3. Jan. 2002.

Dörr, Georg: Muttermythos und Herrschaftsmythos. Zur Dialektik der Aufklärung um die Jahrhundertwende bei den Kosmikern, Stefan George und in der Frankfurter Schule, Würzburg 2007.

Dörr, Volker C.: Mythomimesis. Mythische Geschichtsbilder in der westdeutschen (Erzähl-)Literatur der frühen Nachkriegszeit (1945-1952), Berlin 2004.

Dupuy, Jean-Pierre: The Mechanization of the Mind. On the Origin of Cognitive Science, Princeton / Oxford 2000.

Durst, Uwe: Theorie der phantastischen Literatur [2001], 2., aktualisierte, korrigierte und erweiterte Aufl., Berlin 2010.

Durst, Uwe: Das begrenzte Wunderbare. Zur Theorie wunderbarer Episoden in realistischen Erzähltexten und in Texten des `Magischen Realismus`, Berlin 2008.

Eco, Umberto: Nachschrift zum `Namen der Rose` [1983], übers. von Burkhart Kroeber, München 1986.

Eco, Umberto: Im Wald der Fiktionen. Sechs Streifzüge durch die Literatur [1994], München 1996.

Eco, Umberto: Lector in fabula. Die Mitarbeit der Interpretation in erzählenden Texten, München 1998.

Ernst, Thomas: »Weblogs. Ein globales Literaturformat«, in: Wilhelm Amann / Georg Mein / Rolf Parr (Hg.): Globalisierung und deutschsprachige Gegenwartsliteratur. Konstellationen, Konzepte, Perspektiven, Heidelberg 2010, 281-302. 
Esposito, Elena: »Fiktion und Virtualität«, in: Sybille Krämer (Hg.): Medien, Computer, Realität. Wirklichkeitsvorstellungen und Neue Medien, Frankfurt am Main 1998, 269-296.

Fiedler, Leslie A.: »Überquert die Grenze, schließt den Graben! Über die Postmoderne" [1968/69], in: Wolfgang Welsch (Hg.): Wege aus der Moderne. Schlüsseltexte der Postmoderne-Diskussion, Berlin 1994, 57-74.

Figal, Günter: »Über das Nichtidentische. Zur Dialektik Theodor W. Adornos«, in: Wolfram Ette / Günter Figal / Richard Klein / Günter Peters (Hg.): Adorno im Widerstreit. Zur Präsenz seines Denkens, Freiburg / München 2004, 13-23.

Findeiß, Thomas: »realfiction«, URL: http://www.realfiction.de.

Fischer, Frank: »Der Autor als Medienjongleur. Die Inszenierung literarischer Modernität im Internet«, in: Christine Künzel / Jörg Schönert (Hg.): Autorinszenierungen. Autorschaft und literarisches Werk im Kontext der Medien, Würzburg 2007, 271-280.

Fludernik, Monika: »Metanarrative and Metafictional Commentary. From Metadiscursivity to Metanarration and Metafiction«, in: Poetica 35 (2003), 1-39.

Folger, Robert: »New kids on the blog? Subjektkonstitution im Internet«, in: Jörg Dünne / Christian Moser (Hg.): Automedialität. Subjektkonstitution in Schrift, Bild und neuen Medien, Paderborn 2008, 283-304.

Foucault, Michel: Die Ordnung der Dinge. Eine Archäologie der Humanwissenschaften [1966], übers. von Ulrich Köppen, Frankfurt am Main 1974.

Foucault, Michel: »Von anderen Räumen« [1967/1984], in: Ders.: Schriften in vier Bänden. Dits et Ecrits, Bd. 4: 1980-1988, hg. v. Daniel Defert / François Ewald, unter Mitarb. von Jacques Lagrange, übers. von Michael Bischoff, Leipzig 1992, 931-942.

Frank, Dirk: Narrative Gedankenspiele. Der metafiktionale Roman zwischen Modernismus und Postmodernismus, Wiesbaden 2001.

Freuler, Regula: »Bücherwürmer online«, in: Neue Zürcher Zeitung, 29. Apr. 2007.

Frey, Hans-Peter / Karl Haußer: »Entwicklungslinien sozialwissenschaftlicher Identitätsforschung «, in: dies. (Hg.): Identität. Entwicklungen psychologischer und soziologischer Forschung, Stuttgart 1987, 3-26.

Froud, Brian / Alan Lee: Das große Buch der Geister. Von Elfen, Nixen, Gnomen, Irrwischen und anderen geheimnisvollen Wesen, übers. von Renate Reimann, Oldenburg u. a. 1979.

Gasser, Peter: »Autobiographie und Autofiktion. Einige begriffskritische Bemerkungen «, in: Elio Pellin / Ulrich Weber (Hg.): ’... all diese fingierten, notierten, in meinem Kopf ungefähr wieder zusammengesetzten Ichs‘. Autobiographie und Autofiktion, Göttingen 2012, 13-27. 
Gebauer, Gunter / Christoph Wulf: Mimesis. Kultur - Kunst - Gesellschaft, Reinbek 1992.

Gelzer, Florian: »Oberon ««, in: Jutta Heinz (Hg.): Wieland-Handbuch. Leben - Werk - Wirkung, Stuttgart / Weimar 2008, 227-237.

Genette, Gérard: Die Erzählung [1972/1983], München 1994.

Gerritsen, Willem P. / Anthony G. van Melle (Hg.): A Dictionary of Medieval Heroes. Characters in medieval narrative traditions and their afterlife in literature, theatre and the visual arts, Woodbridge 1998.

Ghezzi, Luigi: »Homepages von Schriftstellern. Zur Konstruktion einer literarischen Identität im Netz«, in: Erhard Schütz / Thomas Wegmann (Hg.): literatur.com. Tendenzen im Literaturmarketing, Berlin 2002, 24-41.

Giacomuzzi, Renate: »Die `Dschungel.Anderswelt $<$ und A. N. Herbsts $>$ Poetologie des literarischen Bloggens « $\lll$, in: die horen 53/231 (2008): Panoramen der Anderswelt. Expeditionen ins Werk von Alban Nikolai Herbst, hg. v. Ralf Schnell, 137-150.

Gide, André: »Die Falschmünzer« [1925], in: Ders.: Gesammelte Werke, Bd. 9: Die Falschmünzer. Tagebuch der Falschmünzer, hg. v. Raimund Theis, übers. von Christine Stemmermann, Stuttgart 1993, 23-365.

Glauch, Lothar: »Die Muse küsst binär«, 30. Apr. 2005, URL: http://www.heise.de/tp/ r4/artikel/19/19939/1.html.

Goetz, Rainald: Rave. Erzählung, Frankfurt am Main 1998.

Goetz, Rainald: Abfall für alle. Roman eines Jahres, Frankfurt am Main 1999, 1998 unter www.rainaldgoetz.de veröffentlicht.

Göttner-Abendroth, Heide: Die Göttin und ihr Heros. Die matriarchalen Religionen in Mythos, Märchen und Dichtung, München 1980.

Gottschalk, Jürn / Tilmann Köppe: »Was ist Literatur? Eine Einleitung «, in: dies. (Hg.): Was ist Literatur? Basistexte Literaturtheorie, Paderborn 2006, 7-21.

Gottschalk, Jürn / Tilmann Köppe (Hg.): Was ist Literatur? Basistexte Literaturtheorie, Paderborn 2006.

Graff, Bernd: »Aus dem Ruder gelaufene Elementarteilchen «, in: Süddeutsche Zeitung, 16. Nov. 2001.

Gronemann, Claudia: » Autofiction $\triangleleft$ und das Ich in der Signifikantenkette. Zur literarischen Konstitution des autobiographischen Subjekts bei Serge Doubrovsky«, in: Poetica 31 (1999), 237-262.

Groß, Nathalie: Autopoiesis. Theorie und Praxis autobiographischen Schreibens bei Alain Robbe-Grillet, Berlin 2008. 
Gymnich, Marion: »Individuelle Identität und Erinnerung aus Sicht von Identitätstheorie und Gedächtnisforschung sowie als Gegenstand literarischer Inszenierung ", in: Astrid Erll / Marion Gymnich / Ansgar Nünning (Hg.): Literatur - Erinnerung Identität. Theoriekonzeptionen und Fallstudien, Trier 2003, 29-48.

Hagner, Michael: »Vom Aufstieg und Fall der Kybernetik als Universalwissenschaft«, in: Michael Hagner / Erich Hörl (Hg.): Die Transformation des Humanen. Beiträge zur Kulturgeschichte der Kybernetik, Frankfurt am Main 2008, 38-71.

Hagner, Michael / Erich Hörl (Hg.): Die Transformation des Humanen. Beiträge zur Kulturgeschichte der Kybernetik, Frankfurt am Main 2008.

Handke, Peter: »Ich bin ein Bewohner des Elfenbeinturms« [1967], in: Ders.: Ich bin ein Bewohner des Elfenbeinturms, Frankfurt am Main 1972, 19-28.

Hartling, Florian: Der digitale Autor. Autorschaft im Zeitalter des Internets, Bielefeld 2009.

Hediger, Markus A. / Benjamin Stein / Hartmut Abendschein (Hg.): Literarische Weblogs. spa_tien. Zeitschrift für Literatur. Sonderausgabe (2007).

Heinen, Sandra: Literarische Inszenierung von Autorschaft. Geschlechtsspezifische Autorschaftsmodelle in der englischen Romantik, Trier 2006.

Heintze, Michael: »Huon de Bordeaux«, in: Rolf Wilhelm Brednich u. a. (Hg.): Enzyklopädie des Märchens. Handwörterbuch zur historischen und vergleichenden Erzählforschung, Bd. 6, Berlin / New York 1990, 1400-1407.

Heinz, Jutta (Hg.): Wieland-Handbuch. Leben - Werk - Wirkung, Stuttgart / Weimar 2008.

Heinzle, Joachim: Einführung in die mittelhochdeutsche Dietrichepik, Berlin / New York 1999.

Henrich, Dieter: »Identität`. Begriffe, Probleme, Grenzen « [1979], in: Odo Marquard / Karlheinz Stierle (Hg.): Identität, 2., unveränd. Aufl., München 1996, 133-186.

Hilmes, Carola: Das inventarische und das inventorische Ich. Grenzfälle des Autobiographischen, Heidelberg 2000.

Hobbes, Thomas: Der Körper [De Corpore, 1655], in: Ders.: Elemente der Philosophie. Erste Abteilung, hrsg. und übers. von Karl Schuhmann, Hamburg 1997.

Hofmann, Michael: Reine Seelen und komische Ritter. Aspekte literarischer Aufklärung in Christoph Martin Wielands Versepik, Stuttgart / Weimar 1998.

Hofstadter, Douglas R.: Gödel, Escher, Bach. Ein Endloses Geflochtenes Band [1979], 5. Aufl., Stuttgart 1985.

Holland, Norman N.: »Unity Identity Text Self«, in: Publications of the Modern Language Society 90/5 (1975), 813-822. 
Holz, Hans Heinz: »Realität«, in: Karlheinz Barck (Hg.): Ästhetische Grundbegriffe. Historisches Wörterbuch in sieben Bänden, Bd. 5, Stuttgart / Weimar 2003, 197-227.

Horkheimer, Max / Theodor W. Adorno: Dialektik der Aufklärung. Philosophische Fragmente [1944/1969], Frankfurt am Main 1988.

Hörl, Erich: »Das kybernetische Bild des Denkens«, in: Michael Hagner / Erich Hörl (Hg.): Die Transformation des Humanen. Beiträge zur Kulturgeschichte der Kybernetik, Frankfurt am Main 2008, 163-195.

Hughes, James: Citizen Cyborg. Why Democratic Societies Must Respond to the Redesigned Human of the Future, Cambridge, Mass. 2004.

Jahn, Manfred / Ansgar Nünning: »A Survey of Narratological Models«, in: Literatur in Wissenschaft und Unterricht 27 (1994), 283-303.

Jamme, Christoph: Einführung in die Philosophie des Mythos. Neuzeit und Gegenwart, Bd. 2, Darmstadt 1991.

Jamme, Christoph: »Mythos und Wahrheit«, in: Monika Schmitz-Emans / Uwe Lindemann (Hg.): Komparatistik als Arbeit am Mythos, Heidelberg 2004, 39-54.

Jannidis, Fotis: Figur und Person. Beitrag zu einer historischen Narratologie, Berlin / New York 2004.

Jannidis, Fotis: »Wer sagt das? Erzählen mit Stimmenverlust«, in: Andreas Blödorn / Daniela Langer / Michael Scheffel (Hg.): Stimme(n) im Text. Narratologische Positionsbestimmungen (Narratologia 10), Berlin / New York 2006, 151-164.

Jannidis, Fotis / Gerhard Lauer / Simone Winko (Hg.): Grenzen der Literatur. Zu Begriff und Phänomen des Literarischen, Berlin u. a. 2009.

Jordan, Tim: Cyberpower. The Culture and Politics of Cyberspace and the Internet, London 1999.

Jørgensen, Sven-Aage / Herbert Jaumann / John A. McCarthy / Horst Thomé: Wieland. Epoche - Werk - Wirkung, München 1994.

Jürgensen, Christoph: »Ich sind auch andere. Zur Pluralisierung des Selbst in der Erzählprosa von Alban Nikolai Herbst«, in: Ivar Sagmo (Hg.): Moderne, Postmoderne - und was noch? Akten der Tagung in Oslo, 25.-26.11.2004 (Osloer Beiträge zur Germanistik 39), Frankfurt am Main 2007, 145-157.

Jürgensen, Christoph: »Unwirkliche Städte, unwirkliches Ich. Zum Verhältnis von Stadt und Individuum in A. N. Herbsts Buenos Aires. Anderswelt«, in: die horen 53/231 (2008): Panoramen der Anderswelt. Expeditionen ins Werk von Alban Nikolai Herbst, 99-111.

Jürgensen, Christoph: »Ins Netz gegangen. Inszenierungen von Autorschaft im Internet am Beispiel von Rainald Goetz und Alban Nikolai Herbst«, in: Christoph 
Jürgensen / Gerhard Kaiser (Hg.): Schriftstellerische Inszenierungspraktiken. Typologie und Geschichte, Heidelberg 2011, 405-422.

Jürgensen, Christoph / Gerhard Kaiser: »Schriftstellerische Inszenierungspraktiken. Heuristische Typologie und Genese«, in: dies. (Hg.): Schriftstellerische Inszenierungspraktiken. Typologie und Geschichte, Heidelberg 2011, 9-30.

Jürgensen, Christoph / Gerhard Kaiser (Hg.): Schriftstellerische Inszenierungspraktiken. Typologie und Geschichte, Heidelberg 2011.

Kalka, Joachim: »Körperphantasien. Von Schafen und Menschen«, in: Kursbuch 128 (Juni 1997): Lebensfragen, 1-14.

Kiedaisch, Petra (Hg.): Lyrik nach Auschwitz? Adorno und die Dichter, Stuttgart 1995.

Kindt, Tom: Unzuverlässiges Erzählen und literarische Moderne. Eine Untersuchung der Romane von Ernst Weiß, Tübingen 2008.

Klauk, Tobias / Tilmann Köppe: "Literatur und Möglichkeiten «, in: Scientia Poetica 14 (2010), 163-204.

Klein, Herbert G.: Konstruierte Wirklichkeiten. Kybernetische Bewußtseinsformen im anglo-amerikanischen Roman des 20. Jahrhunderts, Heidelberg 1998.

Klinkert, Thomas: »Fiktion und Autopoiesis. Überlegungen zum epistemischen Status der Literatur am Beispiel von Don Quijote«, in: Hartmut Schröder / Ursula Bock (Hg.): Semiotische Weltmodelle. Mediendiskurse in den Kulturwissenschaften, Berlin 2010, 303-325.

Klinkert, Thomas: »Autopoiesis. Chrétien de Troyes«, in: Niels Werber (Hg.): Systemtheoretische Literaturwissenschaft. Begriffe - Methoden - Anwendungen, Berlin / New York 2011, 59-76.

Köppe, Tilmann: »Der Konjunktiv in Andreas Maiers Roman Wäldchestag und die Theorie der Metafiktionalität«, in: J. Alexander Bareis / Frank Thomas Grub (Hg.): Metafiktion. Analysen zur deutschsprachigen Gegenwartsliteratur, Berlin 2010, 115133.

Korte, Hermann: »Schreib-Arbeit. Literarische Autorschaft in Kafkas Tagebüchern«, in: Heinz Ludwig Arnold (Hg.): Franz Kafka, 2., gründlich überarbeitete Aufl. (Text + Kritik-Sonderband), 2006, 254-271.

Korten, Lars: Poietischer Realismus. Zur Novelle der Jahre 1848-1888. Stifter, Keller, Meyer, Storm, Tübingen 2009.

Krämer, Sybille (Hg.): Medien, Computer, Realität. Wirklichkeitsvorstellungen und Neue Medien, Frankfurt am Main 1998.

Kreknin, Innokentij: »Kybernetischer Realismus und Autofiktion. Ein Ordnungsversuch digitaler poetischer Phänomene am Beispiel von Alban Nikolai Herbst «, in: 
Martina Wagner-Egelhaaf (Hg.): Auto(r)fiktion. Literarische Verfahren der Selbstkonstruktion, Bielefeld 2013, 279-314.

Kreknin, Innokentij: Poetiken des Selbst. Identität, Autorschaft und Autofiktion am Beispiel von Rainald Goetz, Joachim Lottmann und Alban Nikolai Herbst, Berlin u. a. 2014.

Kuhlbrodt, Dietrich: „Große Schnitte, kleine Schnitte«, in: die tageszeitung, 7. Mai 2003.

Kühlmann, Wilhelm: »Auf nach Hannoversch Münden«, in: Frankfurter Allgemeine Zeitung, 28. Mai 1994.

Kühlmann, Wilhelm: »Herbst, Alban Nicolai [sic!]«, in: Thomas Kraft (Hg.): Lexikon der deutschsprachigen Gegenwartsliteratur seit 1945, Bd. 1, München 2003, 525-527.

Kühlmann, Wilhelm: »Postmoderne Phantasien. Zum mythologischen Schreiben im Prosawerk von Alban Nikolai Herbst (geb. 1955)«. Mit einem Werkverzeichnis, in: Euphorion 97 (2003), 499-516.

Kühlmann, Wilhelm: »Störungen des 'perfektionierten Geistes`. Anmerkungen zu Alban Nikolai Herbsts Der Arndt-Komplex«, in: die horen 53/231 (2008): Panoramen der Anderswelt. Expeditionen ins Werk von Alban Nikolai Herbst, 184-186.

Kühlmann, Wilhelm: »Herbst, Alban Nikolai«, in: ders. (Hg.): Killy Literaturlexikon, 2., vollständig überarbeitete Auflage, Bd. 5, Berlin 2009, 292-294.

Künzel, Christine / Jörg Schönert (Hg.): Autorinszenierungen. Autorschaft und literarisches Werk im Kontext der Medien, Würzburg 2007.

Ladeur, Karl-Heinz / Tobias Gostomzyk: »Ein Roman ist ein Roman ist ein Roman? $\mathrm{Zu}$ den gerichtlichen Auseinandersetzungen um die autobiografischen Werke von Maxim Biller, Alban Nikolai Herbst und Birgit Kempker und der Notwendigkeit einer Rekonstruktion der Kunstfreiheit«, in: Zeitschrift für Urheber- und Medienrecht 48/6 (2004), 426-435.

Landgrebe, Ludwig: "Die Aporien des Dingbegriffs und die Fremdheit der Welt«, in: Actes du XIème Congrès International de Philosophie, Bd. 3, Brüssel 1953.

Landwehr, Jürgen: »Von der Repräsentation zur Selbstbezüglichkeit und die Rückkehr des/zum Imaginären. Konzepte von Literatur und literarischem (Struktur-)Wandel und ein >verkehrtes« Mimesis-Modell«, in: Michael Titzmann (Hg.): Modelle des literarischen Strukturwandels, Tübingen 1991, 275-295.

Larkin, David (Hg.): Faeries. Described and illustrated by Brian Froud and Alan Lee, New York u. a. 1978.

Lehmann, Hartmut: Die Entzauberung der Welt. Studien zu Themen von Max Weber, Göttingen 2009. 
Leiß, Judith: Inszenierungen des Widerstreits. Die Heterotopie als postmodernistisches Subgenre der Utopie, Bielefeld 2010.

Lejeune, Philippe: Der autobiographische Pakt [1975], übers. von Wolfram Bayer / Dieter Hornig, Frankfurt am Main 1994.

Lenzen, Manuela: „Geschaltet. Computer und Geist«, in: Frankfurter Allgemeine Zeitung 18.4.2012.

Levita, David J. de: Der Begriff der Identität [1965], 2. Aufl., Frankfurt am Main 1976.

Lindner, Burkhardt: »Krise der Phantasie«, in: Frankfurter Rundschau 13.3.1999.

LITBLOGS.NET: "Helmut Schulze«, Literarische Weblogs in deutscher Sprache, 29. März 2008, URL: http://www.litblogs.net/helmut-schulze.

Lohberg, Rolf / Theo Lutz: Keiner weiß was Kybernetik ist. Eine verständliche Einführung in eine moderne Wissenschaft, Stuttgart 1968.

Luhmann, Niklas: »Das Kunstwerk und die Selbstreproduktion der Kunst«, in: Hans Ulrich Gumbrecht / K. Ludwig Pfeiffer (Hg.): Stil. Geschichten und Funktionen eines kulturwissenschaftlichen Diskurselements, Frankfurt am Main 1986, 620-672.

MacKillop, James: A Dictionary of Celtic Mythology, Oxford / New York 1998.

Malina, Debra: Breaking the Frame. Metalepsis and the Construction of the Subject, Columbus 2002.

Malsch, Thomas: »Naming the Unnamable. Socionics or the Sociological Turn of/to Distributed Artificial Intelligence«, in: Autonomous Agents and Multi-Agent Systems 4 (2001), 155-186.

Malsch, Thomas: »Vom Wiedereintritt des Autors in seine Geschichte. >Buenos Aires. Anderswelt‘, ein kybernetischer Roman von Alban Nikolai Herbst«, in: Thomas Kron / Uwe Schimank (Hg.): Die Gesellschaft der Literatur, Opladen 2004, 45-80.

Malsch, Thomas / Michael Florian / Michael Jonas / Ingo Schulz-Schaeffer: „Sozionik. Expeditionen ins Grenzgebiet zwischen Soziologie und Künstlicher Intelligenz«, in: Thomas Malsch (Hg.): Sozionik. Soziologische Ansichten über künstliche Sozietät, Berlin 1998, 9-24.

Martinez, Matias / Michael Scheffel: Einführung in die Erzähltheorie [1999], 2., durchgesehene Auflage, München 2000.

Martus, Steffen: »IIn der Hölle soll sie braten ‘. Zur Literatur der Literaturwissenschaft mit einem Seitenblick auf Matthias Polityckis `Weiberroman $<$ und die Computerphilologie«, in: Zeitschrift für Germanistik 17/1 (2007), 8-27.

McHale, Brian: Postmodernist Fiction, London / New York 1987. 
Meier, Albert: »Irony Is Over. Der Verzicht auf Selbstreferenzialität in der neuesten Prosa «, in: Heinrich Detering (Hg.): Autorschaft. Positionen und Revisionen (Germanistische-Symposien-Berichtsbände 24), Stuttgart 2002, 570-581.

Mergenthaler, Volker: »WWeiter schreiben` nach dem 11. September. Barbara Bongartz, Alban Nikolai Herbsts und Norbert Wehrs >Inzest oder Die Entstehung der Welt «, in: Ingo Irsigler / Christoph Jürgensen (Hg.): Nine Eleven. Ästhetische Verarbeitungen des 11. September 2001, Heidelberg 2008, 29-48.

Michalzik, Peter: »Phakten oder Fantasie«, in: Süddeutsche Zeitung 12.11.1998.

Misoch, Sabina: Identitäten im Internet. Selbstdarstellung auf privaten Homepages, Konstanz 2004.

Mitscherlich, Alexander / Margarete Mitscherlich: Die Unfähigkeit zu trauern. Grundlagen kollektiven Verhaltens, München 1967.

Mitscherlich, Margarete: »Wie haben sich deutsche Schriftsteller gegen die Unfähigkeit zu trauern gewehrt? Dargestellt an Wolfgang Koeppens `Der Tod in Rom««, in: Neue Rundschau 94/3 (1983), 137-156.

Moosbach, Anton [d. i. Gregor Patorski]: Das Ribbentrop-Rhizom. Ein Experiment mit den Werken von Alban Nikolai Herbst und Gilles Deleuze/Félix Guattari, Lizentiatsarbeit, Zürich: Philosophische Fakultät der Universität Zürich, 2005, URL: http://www.die-dschungel.de/ANH/txt/pdf/ribbentrop_rhizom.pdf.

Müller, Ernst: »Mythos/mythisch/Mythologie«, in: Karlheinz Barck (Hg.): Ästhetische Grundbegriffe. Historisches Wörterbuch in sieben Bänden, Bd. 4, Stuttgart/ Weimar 2002, 309-346.

Müller, Wolfgang G.: »Interfigurality. A Study on the Interdependence of Literary Figures«, in: Heinrich F. Plett (Hg.): Intertextuality, Berlin u. a. 1991, 101-121.

Munzinger Online: »Herbst, Alban Nikolai«, Stand: 3. April 2012, Personen - Internationales Biographisches Archiv, URL: http://www.munzinger.de/document/ 00000023007.

Neumann, Birgit / Ansgar Nünning: »Metanarration and Metafiction «, in: Peter Hühn / Jan Christoph Meister / John Pier / Wolf Schmid (Hg.): The living handbook of narratology, Hamburg 24. Jan. 2014, URL: http://www.lhn.uni-hamburg.de/ article/metanarration-and-metafiction.

Nietzsche, Friedrich: »Nachgelassene Fragmente. Anfang 1888 bis Anfang Januar 1889«, in: Ders.: Werke. Kritische Gesamtausgabe, hg. v. Giorgio Colli / Mazzino Montinari, Bd. 3, Berlin / New York 1972.

Nünning, Ansgar: »Mimesis des Erzählens. Prolegomena zu einer Wirkungsästhetik, Typologie und Funktionsgeschichte des Akts des Erzählens und der Metanarration", in: Jörg Helbig (Hg.): Erzählen und Erzähltheorie im 2o. Jahrhundert, Heidelberg 2001, 13-47. 
Nünning, Ansgar: »On Metanarrative. Towards a Definition, a Typology and an Outline of the Functions of Metanarrative Commentary«, in: John Pier (Hg.): The Dynamics of Narrative Form. Studies in Anglo-American Narratology, Berlin / New York 2004, 11-57.

Olsen, Stein Haugom: »Wie man ein literarisches Werk definiert« [1976], in: Jürn Gottschalk / Tilmann Köppe (Hg.): Was ist Literatur? Basistexte Literaturtheorie, Paderborn 2006, 72-89.

Ortheil, Hanns-Josef: »Das Lesen - ein Spiel. Postmoderne Literatur? Die Literatur der Zukunft«, in: Die Zeit, 17. Apr. 1987.

Patorski, Gregor / Anton Moosbach: "Die Anderswelt als Rhizom«, in: die horen 53/ 231 (2008): Panoramen der Anderswelt. Expeditionen ins Werk von Alban Nikolai Herbst, 11-21.

Peirce, Charles Sanders: Schriften I. Zur Entstehung des Pragmatismus, hrsg. und mit einer Einl. vers. von Karl-Otto Apel, Frankfurt am Main 1967.

Plutarch: Theseus, in: Große Griechen und Römer, übers. von Konrat Ziegler, Bd. 1, Zürich 1954.

Pongratz-Leisten, Beate: »Hieros Gamos«, in: Hans Dieter Betz (Hg.): Religion in Geschichte und Gegenwart. Handwörterbuch für Theologie und Religionswissenschaft, 4. Aufl., Bd. 3: F-H, Tübingen 2000, 1730-1731.

Porombka, Stephan: »Clip-Art, literarisch. Erkundungen eines neuen Formats (nebst einiger Gedanken zur sogenannten rangewandten Literaturwissenschaft $)_{\text {) }}$, in: Christine Künzel / Jörg Schönert (Hg.): Autorinszenierungen. Autorschaft und literarisches Werk im Kontext der Medien, Würzburg 2007, 223-243.

Porush, David: »Technology and Postmodernism. Cybernetic Fiction«, in: SubStance 9/2 (1980), 92-100.

Porush, David: The Soft Machine. Cybernetic Fiction, New York / London 1985.

Porush, David: „Cybernetic Fiction and Postmodern Science«, in: New Literary History 20/2 (1989), 373-396.

Preußer, Heinz-Peter: »Die Pluralität der Untergänge. Postmoderne bei Alban Nikolai Herbst und der Versuch einer Typologie: Enzensberger - Grass - Strauß«, in: Ders.: Letzte Welten. Deutschsprachige Gegenwartsliteratur diesseits und jenseits der Apokalypse, Heidelberg 2003, 9-32.

Preußer, Heinz-Peter: »Achilles als Barde. Kybernetische Mythenkorrektur bei Alban Nikolai Herbst«, in: die horen 53/231 (2008): Panoramen der Anderswelt. Expeditionen ins Werk von Alban Nikolai Herbst, 73-89.

Pütz, Peter: »Der Mythos bei Nietzsche«, in: Helmut Koopmann (Hg.): Mythos und Mythologie in der Literatur des 19. Jahrhunderts, Frankfurt am Main 1979, 251-262. 
Quante, Michael (Hg.): Personale Identität, Paderborn u. a. 1999.

Rabinowitz, Peter J.: »Truth in Fiction. A Reexamination of Audiences«, in: Critical Inquiry 4/1 (1977), 121-141.

Ranke-Graves, Robert von: Die weiße Göttin. Sprache des Mythos [1948], übers. von Thomas Lindquist, Reinbek 1988.

Reber, Ursula: „Ganz woanders zugleich. Simultaneitäten in Alban Nikolai Herbsts Cybercities«, in: Jahrbuch der ungarischen Germanistik 2003 (2004), 131-151.

Reber, Ursula: "Affektive Landschaften in Alban Nikolai Herbsts AndersweltRomanen «, in: die horen 53/231 (2008): Panoramen der Anderswelt. Expeditionen ins Werk von Alban Nikolai Herbst, 49-65.

Reber, Ursula: Formenverschleifung. Zu einer Theorie der Metamorphose, München u.a. 2009 .

Rimmon-Kenan, Shlomith: Narrative Fiction. Contemporary Poetics, 2. Aufl., London / New York 2002.

Rosenfelder, Andreas: „Ein Labyrinth, das keine Sackgassen kennt. Nachrichten aus der aufregenden Grauzone zwischen Literatur und Nicht-Literatur: Wie sind die Texte in Weblogs beschaffen?«, in: Literaturen 11 (2006), 52-58.

Rühling, Lutz: »Fiktionalität und Poetizität«, in: Heinz Ludwig Arnold / Heinrich Detering (Hg.): Grundzüge der Literaturwissenschaft, München 1996, 25-51.

Rumpf, Marianne: »Berta«, in: Kurt Ranke u. a. (Hg.): Enzyklopädie des Märchens. Handwörterbuch zur historischen und vergleichenden Erzählforschung, Bd. 2, Berlin / New York 1979, 155-162.

Ryan, Marie-Laure: »Fiction, Non-Factuals, and the Principle of Minimal Departure«, in: Poetics 9 (1980), 403-422.

Scheffel, Michael: Magischer Realismus. Die Geschichte eines Begriffes und ein Versuch seiner Bestimmung, Tübingen 1990.

Scherer, Stefan: »Die Metamorphosen des Wolpertingers. Zur Poetik und zum Werk vom [sic!] Alban Nikolai Herbst«, in: Juni 26 (1997), 167-190.

Scherer, Stefan: »Alban Nikolai Herbst«, in: Hermann Korte (Hg.): Kritisches Lexikon zur deutschsprachigen Gegenwartsliteratur, begr. von Heinz Ludwig Arnold, 1. Jan. 2010, URL: http:/ / www. nachschlage. NET / document / 16000000226, Artikel erstmals 1999 erschienen.

Schlaffer, Hannelore: »Poesie und Prosa. Wielands Verserzählungen«, in: Walter Erhart / Lothar van Laak (Hg.): Wissen - Erzählen - Tradition. Wielands Spätwerk, Berlin / New York 2010, 153-167.

Schmidt, Jan: Weblogs. Eine kommunikationssoziologische Studie, Konstanz 2006. 
Schnell, Ralf: »Prosa der Moderne - nach der Postmoderne. Ransmayr - Handke Jelinek - Herbst«, in: Ders.: Geschichte der deutschsprachigen Literatur seit 1945, 2., überarbeitete und erweiterte Auflage, Stuttgart 2003, 602, 604.

Schnell, Ralf (Hg.): Panoramen der Anderswelt. Expeditionen ins Werk von Alban Nikolai Herbst. die horen. 53/231 (2008).

Schnell, Ralf: »Dschungel-Passagen - Zu diesem Band«, in: die horen 53/231 (2008): Panoramen der Anderswelt. Expeditionen ins Werk von Alban Nikolai Herbst, 5-8.

Schnell, Ralf: »Über die Wahrnehmung eines literarischen Kunstwerks. Rückblick auf einen verbotenen Roman: Meere von Alban Nikolai Herbst«, in: die horen 53/231 (2008): Panoramen der Anderswelt. Expeditionen ins Werk von Alban Nikolai Herbst, 195-204.

Schnell, Ralf: »Von 1945 bis zur Gegenwart. Romane der Postmoderne«, in: Volker Meid (Hg.): Geschichte des deutschsprachigen Romans, Stuttgart 2013, 705-734.

Scholz, Manfred Günter / Nikolas Immer: »Leser«, in: Dieter Burdorf / Christoph Fasbender / Burkhard Moennighoff (Hg.): Metzler Lexikon Literatur. Begriffe und Definitionen, 3., völlig neu bearbeitete Auflage, Stuttgart / Weimar 2007, 432-433.

Schopenhauer, Arthur: »Die Welt als Wille und Vorstellung« [1819/1859], in: Ders.: Werke in fünf Bänden, Bd. 1, hg. v. Ludger Lütkehaus, Zürich 1988.

Schulze, Helmut: »parallalie«. Weblog, seit Juli 2004, URL: http://parallalie.twoday. net.

Schütte, Uwe: »Erzählen für morgen. Zur poetologischen Genealogie des Kybernetischen Realismus bei Alban Nikolai Herbst«, in: die horen 53/231 (2008): Panoramen der Anderswelt. Expeditionen ins Werk von Alban Nikolai Herbst, 121-130.

Segeberg, Harro: »Parallelpoesien«. Buch- und/oder Netzliteratur? Einführung und Überblick«, in: Harro Segeberg / Simone Winko (Hg.): Digitalität und Literalität. Zur Zukunft der Literatur, 2005, 11-27.

Simanowski, Roberto: »Autorschaften in digitalen Medien. Eine Einleitung«, in: Text + Kritik 152 (2001): Digitale Literatur, 3-21.

Simanowski, Roberto: Interfictions. Vom Schreiben im Netz, Frankfurt am Main 2002.

Snow, C. P.: The Two Cultures: and a Second Look. An Expanded Version of the Two Cultures and the Scientific Revolution [1959], Cambridge u. a. 1969.

Stanzel, Franz K.: Typische Formen des Romans, Göttingen 1964.

Stein, Benjamin: "Fallen im Kopf», Turmsegler.net, 23. Nov. 2007, URL: http:// turmsegler.net/20071123/fallen-im-kopf. 
Steinbauer, Bernd: »Oberon«, in: Rolf Wilhelm Brednich u. a. (Hg.): Enzyklopädie des Märchens. Handwörterbuch zur historischen und vergleichenden Erzählforschung, Bd. 10, Berlin / New York 2002, 173-176.

Sterne, Laurence: The Life and Opinions of Tristram Shandy, Gentleman [1759-1767], hg. v. Melvyn New / Joan New, London [u.a.] 1997.

Stockinger, Claudia: Das 19. Jahrhundert. Zeitalter des Realismus, Berlin 2010.

Straub, Jürgen: »Identität«, in: Friedrich Jaeger / Burkhard Liebsch (Hg.): Handbuch der Kulturwissenschaften. Grundlagen und Schlüsselbegriffe, Bd. 1, Stuttgart / Weimar 2004, 277-303.

Tepe, Peter: Mythos \& Literatur. Aufbau einer literaturwissenschaftlichen Mythosforschung, Würzburg 2001.

Tiedemann, Rolf: »'Gegenwärtige Vorwelt $\measuredangle$ Zu Adornos Begriff des Mythischen (I)«, in: Frankfurter Adorno Blätter 5 (1998), 9-36.

Todorov, Tzvetan: Einführung in die fantastische Literatur, München 1972.

Trappe, Tobias: „Wirklichkeit«, in: Joachim Ritter / Karlfried Gründer / Gottfried Gabriel (Hg.): Historisches Wörterbuch der Philosophie, Bd. 12, Basel 2004, 829-846.

Trunz, Erich: »Anmerkungen [zu Dichtung und Wahrheit Buch 1-13] «, in: Goethe, Johann Wolfgang von: Werke. Hamburger Ausgabe in 14 Bänden, Bd. 9: Autobiographische Schriften I, hrsg. und komm. von Erich Trunz, München 1998, 640840.

Türcke, Christoph: Sexus und Geist. Philosophie im Geschlechterkampf, Frankfurt am Main 1991.

Vöhler, Martin / Dirck Linck (Hg.): Grenzen der Katharsis in den modernen Künsten. Transformationen des aristotelischen Modells seit Bernays, Nietzsche und Freud, Berlin 2009.

Völker, Klaus: Künstliche Menschen. Dichtungen und Dokumente über Golems, Homunculi, Androiden und liebende Statuen, München 1976.

Wägner, Wilhelm: Nordisch-germanische Götter und Helden, 4. Aufl., Leipzig / Berlin 1887 .

Wagner-Egelhaaf, Martina: Autobiographie, 2., aktualisierte und erw. Aufl., Stuttgart 2005.

Wagner-Egelhaaf, Martina: »Autofiktion. Theorie und Praxis des autobiographischen Schreibens «, in: Johannes Berning / Nicola Kessler / Helmut H. Koch (Hg.): Schreiben im Kontext von Schule, Universität, Beruf und Lebensalltag, Berlin 2006, 80101. 
Watzlawick, Paul: Wie wirklich ist die Wirklichkeit? Wahn, Täuschung, Verstehen [How real is real?, 1976], München / Zürich 1998.

Waugh, Patricia: Metafiction. The Theory and Practice of Self-conscious Fiction, London / New York 1984.

»The Wayback Machine«, Internet Archive, URL: http://archive.org/web/web.php.

Weber, Max:»Wissenschaft als Beruf« [1917/19], in: Ders.: Gesamtausgabe, hg. v. Wolfgang J. Mommsen / Wolfgang Schluchter, in Zsarb. mit Birgitt [sic!] Morgenbrod, Abt. I, Bd. 17, Tübingen 1992, 71-111.

Weidhase, Helmut / Kai Kauffmann: »Realismus«, in: Dieter Burdorf / Christoph Fasbender / Burkhard Moennighoff (Hg.): Metzler Lexikon Literatur. Begriffe und Definitionen, 3., völlig neu bearbeitete Auflage, Stuttgart / Weimar 2007, 628-630.

Weigand, Jörg: »Jerry Cotton - endlich enttarnt«, in: Die Welt, 6. Mai 1998.

Weischedel, Wilhelm: »Die Frage nach der Wirklichkeit«, in: Wirklichkeit und Wirklichkeiten. Aufsätze und Vorträge, Berlin 1960, 118-141.

Welsch, Wolfgang: »'Wirklich`. Bedeutungsvarianten - Modelle - Wirklichkeit und Virtualität«, in: Sybille Krämer (Hg.): Medien, Computer, Realität. Wirklichkeitsvorstellungen und Neue Medien, Frankfurt am Main 1998, 169-212.

Welsen, Peter: Schopenhauers Theorie des Subjekts. Ihre transzendentalphilosophischen, anthropologischen und naturmetaphysischen Grundlagen, Würzburg 1995.

Westermann, Bianca: Anthropomorphe Maschinen. Grenzgänge zwischen Biologie und Technik seit dem 18. Jahrhundert, Paderborn 2012.

Wiegand, Hermann: »Makkaronische Dichtung «, in: Harald Fricke (Hg.): Reallexikon der deutschen Literaturwissenschaft, 3. Aufl., Bd. 2: H-O, Berlin / New York 2000, 527-530.

Wieland, Christoph Martin: Oberon [1780], in: Ders.: Werke, hg. v. Fritz Martini / Hans Werner Seiffert, Bd. 5, München 1968, 162-381.

Wiener, Norbert: Kybernetik. Regelung und Nachrichtenübertragung im Lebewesen und in der Maschine [1948], übers. von E. H. Serr, unter Mitarb. v. E. Henze, Düsseldorf u. a. 1992.

Wikipedia: »Löschkandidaten: Möglichkeitenpoetik«, 20. Feb. 2008-3. März 2008, URL: http:// de. wikipedia.org/wiki/Wikipedia:L\%C3\% B6schkandidaten/20. _Februar_2008\#M.C3.B6glichkeitenpoetik_.28erl.29.

Wikipedia: »Blog«, 17. März 2015, URL: http://de.wikipedia.org/wiki/Blog.

Wikipedia: »Troll (Netzkultur)«, 17. März 2015, URL: http://de.wikipedia.org/wiki/ Troll_(Netzkultur). 
Wikipedia (Englisch): „Orgasmatron«, 20. Jan. 2015, URL: http://en.wikipedia.org/ wiki/Orgasmatron.

Wilhelmy, Thorsten: Legitimationsstrategien der Mythosrezeption. Thomas Mann, Christa Wolf, John Barth, Christoph Ransmayr, John Banville, Würzburg 2004.

Winko, Simone: »Auf der Suche nach der Weltformel. Literarizität und Poetizität in der neueren literaturtheoretischen Diskussion «, in: Fotis Jannidis / Gerhard Lauer / Simone Winko (Hg.): Grenzen der Literatur. Zu Begriff und Phänomen des Literarischen, Berlin u. a. 2009, 374-396.

Wirth, Uwe: Die Geburt des Autors aus dem Geist der Herausgeberfiktion. Editoriale Rahmung im Roman um 180o: Wieland, Goethe, Brentano, Jean Paul und E. T. A. Hoffmann, München 2008.

Wolf, Werner: „Geschichtsfiktion im Kontext dekonstruktivistischer Tendenzen in neuerer Historik und literarischer Postmoderne. Tom Stoppards Travesties«, in: Poetica 18 (1986), 305-357.

Wolf, Werner: Ästhetische Illusion und Illusionsdurchbrechung in der Erzählkunst. Theorie und Geschichte mit Schwerpunkt auf englischem illusionsstörenden Erzählen, Tübingen 1993.

Wolf, Werner: »Metafiktion«, in: Ansgar Nünning (Hg.): Metzler Lexikon Literaturund Kulturtheorie. Ansätze - Personen - Grundbegriffe, 2., überarbeitete und erweiterte Auflage, Stuttgart 2001, 429-430.

Wörtche, Thomas: »Pusteln und Pickel«, in: Freitag, 9. Okt. 1998.

Zipfel, Frank: Fiktion, Fiktivität, Fiktionalität. Analysen zur Fiktion in der Literatur und zum Fiktionsbegriff in der Literaturwissenschaft, Berlin 2001.

Zipfel, Frank: »Autofiktion. Zwischen den Grenzen von Faktualität, Fiktionalität und Literarität?«, in: Fotis Jannidis / Gerhard Lauer / Simone Winko (Hg.): Grenzen der Literatur. Zu Begriff und Phänomen des Literarischen, Berlin u. a. 2009, 285-314.

Zipfel, Frank: »Autofiktion«, in: Dieter Lamping (Hg.): Handbuch der literarischen Gattungen, In Zusammenarbeit mit Sandra Poppe, Sascha Seiler und Frank Zipfel, Stuttgart 2009, 31-36.

\section{Verwendete URLs aus Herbsts Weblog}

URL-1: http://albannikolaiherbst.twoday.net/stories/3491953

URL-2: http://albannikolaiherbst.twoday.net/stories/763903/\#765693

URL-3： http://albannikolaiherbst.twoday.net/stories/763903

URL-4: http://albannikolaiherbst.twoday.net/stories/dreissig/\#64031924 
URL-5: http://albannikolaiherbst.twoday.net/stories/3254132/\#3254672

URL-6: http://albannikolaiherbst.twoday.net/stories/das-spiel-mit-der-vielfaltvon-avataren-kleine-theorie-des-literarisch

URL-7: http://albannikolaiherbst.twoday.net/stories/zehn/\#64959282

URL-8: http://albannikolaiherbst.twoday.net/stories/das-spiel-mit-der-vielfaltvon-avataren-kleine-theorie-des-literarisch/\#5716163

URL-9: http://albannikolaiherbst.twoday.net/stories/erst-einmal-ankommendachte-ich-eben-arbeitsjournal-freitag-der-14-mai/\#6432656

URL-10: http://albannikolaiherbst.twoday.net/stories/acht/\#64967188

URL-11: http://albannikolaiherbst.twoday.net/stories/1441667

URL-12: http://albannikolaiherbst.twoday.net/stories/3491953/\#3495385

URL-13: http://albannikolaiherbst.twoday.net/stories/2861432

URL-14: http://albannikolaiherbst.twoday.net/stories/erst-einmal-ankommendachte-ich-eben-arbeitsjournal-freitag-der-14-mai/\#6384298

URL-15: http://albannikolaiherbst.twoday.net/stories/erst-einmal-ankommendachte-ich-eben-arbeitsjournal-freitag-der-14-mai/\#6394453

URL-16: http://albannikolaiherbst.twoday.net/stories/neunzehn/\#64036497

URL-17: http://albannikolaiherbst.twoday.net/stories/1472205/\#1472283

URL-18: http://albannikolaiherbst.twoday.net/stories/1368871/\#1375260

URL-19: http://albannikolaiherbst.twoday.net/stories/282775

URL-20: http://albannikolaiherbst.twoday.net/stories/142783574/\#142784314

URL-21: http://albannikolaiherbst.twoday.net/stories/307823/\#308333

URL-22: http://albannikolaiherbst.twoday.net/stories/142783574/\#142783781

URL-23： http://albannikolaiherbst.twoday.net/stories/142783574/\#156264263

URL-24: http://albannikolaiherbst.twoday.net/topics/PR\%C3\%84GUNGEN

URL-25: http://albannikolaiherbst.twoday.net/stories/1889428

URL-26: http://albannikolaiherbst.twoday.net/stories/erst-einmal-ankommendachte-ich-eben-arbeitsjournal-freitag-der-14-mai/\#8360558

URL-27: http://albannikolaiherbst.twoday.net/stories/142783574/\#176832292

URL-28: http://albannikolaiherbst.twoday.net/stories/3385068 
URL-29: http://albannikolaiherbst.twoday.net/stories/ach-meine- eitelkeit-sowiejedoch-zurueck-am-lektorat-ff-das-arbeitsjou

URL-30: http://albannikolaiherbst.twoday.net/stories/frauen-zaehlen-email-aneine-junge-verehrerin-lieben/\#11593973

URL-31: http://albannikolaiherbst.twoday.net/stories/733953

URL-32: http://albannikolaiherbst.twoday.net/stories/2089169

URL-33： http://albannikolaiherbst.twoday.net/stories/413046

URL-34: http://albannikolaiherbst.twoday.net/stories/2103602

URL-35: http://albannikolaiherbst.twoday.net/stories/arbeitsjournal-sonntag-der17-mai-2009-mit-alias

URL-36: http://albannikolaiherbst.twoday.net/stories/4929788

URL-37: http://albannikolaiherbst.twoday.net/stories/4562158/\#4562448

URL-38: http://albannikolaiherbst.twoday.net/topics/DSCHUNGELBUCH

URL-39: http://albannikolaiherbst.twoday.net/stories/2498431

URL-40: http://albannikolaiherbst.twoday.net/stories/250631

URL-41: http://albannikolaiherbst.twoday.net/stories/258465

URL-42: http://albannikolaiherbst.twoday.net/stories/2176462

URL-43: http://albannikolaiherbst.twoday.net/topics/DTs

URL-44: http://albannikolaiherbst.twoday.net/stories/4514294

URL-45: http://albannikolaiherbst.twoday.net/topics/InNewYorkManhattanRoman

URL-46: http://albannikolaiherbst.twoday.net/topics/ARGO-ANDERSWELT

URL-47: http://albannikolaiherbst.twoday.net/stories/836842/\#836851

URL-48: http://albannikolaiherbst.twoday.net/stories/64025871/\#64026485

URL-49: http://albannikolaiherbst.twoday.net/stories/2187156

URL-50: http://albannikolaiherbst.twoday.net/topics/Tagebuch

URL-51: http://albannikolaiherbst.twoday.net/topics/Arbeitsjournal

URL-52: http://albannikolaiherbst.twoday.net/stories/im-herzen-der-zeit-dietrolls-und-das-strafrecht-kleine-theorie-des-li

URL-53: http://albannikolaiherbst.twoday.net/stories/232602688/\#232602708

URL-54: http://albannikolaiherbst.twoday.net/stories/2278367 
URL-55: http://albannikolaiherbst.twoday.net/stories/5042104

URL-56: http://albannikolaiherbst.twoday.net/stories/2278611

URL-57: http://albannikolaiherbst.twoday.net/stories/2580020/\#2580820

URL-58: http://albannikolaiherbst.twoday.net/stories/2532561

URL-59: http://albannikolaiherbst.twoday.net/stories/2485662

URL-60: http://albannikolaiherbst.twoday.net/stories/diadorim

URL-61: http://albannikolaiherbst.twoday.net/stories/4439495

URL-62: http://albannikolaiherbst.twoday.net/stories/es-ist-entschieden

URL-63: http://albannikolaiherbst.twoday.net/stories/paul-reichenbach-am-15juni-2010-leben-mit-schmerz-und-der-fruehe-lukc

URL-64: http://albannikolaiherbst.twoday.net/stories/133337662

URL-65: http://albannikolaiherbst.twoday.net/stories/251650

URL-66: http://albannikolaiherbst.twoday.net/stories/2858693

URL-67: http://albannikolaiherbst.twoday.net/stories/55776277

URL-68: http://albannikolaiherbst.twoday.net/stories/nach-einem-langen-kurzennachtgang-durch-eigene-geschichte-boehmers-br

URL-69: http://albannikolaiherbst.twoday.net/stories/arbeitsjournal-sonnabendder-16-mai-2009/\#comments

URL-70: http://albannikolaiherbst.twoday.net/stories/kindesmissbrauch-kleinetheorie-des-literarischen-bloggens-114

URL-71: http://albannikolaiherbst.twoday.net/stories/arbeitsjournal-dienstag-der28-april-2009

URL-72: http://albannikolaiherbst.twoday.net/stories/kinder-und-die-dichtungpp119-2-maerz-2014-sonntag-ein-brief-an-innoke/

URL-73: http://albannikolaiherbst.twoday.net/stories/meditation-masochismustheorie-literarischen-bloggens/\#5705625

URL-74: http://albannikolaiherbst.twoday.net/stories/942003/\#1097915

URL-75: http://albannikolaiherbst.twoday.net/stories/515635/\#515786

URL-76: http : / / albannikolaiherbst . twoday . net / stories / guttenberg - zur bundeswehr-als-ja-wem-denn-heilige-kuh/\#14648839

URL-77: http://albannikolaiherbst.twoday.net/stories/sechzehn/\#64038625

URL-78: http://albannikolaiherbst.twoday.net/stories/dreissig/\#64024267 
URL-79: http://albannikolaiherbst.twoday.net/stories/sieben/\#64970913

URL-80: http://albannikolaiherbst.twoday.net/stories/3468733

URL-81: http://albannikolaiherbst.twoday.net/stories/3265505/\#3429055

URL-82: http://albannikolaiherbst.twoday.net/stories/2178006

URL-83: http://albannikolaiherbst.twoday.net/stories/11579170

URL-84: http : / / albannikolaiherbst . twoday . net / stories / winter - oder - die enthuellung-journal-der-fortgesetzten-melancholie-nunm/

URL-85: http://albannikolaiherbst.twoday.net/stories/890443

URL-86: http://albannikolaiherbst.twoday.net/stories/4521594

URL-87: http://albannikolaiherbst.twoday.net/stories/3065156/\#3068198

URL-88: http : / / albannikolaiherbst . twoday . net / stories / das - arbeits - und trainerjournal-des-dienstags-dem-13-dezember-2011

URL-89: http://albannikolaiherbst.twoday.net/stories/dreiundzwanzig/\#64030096

URL-90: http://albannikolaiherbst.twoday.net/stories/neunzehn/\#64036056

URL-91: http://albannikolaiherbst.twoday.net/stories/64957682/\#64958361

URL-92: http://albannikolaiherbst.twoday.net/stories/5640863/\#5641245

URL-93: http://albannikolaiherbst.twoday.net/stories/5640863/\#5641059

URL-94: http://albannikolaiherbst.twoday.net/topics/BUCHMESSEN

URL-95: http://albannikolaiherbst.twoday.net/stories/neun/\#64960060

URL-96: http://albannikolaiherbst.twoday.net/stories/507869

URL-97: http://albannikolaiherbst.twoday.net/stories/97049942/\#97050067

URL-98: http://albannikolaiherbst.twoday.net/stories/das-arbeitsjournal-desmontags-dem-5-november-2012/\#197335968 